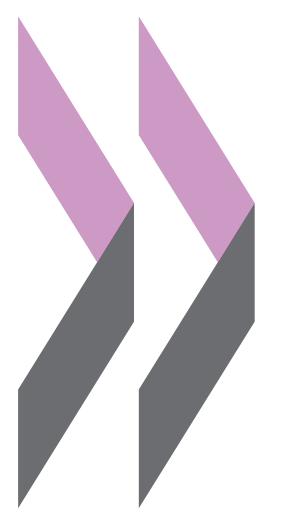

\title{
Pensions at a Glance 2015
} OECD AND G20 INDICATORS 



\title{
Pensions at a Glance 2015
}

\author{
OECD AND G20 INDICATORS
}


This work is published under the responsibility of the Secretary-General of the OECD. The opinions expressed and arguments employed herein do not necessarily reflect the official views of OECD member countries.

This document and any map included herein are without prejudice to the status of or sovereignty over any territory, to the delimitation of international frontiers and boundaries and to the name of any territory, city or area.

\section{Please cite this publication as:}

OECD (2015), Pensions at a Glance 2015: OECD and G20 indicators, OECD Publishing, Paris.

http://dx.doi.org/10.1787/pension_glance-2015-en

ISBN 978-92-64-24063-6 (print)

ISBN 978-92-64-24444-3 (PDF)

Series: OECD Pensions at a Glance

ISSN $1995-4026$ (print)

ISSN 1999-1363 (online)

The statistical data for Israel are supplied by and under the responsibility of the relevant Israeli authorities. The use of such data by the OECD is without prejudice to the status of the Golan Heights, East Jerusalem and Israeli settlements in the West Bank under the terms of international law.

Revised version, March 2016.

www.oecd.org/about/publishing/Corrigendum-Pensions-at-a-Glance2015.pdf.

Corrigenda to OECD publications may be found on line at: www.oecd.org/about/publishing/corrigenda.htm.

(C) OECD 2015

You can copy, download or print OECD content for your own use, and you can include excerpts from OECD publications, databases and multimedia products in your own documents, presentations, blogs, websites and teaching materials, provided that suitable acknowledgement of OECD as source and copyright owner is given. All requests for public or commercial use and translation rights should be submitted to rights@oecd.org. Requests for permission to photocopy portions of this material for public or commercial use shall be addressed directly to the Copyright Clearance Center (CCC) at info@copyright.com or the Centre français d'exploitation du droit de copie (CFC) at contact@cfcopies.com. 


\section{Foreword}

$T_{h}$

his sixth edition of Pensions at a Glance provides a range of indicators for comparing pension policies and their outcomes between OECD countries. The indicators are also, where possible, provided for the other major economies that are members of the G20. Four special chapters (Chapters 1 to 4) provide deeper analysis of recent pension reforms, the role of first-tier pensions, the impact of short and interrupted careers and the sensitivity of future replacement rates to parametric changes.

This report was prepared by the pensions team in the Social Policy Division of the OECD Directorate for Employment, Labour and Social Affairs. The team comprises Hervé Boulhol, Anna Cristina D'Addio, Kristoffer Lundberg and Andrew Reilly. National officials - particularly delegates to the OECD Working Party on Social Policy and members of the OECD pension expert group - provided active and invaluable input to the report. For OECD countries, the results of the OECD pension models have been confirmed and validated by national authorities.

Chapter 1 on "Recent pension reforms" was written by Kristoffer Lundberg. Chapters 2 and 4 entitled "The role of first-tier pensions" and "Sensitivity of replacement rates to the model parameters", respectively, were written by Andrew Reilly. Anna Cristina D'Addio wrote Chapter 3 on "How incomplete careers affect pension entitlements". Herve Boulhol was responsible for the enhancement and the revision of these chapters. Chapters 2 and 3 were edited by Ken Kincaid. Marlène Mohier prepared the manuscript for publication.

The indicators related to private pensions were mainly provided by the OECD's private-pensions unit in the Directorate for Financial and Enterprise Affairs: Pablo Antolín, Stéphanie Payet and Romain Despalins.

The report has benefited from the commentary of many national officials and colleagues in the OECD Secretariat, notably Mark Pearson, Monika Queisser and Stefano Scarpetta. It is a joint project co-financed by the European Commission and the OECD. 



\section{Table of contents}

Editorial - The next frontier for pension policy: Focusing more on social sustainability ..... 9

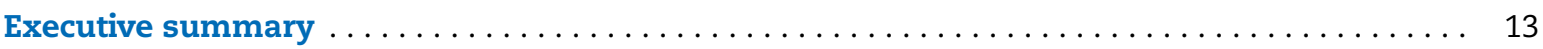

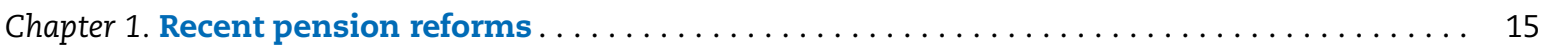

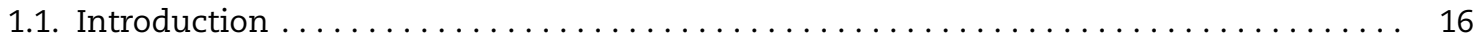

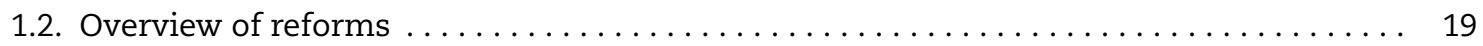

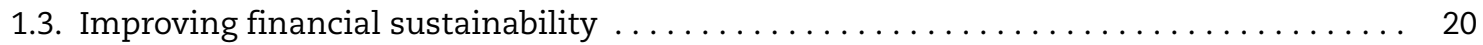

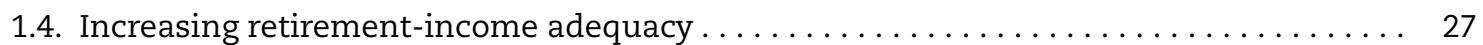

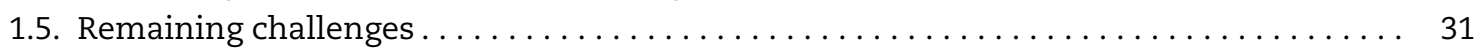

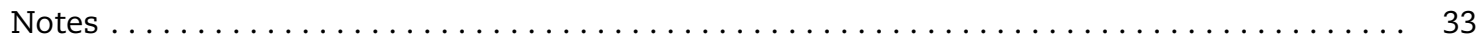

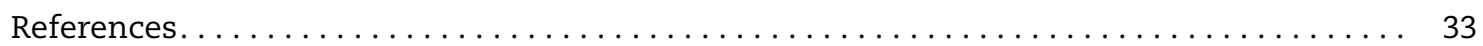

Annex 1.A1. Pension reforms from September 2013 to September 2015 . . . . . . . . . . 34

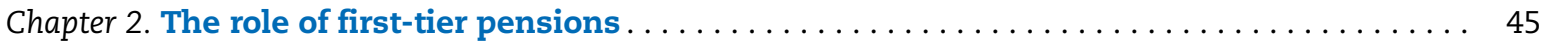

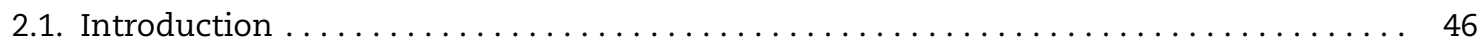

2.2. Eligibility criteria for basic and minimum old-age pensions $\ldots \ldots \ldots \ldots \ldots \ldots \ldots$. 47

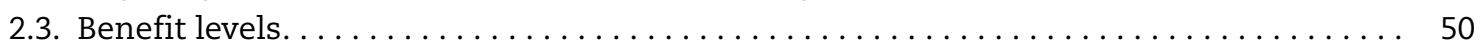

2.4. What happens in the event of ineligibility for contribution-based basic

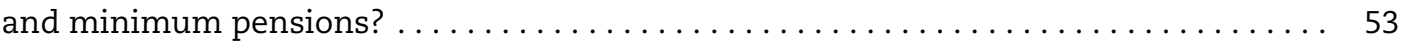

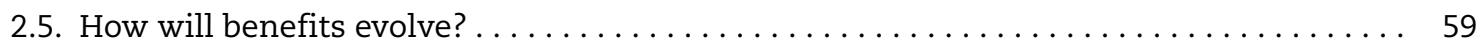

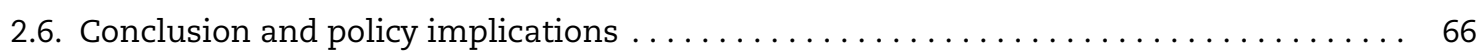

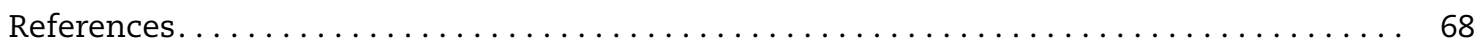

Annex 2.A1. Supplementary figures on the effect of different indexation approaches ..... 69

Chapter 3. How incomplete careers affect pension entitlements $\ldots \ldots \ldots \ldots \ldots \ldots \ldots \ldots \ldots 73$

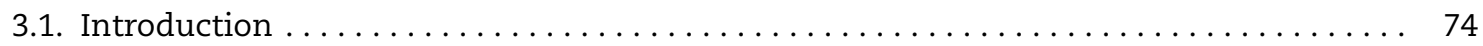

3.2. Setting the scene for an understanding of contribution gaps $\ldots \ldots \ldots \ldots \ldots \ldots \ldots \ldots$

3.3. How scattered careers affect pensions: Theory and practice $\ldots \ldots \ldots \ldots \ldots \ldots \ldots$

3.4. Pension systems components that can mitigate the adverse effects of interrupted

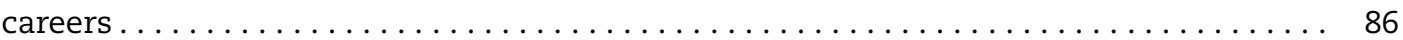

3.5. Pension credits to plug the contribution gap. $\ldots \ldots \ldots \ldots \ldots \ldots \ldots \ldots \ldots \ldots \ldots \ldots \ldots \ldots$

3.6. Simulating pension entitlements for shorter and interrupted careers $\ldots \ldots \ldots \ldots \ldots .91$

3.7. Putting the results in a policy perspective: Pension credits and other measures towards less fragmented careers $\ldots \ldots \ldots \ldots \ldots \ldots \ldots \ldots \ldots \ldots \ldots \ldots \ldots \ldots$

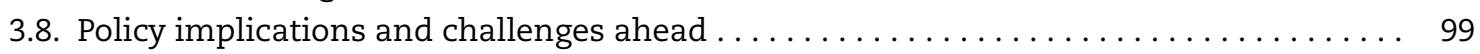

Notes . . . . . . . . . . . . . . . . . . . . . . . . . . . . . . . . . . . . . . 101

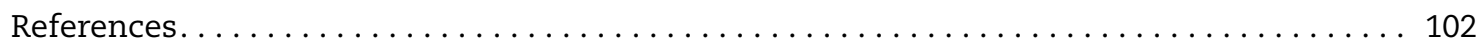

Annex 3.A1. Main rules of pension credits related to childcare and unemployment. ...... 106 
Chapter 4 . Sensitivity of replacement rates to the model parameters . . . . . . . . . . 111

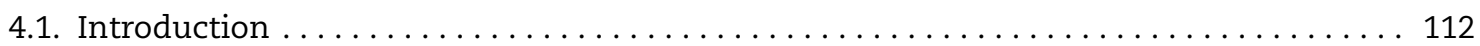

4.2. Impact of parameter changes since Pensions at a Glance $2013 \ldots \ldots \ldots \ldots$

4.3. How changes in inflation affect replacement rate results . . . . . . . . . . . . . . . 114

4.4. How changes in real wage affect replacement rate results . . . . . . . . . . . . . . 114

4.5. How changes in the rate of return affect future replacement rates . . . . . . . . . 116

4.6. How changes in the discount rate affect replacement rates . . . . . . . . . . . . 118

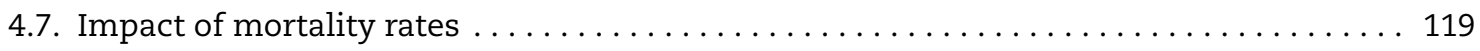

4.8. Country-specific economic assumptions . . . . . . . . . . . . . . . . . . 119

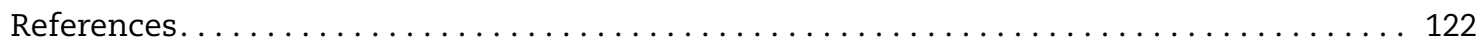

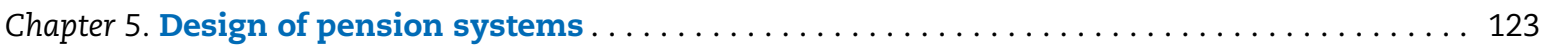

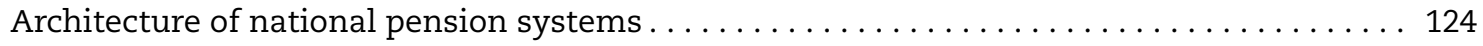

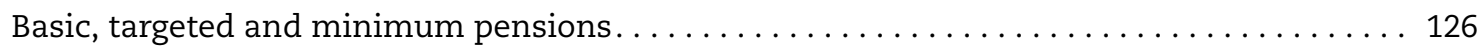

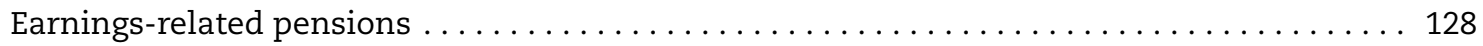

Current retirement ages . . . . . . . . . . . . . . . . . . . . . . . . . . . . . 130

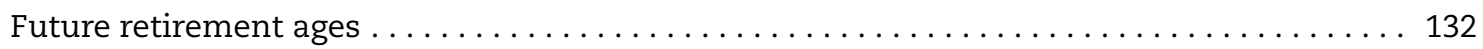

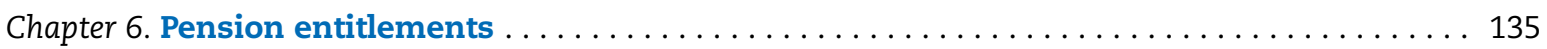

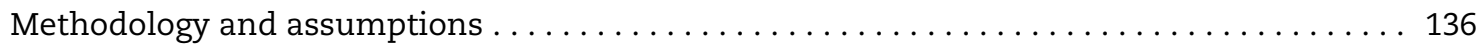

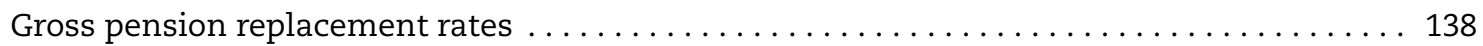

Gross pension replacement rates: Mandatory and voluntary schemes. . . . . . . . . . . . . 140

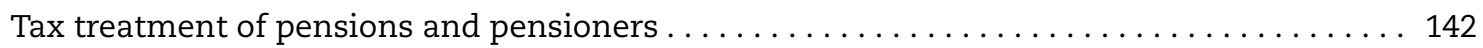

Net pension replacement rates . . . . . . . . . . . . . . . . . . . . . . . . . . . . . . . . . 144

Net pension replacement rates: Mandatory and voluntary schemes . . . . . . . . . . 146

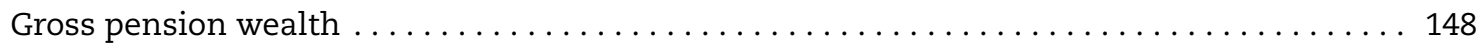

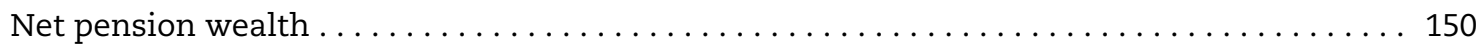

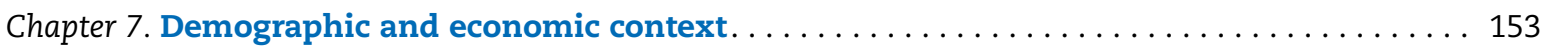

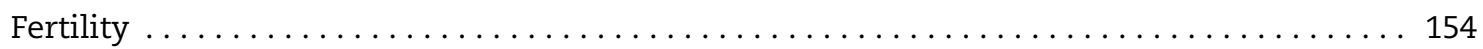

Life expectancy. . . . . . . . . . . . . . . . . . . . . . . . . . . . . . . 156

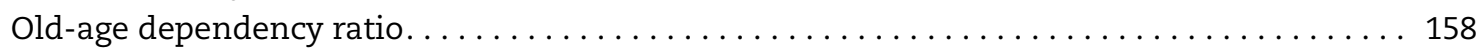

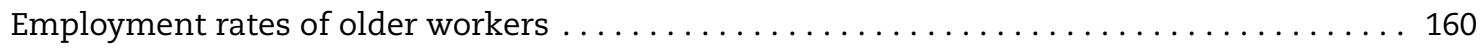

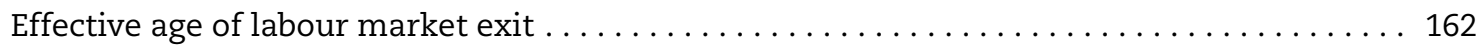

Expected years in retirement . . . . . . . . . . . . . . . . . . . . . . . . . . . 164

Chapter 8. Incomes and poverty of older people . . . . . . . . . . . . . . . . . . 167

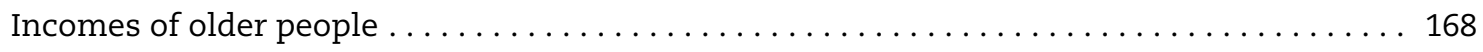

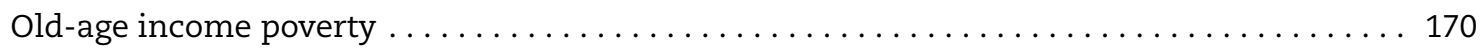

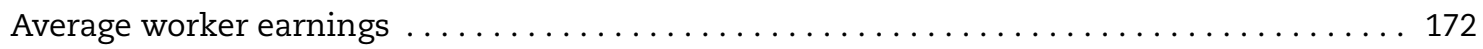

Chapter 9. Finances of retirement-income systems $\ldots \ldots \ldots \ldots \ldots \ldots \ldots \ldots \ldots \ldots$

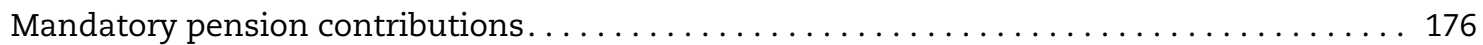

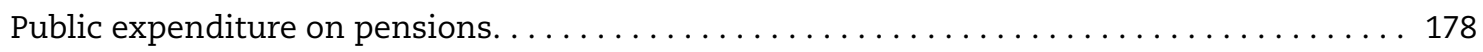

Pension-benefit expenditures: Public and private $\ldots \ldots \ldots \ldots \ldots \ldots \ldots \ldots \ldots \ldots$

Long-term projections of public pension expenditure $\ldots \ldots \ldots \ldots \ldots \ldots \ldots \ldots$

Chapter 10. Private pensions and public pension reserve funds. $\ldots \ldots \ldots \ldots$

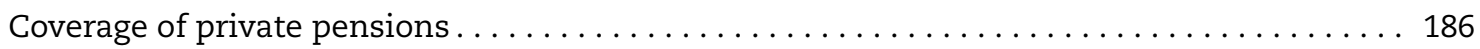

Institutional structure of private pension plans $\ldots \ldots \ldots \ldots \ldots \ldots \ldots \ldots$

Assets in pension funds and public pension reserve funds . . . . . . . . . . . . . . 190

Asset allocation of pension funds and public pension reserve funds . . . . . . . . . . . . 192 
Investment performance of pension funds and public pension reserve funds . . . . . . . . 194

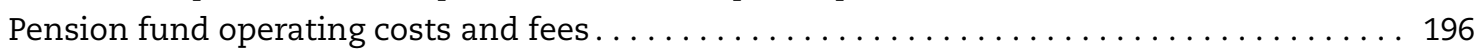

DB funding ratios. . . . . . . . . . . . . 198

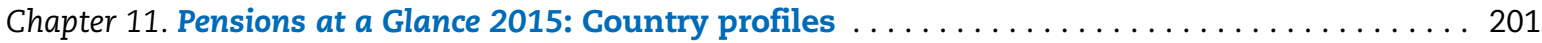

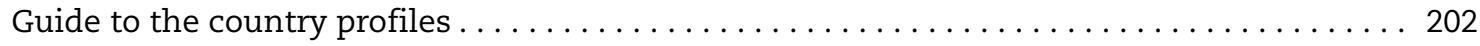

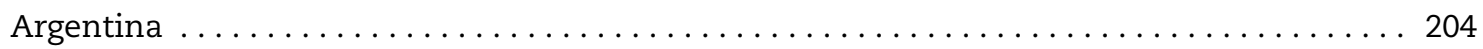

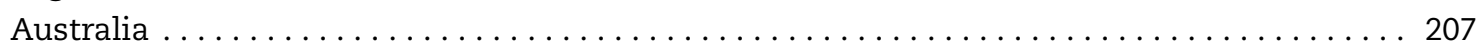

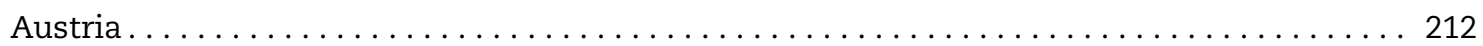

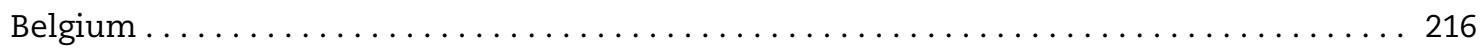

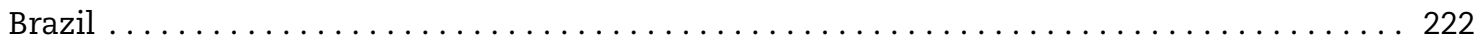

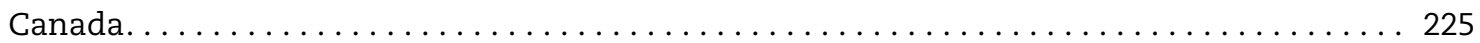

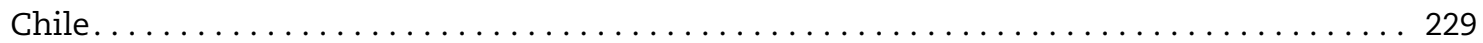

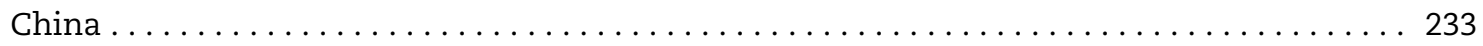

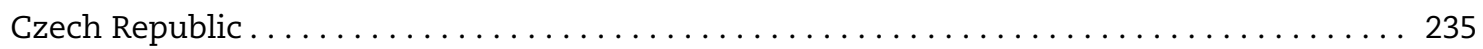

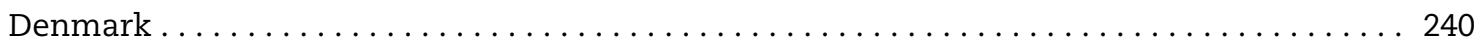

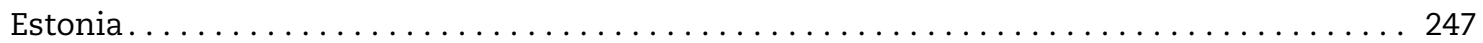

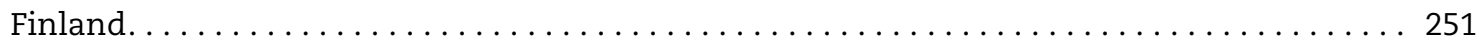

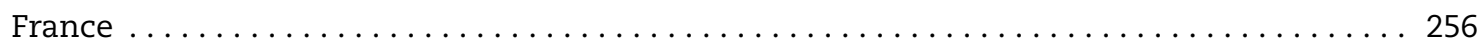

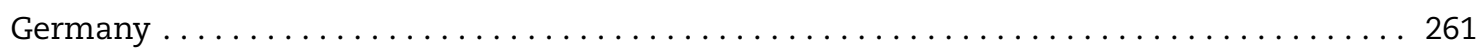

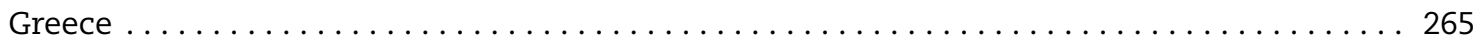

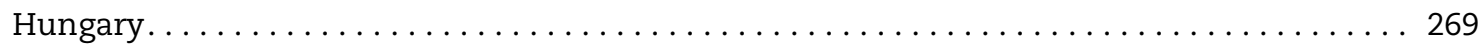

Iceland .................................................... 273

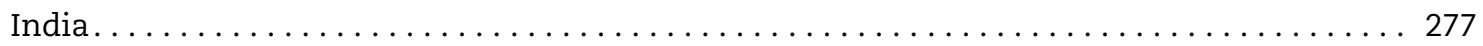

Indonesia. . . . . . . . . . . . . . . . . . . . . . . . . . . . . . . . . . . 280

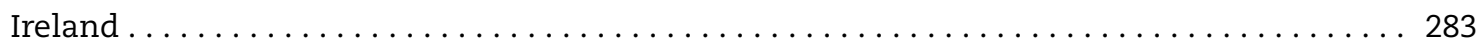

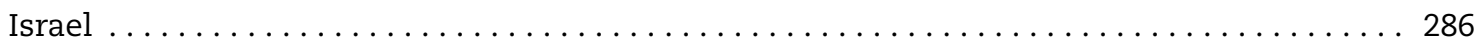

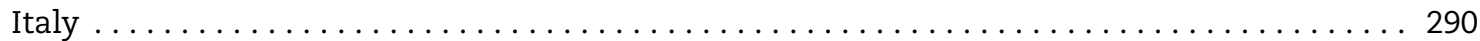

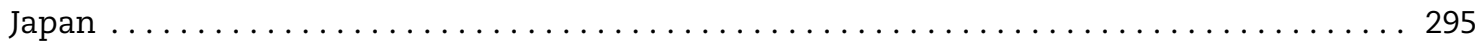

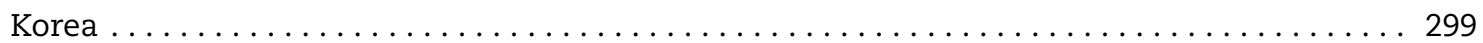

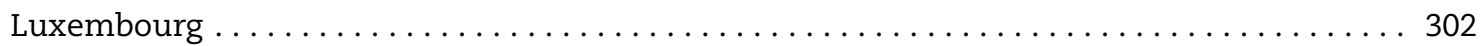

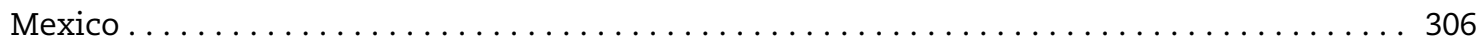

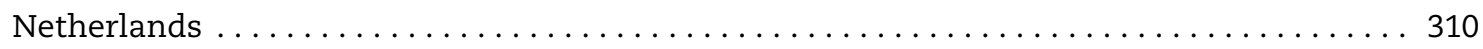

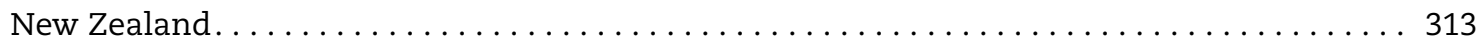

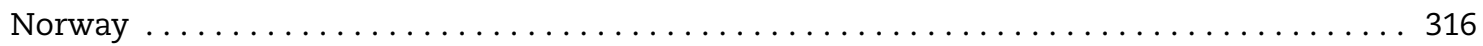

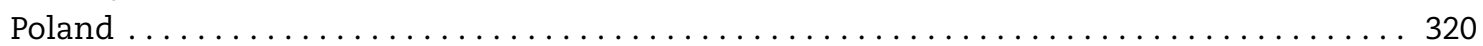

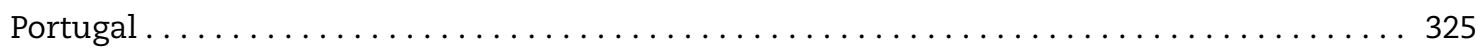

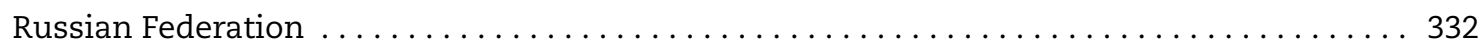

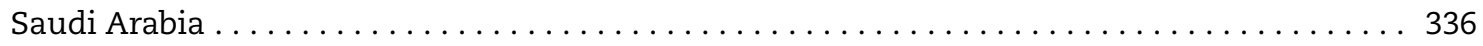

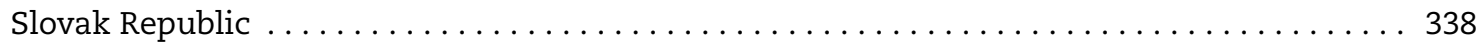

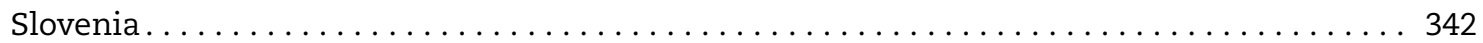

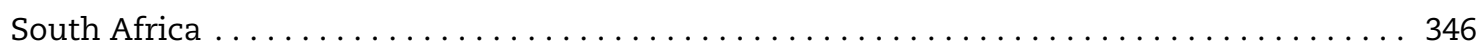

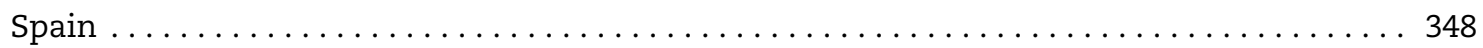

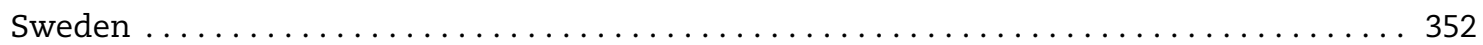

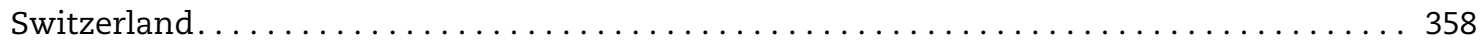

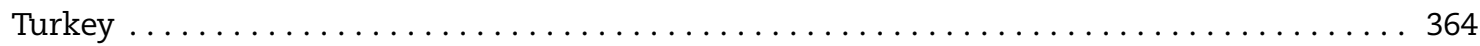

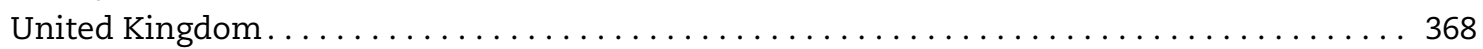

United States . . . . . . . . . . . . . . . . . . . . . . . . . . . . . . . . . . . . 372 


\section{Follow OECD Publications on:}

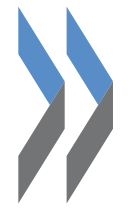

Yhttp://twitter.com/OECD_Pubs

f $h t t p: / / w w w$. facebook.com/OECDPublications

in. http://www.linkedin.com/groups/OECD-Publications-4645871

You hith: ht//www.youtube.com/oecdilibrary

OECD

Alerts

http://www.oecd.org/oecddirect/

This book has...

StatLinks त्ञाज़

A service that delivers Excel files from the printed page!

Look for the StatLinks sills at the bottom of the tables or graphs in this book. To download the matching Excel® spreadsheet, just type the link into your Internet browser, starting with the http://dx.doi.org prefix, or click on the link from the e-book edition. 


\section{Editorial \\ The next frontier for pension policy: Focusing more on social sustainability}

$\Gamma$

his sixth edition of Pensions at a Glance marks the tenth anniversary of the OECD's flagship series on pension systems and retirement incomes. Ten years of scrutiny of member and G20 countries' pension systems and policies, ten years of assessing and predicting workers' pension entitlements, and ten years of recommending reforms that lead to more financially sustainable pay-as-you-go pensions and also respond to citizens' need for stable and adequate incomes in old age.

The good news is that the OECD's call has been heeded in most countries around the world. The last decade has been a period of intense reform activity in the area of pensions, with governments changing key parameters of their retirement income systems and, in some cases, proceeding to overhaul the design of the pension schemes, often scaling down the ambition of public pensions and giving a larger role to funded defined contribution retirement provision.

The most visible progress has been made in raising official pension ages. Many countries have been moving this key parameter beyond the mark of 65 years. As highlighted in previous editions of Pensions at a Glance, 67 has indeed become the new 65, and several countries are going even further towards ages closer to 70 . Raising the pension age has been politically difficult in many countries as it is a parameter that is easily understood; most citizens are not happy to be told that they will have to work longer, often for the same benefit, even though the time spent in retirement is still growing due to continuously increasing life expectancy.

Setting a legal norm, of course, does not mean that all people actually work up to these higher ages. Workers still leave the labour market well before reaching the official pension age in several OECD countries. The gap between official and effective retirement ages, however, is gradually shrinking. Over the past ten years, employment rates of workers aged 55 to 64 years have been rising substantially in many countries: from 45 to $66 \%$ in Germany, for example, from 31 to $46 \%$ in Italy, and from 52 to $57 \%$, on average in the OECD.

The pension reforms undertaken over the past decade are biting. The combination of cuts in future pensions through higher pension ages, fewer options for early retirement, changes in the way benefits are calculated, and lower adjustments of pensions in payment on the one hand, and more people working and contributing longer, on the other hand, has greatly improved the financial sustainability of pay-as-you-go pension systems. The most recent projections of the European Union's Ageing Working Group, for example, foresee a stabilisation of public pension spending as a share of GDP between 2015 and 2060 for most European countries, and in some cases, even reductions in spending, although from a much higher levels than projected just a few years ago.

Does this mean that all is well and that countries have managed to solve the pension puzzle we described in previous editions of Pensions at a Glance? Unfortunately, the answer is no. Fixing the financial challenges of pay-as-you-go pension systems is only one part of the equation. The other part relates to social sustainability and whether pensions in the future will be sufficient to provide adequate living conditions for older people. 
Today, the majority of OECD pensioners enjoy as good living standards as the average population. This is not surprising: many of today's retirees, at least men, have worked for most of their active years in stable jobs. However, a "job for life" and even a "career for life" are rare commodities for people starting out today. Unemployment rates, in particular among younger groups, continue to be high in many countries. While older workers were less hit by the economic crisis than in previous downturns, long-term unemployment rates in this group are still unacceptably high. And we need to be realistic: even with the best of efforts working longer is not an option for everybody; some people will have to retire early due to job strain and declining health no matter how high the pension age is set.

Time out of work means time out of the pension system. Even though many countries provide pension credits during periods of unemployment, maternity or sick leave, future pension entitlements will be lower for many workers, as Chapter 3 of this volume suggests given labour market developments over the last decades. And for the most unfortunate of tomorrow's pensioners, those young people who do not manage to enter the labour market, the outlook is even direr.

The second major challenge for adequate pensions for future retirees relates to the investment of retirement savings. When the financial crisis first struck, public attention focused on the impact on pension funds and the losses that some workers had to shoulder. As we showed at the time, in most countries vulnerable retirees were largely protected from falling into old-age poverty through the interplay of private and public pension systems, but many middle-class workers who were close to retirement were forced to radically change their plans for their life after work.

New longer-term difficulties have emerged in the aftermath of the financial and economic crisis. The current low-growth, low-interest rate environment is making it difficult to earn the returns necessary to reach adequate pension levels, both for individual savers and financial service providers who offer life insurance and annuity contracts and have to honour their obligations. In addition, mortality tables used in many countries do not fully incorporate projected improvements in life expectancy. This can lead to pension funds and life insurers starting to look for higher yields and to pursue riskier investment strategies that could ultimately undermine their solvency. Apart from posing financial sector risks, this behaviour potentially jeopardises both current and future retirement income security.

Pension savings are ideally made over a long period over which returns might substantially rise again, but this is difficult to predict with any degree of certainty. One trend that is certain, however, is the shift from defined-benefit schemes, where the employer shoulders the risk, to definedcontribution schemes, where the risk lies with the individual worker. This trend, well entrenched in occupational pension schemes, is also observed in public pension schemes with much closer links between workers' contributions and their pension benefits, and benefit formulae which more and more often take into account increases in life expectancy.

After having put pension systems on a more sustainable financial track, policy makers now have to turn their attention to also ensuring that pension systems provide adequate retirement incomes to all workers. As discussed in Chapter 2 of this volume, all countries have old-age safety nets in place, but in some cases these are still not strong enough to protect most of the elderly from falling into old-age poverty. But adequacy is not only about preventing poverty. More than ever before we now need consistent and coherent coordination of labour market, social, pension and financial sector policies to ensure that people's careers and life-courses are accompanied by the most effective measures helping them to maximise their chances of retiring comfortably in the future. Many countries are offering pension calculators in order to show people what benefits they may expect in 
the future based on their personal career and contribution developments. These real-life tools complement the OECD's pension calculator and can help raise awareness both among individuals and policy makers. Let us make sure that they are used in time and prompt action to prevent people from encountering nasty surprises when it is too late to change course. We at the OECD are looking forward to the next decade of supporting countries and policy makers around the world in their analysis of pension systems and their design of pension reforms.

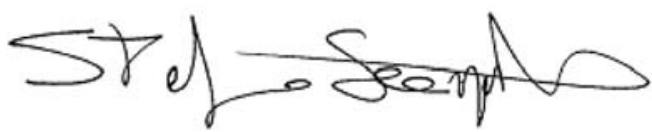

Stefano Scarpetta

Director,

OECD Directorate for Employment, Labour and Social Affairs

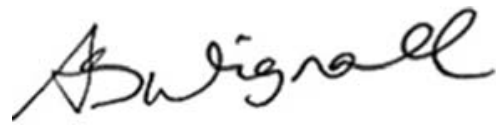

Adrian Blundell-Wignall Director, OECD Directorate for Financial and Entreprise Affairs 



\title{
Executive summary
}

\begin{abstract}
T his edition of Pensions at a Glance reviews and analyses the pension measures enacted or legislated in OECD countries between September 2013 and September 2015. It provides an in-depth review of the first layer of protection of the elderly, first-tier pensions, across countries and assesses the impact of short careers on pension entitlements. This edition analyses also the sensitivity of future replacement rates to parametric changes. As in past editions, a comprehensive selection of pension policy indicators is included as well as profiles of the pension systems for all OECD and G20 countries.
\end{abstract}

\section{The aftermath of the global economic crisis continues to strain pension systems}

The economic recovery remains sluggish in most OECD countries and, as a consequence, pension contributions remain low while fiscal pressure adds urgency to reforming public pension systems. Going forward, the likely protracted uncertainty in financial markets, low returns and record-low interest rates cast doubts on the ability of defined-contribution systems and annuity schemes to deliver adequate pensions. These challenges are compounded by population ageing, which is accelerating in many countries.

However, despite remaining slack in many countries, the average employment rate of people aged 55 to 64 years increased by 7 percentage points in the decade to 2014. Yet, the average effective age of labour market exit remains substantially below the normal retirement ages in several countries. Workers stay the longest in the labour market in Korea, Mexico, Iceland and Japan; men exit the soonest in France and Belgium while women leave the earliest in the Slovak Republic, Poland and Slovenia.

\section{Renewed efforts to improve the financial sustainability of pension systems}

About half of OECD countries have taken measures to improve the financial sustainability of their pension systems over the past two years. Benefits were mostly reduced by switching to less favourable indexation but not cut in absolute terms. The finances of pension systems were also improved by raising taxes and contribution rates in defined-benefit systems. Despite tight constraints on the financing side, efforts have been made to improve the adequacy of retirement income for targeted groups in about one-third of countries.

The main objective of recent reforms was to delay retirement by raising the statutory retirement age, tightening early retirement provisions, and increasing incentives to work longer. These changes might entail distributive effects, however, as work ability at older ages and remaining life expectancy can vary between different socio-economic groups.

The retirement age will increase from 64.0 on average in the OECD in 2014 to 65.5 by 2060 based on current legislation. Men entering the labour market at age 20 will still be able to retire before 65 in Slovenia, Luxembourg, Greece and France. Only in Chile, Israel and Switzerland will women be able to retire before men. 
Future net replacement rates from mandatory schemes for a full-career average-wage worker average $63 \%$ among OECD countries, ranging from $27 \%$ in Mexico (and much lower in Indonesia and South Africa) to $105 \%$ in Turkey. Due to indexation, the gross replacement rate falls by 6 percentage points, on average, between the retirement age and age 80 .

\section{First-tier pensions differ substantially across countries in their design and capacity to fight poverty}

First-tier pensions exist in all countries, but their structure and value vary considerably. On average, safety-net payments for elderly people not entitled to a contributory pension are $22 \%$ of average earnings, ranging from $6 \%$ in Korea and Turkey to $40 \%$ in New Zealand. Minimum pensions, which are based on individual contribution history, exist in one-third of countries. Most countries pay a partial benefit after 20 years of contributions, with full minimum benefits requiring 26 years, on average.

In the countries with high poverty rates amongst the elderly and low safety-net benefits there is scope to increase the value of their safety-net payments, even after taking into account their level of GDP per capita. This is the case in Chile, Korea, Mexico and Turkey, but also in Switzerland and the United States.

The majority of first-tier pensions are indexed to prices and so their replacement rate decline over time, as prices tend to increase slower than wages, both across cohorts at a given age and across ages for a given cohort. Price indexation is appealing for governments facing severe budgetary constraints, but if applied rigidly it also runs the risk of fuelling poverty among the elderly.

\section{Various mechanisms limit the effect of shorter careers on pensions in some countries}

Short careers can substantially reduce pension entitlements, but a number of features cushion their impact: first-tier pensions based on residence or on relatively short contribution periods; reference wages based on best years of earnings; and pension credits. These features imply that, for every year without a job (up to a period of ten years), old-age pensions drop by only $1 \%$ on average across the OECD. In their absence, pensions would fall by $2-2.5 \%$.

Delaying entry into the labour market by five years for an average-wage worker implies, beyond its implications for earnings prospects, a pension loss of $6 \%$ on average. The largest impact is found in Chile and Mexico, at 15\%, and eight other countries have drops greater than $10 \%$. On the other hand, France and Luxembourg record $3 \%$ and $6 \%$ gains, respectively, as people then have to retire four and five years later to be entitled to a pension without penalty.

A woman on average wage interrupting her career for five years to care for two young children would lose about $4 \%$ in pension income on average. The largest declines are recorded in Germany, Iceland, Israel, Italy, Mexico and Portugal, while pensions are not affected in about one-third of countries. Unemployment periods generate similar albeit slightly larger reductions in pension entitlements on average.

Striking the right balance between length of leave from work and benefit entitlements is fundamental to ensure that people return to work but do not lose too much from work interruptions. Policy makers should ensure that pension losses are kept low but also take into account that paying high benefits for long absences may lure workers away from the labour market. 


\section{Chapter 1}

\section{Recent pension reforms}

This chapter sets out the most important elements of pension reform in the 34 OECD countries between September 2013 and September 2015. It updates and extends the analysis from the 2013 edition of OECD Pensions at a Glance which examined pension reforms from January 2009 to September 2013. The time period analysed here has been characterised by sluggish economic growth and increasing government debt. Countries have responded by measures aimed at limiting public pension expenditure while also addressing adequacy concerns in rapidly ageing societies.

The statistical data for Israel are supplied by and under the responsibility of the relevant Israeli authorities. The use of such data by the OECD is without prejudice to the status of the Golan Heights, East Jerusalem and Israeli settlements in the West Bank under the terms of international law. 


\subsection{Introduction}

Pension systems are striving to deliver adequate retirement income while remaining financially sustainable. Population ageing driven by increasing longevity and low fertility rates poses a persistent challenge. The share of individuals aged 65 and above will increase from $8 \%$ of the total world population in 2015 to almost $18 \%$ by 2050 (Figure 1.1), and from $16 \%$ to $27 \%$ in the OECD. In the OECD, the share of the population older than 75 years will be similar in 2050 to the share older than 65 years today. Ageing directly affects the financing of pay-as-you-go (PAYG) pension schemes, as a decreasing number of working-age people has to sustain pension levels for an increasing number of elderly. Ultimately, however, even defined-contribution (DC) schemes are not immune to the lowering of the economy's output potential which might be induced by demographic changes.

Figure 1.1. Share of elderly older than 65 and 75 in the total population

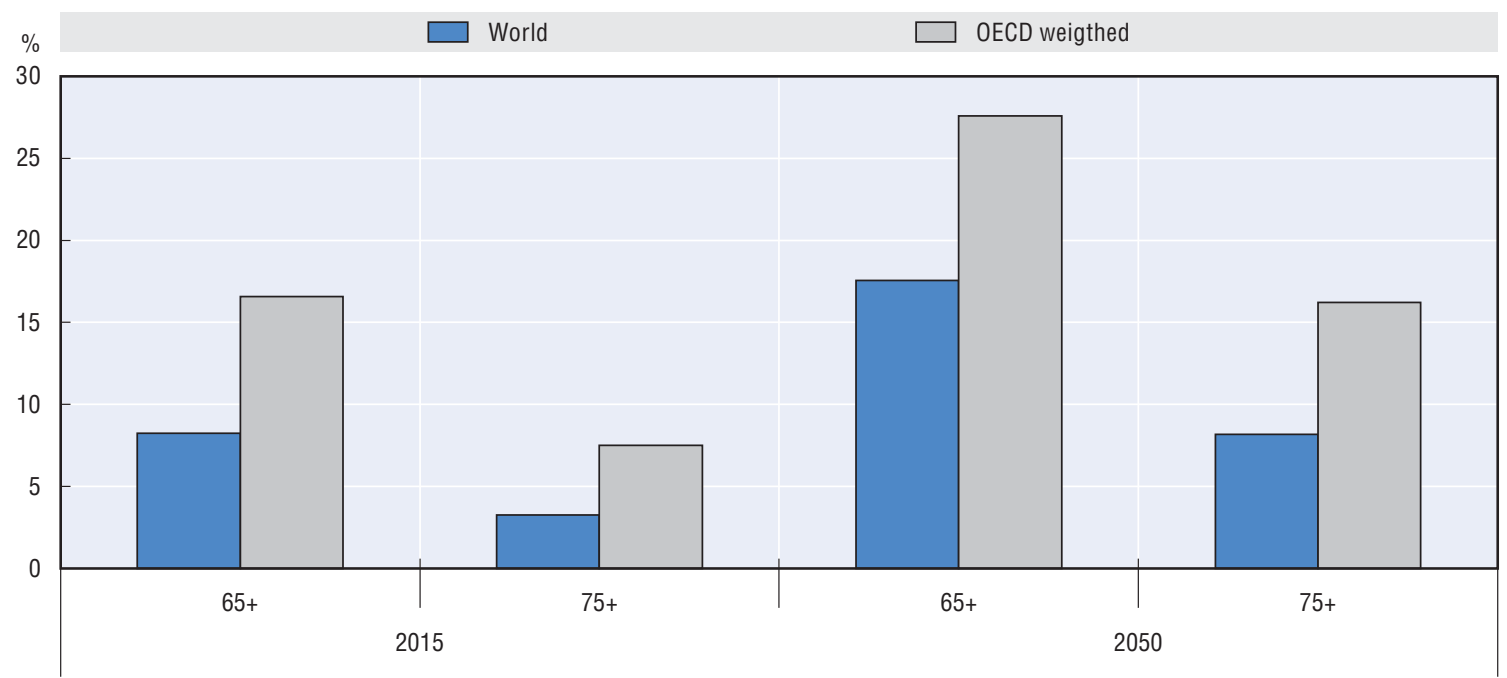

Source: United Nations (2013), World Population Prospects: The 2012 Revision and OECD calculations.

The economic crisis and its aftermath of sluggish economic growth and large government debt levels in many OECD countries have added further strains. Stubbornly high unemployment in many countries and record-low interest and inflation rates persist (OECD, 2015c). Financial sustainability has thus become a concern for the present rather than for the future. Government gross financial liabilities (debt) have increased from 55\% of GDP in 2007 to $88 \%$ in 2014 on average across OECD countries (Figure 1.2). Given that public pension expenditure represents on average $18 \%$ of total public spending across OECD countries (see indicator "Public expenditure on pensions" in Chapter 9), pension reform is typically part of the strategy followed by countries that need to consolidate public finances and curb debt ratios by acting on the spending side.

This chapter reviews and analyses the pension measures enacted or legislated between September 2013 and September 2015. Many OECD countries have recently been implementing reforms that will limit future pension expenditure. According to the latest projections, pension 
Figure 1.2. Pre- and post-crisis government gross financial liabilities, 2007 and 2014 (or latest year available)

Percentage of GDP

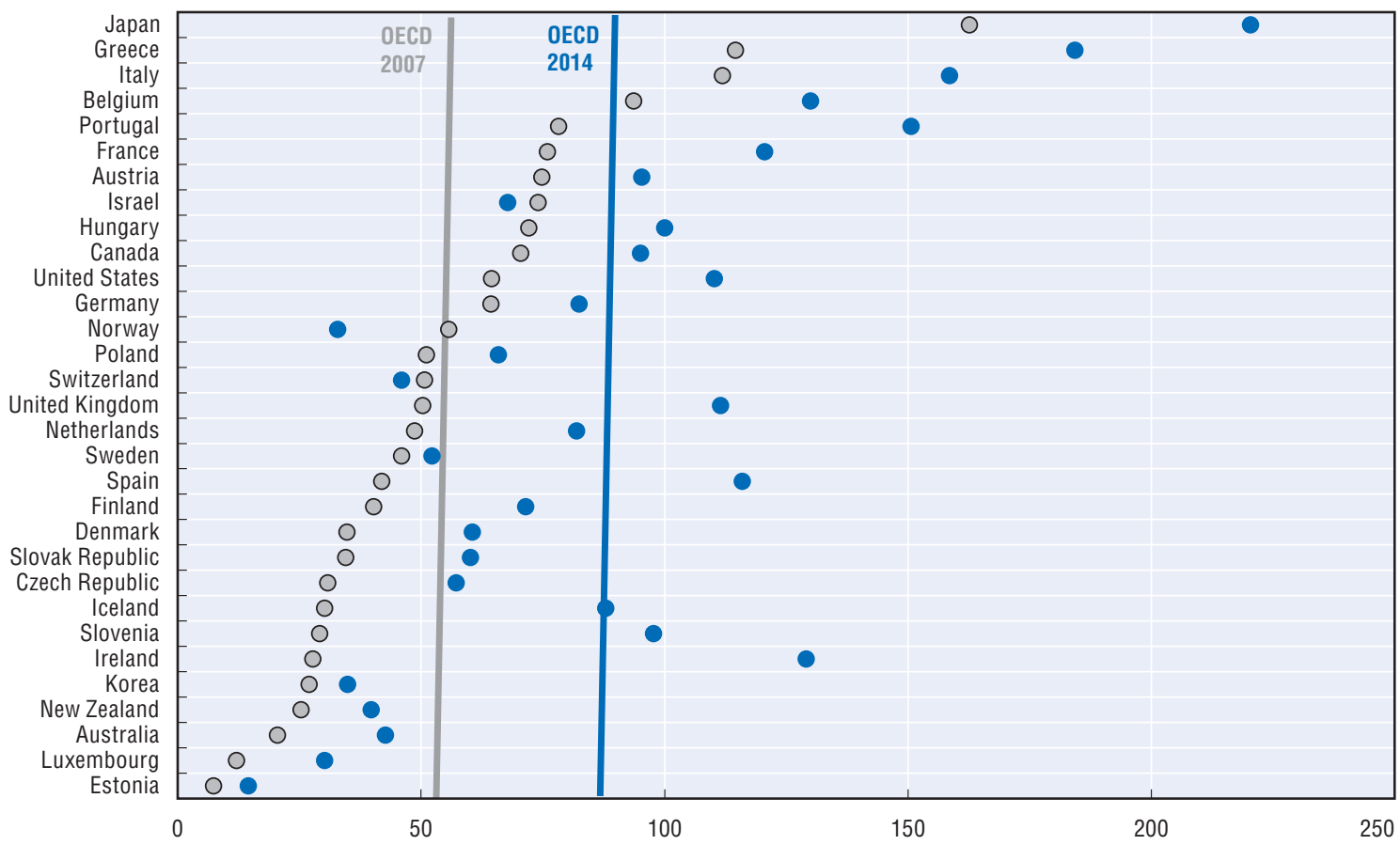

Note: Gross debt data are not always comparable across countries due to different definitions or treatment of debt components. Data for Austria, Iceland, Ireland, Israel, Japan, and Luxembourg is 2013: Switzerland 2012.

Source: OECD (2015), OECD Economic Outlook 97 Database, http://dx.doi.org/10.1787/eo-data-en.

expenditure would increase from the current level of $9.0 \%$ of GDP to $10.1 \%$ in 2050 on average in OECD countries. ${ }^{1}$ This is lower than the 2013 forecasts which projected pension expenditure to grow to almost $12 \%$ of GDP in 2050 (OECD, 2013). Changes in the projections are mainly driven by those made for EU countries: public expenditure on pensions is projected by the EU Ageing Working Group to be roughly stable as a share of GDP (see indicator "Long-term projections of public pension expenditure" in Chapter 9). The average increase is to a large extent driven by Korea and Turkey with the maturing of their pension system in the context of population ageing. ${ }^{2}$

The success of reforms aiming at containing future pension expenditure will depend on both the effective implementation of previously agreed measures and maintaining the momentum for further pension reforms. Particularly those that encourage individuals to work more and longer strengthen the productive capacities of the economy and thereby improve the scope of pension systems to deliver adequate retirement income promises. However, for those unable to extend their working lives, there is a risk that benefits may be insufficient to prevent a sharp fall in standards of living and even poverty in old age.

Relative income poverty rates of the elderly have fallen since the mid-1980s, thus implying higher incomes relative to other groups in society, at least at the bottom of the income distribution (Figure 1.3). While in the mid-1980s individuals over 75 were by far more likely to be poor than other age groups on average, poverty risks have now shifted towards the young; relative old-age poverty has steadily and substantially declined, and the 66-75 age group is now the least at risk of poverty on average in the 18 countries where data are available for the whole period. In contrast, the young are currently the age group that is most likely to face poverty (Figure 1.3). 
Figure 1.3. Poverty has shifted from the old to the young across OECD countries Relative poverty rate of the entire population in each year $=100$, mid-1980s to 2013 or latest year available

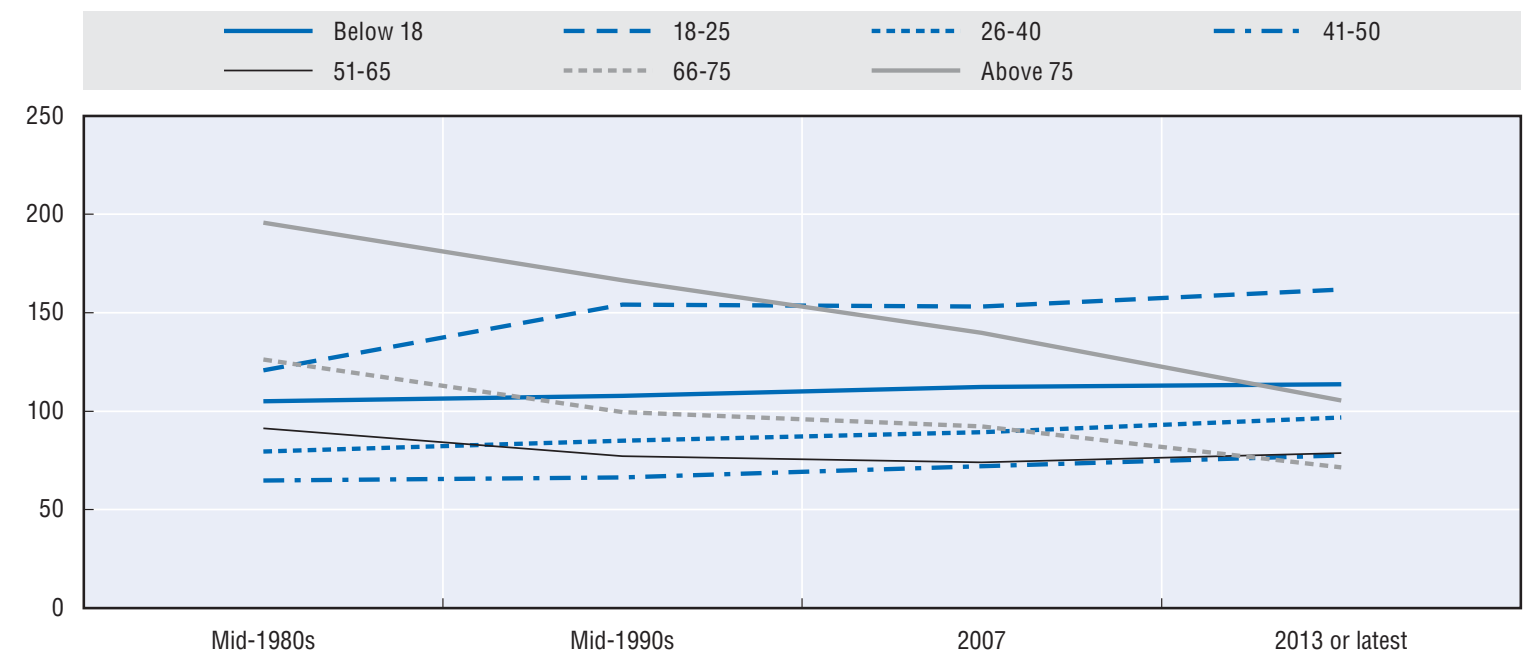

Note: OECD un-weighted average for 18 OECD countries for which data are available from the mid-1980s: Canada, Denmark, Finland, France, Germany, Greece, Israel, Italy, Japan, Luxembourg, Mexico, the Netherlands, New Zealand, Norway, Sweden, Turkey, the United Kingdom and the United States.

Source: OECD Income Distribution Database, www.oecd.org/social/income-distribution-database.htm; OECD (2014), Income Inequality Update - June 2014, OECD Publishing, Paris, www.oecd.org/els/soc/OECD2014-Income-Inequality-Update.pdf.

This shift might translate into more or less severe difficulties later on in life. Being not in employment, education or training (NEETs) for a long period at an early stage in the career could be detrimental to the labour market trajectory, family formation, health outcomes and eventually to retirement income. Chapter 3 has a special focus on how incomplete careers and in particular late entrance into stable employment might affect pension entitlements.

\section{Key findings}

Most OECD countries have been active in changing their pension system since the last publication of Pensions at a Glance (OECD, 2013). Efforts were mostly driven by the widespread need for fiscal consolidation, and a majority of countries indeed implemented reforms to improve the financial sustainability of their pension systems. Some countries have done so while maintaining or improving retirement income adequacy, at least for some population groups.

\section{Improving financial sustainability}

- The most popular measure was to strengthen the incentives to work by increasing the minimum retirement age and/or the main retirement age, thereby enlarging the contribution base while preserving adequacy for those who are able to work longer.

- Almost no country resorted to direct nominal benefit cuts. When benefits were directly reduced, this only happened by switching to a narrower targeting, or by introducing adjustments in the initial pension benefit for new retirees.

- A much larger number of countries changed the indexation of pension benefits to less generous uprating mechanisms.

- Many countries raised revenues by increasing taxes or contribution rates in defined-benefit systems.

- Measures to curb pension administration costs were quite common. 


\section{Increasing retirement-income adequacy}

- Several countries have taken measures to increase the coverage of voluntary private pension schemes.

- Some countries awarded retroactive pension credits or reduced the impact of missing years of contributions on pension levels.

- In some defined-contribution schemes, contribution rates have been increased, while some countries chose to reduce the effective taxation of pensioners' income.

- In a number of countries management costs have been lowered and several improvements were made to the security of pension investments.

The remainder of the chapter is structured as follows. Section 1.2 presents an overview of the pension reforms undertaken or decided over the last two years in OECD countries and their possible effects on improving financial sustainability and increasing retirement-income adequacy. Section 1.3 focuses on measures which should enhance the financing of pension systems, by distinguishing those that would reduce benefits from the others. Section 1.4 analyses the measures taken to improve income adequacy. Section 1.5 summarises the main recent pension policy changes and discusses remaining challenges. Some details of the reforms summarised in this chapter are provided in the Annex Table 1.A1.1 at the end of the chapter.

\subsection{Overview of reforms}

Nearly all OECD countries were active in changing their retirement-income provision systems between September 2013 and September 2015. An overview of the expected effect of reforms on improving financial sustainability and income adequacy, and of their assessed impact and scope is presented in Table 1.1. All reforms are graded from negative (-), unclear (blank) to positive (+). If a country has implemented reforms for which the sign of the expected effect is mixed both + and - grades are shown. The assessed scope ranges from narrow, medium or broad: a narrow reform affects only a small number of people while a broad reform affects a large proportion of the population. Likewise, the assessed impact ranges from minor, moderate to major, depending on the expected quantitative impact on targeted people.

This framework illustrates the key trade-offs between improving financial sustainability and increasing pension adequacy. For example, in a system in which there is a weak link between contributions and benefit payments, such as in defined benefit schemes, increases (reductions) in pensions deteriorate (improve) financial balances. Consequently, the countries that achieve a double plus in the Table 1.1 took a combination of measures, such as increasing contributions in defined contribution schemes and raising retirement ages or cutting pathways to early retirement. This for example happened in Australia where the contribution rate is planned to increase as is the retirement age.

- In 14 OECD countries the focus has been on increasing financial sustainability often through a longer working life. Making people work longer is appealing when the effective retirement age is low, especially given increasing longevity prospects, but requires that both employees and employers adapt their behaviour in order to lengthen working lives and maintain adequate incomes over retirement.

- Improving income adequacy was also common as 11 OECD countries introduced measures that will improve pension benefits at least for some groups of people.

- In several countries measures with mixed outcomes were implemented.

- The scope of the reforms is expected to be broad in 14 countries, medium in nine and narrow in three.

- The overall impact assessment is more balanced. In three OECD countries it is regarded as major whereas it is assessed as moderate in 13 countries and minor in ten countries. 
- The countries that did not make any change were Estonia, Greece, Hungary, Iceland, Mexico, Slovenia, Turkey and the United States. In Greece in particular this followed a period of substantial policy action as described in the last edition of Pensions at a Glance (OECD, 2013).

Table 1.1. Overview of pension measures, September 2013-September 2015

\begin{tabular}{|c|c|c|c|c|}
\hline & Income adequacy & Financial sustainability & Impact & Scope \\
\hline Australia & + & + & Major & Broad \\
\hline Austria & & + & Minor & Medium \\
\hline Belgium & & + & Major & Broad \\
\hline Canada & + & + & Moderate & Medium \\
\hline Chile & + & & Minor & Narrow \\
\hline Czech Republic & - & - & Minor & Narrow \\
\hline Denmark & & + & Moderate & Medium \\
\hline Estonia & \multicolumn{4}{|c|}{ No new measures } \\
\hline Finland & - & + & Moderate & Broad \\
\hline France & & + & Moderate & Broad \\
\hline Germany & + & - & Moderate & Medium \\
\hline Greece & \multicolumn{4}{|c|}{ No new measures } \\
\hline Hungary & \multicolumn{4}{|c|}{ No new measures } \\
\hline Iceland & \multicolumn{4}{|c|}{ No new measures } \\
\hline Ireland & $+/-$ & & Minor & Medium \\
\hline Israel & + & & Moderate & Broad \\
\hline Italy & + +- & $-/+$ & Moderate & Medium \\
\hline Japan & + & - & Minor & Medium \\
\hline Korea & + & - & Minor & Medium \\
\hline Luxembourg & + & - & Minor & Broad \\
\hline Mexico & \multicolumn{4}{|c|}{ No new measures } \\
\hline Netherlands & $+/-$ & + & Moderate & Broad \\
\hline New Zealand & + & + & Minor & Broad \\
\hline Norway & + & & Moderate & Broad \\
\hline Poland & & + & Moderate & Broad \\
\hline Portugal & - & + & Major & Broad \\
\hline Slovak Republic & - & + & Moderate & Broad \\
\hline Slovenia & \multicolumn{4}{|c|}{ No new measures } \\
\hline Spain & - & + & Moderate & Broad \\
\hline Sweden & $+/-$ & & Minor & Medium \\
\hline Switzerland & & + & Minor & Narrow \\
\hline Turkey & \multicolumn{4}{|c|}{ No new measures } \\
\hline United Kingdom & + & +- & Moderate & Broad \\
\hline United States & \multicolumn{4}{|c|}{ No new measures } \\
\hline
\end{tabular}

Note: See Annex 1.A1 for the details of pension reforms.

StatLink नillst http://dx.doi.org/10.1787/888933300957

The overview of the pension reforms is supplemented by a description in greater detail in Annex 1.A1. All reforms are classified in eight different categories: coverage, diversification and security, pension benefits, taxes, indexation, work incentives, administrative efficiency and a residual group of other reforms. The grouping corresponds to the main objectives and principles of retirement-income systems.

\subsection{Improving financial sustainability}

This section deals with policy measures that, temporarily or permanently, enhance financial sustainability of pension systems. It includes reforms implemented over the last two years, on top of those legislated between September 2013 and September 2015 which are described in Annex 1.A1. The first subsection focuses on the recent measures that achieve this by reducing net pension benefits, and the second subsection presents other measures. 


\section{Improving financial sustainability by reducing net pension benefits}

Improving financial sustainability by reducing net pension benefits is possible in several ways, including changes in: outright reductions in benefit levels or pension formulae, lowering the indexation of benefits in payment including through automatic adjustment mechanisms, raising contribution rates in defined-benefit schemes, and increasing taxes and social security contributions on pension income. Policy measures to increase income adequacy, discussed in the following section, might add pressures on the financial sustainability of the pension system, and therefore operate in the opposite direction.

\section{Pension benefits}

Very few OECD countries have carried out extensive reforms to improve the financial sustainability through nominal benefit cuts. In Australia, the asset test in the Age Pension will be more tightly targeted from January 2017, generating both winners and losers while saving public money overall. In Spain, every five years from 2019, the initial pension benefit paid to new retirees will be adjusted based on life-expectancy gains.

\section{Indexation}

The longer retirement lasts the more important indexation becomes for adequacy. In order to contain public pension expenditure, some countries froze benefit indexation as a temporary measure following the crisis. However, nominal freezes of pension benefits in countries, such as Greece which are experiencing falling prices and wages (deflation), actually raise the relative value of benefits and modify relative revenues in favour of current pensioners. As a consequence this could lead to an increase in pension spending as a share of GDP. During the last two years, nominal freezing of benefits has been uncommon. Instead many countries are moving to less generous indexation options.

In the Czech Republic, the government introduced a lower level of indexation until 2015. In Finland, the indexation of earnings-related pensions was limited to $0.4 \%$ instead of well over $1 \%$ according to the previous formula. In France, the indexation of pension benefits was changed and, since 2014, the uprating occurs in October instead of April. Pension indexation has been frozen since 2011 in Greece and since 2015 in Belgium. In Italy, indexation rules for the period 2014-16 were changed into a progressive "cost-of-life" indexation where pensions above a threshold were increased by a fixed amount only. In April 2015 the Constitutional Court ruled that the partial benefit freeze of benefits above EUR 1500 in 2012 and 2013 was unconstitutional. The reimbursement of the "lost indexation" for pensions up to six times the minimum pension which follows the ruling by the Court, while increasing benefit levels, will substantially affect public finances. In the Slovak Republic, pension benefits will have increased by fixed amounts between 2013 and 2017, and thereafter they will follow consumer prices instead of the previous mix of wages and consumer prices.

Other countries introduced automatic adjustment mechanisms to strengthen the link between benefit indexation and the financial standing of the pension system. In Spain, indexation will be adjusted every year within a range depending, among others, on the ratio of pension contributions to expenses, and as noted above initial pension benefits will be revised based on changes in life expectancy. In Canada, an automatic indexation mechanism will be implemented for the Quebec Pension Plan from 2018 to ensure stable funding. In Luxembourg, a "reduction factor" which adjusts benefits to contributions was introduced in 2013. Future wage indexation of pension benefits will only be possible if annual contributions exceed pension expenditure.

\section{Taxes and contributions}

Many counties increased revenues for the financing of public pensions through higher taxes and contributions. This includes higher effective taxation of current pension income, higher pension 
contributions in defined benefit schemes (without generating additional pension entitlements) and lower tax deductions on pension contributions or on pension assets. These higher effective taxes can, however, discourage participation and/or lower savings rates in the voluntary schemes affected by the reform.

In Canada, the contribution rate for the Quebec Pension Plan is increasing from 9.9\% in 2011 to $10.8 \%$ in 2017. In France, the contribution rate will increase by 0.3 percentage points by 2017 for both employees and employers. Moreover, the $10 \%$ pension bonus for having three children will be subject to taxation. In Finland, pensioners have paid an extra tax of $6 \%$ on pension income exceeding EUR 45000 since 2013. Moreover, the social partners decided to increase the contribution rate of mandatory earnings-related systems for private sector workers (TyEL) by 0.4 percentage points annually between 2011 and 2016 .

Some countries tightened the tax incentives on contributions to voluntary schemes. In Ireland, temporary levies on private pension assets were extended and increased in 2014, while tax reliefs on private-pension contributions were reduced for high-income earners. In the Netherlands, the full tax allowance for pension contributions was capped. In addition, the work continuation credit given to all older workers was changed from a general bonus to a credit targeted towards individuals in unemployment or work incapacity or with low income. This measure will increase taxes for the groups that are not eligible for the new credit. In New Zealand, the kick-start government subsidy for each new KiwiSaver account was eliminated in May 2015. Abolishing the subsidy is estimated to save the government NZD 125 million a year over the next four years (which represents about $1 \%$ of public pension expenditure). In Sweden, tax deductions for individual contributions to private personal pensions will be phased out entirely by 2016 .

\section{Other measures to improve financial sustainability}

Strengthening work incentives and enabling more people to work at higher ages can help safeguard the financial sustainability of pension systems. Another possibility to improve financial sustainability is to promote increased administrative efficiency of pension systems. With the use of automatisation and new technologies the cost of running pension systems can be reduced.

\section{Pension age}

The employment rate falls with age well before the retirement age in all OECD and G20 countries. For individuals of age 55 to 59 the average employment rate across all OECD countries was equal to $67 \%$ in 2014 , whereas it was $44 \%$ and $20 \%$ for those aged 60-64 and 65-69 respectively (Figure 1.4). Hence, there is significant room for improvement in the vast majority of countries. Changing the statutory retirement age serves as a signal on how individuals are expected to modify behaviours when planning for retirement, thereby influencing social norms. However, most legislated increases in the retirement age phase in gradually to enable older workers to adapt their retirement planning.

Many OECD countries have reformed their pension rules in order to extend working lives in the broader context of increasing life expectancy. This means that workers need to contribute more towards their pension to help finance longer expected durations in retirement. While this generally leads to higher accrued pension entitlements, the benefit increase is usually low enough to generate net public saving. In pension schemes where there is a weak connection between contributions paid and pension benefits received, this additional contribution might only improve the sustainability of the system, i.e. without necessarily raising pension levels (e.g. France and Korea). Most pension reforms have been focused on prolonging working lives at the end of the career through: i) increases in the statutory retirement age; ii) tightening of early retirement provisions; iii) higher financial incentives to work beyond the pensionable age and higher penalties for early pension benefit; and iv) greater possibilities to combine work and pensions. 
Figure 1.4. Employment rate for people aged 55-59, 60-64 and 65-69, OECD and G20 countries, 2014

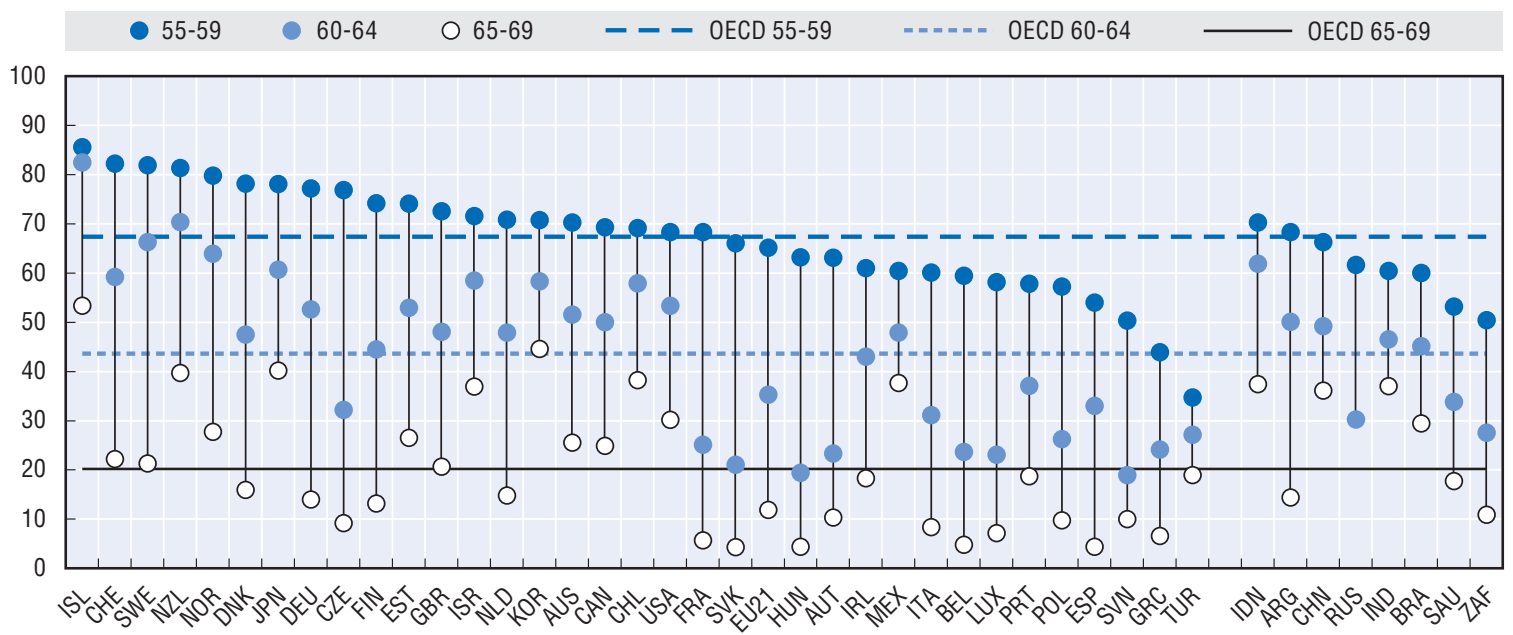

Note: Employment rates for non-OECD G20 countries are latest available.

Source: OECD (2015), OECD Employment Outlook 2015, OECD Publishing, Paris, http://dx.doi.org/10.1787/empl_outlook-2015-en.

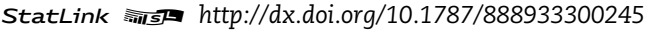

Based on the most recent legislation, the retirement age of males entering the labour market at age 20 will increase from 64 years currently, on average across all OECD countries, to 65.5 years in the late 2050s (Figure 1.5). The lowest retirement age is currently found in Slovenia where it is possible to retire at age 58.7 and the highest is found in Iceland, Israel and Norway. In the future the highest male pension age given labour market entry at age 20 will equal 68 years in the Czech Republic, Ireland and the United Kingdom. The lowest retirement age will be equal to 60 and apply in Slovenia and Luxembourg. Beyond these two countries, full-career males entering the labour market at age 20 in 2014 will be entitled to a full pension before age 64 in only Greece and France.

Figure 1.6 provides the evolution of the retirement-age gap between men and women and highlights the shrinking list of countries where women will be able to retire earlier than men. Currently, thirteen OECD countries record a positive gender gap, i.e. in favour of women, from a few months in Slovenia to five years in Austria, Chile, Israel and Poland. The gap is being eliminated in all countries except Chile, Switzerland and Israel. This primarily is due to an increase in the women's retirement age. In Italy, the retirement age of private sector workers will be equalised to 67 for men and women by 2018. There, the pension age is also increasing for public sector workers from 66.25 years in 2014 to 67 years in 2018. However, workers can still retire at any age if they have contributed a minimum period of 42.5 years for men and 41.5 years for women in 2014. In Poland, the retirement age for men and women is increasing from 65 years and 60 years, respectively, to 67 for both but in 2020 for men and 2040 for women; partial retirement at age 62 for women and 65 for men will still be possible. In the United Kingdom the pension age for women will converge to the men's level of 65 in 2018 against 62 years currently.

More and more OECD countries are raising the overall retirement age, sometimes beyond 65 which has generally been the norm in most countries in the past decade. In Belgium, the government recently announced a gradual increase in the pensionable age to 67 by 2030 . Further increases could happen thereafter through the introduction of a link to life expectancy. In Canada, the normal retirement age to be eligible to the basic pension (Old-Age Security) will gradually increase from 65 to 67 years between 2023 and 2029. In Ireland, the pension age increased from 65 to 66 years in 2014, and will rise to 67 by 2021 and 68 after 2028. In Germany, the retirement age is gradually increasing by 
Figure 1.5. Current and future retirement ages for a man entering the labour market at age 20

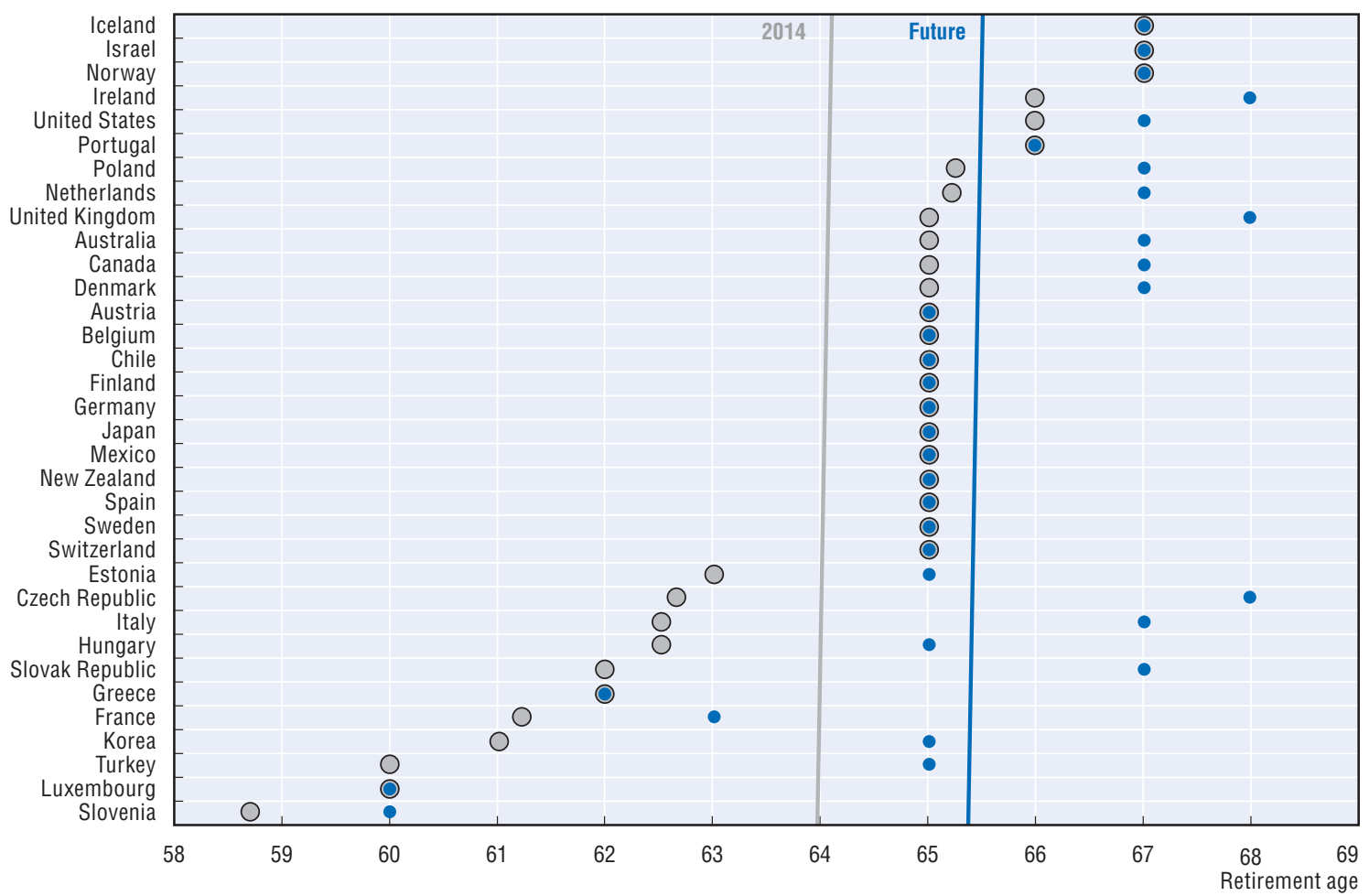

Source: See Chapter 5, Tables 5.7 and 5.9.

StatLink Ainst http://dx.doi.org/10.1787/888933300251

Figure 1.6. Current and future retirement-age gap between men and women entering the labour market at age 20

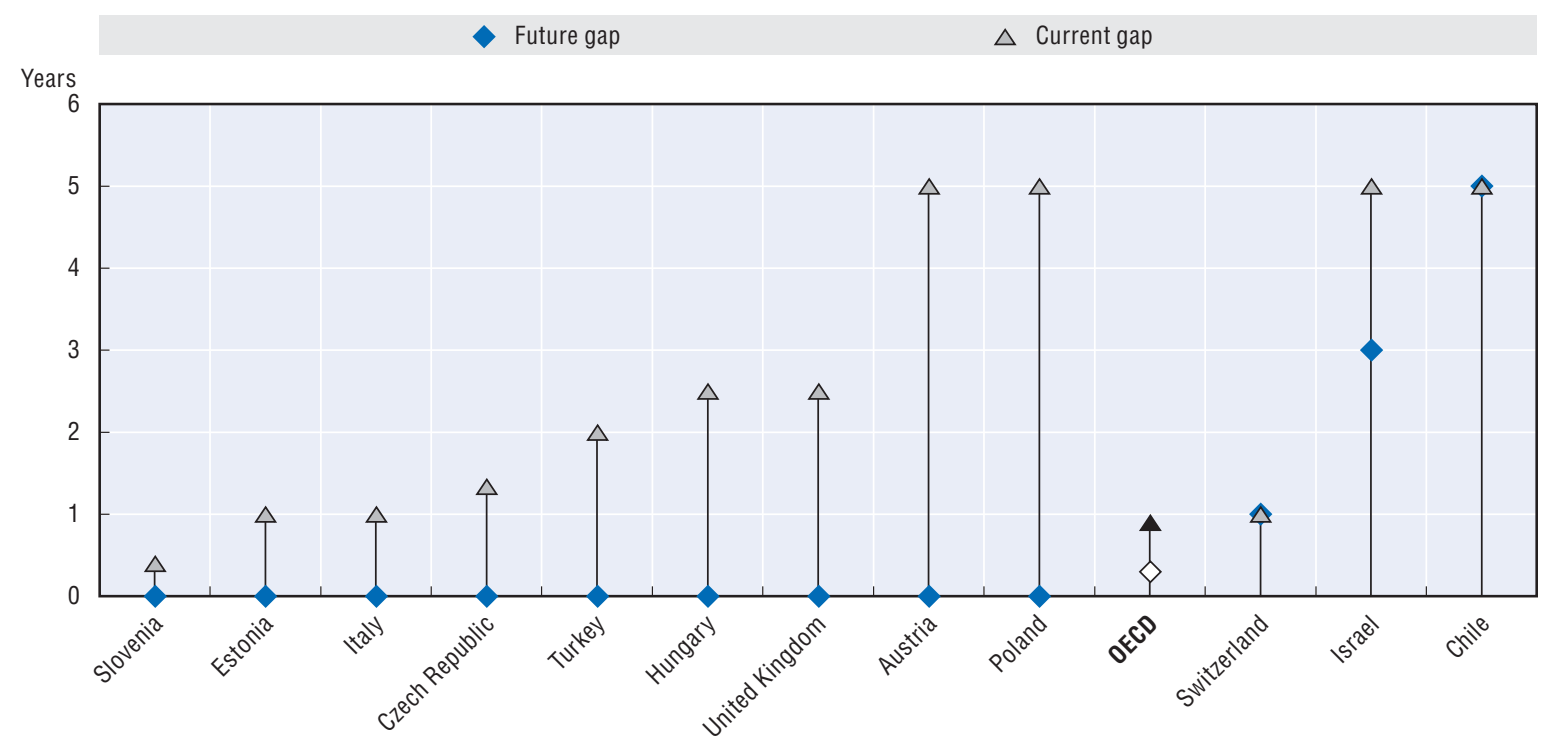

Note: Future gap refers to the age gap remaining between a man and a woman entering a full career at age 20 in 2014.

Source: See Chapter 5, Table 5.7 and Figure 5.10. 
one month a year from the current level of 65 years and four months for the 1950 cohort to reach 67 in the future as a general rule for individuals with less than 45 years of contributions. In Hungary, the pension age is increasing from 62 to 65 years. In Portugal, the retirement age was raised from 65 to 66 years and will be linked to changes in life expectancy.

In the Netherlands, the retirement age for the basic pension will reach 66 by 2018 and 67 by 2021. Since 2014 the retirement age for occupational pensions has been increasing from 65 to 67 . The retirement age is also increasing in Slovenia, although from a very low level: the retirement age will increase from 58.25 years for workers having contributed for at least 40 years in 2014 to 60 years in 2019. For individuals with less than 40 years of contributions the retirement age will be 65. The normal pension age has been increasing in Spain from 65 in 2013 to 67 in 2027, but full pension benefits are still available at age 65 with 38.5 years of contributions. In the United Kingdom, the pension age will increase to 66 in 2026 and 67 by 2028. In addition the earliest age for private pension withdrawal will be set at ten years prior to the normal pension age. In Australia, the pension age (which has been equal across gender since July 2013) will gradually increase from 65 in 2017 to 67 in 2023, as was decided in 2012. A further gradual increase to 70 in 2035 is currently being discussed. In France, the minimum contributory periods will increase from 41.5 currently to 43 years in 2035 .

\section{Early retirement age}

Many OECD countries are also restricting access to early retirement. In Austria, the required insurance period for individuals to be eligible for early retirement (Korridorpension) is increasing from 38 years in 2013 to 40 years in 2017 . On top of this, the minimum early retirement age increased in 2014, from 60 to 62 years for men and from 55 to 57 years for women. In Belgium, the age for the early retirement benefit will increase from 60.5 years in 2013 to 62 years in 2016, and the necessary contribution period will increase as well from 38 years to 40 years. Further tightening of early exit pathways in some special regimes (such as for policemen) are being considered. In Denmark, the early retirement age is currently being increased from 60 years to 64 years in 2023 while a new senior disability benefit for workers with low work capacity due to health problems is being introduced.

In Finland, the part-time pension age is being increased to 61 and early retirement is abolished for private sector workers (TyEL scheme). For workers born after 1951 the early retirement age is increased from age 62 to 63 . The early retirement pension for the unemployed is also being phased out, while unemployed individuals born before 1958 will still be able to retire at age 62 without reductions. In the Netherlands, early retirement options for workers in physical demanding occupations are being phased out. In Portugal, early retirement has been suspended until the beginning of 2015. However, long-term unemployed workers can retire from age 57. In Spain, the early-retirement age is increasing in line with the change in legal retirement age from 61 to 63 by 2027 in cases of registered unemployment; the contribution period for involuntary early retirement is increasing from 31 years to 33 years; and for voluntary early retirement, the pensionable age will be 65 and the contribution period will increase to 35 years.

\section{Financial incentives to work longer}

Financial incentives to prolong working lives have been strengthened in a number of countries and are often accompanied by increasing flexibility in the opportunities to combine pensions and work. Their overall impact on the financial balance of pension systems is not always clear-cut though as additional contributions are typically offset by additional spending. In Australia, the economic incentives for employers to hire and retain older workers were increased, thus potentially reducing public spending on Age Pension. In Austria, annual penalties for each year of early pension 
withdrawal will increase from $4.2 \%$ to $5.1 \%$ for individuals born in 1955 or after. In Canada, the benefits from delaying retirement after age 65 were increased and it is now possible to combine work and pension benefit receipt from the mandatory public scheme (Canada Pension Plan). While contributions are mandatory for individuals under 65, working beneficiaries under age 70 can now increase their benefit through additional contributions. In Norway, new requirements for occupational pensions to offer a flexible retirement age from age 62 to 75 at partial withdrawal ranging from $20 \%-80 \%$ will enable more people to accommodate further work and pension withdrawal according to their preferences. In Spain, it is now possible to work and withdraw pension benefits at the same time. In Switzerland, incentives to work and coverage of private pension plans amongst the elderly will rise, as the age limits for the payments of pension contributions were increased. In Sweden, the financial incentives to work more and longer were strengthened in 2014 with the increase in the earned income tax credit for workers over 65.

In contrast, full pension benefits (without penalties) will be awarded below the legal retirement age to people who started their career early in both France and Germany. These measures increase pension entitlements, but encourage the targeted people to exit the labour market at a relatively young age. In France, the minimum legal retirement age remains at 62; however, the age at which people may withdraw full pension benefit was lowered back from 62 to 60 for people who entered the labour market before 18 and have worked at least 41.5 years. In Germany, the pension age was decreased from 65 to 63 for individuals with 45 years of contributions. From 2015 this age will increase by two months each year until it reaches 65 , once again.

\section{Administrative efficiency}

In pay-as-you-go public defined benefit schemes, improving administrative efficiency reduces administrative costs and strengthens public finances. Indeed, the connexion between pension benefit and administration cost is often weaker than in a defined contribution scheme where administration fees more directly reduce the value of accumulated pension savings. Costs have been reduced and performance increased in a number of countries through the merging of administrations, the implementation of regulatory measures or the use of a new technology.

In Greece, government-sponsored auxiliary pension funds have been merging since 2011. In Japan, pension systems for public servants and private school employees are being merged into the employees' pension. In Spain, the administrative efficiency with regards to collecting contributions will increase as of 2014 as the General Social Security Treasury will be enabled to bill employers directly instead of having employers calculate the employee's contributions as was the case previously. This measure will most likely also reduce the administrative burden of employers.

In Poland, 51.5\% of the net assets of privately managed pension funds (corresponding to the part invested in public bonds at the time) were transferred to the Social Insurance Institution in February 2014, which came at the expense of reduced diversification and partially reversed the 1999 reform. Pension contributions to the mandatory second pillar were by default redirected to the public pension scheme, even though workers can choose to keep contributing to pension funds instead. Moreover, accumulated assets of those who choose to stay in privately managed pension funds and likewise of those who decided to move to the public pension scheme will be gradually transferred to the social security fund ten years prior to the retirement age. These measures will reduce both the public debt and the government deficit in the short term, but will increase the implicit debt of the public pension system and possibly reduce retirement income in the long term (OECD, 2014b). 
Finally, strengthening institutional oversight might improve financial sustainability. In Spain, a new independent public agency, the Independent Agency for Fiscal Responsibility, was created in November 2013. The agency will express opinions about annual adjustments of benefits and changes in the sustainability factor.

\subsection{Increasing retirement-income adequacy}

The tightening of benefits as part of fiscal consolidation programmes can have serious consequences for the living standards of the elderly, and could be especially painful if the cuts are made from an already low level. Despite the heavy focus of recent pension policy action on improving the financial side of pension systems, some measures have also been taken to boost retirementincome adequacy. The section describes the improvements that occurred to improve adequacy of pension benefits, including those implemented over the last two years, thus covering a broader range of reforms than those presented in Annex 1.A1.

Reforms to improve adequacy include increasing coverage or benefit levels or both. Improvements in disposable income for retired people can also be achieved by lowering taxes targeted towards them. In systems with a stronger direct link between contributions paid and benefits received retirement-income adequacy tends to increase when higher contributions are paid into the system, through either higher contribution rates or longer contribution periods. This is especially the case in defined-contribution-type schemes.

The so-called replacement rate is one measure of adequacy (for a comprehensive overview of all OECD pension entitlement indicators and the assumptions underlying their estimation, see Chapter 6). The net replacement rate is equal to the ratio of the net pension entitlement to life-time average net earnings. Theoretical replacement rates are forward-looking and assume that currently legislated pension rules apply throughout an individual's career until reaching the normal pensionable age in each country. Pensionable age is defined here as the age at which individuals can first withdraw their full pension benefits, i.e. without actuarial reductions or penalties, assuming they start a full career in 2014 at age 20.

Figure 1.7 shows theoretical net pension replacement rates across OECD and G20 countries for a full-career worker at either low or average earnings. The OECD average for net replacement rates for average-income earners is equal to $63 \%$, ranging from $28 \%$ in Mexico to $105 \%$ in Turkey. Low-income earners generally have higher net replacement rates than average-income earners due to the progressivity of the tax-pension benefit systems that is in place in most OECD countries. Countries with the highest net pension replacement rates for low-income earners are Denmark, Luxembourg, the Netherlands and Turkey. In Mexico, net replacement rates for low-income earners, at about 35\%, is well below the OECD average, which is equal to $75 \%$.

\section{Coverage}

Ensuring adequate population coverage by retirement schemes is a significant policy concern in a number of OECD countries in order to fight income-poverty in old age. All OECD countries have set up mandatory or quasi-mandatory pension systems so as to achieve high coverage in public and/or private pension schemes. Yet, countries with a large informal sector, such as Mexico and Chile and some G20 countries may have lower coverage levels even in mandatory schemes (OECD/IDB/ The World Bank, 2014).

Since 2013, a number of OECD countries have undertaken reforms to extend the coverage of pension benefits to groups previously not covered by mandatory or quasi-mandatory pension entitlements. Others have introduced new benefits altogether to extend coverage. In Japan, from April 2017 the qualifying period for the national pension will decrease from 25 to 10 years hence increasing coverage and benefiting short-career workers. In addition, the employees' pension 
Figure 1.7. Future net replacement rates for low and average income earners in OECD and G20 countries

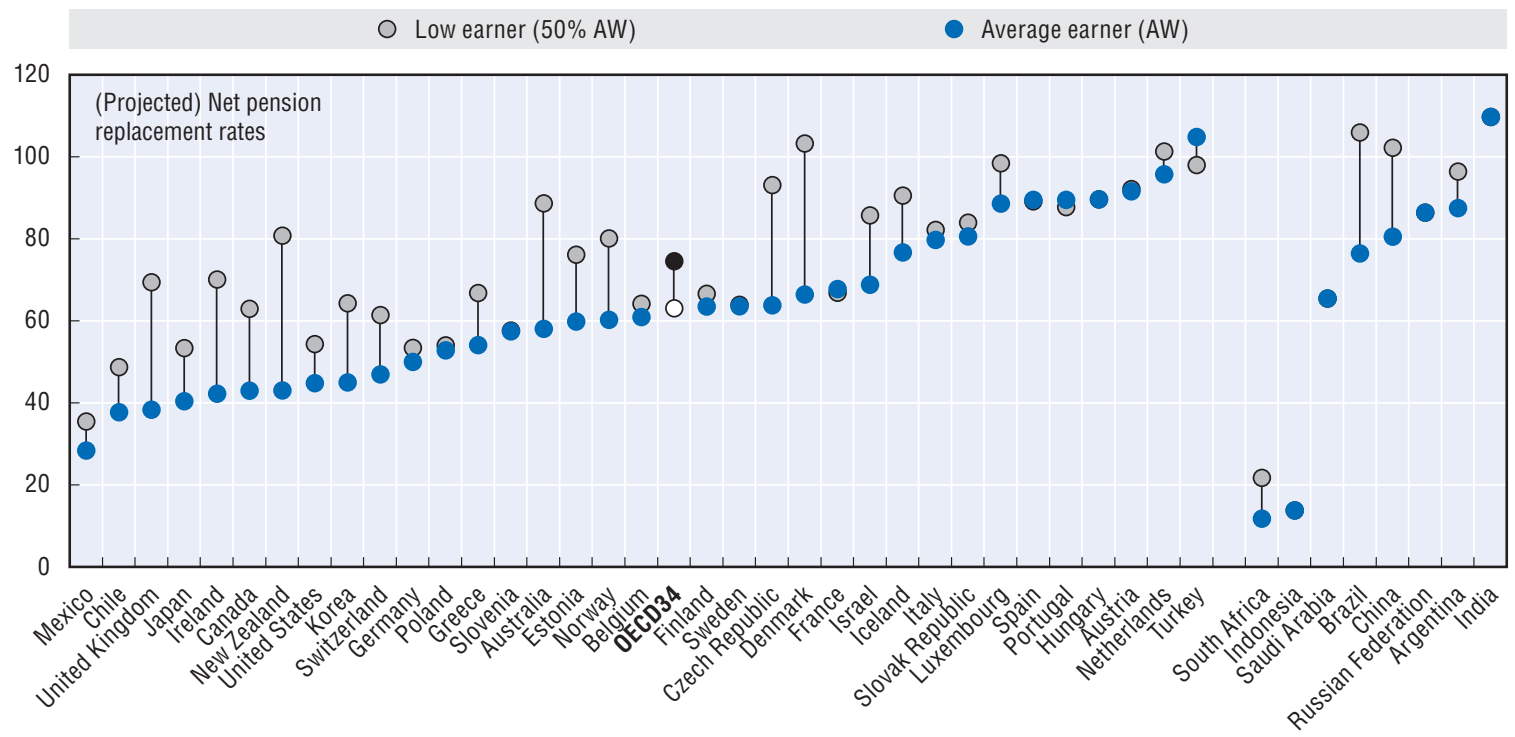

Note: The net replacement rate is calculated assuming labour market entry at age 20 in 2014 and a working life equal to the pensionable age in each country The net replacement rates shown are calculated for an individual with $100 \%$ and $50 \%$ of average worker earnings (AW).

Source: See Chapter 6, Table 6.7 and Figure 6.9.

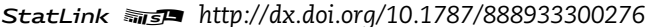

insurance will be extended to cover more part-time workers from October 2016 and the survivor's pension was extended to motherless families from April 2014. A new targeted benefit was introduced in Korea in July 2014, doubling the level of the preceding scheme. The measure benefits about $70 \%$ of those aged 65 and over.

Following reforms over the last two decades in many OECD countries, voluntary private pensions might increasingly become an important complement to public pensions as replacement rates from the latter are often expected to diminish. As a result, obtaining adequate coverage levels in private schemes is a policy objective which is attracting more and more attention. This might, however, lead to additional public spending if governments encourage their development through financial incentives.

Countries such as Canada, Ireland, the United Kingdom and the United States have had the longest tradition of complementing public pensions with voluntary private pensions. In the past two years, some countries introduced saving incentives (matched contributions, subsidies, tax deductions or credits) to increase coverage in voluntary private pensions, even though current budget pressures limit the room for manoeuvre in this area. Other countries focused on non-financial incentives, including auto-enrolment and mandatory pension savings. In the United Kingdom, auto-enrolment in a workplace pension scheme is being introduced gradually, depending on the size of the employer. While large employers must automatically enrol workers in a company scheme or in the state-run National Employment Saving Trust (NEST) since October 2012 and medium-size employers since April 2014, small employers must comply from January 2016. A similar reform introducing an occupational pension scheme (MySaver) for uncovered workers is planned in Ireland and is supposed to be implemented once the economic conditions become more favourable. In Canada, new schemes were created to encourage participation and savings in voluntary private pension plans. A new type of retirement savings plan (the Pooled Registered Pension Plan, PRPP) is now available in some provinces and in sectors governed by federal legislation; others provinces are expected to follow. The PRPP is voluntary for employers and based on auto-enrolment of employees; it is meant to address low workplace pension coverage, increase portability, reduce administrative fees and lower employers' investment risks. 
Some countries went in the other direction and abandoned the efforts to introduce mandatory or voluntary accounts altogether. In the Czech Republic the second pillar of voluntary individual accounts that has been effective since 2013 will be closed in 2016 due to low take-up. In the Slovak Republic, the mandatory defined contribution system was made voluntary in 2015 for the fourth time since its introduction in 2005. Voluntary participation is possible for new entrants and voluntary entrance is possible before the age of 35 years for those who choose to switch some of their pension contributions.

\section{Pension benefits}

Increasing the existing pension benefits of current retirees is the most direct way to address ongoing adequacy concerns. ${ }^{3}$ A number of countries enacted ad hoc improvements in pension benefits targeting vulnerable groups. There have been upgrades in the targeted household benefits in Ireland in 2015 , and the basic pension has increased by about $0.4 \%$ per year on top of wage growth in Luxembourg from October 2012. Low-income old-age pensioners will receive welfare benefits in Japan from April 2017 (Chapter 2 focuses on first-tier pensions more generally).

Over the course of a working life, individuals might experience voluntary or involuntary career breaks. Such breaks can be detrimental to pension benefit levels, and, in some cases, to incentives to work longer (see Chapter 3). In order to mitigate the effects of career breaks some countries chose to ease the rules on how periods of low or no income are accounted for in the pension benefit formula. In Canada, past earnings are ranked in descending order and the months with the lowest earnings are dropped from the pension benefit calculation. In 2014 the share of disregarded months was increased from $16 \%$ to $17 \%$. In France, the accrual of pension entitlements during periods of maternity leave, professional training, tertiary education and unemployment will become more generous. In Japan, workers will be able to make up gaps in their contribution record by paying additional voluntary contributions. In Germany, the introduction of credits for children born before 1992 (i.e. the mothers' pension) will increase current and future pension benefits retroactively.

Higher contribution rates in defined contribution schemes is another way to improve adequacy. In Australia, mandatory defined contribution rates will start to increase in July 2021 from 9.5\% (the current level) and reach $12 \%$ in 2025 . In Israel, the mandatory minimum contribution rate increased from $15 \%$ to $17.5 \%$ in 2014 . In Norway, the new notional defined contribution system that is gradually introduced for cohorts born from 1954 with a contribution rate equal to $18.1 \%$ of pensionable income creates a stronger link between life-time earnings and the size of the pension benefit, and will increase flexibility to combine work and pensions. In the United Kingdom, the minimum NEST contribution rate will increase between 2017 and 2018 from 1\% to 3\% for employers with employees obliged to supplement this to an overall minimum contribution level of $8 \%$ (including $0.2 \%$ to $1 \%$ of tax relief). Also, from 2016, a new state pension will replace the basic pension and the state second pension (earnings-related public pension), as well as the savings credit of the Pension Credit (targeted benefit, see the United Kingdom country profile in Chapter 9 of OECD, 2013), thereby improving the benefit level overall.

\section{Taxation}

The tax and social contribution system plays an important role for net retirement income. Given the progressivity of income tax systems and the fact that pension income is generally lower than income from work, effective tax rates on retirement income tend to be lower than those on income from work. Moreover, most tax systems give preferred treatment to pension income or pensioners, thereby addressing pension adequacy concerns, however at the cost of creating tax distortions. 
A number of OECD countries have improved net retirement incomes by reducing total taxes and social contributions paid by pensioners. In Portugal, the extraordinary solidarity surcharge introduced in 2013-14 will be limited to pensions exceeding EUR 4611 from 2015. The applicable rate is $15 \%$ for pensions up to EUR 7127 ansd $40 \%$ beyond. In Poland, a new tax incentive for voluntary personal plans was introduced. Increased tax relief was given to older people in Sweden in 2014. In the United Kingdom, the taxes on withdrawals from pension accounts were lowered and tax-free amounts for pension lump sum withdrawal were increased in 2015. These measures will make it cheaper to withdraw money from pension accounts. On a different note, women on maternity leave in Japan have had an increase in their disposable income as they have been exempt from employees' pension contributions since April 2014.

\section{Other ways of improving retirement income adequacy}

There are other possibilities to improve pension adequacy. In defined contribution plans lower costs and higher administrative efficiency directly affect the pension benefit. In addition better information and services to limit myopic behaviour improve individuals' choice. Finally, the diversification between funded and pay-as-you-go, and between defined benefit and defined contribution enables risk mitigation as systems have different strengths and weaknesses, thus achieving a better risk-return profile of pension income.

\section{Administrative efficiency}

In the design of voluntary pension schemes, there is a clear trade-off between on the one hand greater flexibility and choice in these plans to meet the needs of different workers at differing stages of their lifecycle and on the other hand minimising fees. High fees might discourage workers from joining voluntary plans and make mandatory plans costly. More generally, excessive cost structures could threaten not only financial sustainability and income adequacy of all pension schemes, but also their entire legitimacy. Recent reforms that aim to reduce costs directly and provide more information to increase transparency and competition through the disclosure of costs, fees and performance are successively discussed.

Reducing fees in defined contributions schemes has been a key objective for many regulators. In Chile, Planvital, one of the six private pension fund administrators, won the tender to manage defined contribution accounts for new entrants; the new annual fee will be $0.47 \%$ on account holder's earnings compared to $0.77 \%$ previously. In Australia, a new simple defined contribution scheme (MySuper) will cover new default pension funds chosen by employers (default contributions) from 1 January 2014, and will offer a more uniform, easier to compare set of products. All pre-existing employer-nominated default fund balances will be transferred into a MySuper account by 1 July 2017. In the United Kingdom, the new National Employment Savings Trust (NEST) scheme will create economies of scale and is hoped to lower administration costs.

Better information disclosure and data collection can improve the efficiency of a pension system. In Australia, the SuperStream project will establish mandatory, uniform e-commerce standards for contributions to superannuation funds and for transfers between funds ("rollovers"). Implementation will be completed by the end of 2015-16. In France, beginning in 2016 all workers covered by pension insurance will have an electronic account that provides relevant pension related information, such as past contributions, work history and projected pension benefits from both public and mandatory occupational systems. In an attempt to increase competition and public awareness in New Zealand, providers of the government-subsidised voluntary retirement saving scheme (the so-called "Kiwisaver") are required to post on their websites information regarding fund performance, fees, returns, portfolios and key staff information on a quarterly basis. In addition KiwiSaver default providers will have to offer financial education and impartial financial advice to account holders. In 
the United Kingdom, pension providers and trust based managers must offer members of defined contribution schemes free and impartial face-to-face advice. Small defined contribution plans are automatically transferred to the new pension plan when workers change jobs.

Finally, automatic enrolment and enhanced automatisation increase both prospective adequacy and financial sustainability as it aims both to increase take-up and to lower administrative costs. In Canada, between 2013 and 2016, an automatic enrolment regime for the minimum pension (Old-Age Security) benefit is being phased in aimed at lowering both the administrative burden on seniors and the pension administrative costs, and should also increase take-up.

\section{Diversification and security}

Some countries have focused their effort on increasing investor choice for funded schemes. In the United Kingdom, new rules for defined contribution pension withdrawals were legislated in May 2014 and will enable large lump-sum withdrawals. While this measure might increase pensioners' control over their accumulated funds, it could be detrimental to both retirement-income adequacy and incentives to work, due to individuals' myopic behaviour and insufficient financial literacy. The overall outcome depends on how successful individuals are in assessing their needs over their remaining life expectancy. In any case, such withdrawals run the risk that retirees outlive their savings, especially those with low wealth.

Other countries chose to improve the security of investment. These measures can consist of improving the governance and risk management of pension plans or in reducing individuals' investment risks. In Chile, minimum and maximum limits for foreign currency hedges have been established in order to lower risk. In Ireland, major changes were implemented to increase the overall security of private pensions. They involve a new benefit security in case of company bankruptcy, increased risk reserves from 2016, stricter reporting of actuarial reserves and an age-dependent capitalisation amount used for defined benefit pensions from 2014. In Italy, new pension fund investment regulations have been introduced since 2014 . The new rules aim to create more prudent management of investments and more diversified portfolios. A law to improve the governance of occupational pension plans was also passed in the Netherlands in 2013. In New Zealand, KiwiSaver default providers will maintain a conservative investment strategy with only $15-25 \%$ allocation in growth (i.e. riskier) assets such as shares and property. In Mexico, the pension funds within the individual accounts system have loosened age-dependent limits on fund investments in equities. In the Slovak Republic, a rate-of-return guarantee was introduced for the low-risk investment option. In Norway, the occupation pension plans are allowed more flexibility in their system design to better complement the new public notional accounts system, hence resulting in greater choice for employers and individuals.

In Japan, financially unsound employees' pension funds (EPFs) have been under dissolution since April 2014. The EPFs with assets above the minimum reserve level can continue, but must pass an annual asset test, and no new EPFs can be set up.

\subsection{Remaining challenges}

Pension systems across OECD countries face considerable social and economic challenges in the wake of the economic crisis and given the ongoing population ageing. The widespread large increase in government debt levels in many counties have motivated more pension reforms in most OECD countries during the last two years. In many cases, the problem of weak financial sustainability is not new but has been compounded by the crisis and its aftermath.

Pension systems still need to adjust to persisting demographic changes. The extent to which individuals, of all ages, will be willing and able to work more and longer will be a crucial issue in ageing societies. Concerns about income security at a much higher age than what we are used to will 
grow in importance, in a context where more countries opt for less generous indexation of pension benefits and more elderly are likely to outlive their accumulated resources (Chapter 2). Some countries have opted for introducing automatic adjustment mechanisms into their pension systems, based on demographic and economic developments. Although these innovations are promising to reduce political risks their correct design and implementation still need to be worked out.

Older workers who are laid off still too often enter into early-retirement programmes. This approach, which is internalised by both employers and employees, gives older workers little opportunity to re-train and acquire new skills in order to strengthen their employability. Early retirement also exposes individuals to future poverty as income needs at a much higher age are often underestimated. Early retirement systems should be eliminated, and employment difficulties faced by the elderly should be dealt with by unemployment systems that promote activity as a way to protect and help people remain on the labour market longer. Beyond this, with the tightening of benefit eligibility criteria in most OECD pension systems, ensuring that the labour market is conducive to longer working lives is vital. In that respect, increases in the labour supply of older workers have to be met by a higher demand. Upgrading of skills and lifelong learning will therefore become important to retain older workers in the labour market.

Private pension systems face specific challenges. Low interest rates reduce the capacity of pension funds and life insurance companies to fulfil their commitments to retirees and pension savers in defined benefit pension plans (OECD, 2015b). In defined contribution schemes it might be difficult for individuals to achieve adequate pension levels if rates of return remain low. One important concern in this context is that individuals might not be contributing enough.

Rebuilding trust is also demanding. Better information and increased transparency about administrative cost and pension entitlements would improve confidence in the pension systems and help improve governance. Young people in particular need to believe in the long-term stability of the pension system and the pension promises that are made to them in order to have them endorse the generational contract.

Pension reform activity should be deepened in several areas. While special regimes have been reduced, and there has been a convergence of public-sector and private-sector schemes in many OECD countries, wide differences persist in some. Also, the self-employed do not contribute enough in some countries due to a combination of their short-sightedness and ineffective policies. Increasing their pension coverage remains a challenge, which might relate in some cases to reducing informality and increasing tax collection.

Furthermore, the extent to which pension regimes can tackle the situation of individuals who have worked in arduous conditions is not obvious and early-retirement pathways due to arduous work have often been misused in the past. While these schemes might be justified for some narrowly defined groups, they generally are an inefficient policy response to compensate individuals for impaired health or shorter life expectancy. Instead policy makers should seek to prevent hazardous or arduous working conditions from happening in the first place, shifting the focus from a passive pension problem towards the end of life to a health and work-environment issue when the arduous work occurs. Finally, survivors' pensions should be reformed in many OECD countries, by moving closer to actuarial fairness while taking into account life events such as divorce; the objective would be to contribute to enhancing gender equality and boosting women's labour supply through stronger incentives to economic independence and work. In the short term, however, reforming survivors' pensions might increase vulnerabilities, and phasing-in effects should be closely analysed. 
Pension systems might in fact extend inequalities that already compound through the working-life cycle due to the interrelation between poor health and poor labour market experience. Pension rules or annuity formulae used to compute the benefits, in either defined benefit or defined contribution systems, typically do not take into account the disparities in mortality rates that are correlated with income. The latter imply that poor pensioners tend to receive their pensions for a shorter period on average. This makes pension systems less redistributive than expected when ignoring inequalities in life expectancy, and might make some of them even regressive.

\section{Notes}

1. Source: European Commission (2015), Ageing Report; Australia: Commonwealth of Australia (2015), 2015 Intergenerational Report: Australia in 2055; Standard and Poor's (2013), Global Aging 2013: Rising to the Challenge: Argentina, Brazil, China, Iceland, India, Indonesia, Japan, Korea, Mexico, Saudi Arabia and the United States.

2. Public pension spending is projected to increase from $1.7 \%$ to $12.5 \%$ of GDP in Korea and from $6.3 \%$ to $17.0 \%$ in Turkey according to Standard and Poor's (2013), Global Aging 2013: Rising to the Challenge.

3. Increases in pension benefits linked to the adjustments of indices are treated below.

\section{References}

European Commission (2015), The 2015 Ageing Report: Economic and budgetary projections for the 28 EU Member States (2013-2060), Publications Office of the European Union, Luxembourg.

European Commission (2012), The 2012 Ageing Report: Economic and budgetary projections for the 27 EU Member States (2010-2060), Publications Office of the European Union, Luxembourg.

OECD (2015a), OECD Employment Outlook 2015, OECD Publishing, Paris, http://dx.doi.org/10.1787/empl_outlook-2015-en.

OECD (2015b), OECD Business and Finance Outlook 2015, OECD Publishing, Paris, http://dx.doi.org/10.1787/ 9789264234291-en.

OECD (2015c), Interim Economic Assessment - 18 March 2015: Tailwinds driving a modest acceleration... but storm clouds on the horizon?, OECD Publishing, Paris, www.oecd.org/eco/outlook/Interim-Assessment-Handout-Mar-2015.pdf.

OECD (2014a), Income Inequality Update - June 2014, OECD Publishing, Paris, www.oecd.org/els/soc/OECD2014-IncomeInequality-Update.pdf.

OECD (2014b), OECD Economic Surveys: Poland 2014, OECD Publishing, Paris, http://dx.doi.org/10.1787/eco_surveys-pol2014-en.

OECD (2013), Pensions at a Glance 2013: OECD and G20 Indicators, OECD Publishing, Paris, http://dx.doi.org/10.1787/ pension_glance-2013-en.

OECD/IDB/The World Bank (2014), Pensions at a Glance: Latin America and the Caribbean, OECD Publishing, Paris, http://dx.doi.org/10.1787/pension_glance-2014-en.

Standard and Poor's (2013), Global Aging 2013: Rising To The Challenge.

United Nations, Department of Economic and Social Affairs, Population Division (2013), World Population Prospects: The 2012 Revision. 


\section{Pension reforms from September 2013 to September 2015}

Table 1.A1.1. Details of pension reforms, September 2013-September 2015

By country and prime objective

\begin{tabular}{|c|c|c|c|c|c|c|c|c|}
\hline & Coverage & $\begin{array}{l}\text { Diversification } \\
\text { and security }\end{array}$ & Pension benefits & $\begin{array}{l}\text { Taxes and defined } \\
\text { benefit } \\
\text { contributions }\end{array}$ & Indexation & Work incentives & $\begin{array}{l}\text { Administrative } \\
\text { efficiency }\end{array}$ & Other \\
\hline Australia & & & $\begin{array}{l}\text { Mandatory } \\
\text { DC contributions } \\
\text { increased } \\
\text { from } 9 \% \text { to } 9.5 \% \\
\text { from July } 2014 \text {. } \\
\text { The contribution } \\
\text { rate will remain } \\
\text { at } 9.5 \% \text { until } \\
\text { July } 2021 \\
\text { and reach } 12 \% \\
\text { by July } 2025 . \\
\text { The assets test } \\
\text { in the Age Pension } \\
\text { is rebalanced } \\
\text { from Jan. } 2017 . \\
\text { The benefit will } \\
\text { become more } \\
\text { targeted but also } \\
\text { more generous. } \\
\text { The overall effect } \\
\text { is estimated } \\
\text { create savings } \\
\text { for the Treasury. }\end{array}$ & & $\begin{array}{l}\text { General } \\
\text { concessional } \\
\text { contributions cap } \\
\text { indexes } \\
\text { to AUS } 30000 \\
\text { from July } 2014 \text {. }\end{array}$ & $\begin{array}{l}\text { Restart Wage } \\
\text { Subsidy Program } \\
\text { commenced } \\
1 \text { July 2014, } \\
\text { replacing } \\
\text { the Seniors } \\
\text { Employment } \\
\text { Incentive Payment } \\
\text { and Mature Aged } \\
\text { Worker Tax Offset. }\end{array}$ & $\begin{array}{l}\text { In } 2014 \text { MySuper } \\
\text { products replaced } \\
\text { default } \\
\text { superannuation } \\
\text { products for all } \\
\text { new accounts } \\
\text { and all existing } \\
\text { default balances } \\
\text { will have to be } \\
\text { transferred into a } \\
\text { MySuper account } \\
\text { by } 1 \text { July } 2017 . \\
\text { The SuperStream } \\
\text { project will } \\
\text { establish } \\
\text { mandatory, } \\
\text { uniform } \\
\text { e-commerce } \\
\text { standards } \\
\text { for contributions } \\
\text { to superannuation } \\
\text { funds and } \\
\text { for transfers } \\
\text { between funds } \\
\text { ("rollovers"). } \\
\text { Implementation } \\
\text { will be complete } \\
\text { by the end } \\
\text { of } 2015-16 \text {. }\end{array}$ & \\
\hline Austria & & & & & & $\begin{array}{l}\text { For cohorts } \\
\text { born } 1955 \\
\text { and later the early } \\
\text { retirement penalty } \\
\text { will increase } \\
\text { from } 4.2 \% \\
\text { to } 5.1 \% \\
\text { (max. of } 15.3 \% \text { ). }\end{array}$ & & \\
\hline
\end{tabular}


Table 1.A1.1. Details of pension reforms, September 2013-September 2015 (cont.)

By country and prime objective

\begin{tabular}{|c|c|c|c|c|c|c|c|c|}
\hline & Coverage & $\begin{array}{l}\text { Diversification } \\
\text { and security }\end{array}$ & Pension benefits & $\begin{array}{l}\text { Taxes and defined } \\
\text { benefit } \\
\text { contributions }\end{array}$ & Indexation & Work incentives & $\begin{array}{l}\text { Administrative } \\
\text { efficiency }\end{array}$ & Other \\
\hline Belgium & & & & & & $\begin{array}{l}\text { The government } \\
\text { recently } \\
\text { announced } \\
\text { a gradual increase } \\
\text { in the pensionable } \\
\text { age to } 67 \text { by 2030, } \\
\text { a link to life } \\
\text { expectancy } \\
\text { thereafter, a } \\
\text { one-year increase } \\
\text { in the early- } \\
\text { retirement age, } \\
\text { the further } \\
\text { tightening of the } \\
\text { unemployment- } \\
\text { exit pathway, the } \\
\text { abolition of lower } \\
\text { retirement ages } \\
\text { in some special } \\
\text { regimes (such as } \\
\text { for the policemen). }\end{array}$ & & $\begin{array}{l}\text { The government } \\
\text { has initiated } \\
\text { a proposal } \\
\text { to introduce } \\
\text { a point scheme } \\
\text { aligning the public } \\
\text { and private } \\
\text { pension schemes } \\
\text { and some } \\
\text { mechanisms } \\
\text { to develop further } \\
\text { the private pension } \\
\text { pillar. }\end{array}$ \\
\hline Canada & $\begin{array}{l}\text { A new voluntary } \\
\text { retirement savings } \\
\text { plan (Pooled } \\
\text { Registered Pension } \\
\text { Plan, PRPP), based } \\
\text { on auto-enrolment } \\
\text { of employees } \\
\text { working for an } \\
\text { employer who opted } \\
\text { in has been } \\
\text { introduced in sectors } \\
\text { under federal } \\
\text { jurisdictions. } \\
\text { In 2014 British } \\
\text { Columbia and Nova } \\
\text { Scotia where added } \\
\text { to this group, while } \\
\text { legislation was } \\
\text { adopted in Ontario } \\
\text { in } 2015 \text {. The Quebec } \\
\text { version of PRPPs } \\
\text { was adopted } \\
\text { in Dec. 2013. } \\
\text { Legislation creating } \\
\text { the Ontario } \\
\text { Retirement Pension } \\
\text { Plan (ORPP) was } \\
\text { adopted in } \\
\text { April } 2015 \text {, which } \\
\text { will introduce a new } \\
\text { mandatory pension } \\
\text { scheme for Ontario } \\
\text { employers and } \\
\text { employees not } \\
\text { participating in a DB } \\
\text { and some DC plans } \\
\text { (starting in 2017). }\end{array}$ & & $\begin{array}{l}\text { Increase of the } \\
\text { general drop-out } \\
\text { provision for } \\
\text { the Canada } \\
\text { Pension Plan } \\
\text { to exclude } 17 \% \\
\text { (from } 16 \% \text { ) } \\
\text { of the contributory } \\
\text { period of low } \\
\text { earnings from } \\
\text { the benefit } \\
\text { calculation } \\
\text { in } 2014 \text {. }\end{array}$ & $\begin{array}{l}\text { Contribution rate } \\
\text { for the Quebec } \\
\text { Pension Plan is } \\
\text { increasing } \\
\text { from } 10.2 \% \\
\text { in } 2013 \text { to } 10.35 \% \\
\text { in } 2014 \text { and } 10.5 \% \\
\text { in } 2015 \text {. }\end{array}$ & & $\begin{array}{l}\text { People over } 60 \text { are } \\
\text { now able to collect } \\
\text { CPP benefits } \\
\text { and work. } \\
\text { As well, the } \\
\text { Post-Retirement } \\
\text { Benefit was } \\
\text { introduced } \\
\text { for individuals who } \\
\text { work while } \\
\text { receiving CPP } \\
\text { benefits. } \\
\text { Contributions are } \\
\text { mandatory } \\
\text { for people under } \\
65 \text { and optional } \\
\text { from } 65 \text { to } 70 . \\
\text { The CPP } \\
\text { requirement } \\
\text { to stop working } \\
\text { or reduce income } \\
\text { to become eligible } \\
\text { for an early } \\
\text { retirement pension } \\
\text { was eliminated. }\end{array}$ & & \\
\hline
\end{tabular}


Table 1.A1.1. Details of pension reforms, September 2013-September 2015 (cont.)

By country and prime objective

\begin{tabular}{|c|c|c|c|c|c|c|c|c|}
\hline & Coverage & $\begin{array}{l}\text { Diversification } \\
\text { and security }\end{array}$ & Pension benefits & $\begin{array}{l}\text { Taxes and defined } \\
\text { benefit } \\
\text { contributions }\end{array}$ & Indexation & Work incentives & $\begin{array}{l}\text { Administrative } \\
\text { efficiency }\end{array}$ & Other \\
\hline Chile & $\begin{array}{l}\text { Since 2012-14 } \\
\text { self-employed are } \\
\text { automatically } \\
\text { enrolled with } \\
\text { the option to opt- } \\
\text { out. From } 2015 \\
\text { all eligible } \\
\text { self-employed } \\
\text { workers are obliged } \\
\text { to contribute } \\
\text { to the system. }\end{array}$ & $\begin{array}{l}\text { Minimum } \\
\text { and maximum } \\
\text { limits for foreign } \\
\text { currency hedges } \\
\text { have been } \\
\text { established. }\end{array}$ & & & & & $\begin{array}{l}\text { As an outcome } \\
\text { of the auction } \\
\text { in } 2014 \text { of new } \\
\text { members } \\
\text { the minimum } \\
\text { management fees } \\
\text { decreased } \\
\text { from } 0.477 \% \\
\text { to } 0.47 \% \text { of an } \\
\text { account holder's } \\
\text { monthly earnings. } \\
\text { Also, the fees } \\
\text { for providing } \\
\text { disability and } \\
\text { survivor insurance } \\
\text { decreased } \\
\text { from } 1.49 \% \\
\text { to } 1.15 \% \text {. }\end{array}$ & \\
\hline Czech Republic & $\begin{array}{l}\text { The voluntary } \\
\text { individual accounts, } \\
\text { effective from } 2013 \\
\text { will be closed as } \\
\text { of } 2016 \text { due to low } \\
\text { take-up. }\end{array}$ & & & & & & & \\
\hline Denmark & & & & & & $\begin{array}{l}\text { Increased early } \\
\text { retirement age } \\
\text { (2014). A new } \\
\text { "senior disability } \\
\text { benefit" } \\
\text { for workers } \\
\text { in physically } \\
\text { demanding jobs } \\
\text { with work-related } \\
\text { health problems is } \\
\text { being created } \\
\text { (2014). }\end{array}$ & & \\
\hline
\end{tabular}


Table 1.A1.1. Details of pension reforms, September 2013-September 2015 (cont.)

By country and prime objective

\begin{tabular}{|c|c|c|c|c|c|c|c|c|}
\hline & Coverage & $\begin{array}{l}\text { Diversification } \\
\text { and security }\end{array}$ & Pension benefits & $\begin{array}{l}\text { Taxes and defined } \\
\text { benefit } \\
\text { contributions }\end{array}$ & Indexation & Work incentives & $\begin{array}{l}\text { Administrative } \\
\text { efficiency }\end{array}$ & Other \\
\hline Finland & & & & $\begin{array}{l}\text { The social partners } \\
\text { have agreed } \\
\text { to increase } \\
\text { the combined } \\
\text { employer/ } \\
\text { employee } \\
\text { contributions } \\
\text { to earnings-related } \\
\text { plans (TyEL) } \\
\text { by } 0.4 \% \text { annually } \\
\text { between } 2011 \\
\text { and } 2016 \text {. }\end{array}$ & $\begin{array}{l}\text { In } 2015 \text { the } \\
\text { pension indexation } \\
\text { planned for } \\
\text { (earnings-related } \\
\text { and KELA) was } \\
\text { limited to } 0.4 \% \\
\text { instead of well } \\
\text { over } 1 \% \text {. }\end{array}$ & $\begin{array}{l}\text { The legislation } \\
\text { enabling disability } \\
\text { pensioners to have } \\
\text { work for two years } \\
\text { without losing } \\
\text { right to a pension } \\
\text { will be extended } \\
\text { until the end } \\
\text { of } 2016 \text {. } \\
\text { The part-time } \\
\text { pension age will } \\
\text { increase to } 61 \\
\text { for those born } \\
\text { after } 1953 \text { and } \\
\text { cuts in pension } \\
\text { accrual will be } \\
\text { implemented. } \\
\text { Early retirement is } \\
\text { eliminated under } \\
\text { TyEL for workers } \\
\text { born after } 1951 . \\
\text { For KELA the early } \\
\text { retirement age is } \\
\text { increasing to } 63 \text {. } \\
\text { The } \\
\text { unemployment } \\
\text { pension } \\
\text { programme is } \\
\text { phased out } \\
\text { in } 2014 \text {. Long- } \\
\text { term unemployed } \\
\text { born before } 1958 \\
\text { can still retire at } 62 \\
\text { with a full pension. }\end{array}$ & $\begin{array}{l}\text { New rules } \\
\text { on transparency } \\
\text { for private sector } \\
\text { providers have } \\
\text { been accepted } \\
\text { by Parliament. } \\
\text { The new law will } \\
\text { require employees } \\
\text { able to influence } \\
\text { the company's } \\
\text { investment } \\
\text { decisions to report } \\
\text { their stock } \\
\text { exchange holdings } \\
\text { and business } \\
\text { dealings } \\
\text { (Jan. 2015). }\end{array}$ & $\begin{array}{l}\text { In } 2014 \\
\text { the government } \\
\text { and social partners } \\
\text { reached } \\
\text { an agreement } \\
\text { on pension } \\
\text { reform, beginning } \\
\text { in } 2017 \text {, including } \\
\text { gradually raising } \\
\text { the minimum } \\
\text { and maximum } \\
\text { retirement ages } \\
\text { and changing } \\
\text { the benefit formula } \\
\text { for the earnings- } \\
\text { related old-age } \\
\text { pension. } \\
\text { The pension } \\
\text { reform proposal } \\
\text { has been sent } \\
\text { to parliament } \\
\text { in Sept. } 2015 \text {. }\end{array}$ \\
\hline France & $\begin{array}{l}\text { The contribution } \\
\text { period used } \\
\text { for benefit } \\
\text { computation will be } \\
\text { more generous for } \\
\text { maternity, training, } \\
\text { unemployment, } \\
\text { apprenticeships, } \\
\text { students and } \\
\text { part-time work. }\end{array}$ & & & $\begin{array}{l}\text { The } 10 \% \text { pension } \\
\text { bonus for having } \\
\text { at least three } \\
\text { children will be } \\
\text { subject to taxes. } \\
\text { The contribution } \\
\text { rate will increase } \\
\text { by } 0.3 \text { percentage } \\
\text { points for both } \\
\text { employees } \\
\text { and employers } \\
\text { by } 2017 \text {, by } 0.15 \% \\
\text { in } 2014 \text { and } \\
\text { by } 0.05 \% \text { a year } \\
\text { from } 2015 \\
\text { to } 2017 \text {. }\end{array}$ & $\begin{array}{l}\text { From } 2014 \text {, } \\
\text { indexation occurs } \\
\text { in Oct. against Apr. } \\
\text { previously. } \\
\text { Pensions below } \\
\text { EUR } 1200 \text { were } \\
\text { frozen } \\
\text { between April } \\
\text { and Oct. } 2014 .\end{array}$ & $\begin{array}{l}\text { The contribution } \\
\text { period for a full } \\
\text { pension will } \\
\text { increase by one } \\
\text { quarter every three } \\
\text { years and reach } \\
43 \text { years in } 2035 . \\
\text { While the } \\
\text { retirement age } \\
\text { remains at } 62 \text {, } \\
\text { a person having } \\
\text { contributed a full } \\
\text { period will be able } \\
\text { to retire without } \\
\text { any penalty } \\
\text { from the age of } 60 \text {. } \\
\text { Individual } \\
\text { accounts will be } \\
\text { established to take } \\
\text { into account } \\
\text { arduous work; } \\
\text { they will open } \\
\text { rights to } \\
\text { professional } \\
\text { training and allow } \\
\text { a shorter } \\
\text { contribution } \\
\text { period. }\end{array}$ & $\begin{array}{l}\text { Beginning in } 2016 \\
\text { all insured will } \\
\text { have an electronic } \\
\text { account that } \\
\text { provides all } \\
\text { relevant pension } \\
\text { related } \\
\text { information, } \\
\text { such as past } \\
\text { contributions, } \\
\text { work history } \\
\text { and projected } \\
\text { pension benefits } \\
\text { from both public } \\
\text { and mandatory } \\
\text { occupational } \\
\text { systems. }\end{array}$ & \\
\hline
\end{tabular}


Table 1.A1.1. Details of pension reforms, September 2013-September 2015 (cont.)

By country and prime objective

\begin{tabular}{|c|c|c|c|c|c|c|c|c|}
\hline & Coverage & $\begin{array}{l}\text { Diversification } \\
\text { and security }\end{array}$ & Pension benefits & $\begin{array}{l}\text { Taxes and defined } \\
\text { benefit } \\
\text { contributions }\end{array}$ & Indexation & Work incentives & $\begin{array}{l}\text { Administrative } \\
\text { efficiency }\end{array}$ & Other \\
\hline Germany & & & $\begin{array}{l}\text { Parents of children } \\
\text { born before } 1992 \\
\text { will now receive } \\
\text { pension credits for } \\
\text { the first two years } \\
\text { of their child's life } \\
\text { (July 2014). }\end{array}$ & $\begin{array}{l}\text { In } 2015 \\
\text { the contribution } \\
\text { rates for old-age, } \\
\text { survivors and } \\
\text { disability } \\
\text { insurance was } \\
\text { reduced } \\
\text { to } 9.35 \% \text { for the } \\
\text { employer } \\
\text { and employees } \\
\text { each from } 9.45 \% \text {. }\end{array}$ & & $\begin{array}{l}\text { The retirement age } \\
\text { was lowered from } \\
65 \text { to } 63 \text { for people } \\
\text { with } 45 \text { years } \\
\text { of contributory } \\
\text { years in July } 2014 \text {. } \\
\text { From } 2016 \text { this } \\
\text { age will increase } \\
\text { by two months } \\
\text { a year until it } \\
\text { reaches } 65 .\end{array}$ & & \\
\hline \multicolumn{9}{|l|}{ Greece } \\
\hline \multicolumn{9}{|l|}{ Hungary } \\
\hline \multicolumn{9}{|l|}{ Iceland } \\
\hline Ireland & $\begin{array}{l}\text { In Mar. } 2014 \text {, } \\
\text { a road-map for } \\
\text { the introduction } \\
\text { of an occupational } \\
\text { pension scheme } \\
\text { for those currently } \\
\text { not covered is being } \\
\text { implemented. } \\
\text { Its implementation } \\
\text { will depend on } \\
\text { economic recovery } \\
\text { and stability. }\end{array}$ & $\begin{array}{l}\text { A new benefit } \\
\text { priority was } \\
\text { established from } \\
25 \text { Dec. } 2013 \\
\text { improving the } \\
\text { priority given to } \\
\text { future pensioners } \\
\text { and reducing the } \\
\text { rights of current } \\
\text { pensioners in the } \\
\text { distribution of DB } \\
\text { plan assets in case } \\
\text { of bankruptcy. } \\
\text { DB plans have } \\
\text { to hold additional } \\
\text { assets from } 2016 \text {. } \\
\text { The Standard Fund } \\
\text { Threshold, i.e. the } \\
\text { pension fund limit } \\
\text { eligible for tax } \\
\text { relief, is being } \\
\text { reduced from } \\
\text { EUR } 2.3 \text { million } \\
\text { to EUR } 2 \text { million } \\
\text { from } 2014 \text {. } \\
\text { The capitalisation } \\
\text { factor used } \\
\text { to compute DB } \\
\text { pension amounts } \\
\text { is age-dependent } \\
\text { since } 2014 .\end{array}$ & $\begin{array}{l}\text { New affordability } \\
\text { measures to assist } \\
\text { pensioners, } \\
\text { persons with } \\
\text { disabilities, and } \\
\text { carers who receive } \\
\text { the Household } \\
\text { Benefits Package. } \\
\text { The HBP will also } \\
\text { assist with water } \\
\text { costs. The value } \\
\text { of this additional } \\
\text { benefit will be } \\
\text { approximately } \\
\text { EUR } 100 \text { a year } \\
\text { to each recipient, } \\
\text { beginning in } 2015 \text {. }\end{array}$ & $\begin{array}{l}\text { A temporary tax } \\
\text { levy of } 0.15 \% \text { of } \\
\text { occupational } \\
\text { pension assets } \\
\text { was introduced } \\
\text { in } 2014 \text { replacing } \\
\text { the } 0.6 \% \text { levy that } \\
\text { was introduced } \\
\text { in } 2011 \text {. }\end{array}$ & & & & \\
\hline Israel & & & $\begin{array}{l}\text { The minimum } \\
\text { contribution rate } \\
\text { of mandatory } \\
\text { pension savings } \\
\text { increased } \\
\text { from } 15 \% \\
\text { to } 17.5 \% \text { in } 2014 \text {. }\end{array}$ & & & & & \\
\hline
\end{tabular}


Table 1.A1.1. Details of pension reforms, September 2013-September 2015 (cont.)

By country and prime objective

\begin{tabular}{|c|c|c|c|c|c|c|c|c|}
\hline & Coverage & $\begin{array}{l}\text { Diversification } \\
\text { and security }\end{array}$ & Pension benefits & $\begin{array}{l}\text { Taxes and defined } \\
\text { benefit } \\
\text { contributions }\end{array}$ & Indexation & Work incentives & $\begin{array}{l}\text { Administrative } \\
\text { efficiency }\end{array}$ & Other \\
\hline Japan & $\begin{array}{l}\text { The qualifying period } \\
\text { for the national } \\
\text { pension will be } \\
\text { shortened from } 25 \\
\text { to } 10 \text { years from } \\
\text { Apr. } 2017 \text {. }\end{array}$ & $\begin{array}{l}\text { The bill } \\
\text { to terminate } \\
\text { employees' } \\
\text { pension funds } \\
\text { (EPFs) came } \\
\text { into effect } \\
\text { in April } 2014 . \\
\text { Financially } \\
\text { unsound EPFs are } \\
\text { being contracted } \\
\text { out or dissolved } \\
\text { within five years. } \\
\text { No new EPFs can } \\
\text { be set up. EPFs } \\
\text { with assets above } \\
\text { the minimum } \\
\text { reserve can } \\
\text { continue subject to } \\
\text { annual asset tests } \\
\text { beginning in } 2019 \text {. } \\
\text { Financially sound } \\
\text { EPFs are also } \\
\text { encouraged } \\
\text { to switch to other } \\
\text { types of pension } \\
\text { plans. }\end{array}$ & $\begin{array}{l}\text { Provide } \\
\text { low-income, } \\
\text { old age pensioners } \\
\text { with welfare } \\
\text { benefits from } \\
\text { Apr. } 2017 . \\
\text { The ad hoc } \\
\text { nominal freeze } \\
\text { of pension benefits } \\
\text { is abolished } \\
\text { and a new wage } \\
\text { and price } \\
\text { indexation (called } \\
\text { "macroeconomic } \\
\text { indexation") is } \\
\text { being introduced } \\
\text { from Apr. 2015. }\end{array}$ & $\begin{array}{l}\text { Women } \\
\text { on maternity leave } \\
\text { are exempt } \\
\text { from pension } \\
\text { contributions } \\
\text { since Apr. } 2014 .\end{array}$ & $\begin{array}{l}\text { The ad hoc } \\
\text { nominal freeze } \\
\text { of pension benefits } \\
\text { is being abolished } \\
\text { by } 2015 \text {. }\end{array}$ & & $\begin{array}{l}\text { Public servants } \\
\text { and private school } \\
\text { employee's } \\
\text { pension systems } \\
\text { are being unified } \\
\text { into the } \\
\text { employees' } \\
\text { pension from } \\
\text { Oct. } 2015 \text {. }\end{array}$ & \\
\hline Korea & $\begin{array}{l}\text { New basic pension } \\
\text { introduced in } \\
\text { July } 2014 \text {. }\end{array}$ & & & & & & & \\
\hline Luxembourg & & & $\begin{array}{l}\text { The basic pension } \\
\text { is increasing } \\
\text { slightly on average } \\
\text { by about } \\
0.44 \% \text { per year } \\
\text { since } \\
\text { October } 2012 \\
\text { on top of wage } \\
\text { growth. }\end{array}$ & & & & & \\
\hline Mexico & & & & & & & & \\
\hline
\end{tabular}


Table 1.A1.1. Details of pension reforms, September 2013-September 2015 (cont.)

By country and prime objective

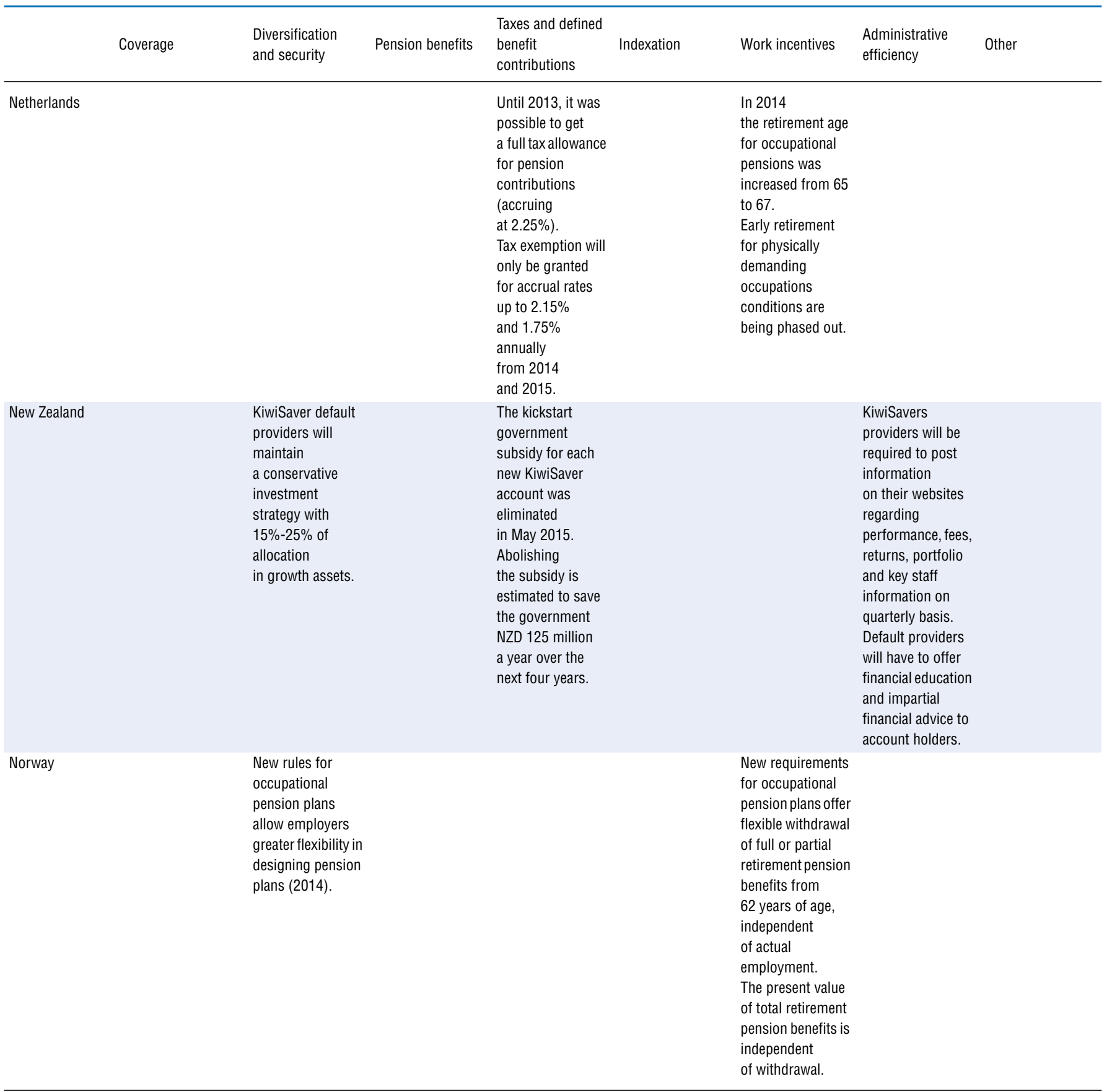


Table 1.A1.1. Details of pension reforms, September 2013-September 2015 (cont.)

By country and prime objective

\begin{tabular}{|c|c|c|c|c|c|c|c|c|}
\hline & Coverage & $\begin{array}{l}\text { Diversification } \\
\text { and security }\end{array}$ & Pension benefits & $\begin{array}{l}\text { Taxes and defined } \\
\text { benefit } \\
\text { contributions }\end{array}$ & Indexation & Work incentives & $\begin{array}{l}\text { Administrative } \\
\text { efficiency }\end{array}$ & Other \\
\hline Poland & $\begin{array}{l}\text { Mandatory } \\
\text { contributions to the } \\
\text { privately managed } \\
\text { DC scheme (OFE) } \\
\text { were turned optional: } \\
\text { workers can opt-in to } \\
\text { allocate } 2.92 \% \text { of } \\
\text { their gross wages } \\
\text { to OFEs while the } \\
\text { default option is } \\
\text { to contribute to the } \\
\text { public NDC scheme. }\end{array}$ & $\begin{array}{l}\text { OFEs are } \\
\text { prohibited } \\
\text { to invest in Polish } \\
\text { treasury bonds } \\
\text { or in debt } \\
\text { instruments } \\
\text { guaranteed by the } \\
\text { Treasury. In 2014, } \\
\text { pension funds } \\
\text { have to hold } \\
\text { a minimum } \\
\text { threshold } \\
\text { of } 75 \% \text { of their } \\
\text { assets in equities. } \\
\text { That threshold will } \\
\text { gradually decrease } \\
\text { to } 15 \% \text { in } 2017 \text {. }\end{array}$ & & $\begin{array}{l}\text { New tax incentives } \\
\text { for IKZE (a type } \\
\text { of voluntary } \\
\text { personal plan) } \\
\text { - Exempt-Exempt- } \\
\text { Tax scheme, with } \\
\text { special, } 10 \% \text { flat } \\
\text { tax rate (i.e. lower } \\
\text { than standard } \\
\text { income tax). }\end{array}$ & $\begin{array}{l}\text { Generally pensions } \\
\text { are indexed } \\
\text { by factor which is } \\
\text { a combination } \\
\text { of inflation } \\
\text { and } 20 \% \text { of wage } \\
\text { growth. } \\
\text { This indexation } \\
\text { principle was } \\
\text { applied in } 2015 \\
\text { without setting it } \\
\text { as a rule for next } \\
\text { years. However, } \\
\text { in } 2015 \\
\text { the increase of } \\
\text { individual pension } \\
\text { could not be lower } \\
\text { than PLN } 36 \text {. }\end{array}$ & & $\begin{array}{l}\text { On Feb. } 2014 \text {, } \\
51.5 \% \text { of the net } \\
\text { assets of privately } \\
\text { managed pension } \\
\text { funds were } \\
\text { transferred to the } \\
\text { Social Insurance } \\
\text { Institution. } \\
\text { Moreover, } \\
\text { the assets of those } \\
\text { who chose to stay } \\
\text { in OFEs will be } \\
\text { gradually } \\
\text { transferred to } \\
\text { the public system } \\
\text { ten years prior to } \\
\text { the retirement age. } \\
\text { Assets so far } \\
\text { accumulated by } \\
\text { those who decided } \\
\text { to move to } \\
\text { the public pension } \\
\text { scheme will also } \\
\text { be transferred } \\
\text { on the same basis. }\end{array}$ & \\
\hline Portugal & & & & $\begin{array}{l}\text { In } 2015 \text { the } \\
\text { pension-income } \\
\text { threshold for the } \\
\text { CES (extraordinary } \\
\text { solidarity } \\
\text { surcharge) } \\
\text { was changed } \\
\text { and applied just } \\
\text { to the highest } \\
\text { pensions. }\end{array}$ & $\begin{array}{l}\text { The determination } \\
\text { of the } \\
\text { sustainability } \\
\text { factor, which links } \\
\text { the level } \\
\text { of pensions } \\
\text { to increasing life } \\
\text { expectancy, was } \\
\text { changed. It will be } \\
\text { computed as } \\
\text { the ratio between } \\
\text { life expectancy } \\
\text { in } 2000 \text { and life } \\
\text { expectancy } \\
\text { in the year prior } \\
\text { to retirement. } \\
\text { The sustainability } \\
\text { factor will be used } \\
\text { to increase } \\
\text { the retirement age } \\
\text { rather than } \\
\text { to reduce } \\
\text { retirement pension } \\
\text { and applies only } \\
\text { to people claiming } \\
\text { old-age pensions } \\
\text { before the normal } \\
\text { retirement age. }\end{array}$ & $\begin{array}{l}\text { The retirement age } \\
\text { was increased } \\
\text { from } 65 \text { to } 66 \\
\text { in } 2014 \text {. } \\
\text { Long-term } \\
\text { unemployed can } \\
\text { retire at } 57 . \\
\text { Retirement age } \\
\text { will be linked } \\
\text { to life expectancy. }\end{array}$ & & \\
\hline Slovak Republic & $\begin{array}{l}\text { In } 2015 \\
\text { the DC scheme was } \\
\text { made voluntary } \\
\text { and individuals now } \\
\text { have the possibility } \\
\text { to opt into the public } \\
\text { earnings-related } \\
\text { scheme for the } \\
\text { fourth time since its } \\
\text { introduction in } 2005 \text {. }\end{array}$ & & & & $\begin{array}{l}\text { From } 2013 \\
\text { to } 2017 \text { pension } \\
\text { benefits will be } \\
\text { increased by fixed } \\
\text { amounts } \\
\text { and thereafter } \\
\text { valorisation will } \\
\text { follow consumer } \\
\text { prices. }\end{array}$ & & & \\
\hline Slovenia & & & & & & & & \\
\hline
\end{tabular}


Table 1.A1.1. Details of pension reforms, September 2013-September 2015 (cont.)

By country and prime objective

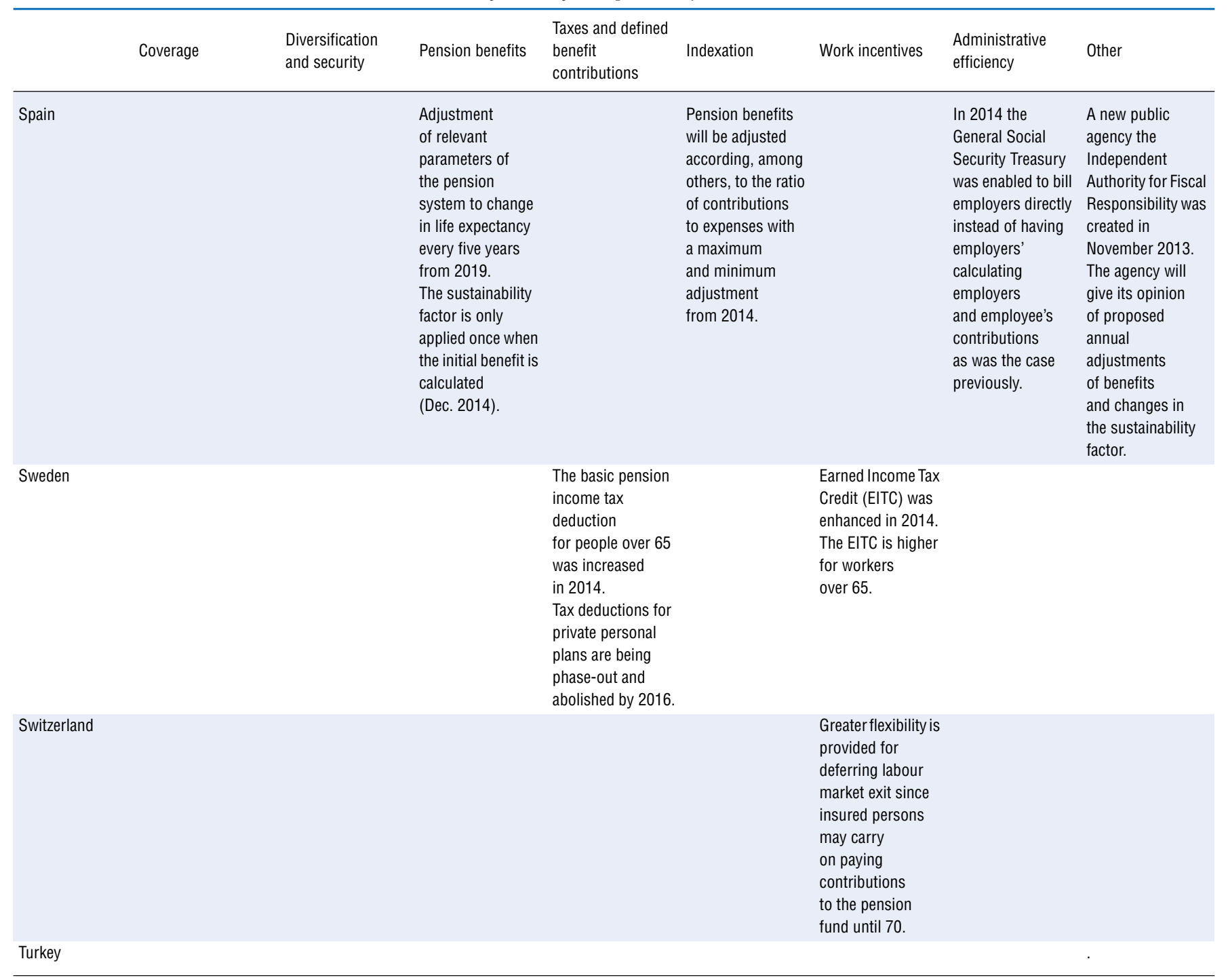


Table 1.A1.1. Details of pension reforms, September 2013-September 2015 (cont.)

By country and prime objective

\begin{tabular}{|c|c|c|c|c|c|c|c|c|}
\hline & Coverage & $\begin{array}{l}\text { Diversification } \\
\text { and security }\end{array}$ & Pension benefits & $\begin{array}{l}\text { Taxes and defined } \\
\text { benefit } \\
\text { contributions }\end{array}$ & Indexation & Work incentives & $\begin{array}{l}\text { Administrative } \\
\text { efficiency }\end{array}$ & Other \\
\hline United Kingdom & $\begin{array}{l}\text { The National } \\
\text { EmploymentSavings } \\
\text { Trust (NEST) is } \\
\text { being extended } \\
\text { to small employers } \\
\text { from January } 2016 .\end{array}$ & $\begin{array}{l}\text { New rules } \\
\text { for defined } \\
\text { contribution } \\
\text { pension } \\
\text { withdrawals were } \\
\text { legislated } \\
\text { in May } 2014 \\
\text { and will enable } \\
\text { large lump-sum } \\
\text { withdrawals. }\end{array}$ & $\begin{array}{l}\text { From 2016, a new } \\
\text { state pension } \\
\text { (single-tier } \\
\text { pension, STP) will } \\
\text { replace at a higher } \\
\text { level both the basic } \\
\text { pension and } \\
\text { the minimum } \\
\text { income guarantee } \\
\text { (Pension Credit). }\end{array}$ & $\begin{array}{l}\text { Taxes } \\
\text { on withdrawals } \\
\text { from pension } \\
\text { accounts were } \\
\text { lowered and } \\
\text { tax-free amounts } \\
\text { were increased } \\
\text { in } 2015 \text {. }\end{array}$ & & $\begin{array}{l}\text { Bring forward } \\
\text { pension age to } 66 \\
\text { by } 2026 \text { and to } 67 \\
\text { by } 2028 \text {. } \\
\text { Gradually } \\
\text { increasing } \\
\text { the private pension } \\
\text { savings age } \\
\text { from } 55 \text { to } 57 \\
\text { in } 2028 \text {. Private } \\
\text { pension will be } \\
\text { available for } \\
\text { withdrawal from } \\
10 \text { years before } \\
\text { the normal } \\
\text { pension age. }\end{array}$ & $\begin{array}{l}\text { NEST scheme will } \\
\text { create economies } \\
\text { of scale compared } \\
\text { to current DC } \\
\text { plans. Pension } \\
\text { providers } \\
\text { and trust-based } \\
\text { managers must } \\
\text { offer DC members } \\
\text { free and impartial } \\
\text { face-to-face } \\
\text { advice. Small DC } \\
\text { plans are } \\
\text { automatically } \\
\text { transferred to } \\
\text { the new pension } \\
\text { plan when workers } \\
\text { change jobs. } \\
\text { The government's } \\
\text { authority to } \\
\text { introduced } \\
\text { minimum } \\
\text { governance } \\
\text { standards, fees, } \\
\text { etc. have been } \\
\text { strengthened } \\
\text { to mitigate } \\
\text { excessive charges } \\
\text { and to increase } \\
\text { standards. }\end{array}$ & \\
\hline United States & $\begin{array}{l}\text { My retirement } \\
\text { accounts (myRAs) } \\
\text { were announced } \\
\text { in January } 2014 \\
\text { to encourage more } \\
\text { to save for their } \\
\text { retirement. } \\
\text { Contributions } \\
\text { will be invested } \\
\text { in government } \\
\text { bonds } \\
\text { and the principal } \\
\text { is guaranteed. } \\
\text { Final regulations } \\
\text { were announced } \\
\text { by the US Treasury } \\
\text { in December } 2014 \text {, } \\
\text { with the programme } \\
\text { available from } \\
\text { November } 2015 .\end{array}$ & & & & & & & \\
\hline
\end{tabular}

Note: Admin. = Administrative; cohort = Date-of-birth group; $C P I=$ Consumer price index; $D B=$ Defined benefit; DC = Defined contribution; GDP $=$ Gross domestic product; NDC $=$ Notional accounts . 



\section{Chapter 2}

\section{The role of first-tier pensions}

This chapter examines the role of first-tier benefits within OECD and G20 countries. It concentrates on the three main components of first-tier pensions: basic, minimum and means-tested old-age social assistance payments. The structure of the first-tier pension systems including eligibility rules are first detailed. Then the level of the benefits as a proportion of average earnings is compared across OECD countries and studied in relation to old-age poverty rates. The chapter also highlights the other forms of assistance that are available for retirees including rent or health. This chapter analyses the implications of indexation policies for first-tier benefits levels and for public spending, given population ageing, depending on how age thresholds on first-tier pensions are adjusted.

The statistical data for Israel are supplied by and under the responsibility of the relevant Israeli authorities. The use of such data by the OECD is without prejudice to the status of the Golan Heights, East Jerusalem and Israeli settlements in the West Bank under the terms of international law. 


\subsection{Introduction}

Provisions to protect the most vulnerable pensioners are a common feature in OECD countries. These benefits play a more important role in times of high unemployment, or if general pension benefits are being reduced. Aligned with an increasingly ageing society their role could become more pronounced in the years to come as public finances come under increasing pressure. The level of protection they provide varies considerably across countries, however, reflecting the very different designs of pension systems overall (see Table 5.2 later in this volume and the "Country profiles" in Chapter 11).

The first pension system, for private-sector workers, was introduced in 1889 in Germany. It was designed to provide an income to all workers reaching the age of 70 , subject to having made contributions for at least 30 years. At the start of the 20th century the United Kingdom established a retirement income system that made a regular weekly payment to everyone over the age of 70, irrespective of their career and earnings history, if their income was below a particular level. That was the first example of a pension benefit designed to help alleviate poverty among the elderly.

First-tier old-age pensions are defined as the first layer of protection of the elderly within the pension system. In most countries it combines financial support to those who were unable to provide for their retirement and are vulnerable to poverty with a mechanism that rewards workers who have paid in minimum levels of contribution. First-tier pensions can thus have up to three components:

- Basic pensions. This component can take two different forms:

* A benefit paid to everyone irrespective of any contributions made, although beneficiaries might have to meet some residence criteria. In some countries residence-based benefits are potentially offset against other pension income.

* A benefit paid solely on the basis of the number of years of contributions, i.e. independently of earnings.

- Minimum pensions. They can refer to either the minimum of a specific contributory scheme or of all schemes combined. The benefit level can take into account other pension income.

- Social assistance. These are means-tested benefits available for those who have been unable to achieve sufficient income through their pension entitlements and therefore require a top-up to reach a minimum income level which is often set in line with general social assistance levels.

This chapter examines the provisions which ensure protection of the least well-off pensioners in each OECD country, whether they are basic or minimum pensions, dependent on residency or contribution history, or whether they are safety-net provisions designed to ensure a certain level of income. The next section compares the criteria for non-earnings-related pensions, concentrating particularly on the number of years of residency or contribution required. Basic or minimum pension amounts, relative to the average earnings of the total population, are the subject of Section 2.3. The analysis then considers people unable to meet contribution requirements. Section 2.4 assesses social-assistance payments and looks at other benefits or means of support that are available. Section 2.5 explains how statutory benefit rates for people on first-tier pensions are designed to evolve over time and demonstrates the effect that indexation policies might have. Section 2.6 concludes and summarises the main policy issues. 


\section{Key findings}

- First-tier pensions exist in all countries but their structure and value vary considerably between countries. Residence-based basic pensions range from $6 \%$ of average earnings in Iceland to $40 \%$ in New Zealand, whereas safety-net payments vary from $2 \%$ in China and $6 \%$ in Turkey to $50 \%$ in Brazil, though both China and Turkey also have high minimum pensions above $40 \%$ of average earnings.

- One-half of OECD countries provide a basic pension to all citizens either based solely on residence or on the number of years of contribution made, while one-third of countries have a minimum pension within their earnings-related schemes.

- The number of years of contribution for eligibility to minimum pensions ranges from one year in Switzerland for a partial pension (44 years are required for the full pension for men, 43 years for women) to 35 years in the Czech Republic for any payment to be made. On average full minimum benefits require 26 years of contribution, with a partial benefit available in the majority after 20 years.

- The majority of first-tier pensions are indexed to prices and so their value decline, relative to wages over time, as productivity gains translate into real-wage growth over the medium term. If take-up rates remain steady and these indexation rules are applied rigidly then the prevalence of pensioner poverty is likely to increase in the long-term.

- There is significant scope for a number of countries that combine relatively high elderly poverty rates and low safety-net benefits, to increase the value of their safety-net payments, even after taking into account the level of GDP per capita. This is particularly the case in Chile, Korea, Mexico and Turkey but also Switzerland and the United States.

- Nearly half of OECD countries provide additional services or payments to elderly people covering housing or heating costs as well as health and care commitments. Numerous services are also provided as benefits-in-kind in the form of free television licences or free or reduced transport costs. As the payments of these services are generally universal many recipients who could easily afford the cost of such services are also benefitting. Introducing means-testing for at least some of these payments could reduce future expenditure.

- Current indexation policies will lead to rises in expenditure in many countries if take-up rates remain constant. While stabilising first-tier pension spending relative to GDP is not a goal in itself, and does not, alone, bear a normative significance, it can serve as a useful baseline given that financing resources tend to follow GDP. In particular, the starting point in each country, in terms of spending levels or income inequalities affecting the bottom part of the distribution, matters.

- If age thresholds were increased by five years by 2060, many countries would be close to stabilising first-tier spending as a percentage of GDP under their current indexation policies. On average across OECD countries, given projected population ageing, first-tier benefits should be indexed to wages minus $0.8 \%$ (i.e. prices plus $0.5 \%$ based on OECD assumptions) to stabilise spending (as a share of GDP) if age thresholds were gradually increased by five years by 2060 .

- Alternative mechanisms, such as auto-enrolment or incentives like tax breaks and matching contributions, will help reduce the reliance on means-tested first-tier benefits as greater emphasis will be given to the individual to save for their retirement.

\subsection{Eligibility criteria for basic and minimum old-age pensions}

Table 2.1 summarises the structure of basic and minimum pensions in OECD countries, for which the eligibility criteria differ both across countries and across the various pension benefits within countries. This part first discusses basic pensions and then minimum pensions. 
Table 2.1. Structure of basic and minimum pensions

\begin{tabular}{|c|c|c|c|c|c|}
\hline & Basic & Minimum & & Basic & Minimum \\
\hline OECD members & & & OECD members (cont.) & & \\
\hline Australia $^{1}$ & $\mathrm{R}$ & & New Zealand & $\mathrm{R}$ & \\
\hline Austria & & & Norway $^{1}$ & $\mathrm{R}$ & \\
\hline Belgium & & $x$ & Poland & & $x$ \\
\hline Canada & $\mathrm{R}$ & & Portugal & & $x$ \\
\hline Chile & $\mathrm{R}$ & & Slovak Republic & & \\
\hline Czech Republic & C & $x$ & Slovenia & & $\mathrm{x}$ \\
\hline Denmark & $\mathrm{R}$ & & Spain & & $\mathrm{x}$ \\
\hline Estonia & C & & Sweden $^{1}$ & $\mathrm{R}$ & \\
\hline Finland $^{1}$ & R & & Switzerland & & $\mathrm{x}$ \\
\hline France & & $x$ & Turkey & & $\mathrm{x}$ \\
\hline Germany & & & United Kingdom & C & \\
\hline Greece & $\mathrm{R}$ & & United States & & \\
\hline Hungary & & $\mathrm{x}$ & & & \\
\hline Iceland & $\mathrm{R}$ & & Other major economies & & \\
\hline Ireland & C & & Argentina & c & $x$ \\
\hline Israel & $R / C$ & & Brazil & & $x$ \\
\hline Italy & & $x$ & China & & $x$ \\
\hline Japan & C & & India & & $x$ \\
\hline Korea & & & Indonesia & & \\
\hline Luxembourg & c & $x$ & Russian Federation & c & \\
\hline Mexico & & $x$ & Saudi Arabia & & $x$ \\
\hline Netherlands & $\mathrm{R}$ & & South Africa & $\mathrm{R}$ & \\
\hline
\end{tabular}

Note: $\mathrm{R}=$ Residence based; $\mathrm{C}=$ Contribution based.

1. The Age Pension in Australia, the national pension in Finland, the guarantee pension in Norway and the guarantee pension in Sweden are residence-based and so have been classified as basic. Source: "Country profiles" in Chapter 11 of this publication.

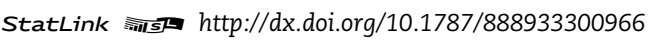

\section{Basic pension}

For basic schemes, the eligibility criteria could be either residence-based or contribution-based. Residence-based pensions are common in the Nordic countries, where all five countries require 40 years of residence for full benefit (Figure 2.1), and shorter periods for lower levels of entitlement. In both Canada and the Netherlands, drawing a full basic pension also requires 40 years of residence, whereas just 20 are needed in Chile. Australia and New Zealand are the OECD countries with the lowest residential eligibility criteria, as full benefit is paid after residing in the country for only ten years, with Australia requiring five years of continuous residence and New Zealand the same after the age of 50. Greece was supposed to have introduced a basic pension in January 2015 for people who have been resident in the country for 15 years, but implementation was delayed. Outside the OECD the basic component in South Africa is payable for just being a resident.

How many years of contributions are required for eligibility to contribution-based basic pensions varies substantially across countries. In Luxembourg, full benefit comes after 40 years, whilst 30 years are needed in both the Czech Republic, increasing to 35 from 2019, and the United Kingdom. There, the current basic pension eligibility criterion will be in place until 2016, when it will give way to the new state pension (nSP) with a 35-year contribution requirement for a full benefit. Most countries also require a minimum number of years of contributions in order to receive any benefit payment. They range from one year in the United Kingdom under the current scheme, increasing to ten with the introduction of nSP, to ten years in Luxembourg. Those with contributions below the minimum will not receive anything. In the Czech Republic the benefit is paid after 30 years of contributions, rising to 35 in 2019, with no increase in value for additional years. In Ireland the total number of weeks of contribution made (minimum 520) is averaged annually over the entire working 
Figure 2.1. Years of contribution or residence required for basic pensions

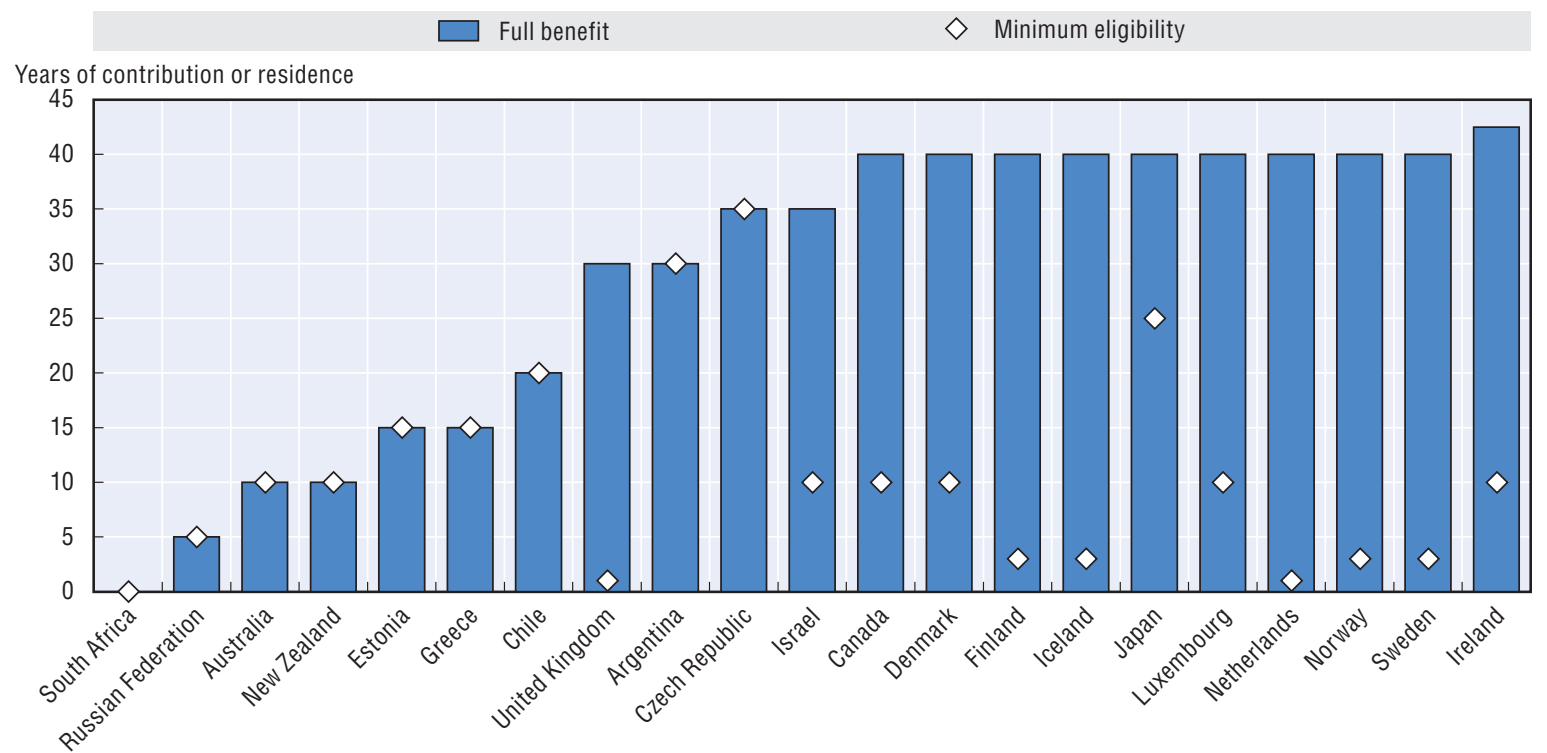

Note: For the United Kingdom the new state pension will require 35 years for the full benefit and 10 years for the minimum. For Ireland the 42.5 years reflects entry at age 20 and retirement at age 66 with an average of 48 weeks of contributions.

Definition: Basic pensions refer to the benefit paid based on either the length of residency or the duration of contributions, irrespective of earnings.

Source: "Country profiles" in Chapter 11 of this publication.

life i.e. from the time of the first contribution to retirement age. If the average is over 48 weeks per year the individual receives the full benefit; shorter contribution periods result in a pro-rated payment with a minimum of 24 weeks average. It is therefore possible to achieve eligibility for the full pension if workers started to contribute during the last 520 weeks prior to retirement. Outside the OECD, the contribution-based basic flat-rate benefit in the Russian Federation is payable after only five years of contributions.

\section{Minimum pension}

Whereas the basic contribution-based pension mostly takes the form of a flat rate benefit, the minimum pension element acts effectively as a top-up in many countries, since other income is considered when assessing eligibility. As with the basic schemes the number of years of contribution required for the full minimum-pension benefit varies greatly, ranging from 15 years in Slovenia, Spain and Turkey to 45 in Belgium (Figure 2.2). In France, to be eligible for the contributory minimum benefit, being aged at least 61 years and 2 months (62 from 2017) and having 41.5 years of contributions, or being aged 65 and over (increasing to 67 by 2022), are required. However, there is a slightly higher minimum pension in France if more than 30 years of contributions have been made. Under Mexico's new system, private-sector workers who had not contributed before 1997 must contribute for 1250 weeks (about 24 years) to be eligible for the minimum pension, whereas the old system, which still governs retirement for many, requires only 500 weeks of contribution for the minimum.

In general, there has been very little change in eligibility rules for minimum pensions over recent years. However in the Czech Republic the number of years of contribution is increasing in line with the increase in the retirement age. France, too, has recently raised its years of contribution requirement from 40 to 41.5 and will increase it to 43 by 2035 in line with longer life expectancy. People are, however, able to retire at the age of 65 , increasing to 67 , irrespective of how long they have contributed. However, if contributions have been made for at least 30 years the level of the minimum 
Figure 2.2. Years required for minimum pension

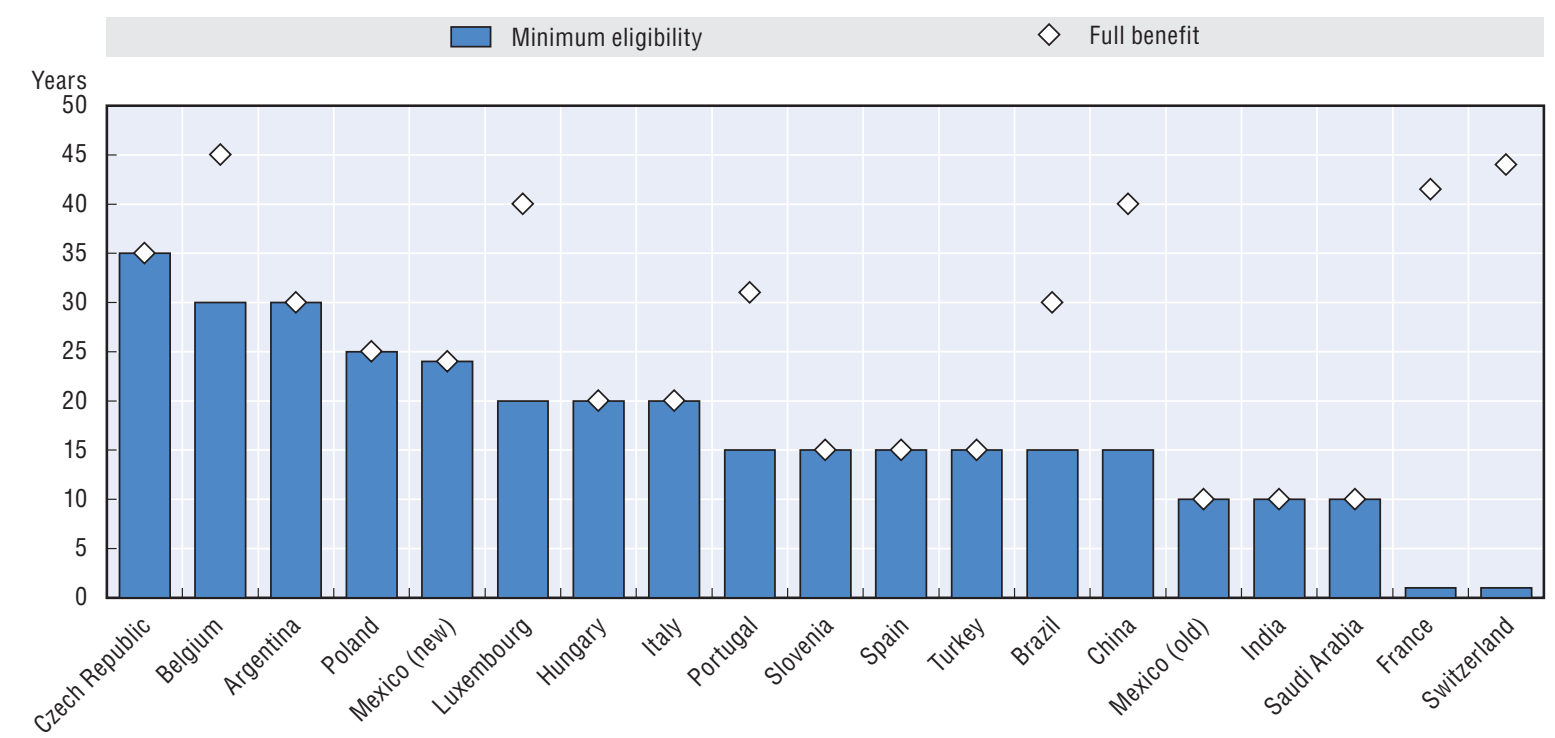

Definition: Minimum pensions refer to either the minimum of a specific scheme or of all schemes combined. The benefit level can take into account other pension income.

Source: "Country profiles" in Chapter 11 of this publication.

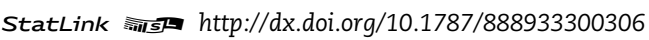

is increased by around $10 \%$. In Poland the number of years that men must contribute if they are to receive the minimum pension has remained constant at 25 . For women, by contrast, it has gradually climbed from 21 years since 2014 and will reach 25 years by 2022, in line with the decision that retirement ages for men and women should converge over time.

The number of years of residence or contribution is not the sole determinant of entitlement to full benefit. There is also an age requirement and, once again, there is some variation between countries. In the long-term the retirement ages will be at least 67 for both men and women across most of the OECD area. Currently, though, many countries are in a period of transition, either equalising men's and women's retirement ages and/or increasing it over the coming decades. Table 2.2 shows the ages at which people may retire with basic and minimum pension entitlements.

\subsection{Benefit levels}

Beyond the heterogeneity in the eligibility criteria, there is a considerable variation in the monetary value of the payments across countries. Furthermore, some benefits are also means-tested (Section 2.4), so are reduced more or less quickly as income or assets rise. The analysis focuses first on basic pensions and then on minimum pensions.

The value of basic benefits is an important factor in ensuring an adequate retirement income. The country with the largest basic pension is New Zealand, which guarantees an income over $40 \%$ of average earnings - despite, as already noted, only having ten years of residence required (Figure 2.3). Australia, too, ensures a reasonably high income. Its scheme, Age Pension, offers a benefit of just over $25 \%$ of average earnings with, on top of that, a comprehensive system of concessions and assistance for health, rent assistance, medication, and other living expenses; the benefit is means-tested (against both income and assets), but as the test is not very strict about $80 \%$ of Australian pensioners receive at least some amount of Age Pension. In the Netherlands, full basic benefit is over $25 \%$ of average earnings, and is prorated to the number of years of residence. 
Table 2.2. Retirement ages for basic and minimum pensions, 2014

\begin{tabular}{|c|c|c|c|c|c|}
\hline & Men & Women & & Men & Women \\
\hline OECD members & & & OECD members (cont.) & & \\
\hline Australia & 65.0 & 65.0 & Norway & 67.0 & 67.0 \\
\hline Austria & 65.0 & 60.0 & Poland & 65.0 & 60.0 \\
\hline Belgium & 65.0 & 65.0 & Portugal & 66.0 & 66.0 \\
\hline Canada & 65.0 & 65.0 & Slovak Republic & 62.0 & 62.0 \\
\hline Chile & 65.0 & 60.0 & Slovenia & 65.0 & 65.0 \\
\hline Czech Republic & 62.7 & 61.3 & Spain & 65.2 & 65.2 \\
\hline Denmark & 65.0 & 65.0 & Sweden & 65.0 & 65.0 \\
\hline Estonia & 63.0 & 61.0 & Switzerland & 65.0 & 64.0 \\
\hline Finland & 65.0 & 65.0 & Turkey & 60.0 & 58.0 \\
\hline France & 61.2 & 61.2 & United Kingdom & 65.0 & 62.0 \\
\hline Germany & 65.3 & 65.3 & United States & 65.0 & 65.0 \\
\hline Greece & 65.0 & 65.0 & OECD average & 64.7 & 63.5 \\
\hline Hungary & 62.5 & 62.5 & & & \\
\hline Iceland & 67.0 & 67.0 & Other major economies & & \\
\hline Ireland & 66.0 & 66.0 & Argentina & 65.0 & 60.0 \\
\hline Israel & 67.0 & 62.0 & Brazil & 65.0 & 60.0 \\
\hline Italy & 66.3 & 62.3 & China & 60.0 & 60.0 \\
\hline Japan & 65.0 & 65.0 & India & 58.0 & 58.0 \\
\hline Korea & 65.0 & 65.0 & Indonesia & 55.0 & 55.0 \\
\hline Luxembourg & 65.0 & 65.0 & Russian Federation & 60.0 & 55.0 \\
\hline Mexico & 65.0 & 65.0 & Saudi Arabia & 60.0 & 55.0 \\
\hline Netherlands & 65.2 & 65.2 & South Africa & 60.0 & 60.0 \\
\hline New Zealand & 65.0 & 65.0 & & & \\
\hline
\end{tabular}

Source: "Country profiles" in Chapter 11 of this publication.

Figure 2.3. Basic pensions as a percentage of average earnings

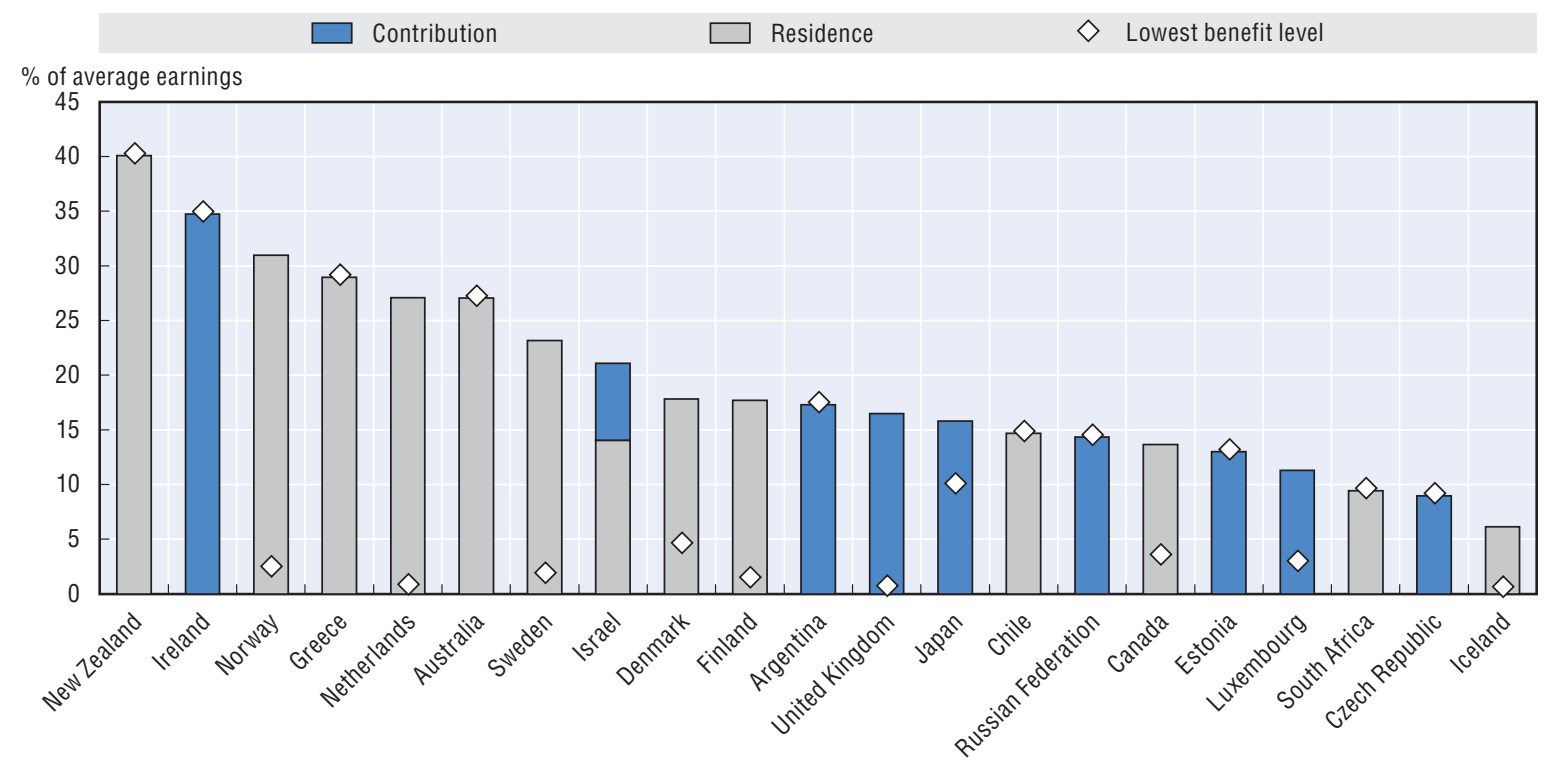

Note: Lowest benefit level is the benefit available once the lowest level of period eligibility has been achieved (see Figure 2.1). Source: "Country profiles" in Chapter 11 of this publication. 
The Nordic countries set some benefits against income from other sources. Finland, Norway, and Sweden, for example, regard benefits as top-up support rather than flat-rate income, and not everyone receives the full amount. The basic benefit provides an income equivalent to $31 \%$ of the average wage in Norway, and around 18\% in both Denmark and Finland. In Sweden, the benefit rate is higher at $23 \%$ of average earnings but, as in Finland and Norway, it is offset against income from the earningsrelated pension (the impact of how the benefit is withdrawn will be covered in the next section). Canada and Chile also provide basic pensions albeit at lower levels than in Australia, New Zealand and Northern Europe - at close to $15 \%$ of average earnings, topping them up with an income-tested component. Finally, at the lower end of the spectrum, Iceland has a basic benefit equivalent to only $6 \%$ of average earnings although as shown later - there are additional safety-net payments.

For the countries in Figure 2.3 that have contribution-based basic pensions the value of the benefit is generally set at a lower proportion of average earnings than the residence-based schemes in the other countries. Ireland, though, is an exception with a basic benefit equivalent to $35 \%$ of average earnings in 2014. Full benefit rates are just above 15\% of average earnings in Japan and the United Kingdom, and below that in Estonia, Luxembourg, South Africa and the Czech Republic. As pointed out earlier, the United Kingdom's numbers reflect the level of the current basic pension rather than that of the new state pension, which will be introduced in 2016, where the benefit will stand at $22 \%$ of average earnings with 35 years of contributions.

Among countries with minimum pension arrangements in place, the full benefit is equivalent to $25 \%$ of average earnings on average compared to $20 \%$ in the basic pension scheme. The level of minimum pensions varies from $12 \%$ of average earnings in both the Czech Republic and Hungary to $42 \%$ in Turkey and 50\% in Brazil (Figure 2.4).

Figure 2.4. Full minimum pensions as percentage of average earnings

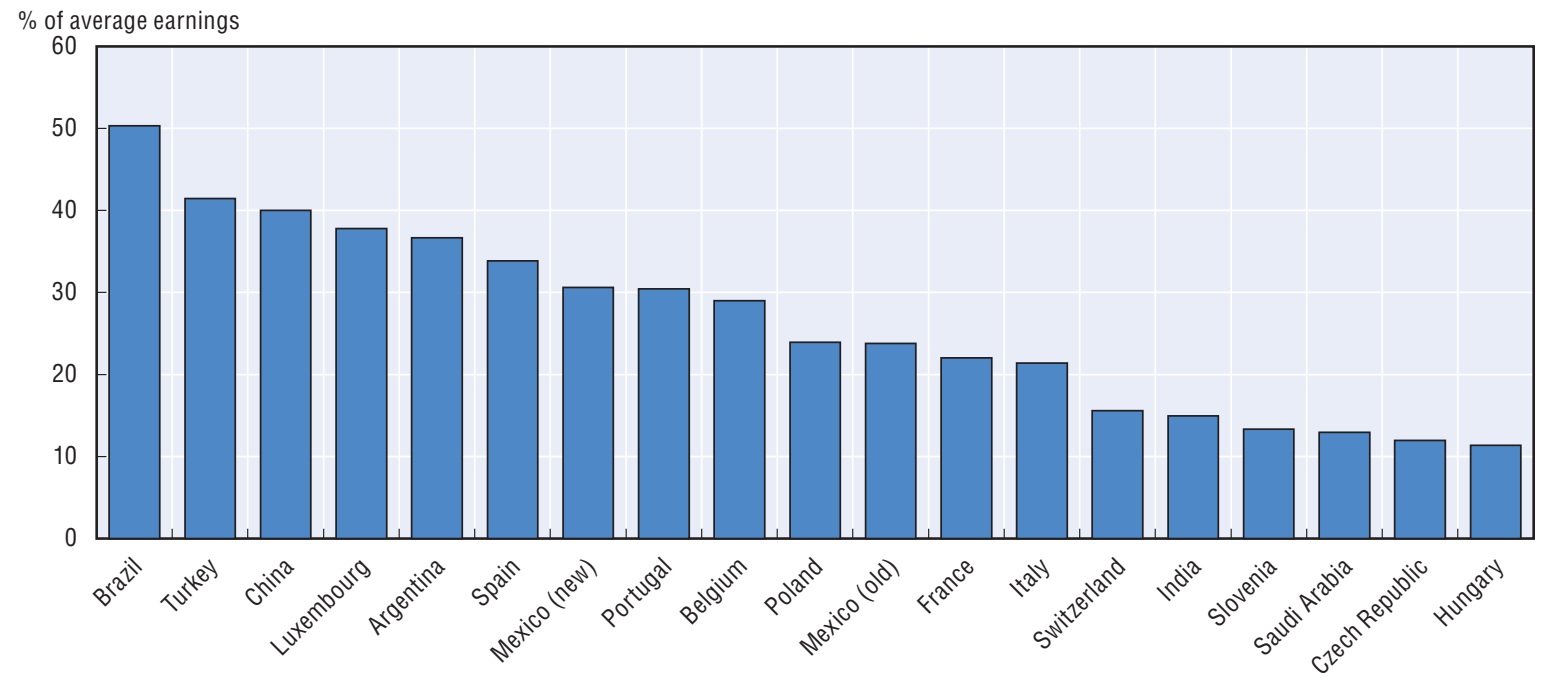

Source: "Country profiles" in Chapter 11 of this publication.

The relationship between levels of full benefit and the number of contribution years required for eligibility is of critical interest. In Luxembourg, for example, the minimum pension is equivalent to $38 \%$ of average earnings for only 20 years contribution, while in Belgium the figures are $29 \%$ and 45 years. The full benefit rates shown in Figure 2.4 assume that beneficiaries have contributed for long enough to be entitled to full benefit. Yet a number of countries operate staggered payment schemes. Portugal, for example, pays minimum pension in full for at least 31 years of contributions, reducing it by $20 \%$ for between 21 and 30 years of contributions, by $27 \%$ for 15 to 20 years, and by 
$33 \%$ for less than 15 years. Many countries reduce benefit levels proportionally to shortfalls in full contribution criteria, while Belgium has a minimum annual credit scheme to assist low earners or people who worked part-time through much of their career.

Although most countries have left eligibility criteria untouched, a number have made amendments to policies over the last few years that have affected benefits. Such moves have chiefly involved freezing nominal amounts, as Hungary, Ireland and Portugal have all done - with no increase in benefits since the late 2000s. The impact and consequences of freezes and indexation policies in general are addressed in Section 2.5.

The share of the population receiving minimum pension varies (Figure 2.5 ) from less than $1 \%$ of the 65 s-and-over in Hungary to roughly $60 \%$ in Portugal. The low coverage in Hungary comes from the fact that the minimum pension is worth only $11 \%$ of average earnings, whilst a worker at $50 \%$ of average earnings would receive a pension above this level after only ten years of contributions to the earnings-related scheme. Nearly $37 \%$ of those aged 65 or over are receiving minimum pension payments in France, with Luxembourg closely behind at $29 \%$. The range of take-up rates of targeted safety-net benefits is wider. On the one hand, nearly $90 \%$ receive a payment in Denmark and just fewer than $80 \%$ in Australia. In both cases the benefit is offset against other income, and so many only receive a partial amount. By contrast more than two-thirds of the countries shown have take-up rates below $20 \%$, as pensioners often have income from personal pensions or other sources which takes them above the threshold.

Figure 2.5. Take-up of minimum and safety-net pensions, 2012

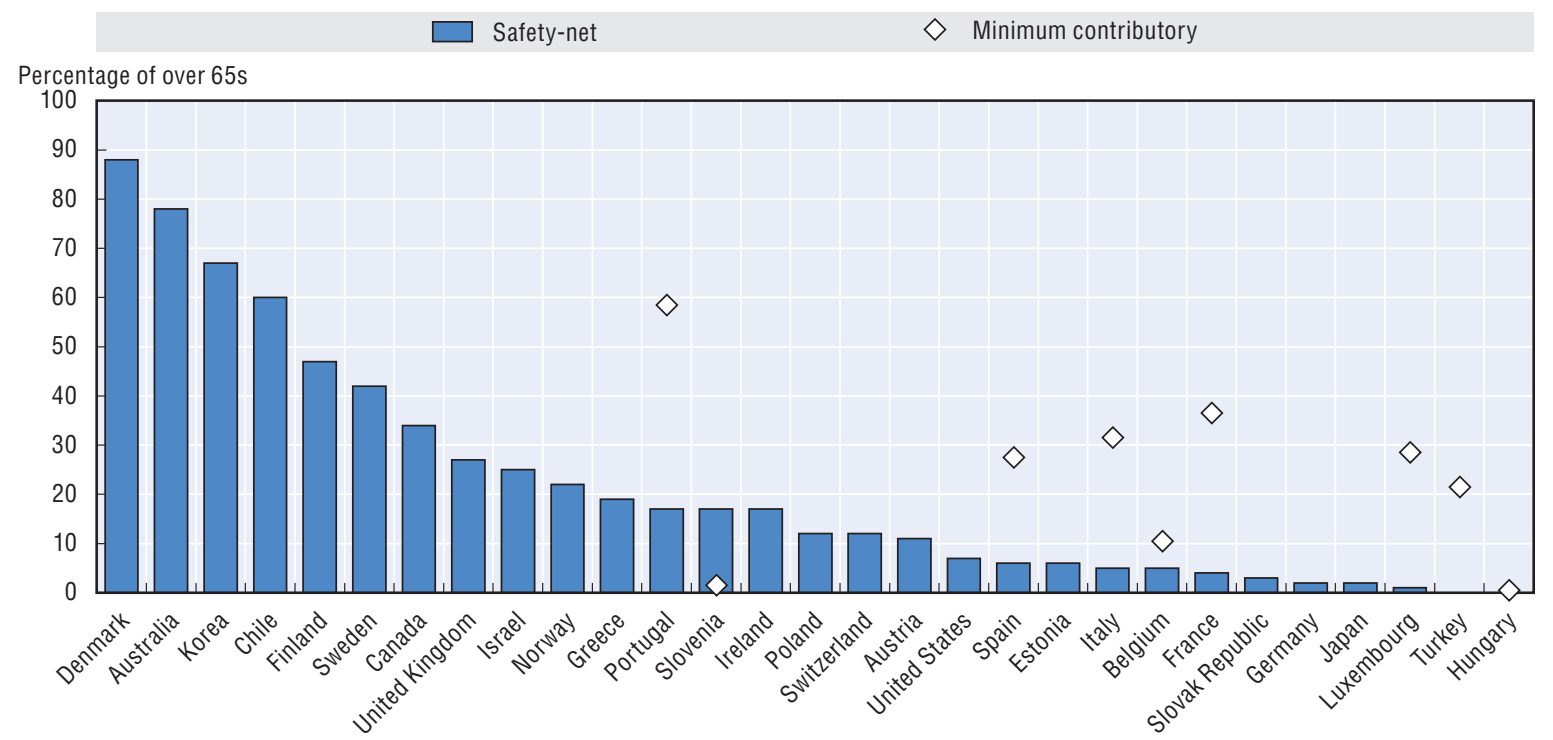

Source: Information provided by OECD country delegates.

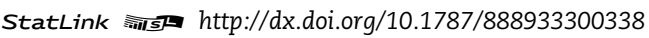

\subsection{What happens in the event of ineligibility for contribution-based basic and minimum pensions?}

When elderly people have not contributed for long enough to be entitled to a contribution-based pension, they rely on safety-net benefits, chiefly in the form of social assistance. It constitutes the last line of support for society's most vulnerable members. Social assistance benefit differs considerably in design across the OECD. Some schemes incorporate income or asset ceilings, while others are gradually withdrawn based on income. There are also wide disparities in the level of support actually provided. Many countries provide additional support for housing or heating or care, as well as supplements for clothes or services, such as travel, as is shown later in the section. 
This chapter defines safety-net benefits as the total amount of benefits that individuals receive, assuming they have made no contributions towards their pension during their working lives, excluding lump-sum repayments of contributions. The chapter also assumes that individuals have been resident since birth of the country in which they retire. They are therefore entitled to the full residence-based payments. From that standpoint, residence-based pensions are one form of safety-net scheme, even the basic pension.

Figure 2.6 combines the information presented in Figures 2.3 and 2.4 with the values of the safety-net benefits to complete the picture for first-tier benefits. The highest safety-net benefits are found in Brazil, at $50 \%$ of average earnings, and in New Zealand at just over $40 \%$. The lowest safety-net benefits are found in China and India accounting for less than $3 \%$ of average earnings, but there are no safety net in Indonesia and Saudi Arabia although the latter has a minimum pension.

Figure 2.6. Value of first-tier benefits as a percentage of average earnings

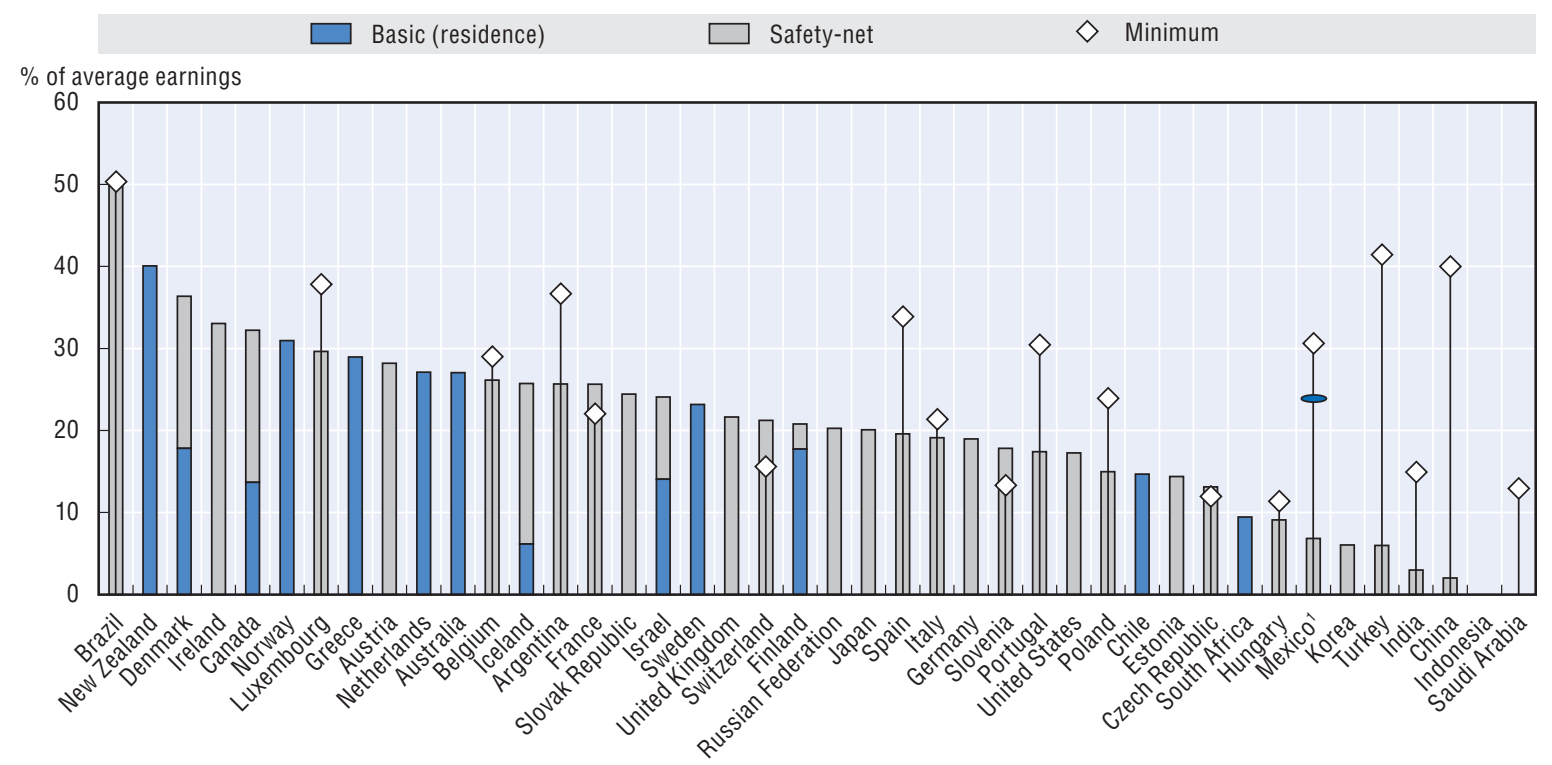

1. The additional marking for Mexico reflects the benefit from the old private-sector system, which is still relevant for many workers, and is equivalent to $23.8 \%$ of average earnings.

The minimum for all countries is based on a full career worker.

Source: "Country profiles" from Chapter 11 of this publication.

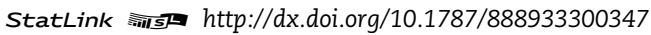

In assessing differences in the levels of safety-net benefits, the design of first-tier pensions should be taken into account. New Zealand's basic pension is based solely on residence and financed directly through taxation, rather than requiring individuals to make individual contributions and is the only mandatory scheme. There is a similar system in Australia, where Age Pension is also based on residency and also purely taxpayer-funded. The main difference between the two countries is that, in Australia, when individuals have contributed to the mandatory employer-financed private pension plan (Superannuation Guarantee) the Age Pension's safety-net provision may be phased out depending on income from other sources. However, as it is assumed here that individuals have made no contributions, they will receive the full Age Pension amount. Similarly the full level of benefit is assumed for the residence-based benefits that exist in Canada, Chile, Denmark, Iceland, the Netherlands, Norway and Sweden.

Other OECD countries have taken different approaches. Korea, for example, targets the benefit at the poorest $70 \%$ of the elderly population, providing them with an income equivalent to $6 \%$ of average earnings. Similarly, safety-net provisions in Mexico and Turkey afford an income of below $7 \%$ of 
average earnings for the elderly who have never contributed. The new schemes in China and India are even lower, at $2 \%$ and $3 \%$ respectively. Elsewhere safety-net benefits are generally designed to top up contributory pensions with amounts that are considerably higher than in China, India, Korea, Mexico and Turkey. However, when no contribution is the default assumption they act purely as social assistance payments. Austria and Luxembourg, for instance, have income-tested top-up provisions that ensure a minimum old-age income of about $30 \%$ of average earnings, while in Estonia and Portugal the top-up supplies an income of around only $15 \%$ of average earnings.

Valuable insight is to be drawn from comparisons between social assistance benefit levels and minimum guarantees for workers who have met the requirements for minimum contribution years. Indeed, there is a considerable gap between social assistance and minimum pensions (Figure 2.7). In Turkey, for example, the minimum pension benefit is nearly seven times higher than the means-tested safety-net provision. In Mexico, it is five times greater. The scale of disparity is a stark reminder of the importance of meeting pension eligibility criteria through contributions in both countries. Minimum pensions in both Portugal and Spain are around two-thirds more than the safety-net benefit - assuming, that is, full contribution histories.

\section{Figure 2.7. Comparisons between safety-net benefits and basic/minimum pensions}

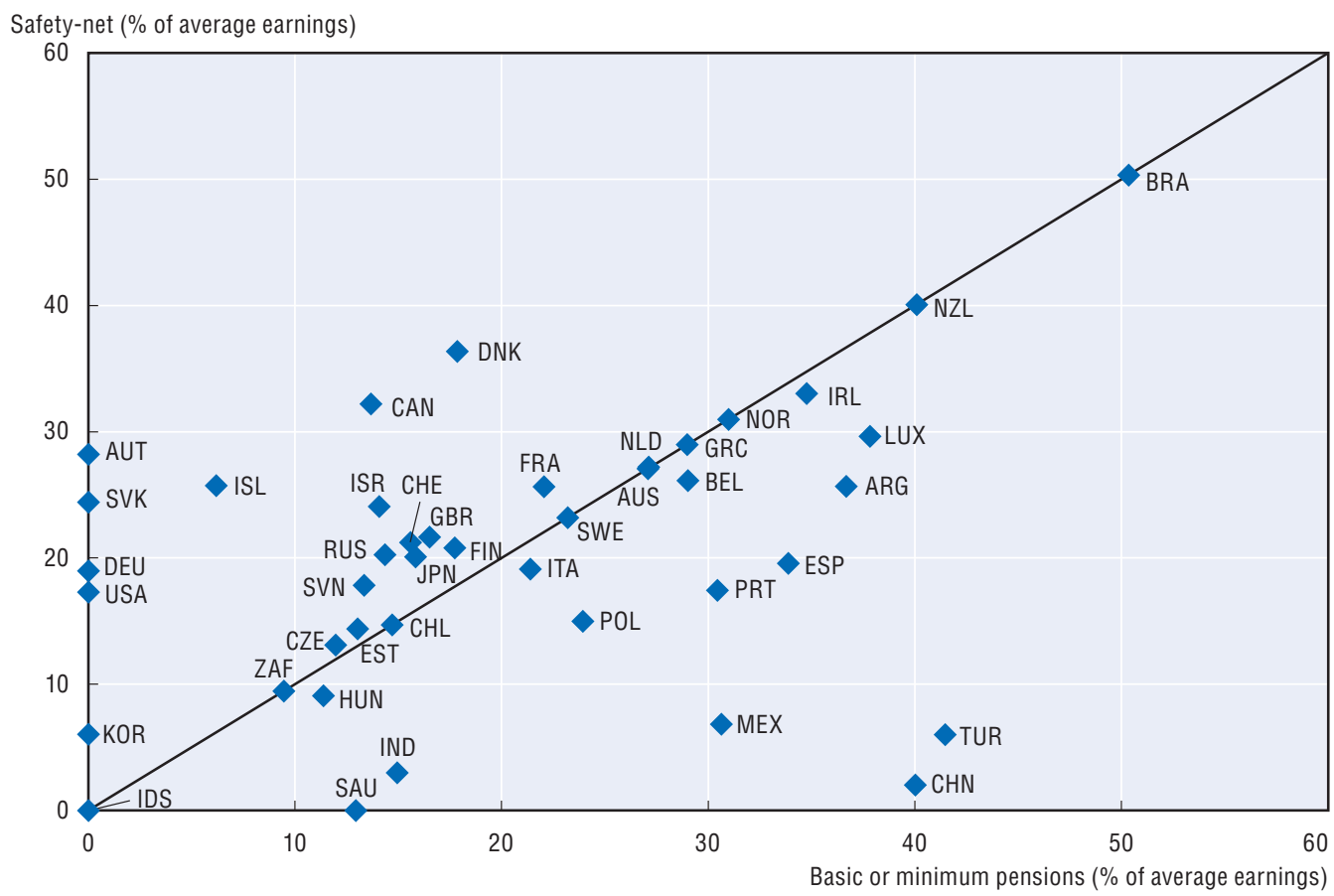

Source: "Country profiles" in Chapter 11 of this publication.

All the countries on the left of Figure 2.7 (Austria, Germany, Korea, the Slovak Republic and the United States) have safety-net provisions, but no basic or minimum pension. Instead, pensioners receive a pension based solely on their personal contributions.

Beyond these, the three countries furthest above the line, Canada, Denmark and Iceland, have additional supplementary pensions above the basic pension, thus increasing the overall safety net. As these supplementary benefits are offset against income from other sources, pensioners who have contributed do not necessarily receive the full safety net. Canada offsets its guaranteed income supplement (GIS) at a rate of 50\% against income other than the basic pension. In Denmark the deduction rate is $30.9 \%$ for income, including the basic pension, of above $35 \%$ of average earnings, 
while in Iceland the rate is either $13.35 \%$ or $38.35 \%$, depending on thresholds for income from earnings, occupational pension, or capital. There is therefore an element of "clawback" within the system in Canada, Denmark, Iceland and Chile, where personal pensions gradually lower the entitlement to the supplementary means-tested benefit and, sometimes, even the basic pension.

The interaction between the various components of the pension system varies along the earnings distribution as illustrated in Figure 2.8 for these four countries. Some components though do not change, for example, the basic pension in Denmark is universal and so remain constant. In both Canada and Iceland the basic pension is also set against other income. In Canada, however, as no additional income from voluntary pensions is assumed here the basic pension is at the full level across the earnings distribution.

Figure 2.8. Clawback in the supplementary schemes
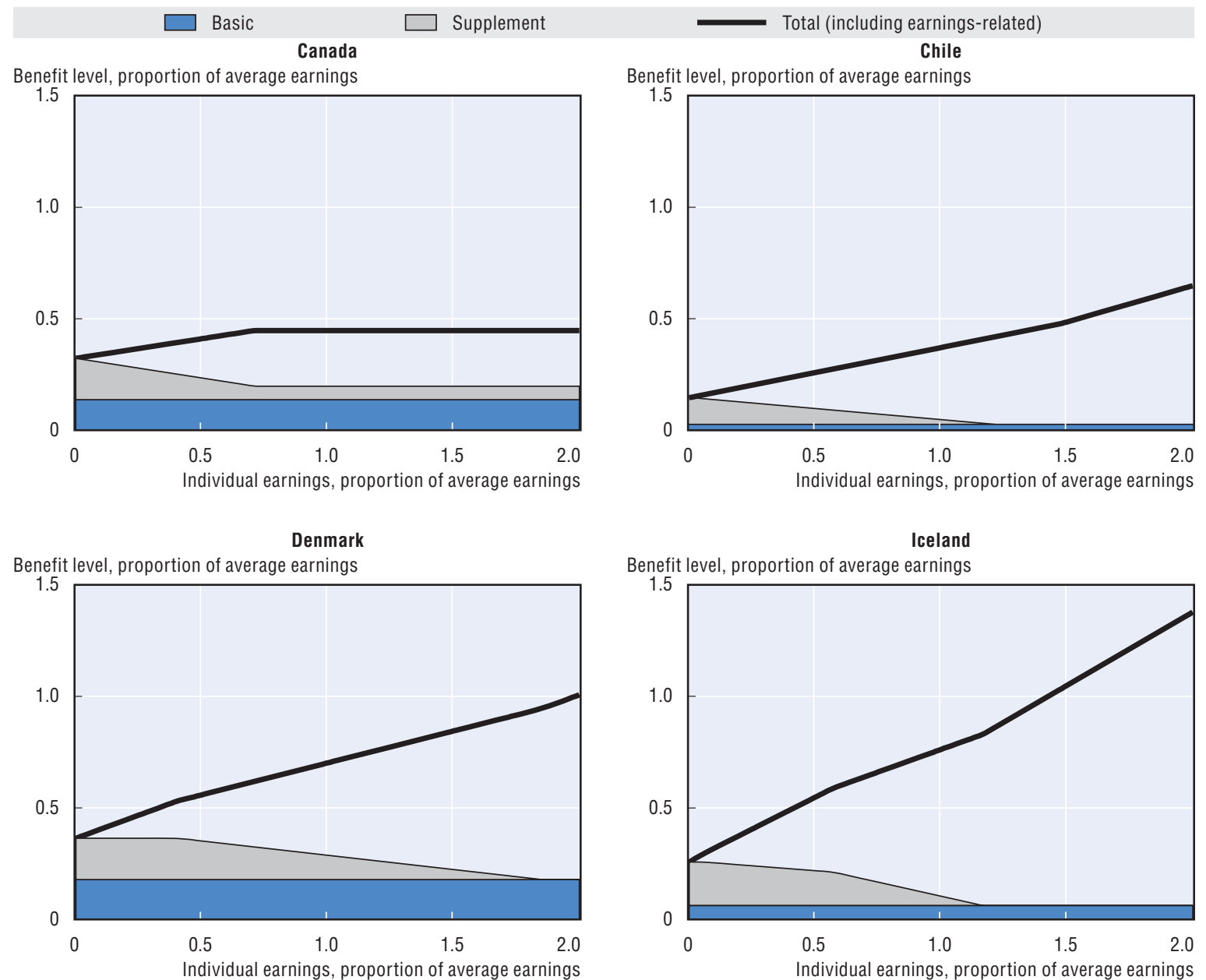

Note: Calculations for full-career worker starting at age 20 in 2014 assuming full contribution to all mandatory earnings-related schemes.

Source: OECD pension models.

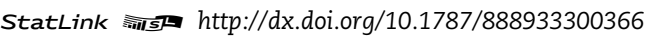

Beyond the basic pensions however the level of other components diminishes as past earnings increase. The level of the supplement declines in all countries, apart from Denmark, with any earnings-related pension. For Denmark the decline begins at around $40 \%$ of average earnings. For average earners the supplementary benefit is minimal in Chile and Iceland at about $4 \%$ of average earnings, but still accounts for over $10 \%$ of average earnings in Denmark as the level of withdrawal is 
lower. For higher earners, at $150 \%$ of the average, the entire pension in Chile comes from the earnings-related component as the supplementary pension ceases just below this earnings level. The same is true in Iceland where the supplementary benefit ends around 1.2 times average earnings, but the universal pension is also there. Both Canada and Denmark still have some supplementary pension at this earnings level and in fact for Denmark it is still relevant up to a about $180 \%$ of average earnings. In Canada the levels of benefit paid remain constant from around $70 \%$ of average earnings as with no income from voluntary pensions the withdrawal rules do not change.

In a few OECD countries, however, safety nets afford a marginally higher income than basic and minimum pensions, as for example in the Czech Republic and Estonia. In Ireland, income from the non-contributory pension is only $5 \%$ lower than the full contribution-based basic pension, even though the state pension (the basic scheme) is the only mandatory component. The sole prospect of enjoying an income upon retirement may not, therefore, be enough of an incentive to contribute in Ireland. However both the Czech Republic and Estonia have additional mandatory earnings-related schemes which provide an additional source of pension income. In many other countries (Canada, Denmark, Iceland, Israel and Slovenia) the level of safety-net benefits is considerably higher than that of the basic or minimum pensions (Figure 2.6). However, as with the Czech Republic and Estonia, mandatory earnings-related schemes reduce reliance on safety-net benefits. In both Mexico and Turkey the levels of the minimum pensions are amongst the highest in the OECD, with Turkey offering $41 \%$ of average earnings. However, the safety-net benefits are, along with Hungary and Korea, the lowest in the OECD at around 6\% of average earnings for Korea, Mexico and Turkey and 9\% for Hungary, with an OECD average of $24 \%$ of average earnings for all countries with a minimum or basic pension.

Figure 2.9 shows that there is a correlation across countries between the value of safety-net benefits relative to average earnings and the level of economic development, with relatively few outliers. Yet, the four countries mentioned earlier, namely Hungary, Korea, Mexico and Turkey, fall well below the safety-net level "explained" by GDP per capita. Considering that Korea, Mexico and Turkey also have amongst the highest old-age poverty levels in the OECD, there is a particular need for higher levels of benefit in these countries. Similarly, old-age poverty rates are also an issue in both Switzerland and the United States, where the level of safety nets is much lower than in other countries with comparable aggregate income level.

\section{Figure 2.9. Safety-net benefits compared to GDP per capita}

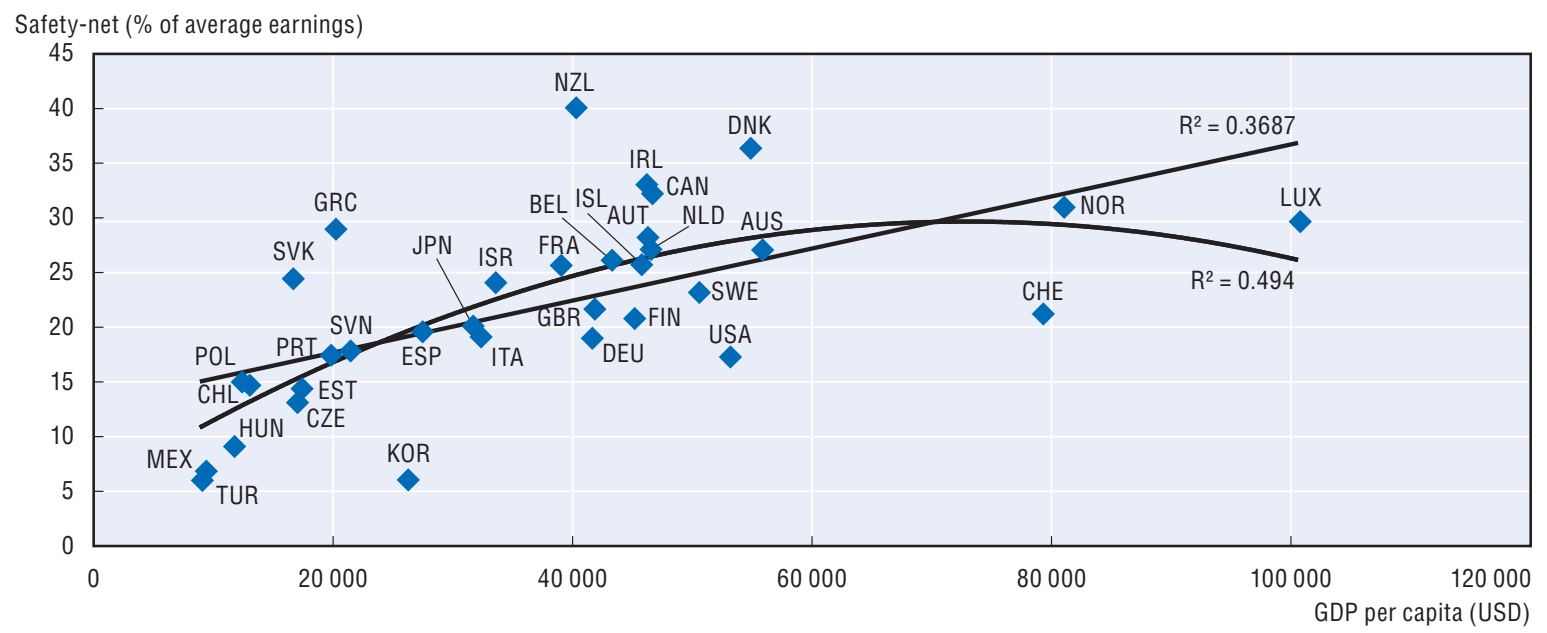

Source: "Country profiles" in Chapter 11 of this publication. 
As well as the support afforded by safety-net benefits, pensioners are also eligible to additional state support, chiefly to cover housing expenses but also other needs. In Australia, for example, they may be entitled to a comprehensive system of allowances and assistance for health, rent, medical, and other living expenses (Table 2.3). In Austria, too, additional payments cover housing and heating costs, at least partially, with some pensioners entitled to a flat-rate allowance and others to adjustable housing benefit. Similarly, New Zealand offers a supplementary housing allowance that subsidises up to $70 \%$ of weekly housing expenses. Sweden's housing benefit, too, covers as much as $93 \%$ of a single pensioner's housing costs up to a ceiling that is equivalent to $15 \%$ of average earnings. Indeed, most OECD countries offer supplementary housing or heating benefit provisions.

Table 2.3. Supplementary benefits for pensioners in OECD countries

\begin{tabular}{|c|c|c|c|c|c|c|c|}
\hline & Housing/heating & Health/care & Social assistance & & Housing/heating & Health/care & Social assistance \\
\hline Australia & $x$ & $x$ & $x$ & Japan & $x$ & & \\
\hline Austria & $x$ & & & Korea & & & $\mathrm{x}$ \\
\hline Belgium & & & & Luxembourg & & & \\
\hline Canada & & & & Mexico & & & \\
\hline Chile & & & & Netherlands & & & \\
\hline Czech Republic & $x$ & & & New Zealand & $x$ & & \\
\hline Denmark & $x$ & $x$ & $x$ & Norway & & & \\
\hline Estonia & $x$ & & $x$ & Poland & & & \\
\hline Finland & $x$ & $x$ & $x$ & Portugal & & & \\
\hline France & $x$ & $x$ & $x$ & Slovak Republic & $x$ & & $x$ \\
\hline Germany & & & & Slovenia & & & \\
\hline Greece & & & & Spain & $x$ & & \\
\hline Hungary & $x$ & $x$ & $x$ & Sweden & $x$ & & \\
\hline Iceland & $x$ & & $x$ & Switzerland & & & \\
\hline Ireland & $x$ & $x$ & $x$ & Turkey & & & \\
\hline Israel & $x$ & & & United Kingdom & $x$ & $x$ & $\mathrm{x}$ \\
\hline Italy & & & & United States & & & \\
\hline
\end{tabular}

Source: Information provided by OECD country delegates.

In Denmark, old-age pensioners are entitled to a considerable number of supplementary benefits - particularly favourable housing benefits, heating benefits, health allowances, and reduced tax rates on owner-occupied accommodation - most of which are offset against income or assets, however. Pensioners are entitled to a number of free services, such as home-help and hospital treatment. The Housing allowance could be as high as $20 \%$ of average earnings in 2014 , though it may not exceed $15 \%$ of housing costs. Furthermore, particularly disadvantaged pensioners, like those not entitled to a full basic pension because they have less than 40 -years' residence, can be granted a personal allowance if so warranted by individual assessments of their needs.

In Finland the most important benefits are care allowance and housing benefit. The care allowance is paid to pensioners at three different rates up to a ceiling of around $10 \%$ of average earnings, depending on their needs and costs arising from home care and illness or injury. Housing allowance varies, the amount being offset against personal income and housing costs. The maximum amount is around $20 \%$ of average earnings.

All these instances of supplementary benefits show that social assistance may well be just a start when it comes to income support for pensioners. There are often additional benefits available, be they cash, free services, or reduced-rate entitlements. The overall monetary cost of supplementary allowances is impossible to calculate on a comparable basis. Yet it is clear that they can play a 
significant role in assisting society's most vulnerable members when they retire. However, with many payments or services being universal, they are not targeted at the vulnerable and will also benefit those who do not require any assistance e.g. free television licenses for pensioners.

\subsection{How will benefits evolve?}

\section{Impact of indexation policy}

Countries' indexation policies determine how benefits will evolve over time if the rules do not change. Indexation is the mechanism whereby pensions are adjusted - be it annually, quarterly, or monthly - according to wages or prices, for example. If benefits are wage-indexed they tend to remain constant in relative terms for future generations, as pensioners' income grows in line with that of active workers. If price-indexed, retirement benefits are flat in real terms, thus stabilising the standard of living of retirees. This would mean, however, that the benefits decline in relative terms as wages are expected to grow faster than prices over time due to gains in productivity.

This issue is especially relevant for first-tier pensions because the indexation policy does not only determine the evolution of the purchasing power of beneficiaries through the retirement period, but also the initial level of income at the time of retirement. If first-tier pensions are price-indexed for a long time, i.e. across cohorts, the purchasing power of the elderly beneficiaries would not grow from an older to a younger cohort at the same age.

As Chapter 5 discusses in detail, OECD pension models assume that prices increase by $2 \%$ per year on average, while real wages rise by $1.25 \%$. As a consequence, for every year that the pension is price-indexed it is projected to fall by $1.25 \%$ relative to wages. In a country that practices price indexation over time, pensions will fall substantially relative to workers' incomes over a full career. Fully price-indexed benefits would fall at retirement relative to wages to about $56 \%$ of their current relative value for someone who starts a full career at the age of 20 . After retirement, benefits would continue to decline in relative value and would only be $45 \%$ of their current relative value when the individual reached age 85 . The implications for the risk of old-age poverty, which is commonly measured in relation to median incomes, are clear.

If the price indexation of first-tier pensions is maintained over the long term the value of benefits relative to earnings will converge to zero, which is an unrealistic scenario, at least unless alternative means of support are provided. Therefore, price indexation, for example, is implicitly based on occasional discretionary adjustments, but by definition given the uncertainty related to the extent and the timing of these adjustments it is impossible to account for them in a forward looking analysis.

\section{Indexation of basic and minimum pensions}

Indexing basic pensions, whether residence- or contribution-based, to prices alone is not that common across the OECD. It is, however the practice in Canada, Chile, Finland, Greece and Sweden for the residence-based pensions (Table 2.4). Other countries have adopted alternative approaches. One example is the United Kingdom, where basic state pension increases are indexed on whatever is the highest: annual changes in earnings, in prices, or a rate of $2.5 \%$. Norway's basic pension is wageindexed minus $0.75 \%$. So, for someone entering the labour market today at the age of 20 , the basic pension - as a proportion of the average wage - is projected to fall to about $80 \%$ of its current relative value upon their retirement at the age of 67 . Pensions in Japan are indexed to wages until age 67 and then to prices thereafter, whilst Luxembourg periodically also adjusts pensions in line with wages in addition to its standard practice of indexing benefit on the cost of living. 
Table 2.4. Indexation of pension benefits by component of the system

\begin{tabular}{|c|c|c|c|}
\hline & Basic & Minimum & Safety-net \\
\hline Australia & Whatever is higher: prices or cost of living & & Whatever is higher: prices or cost of living \\
\hline Austria & & & Discretionary \\
\hline Belgium & & Prices & Prices \\
\hline Canada & Prices & & Prices \\
\hline Chile & Prices & & Prices \\
\hline Czech Republic & $33.3 \%$ wages $/ 66.7 \%$ prices & $33.3 \%$ wages $/ 66.7 \%$ prices & $33.3 \%$ wages $/ 66.7 \%$ prices \\
\hline Denmark & Wages & & Wages \\
\hline Estonia & $80 \%$ wages $/ 20 \%$ prices & & $80 \%$ wages $/ 20 \%$ prices \\
\hline Finland & Prices & & Prices \\
\hline France & & Prices & Prices \\
\hline Germany & & & Wages \\
\hline Greece & Prices & & Prices \\
\hline Hungary & & Prices and net average monthly earnings & Prices and net average monthly earnings \\
\hline Iceland & Whatever is higher: wages or cost of living & & Prices \\
\hline Ireland & Wages & & Wages \\
\hline Israel & Prices & & Prices \\
\hline Italy & & Prices & Prices \\
\hline Japan & Wages until age 67 , then prices & & Cost of living and wages \\
\hline Korea & & & Prices \\
\hline Luxembourg & Cost of living and annually consider wages & Cost of living and annually consider wages & Cost of living and annually consider wages \\
\hline Mexico & & Prices & Prices \\
\hline Netherlands & Legal minimum wage & & Legal minimum wage \\
\hline New Zealand & Prices and periodically net average wage & & Prices and periodically net average wage \\
\hline Norway & Wages minus $0.75 \%$ & & Wages minus $0.75 \%$ \\
\hline Poland & & Prices & Prices \\
\hline Portugal & & GDP and consumer price index without housing & Prices \\
\hline Slovak Republic & & & Prices \\
\hline Slovenia & & $60 \%$ wages $/ 40 \%$ prices & \\
\hline Spain & & Between $0.25 \%$ and (consumer price index $+0.5 \%$ ) & At least equal to contributory pension increase \\
\hline Sweden & Prices & & Prices \\
\hline Switzerland & & & $50 \%$ wages $/ 50 \%$ prices \\
\hline Turkey & & Prices & Prices \\
\hline United Kingdom & Whatever is highest: prices, wages or $2.5 \%$ & & Whatever is higher: prices, wages or $2.5 \%$ \\
\hline United States & & & Prices \\
\hline
\end{tabular}

Source: "Country profiles" in Chapter 11 of this publication and additional information provided by OECD delegates.

StatLink त्नाजम http://dx.doi.org/10.1787/888933300993

Countries that have minimum pensions, in addition to the basic scheme, generally have similar indexation rules. One example is the Czech Republic, where the minimum pension is indexed to $33.3 \%$ wages $/ 66.7 \%$ prices. Luxembourg indexes it to the cost of living, but must adjust pensions every year in relation to increases in real earnings if annual income from contributions exceeds pension expenditure. Overall, however, half of the countries with minimum pensions index solely to prices.

\section{Indexation of other old-age safety nets}

The majority of countries index their social-assistance benefit to prices (Table 2.4). The exceptions include the Czech Republic where the wage and price indexation shares are 33.3\% and $66.7 \%$, Estonia with $80 \%$ and $20 \%$, and Switzerland with $50 \%$ and $50 \%$. Norway also indexes to wages, offset by 0.75 percentage points per annum, while Denmark is an isolated case as its safety net is fully indexed to wages. Also in the United Kingdom, the three prong indexation approach implies indexation to wages under OECD long-term assumptions. 


\section{Poverty risks}

Poverty rates by age group are shown in Figure 8.4 in Chapter 8 . On average across OECD countries, the poverty level is $11.2 \%$ among 66 to 75 year-olds and, $14.7 \%$ among the over- $75 \mathrm{~s}$, in contrast to $11.4 \%$ for the total population. The cross-country relationship between low safety-net benefits and old-age poverty levels is not straightforward (Figure 2.10). One obvious reason is that the level of the safety-net benefit can be significantly different from the relative poverty line, defined here as half the median equivalent household income. In addition, some particular features of the pension system can give a somewhat misleading impression of poverty:

- Australia, for example, has a very high poverty level despite the safety-net benefit (relative to earnings) being above the average for OECD countries - albeit below the poverty threshold; in Australia, the poverty figures are inflated, as pensions are mostly taken as a lump-sum, not regarded as a regular annual income, and therefore not considered in the income statistics on which poverty calculations are based.

- In the Czech Republic, the level of pensioner poverty is among the lowest in the OECD while first-tier benefits are relatively low. However, the poverty figure for population as a whole is also amongst the lowest in the OECD and pensions are particularly high for low earners if they have had a reasonably long career as was the case for most before the economic transition period.

- The United States, which has virtually an identical safety-net benefit rate (as a percentage of average earnings) as Portugal, shows a poverty rate that is much higher than that of Portugal. This partly reflects the wider distribution of earnings resulting in more working-age poverty which in turn is reflected in retirement incomes. Pensioners with at least 15 years of contributions in Portugal are also further protected by the minimum pension, which level is above that of the safety net whilst there is no minimum pension in the United States.

- The clear stand-out country is Korea which has both the lowest safety-net benefit and by far the highest elderly poverty level. Mexico presents a similar albeit less extreme case.

Figure 2.10. Safety-net benefits and poverty levels among the over-65s

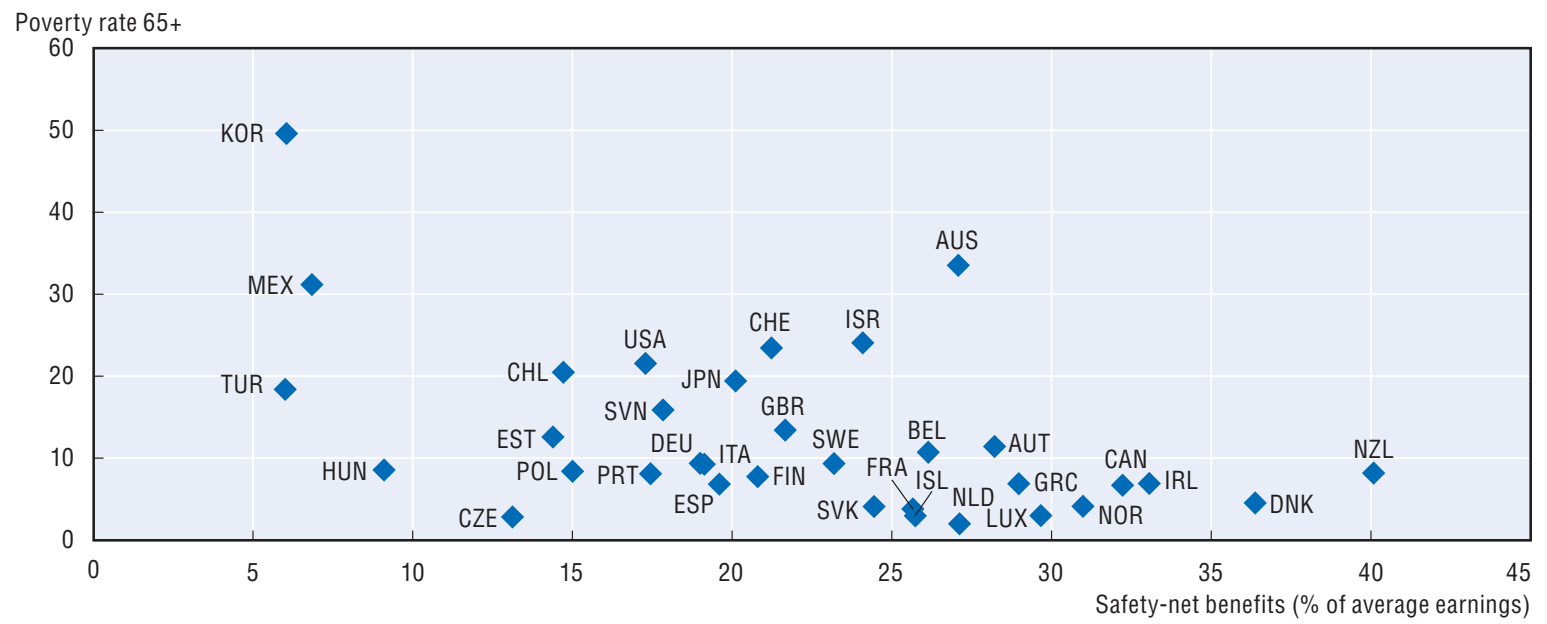

Source: "Country profiles" in Chapter 11 of this publication; OECD (2015), In it Together: Why Less Inequality Benefits All, OECD Publishing, Paris, http://dx.doi.org/10.1787/9789264235120-en. 
If contribution histories remain stable then price indexation is likely to gradually increase poverty for future retirees. However, today's workers are likely to have different career paths than current pensioners had, particularly as growing numbers of women enter the labour market and given the current labour market difficulties faced by the youth in many countries. What is more, the pensions currently being paid do not reflect the rules of the systems to which workers are currently contributing as there have been numerous reforms in most OECD countries. Although predicting long-term poverty levels is a very difficult exercise, long-term price indexation of first-tier pensions will lower the relative value of retirement benefits, unless accompanied by periodic reassessments of the benefit level.

If indexation rules are strictly enforced, the risks of increasing old-age poverty rates from an already high level are the most serious in four OECD countries. Over the next 50 years, the population aged 65 and over is forecast to more than double across the OECD, with the largest increases coming in Mexico (440\%), followed by Turkey (360\%), Chile $(280 \%)$ and Korea $(240 \%)$. All four countries are among those with the highest elderly poverty rates and index their first-tier pensions to prices. While the decline in the relative value of benefits over time would mitigate the impact of population ageing on public spending to an extent, the social cost would be very high.

Although in most countries clear rules govern legislation on pension indexation, they were not always fully followed and the legislation was not always implemented, especially as wages declined in the wake of the financial crisis. Ireland, for example, froze the value of pensions between 2009 and 2010 despite falling wages and has kept them frozen since, despite periods of subsequent earnings growth. However, going further back in history to the late 1990s and early 2000s shows that most countries which index pensions on prices have complied with the statutory indexation rates. Of the 13 countries* that have practiced price indexation for a number of years (Table 2.4) ten have abided by the legislation over the long term, only Belgium, Poland and Spain did not. Pension increases in both Canada and the United States have matched the changes in price inflation index exactly, resulting in a decline of the basic pension in Canada and safety-net benefits in the United States by about 7\% in relative terms between 2002 and 2014.

With careers set to last longer, in part due to statutory increases in retirement ages, pension entitlements might increase, which would, other things being equal, reduce the reliance on safety-net payments and basic pensions. However, for the most vulnerable, primarily those who have been unable to contribute sufficiently during their working careers, the safety-net benefits on retirement in 45 years' time are unlikely to provide sufficient income if current price indexing rules are rigidly applied.

\section{Indexation policy options and public finance pressure}

There is no single optimal indexation rule from a normative standpoint. The spectrum of indexing rules which countries apply over the long term generally extends from price indexing, i.e. freezes in real terms, to wage indexing, i.e. stability relative to average wages. On the one hand, price indexation preserves the standard of living of retirees in absolute terms and when applied to first-tier pensions in addition prevents an increase in the standard of living of beneficiaries across cohorts at the same age. This gradually leads to a fall in the income of beneficiaries relative to that of wage-earners, potentially inducing large shifts in inequality. On the other hand, wage indexation maintains relative position on average. However, indexing payments to wages might be an expensive, and ultimately unaffordable, option in the long term as populations age, especially for countries already experiencing public finance pressure. Indeed, the change in the old-age dependency ratio is

* Belgium, Canada, Chile, Finland, France, Israel, Italy, Mexico, Poland, the Slovak Republic, Spain, Sweden and the United States. The benefits in Greece and Korea are relatively new and Turkey has recently changed to price indexation. 
one main driver of the trend in the cost of the provision over time, assuming that the proportion of claimants of a particular benefit remains constant amongst the elderly population (Box 2.1). The impact on the financial cost is compounded for first-tier pensions through the effect of indexation on the initial level of pensions.

\section{Box 2.1. Indexation rules to stabilise public spending on first-tier pensions}

First-tier pension spending as a percentage of GDP is given by $S=b R / p Y$, where $b$ is the benefit level, $R$ the number of recipients, $Y$ is real output and $p$ the GDP price index. It is assumed that recipients are a constant share $\theta$ of the old-age population $N$, and that the labour share of GDP, $w L / p Y$, where $w$ is the average wage and $L$ total employment, remains stable and equal to $\alpha$ (this implicitly assumes that the aggregate production function is Cobb-Douglas). In that case, the spending share is given by $S=\frac{b R}{p Y}=\theta \frac{b N}{p Y}=\theta \alpha \frac{b}{w} \frac{N}{L}$ and, to maintain the share of total benefits in GDP constant, individual benefit needs to follow the following rule: $\frac{\Delta b}{b}=\frac{\Delta w}{w}-\frac{\Delta N / L}{N / L}$, i.e. first-tier pension should be indexed to wages minus the relative change in the old-age dependency ratio. This differs from the indexation of defined-contribution or defined-benefit pensions which applies only through the individuals' retirement period.

For the purpose of calculation, the evolution of the old-age dependency ratio is calculated using data for those aged 65 and over in 2015 and for either those aged 65, 70 or 75 and over in 2060 to account for potential increases in effective retirement ages over the time period.

A potentially more balanced approach between indexation to prices and to wages should therefore factor in demographic trends into the design of the indexation rule in a way that at least preserves the standard of living (price indexation) while being financially sustainable (less than wage indexation in the context of population ageing, see below). One scenario would be to maintain the current levels of first-tier spending relative to GDP in spite of the ageing population. Since in the steady state the financing, whether tax- or contribution-based, tends to follow GDP, the indexation rule that stabilises the financing of first-tier payments as a percentage of GDP given projected demographic changes has been derived. This scenario does not bear any normative significance as other objectives matter which could conflict with financial stability, such as the fight against inequality and old-age poverty. Furthermore, this exercise does not take the starting point into account which in some countries involves high old-age poverty rates, or overly generous spending.

As explained in Box 2.1, the rule stabilising first-tier spending would lead to benefits being indexed on earnings minus the annual percentage change in the old-age dependency ratio. In the same spirit, Norway applies a similar rule as first-tier pensions are indexed to wages minus $0.75 \%$. Figure 2.11 provides the then required adjustment to wage indexation given by the projected demographic changes under three scenarios: computing the old-age dependency ratio, i.e. the share of the elderly relative to the working-age population, by maintaining the age threshold constant at 65 or by increasing it to 70 in 2060 or to 75 . To put this in context, the life expectancy at birth has increased by about 12 years between the 1950 and the 1995 cohorts (i.e. those that will turn 65 in 2015 and 2060, respectively). If old-age employment rates increase, for example via a higher effective retirement age, the factor deducted from wage indexation (i.e. the change in the old-age dependency ratio) is lower in absolute terms, and the first-tier indexation rule can be closer to wage indexation without threatening financial sustainability. For example, in the case of Poland, maintaining 65 years as the age threshold to compute the elderly population throughout the 2015-60 period leads to an annual increase of $2.3 \%$ in the old-age dependency ratio. However, if the age threshold is gradually increased to 70 years in 2060 , then the old-age dependency ratio would rise by $1.5 \%$ each year on average. 


\section{Figure 2.11. Indexation of first-tier pensions to achieve constant expenditure (as a share of GDP) over 2015-60 given population ageing}

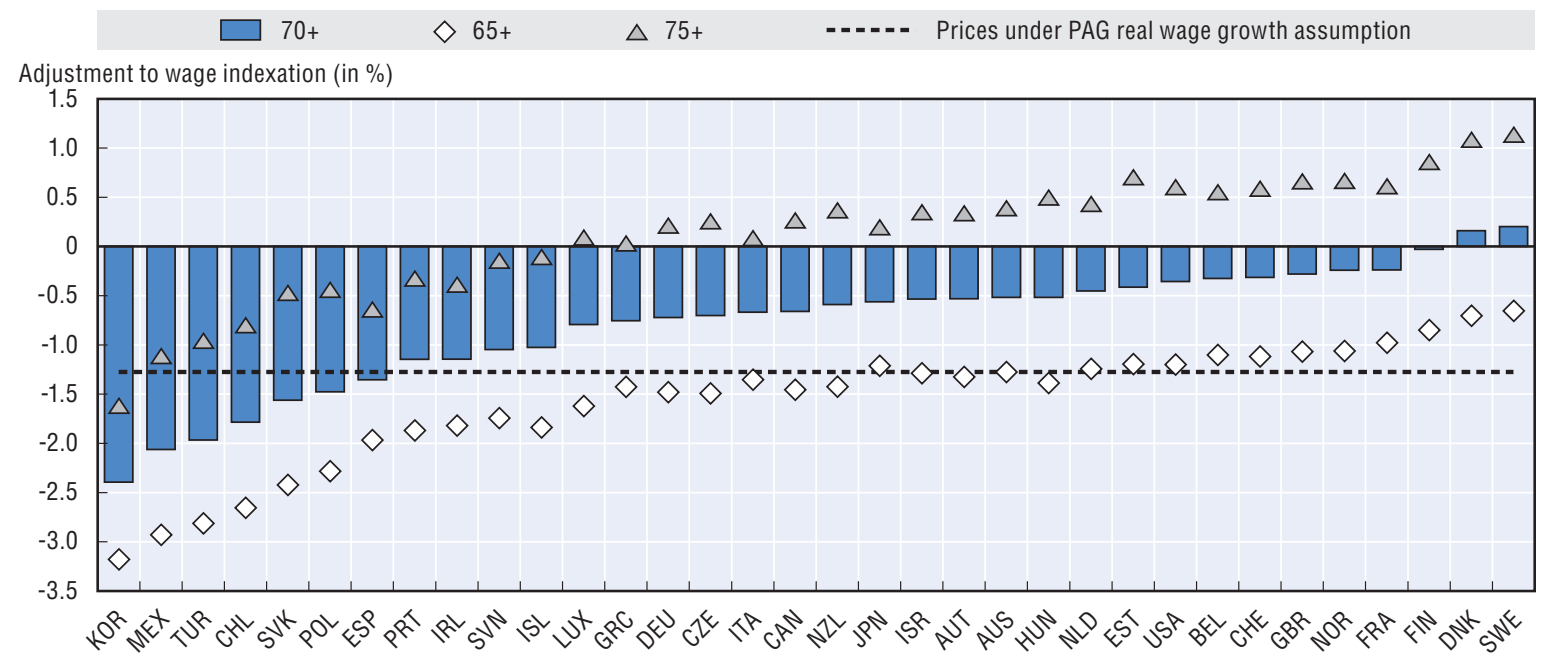

Note: The headings $65+, 70+$ and $75+$ refer to the age threshold $(65,70,75)$ used to compute the prospective old-age dependency ratios in 2060, with the working age population calculated from age 20 in all cases (see Box 2.1).

Source: OECD calculations based on the United Nations, World Population Prospects - 2012 Revision Data.

In order to stabilise spending on first-tier pensions (as a percentage of GDP) between 2015 and 2060 (Figure 2.11), benefits would need to be indexed to:

- wages minus 1.6 percentage points on average across the OECD holding the age threshold constant at 65 to compute the old-age dependency ratio

- wages minus 0.8 percentage points using the 70-year threshold for old age in 2060

- wages plus 0.1 percentage points with the 75-year threshold.

Virtually all OECD countries would have indexation well below wages even if effective age parameters were increased by five years by 2060 . However, this would allow indexing first-tier benefits to prices plus 0.5 percentage points on average across countries, assuming real-wage growth of $1.25 \%$ per year as in the baseline PAG projections. In other words, indexing to prices for the next 50 years would generate direct savings on average despite population ageing, thus lowering the relative positions of those eligible to a greater extent than justified by any spending stabilisation requirement.

This average masks of course substantial differences across countries. In particular, based on the 70-year threshold, first-tier benefits in Chile, Korea, Mexico, Poland, the Slovak Republic and Turkey would need to be indexed to wages minus 1.5 to 2.4 percentage points for constant expenditure because of the rapidity of population ageing. This would imply indexation by less than prices according to PAG assumptions for real-wage growth. The upshot is that in these countries, even if age thresholds are increased by five years by 2060, either expenditure would increase (and in some of them the spending level is currently low) or the standard of living of beneficiaries will fall in the future. Conversely, the first-tier benefit levels in both Denmark and Sweden could be increased each year by around 0.2 percentage points above wage growth under the assumption of a five-year increase in the age at retirement.

Many countries are close to stabilising spending on first-tier pensions (as a percentage of GDP) under their current indexation policies based on OECD economic assumptions, provided that age thresholds are increased by five years by 2060 (Figure 2.12 for a subset of countries and the annex for all countries). In Estonia maintaining a constant expenditure under the OECD economic assumptions could be achieved by indexing first-tier pensions to around $70 \%$ of nominal wage growth (and $30 \%$ of 
Figure 2.12. Comparison between different indexation approaches to first-tier benefits, assuming the age threshold increases by five years

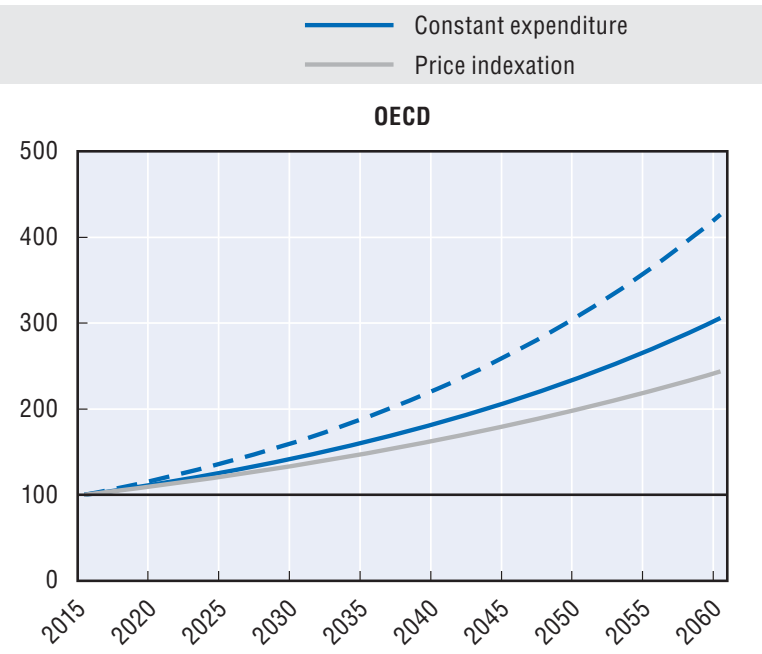

--- Wage indexation
--- Legislation

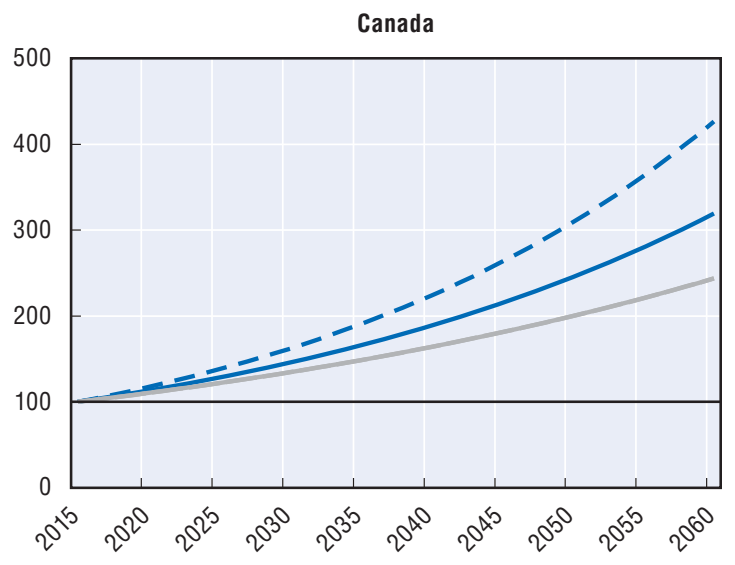

Czech Republic

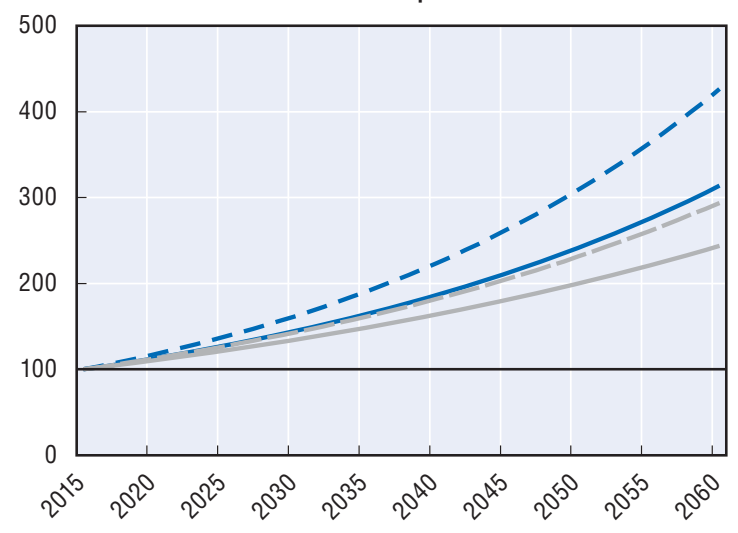

New Zealand

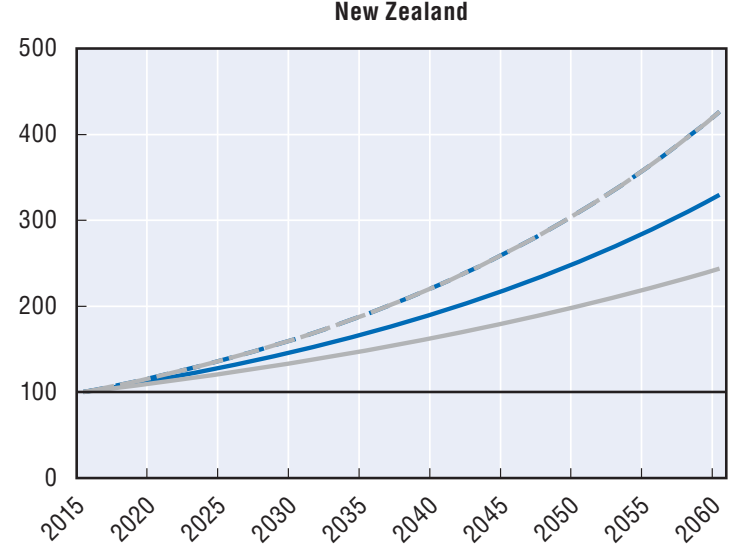

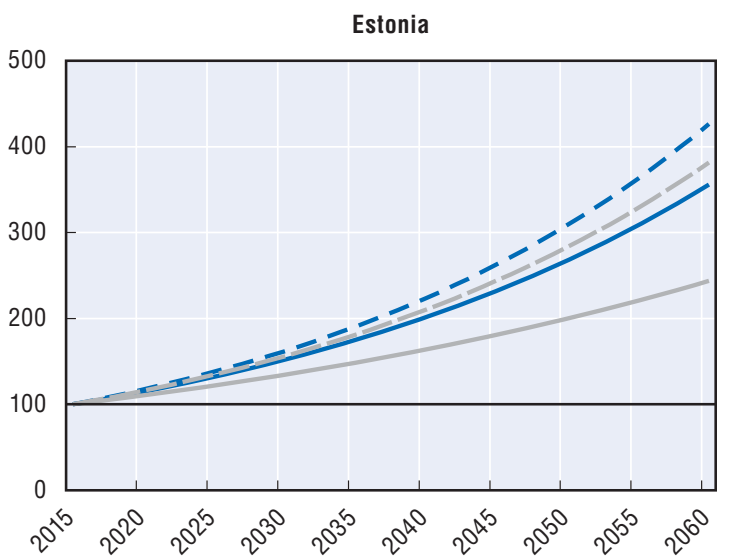

Switzerland

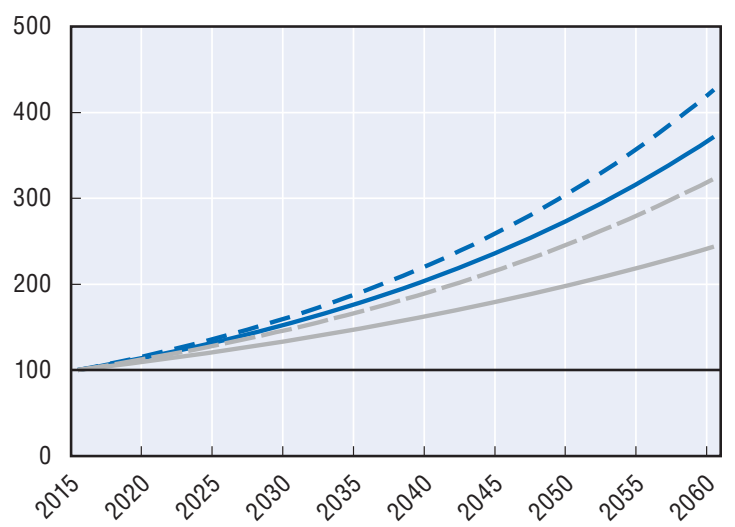

Note: Vertical axis is benefit level in nominal terms, $2015=100$. The figures show the evolution on benefits under various indexation scenarios: price indexation, wage indexation, legislation and that which would result in the stabilisation of first-tier pension expenditure as a percentage of GDP given projected demographic changes (Box 2.1).

Source: OECD calculations based on the United Nations, World Population Prospects - 2012 Revision Data. 
price inflation) while according to current rules the indexation is close to this at $80 \%$ to wages (and $20 \%$ to prices). Likewise the Czech Republic could maintain a constant expenditure rate by indexing to approximately one-third wages and two-thirds prices, which is the policy adopted. In Switzerland indexation is to $50 \%$ wages and $50 \%$ prices which leaves some fiscal space: long-term constant expenditure could be achieved with a slightly more generous indexation formula.

In some countries, the current first-tier indexation legislation would even generate substantial savings (as a share of GDP) in the long term if it were strictly applied: Belgium, Canada, Finland, France, Israel, Italy, Sweden and the United States. In Canada, for example, according to the legislation, indexation is to prices but stabilising first-tier expenditure in GDP could be achieved by indexing to wages minus 0.75 percentage points, i.e. to 0.5 percentage points above prices according to OECD assumptions.

On the other hand, current legislation if applied strictly would boost spending at a faster pace than GDP growth in Chile, Germany, Hungary, Iceland, Ireland, Japan, Korea, Mexico, the Netherlands, New Zealand, Slovenia and the United Kingdom. For example, in New Zealand indexation could be to 0.5 percentage points above prices, whilst actual indexation includes a reference to the average wage. In assessing these expenditure projections, however, initial spending levels should also be taken into account. In Mexico, for example, the current level of both social and pension spending is low as a percentage of GDP. There is therefore room to allow an expansion of expenditure on old-age safety nets even though the pension system will be facing financial pressure due to the generosity of old pension schemes, which are being phased out over a long period of time, and to its deeply seated fragmentation (OECD, 2015a). Similarly in Chile, Iceland and Korea current spending is also very low.

\subsection{Conclusion and policy implications}

\section{Main results}

This chapter has analysed the eligibility criteria for basic and minimum pensions, either based on career-long contributions or length of residence in the country on reaching a particular age, and their value. The analysis also considered the role of social assistance benefits, aimed specifically at people over the retirement age who might have been unable to make sufficient contributions during their working lives, in providing protection against old-age poverty. The impact of benefit indexation was then discussed to show how benefits would evolve over time based on the current legislation.

All countries have old-age safety nets of one form or another, whether they are specifically designed as a minimum income guarantee or whether they are provided through a residence-based (basic) pension. One-half of OECD countries provide a basic residence-based or contribution-based pension. The benefit value ranges from $6 \%$ of average earnings in Iceland to $40 \%$ in New Zealand, although there is no mandatory component in New Zealand in addition to the tax-financed basic pension scheme. As for countries where the basic pension is based on contributions, Luxembourg and the United Kingdom (in its new system) require only ten years for an initial benefit which increases with additional years of contribution, while the Czech Republic requires workers to contribute for more than 35 years to be eligible for any benefit.

Minimum first-tier pensions, which are based on individual contribution history to the pension system, are present in one-third of countries; the Czech Republic and Luxembourg have both a basic and a minimum pension. The value of minimum pensions is around $40 \%$ of average earnings in Luxembourg and Turkey, but below 15\% in the Czech Republic, Hungary and Slovenia. Only 15 years of contributions are required in Slovenia and Turkey, whereas the eligibility period is 35 years in the Czech Republic. 
Behind the OECD's average of $22 \%$ of average earnings for the safety-net benefits covering those ineligible for a contributory pension, lie wide variations in their monetary value, ranging from $6 \%$ of average earnings in Turkey and Korea to $36 \%$ in Denmark and $40 \%$ in New Zealand. The values of minimum contributory pensions are actually lower than safety-net benefits in ten OECD countries, where pensioners can apply though for the means-tested safety net as a top-up.

How all these first-tier benefits are indexed over time is a key part of income prospects for the beneficiaries. It affects the future relative value of benefits, especially for workers just embarking on their careers, and also has an impact on the risk of poverty through retirement years. Price indexation is the most common mechanism for first-tier benefits due to its prevalence for social-assistance benefits; as wages grow more rapidly than prices, adjusting pension benefits to prices over time will reduce the relative income position of pensioners compared to that of workers. Under standard OECD assumptions, price indexation would result in a 56\% reduction of the initial ratio of first-tier pensions to wages after 45 years. Chile, Korea, Mexico and Turkey all have price-indexation of their first-tier benefits, high old-age poverty rates and fast projected population ageing.

\section{Policy implications}

With governments facing growing budgetary constraints adjusting pensions to prices rather than wages is appealing. However, the resulting decline of the relative benefit value could lead to rising risks of old-age poverty in the future. Furthermore, the period of economic turmoil in a number of countries, which has resulted in higher rates of unemployment, particularly among younger workers (OECD, 2014), is likely to make it harder in the future for workers to contribute to pension systems throughout their careers (see Chapter 3). The result could be a greater reliance on first-tier pensions.

In some countries, the number of years of contributions required for the minimum pensions is high. For example, 35 years of contribution are required in the Czech Republic, 25 years in Poland and 24 years in Mexico. In some of these cases it might be necessary to lower the eligibility period with a corresponding benefit reduction or introduce a staggered minimum benefit which would increase in relation to the contribution period. For example only ten years are needed in France and 15 years in Portugal.

In some countries old-age poverty rates are relatively high and the level of first-tier pensions is low in cross-country comparison. This applies, even after controlling for the level of economic development, to Korea, Mexico and Turkey which currently spend the least on such benefits amongst OECD countries, and to Chile to a lesser extent; both Switzerland and the United States also have low levels of benefit given their level of GDP per capita and relatively high old-age poverty rates.

Current indexation policies will lead to rises in expenditure in many countries if take-up rates remain constant. While stabilising first-tier pension spending relative to GDP is not a goal in itself, and does not, alone, bear a normative significance, it can serve as a useful baseline given that financing resources tend to follow GDP. Yet, the starting point, in terms of spending levels or income inequalities affecting the bottom part of the distribution, matters a lot too. Hence, irrespective of demographic change, the scope and need to expand or reduce first-tier expenditures varies a lot across countries. Increasing the retirement age for eligibility to first-tier benefits would help in allowing first-tier pensions to be paid at a decent level at an affordable cost, but this might particularly penalise lower earners if not accompanied by similar increases in statutory retirement ages. An appealing compromise for contributory first-tier pensions might consist in indexing the benefit available to wages until retirement, and then the benefit payments to prices during retirement. The downside is to have different levels of minimum pensions depending on the year of retirement. Japan has such a policy for its contribution-based basic pension. 
If age thresholds were increased by five years by 2060, many countries would be close to stabilising first-tier spending as a percentage of GDP under their current indexation policies. On average across OECD countries, given projected population ageing, first-tier benefits should be indexed to wages minus $0.8 \%$ (i.e. prices plus $0.5 \%$ based on OECD assumptions) to stabilise spending (as a share of GDP) if age thresholds were gradually increased by five years by 2060 . By contrast, if age thresholds were kept constant despite population ageing, stabilising spending as a share of GDP would imply indexing to wages minus $1.6 \%$ (i.e. to prices minus $0.3 \%$ ) on average across countries. However, those countries where all are entitled to basic pensions, whether residence- or contribution-based, will face greater financial pressure in case of wage indexation.

In Canada, the pension benefit is indexed to prices and therefore falls relative to wages over time; over one-third of current pensioners claim it, as voluntary pension coverage is weak among low earners, which suggests that future retirees will still need to rely on this benefit. In Chile, $60 \%$ of pensioners claim the targeted benefit and, as the population ages rapidly, spending will have to increase or benefits will have to rise more slowly than inflation to maintain constant expenditure under OECD economic assumptions.

Encouraging individuals to save, e.g. through auto-enrolment or incentives like tax breaks and matching contributions, will help reduce the reliance on means-tested first-tier benefits. Most OECD countries may need to consider such saving mechanisms in the coming years, depending on the success and effectiveness of current earnings-related schemes in providing sufficient retirement income for new pensioners and on employment performance, of older-workers in particular. Ireland and New Zealand, for instance, both have young populations today but they will be exposed to the pressures of ageing. Wage-indexed basic pensions are the main source of retirement income as neither country has any other mandatory pension scheme. The introduction of the KiwiSaver (an auto-enrolment defined-contribution system) in New Zealand will improve future pensioners' standard of living, but if the basic pension remains indexed to wages the fiscal cost will be high. Iceland, Luxembourg and Japan are similarly affected, but as these countries have mandatory earnings-related pension schemes, the value of their safety-net benefits is currently much lower than in Ireland and New Zealand.

Expenditure for the elderly is not solely limited to direct benefit payments. There are often many universal payments solely dependent on age, for example television licenses, fuel payments or public transport concessions. As the payments of these services are generally universal many recipients who could easily afford the cost of such services are also benefitting. By introducing an element of means-testing for at least some of these payments, future expenditure could be reduced.

\section{References}

OECD (2015a), OECD Reviews of Pension Systems: Mexico, OECD Publishing, Paris.

OECD (2015b), In it Together: Why Less Inequality Benefits All, OECD Publishing, Paris, http://dx.doi.org/10.1787/ 9789264235120-en.

OECD (2014), OECD Pensions Outlook 2014, OECD Publishing, Paris, http://dx.doi.org/10.1787/9789264222687-en. 


\section{Supplementary figures on the effect of different indexation approaches}

Figure 2.A1.1. Effect of different indexation approaches on benefit level, assuming the age threshold increases by five years

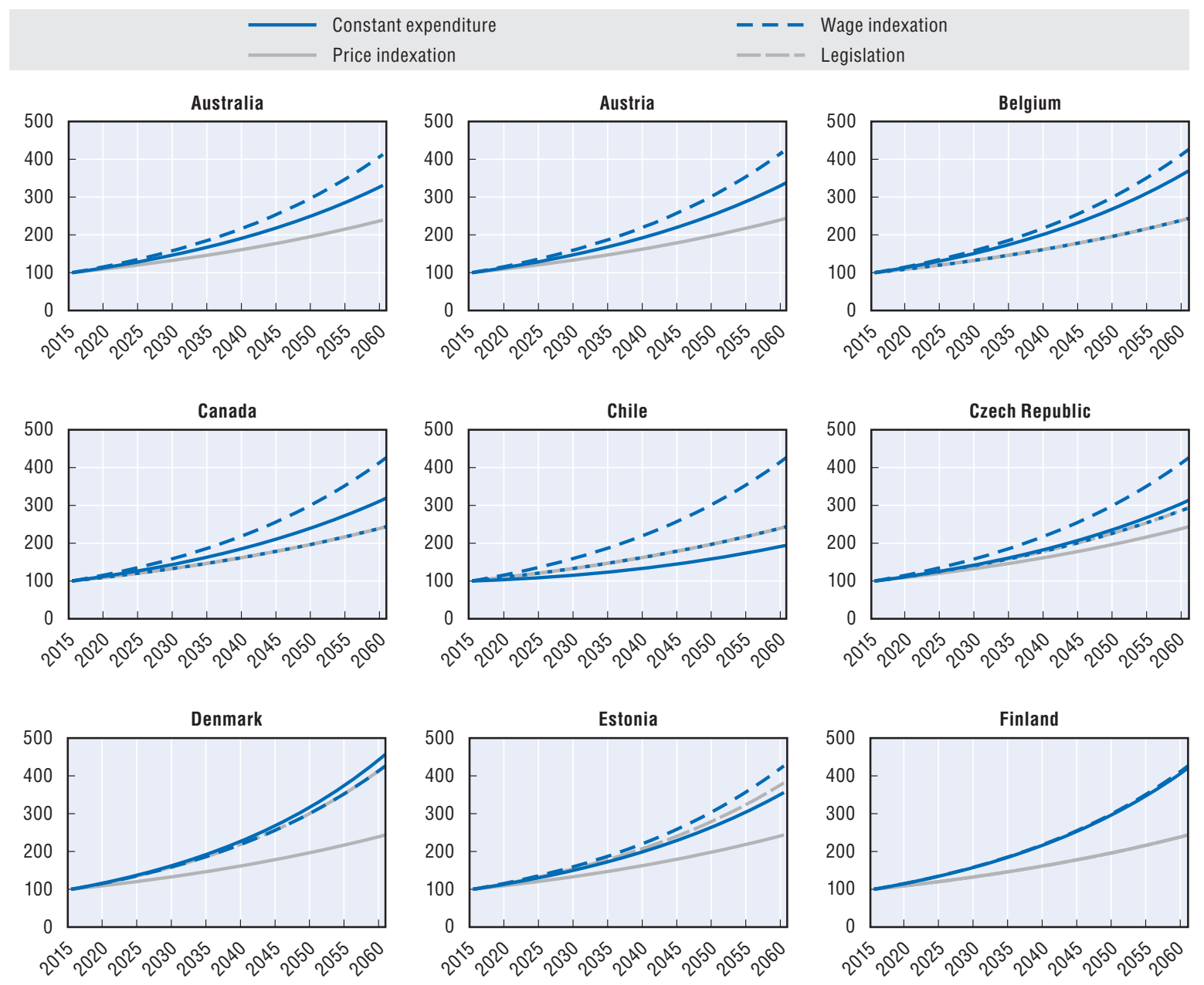


Figure 2.A1.1. Effect of different indexation approaches on benefit level, assuming the age threshold increases by five years (cont.)
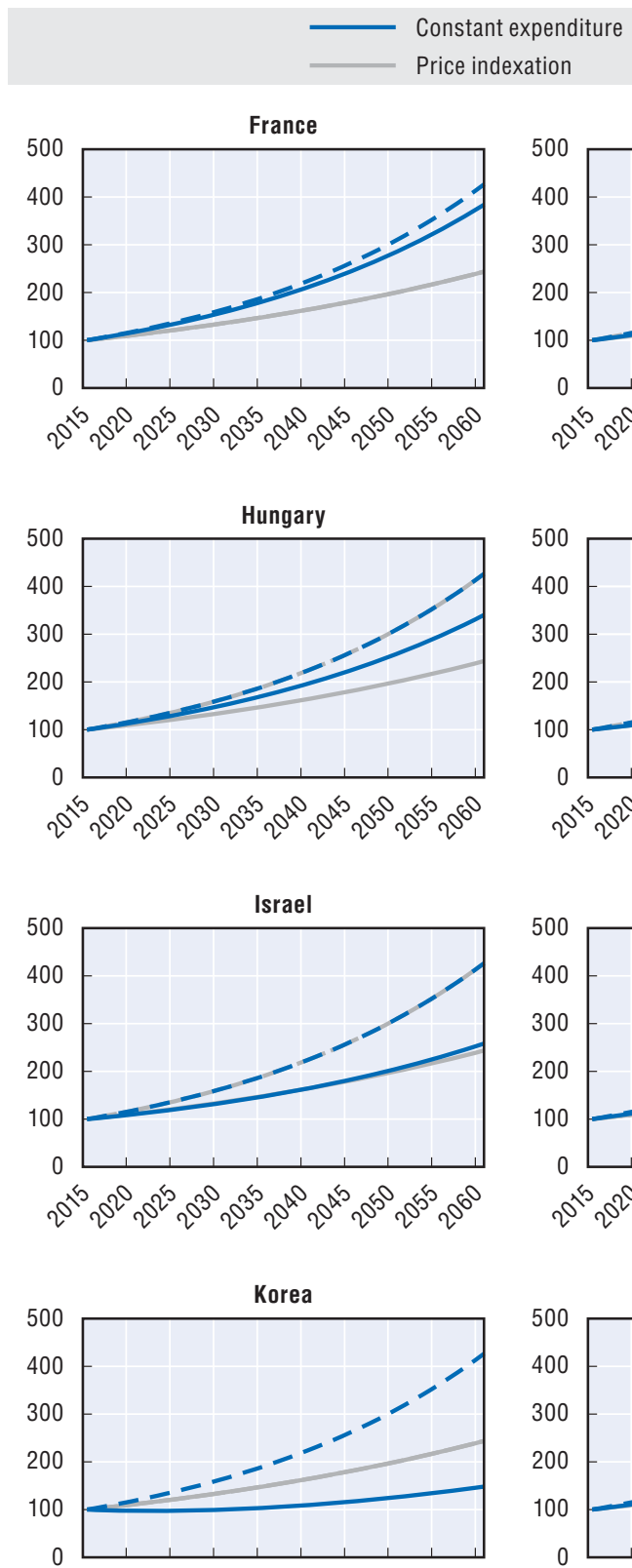

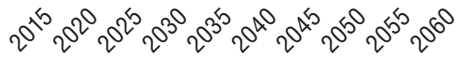

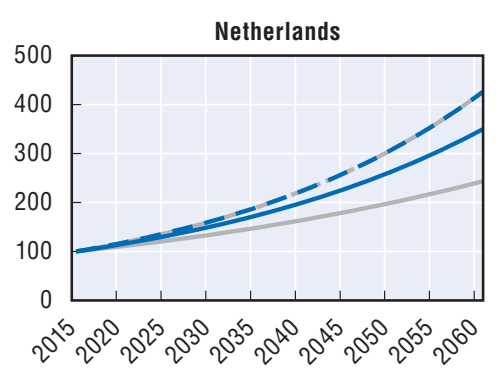

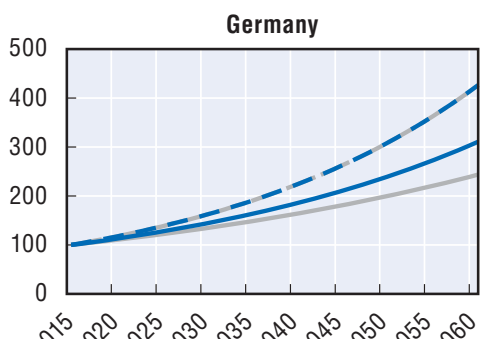

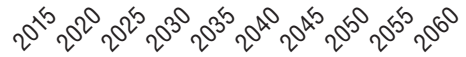

-- Wage indexation

Legislation
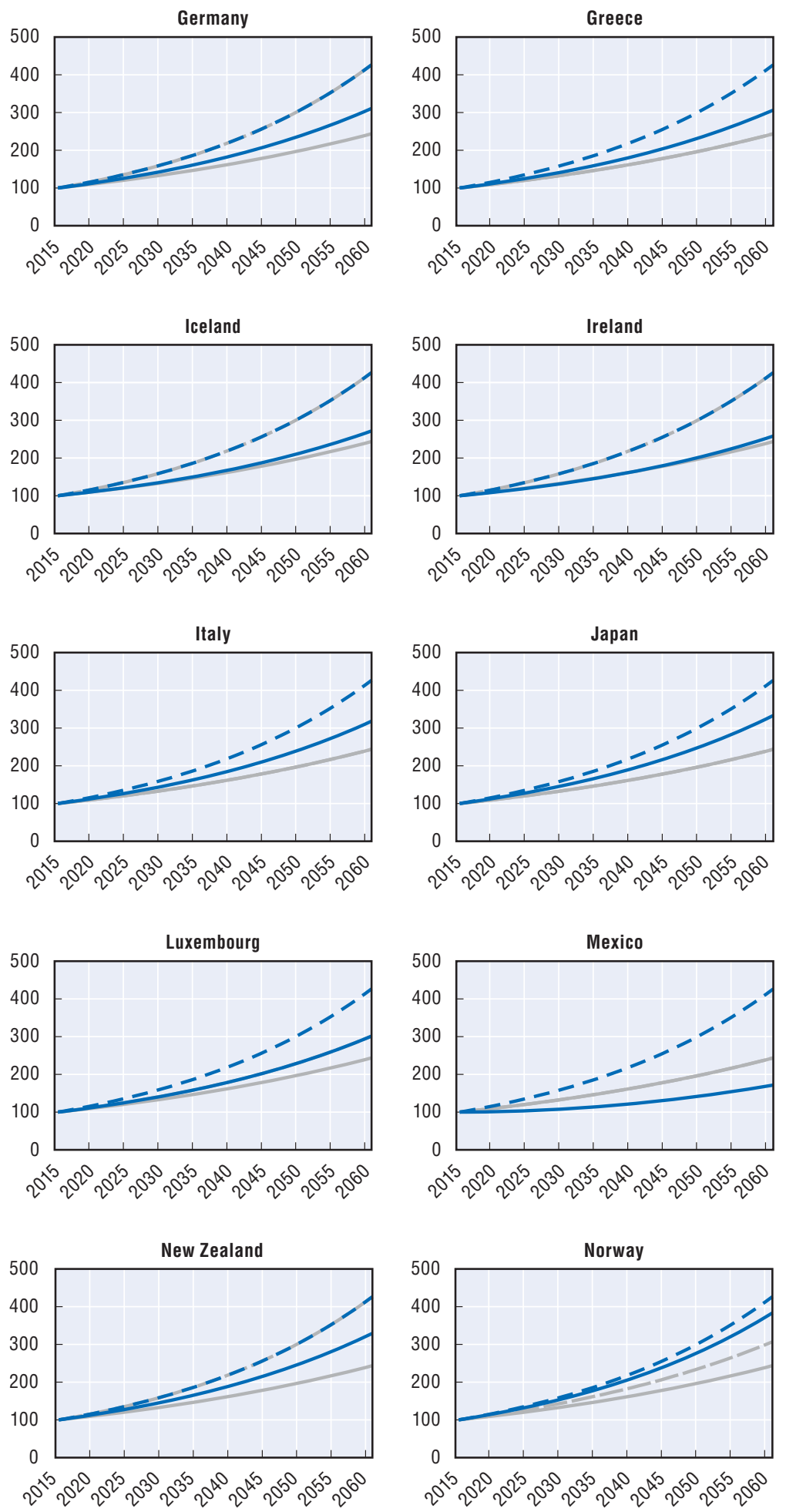
Figure 2.A1.1. Effect of different indexation approaches on benefit level, assuming the age threshold increases by five years (cont.)

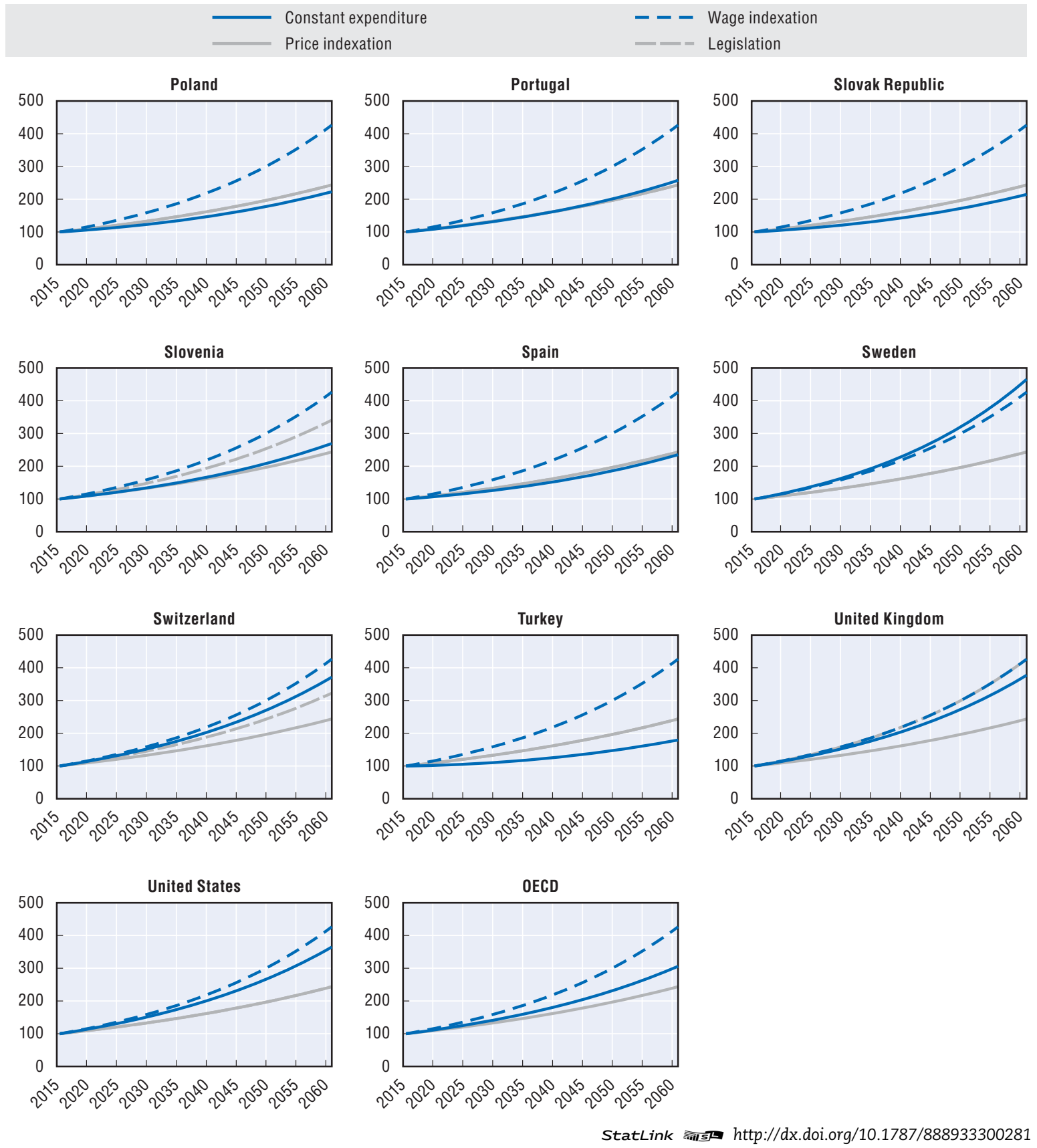





\section{Chapter 3}

\section{How incomplete careers affect pension entitlements}

This chapter assesses the impact of shorter, more fragmented careers on the pension entitlements from mandatory schemes taking into account all pension components including pension credits and other redistributive mechanisms in pension systems. The analysis focuses on delayed labour market entry and career interruptions related to childcare and unemployment.

The analysis shows that with slightly more than a 1\% drop in old-age pension for every year without a job on average, pension systems play a key role in offsetting the potential losses in retirement income due to delayed or interrupted employment. In the absence of any redistribution, the pension would fall by $2-2.5 \%$ based on the economic assumptions used in the OECD model. Pension credits and other redistributive components of pension systems while not being able to fully offset the contribution gaps related to delayed or interrupted employment, are therefore effective instrument to boost earnings-related pensions. The effects vary widely across countries and depend on the periods covered, the pensionable earnings used during these periods, and the provision of other redistributive tools in pension systems.

The results also highlight that pension systems are not typically designed to offset all kinds of income shocks which affect individual life courses. The increasing diversity of work paths requires a more comprehensive and integrated approach to the challenges faced by individuals through effective labour market, education, family and pension policies.

The statistical data for Israel are supplied by and under the responsibility of the relevant Israeli authorities. The use of such data by the OECD is without prejudice to the status of the Golan Heights, East Jerusalem and Israeli settlements in the West Bank under the terms of international law. 


\subsection{Introduction}

Retirement income is mainly a product of the past. It depends on job and earnings histories and on the pension rules in place at the time entitlements accrued, but also during retirement itself. On top of the various features of social protection systems, key determinants of retirement incomes are the extent to which men and women participated in the paid labour market; their earnings, and the duration of their working lives.

Unlike their parents' generation, many of today's workers face growing job insecurity and the need to continuously update their skills. The standard employment relationship has given way to more flexible, but often more precarious, arrangements, such as part-time work, fixed-term contracts and various forms of self-employment. Working mothers in particular often use such arrangements, as they seek to juggle work and family responsibilities. In most households across the OECD, both spouses are likely to work and, in some, both may well take career breaks to care for their children that translate into earnings losses and lower pensions. Unemployment, one of the great life-course risks that affect individuals and households, may also account for losses of earnings.

The financial consequences of life events for retirement income may be eased or amplified by a complex mix of factors. For example, some recent pension reforms that have tightened the link between contributions paid and pensions received have also shifted much of the burden of labour market risk to individuals. At a time of persistently high unemployment in many countries, de-standardisation of employment arrangements, and less and less steady lifelong careers, such reforms may result in lower pension entitlements, at least for those failing to remain employed. In earnings-related pension systems (when pensions depends on contributions paid into the system), career interruptions typically mean lost contributions and lower retirement incomes.

This chapter assesses the impact of shorter and more fragmented careers on mandatory public and private pension entitlements of future retirees modelled with the OECD pension models (see Chapter 5 in this volume) taking into account pension credits (i.e. ways to continue building pension entitlements during periods of limited or no pension contribution) and other redistributive mechanisms in pension systems. The analysis focuses particularly on delayed labour market entry and career interruptions related to childcare and unemployment. Although the chapter discusses the issues of careers shortened by early exit, analysis of their impact on future pension entitlements is beyond its scope and will be the subject of later work.

The chapter is organised as follows. After a summary of key findings, it sets the scene for understanding contribution gaps, looking at evidence of how periods of care, unemployment, and delayed labour entry vary across cohorts and age groups in OECD countries. Section 3.3 presents theory and evidence on the effects of career interruptions and delayed entry, while Section 3.4 briefly describes some of the pension components that may mitigate the effect of lost contributions on pension entitlements. Section 3.5 describes pension credits and Section 3.6 presents the estimates of the impact of interrupted and shorter careers on the pension entitlements of future cohorts of retirees. Section 3.7 discusses the results in the light of the current pension reforms and of other policies that affect the length of working lives. Finally, Section 3.8 draws some policy implications and summarises the main challenges ahead. 


\section{Key findings}

- Residence-based basic pensions and contributory schemes based on relatively short contribution periods mitigate the effect of contribution gaps. Benefit calculation formulae based on highly redistributive pension schemes or on best years of earnings also help to provide adequate retirement incomes in case of incomplete careers. The referencing periods that apply in OECD countries (for the private sector at least) are long enough to avoid incentives for excessive wage increases at the end of the career.

- Pension credits in earnings-related pension systems boost the pension entitlements of people with interrupted work histories, but not enough in general to fully offset their contribution shortfalls. The effects vary widely across countries and depend on the periods covered, the pensionable earnings used during these periods, and the provision of other redistributive tools in pension systems.

- Pension credits for unemployment typically cover the periods during which unemployment benefits are paid. Credits for periods of childcare typically cover periods up to specific ages of the children. To benefit from these credits people need to have contributed some minimum period into the system and they are generally provided up to specific earnings threshold. The effects of pension credits vary with earnings due to such instruments as credit ceilings or flat-rate contributions: they are most useful to lower earners, and for employment breaks of limited duration (at least for childcare).

- In some countries, people whose careers are interrupted by unemployment or care will not be able to retire on the same terms as full-career workers. They will need to retire later or otherwise brace themselves to be heavily penalised.

- With slightly more than a $1 \%$ drop in old-age pension for every year without a job on average, pension systems play a key role in offsetting the potential losses in retirement income due to interrupted employment. In the absence of any redistribution, the pension would fall by $2-2.5 \%$ based on the economic assumptions used in the OECD model.

- Delaying entry into the labour market by five years for an average-wage worker implies a pension gap of $6 \%$ relative to full-career workers on average across countries. At one end of the spectrum, with $15 \%$ pension losses lie Chile and Mexico, which have no offsetting mechanisms built into their pension system in that case. Austria, Estonia, Hungary, Israel, Korea, Norway, the Slovak Republic and Sweden also have drops greater than $10 \%$. At the opposite end, France and Luxembourg record $3 \%$ and $6 \%$ gains, respectively, as, given pension rules in these countries, people have to retire four and five years later to be entitled to a pension without penalty following delayed entry. Of course, if delayed entry is due to upgrading human capital, e.g. through higher education, it is likely to increase pension entitlements overall by improving wage prospects.

- An average-wage earning woman with two young children who interrupts her career for five years to care for her children would lose $4 \%$ of pension income relative to the full-career case on average across OECD countries. The average gap increases to $11 \%$ after a ten-year break. Pension benefits drop slightly less for half-average-wage earners, by $3 \%$ after five-year break on average, while for workers on twice the average wage pensions drop more, i.e. by $5 \%$. The largest declines are recorded in Germany, Iceland, Israel, Italy, Mexico and Portugal for the average-wage earner, while pensions are not affected by a five-year care break in about one third of OECD countries.

- Unemployment periods generate similar albeit slightly larger reductions in pension entitlements than childcare breaks on average.

\section{Policy messages}

- In the absence of mechanisms to counteract, at least to some extent, the impact of employment breaks, earnings-related pension systems make people pay for breaks in their employment 
histories when they retire. Inequalities may be widened in old age by some current developments in pension systems - such as the development of individual private pensions and the trend towards closer links between individual benefits and contributions in public pension systems.

- Employment breaks and shorter careers more generally raise important policy issues. Policy makers should seek to cushion the effects of involuntary unemployment that account for substantial pension losses, and possibly to reduce drastically the impact of relatively short childcare breaks on pension benefits. At the same time, over-generous benefits paid during long absences may lure workers away from the labour market, so entailing substantial losses of contributions and human capital, and eventually prove too costly for the state. Striking the right balance between length of leave from work and benefit entitlements is a fundamental issue that policy makers should address to ensure that people go back to work but do not lose out too much from long interruptions.

- Pension credits are effective instruments to offset the effects of career interruptions and to minimise old-age poverty.

- The majority of OECD countries which had credits for periods of higher education are phasing them out. These mechanisms are generally regressive as they tend to reward people with higher lifetime earnings. Recent labour market developments, such as the strong rise of unemployment, especially for younger workers, and of precarious forms of employment, highlight the need to overcome some of the limitations of pension systems that link pension entitlements closely to contributions.

- Pension plans are not typically designed to offset all kinds of income inequalities in old age which result from individual life course experiences. There must be a more comprehensive and integrated approach to the challenges faced by individuals with precarious incomes and stop-go career paths through effective labour market, education, family and pension policies.

\subsection{Setting the scene for an understanding of contribution gaps}

\section{Career paths across genders, age groups, and cohorts: A general overview}

Among the factors that shape retirement incomes, labour market experience is critical. Women's employment rates have progressively risen relative to those of older cohorts', while the trend has been the opposite among men, albeit on a much lower scale (Figure 3.1). For both men and women, employment rates have, in recent years, declined at young ages and risen among older workers. Yet, employment gender gaps generally remain substantial (see more on this below).

The age of entry into the labour market and later life events (such as childbirth and childcare) influence retirement incomes, depending on the pension system, through the potential length of paid-employment periods. Dismissals and the termination of fixed-term contracts are the main reasons for labour market exits among 25-to-49 year-olds in OECD countries - 63\% among men and $47 \%$ for women (Figure 3.2). There is a particularly wide gender disparity when it comes to care - onequarter of women, but just $4 \%$ of men, who leave work do so to care for a close relative.

Differences between countries are wide. For example, fixed-term jobs that come to an end account for nearly half of all exits in the 25-to-49 age group in Finland, France, Italy, Spain, and Turkey, but much less in Denmark among men and the United Kingdom among women. Dismissals and redundancies underlie $40 \%$ or more of men's exits in the Czech Republic, Greece, Hungary, Ireland, Italy, Portugal, and the Slovak Republic but relatively few in Austria, Belgium, Denmark, Spain and Switzerland. Between one-fifth and one-half of exits among women, but very few among men, are related to care giving in Austria, the Czech Republic, Germany, Poland, the Slovak Republic, Switzerland, and the United Kingdom. Finally, in Austria, Belgium, Denmark, and the Netherlands, $15 \%$ or more of men and women quit work because of illness and disability, but less than $3 \%$ in Greece and Italy. 
Figure 3.1. Employment rates by birth cohort and age group, OECD average

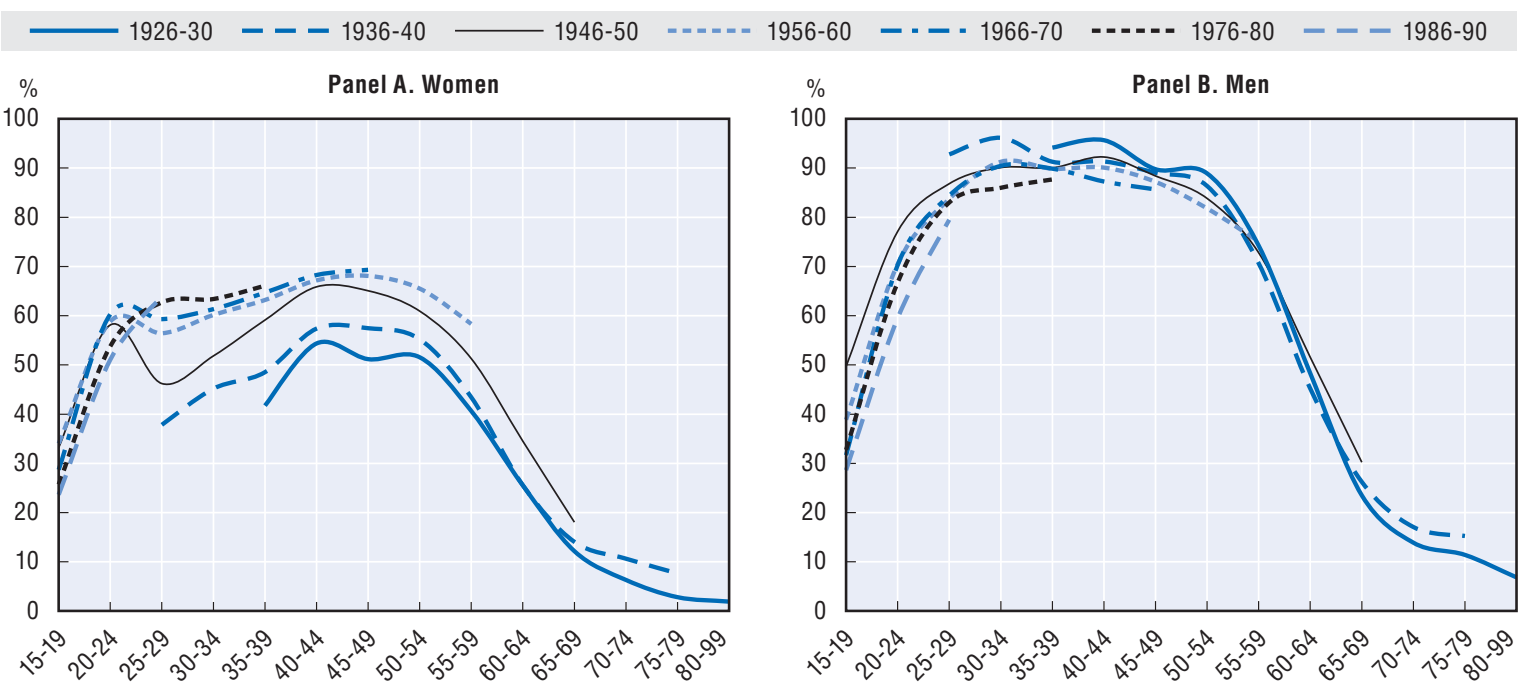

Note: Each curve illustrates the employment rate (y axis) for each birth cohort at different ages (indicated on the $\mathrm{x}$ axis). For example, the thin line (black) curve in the left-hand panel indicates that women born between the years 1946 and 1950 had labour market participation rates of $60 \%$ between the age $20-24$, falling to $46 \%$ between the age $25-29$ and rising to around $65 \%$ between the age 40-44 on average in the OECD.

Source: OECD calculations based on OECD Employment and Labour Market Statistics, www.oecd-ilibrary.org/employment/data/oecdemployment-and-labour-market-statistics_lfs-data-en as in D'Addio, A.C. (2015), "Explaining the Gender Pension Gap in OECD Countries: Socio-economic Determinants and Pension Rules That Matter", unpublished manuscript.

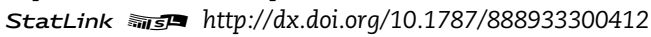

Shorter, fragmented, and precarious contribution histories can result in lower pension entitlements and coverage and thus have profound long-term effects. The length and timing of career breaks may be reasons for losses of retirement benefits in countries where pension levels are determined not only by total contributions made but also by their sequence, as happens with fully-funded defined-contribution pensions, where contributions made early will accrue more interest over time than those made later due to compounded interests. Moreover, the timing of involuntary career breaks may affect their length - when workers lose their jobs during a recession, for example, they may be out of work for longer than in good economic conditions. The accumulation of pension rights may also be affected by age-specific unemployment benefit rules as older workers usually receive more generous unemployment benefits than younger ones. ${ }^{1}$

\section{Age of entry}

In 2013, the estimated average age of entry into the labour market stood at 21.9 years among men and 23.5 for women in 21 OECD countries (Figure 3.3). The gender gap in the age of entry was wider than two years in the Czech Republic, Hungary, Italy, Poland and the Slovak Republic while it was relatively narrow in Finland, Portugal, Spain and Sweden, for example. The gender gap also varies across countries: more than four years separate the United Kingdom and Italy in terms of the average age of labour market entry for both men and women.

Differences in the age of labour market entry are driven by factors such as education systems, training opportunities, and labour market conditions. Most OECD countries have seen sharp rises in numbers of students and the length of time they stay in education over time - the average length of schooling increased by more than eight months on average in the OECD area between 2004 and 2012 (OECD, 2014a). While the nature of jobs tends now to require higher skills and standards of education, the demand for education might also have increased because it increasingly acts as a screening device helping people with better education levels find a job more quickly. 
Figure 3.2. Reasons for exiting the labour market, men and women, aged 25-49, 2014
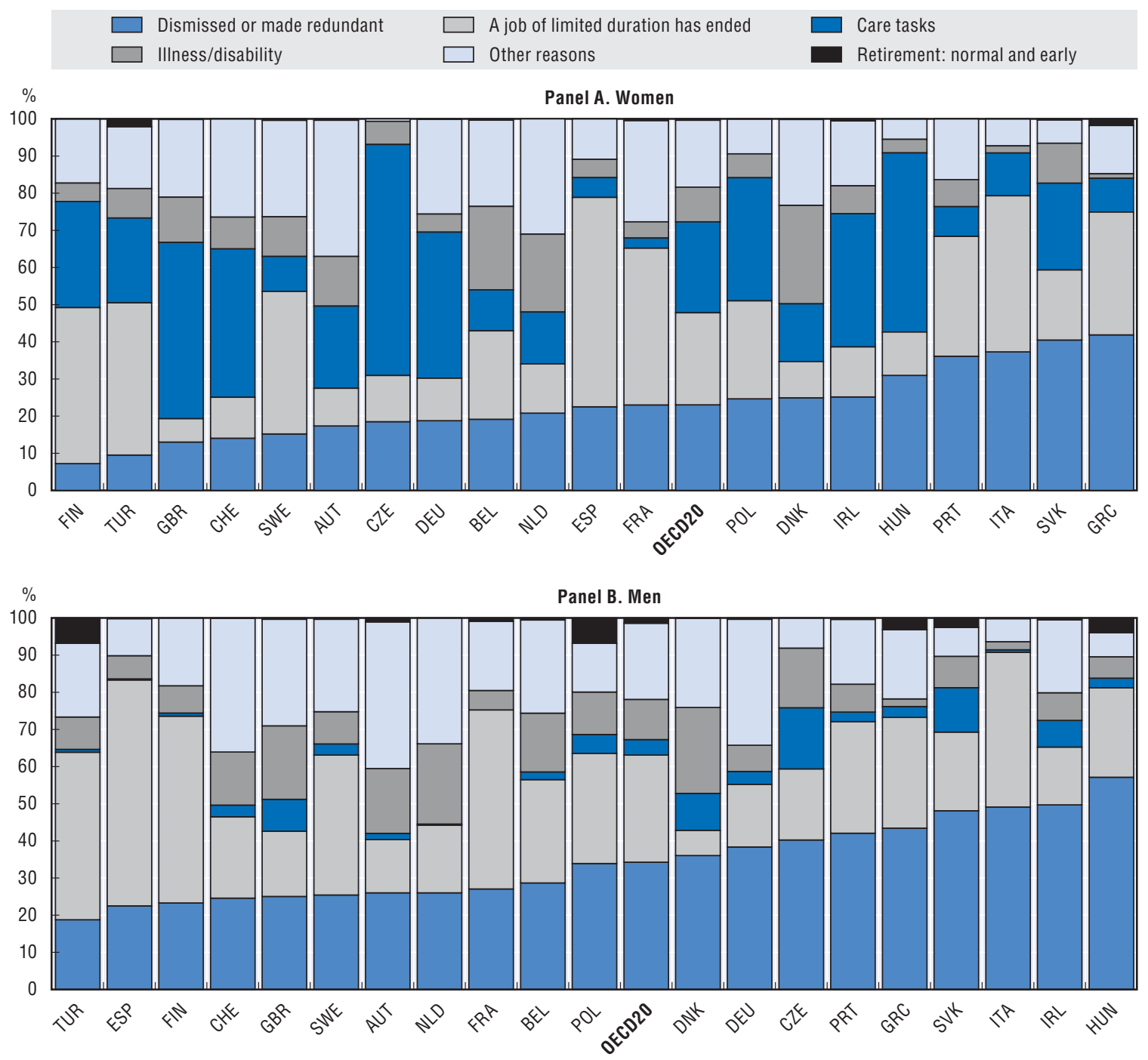

Source: OECD calculations based on data extracted from the European Union Labour Force Survey 2014 (EU-LFS).

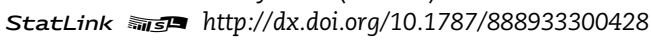

People entering the labour market in periods of recession feel the pinch of unemployment most sharply. They face scarce employment opportunities and, as a result, part-time employment and inactivity are widespread (Carcillo et al., 2015). The rates of young people who are neither in employment nor in education or training (NEETs) in countries worst hit by the crisis are very high. In Greece, Ireland, Italy, and Spain at least $20 \%$ of 16-29 year-olds are NEETs, while rates are also high in Turkey (35\%), Israel (28\%), Mexico (23\%) and Chile (22\%). As individual long-term career prospects are largely determined in the first ten years of the working life (OECD, 2015c), NEET periods may adversely affect old-age pensions, too.

\section{Career interruptions related to unemployment and care}

\section{Unemployment}

Overall unemployment looks likely to remain very high in 2016 in many OECD countries (OECD, 2015b). While young people have been strongly affected by employment losses, older workers have been less so, in part as a result of recent pension reforms, which made early retirement routes more difficult to access and less attractive. Nevertheless, once they lose their jobs, older people face severe 
Figure 3.3. Age of labour market entry in selected OECD countries, 2013

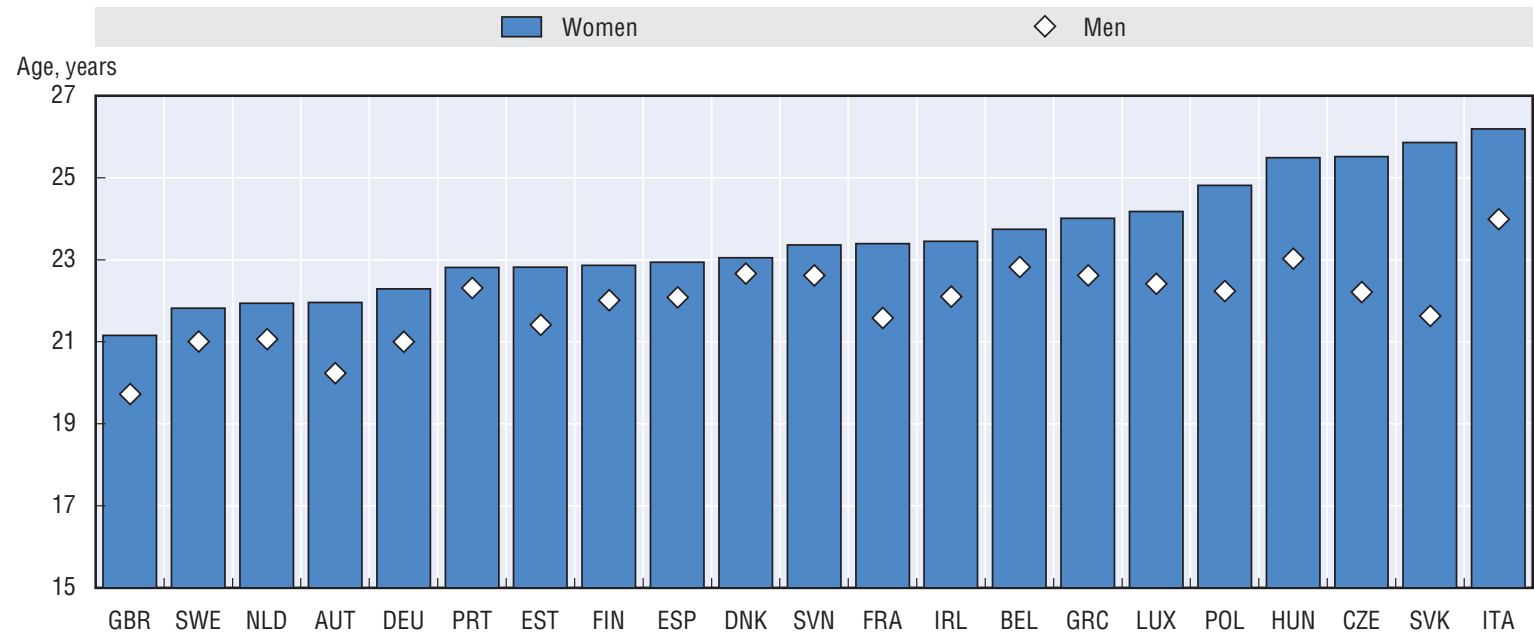

Source: Based on estimations by the EPC Working Group on Ageing Population and Sustainability (AWG), European Union.

difficulties to find work again and often remain long-term unemployed (OECD, 2014b, c, d; 2015a, b). Unemployment spells longer than one year, on average, were observed in about a quarter of OECD countries (Belgium, the Czech Republic, Estonia, Greece, Hungary, Ireland, Italy, Poland and Slovenia) in 2010, while they lasted less than six months in Canada, Israel, Japan, Korea and Mexico (OECD, 2014f).

Effective unemployment insurance may partly alleviate unemployment's direct impact on income (Figure 3.4). Longer coverage and higher income replacement can also ease its effect on pension entitlements, although they might also reduce the incentive to work. The periods over which unemployment insurance benefits are paid vary substantially from one country to another, from

Figure 3.4. The effectiveness of unemployment insurance provisions, OECD countries

Percentage of previous net earnings averaged across household types, 2010

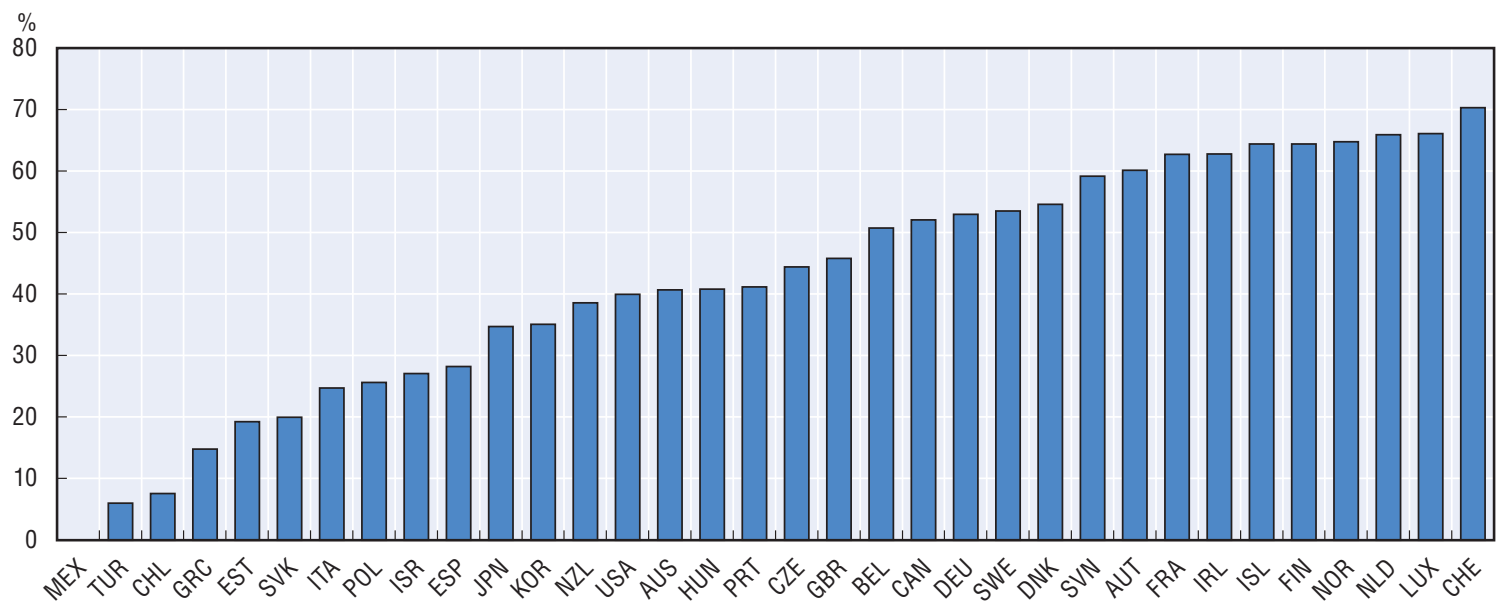

Note: Effective unemployment insurance is defined as the coverage rate of unemployment insurance (UI) times its average net replacement rate among UI recipients plus the coverage rate of unemployment assistance (UA) times its net average replacement rate among UA recipients plus the share of those not covered by unemployment benefits [or the ratio of the number of social assistance (SA) recipients to the number of unemployed if this is lower] times the SA replacement rate. Average replacement rates among recipients of UI and UA take account of family benefits, housing benefits and social assistance if eligible.

1. Replacement rates for Chile represent 2011 figures.

Source: OECD (2014), OECD Employment Outlook 2014, OECD Publishing, Paris, http://dx.doi.org/10.1787/empl_outlook-2014-en. 
between just a few weeks in Japan to a very long period in Belgium (unemployment benefits are paid without any duration limit). According to the aggregate measure in Figure 3.4, Chile, Estonia, Greece, Mexico, the Slovak Republic and Turkey offer the scantiest unemployment insurance, while Finland, Iceland, Luxembourg, the Netherlands, Norway and Switzerland afford the greatest protection.

\section{Specific features of women's careers: Employment and children}

The employment gap between men and women has, on average, more than halved since the early 1970s in the OECD. Nearly 58\% of women aged 15 to 64 were employed in the OECD in 2013, compared to $40 \%$ in 1960 . By contrast, male employment rates declined by 10 percentage points on average over the same period (Figure 3.5, Panel A). Nevertheless, female employment rates were still 15 percentage points below men's in 2013 (Panel B).

Part-time jobs are also far more widespread among women than men. In all countries, the share of female part-timers in total employment is substantially higher than among their male peers. On average in OECD countries, $5 \%$ of men and about $22 \%$ of women aged $25-54$ work part-time. Very high

Figure 3.5. Employment rates among men and women
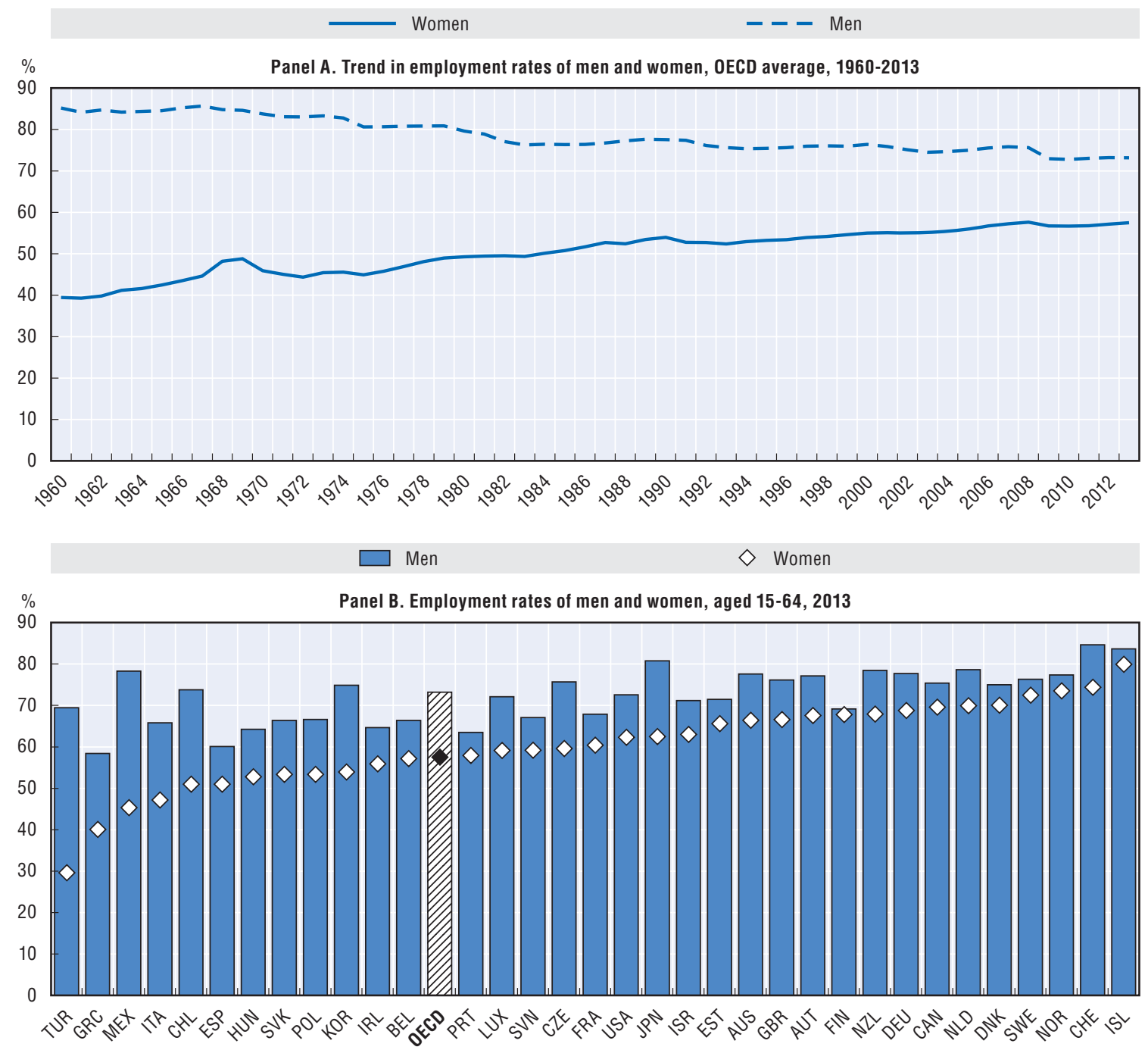

Source: Data extracted from OECD Employment and Labour Market Statistics, www.oecd-ilibrary.org/employment/data/oecd-employmentand-labour-market-statistics_lfs-data-en. 
Figure 3.6. Incidence of part-time employment by gender, 2013

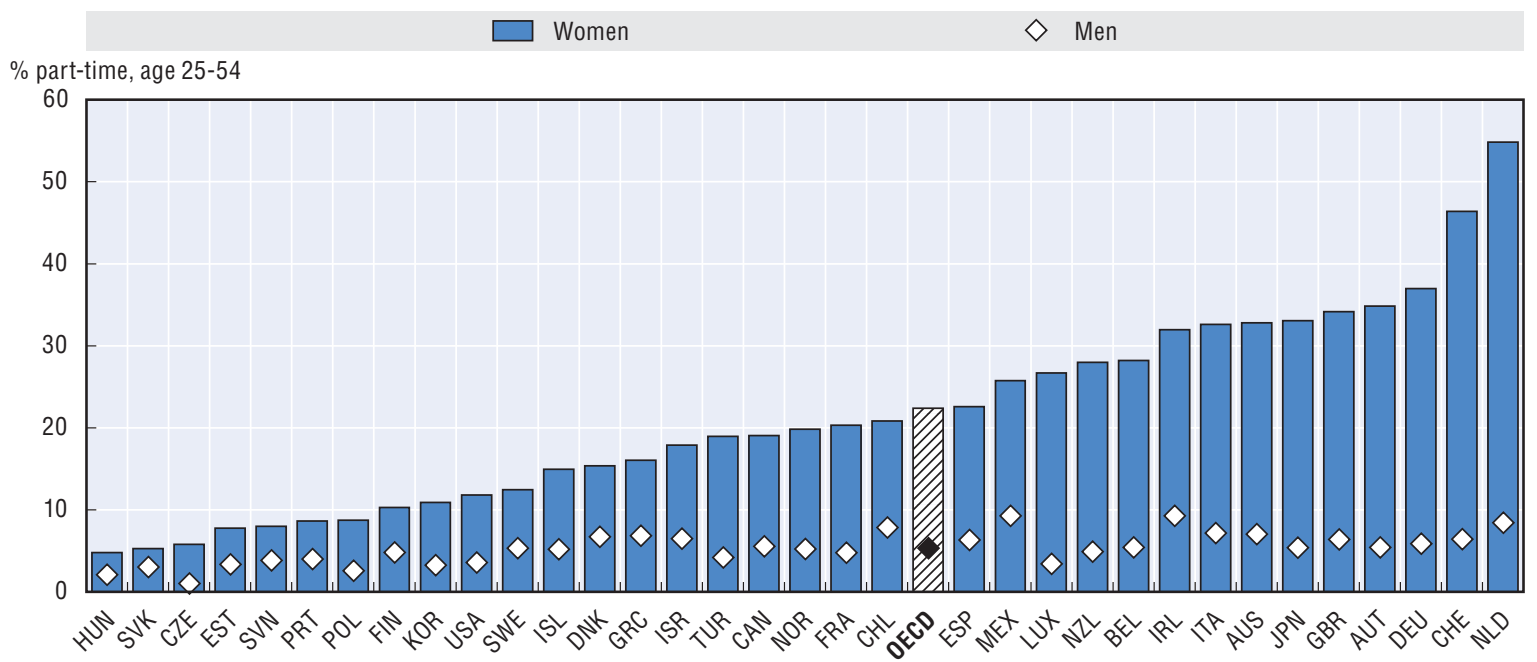

Note: Part-time employment refers to persons who usually work less than 30 hours per week in their main job. The indicator shows the proportion of part-time employees in the total employed workforce. It is also called the incidence of part-time employment.

Source: OECD Family Database, www.oecd.org/els/family/database.htm and OECD Employment and Labour Market Statistics, www.oecdilibrary.org/employment/data/oecd-employment-and-labour-market-statistics_lfs-data-en.

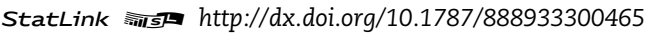

shares of female part-timers are to be found in Australia, Austria, Germany, Ireland, Italy, Japan, the Netherlands, New Zealand, Switzerland and the United Kingdom (Figure 3.6). By contrast, female part-timers account for no more than 5\% of women's employment in the Czech Republic, Hungary and the Slovak Republic, but less than $3 \%$ for men in those countries.

Women also have shorter effective working lives than men in all OECD countries. Women aged 65 and over in 2008-09 worked 13 years less than men on average in the 13 OECD countries covered by the SHARELIFE survey ${ }^{2}$ (D'Addio, 2009 and 2015). According to Eurostat, 18-year-old women today still have an expected working life expectancy of three years less than men's. Moreover, women typically earn less than men - the difference between the median wages of full-time male and female employees was $14 \%$ on average in the OECD in 2012, ranging from 6\% in New Zealand to $37 \%$ in Korea. Those disparities translate into lower old-age pensions - women's average mandatory pension benefits being 28\% lower than men's in 2011 in 25 OECD countries (D'Addio, 2015). ${ }^{3}$

One key factor in the reduced female labour supply is the presence of children in the household. The average employment rate among mothers aged 25 to 54 with at least one child under 15 living at home is 8 percentage points lower than the overall employment rate of childless women in that age group (68\% compared to $76 \%$ in 2013), according to the OECD Family Database. In some OECD countries (e.g. the Czech Republic, Estonia, Hungary, and the Slovak Republic), the employment rates of mothers with a child under three years of age are also very low. The average OECD-wide employment rate is $55 \%$, rising to $69 \%$ when the youngest child is between 3 and 5 years old, and $75 \%$ when between 6 and 14 years (Figure 3.7, Panel A). Generally speaking, mothers' average employment rates decline as the number of children they have rises - from about $71 \%$ for one child to $51 \%$ for three (Panel B). In the Czech Republic, Hungary, Italy and the Slovak Republic, the employment rates of mothers with at least three children are very low.

Family policies are important to help parents balance work and family life. When childcare is unaffordable, of low-quality, or difficult to access, parents may opt for atypical work schedules and mothers in particular may drift away from the labour market as they care for their children at home. 


\section{Figure 3.7. Maternal employment rates by the age of the youngest child and by the number of children, 2014}
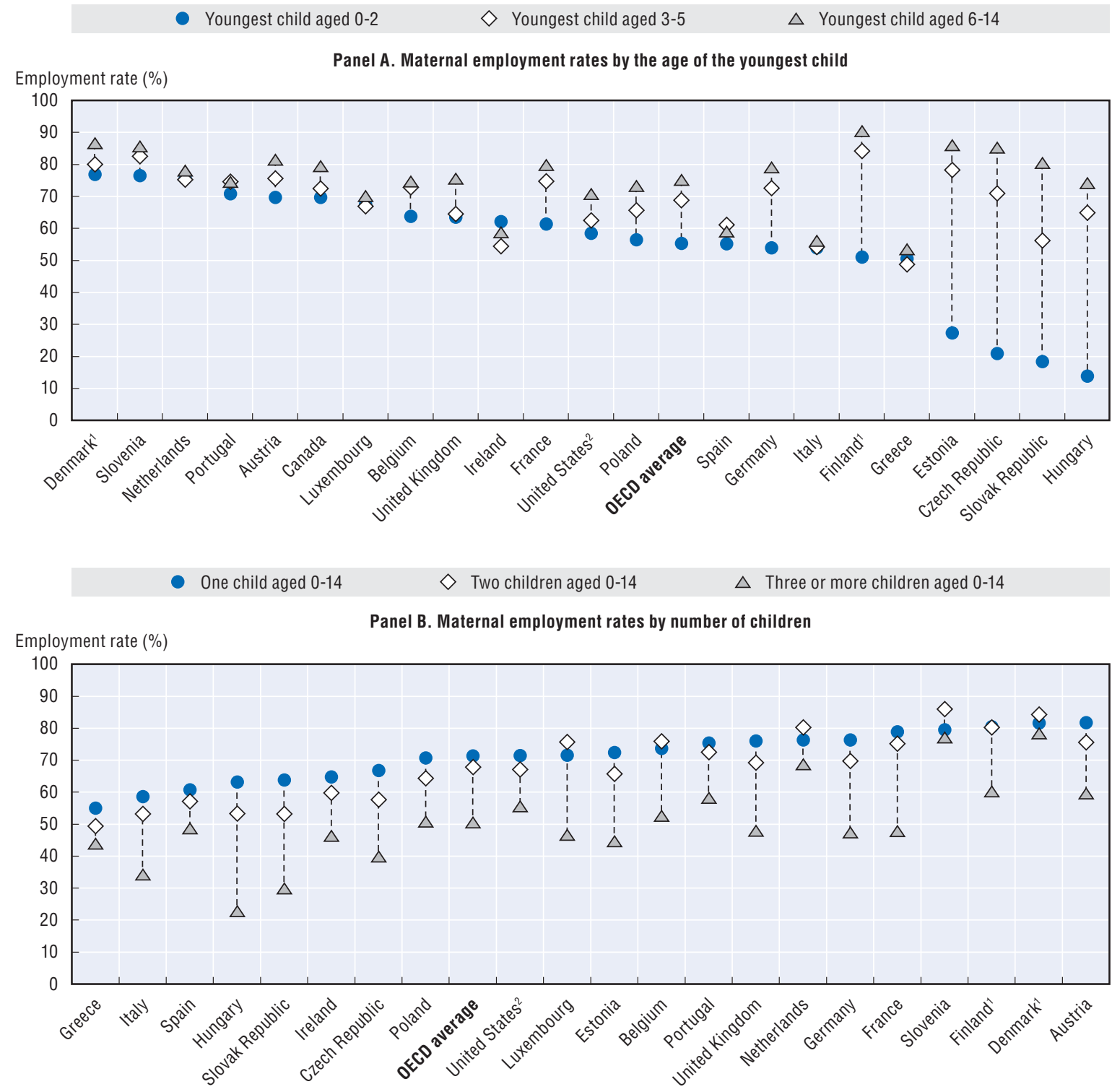

1. Data for Denmark and Finland refer to 2012.

2. Data for the United States are for women with a child under 18 , and the age groups used in Panel A are 0-2, 3-5 and 6-17. Source: OECD Family Database, www.oecd.org/els/family/database.htm.

The design of some maternity leave provisions can actually harm their career prospects and financial security. Very long leaves, for example, can foster disconnect from employment, so diminishing work and earnings prospects.

Since the early 1980s, most OECD countries have relied on combinations of different types of leaves. Statutory paid maternity leave exists everywhere in the OECD except in the United States. In general, maternity benefit is proportional to previous earnings and is often paid at full rate with pension entitlements maintained. The length of parental leave, the size of benefits and the legal enforcement of leave policies, however, vary widely across OECD countries (Figure 3.8). Consequently, pension credits relating to those provisions also vary widely from country to country. 


\section{Figure 3.8. The duration and benefit entitlements of parental and home care leave in OECD countries, 2014}

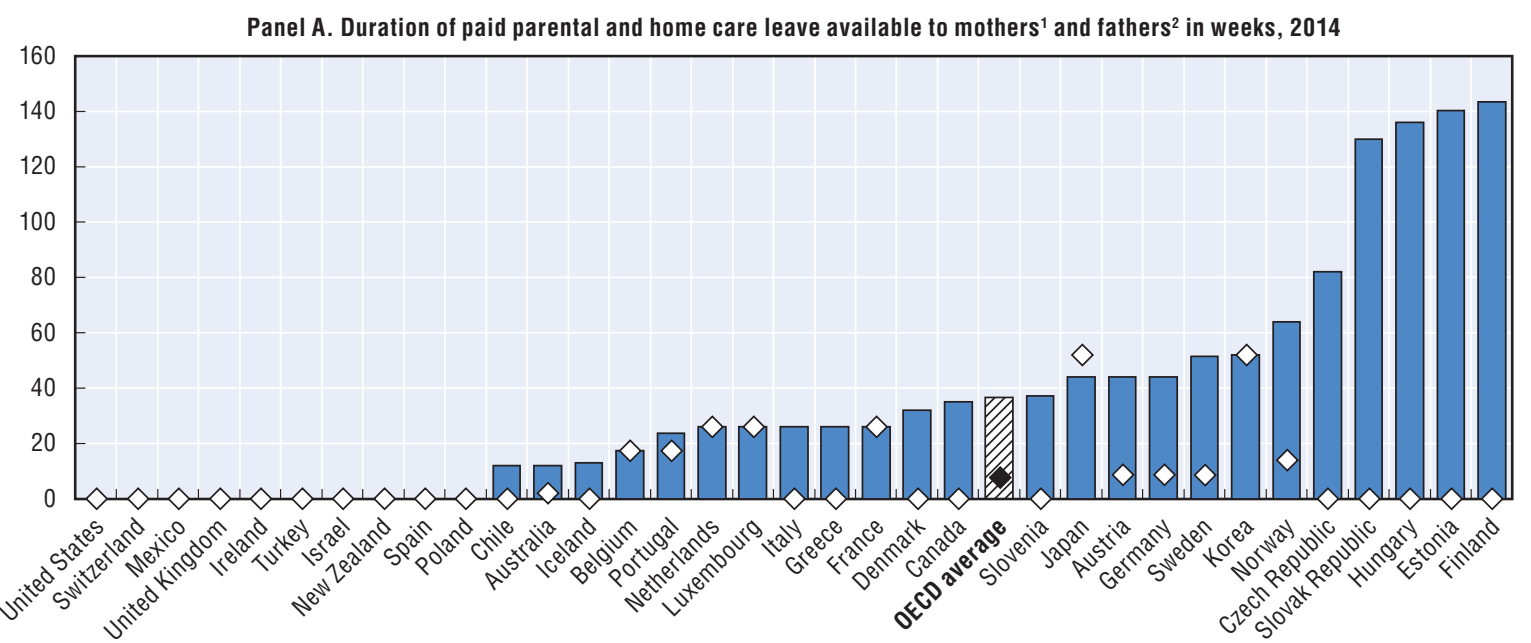

Panel B. Average payment rate ${ }^{3}$ across weeks of paid parental and home care leave (\%), 2014

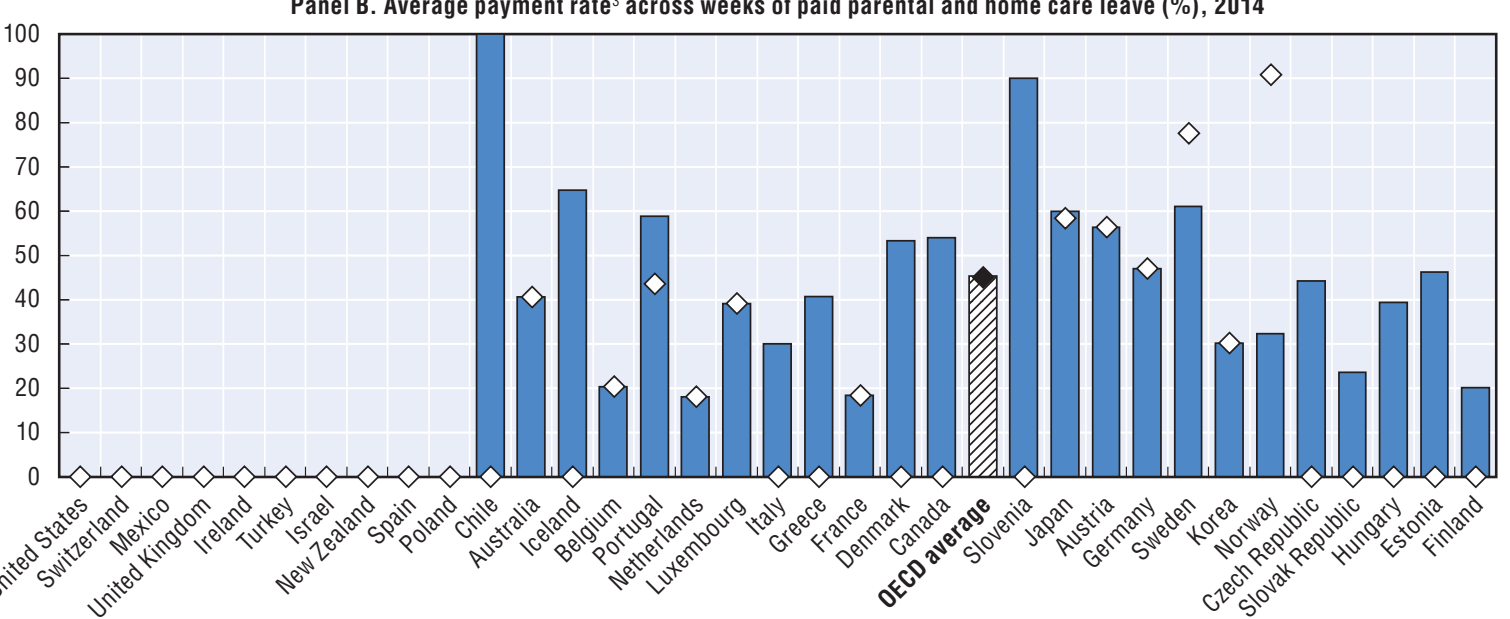

1. Information on paid parental and home care leave available to mothers refers to weeks of parental leave and subsequent periods of home care leave to care for young children (sometimes under a different name, for example, "childcare leave" or "child raising leave", or the Complément de Libre Choix d'Activité in France) that are available to mothers.

2. Information on paid parental and home care leave reserved for fathers refers to "father quotas" or periods of parental or home care leave that can be used only by the father and cannot be transferred to the mother, and any weeks of sharable leave that must be taken by the father in order for the family to qualify for "bonus" weeks of parental leave.

3. Payments rates reflect the proportion of previous gross earnings that are replaced over the weeks of parental and home care leave by the associated benefit(s). If benefits cover more than one period of leave at different payment rates then a weighted average is calculated from the length of each period. The recipient is assumed to live in a dual-earner family with a partner on $100 \%$ of average wages and with no other dependents. In other words, recipients are assumed to be having their first child. Source: OECD Family Database, www.oecd.org/els/family/database.htm.

One factor behind women's shorter working lives is care for both children and elderly relatives. Close to two-thirds of family carers in the OECD are women (OECD, 2011; and 2013c; OECD, 2015). For example, $48 \%$ of the mothers and less than $1 \%$ of the fathers of a child aged less than 1 were on parental leave in 2011 in 18 OECD countries on average. The majority of long-term care paid workers are women, who are also most often informal carers: $61 \%$ on average in 17 OECD countries among all informal carers aged 50 and over (OECD, 2015d). This proportion ranges from a high of $71 \%$ in Slovenia to a low of $55 \%$ in Sweden. As populations age, care-giving needs look set to increase steeply in coming decades, a trend that could see a rise in informal care which would curtail carers' retirement income (see D'Addio, 2015). 


\section{Age of labour market exit}

Policies to promote longer working lives - through later retirement ages and early-retirement restrictions, for example - have emerged in most OECD countries, and were instrumental in the recent slight rise in the effective age of labour market exit from its low in the early 2000s (Figure 3.9). ${ }^{4}$

Figure 3.9. Trends in the average effective age of labour market exit, OECD and EU average
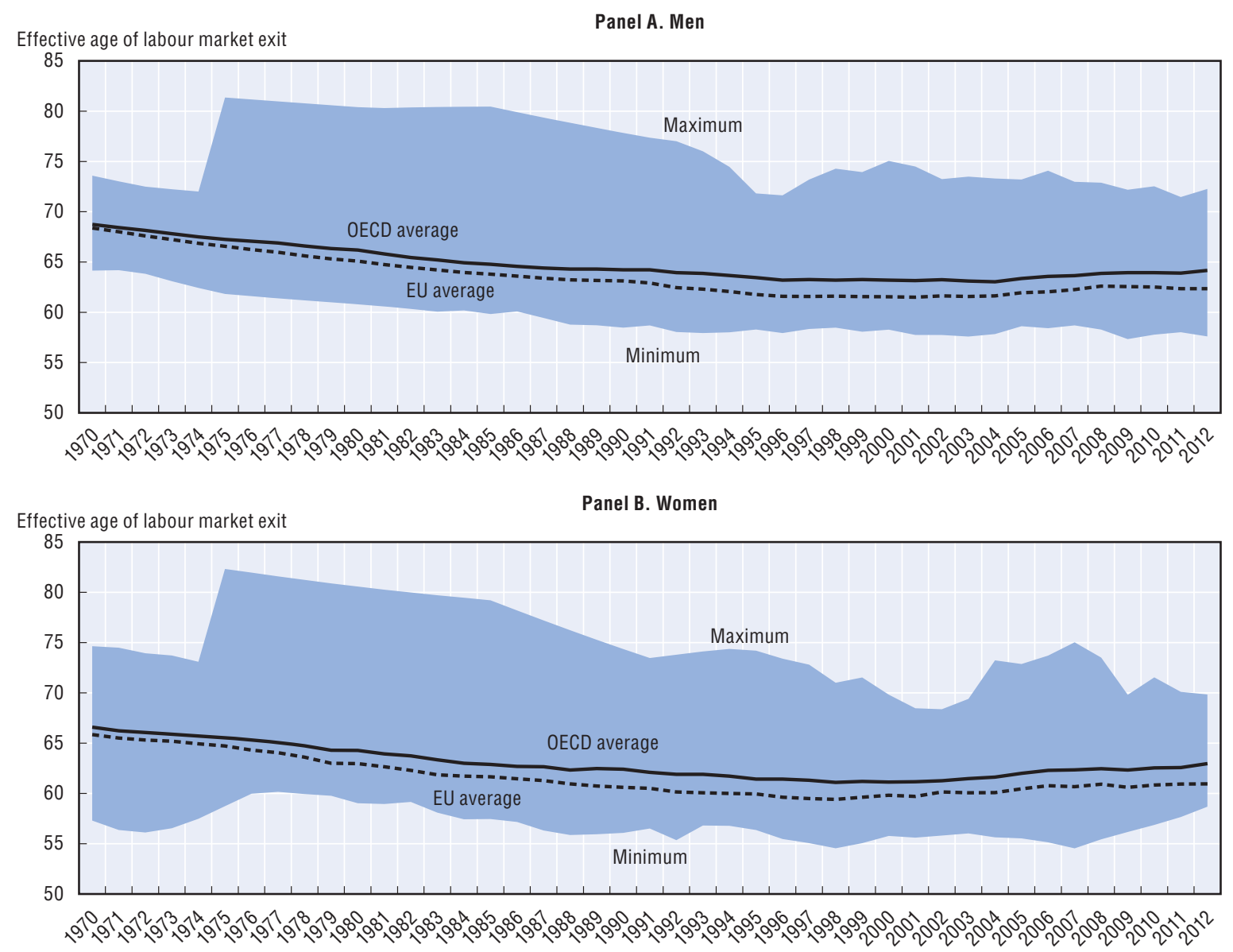

Source: OECD estimates based on the results of national labour force surveys, the European Union Labour Force Survey (EU-LFS) and, for earlier years in some countries, national censuses. OECD Employment and Labour Market Statistics, www.oecd-ilibrary.org/ employment/data/oecd-employment-and-labour-market-statistics_lfs-data-en.

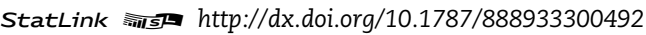

Yet, for employment opportunities for the elderly to exist in practice it is not sufficient to tighten early retirement options, to raise retirement ages, to lengthen contribution periods and to change parameters and rules in order to raise marginal returns to work longer. Job retention at older ages is much more common than hiring (OECD, 2015a; 2014b, c, d; 2013); thus, for many, unemployment late in working life spells labour market exit.

Early retirement accounted for nearly $19 \%$ and $22 \%$ of women's and men's labour market exits, respectively, in the 55-to-64 year-old age group on average across countries. In Austria, Denmark, the Netherlands, Poland, the Slovak Republic, Switzerland, and the United Kingdom, more than one-third of men who left the labour market in 2013 did so through early retirement. Other non-EU OECD countries also allow the early drawing down of pension benefits. In Australia, it is currently possible from the age of 55. In Mexico, workers may retire from age 60 with a 5\% penalty for each year of anticipation; future retirees will be able to retire early if they have contributed for at least 
1250 weeks (about 24 years) and the accrued capital in their account allows them to buy a life annuity that is at least $30 \%$ higher than the minimum guaranteed pension. In Chile, workers who have paid into a defined contribution scheme may also draw a pension early, but only as long as the capital accumulated in the account is sufficient to finance a pension equal to $80 \%$ of the minimum pension with a replacement rate of at least 70\% (relative to earnings in the ten years prior to drawing the pension).

The data suggest that, apart from retirement - be it early or at the statutory age - people who exit the labour market between the ages of 55 and 64 take a number of involuntary paths out, such as dismissals, redundancy, illness and disability (Figure 3.10). Family caring duties are behind only $4 \%$ of women's exits on average, although shares are $7 \%$ or more in Germany, Ireland, and the United Kingdom.

\section{Figure 3.10. Labour market exit paths among men and women, aged 55-64}
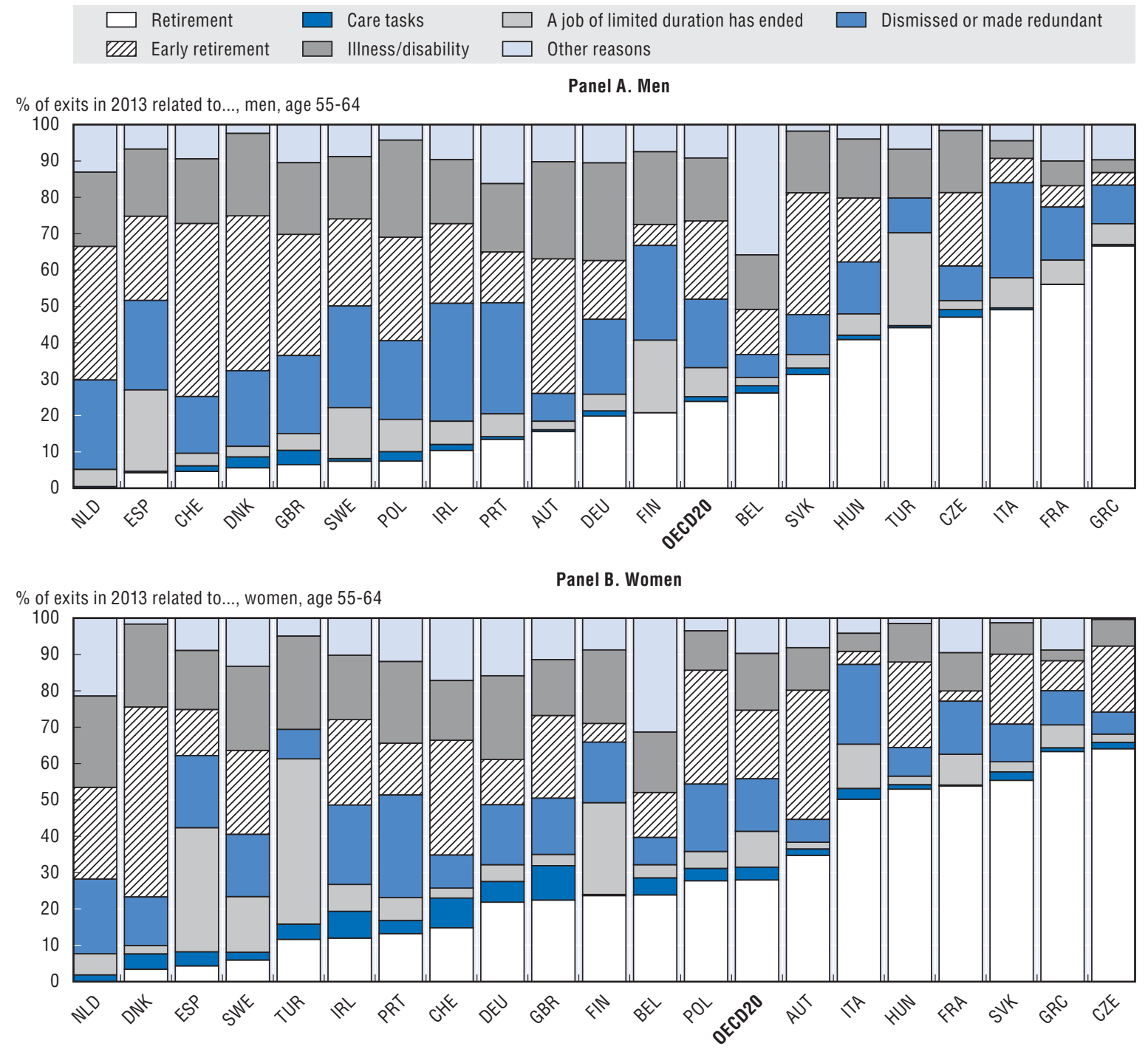

Source: OECD calculations based on the results of national labour force surveys, the European Union Labour Force Survey 2014 (EU-LFS). 


\subsection{How scattered careers affect pensions: Theory and practice}

Delayed labour market entry and employment breaks affect retirement incomes in various ways:

- Taking time out of paid employment, together with shorter working lives, typically entails wage and, by the same token, contribution losses.

- Short, interrupted careers lead to losses of human capital with repercussions over time. ${ }^{5}$

Understanding why labour market entry is delayed is essential to assessing its total impact on earnings and pensions. If it is for the purposes of higher education and the acquisition of better qualifications or professional experience, it may eventually spell higher wages and pensions. If, by contrast, it is for reasons of unemployment and inactivity, human capital might depreciate having an adverse effect on retirement incomes.

The time at which people begin work and higher education affects labour market outcomes. Holmlund et al. (2006) report, for example, that putting off university entry by two years in Sweden is associated with considerable drops in lifetime earnings - about $40-50 \%$ of annual earnings at the age of $40 .^{6}$ Career breaks, too, depreciate human capital, resulting in lower lifetime earnings (Mincer and Polachek, 1974, 1978; Polachek, 2007; Braga, 2014). Workers can recover income and pension losses related to career breaks if they are able to work long enough afterwards. However, how much ground they can make up is generally determined by when the career break occurs and how long it lasts.

Women's lower wages are partly attributable to career interruptions to care for children. ${ }^{7}$ The longer the break and the earlier it comes, the larger the wage losses are. ${ }^{8}$ Like interruptions for childcare, unemployment produces persistent earnings losses, too. ${ }^{9}$ And unemployment early in a worker's career might also have a scarring effect, jeopardising young workers' future labour market possibilities, though evidence to that effect is mixed (see Arulampalam et al., 2001 for a survey of scarring effects).

The limited empirical findings available from studies that assess the impact of career interruptions on pensions suggest that breaks attributable to unemployment and care cause substantial losses in retirement income. For example, Geyer and Steiner (2010) report that the higher frequency of unemployment and of precarity over the working life lie behind substantial increases in the shares of people with retirement income below the single pensioner's subsistence level in East Germany - from about 4 to more than 30 percentage points among men, and from 25 to 50 points among women (Potrafke, 2011). De Freitas et al. (2011) found that the generous pension credits almost offset the effects of career breaks that total up to five years in EU countries on average. Along similar lines, Brugiavini et al. (2012) suggest that the design of family policies and pensions is a very important factor in cancelling out the substantial losses that may arise in the European countries covered by the SHARELIFE survey (referring to the year 2010/11) when parents break off their careers to care for their children.

The policy implications are important. Purpose-built schemes may be called for to soften the blow to lifetime income from contribution gaps caused by involuntary career breaks or delayed labour market entry. Long voluntary breaks from paid employment unless they are taken to further career prospects, through training or further education, should be limited. Assessing the extent to which pension credits cushion the impact of these contribution gaps is the focus of the following section.

\subsection{Pension systems components that can mitigate the adverse effects of interrupted careers}

Pension system design may or may not ease the impact that periods of time away from paid work could have on retirement incomes. Plans that do not depend on previous contribution histories, for example, such as basic residence-related or universal pension schemes, may cushion the impact. And nearly all OECD countries do have first-tier redistributive schemes, albeit of varying scope 
(Chapter 2). However, first-tier programmes that predicate full benefits on a minimum number of contribution years may make it difficult for people with long career-breaks or shorter working lives to qualify for the benefit, especially if the (minimum) required contribution period is long, as it is in countries like the Czech Republic, Ireland and Japan - although other targeted benefits may kick in at that point and act as safety nets.

Conversely, the effect of contribution gaps on pension entitlements is unlikely to be alleviated in systems, which link contributions more tightly to benefits - such as private DC schemes and public notional defined contribution (NDC) or points systems without redistributive provisions. For example, Italy's move towards an NDC scheme was accompanied by the abolition of the minimum pension. More generally, where pension systems determine pensionable earnings from whole career earnings, pension benefits are more affected by shorter or fragmented working lives.

However, for many women who leave paid work in middle age to care for elderly relatives and for workers who lose their jobs late in their careers, the outcome does not have to be lower pensions. Most mandatory public earnings-related pension schemes provide special pension credits to care for children, for periods of unemployment or even in some case for periods of education. Insuring against labour market risks, allowing workers to care for children and other frail relatives, minimising poverty among the elderly, and affording them a decent income are some of the important reasons behind pension credits.

In recent years, reforms have modified pension credits, with some countries curbing their generosity, and others increasing it. Since 2014, Austria, for example, has substantially cut back on the types of events its pension credits once covered. Only military or civilian service (up to 30 months), time out of the workplace to raise children (up to four years per child) and some periods of unemployment now qualify for pension credits. In particular, it is no longer possible to purchase contributions for periods of school and university studies. Belgium has introduced a distinction between time out of work for "particular reasons", such as raising or educating children, or "without reason". Since 2012, only 12 months may be credited for calculating pensions in the event of "breaks without reason", while as much as 36 months may qualify for pension credits for parents who drop out of employment to raise their children. France's 2011 and 2014 reforms have made it easier for young people to get partial or total credit for periods of higher education or apprenticeship that should not exceed 12 quarters, and have made it less costly for young workers to pay back missing contributions. In general, however, credits for periods of higher education are being phased out. These credits are potentially regressive because they reward people that will likely have higher earnings relative to those with lower education, and their elimination generates public savings.

\subsection{Pension credits to plug the contribution gap}

\section{Main characteristics of pension credits}

Credits may raise pension entitlements in two ways that are not mutually exclusive. First, they lengthen the duration of the insurance period, which in a contributory pension plan typically yields a better income on withdrawal. Second, they can increase the pension benefit directly, with the quantitative effect depending on individuals' earnings and contributions paid into the system during employment drop-out periods.

Explicit credit mechanisms to plug the contribution gaps exist in the majority of (public) earnings related pension systems of OECD countries (Table 3.1), though not in Australia, Israel, Mexico, the Netherlands, New Zealand and the United States. In addition, Chile, Estonia, Ireland, Korea, Turkey and the United Kingdom do not have credits for unemployment while they have credits for childcare. The opposite applies in Iceland. Portugal and Slovenia, which have explicit pension credits for unemployment periods, grant credits for childcare-related periods only in case of part-time employment, which then qualify as full-time contribution periods. Employment breaks are irrelevant 
Table 3.1. Explicit credits in earnings-related pension systems for unemployment and childcare

\begin{tabular}{|c|c|c|c|c|c|c|c|c|c|}
\hline & \multicolumn{2}{|c|}{ Childcare } & \multicolumn{2}{|c|}{ Unemployment } & & \multicolumn{2}{|c|}{ Childcare } & \multicolumn{2}{|c|}{ Unemployment } \\
\hline & Explicit & Implicit & Explicit & Implicit & & Explicit & Implicit & Explicit & Implicit \\
\hline Australia & .. & $\sqrt{ }$ & .. & $\sqrt{ }$ & Israel & .. & & .. & \\
\hline Austria & $\sqrt{ }$ & & $\sqrt{ }$ & & Italy & $\sqrt{ }$ & & $\sqrt{ }$ & \\
\hline Belgium & $\sqrt{ }$ & & $\sqrt{ }$ & & Japan & $\sqrt{ }$ & & $\sqrt{ }$ & \\
\hline Canada & $\sqrt{ }$ & & $\sqrt{ }$ & & Korea & $\sqrt{ }$ & & .. & $\sqrt{ }$ \\
\hline Switzerland & $\sqrt{ }$ & $\sqrt{ }$ & $\sqrt{ }$ & $\sqrt{ }$ & Luxembourg & $\sqrt{ }$ & & $\sqrt{ }$ & \\
\hline Chile & $\sqrt{ }$ & & .. & & Mexico &.. & $\sqrt{ }$ &.. & $\sqrt{ }$ \\
\hline Czech Republic & $\sqrt{ }$ & & $\sqrt{ }$ & & Netherlands &.. & $\sqrt{ }$ & .. & $\sqrt{ }$ \\
\hline Germany & $\sqrt{ }$ & & $\sqrt{ }$ & & Norway & $\sqrt{ }$ & & $\sqrt{ }$ & \\
\hline Denmark & $\sqrt{ }$ & & $\sqrt{ }$ & & New Zealand &.. & $\sqrt{ }$ & .. & $\sqrt{ }$ \\
\hline Estonia & $\sqrt{ }$ & &.. & $\sqrt{ }$ & Poland & $\sqrt{ }$ & & $\sqrt{ }$ & \\
\hline Spain & $\sqrt{ }$ & & $\sqrt{ }$ & & Portugal & $\mathrm{pt}$ & & $\sqrt{ }$ & \\
\hline Finland & $\sqrt{ }$ & & $\sqrt{ }$ & & Slovak Republic & $\sqrt{ }$ & & $\sqrt{ }$ & \\
\hline France & $\sqrt{ }$ & & $\sqrt{ }$ & & Slovenia & $\mathrm{pt}$ & & $\sqrt{ }$ & \\
\hline Greece & $\sqrt{ }$ & & $\sqrt{ }$ & & Sweden & $\sqrt{ }$ & & $\sqrt{ }$ & \\
\hline Hungary & $\sqrt{ }$ & & $\sqrt{ }$ & & Turkey & $\sqrt{ }$ & &.. & \\
\hline Ireland & $\sqrt{ }$ & &.. & $\sqrt{ }$ & United Kingdom & $\sqrt{ }$ & & .. & $\sqrt{ }$ \\
\hline Iceland & .. & $\sqrt{ }$ & $\sqrt{ }$ & & United States &.. & $\sqrt{ }$ & .. & $\sqrt{ }$ \\
\hline
\end{tabular}

Note: The abbreviations denote: $\sqrt{ }=$ Explicit pension credits exist in the earnings-related pension system; .. $=$ Not available in the earnings-related pension scheme; Implicit refers to mechanisms not explicitly designed to cover periods of interruptions but that implicitly exert that same function either thanks to pension rules or first-tier components; $\mathrm{pt}=$ Credit only exists for part-time workers.

Source: Based on information received by national country delegates and from the "Country profiles" in Chapter 11.

in non-contributory schemes (like that of New Zealand, Canada or the Netherlands' basic pension), and are implicitly ruled out in some pension plan designs. For example, the United States' maximum pension rate requires only 35 years of contribution, so any years out of work in excess of that duration may not affect public retirement income. As for Canada, first-tier schemes (the means-tested Guaranteed Income Supplement - GIS, and Old Age Security - OAS) help mitigate the retirement income losses experienced by certain low-income groups due to frequent interruptions in their careers; these schemes exclude time spent outside the labour force or with low earnings while caring for children under the age of seven from the averaging period to determine the reference wage used to calculate the amount of earnings-related public pension.

Pension credits are seldom a feature of privately run personal or occupational pension schemes. Exceptions are the Swedish and the Danish occupational pensions (ITP and ATP, respectively). The mandatory DC programmes in Estonia and Sweden also provide pension credits during childcare absences. France's public mandatory occupational pension plans provide credit for career interruptions related to unemployment and a $10 \%$-increase in retirement benefits only for parents with at least three children. In voluntary private pension schemes, savers may buy extra accrual periods by paying voluntary contributions into the system; for example, Germany introduced such a practice in 2005 , and the government makes a deposit at the end of the year in one parent's individual private pension account.

How effective credits are in offsetting interruptions in employment depends on the length of leave, the pensionable earnings base, and the ways in which those parameters count towards pension entitlements (see Table 3.A1.1 for childcare and Table 3.A1.2 for unemployment in Annex 3.A1). 


\section{Periods covered by pension credits}

Credits for childcare typically cover career breaks until children reach a certain age. They are generally less generous for longer breaks and for older children. Many OECD countries credit time spent caring for very young children (usually up to 3 or 4 years old) as insured periods and consider it as paid employment. By contrast, extended periods of leave to raise older children (usually aged between 6 and 16) are typically taken into account only to determine eligibility for early retirement and the minimum pension. Some countries (the Czech Republic, Greece, Hungary and Luxembourg) factor childcare into assessments of eligibility, but disregard them when computing the earnings base.

Only France, Germany, Italy, and the United Kingdom (up to an earnings threshold) grant some of the pension credits regardless of whether parents stop working or not. A condition to benefit from these credits is to have at least one dependent child. For example, in France the public pension system (i.e. the régime général) awards mothers (since January 2004) and fathers (since January 2010) one year of insurance after the birth or adoption of a child (Majoration de durée d'assurance or MDA). An additional quarter is awarded at the child's birthday every year after birth or adoption up to a maximum of eight quarters per child in total which matter only for people who do not record full-contribution histories. In some countries (including France and Italy), pension credits also become more generous as the number of children increases. In France, for example, increases are granted to parents of three and more children by the public pension scheme (which adds to the MDA) and by the two main occupational plans - ARRCO for employees and AGIRCC for managerial staff. The country chapters at the end of this report provide detailed descriptions of all crediting mechanisms and methods.

The recipient of childcare credits is either the mother or the father - usually mothers as credits are closely related to the actual take-up of parental leave, though fathers are coming increasingly to the fore in countries like Denmark and Sweden. This is also the case in countries having introduced father-specific parental leave entitlements or redesigned payments systems to reduce financial disincentives for take up by fathers. ${ }^{10}$ Luxembourg pays a flat-rate old-age allowance to people who contributed too little to benefit from credits, so most recipients are women. In Chile, out of the 24 weeks of parental leave, the first 18 are exclusively for mothers, while fathers may take it up from the 19th to the 24th week, which then counts towards their pension entitlement.

As a general principle, the person receiving the credit should be the one interrupting his or her career. Some exceptions, however, exist particularly when the credit does not generate additional gains - e.g. when full-time stay-at-home parents are the main carers. Some countries, e.g. Norway, therefore allow households to choose. In Greece, fathers can use the credit when it makes no difference to mothers' pension entitlements. As for Germany, credits for children born in 1992 or later can be taken up by either employed or unemployed parents, or shared between them. Sweden has a flexible system under which the parent with the lowest income receives the credit, unless both parents choose otherwise.

When it comes to the unemployed, credit is generally limited to periods of benefit recipiency, which in some countries depend on the age of the beneficiary. In other countries, only tranches of periods out of work count towards pensions, while in others still the credit varies according to age or family status. For example, in Belgium, only involuntary and end-of-career unemployment benefit - the so-called bridging pension - counts towards retirement pensions. In France, unemployment without benefit can be credited for a period of up to one year - or five years for some categories of unemployed. In Spain, the credit takes also into account the family status of the unemployed.

Credits for late-career unemployment are generally more generous as they are intended to ensure practically unchanged pensions, which makes them a de facto early-retirement pathway. Austria provides an unemployment bridging benefit that enables workers to leave the labour market early, although it will be totally phased out by the end of 2015. Belgium, too, grants a bridging pension 
to the over-59s until they reach retirement age, while Spain credits unemployment assistance for over-55s only, with the government paying in contributions for their old-age pension until they reach retirement age. As for Denmark, it links unemployment insurance to a voluntary early-retirement scheme which grants special early-retirement benefits to people between the age of 60 (set to gradually rise to 62 between 2014 and 2017) and the normal pension age (which is 65 but is due to be raised to 67). To qualify for this benefit, individuals must have paid into the unemployment insurance fund for at least 30 years and have made voluntary early-retirement contributions during that time.

In Finland, it is possible to retire on old-age pension from the age of 62 (rising to 63 for people born after 1958) after a period of long-term unemployment in both the national and earnings-related pension systems with no actuarial reductions for early retirement. If 59-year-olds lose their job, they will receive unemployment benefit until they are 65, although their pension entitlement accrues only up to the age of 63 if they opt for the old-age pension at that age. For workers aged at least 57 who have paid into national insurance for 35 years, their unemployment contributions are extended for up to two years so that they can qualify for retirement pension. The value of unemployment benefits (both insurance and assistance payments) is factored into the calculation of pension benefits. In the Czech Republic, the duration of unemployment insurance is five months up to the age of 50, eight months from 50 to 55, and 11 months for the over-55s. In addition, one year of unemployment without benefits before the age of 55 , and up to three years thereafter, are also credited for pensions. In both cases, the unemployment period used to calculate the pension entitlement is shortened by $20 \%$.

\section{Pensionable earnings base of pension credits}

There are wide cross-country differences when it comes to the pensionable earnings on which credit is based. For childcare-related leaves, Belgium, Finland, Japan, Luxembourg and Sweden take earnings immediately prior to parental leave, while others - such as the Slovak Republic - average earnings over the 24 months before leave. Some countries, however, use a flat-rate amount to compute the credit. In Austria, for instance, credits are based on a notional pensionable salary, which amounted to EUR 1650 per month in 2014. In Finland, periods that exceed the 10-to-11 months of parental leave and last until the child is 3 years old are credited on the basis of a flat-rate salary of EUR 707 per month (2014).

Another group of countries (which include Hungary and the United Kingdom) choose care-related benefits or the minimum wage as reference earnings. Poland also took the minimum wage, but since 2012 pensionable earnings have been benchmarked at $60 \%$ of the average wage earned in the previous 12 months. In France, parents who do not work in order to care for their children (or who, when they do work, earn less than specific threshold amounts and are eligible for special family benefits) are affiliated to a mandatory old-age insurance (Allocation vieillesse parents au foyer) which uses the minimum wage as pensionable earnings.

Contributions based on reference earnings are notionally paid (i.e. contributions during the breaks are paid by the State and mainly financed through the general budget or specific public reserve funds as if the individual was working) during career breaks in most of the countries that grant credits for childcare. Examples are Austria, Poland, the Slovak Republic, and Sweden. In some countries, e.g. Norway, credits are granted only up to an earnings threshold, while in others, such as Denmark and Estonia, the insured pay a share of contributions.

Where information on funding sources is available, it appears to show that pension credits are financed primarily out of general taxes In Austria, both the separate Family Allowances Equalisation Fund (FLAF), which depends on federal income taxation, and the public budget are responsible for funding childcare credits. In France, a public fund (Fond de solidarité vieillesse) financed through various earmarked taxes, such as taxes on alcohol, was the main funding source until it registered a deficit in 2009. Since then transfers from the family benefits provider (Caisse nationale d'allocations 
familiales) mainly cover the cost of childcare credits for pensions. The German federal government pays contributions for child-raising periods - tax-funded - on a flat-rate basis into the pension insurance. In the Slovak Republic, the government pays contributions on behalf of people caring for children up to age 6 . The amount is equivalent to $20 \%$ of $60 \%$ of an assessment base (average monthly wage). In other countries (such as Denmark, Hungary and Sweden), however, mandatory contributions are at least in part to be paid by the beneficiary.

Such mechanisms are also expensive. France, for example, spent more than $0.75 \%$ of GDP on childcare-related pension credits in 2011 (Commission pour l'avenir des retraites, 2013). In Sweden, pension contributions paid by the state to enable parents to break their careers to raise their children accounted for about $2.5 \%$ of all contributions in 2012. As for Germany, the cost of the three points per child was estimated at nearly $6 \%$ of all contributions made in 2012. In Austria, the cost of pension credits related to childcare unemployment accounted for 0.3\% and 0.4\% of GDP, respectively, in 2014.

As for unemployment, the pensionable earnings are either the earnings up to job loss, a percentage of those earnings, or the benefit received during the break in employment. However, there are countries where the age of the unemployed and the length of time they were out of work determine different rules. In Belgium, for example, rules are different for the under- and over-59s, with credits for unemployment being based on the "minimum annual credit" - i.e. EUR 22189 per annum in 2014 - up to a person's 59th birthday. Thereafter, the reference income is the last wage.

\subsection{Simulating pension entitlements for shorter and interrupted careers}

\section{Assumptions for childcare, unemployment, and delayed entry}

The pension entitlements simulated here assume that men and women enter the labour market in 2014 and have either shorter or interrupted careers caused by late entry into employment or periods of unemployment or childcare during their working lives.

The OECD baseline full-career simulation model assumes labour market entry at the age of 20. In the simulation examined here for delayed entry, the individual enters employment five years later, at the age of 25. For career interruptions, workers are assumed to embark on their careers as full-time employees at 20, and to stop working during a break of up to ten years either between the ages of 30 and 40 to care for their children or between 35 and 45 because they are unemployed; they are then assumed to resume full-time work until normal retirement age. When it comes to childcare, the simulations also assume that a woman has two children born when the mother is 30 and 32, respectively. For purposes of simplification, the results are those of single individuals and not couples.

The simulations are based on parameters and rules set out in Chapter 11. The computed pension entitlements reflect the projected pension income governed by legislation enacted in 2014, which provides for the changes to the pension system to be gradually ushered in. For each country, mandatory and quasi-mandatory first- and second-tier schemes for private-sector employees are modelled - they encompass all compulsory public and private and wide-coverage occupational pension schemes. The model also projects resource-tested benefits for which retired people may be eligible.

\section{Delayed entry simulation results}

In countries where the pensionable age is 65 , the OECD model assumes that labour market entry at the age 20 results in a 45 -year-long career. In countries with lower (higher) pensionable ages, full careers are shorter (longer): the later retirement ages in the Czech Republic, Denmark, Greece, Iceland, Ireland, Italy, Norway, the United Kingdom and the United States suggest working careers that are at least 47 years long. In reality, careers tend to be shorter than the full-career baseline assumption. Indeed, there are workers who do not begin gainful employment until after they are 20 (as Figure 3.3 illustrated), and many spend time out of paid employment for various reasons. And early retirement is still common in some OECD countries. 
In countries where pension benefits are more tightly tied to years of contributions, delayed entry might directly lower pension entitlements. In most OECD countries, contribution periods shorter than 40 years will not be enough for retirees to claim a full pension in earnings-related pension schemes. In France, for example, age cohorts currently embarking on their careers at 20 might be entitled to full-rate pensions after a full career by the age of 63 . By contrast, those who take up their first job at 25 would have to work until they are 67 to be able to claim a pension that is penalty-free yet prorated to the contribution period, which would then be one year shorter than in the baseline model. In Belgium, where the statutory pension age is 65 and a full-length contribution history is 45 years, entry at the age of 25 and retirement at the standard age would mean proportionally lower pension entitlements. However, if delayed entrants extend their retirement age, they may be entitled to a higher pension (see below).

Figure 3.11 compares the gross pension entitlement for average-income workers who started work at 20 and those who delayed their labour market entry until they were 25 . The pension gap in the OECD area is $7 \%$ on average, but this average hides wide cross-country differences. At one end of the spectrum, with about $85 \%$ of the baseline full-career entitlements, lie Chile and Mexico, where the $85 \%$ ratio results from the actuarial fairness rules built into the DC scheme if the same retirement age is maintained and the economic assumptions of OECD model hold. At the opposite end of the range with 103\% and 106\% come France and Luxembourg, respectively, where such a late entry also delays the full-pension retirement age by four and five years. Germany, Greece and Slovenia are the three other OECD countries where delaying labour market entry requires working at an older age to be entitled to a full pension given the contribution-period rules.

\section{Figure 3.11. Estimates of prospective pension entitlements for delayed entry at the age of 25 and exit at national retirement age compared to baseline, average-wage worker}

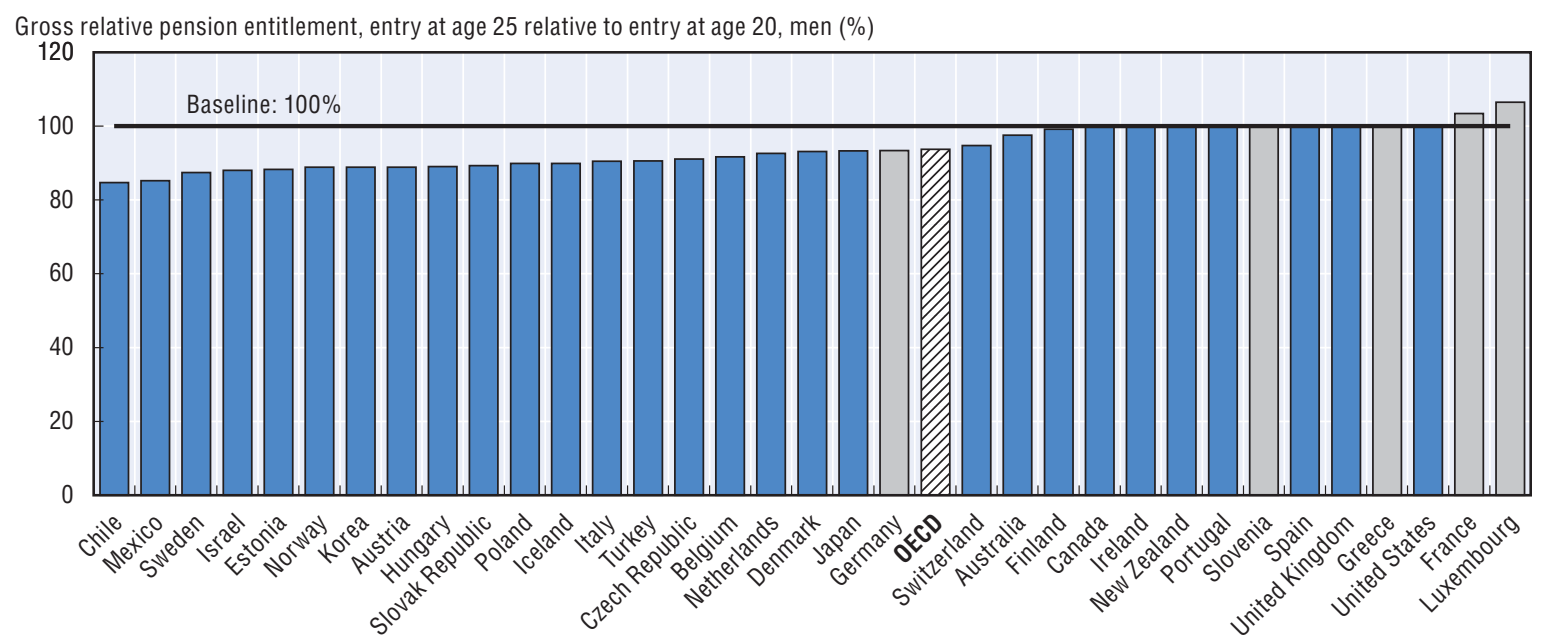

Note: Gross pension entitlements are computed for average-wage workers according to whether workers enter the labour market at age 25 or 20. Countries in light grey are countries where delayed entry delays retirement. Because of the changes introduced by recent pension reforms future retirees with five-year shorter contribution histories will need to work longer to obtain a full pension relative to current retirees. The pension entitlements are forward-looking and assume that pension rules of the year 2014 will apply throughout the career until workers reach the standard pension age in their country. Legislated rules that will be implemented gradually over the long-term are also included in the modelling.

Source: Estimates from the OECD pension models. See Chapter 6 and Chapter 11 in this report.

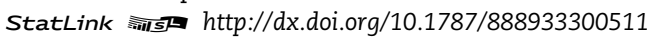

Austria, Estonia, Hungary, Israel, Korea, Norway, the Slovak Republic and Sweden have also rates below $90 \%$. In Canada, Ireland, New Zealand, Portugal, Spain, the United Kingdom and the United States, the pension entitlements are not affected by late entry. In Ireland and New Zealand, the reason is that benefits are based on flat-rate pensions, while workers in the United Kingdom and the 
United States reach the maximum pension after 35 years, in Spain after 37, in Canada after 39 and in Portugal after 40 years. Five years less of contributions does not therefore change pension benefit levels, unless the earliest working years are highly paid enough to be included in the averaging period. In short, delayed entry adversely affects pension entitlements in most OECD countries, translating into lower pension benefits unless workers work longer. The only other option open to delayed entrants to maintain retirement income is to save more over their working lives.

\section{The impact of career breaks on pension entitlements}

How different is the pension entitlement of a person who has a history of career breaks and might have been granted credits from that of a baseline retiree who has worked a full, uninterrupted career? To what extent do credits affect the pension entitlements of people who have experienced career interruptions? This section seeks to answer those questions.

\section{Overall picture}

Figure 3.12 illustrates the impact of career breaks for childcare (Panel A) and unemployment (Panel B) on average in the OECD at different earnings levels. Panel A depicts the ratio between the gross pension level of a woman who has interrupted her career between the age of 30 and 40 to care for two children and that of a woman who, having two children, has not stopped working. Panel B illustrates the gross pension level of someone who has been unemployed between the age of 35 and 45 relative to that of someone who has worked uninterrupted from the age of entry into the labour market to normal statutory pension age.

\section{Figure 3.12. Impact of career breaks for childcare and unemployment on future pension entitlements at different earnings levels, OECD average}

As a percentage of baseline gross pension

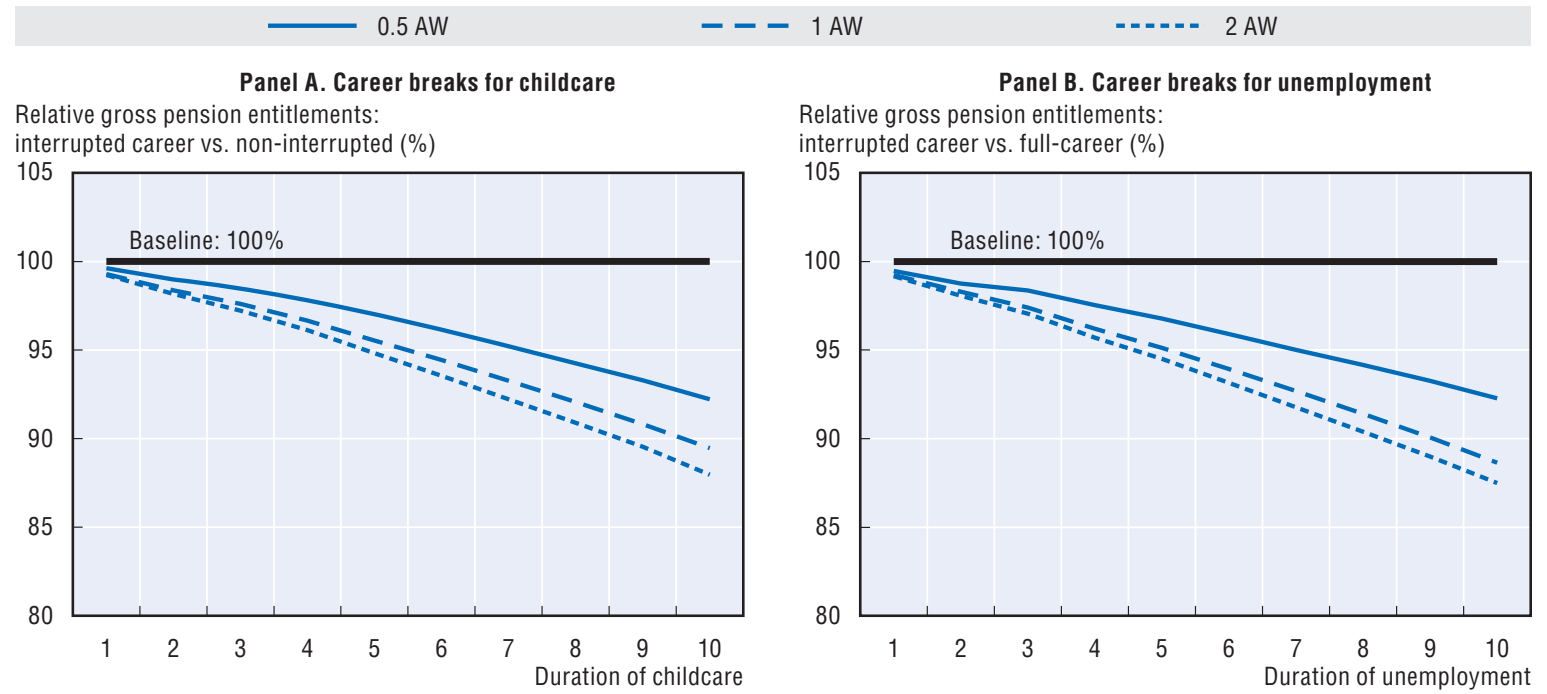

Note: The baseline denotes normalisation to full career. AW is the average wage worker concept used by the OECD. 0.5 AW denotes half of the AW ("low earnings"), and 2 denotes twice the AW ("high earnings"). For childcare, the models assume that after labour market entry at age 20, a woman with two children aged 2 and 4 interrupts her career for up to ten years between the age of 30 and 40 and then resumes full-time employment up to the national retirement age. For unemployment, the model assumes entry at age 20 and unemployment for up to ten years between the age of 35 and 45 and then resumes full-time employment up to the national retirement age. The indicators illustrated are: in Panel A the ratio between the pension entitlement of someone who interrupts the careers for childcare and someone with two children who work a full career without interruption; and, in Panel B, the ratio between the pension entitlement of someone who interrupts the careers for unemployment and someone who work a full career without interruption. The pension entitlements are forward-looking and assume that pension rules of the year 2014 will apply throughout the career until workers reach the standard pension age in their country. Legislated rules that will be implemented gradually over the long-term are also included in the modelling.

Source: Estimates from the OECD pension models. See Chapter 6 and Chapter 11 in this report. 
The gross pension of a woman who earns the average wage and interrupts her career for five years to care for two young children would drop by $4 \%$ on average in the OECD area relative to a woman with two children who has not interrupted her career. The gap increases to an average of $11 \%$ after a ten-year break. The pension drops slightly less when earnings are lower - by $3 \%$ after a five-year break and $8 \%$ after a ten-year break. Shortfalls at higher earnings levels are larger as the childcare break lengthens -averaging $5 \%$ after five years and $12 \%$ after ten years away from the workplace.

Unemployment gives rise to slightly larger shortfalls in pension entitlements than childcare as earnings increase and the employment break lengthens. For an average-wage worker who is unemployed for three years - and after returns to work at the average wage - the pension gap with an unbroken career is $3 \%$ on average. It reaches $5 \%$ after five years out of work and $11 \%$ after ten years. Among low-wage earners, the decline in pension entitlements is $2 \%$ after a three-year unemployment break to reach $8 \%$ after a ten-year break in the OECD on average. Among the high-earners, the decline is 3\% after a three-year break to reach $13 \%$ after a break of ten years.

While the figures point to drops in old-age pensions of about $1 \%$ for every year without a job on average across countries, they also show that pension systems play a key role in offsetting the losses in old-age pensions attributable to interrupted employment. Indeed, the $1 \%$ drop per missed contribution year is substantially below the actuarially fair adjustment: in the absence of any redistribution, the pension loss would be at around 2 to $2.5 \%$ per missed contribution year, depending on the workers' age at the time of the break, and based on the economic assumptions used in the OECD model.

\section{Country-specific simulation results for children and childcare}

Comparison of the pension entitlements of women who have children and have not interrupted their careers with those of full-career childless women yields an estimate of the advantage of being a mother, in a few countries, when it comes to pension entitlements. Conversely, for women with two children, comparing the pension entitlements when careers are interrupted to care for the children with those of full-career mothers produces an estimate of the cost of career breaks.

Having two children increases the pensions of women who do not interrupt their careers in Germany and Italy only. In Germany, the higher pension stems from the credit of one pension point per year granted until the child, born after 1992, turns three on the basis of a benchmark wage equal to average earnings. This translates into an increase in pension entitlement of less than $1 \%$ at average wage (for children born before 1992 only one pension point in total is credited following the 2013 reform). Moreover, parents who work when their youngest child is under 10 receive a bonus of between 0.33 and 1 point per year, depending on their earnings. Under Italy's NDC system, mothers convert their notional capital into a pension annuity at a more favourable rate upon retirement. For one or two children the more generous conversion rate amounts to granting benefits as if the mother's retirement age is increased by one year, and by two years for three or more children. The effect is a pension increase of around 3.3\% for mothers of one or two children, and around $6.6 \%$ when they have three or more children. ${ }^{11}$

The gross pension rates of mothers who take time out of employment and those who take none is illustrated in Figure 3.13 at different earnings levels and for breaks from work of five and ten years respectively. In Ireland, New Zealand, Spain, the United Kingdom and the United States, pensions are not affected by breaks whatever the earnings. In Ireland the reason is that career breaks to care for children under 12 are considered insured periods up to a maximum of 20 years, provided that the carer does not earn above a certain threshold (EUR 38 per week in the Homemaker's scheme). Those breaks are therefore excluded from the averaging periods used to compute pension entitlements. In Spain, too, the three years that mothers may spend looking after their children count as insured 
Figure 3.13. The gross pension entitlements of low-, average-, and high-earning mothers who interrupt their careers for five and ten years versus those of their peers with unbroken careers
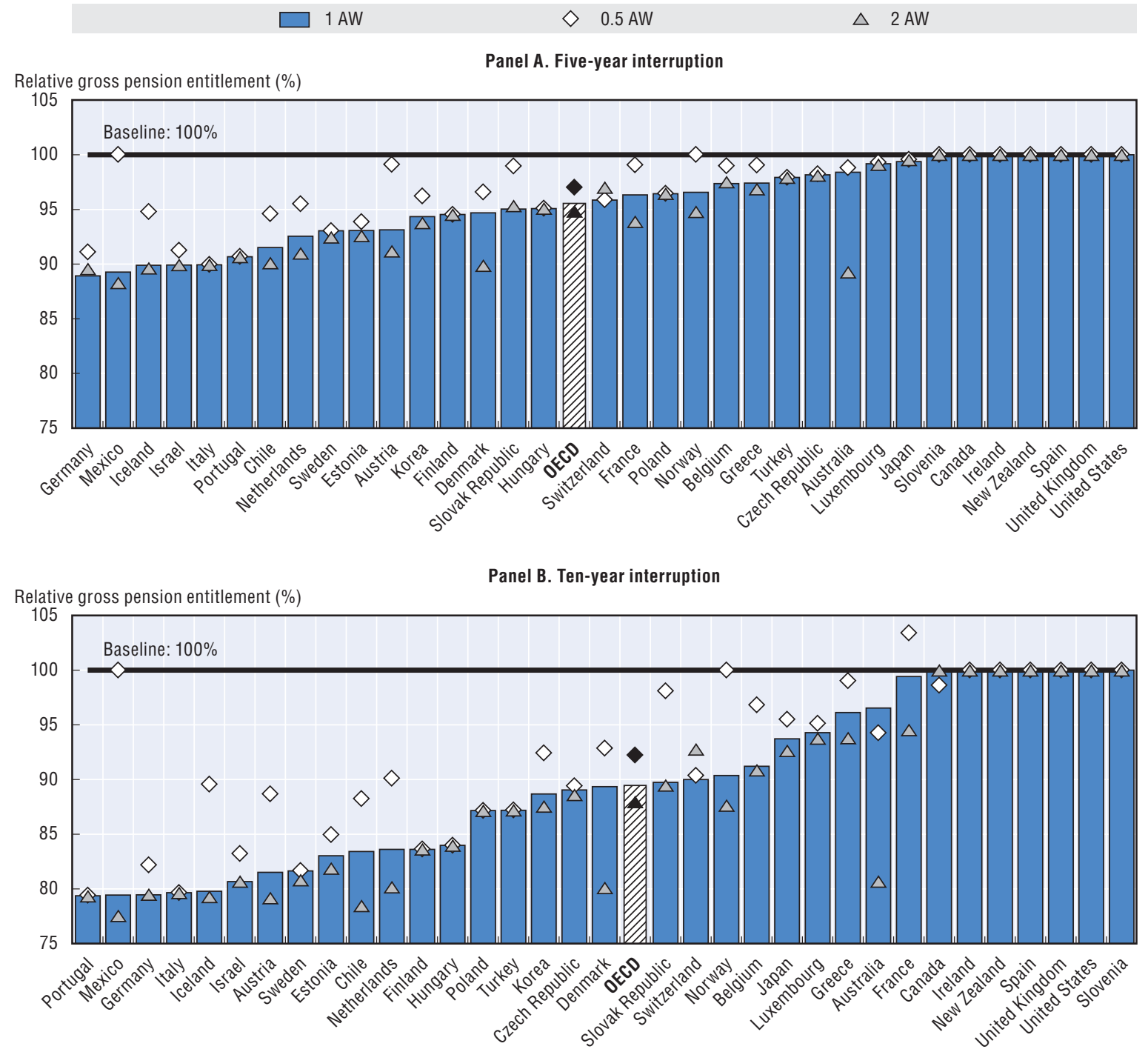

Note: AW is the average-wage worker concept used by the OECD. 0.5 AW denotes half of the AW ("low earnings"), and 2 denotes twice the AW ("high earnings"). The models assume that after labour market entry at age 20, a woman with two children aged 2 and 4 interrupts her career for up to ten years between the age of 30 and 40 and then resumes full-time employment up to the national retirement age. The indicator illustrated is the ratio between the pension entitlement of this woman and that of a woman with 2 children who work a full-career without interruption (i.e. the baseline in the figure). The pension entitlements are forward-looking and assume that pension rules of the year 2014 will apply throughout the career until workers reach the standard pension age in their country. Legislated rules that will be implemented gradually over the long-term are also included in the modelling.

Source: Estimates from the OECD pension models. See Chapter 6 and Chapter 11 in this report.

periods; as only 37 years are needed for a full pension, this credit allows a complete offset of the effect of the childcare employment break on pensions. In New Zealand, the public pension is simply residence-based, so any period spent out of the labour market does not change the benefits.

In Austria, Finland, Hungary, Iceland, Israel, Italy, Mexico, Portugal, Sweden and Turkey, contribution gaps can make a substantial dent in retirement income, especially if the childcare period lengthens. In some of these countries crediting mechanisms for childcare do not exist (such as in Iceland, Israel, Portugal and Mexico). In the other countries where they do exist they better cover short interruptions and/or low-earners. In some countries, there are also private DC schemes that 
generally do not grant credits, which imply that childcare-related absences mean both lost contributions and retirement income. In Estonia, the state pays employer contributions for up to three years, so any career interruption that is longer also mean higher contribution gaps and lower pensions. Mexico has no arrangements for childcare-specific credits, so the pension gap is substantial. However, low-wage earners will receive the minimum pension only, even full-career workers, provided that they have contributed for at least 24 years, so that the care break does not affect retirement income.

In five countries, France, Germany, Greece, Luxembourg and Slovenia, employment breaks imply that workers have to retire later to be entitled to a pension without penalty due the rules governing required contribution periods. In Slovenia, for example, a worker who enters paid employment at 20 but takes ten years out of work will have contributed for less than 40 years at age 60, and will therefore have to work until 65 to be able to retire without penalty.

In most countries, lost contributions eat further into future retirement income as childcare leave lengthens. In Belgium, the Czech Republic, Luxembourg, Poland, and the Slovak Republic, for example, the gap in pension entitlements is small when interruptions in employment are in their first few years. It widens thereafter, but varies from one country to another, as different crediting rules apply to pensionable earnings and to the lengths of career interruptions (see Section 3.4). Poland, for example, grants pension credits for up to 36 months per child. With two children, the effect on entitlements is well cushioned for the first six years of leave from the workplace, after which contribution gaps begin to bite.

Earnings, too, are a factor in the way career breaks determine pensions. In countries where the earnings immediately prior to the take-up of childcare leave are pensionable (such as Belgium, Finland, Japan and Sweden), the impact of career breaks on pensions is more evenly spread over the earnings scale. In others, where the government pays the contributions of employees taking a career break, and credits are based on pensionable earnings that are lower than the salary earned, they are of little effect to offset contribution gaps for high earners. Austria, for example, provides credits for care at a flat rate so that their effectiveness in maintaining retirement income levels lessens as the break lengthens.

Australia, Austria, Chile, Denmark, France, Iceland Mexico, the Netherlands, Norway and the Slovak Republic cushion the impact of five-year childcare-related employment breaks on the pensions of low earners relatively better than on those of high-earning women. High earners are less affected in Canada due to the exclusion of the childcare-related employment breaks from the contributory period in calculating pension benefits. For high earners some studies suggest that, beyond pension entitlements, pension system design could affect women's childbearing decisions - even though any link between earnings and the total fertility rate lacks robustness. ${ }^{12}$ Career prospects, the availability of childcare services, and foregone earnings losses may be more compelling reasons for deciding for or against having children than old-age benefits.

\section{Country-specific simulation results for unemployment-related career breaks}

The indicator used here is the long-term gross pension entitlement, at different earnings levels, of someone whose career was interrupted by unemployment at the age of 35 from a period of one to ten years. The benchmark is a full-career entitlement (Figure 3.14). It is assumed that when the unemployed worker finds a job again, relative pay is the same as in their old position- e.g. an average-wage worker becoming unemployed finds a few years later a job at the then average wage. In other words, any earnings scarring effect is assumed away, so that the impact of the career break on the worker's pension may actually be higher than the one estimated here. 
Figure 3.14. The gross pension entitlements of low-, average-, and high-earning workers with unemployment-related career breaks versus workers with unbroken careers
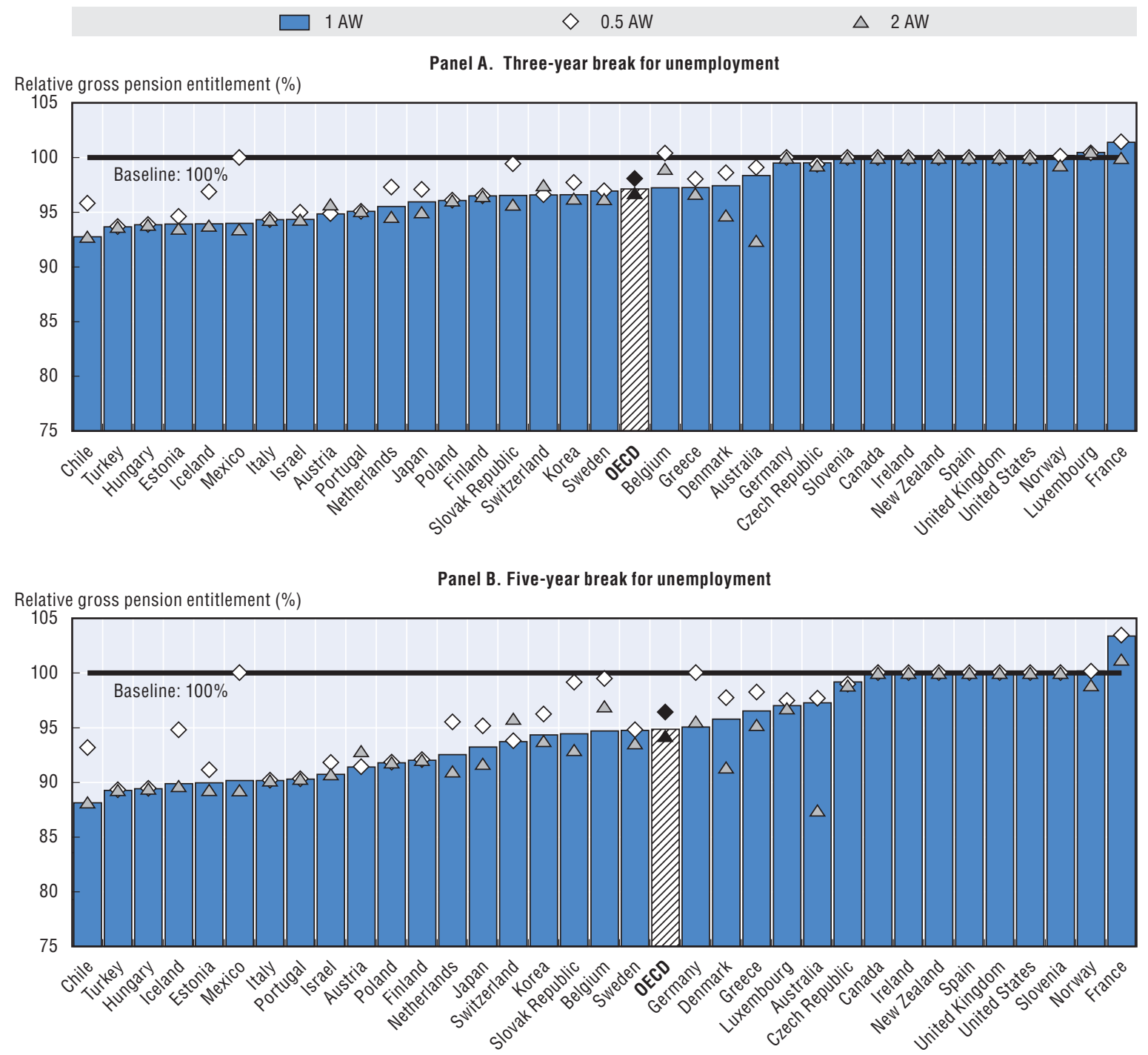

Note: AW is the average-wage worker concept used by the OECD. $0.5 \mathrm{AW}$ denotes half of the AW ("low earnings"), and 2 denotes twice the AW ("high earnings"). The model assumes entry at age 20 and unemployment for up to ten years between the ages of 35 and 45 years and then resumes full-time employment up to the national retirement age. The indicator illustrated is the ratio between the pension entitlement of someone who interrupts the careers because of unemployment and someone who work a full career without interruption (i.e. the baseline in the figure). The pension entitlements are forward-looking and assume that pension rules of the year 2014 will apply throughout the career until workers reach the standard pension age in their country. Legislated rules that will be implemented gradually over the long-term are also included in the modelling. Data are ranked according to the estimates for average-wage workers.

Source: Estimates from the OECD pension models. See Chapter 6 and Chapter 11 in this report.

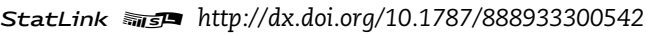

For the average-wage worker, pension shortfalls relative to someone with a full, unbroken career varies widely across countries. They are generally larger for longer duration and for high-earners. In Chile, Hungary and Turkey, the pension loss after a five-year unemployment break is larger than $10 \%$. On the other hand, in some countries, pension rules can offset the fallout from spells of unemployment. This applies for example in Canada, Ireland, Norway, Spain, the United Kingdom and the United States. The Netherlands' residence-based basic pension affords some protection against unemployment, while the occupational pension is sharply reduced by unemployment breaks. In New Zealand, periods of unemployment do not affect the basic pension but, as for childcare-related 
breaks, they may seriously affect the voluntary private pension entitlement, which is not taken into account in the simulations. This also applies to other countries with substantial voluntary private pension component such as Canada, Ireland, the United Kingdom and the United States.

There are countries which afford the low-paid better protection against long-term unemployment than average earners, because minimum pension and resource-tested schemes play a crucial role in some of them - Australia, Chile, Denmark, Germany, Iceland, Mexico and the Slovak Republic. In Germany, unemployment credits for long-term joblessness are effectively flat-rated based on average earnings, thus protecting low earners relatively better than people on average pay. Low-earners' pensions in Australia are also little affected by unemployment thanks to basic and resource-tested benefits.

Where there is no pension credit provision - in Chile, Estonia, Israel, Korea, Mexico and Turkey, for example - pension losses are more substantial for average-wage earners with effects felt most keenly in countries whose compulsory pension programmes link pensions and earnings closely - e.g. Chile and Mexico - and at higher earnings levels. In five countries (France, Germany, Greece, Luxembourg and Slovenia), periods of unemployment imply retiring later due the required contribution rules. In France only, this generates higher pension benefits (Figure 3.14) because pensions of full career workers who retire earlier are indexed to prices. However, the interrupted-career worker will receive pension benefits over a shorter period due to a later retirement age, inducing a lower pension wealth overall.

\subsection{Putting the results in a policy perspective: Pension credits and other measures towards less fragmented careers}

Many recent pension reforms have striven to balance retirement-income adequacy and financial sustainability. With the aim of making pension systems more sustainable, countries have typically implemented reforms that reduce the generosity of public pensions systems. They have done so by, for example, tightening the link between pension benefits and contributions paid, and widely sought to move away from the traditional defined-benefit pensions, thus shifting labour- and financialmarket risks onto insured individuals. It was to that end that Sweden, Italy, Norway, Poland, and Greece (with its auxiliary funds) replaced DB by NDC schemes, that other countries reduced the size of their public DB schemes, and that most strengthened the role of private pensions, as in Mexico, Chile, Australia and Norway.

As longer working lives may help achieve both financial sustainability and retirement income adequacy, most governments have put great effort into closing down early-retirement schemes, raising retirement ages, lengthening contributory periods, tightening job-search requirements for older workers, reducing the scope of pension schemes for arduous work, restricting disability benefits to those "genuinely" sick and unable to work, and so on. Table 1.A1.1 at the end of Chapter 1 reports the measures OECD countries have taken to extend working lives since September 2013 (see also OECD, 2014f). However, both labour demand and labour supply factors have a bearing on the effective age of exit from the labour market (OECD, 2006; 2013; 2014b, c, d, e; 2015a).

Governments have also changed the parameters of pension systems to raise the marginal returns from working longer, thereby encouraging working at older ages. Across the OECD area, people might need to work longer to retire on unchanged pension benefits, which is consistent with changes induced by life expectancy gains. Many countries have also extended the period over which earnings are measured in a way that will reduce pension benefits, taking the average over the lifetime instead of the average of the best years or final earnings which are usually higher. While changes in pensionable earnings may affect workers differently, depending on how earnings evolve over a career, anyone with longer career breaks or part-time periods, typically women, will be at a disadvantage. 
To limit the negative impact of these recent measures on certain groups, such as women and the unemployed, many OECD countries have developed pension credits and other redistributive mechanisms since the 1990s. The recent global economic crisis, however, has prompted fiscal consolidation measures and proposals to make pension credits less generous.

Even though pension policies can mitigate some labour market problems, they cannot fix them all. A much wider policy perspective is needed. In addition to redistributive mechanisms which soften the blow to pensions from low earnings and interrupted careers paths ex post, a wide range of social policies seek to narrow different types of inequality and, thereby, their effect on pension entitlements. By its very nature, longer schooling delays labour market entry. But because it helps provide education and skills, it also boosts employment and wages over the long term. Family policies are intended to help parents strike a work-life balance, thus helping to brighten parents' labour market prospects, and those of carers in general.

Bringing young people into the labour market should be a primary concern in OECD countries. Beyond compulsory school-age statutes, economic and labour-market-related conditions play an important role for demand of education, too. For example, policies to ensure better matches between employment opportunities and skills acquired at school, to improve the availability and dissemination of information, to provide career advice and guidance, and to ease the transition from school to work all play a crucial part in plugging the contribution gaps related to delayed entries into the labour market as young people struggle to find their first job.

Career interruptions to care for children may be influenced by a wide range of policies designed to help people balance family and workplace obligations more easily - a theme the OECD addresses in its many reports (OECD, 2007, 2011, 2012). Family-friendly policies have in recent years become a top priority in most OECD countries - women who want to work and have children should be able to do so. The ample provision of good-quality childcare at affordable costs and after-school activities, leave arrangements that enable care duties to be shared evenly within families (e.g. take-it-or-lose-it parental leave for fathers) are just some ways of preventing parents, especially mothers, from leaving paid employment for too long or getting stuck in part-time jobs. Tax provisions that foster a second-earner labour supply would also be a welcome move.

Policies to cut the length of unemployment by helping labour markets function more efficiently and matching people, skills and jobs are essential. The first step is good training and education programmes that groom young people for the job market and help workers stay up-to-date and suitably skilled. Indeed, activation, lifelong learning, and proper unemployment benefit coverage are associated with better labour market performance. Policies that improve occupational mobility and offer stronger incentives to seek and accept jobs are an important part of the effort to reduce the incidence and length of unemployment (OECD, 2014f). Tax and benefit measures (such as active labour market programmes and lower marginal tax rates for people on low income) could also wean people off welfare benefits, so helping to shorten the length of unemployment. Policies that boost geographical mobility, encourage entrepreneurship and innovation, and enhance aggregate demand can also help to fight unemployment and thereby reduce its long-term consequences on earnings.

\subsection{Policy implications and challenges ahead}

Life-cycle income profiles are more diverse nowadays than ever before. Longer schooling, wider skill-based pay differentials, more complex patterns of partnership, lower fertility rates, greater employment opportunities for women, longer average life expectancy, rising unemployment and flexiwork all contribute to shaping different lifetime earnings histories. Workers increasingly combine their work with activities like caring, leisure, and learning, while having to contend with unstable career paths. 
Two important policy concerns for the adequacy of retirement income emerge from all of the above: on one hand, the "sandwich pressure" of work and caregiving for children or elderly relatives, and on the other, unemployment. The resulting shorter, interrupted careers often mean lower retirement incomes. Therefore, in the absence of mechanisms helping to counteract the impact of employment breaks on pension entitlements current developments in pension systems, such as the drift towards DC and tighter links between benefits and contributions, may negatively affect income adequacy in retirement and heighten the risk of poverty in old age.

Many OECD countries assist people who interrupt their careers to raise children or because they have lost their job. The estimates presented in this chapter show the extent to which mechanisms like pension credits can soften the blow of career breaks to their retirement incomes. The results suggest that they are effective ways to cushion the shock of relatively short career breaks, especially at low earnings levels where they trigger other redistributive mechanisms into action. Pension credits are somewhat less effective for high earnings - particularly when employment breaks lengthen. They might become even more relevant in countries where there is a tight link between contributions paid and pension received in both private and compulsory public schemes.

Pension credits achieve, at least partially, some of their goals such as - when it comes to childcare career breaks - rewarding a vital social activity and limiting gender inequality. In particular, pension credits remain valuable tools where the scarcity of childcare services is an obstacle to mothers resuming paid employment (whether full-time or part-time), and where the incidence of unemployment and precarity are high. Moreover, by helping people to qualify for old-age pension, the pension credits contribute also to reducing old-age poverty and to enhancing retirement-income adequacy.

However, pension credits are only one part of the equation when it comes to income redistribution and poverty among the elderly. Better interactions between public and private pension schemes with some elements of clawbacks (i.e. when first-tier benefits are gradually withdrawn based on other sources of income), such as in Canada, Chile, Denmark and Iceland, may help. Basic or targeted pension schemes and other redistributive elements of pension systems in many countries may also be useful for protecting the pensions of the most vulnerable (Chapter 2). But fiscal costs and work incentives need also to be kept in mind, as trade-offs may have unintended consequences, especially when the mechanisms in place offer rights without obligations. For example, overgenerous flat-rate benefits for care-related career breaks may weaken the second earner's connection to labour market.

While later retirement ages and longer contributory periods are important measures towards a more sustainable pension system, the ultimate goal should be to bring about longer, fuller working lives based on individuals' preferences. The design of social protection institutions should take into account today's complex realities and look beyond solutions based on traditional instruments. Solutions should seek ways to offer them greater choice in dividing their time between work, care, leisure and learning in a flexible manner. Policies based on a better use of time and money are essential, in fact, as they help balance domestic care responsibilities with the obligations of the workplace. For example, even though fathers' take-up of leave has improved in some countries, women are still the main carers, even in countries where fathers have an individual or household entitlement. The level of income replaced during career breaks, together with flexibility, are important pre-conditions for promoting the shift in men's behaviour. Moreover, while opting for periods of part-time work could also enhance work-family integration, in many countries, they tend to reduce career advancement or even generate downward mobility, which also impact negatively on the accrual of pension entitlements. 
Such an agenda seeks to boost the opportunities for all to stay longer in paid employment. If this does not happen, the most vulnerable people, who have often precarious lifetime contribution histories, might come to increasingly depend on social assistance and other safety nets in retirement. Such an outcome would cancel out some of the savings obtained by recent pension reforms in public earnings-related schemes. It will also mean additional public expenditure in countries having private defined-contribution pension plans. Financial sustainability would be improved in parts of the pension system, but not in the retirement-income provision as a whole.

As always, prevention is better than cure. Policy makers should seek to transform periods of lost contributions and unused human capital into times during which people build and sustain their human capital. Well-designed social policies in these areas may enhance the capacity of individuals, families, and communities to cope with life events and attendant risks, and help societies advance towards a range of social and economic objectives. They may also improve employment opportunities across all age groups, and so contribute to effectively longer and fuller working lives.

Even when pension systems are able to absorb some of the shocks generated by different career and earnings paths, they are not - however well designed they may be - typically intended to address inequalities between men and women or parents and the childless in the labour market. This is probably as it should be. Actions to narrow labour market inequalities in the family and other social structures go far beyond pension policies and involve many social and labour market policy interventions and legislation which should be coherent over the life cycle and across age groups. Coherence must run through unemployment schemes for older workers, early retirement and old age pension systems, invalidity schemes, and policies to stimulate flexible working conditions and life-long learning.

As people are increasingly free to construct their own biographies, they become more responsible for their life courses. A challenge in that respect is to better prepare them to take responsibility for their employability, social insurance, and financial planning. Schools, employers, and unions can play an important role in helping people build the necessary financial competencies and life and work skills. There may also be greater awareness among voters of the fundamental trade-offs in social policy, thereby enhancing the quality of the political debate and policy making.

In a world characterised by growing complexity and heterogeneity, the limitations of modern pension systems need to be identified and addressed. Against that background, a fundamental policy question is how to improve the designs of current pension systems to make them better suited to modern life-course realities. There is no clear-cut answer. All OECD countries have pension systems with mechanisms that redistribute some resources from the better-off to the worse-off. But an issue that should be raised is whether redistribution happens at the right stages in the life course, and whether existing programmes adequately cover risks and periods of need. Concrete responses may eventually contribute to more balanced, equitable ageing.

\section{Notes}

1. For example, older worker are still exempted from the requirement to actively seek work and are no longer expected to take up a new job in some OECD countries (including Belgium, Germany, and the United Kingdom). Some countries also have special rules governing unemployment at the outset of a career. In France, older unemployed aged 50 years and more may benefit from unemployment insurance for 36 months, instead of 24 months for those aged below 50. Moreover the decree dated 15 July 2015 has re-established the equivalent retirement allowance (AER), intended for jobseekers who have not reached retirement age but have contributed the number of quarters required for a full pension. Austria, for example, requires just 26 weeks of insured employment for the under-25s years of age rather than 52 .

2. SHARELIFE was the third wave of data collection in the Share survey on life histories of people aged 50 and over. For more, go to www.share-project.org/sharelife/. Countries covered were Austria, Belgium, the Czech Republic, Denmark, France Germany, Greece, Italy, Switzerland, the Netherlands, Poland, Spain, and Sweden. 
3. Countries included in the average are Austria, Belgium, Finland, France, Germany, Greece, Hungary, Iceland, Ireland, Italy, Luxembourg, the Netherlands, Norway, Poland, Portugal, Slovenia, Spain, Sweden, Switzerland, the United Kingdom and the United States (2010).

4. Early retirement schemes were actually phased out (in Denmark, Greece, Hungary, Italy and Poland) or access was tightened by raising the age or lengthening the minimum contribution periods required for early retirement (as in Austria, Belgium, France, the Netherlands, Portugal, Slovenia and Spain). Some countries have also increased penalties for early retirement (Greece and Italy) to bring them closer to actuarial principles. (See also D'Addio, 2009, 2015; D'Addio and von Nordheim, 2014.)

5. In accordance with the human capital framework, education is seen as an investment good that yields additional dividends, such as higher lifetime earnings (Becker, 1975; 1985; Mincer, 1974; Ben-Porath, 1967). From an individual standpoint, the concentration of human capital investment at an early age offers the brightest prospects. The acquisition of additional human capital also reduces both the risk and duration of unemployment (Nickell, 1979; Mincer 1991; D'Addio 1998, 2000; Kettunen, 1997; Riddel and Song, 2011).

6. Ahituv (2000) reported that in Israel each year of delayed entry into the labour market reduces lifetime earnings by between 1.6 and $4.4 \%$ depending on individuals' educational attainment. Velfaerdskommissionen (2006) reported that entering the labour market one year earlier in Denmark translates into increases of about $2 \%$ in lifetime disposable income.

7. They would explain $17 \%$ of the gender wage gap in Denmark (Meilland, 2001), 27\% in France (Meurs and Ponthieux, 2000), 14\% in the United Kingdom (Chambaz, 2003) and 19\% in Germany (Beblo et al., 2003, 2009; Dupuy et al., 2009). Light and Ureta (1995) found that $12 \%$ of the gender-wage gap is explained by differences in the timing of childbirth (Albrecht et al., 1999; and Kunze, 2002). See also Blau and Kahn (1995) and Datta Gupta and Smith (2002) and Phillips et al. (2001).

8. Mothers' labour market participation rates are negatively affected by childbirth, particularly in the first year after birth. The magnitude of the effect increases with the number of children (Joshi et al., 1996; Gornick et al., 1997; Falzone, 2000; Kaufman and Uhlenberg, 2000; Kenjoh, 2003). Gornick et al. (1997) find an employment penalty related to the presence of children in half of the 14 OECD countries analysed i.e. Australia, Canada, Germany, the Netherlands, Norway, the United States and the United Kingdom. The largest effect is reported for the United Kingdom. See also De Henau et al. $(2006,2008)$ and Maron and Meulders (2008).

9. See Fallick (1996); Kletzer (1989, 1998); Couch and Placzek (2010) and Cooper (2014). Davis and von Wachter (2011) reported that workers displaced during recessions might experience earnings losses of roughly 19\%, which is much higher compared to workers displaced during non-recession years. Greenstone and Looney (2011) suggest that two years following their job loss, the average earnings declined by $48 \%$ relative to their average pre-job earnings.

10. In Iceland, following the introduction in 2001 of a three-month father-specific entitlement to paid parental leave. the proportion of leave days taken by fathers has increased to around one third from less than 5\% (Eydal and Gíslason, 2014). Similarly, in Germany, reform in 2007 of the parental leave payment scheme has been followed by a tenfold increase in the proportion of fathers claiming parental leave allowance, from around 3.5\% in 2006 to just over 32\% by 2013 (Destatis, 2015).

11. In France, a quarter of insurance is awarded on the child's birthday every year after birth or adoption up to a maximum of eight quarters per child. Concretely, two years maximum are credited for each child aged less than 16. However, these quarters matter only for people who do not record full-contribution histories.

12. The literature observes that the disincentive to have children is greater when the pension system is earnings-related rather than flat-rated. For an analysis of how different types of pension systems may influence childbearing decisions see for example Nishimura and Zhang (1992, 1995); Cigno (1993); Cigno et al. (2003); Rosati (1996); Cigno and Rosati (1996); Billari and Galasso (2009, 2014).

\section{References}

Ahituv, A. (2000), "Employment and Earnings Structure, Evidence from Israel”, Discussion Paper, No. 0008, The Maurice Falk Institute for Economic Research in Israel.

Albrecht, J.W. et al. (1999), "Career Interruptions and Subsequent Earnings: A Reexamination Using Swedish Data”, Journal of Human Resources, Vol. 34, No. 2, pp. 294-311.

Arulampalam, W., P. Gregg and M. Gregory (2001), "Unemployment Scarring”, The Economic Journal, Vol. 111, No. 475, pp. F577-F584.

Beblo, M., S. Bender and E. Wolf (2009), "Establishment-level Wage Effects of Entering Motherhood", Oxford Economic Papers, No. 61, pp. i11-i34.

Becker, G.S. (1985), "Human Capital, Effort, and the Sexual Division of Labor", Journal of Labor Economics, Vol. 3, No. 1, pp. S34-S58. 
Becker, G.S. (1975), Human Capital: A Theoretical and Empirical Analysis, with Special Reference to Education, Second Edition, NBER Books, National Bureau of Economic Research, Inc., No. beck75-1, June.

Ben-Porath, Y. (1967), “The Production of Human Capital and the Life Cycle of Earnings”, Journal of Political Economy, Vol. 75, pp. 352-365.

Billari, F.C. and V. Galasso (2014), "Fertility Decisions and Pension Reforms. Evidence from Aatural Experiments in Italy”, IdEP Economic Papers, No. 1403, USI Università della Svizzera Italiana.

Billari, F.C. and V. Galasso (2009), "What Explains Fertility? Evidence from Italian Pension Reforms", CESifo Working Paper Series, No. 2646, May, http://ssrn.com/abstract=1406946.

Blau, F. and L.M. Kahn (1995), “The Gender Earnings Gap: Some International Evidence”, in Freeman and Katz (eds.), Differences and Changes in Wage Structures, National Bureau of Economic Research, Comparative Labor Market Series, University of Chicago Press.

Braga, B. (2014), “Three Essays in Labor and Education Economics”, PhD Thesis, University of Michigan.

Brugiavini, A., G. Pasini and E. Trevisan (2012), “Maternity Leave Arrangements: The Impacts on Women's Careers and Pensions", Paper presented at the Royal Economic Society's 2012 annual conference.

Carcillo, S. et al. (2015), "NEET Youth in the Aftermath of the Crisis: Challenges and Policies", OECD Social, Employment and Migration Working Papers, No. 164, OECD Publishing, Paris, http://dx.doi.org/10.1787/5js6363503f6-en.

Chambaz, C. (2003), “L’accueil des jeunes enfants au Royaume-Uni”, Études et résultats, No. 234, pp. 1-8.

Cigno, A. (1993), “Intergenerational Transfers without Altruism: Family, Market and State”, European Journal of Political Economy, Vol. 9, pp. 505-518.

Cigno, A. and F.C. Rosati (1996), "Jointly Determined Saving and Fertility Behaviour: Theory, and Estimates for Germany, Italy, UK and USA", European Economic Review, Vol. 40, pp. 1561-1589.

Cigno, A., L. Casolaro and F.C. Rosati (2003), "The Impact of Social Security on Saving and Fertility in Germany", FinanzArchiv, Vol. 59, pp. 189-211.

Commission pour l'Avenir des retraites (2013), "Nos retraites demain : équilibre financier et justice”, Rapport au Premier ministre (Rapport Moreau).

Cooper, D. (2014), “The Effect of Unemployment Duration on Future Earnings and Other Outcomes”, Working Paper, No. 13-08, Federal Reserve Bank of Boston.

Couch, K.A. and D.W. Placzek (2010), "Earnings Losses of Displaced Workers Revisited", American Economic Review, Vol. 100, No. 1, pp. 572-589.

D’Addio, A.C. (2015), “Explaining the Gender Pension Gap in OECD Countries: Socio-economic Determinants and Pension Rules That Matter", unpublished manuscript.

D’Addio, A.C. (2009), "Pension Entitlements of Women with Children”, Chapter 12 in R. Holtzmann, E. Plamer and D. Robalino (eds.), Nonfinancial Defined Contribution Pension Schemes in a Changing Pension World, Vol. 2, pp. 75-111.

D'Addio, A.C. (2000), "Mobility of Young people on the French Labour Market, Methodological Considerations and Empirical Analyses", CIACO, ed. Louvain-la-Neuve, Belgium.

D’Addio, A.C. (1998), "Unemployment Durations of French Young People: the Impact of Individual, Family and Other Factors on the Hazard Rate", CORE Discussion Paper, No. 9851, Université Catholique de Louvain.

D'Addio, A.C. and F. von Nordheim (2014), “Towards an Integrated Agenda to Deliver Effective Higher Retirement Ages: An Issue Note from the Pension Perspective Background Note for the Joint OECD-EU Workshop on 'Delivering longer working lives and higher retirement ages'", Brussels, 12 and 13 November 2014.

Datta Gupta, N. and N. Smith (2002), “Children and Career Interruptions: The Family Gap in Denmark”, Economica, Vol. 69, pp. 609-629.

Davis, S.J. and T. von Wachter (2011) "Recessions and the Cost of Job Loss", NBER Working Paper, No. 17638, December 2011.

De Henau, J., D. Meulders and S. O’Dorchai (2006), "Maybe Baby! The Comparative Effectiveness of Public Policies to Fight Motherhood-Induced Employment Penalties and Decreasing Fertility in the Former EU-15", Working Paper, No. 06-02.RS, DULBEA, Brussels.

De Henau, J., D. Meulders and S. O’Dorchai (2008), "Parent's Care and Career: Comparing Parental Leave Policies", in D. Del Boca and C. Wetzels (eds.), Social Policies, Labour Markets and Motherhood. A Comparative Analysis of European Countries, Cambridge University Press, Cambridge, pp. 63-106.

Dupuy, A., D. Fouarge and B. Buligescu (2009), "Development of Econometric Methods to Evaluate the Gender Pay Gap Using Structure of Earnings Survey Data”, Eurostat Methodologies and Working Papers.

El Mekkaoui de Freitas, N. et al. (2011), “Career Interruptions: How They Impact Pension Rights?”, The Geneva Papers on Risk and Insurance, Vol. 36, No. 3. 
Fagnani, J. (1995), “L'allocation parentale d'éducation : Effets pervers et ambiguïtés d'une prestation”, Droit social, Vol. 3, pp. 287-295.

Fallick, B.C. (1996), “A Review of the Recent Empirical Literature on Displaced Workers”, Industrial and Labor Relations Review, ILR Review, Cornell University, ILR School, Vol. 50, No. 1, pp. 5-16, October.

Falzone, J.S. (2000), "Labor Market Decisions of Married Women: With Emphasis on Part-time Employment", International Advances in Economic Research, Vol. 6, No. 4, pp. 662-671.

Farber, H.S. (2004), “Job Loss in the United States, 1981-2001”, Research in Labor Economics, Vol. 23, pp. 69-117.

Geyer, J. and V. Steiner (2010), "Public Pensions, Changing Employment Patterns, and the Impact of Pension Reforms Across Birth Cohorts - A Microsimulation Analysis for Germany", School of Business and Economics Discussion Paper, No. 2010/8, Free University Berlin.

Gornick, J., M.K. Meyers and K.E. Ross (1997), "Supporting the Employment of Mothers: Policy Variation Across Fourteen Welfare States”, Journal of European Social Policy, Vol. 7, No. 1, pp. 45-70.

Greenstone, M. and A. Looney (2011), “Have Earnings Actually Declined?”, Brookings on Job Numbers, 4 March 2011.

Holmlund, B., Q. Liu and O. Nordstrom Skans (2006), "Mind the Gap? Estimating the Effects of Postponing Higher Education", CESifo Working Paper Series, No. 1792, http://ssrn.com/abstract=932496.

Joshi, H., S. Macran and D. Shirley (1996), “Employment After Childbearing and Women's Subsequent Labour Force Participation: Evidence from the British 1958 Birth Cohort", Journal of Population Economics, Vol. 9, No. 3, pp. 325-348.

Kaufman, G. and P. Uhlenberg (2000), "The Influence of Parenthood on the Work Effort of Married Men and Women", Social Forces, Vol. 78, No. 3, pp. 931-947.

Kenjoh, E. (2003), “Women's Employment Around Birth of the First Child in Britain, Germany, the Netherlands, Sweden and Japan", Working Papers of the Institute for Social and Economics Research/Paper, No. 2003-16, University of Essex, Colchester.

Kettunen, J. (1997), “Education and Unemployment Duration”, Economics of Education Review, Vol. 16, No. 2, pp. $163-170$.

Kletzer, L.G. (1998), “Job Displacement”, Journal of Economic Perspectives, Vol. 12, No. 1, pp. 115-136.

Kletzer, L.G. (1989), "Returns to Seniority after Permanent Job Loss”, American Economic Review, Vol. 79, pp. 536-543.

Kunze, A. (2002), “The Timing of Working Career and Depreciation of Human Capital”, IZA Discussion Paper, No. 509, Bonn, May.

Light, A. and M. Ureta (1995), "Early-Career Work Experience and Gender Wage Differentials", Journal of Labor Economics, Vol. 13, No. 1, pp. 121-154.

Maron, L. and D. Meulders (2008), "Les effets de la parenté sur l'emploi”, Document de travail DULBEA, No. 08-21.RS, Université Libre de Bruxelles.

Meilland, C. (2001), “Danemark - L'égalité hommes-femmes sur le marché du travail mis à mal par les congés parentaux", Chronique Internationale de l'IRES, No. 71, pp. 1-8.

Meurs, D. and S. Ponthieux (2000), "Une mesure de la discrimination dans l'écart de salaire entre hommes et femmes", Économie et statistique, No. 337-338.

Mincer, J. (1974), Schooling, Experience and Earnings, Columbia University, New York.

Mincer, J. and S. Polachek (1978), “Women's Earnings Reexamined”, Journal of Human Resources, Vol. 13, No. 1, pp. 118-134.

Mincer, J. and S. Polachek, (1974), "Family Investment in Human Capital: Earnings of Women", Journal of Political Economy, Vol. 82, No. 2, pp. S76-S108.

Nickell, S. (1979), “Education and Lifetime Patterns of Unemployment”, Journal of Political Economy, Vol. 87, No. 5, pp. 117-131.

Nishimura, K. and J. Zhang (1995), "Sustainable Plans of Social Security with Endogenous Fertility”, Oxford Economic Papers, Vol. 47, pp. 182-194.

Nishimura, K. and J. Zhang (1992), "Pay-As-You-Go Public Pensions with Endogenous Fertility”, Journal of Public Economics, Vol. 48, pp. 239-258.

OECD (2015a), Ageing and Employment Policies: Poland 2015, OECD Publishing, Paris, http://dx.doi.org/10.1787/ 9789264227279-en.

OECD (2015b), OECD Economic Outlook, Vol. 2015, No. 1, http://dx.doi.org/10.1787/eco_outlook-v2015-1-en.

OECD (2015c), OECD Employment Outlook 2015, OECD Publishing, Paris, http://dx.doi.org/10.1787/empl_outlook-2015-en. 
OECD (2015d), Health at a Glance 2015: OECD Indicators, OECD Publishing, Paris, http://dx.doi.org/10.1787/health_glance2015-en.

OECD (2014a), Education at a Glance 2014: OECD Indicators, OECD Publishing, Paris, http://dx.doi.org/10.1787/eag-2014-en.

OECD (2014b), Ageing and Employment Policies: Netherlands 2014: Working Better with Age, OECD Publishing, Paris, http://dx.doi.org/10.1787/9789264208155-en.

OECD (2014c), Ageing and Employment Policies: France 2014: Working Better with Age, OECD Publishing, Paris, http:// dx.doi.org/10.1787/9789264207523-en.

OECD (2014d), Vieillissement et politiques de l'emploi : Suisse 2014 : Mieux travailler avec l'âge, OECD Publishing, Paris, http://dx.doi.org/10.1787/9789264222823-fr.

OECD (2014e), OECD Employment Outlook 2014, OECD Publishing, Paris, http://dx.doi.org/10.1787/empl_outlook-2014-en.

OECD (2014f), OECD Pensions Outlook 2014, OECD Publishing, Paris, http://dx.doi.org/10.1787/9789264222687-en.

OECD (2013), Ageing and Employment Policies: Norway 2013: Working Better with Age, OECD Publishing, Paris, http:// dx.doi.org/10.1787/9789264201484-en.

OECD (2007), Babies and Bosses - Reconciling Work and Family Life: A Synthesis of Findings for OECD Countries, OECD Publishing, Paris, http://dx.doi.org/10.1787/9789264032477-en.

OECD Employment and Labour Market Statistics, www.oecd-ilibrary.org/employment/data/oecd-employment-and-labourmarket-statistics_lfs-data-en.

Phipps, S., P. Burton and L. Lethbridge (2001), "In and Out of Labour Market: Long-term Income Consequences of Child-Related Interruptions to Women's Paid Work", Canadian Journal of Economics, Vol. 34, No. 2, pp. $411-429$.

Polachek, S.W. (2007), "Earnings Over the Lifecycle: The Mincer Earnings Function and Its Applications", IZA Discussion Paper, No. 3181, Bonn.

Potrafke, N. (2011), "Unemployment, Human Capital Depreciation and Pension Benefits: An Empirical Evaluation of German Data", Working Paper Series, No. 2011-05, University of Konstanz.

Riddell, W.C. and X. Song (2011), "Education, Job Search and Re-employment Outcomes among the Unemployed", IZA Discussion Papers, No. 6134, Bonn.

Velfærdskommissionen (2006), “Fremtidens velfærd - vores valg”, Report from the Danish Welfare Commission, www.fm.dk/404?item=\%2fr\%2fmedia\%2fpublikationer\%2fimported\%2fuelfaerdskommissionen\%2f2006\%2ffremtidensvelfaerd-vores-vdg-analyserapport-januar-2006\&user=extranet\%5cAnonymous\&site=fmdk. 


\section{Main rules of pension credits related to childcare and unemployment}

\section{Table 3.A1.1. Main rules of pension credits related to childcare}

\begin{tabular}{|c|c|c|c|}
\hline & Length covered & Pensionable earnings & Extra bonus/allowances \\
\hline Australia & Covered only in the first-tier. & & \\
\hline Austria & $\begin{array}{l}\text { Four years with a max. of five years for multiple births. } \\
\text { If the birth of the } 2 \text { nd child occurs within this time, a new } \\
\text { period of } 4 \text { or } 5 \text { years starts. }\end{array}$ & $\begin{array}{l}\text { Pensionable earnings (PE) are a flat rate amount: } \\
\text { EUR } 1649.84 \text { in } 2014 .\end{array}$ & \\
\hline Belgium & 36 months max. over the career. & PE are the earnings prior to the break. & \\
\hline Canada & $\begin{array}{l}\text { Up to seven years per child are excluded } \\
\text { from the averaging period. }\end{array}$ & $\begin{array}{l}\text { The leave period is excluded from the average period used } \\
\text { to determine pensionable earnings, assuming it is } \\
\text { advantageous to do so. }\end{array}$ & \\
\hline Chile & 24 weeks of parental leave count as insured periods. & $\begin{array}{l}\text { The basis for the } 10 \% \text { contributions (i.e. the PE) is } \\
\text { the average salary three months before the break. }\end{array}$ & $\begin{array}{l}\text { Each woman who has had a child born alive } \\
\text { receives a voucher at age } 65 \text { which is } \\
\text { equivalent to } 10 \% \text { of } 18 \text { months min. wages } \\
\text { at the time of birth+ the average net rate } \\
\text { of returns on the balance of the } D C \text { account } \\
\text { form birth until retirement. }\end{array}$ \\
\hline Czech Republic & $\begin{array}{l}\text { Four years count as insurance period, not increased } \\
\text { for higher number of children. }\end{array}$ & $\begin{array}{l}\text { The leave period is excluded from the average period used } \\
\text { to determine pensionable earnings. }\end{array}$ & \\
\hline Denmark & $\begin{array}{l}\text { In the occupational ATP pension: beyond the maternity/ } \\
\text { paternity leave, the parental leave of } 32 \text { weeks is } \\
\text { considered as insured period. }\end{array}$ & $\begin{array}{l}\text { Two times the rate of the ATP contributions are paid: } \\
\text { one-third by the beneficiary and two-thirds } \\
\text { by the government/municipality. }\end{array}$ & \\
\hline Estonia & Three years. & $\begin{array}{l}\text { State pays employer contributions on } 20 \% \text { of min. wage } \\
\text { (EUR } 355 \text { in 2014) in the first-tier pension scheme. Paid } \\
\text { contributions for the DC scheme are } 4 \% \text { of the national } \\
\text { average wage (EUR } 921 \text { in 2014). }\end{array}$ & \\
\hline Finland & $\begin{array}{l}\text { Parental leave of } 260 \text { day } / 6 \text { days per week } \\
\text { (i.e. } 10-11 \text { months); after this period up to the three years } \\
\text { of the child. }\end{array}$ & $\begin{array}{l}\text { During the first } 3 \text { months (this period may vary according } \\
\text { to agreements between partners) of leave during which } \\
\text { the carer receives the salary, pensionable earnings is } \\
\text { [(pay } \times 0.17)+ \text { wage]. For the periods exceeding the first } \\
3 \text { months up to the end of the paid parental leave, } \\
\text { the pensionable earning is [earnings prior to birth, i.e. the } \\
\text { salary on which the maternity benefit is based, } \times 1.17] \text {. } \\
\text { Both these amounts accrue to } 1.5 \% \text { for pensions. Beyond } \\
\text { these periods, if a parent takes care of children } \\
\text { the pensionable earnings are computed on a flat rate } \\
\text { amount of EUR } 706.87 / \text { month in } 2014 \text {. Contributions are } \\
\text { paid by the state during this period. }\end{array}$ & \\
\hline
\end{tabular}




\section{Table 3.A1.1. Main rules of pension credits related to childcare (cont.)}

\begin{tabular}{|c|c|c|c|}
\hline & Length covered & Pensionable earnings & Extra bonus/allowances \\
\hline France & $\begin{array}{l}\text { For each child: four quarters to the mothers for maternity; } \\
\text { four quarters for education to the mother or the father } \\
\text { (MDA). An alternative leave, which cannot be cumulated } \\
\text { with the previous, is the increase in the insurance period } \\
\text { for parental leave up to a maximum of three years } \\
\text { of the child (MDA parental leave). These periods increase } \\
\text { the insurance periods. Moreover, people on low earnings, } \\
\text { that have a limited professional activity and receive family } \\
\text { benefits, receive the pension for parents at home (AVPF). } \\
\text { The length covered in the case of two children aged } 2 \\
\text { and } 4 \text { is five years at most (three years per children up } \\
\text { to the third birth of the youngest child). The MDA } \\
\text { and the AVPF increase the insurance period only } \\
\text { in the general insurance scheme. }\end{array}$ & $\begin{array}{l}\text { The pensionable earnings for the credits which increase } \\
\text { the insurance periods (MDA) is the average earnings } \\
\text { of the best } 25 \text { years determined thus on retirement. } \\
\text { For the AVPF is the minimum wage on which } \\
20 \% \text { of contributions are paid. }\end{array}$ & $\begin{array}{l}\text { Parents of three or more children receive } \\
\text { a bonus of } 10 \% \text { in each pension regime. }\end{array}$ \\
\hline Germany & $\begin{array}{l}\text { 1) Parents of children born after } 1992 \text { receive one point } \\
\text { for one child aged below } 4.2 \text { ) Parents that continue } \\
\text { working up the age of } 10 \text { of the child. 3) Parents that have } \\
\text { at least two children below } 10 \text { irrespective of their labour } \\
\text { market status. }\end{array}$ & $\begin{array}{l}\text { 1) Receive one pension point each year based on average } \\
\text { earnings. 2) Receive in addition of the normal point } \\
\text { amount based on their salary, a } 0.33 \text { additional point based } \\
\text { on average earnings but the total accrual cannot exceed } \\
1 \text { point. 3) Receive a } 0.33 \text { per year. In "2" and " } 3 \text { " } \\
\text { the } 0.33 \text { point is based on average wage. }\end{array}$ & \\
\hline Greece & $\begin{array}{l}\text { 1st child: } 1 \text { year } / 300 \text { day; } 2 \text { nd child: two years; with a max. } \\
\text { of five years for children. This duration increase the } \\
\text { insurance period. }\end{array}$ & Average lifetime earnings. & \\
\hline Hungary & $\begin{array}{l}\text { After pregnancy confinement benefit, carers can benefit of: } \\
\text { 1) Childcare fee period for a max. of } 84 \text { weeks provided } \\
\text { as long as the insurance period of the parents lasts, } \\
\text { up to the age of two years of the child. In case of twins the } \\
\text { eligibility period is extended by one year. 2) Child home } \\
\text { care allowance for a max. of three years of the child (aged } \\
\text { under } 10 \text { for children with disabilities). In case of twins the } \\
\text { allowance is paid until the children reach the compulsory } \\
\text { schooling age. 3) Child raising support between the age } \\
\text { of } 3 \text { and } 8 \text { of the child in case of a family raising at least } \\
\text { three children, until the youngest child reaches the age } \\
\text { of } 8 \text { years. }\end{array}$ & $\begin{array}{l}\text { 1) During "childcare fee" periods pensionable earnings } \\
\text { amount at } 70 \% \text { of the previous daily gross average } \\
\text { earnings (HUF } 142000 \text { in 2014). 2) During child home } \\
\text { care allowance, PE is HUF } 28500 \text {. 3) When receiving } \\
\text { the child raising support, the PE is the minimum old-age } \\
\text { pensions. } \\
\text { The admitted childcare periods (points " } 2 \text { " and " } 3 \text { ") } \\
\text { are credited as a lifetime PE, if it is favourable } \\
\text { for the beneficiary; Hungary factors admitted childcare } \\
\text { periods into assessment of eligibility and service years, } \\
\text { but disregards them when computing the earnings base. }\end{array}$ & $\begin{array}{l}\text { The beneficiary has to pay mandatory } \\
\text { contribution of } 10 \% \text { on the benefit she } \\
\text { receives. }\end{array}$ \\
\hline Iceland & Covered only in the first-tier. & & \\
\hline Ireland & $\begin{array}{l}\text { Caring for children under } 12 \text { years of age, within } \\
\text { a maximum of } 20 \text { years are disregarded (Homemaker } \\
\text { scheme). }\end{array}$ & $\begin{array}{l}\text { For the State Pension (contributory), the homemaker } \\
\text { scheme allows to disregard these period from the yearly } \\
\text { average contributions ( } 48 \text { weeks a year). }\end{array}$ & \\
\hline Israel & Covered only in the first-tier. & & \\
\hline Italy & $\begin{array}{l}\text { The different transformation coefficient implies that } \\
\text { one year is credited for one or two children and two years } \\
\text { for three more children. }\end{array}$ & $\begin{array}{l}\text { Mothers receive a more generous transformation } \\
\text { coefficient: up to two children it is equivalent } \\
\text { to the coefficient to the effective age of retirement }+1 \text {, } \\
\text { while for three and more children it is the transformation } \\
\text { coefficient applied to the effective age }+2 \text { years. }\end{array}$ & \\
\hline Japan & Three years per child, until the youngest child is three. & $\begin{array}{l}\text { The pensionable earnings are the earnings prior } \\
\text { to the break. For periods beyond three years per child } \\
\text { and when income are below certain thresholds the same } \\
\text { rule as for unemployment (see Table 3.A1.2) are applied. }\end{array}$ & \\
\hline Korea & $\begin{array}{l}\text { Parental leave granted for periods between } 12 \text { and } \\
50 \text { months ( } 50 \text { months max. with } 2 \text { children). }\end{array}$ & Only if voluntary contributions are paid. & \\
\hline Luxembourg & $\begin{array}{l}\text { 1) Six months of parental leave full-time or } 12 \text { month } \\
\text { part-time. 2) Baby years: two years credited for each child } \\
\text { below } 4 \text {, with a max. of four years. } 3 \text { ) Non-contributory } \\
\text { periods caring for child below age } 8 \text {. }\end{array}$ & $\begin{array}{l}\text { 1) Pensionable earnings is EUR } 1778.2 \text { ) During the BY } \\
\text { the } P E \text { is the earnings prior to the break. } 3 \text { ) No PE. }\end{array}$ & $\begin{array}{l}\text { A monthly allowance is paid to carers } \\
\text { who do not qualify for the BY. It amounted } \\
\text { to EUR } 109 \text { per child in } 2014 \text {. }\end{array}$ \\
\hline Mexico & Covered only in the first-tier. & & \\
\hline Netherlands & Covered only in the first-tier. & & \\
\hline New Zealand & Covered only in the first-tier. & & \\
\hline Norway & Up to six years of age. & Pensionable earnings is 4.5 times the base amount. & \\
\hline Poland & $\begin{array}{l}\text { 1) } 26 \text { weeks (urlop rodzicielski). 2) Max. of three years } \\
\text { per child. }\end{array}$ & $\begin{array}{l}\text { 1) } 80 \% \text { of the average wage during the first year. } \\
\text { 2) } 75 \% \text { to } 60 \% \text { of average wage depending on the length } \\
\text { of the break. }\end{array}$ & \\
\hline
\end{tabular}


Table 3.A1.1. Main rules of pension credits related to childcare (cont.)

\begin{tabular}{|c|c|c|c|}
\hline & Length covered & Pensionable earnings & Extra bonus/allowances \\
\hline Portugal & $\begin{array}{l}\text { Covered in the first-tier/part-time workers for childcare } \\
\text { covered. }\end{array}$ & & Part-time considered as full-time. \\
\hline Slovak Republic & Six years. & $\begin{array}{l}60 \% \text { of the average wage two years before the break. } \\
\text { State pays contributions. }\end{array}$ & \\
\hline Slovenia & Only cover people working part-time to raise a child. & & \\
\hline Spain & Three years. & Average salary during the six months preceding the break. & Part-time considered as full-time. \\
\hline Sweden & A. Child below 5 years. B. Parental benefit 480 days. & $\begin{array}{l}\text { A. In this case three alternatives exist: } 1 \text { ) If } 0<\text { income } \\
\text { during childcare < previous earnings, PE is the earnings } \\
\text { before; 2) People who were not working prior to childbirth } \\
\text { or had very low income: PE is } 75 \% \text { of average wage; } \\
\text { 3) Income does not change relative to before } \\
\text { the interruption: PE is } 1 \mathrm{BA} \text {. B. } 80 \% \text { of previous earnings } \\
\text { up to } 10 \mathrm{BA} \text {; the last } 90 \text { days at SEK } 180 / \text { day. } \\
\text { Total contributions are paid for both the NDC and the } \\
\text { premium pension by the State. For ITP employers } \\
\text { contribute generally for the first } 13 \text { months. }\end{array}$ & \\
\hline Switzerland & $\begin{array}{l}\text { Up to } 16 \text { years of age of the child; nothing } \\
\text { in the occupational. }\end{array}$ & $\begin{array}{l}\text { PE is three times the minimum pension of the year } \\
\text { when the caring parent retires. }\end{array}$ & \\
\hline Turkey & Max. two years. & the beneficiary should pay contributions. & \\
\hline United Kingdom & Until the child is 12 . & $\begin{array}{l}\text { PE is the child benefit which counts towards the basic } \\
\text { SP and the S2P. }\end{array}$ & \\
\hline United States & Offset by pension rules if the career is 35 years. & & \\
\hline
\end{tabular}

Note: $\mathrm{PE}=$ Pensionable earnings; $\mathrm{BY}=$ Baby years; $\mathrm{BA}=$ Base amount.

Source: Compiled with information received by national country delegates and contained in the "Country profiles" in Chapter 11 of this volume. 


\section{Table 3.A1.2. Main rules of pension credits related to unemployment}

\begin{tabular}{|c|c|c|}
\hline & Length covered & Pensionable earnings \\
\hline Australia & Only with first-tier pension components; ER: Not available. & Only if voluntary contributions. \\
\hline Austria & $\begin{array}{l}\text { Any eligible person qualifies (at least) for } 20 \text { weeks of unemployment benefit } \\
\text { and after that period for } 54 \text { weeks of unemployment assistance (re-application } \\
\text { possible - therefore practically for an unlimited time). }\end{array}$ & $\begin{array}{l}\text { For all insured born after } 1954 \text {, the assessment base for pension is } 70 \% \\
\text { (respectively } 92 \% \text { of } 70 \% \text { in case of unemployment assistance) of the daily } \\
\text { entitlement to unemployment benefit. }\end{array}$ \\
\hline Belgium & The entire period of (involuntary) unemployment. & $\begin{array}{l}\text { The pensionable earnings are the benefits paid over unemployment. Rules differ } \\
\text { according to the age of the unemployed person. In general for people less } \\
\text { than } 59 \text {, there are three distinct phases over which unemployment benefits } \\
\text { decline passing from a \% of lost earnings (within a celing) to flat rate amount } \\
\text { per day. }\end{array}$ \\
\hline Canada & $\begin{array}{l}\text { Up to } 17 \% \text { of the contributory period may be excluded when calculating average } \\
\text { earnings in the earnings-related scheme for a variety a reasons, } \\
\text { such as unemployment, to determine pension benefit. }\end{array}$ & \\
\hline Chile & Not available. & Only if voluntary contributions. \\
\hline Czech Republic & $\begin{array}{l}\text { The duration of unemployment insurance entitlement varies with age: five months } \\
\text { up to age } 50 \text {, eight months from } 50 \text { to } 55 \text { and } 11 \text { months for over } 55 \mathrm{~s} \text {. } \\
\text { Unemployment period without benefits for a max. of one year before the age of } 55 \\
\text { is also credited. As a general rule only } 80 \% \text { of the total unemployment duration } \\
\text { over the career is considered. For example only four years will be counted } \\
\text { for pensions in case of five-year unemployment duration over the career. }\end{array}$ & $\begin{array}{l}\text { This period is excluded from the average period to determine pensionable } \\
\text { earnings. }\end{array}$ \\
\hline Denmark & $\begin{array}{l}\text { In the occupational ATP pension: the duration covered by unemployment } \\
\text { insurance or unemployment assistance. }\end{array}$ & $\begin{array}{l}\text { During unemployment insurance: two times the rate of the ATP contributions are } \\
\text { paid by government/municipality; during the: unemployment assistance period } \\
1 / 3 \text { by the beneficiary and } 2 / 3 \text { by the government/municipality. }\end{array}$ \\
\hline Estonia & Only first tier; ER: Not available. & \\
\hline Finland & $\begin{array}{l}\text { Periods of unemployment during which benefits are paid before the age of } 63 \\
\text { (insurance benefits are paid for } 500 \text { days ca } 23 \text { months, with average } 21.5 \text { days } \\
\text { per month). If an unemployed person reaches age } 59 \text { before the } 500 \text { days have } \\
\text { accrued (age } 60 \text { for persons born in } 1955 \text { or after), earnings-related } \\
\text { unemployment can be paid until age } 65 \text {. Individuals receiving allowance } \\
\text { after } 500 \text { days are entitled to choose claiming old-age pension from age } 63 \text {. } \\
\text { After the period with earnings-related unemployment benefits, flat rate } \\
\text { or income-tested (under various conditions) unemployment assistance could be } \\
\text { claimed but the period under these benefits are not credited for the pension } \\
\text { entitlement. }\end{array}$ & $\begin{array}{l}\text { Pensionable earnings are } 75 \% \text { of the earnings on which the unemployment } \\
\text { benefit is based. }\end{array}$ \\
\hline France & $\begin{array}{l}\text { Each completed } 50 \text { days attributes one quarter of contributions for pensions, } \\
\text { with a maximum of four quarters per year and two years in total. These periods } \\
\text { do not enter into the calculation of the average reference wage based } \\
\text { on the } 25 \text { best years of earnings and therefore not into the pension calculation. } \\
\text { In addition people benefit of four quarters for unemployment which is not } \\
\text { insured. }\end{array}$ & $\begin{array}{l}\text { For periods covered by unemployment benefit: the PE is a "daily reference wage" } \\
\text { which is the last wage (on a year basis). Pension points accrue on the basis of this } \\
\text { wage also in the occupational pension scheme. }\end{array}$ \\
\hline Germany & 1) Arbeitlosengeld I: 6-24 months. 2) Arbeitlosengeld II. & $\begin{array}{l}\text { 1) Unemployment benefits amounting to } 80 \% \text { of previous gross earnings } \\
\text { (contibutions are paid by the scheme). 2) Means-tested benefit (no contributions } \\
\text { paid for pensions). }\end{array}$ \\
\hline Greece & Not $>300$ days. & Unemployment benefit. \\
\hline Hungary & $\begin{array}{l}\text { Max. } 90 \text { days of Jobseeker benefits (one day is paid for every ten days of previous } \\
\text { insurance). }\end{array}$ & $\begin{array}{l}\text { Pension contributions are paid by the benefit recipient. The PE is } \\
\text { the unemployment benefits or the earnings when they are more favourable. }\end{array}$ \\
\hline Iceland & Periods of unemployment insurance. & $P E$ is the unemployment benefit, contributions are paid by the scheme. \\
\hline Ireland & Not available. & \\
\hline Israel & Not available. & ER: only if voluntary contributions. \\
\hline Italy & $\begin{array}{l}\text { 1) Restructuration following business distress: } 12-24 \text { months. 2) Involuntary } \\
\text { unemployment: } 8 \text { months if age }<50 ; 12 \text { months if age between } 50 \text { and } 55 \text {; } \\
14 \text { months if age }>55 \text {. }\end{array}$ & $\begin{array}{l}\text { 1) PE is equivalent to } 80 \% \text { of the last salary, but there are ceilings. In } 2014 \\
\text { the maximum net benefit was of EUR } 913.14 \text { per month for workers } \\
\text { with a working salary up EUR } 25176.48 \text { per year and of EUR } 1097.51 \text { for higher } \\
\text { earners. 2) A. if the average salary below EUR } 1192.98 \text {, the PE is } \\
75 \% \text { of the monthly average salary in the last two years before the dismissal; } \\
\text { B. } 75 \% \text { of EUR } 1192.98 \text { in } 2014 \text { and } 25 \% \text { of the difference between the monthly } \\
\text { average salary and the threshold of EUR } 1165.58 \text {. The allowance declines } \\
\text { by } 15 \% \text { after six months and by a further } 15 \% \text { after } 12 \text { months. }\end{array}$ \\
\hline Japan & & $\begin{array}{l}\text { Contribution schedule varies according to earnings: } \\
<\text { JPY } 570000 \text { are exempted from contributions but entitled to half of basic } \\
\text { pension; < JPY } 780000 \text { pay one-fourth of contributions and are entitled } \\
\text { to five-eights of basic pensions; < JPY } 1180000 \text { pay half of contributions } \\
\text { and are entitled to three-quarters of basic pension; < JPY } 1580000 \text { pay } \\
\text { three-quarters of contributions and are entitled to seven-eights of basic pension. }\end{array}$ \\
\hline
\end{tabular}


Table 3.A1.2. Main rules of pension credits related to unemployment (cont.)

\begin{tabular}{|c|c|c|}
\hline & Length covered & Pensionable earnings \\
\hline Korea & First-tier pension; ER: Not available. & Only voluntary contributions. \\
\hline Luxembourg & $\begin{array}{l}\text { Insured periods of unemployment count are considered as periods of } \\
\text { employment for pension }\end{array}$ & $\begin{array}{l}\text { Unemployment benefit is the PE. Contributions are paid for } 1 / 3 \text { by the beneficiary } \\
\text { and } 2 / 3 \text { by the State. }\end{array}$ \\
\hline Mexico & covered only in the first-tier & Only if voluntary contribution. \\
\hline Netherlands & covered only in the first-tier & Only if voluntary contribution. \\
\hline New Zealand & covered only in the first-tier & \\
\hline Norway & $\begin{array}{l}\text { Insured periods of unemployment are considered as periods of employment } \\
\text { for pension. }\end{array}$ & Pensionable earnings: $7.1 \mathrm{BA}$. \\
\hline Poland & $\begin{array}{l}\text { Periods in receipt of UB (vary according to local labour market conditions } \\
\text { and previous duration of unemployment and family status). }\end{array}$ & $\begin{array}{l}\text { The PE is the unemployment benefit on which the government pays the } \\
\text { contributions. }\end{array}$ \\
\hline Portugal & Periods in receipt of UB. & $\begin{array}{l}\mathrm{PE} \text { is the pay in the six months before the second month of the start of the } \\
\text { unemployment period. }\end{array}$ \\
\hline Slovak Republic & Not available. & Only if unemployed pays voluntary contributions. \\
\hline Slovenia & $\begin{array}{l}\text { Periods in receipt of UB (duration depending on age and previous working } \\
\text { history). }\end{array}$ & $P E$ is the UB and contributions are paid by the State. \\
\hline Spain & $\begin{array}{l}\text { Periods in receipt of UB; unemployment assistance only count for people aged } 55 \\
\text { and over. }\end{array}$ & $\begin{array}{l}\text { PE is average salary during the } 6 \text { months preceding the break. Individual need to } \\
\text { pays the contributions. }\end{array}$ \\
\hline Sweden & Periods in receipt of unemployment insurance or assistance. & $\begin{array}{l}\text { The State pays the employer contribution. PE is as follows: 1) First } 200 \text { days it is } \\
80 \% \text { of previous earnings. 2) Between } 201 \text { and } 300 \text { days it is } 70 \% \text { of previous } \\
\text { earnings (with children this period is extended by } 150 \text { days). The benefit } \\
\text { considered PE varies between SEK } 320 \text { and SEK } 680 \text {. }\end{array}$ \\
\hline Switzerland & For the public pension: $90-640$ days; for the occupational pension: not available. & $\begin{array}{l}\text { The unemployment scheme pays } 80 \% \text { of the previous earnings which is then the } \\
\text { PE. For people on very low income the minimum contribution is paid often by the } \\
\text { municipality. In the other case individuals pays the contribution into the public } \\
\text { scheme. }\end{array}$ \\
\hline Turkey & ER: Not available. & Contributions are mandatory but do not count for pensions. \\
\hline United Kingdom & $\begin{array}{l}\text { Periods of unemployment on insurance or assistance benefits are considered as } \\
\text { employment only for the basic state pension. }\end{array}$ & $\begin{array}{l}\text { National insurance contributions are paid on the benefit received who are credited } \\
\text { for pensions. }\end{array}$ \\
\hline United States & Offset by pension rules if the career is 35 years. & \\
\hline
\end{tabular}

Note: $\mathrm{BA}=$ Base amount; $\mathrm{ER}$ = Earnings-related pension scheme; $\mathrm{PE}$ = Pensionable earnings.

Source: Compiled with information received by national country delegates and contained in the "Country profiles" in Chapter 11 of this report. 


\section{Chapter 4}

\section{Sensitivity of replacement rates to the model parameters}

This chapter examines how changes made to each economic parameter affect the theoretical replacement rate estimations. The analysis also compares the new baseline economic assumptions to those used in previous editions of the publication before finally contrasting these new results with country-specific assumptions based on the level of economic development.

The statistical data for Israel are supplied by and under the responsibility of the relevant Israeli authorities. The use of such data by the OECD is without prejudice to the status of the Golan Heights, East Jerusalem and Israeli settlements in the West Bank under the terms of international law. 


\subsection{Introduction}

The underlying economic assumptions behind any pension model are critical for calculating future replacement rates. Full descriptions of the economic parameters used in this publication are provided in Chapter 5. Beyond demographics, they mostly pertain to discount rates, rates of return on pension assets, price inflation and real-wage and real-GDP growth.

This chapter is organised as follows. After a run-down of key findings, it examines the impact of the change in economic parameters between Pensions at a Glance 2013 and this current edition in Section 4.2. Sections 4.3 to 4.6 then analyse the impact of changing each of the parameters in turn, i.e. inflation, real wage and real GDP growth, the rate of return and the discount rate. Section 4.7 focuses on life expectancy and presents two alternative estimates of mortality rates, while finally Section 4.8 provides projections based on country specific economic parameters in contrast to the OECD wide parameters used with the OECD Pensions at a Glance series.

There are obvious limitations in analysing the impact of each parameter taken separately. For example, long-term trends in wage growth and in financial rates of return are often interrelated in practice. If higher real wages result from better economic prospects over time, the marginal productivity of capital and therefore equilibrium rates of return are likely to be higher also. Also, economic developments that diminish risk-free interest rates over the long term are also likely to drive down financial returns. These analyses should therefore be viewed as measuring the impact of relative changes between variables.

\section{Key findings}

- The new economic assumptions used in the 2015 edition of Pensions at a Glance have a small average impact. Replacement rates increase by 1.5 percentage points for the full-career averagewage worker on average across the OECD countries. Sixteen countries show an increase, nine countries a decline and the remaining nine have unchanged replacement rates. The change ranges from a decline of 3.4 percentage points in Chile to a rise of 8 percentage points in Belgium.

- The replacement rates in defined-contribution schemes are generally more sensitive to the change in the values of the economic parameters in comparison to either defined-benefit or flat-rate schemes.

- Changing the rate of return has the greatest impact on the replacement rate, with an increase slightly over 7 percentage points on average for the nine countries affected. The largest variations are found in Israel, increasing by 15 percentage points, and in Chile and Denmark, both by 10 percentage points. These three countries have amongst the highest rates of contribution to defined contribution (DC) schemes, which also implies that the DC component represents a large proportion of the overall pension.

- As with rates of return changes in the discount rate only affects the replacement rate in the same nine countries, with an average impact of 3 percentage points across those countries for a change of 1 percentage point in the real discount rate. Israel has the highest sensitivity (6 percentage points) as the country has the largest defined-contribution scheme; in contrast, the sensitivity is less than 1 percentage point in Norway, where the defined contribution component is a small part of the total pension (the DC contribution rate is only $2 \%$ against $17.5 \%$ in Israel). 
- The majority of countries are affected by changes in the real-wage growth assumption. Exceptions include countries that index all their parameter values (including flat-rate benefits) to real wage growth, as then everything increases in proportion resulting in a constant replacement rate. Variations in real-wage growth assumptions affect the replacement rate in five OECD countries beyond their direct impact, through their impact on real GDP growth in the OECD pension model.

- Lowering the annual rate of real-wage growth from $1.25 \%$ in the baseline to $0.5 \%$ increases replacement rates by 4 percentage points on average across the OECD, whilst increasing wage growth to $2 \%$ lowers the average by 3 percentage points. The largest variation is found in Israel and Australia as increases/decreases in wage growth affect the denominator (wages) more than asset accumulation (numerator), but in Australia the losses are mostly covered by the first-tier component (Age Pension). For those countries without defined-contribution schemes Turkey has the largest variation, of around 9 percentage points, in part due to a high replacement rate in the baseline to start with.

- Changes in price inflation trends only affect three countries and the impact on the replacement rates is minimal.

- Moving from the baseline common assumptions across countries to country-specific assumptions based on the level of economic development (measured by GDP per capita in PPP terms) brings limited differences in replacement rates. The majority of countries would have replacement rates within 2 percentage points of the baseline value, with only seven countries having greater changes in absolute terms.

\subsection{Impact of parameter changes since Pensions at $a$ Glance 2013}

All results in previous editions of Pensions at a Glance were based on a consistent set of economic parameters across the series. However, major economic developments affecting all OECD countries over the last decade have called for a revision of the value of some key parameters. Long-term trends suggest lower future rates of real-wage growth, price inflation and financial return (Table 4.1). Moreover, the previous Pensions at a Glance editions were assuming that annuity providers were paying annuities from accumulated assets based on an actuarial formula that assumed away any fee and any reward from taking mortality risks in particular. In contrast, there is evidence that annuity amounts fall short of the actuarial no-fee computation (see e.g. Brown et al., 1999 and St. John, 2004 which suggest a wedge of 10 to $30 \%$ ). The 2015 Pensions at a Glance assumption includes a conversion factor of $85 \%$ between annuities that are effectively paid and those that would result from a no-fee calculation.

Table 4.1. Economic parameters used in Pensions at a Glance (PAG) 2013 and 2015

\begin{tabular}{lcc}
\hline & PAG 2013 (\%) & PAG 2015 (\%) \\
\hline Price inflation & 2.50 & 2.00 \\
Real wage growth & 2.00 & 1.25 \\
Real discount rate & 2.00 & 2.00 \\
Real rate of return & 3.50 & 3.00 \\
Annuity conversion factor & 100.00 & 85.00 \\
\hline
\end{tabular}

Note: For Pensions at a Glance 2015, GDP growth is $0.75 \%$ in Italy and Poland and $1.55 \%$ in Turkey.

Source: OECD (2013), Pensions at a Glance 2013: OECD and G20 Indicators, OECD Publishing, Paris, http://dx.doi.org/10.1787/ pension_glance-2013-en; Chapter 5 of this publication.

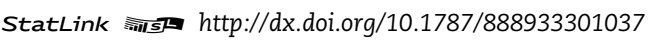

The full results for future gross replacement rates across various earnings levels under the new economic assumptions are shown in Chapter 6, Table 6.1, later in this publication. Figure 4.1 compares those baseline projections with those estimated based on the 2013 Pensions at a Glance economic assumptions summarised in Table 4.1. 


\section{Figure 4.1. Future gross replacement results for male average earners under the new and old economic assumptions}

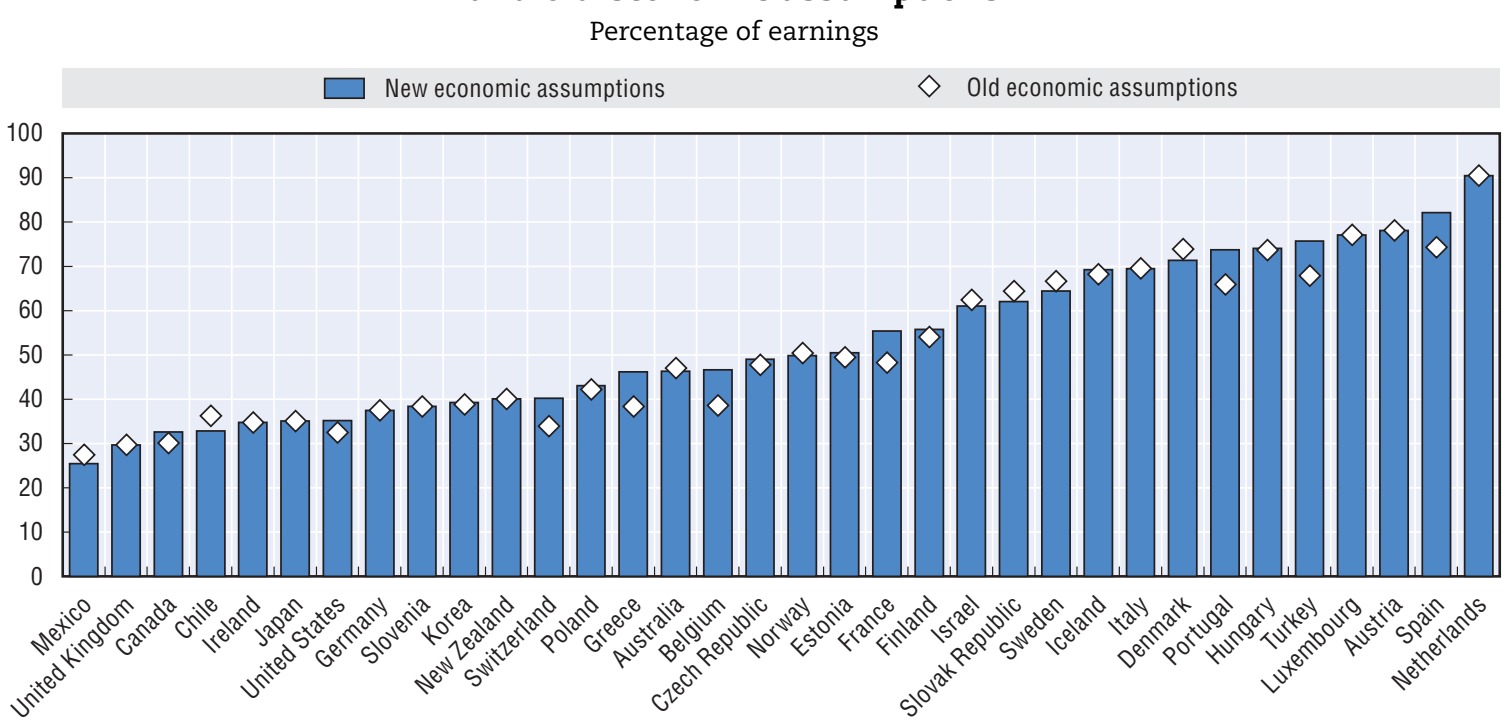

Source: Author calculations using OECD pension model.

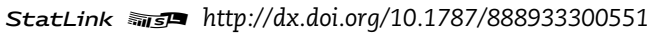

From Figure 4.1 it is clear that although a few countries have seen a decrease in projected replacement rates following the economic parameter changes more have actually had an increase. How much of this can be attributed directly to the change in each specific economic parameter will now be covered in the following sections.

\subsection{How changes in inflation affect replacement rate results}

The analysis begins by varying the price inflation parameter whilst keeping all the other parameters constant. Only three OECD countries, Hungary, Spain and the United States, show any variation in their future replacement rates when either increasing or decreasing annual price inflation by 1 percentage point. ${ }^{*}$ In these three countries, the variation is due to the same factor: previous earnings immediately prior to retirement used to compute the reference wage are held constant in nominal terms whatever the inflation rate. In the United States previous earnings are revalued up to the year in which the recipient reaches age 60 in line with growth in economy-wide average earnings. There is no adjustment of earnings for the two subsequent years until the benefit amount is calculated (at age 62). Similarly in Spain, the valorisation of previous earnings ceases two years prior to retirement age. The effect in both cases is to lower the replacement rate by 2-3 percentage points with each additional 1 percentage point increase in price inflation. This amounts to a fall in pension entitlements of $6 \%$ in the United States and only $2 \%$ in Spain as the replacement rate is more than double in the latter. In Hungary the non-valorisation of earnings only affects the final year and so the decline in replacement rate is only around 1 percentage point when moving from price inflation of $1 \%$ to $2 \%$.

\subsection{How changes in real wage affect replacement rate results}

Higher wage growth assumptions increase the future pension amount. However, they generally lower the replacement rates as pension entitlements do not rise faster than wages (which is the

* Earnings immediately prior to retirement are also price indexed for one year in Austria. However, the pension calculation uses the best 40 years valorised with earnings, and under the assumption of a constant earnings profile the price indexation for the final year has no effect on the calculation. 
denominator of the replacement rate) in both defined-benefit and defined-contribution schemes. For example, in countries such as Austria, Hungary and the Netherlands, the modelled mandatory pension is an earnings-related defined-benefit scheme. In all three countries, pension benefits are calculated based on an exogenous annual accrual rate, $x$, where the benefit amounts to N.x.w where $\mathrm{N}$ is the number of contributed years and $w$ the reference wage. The replacement rate is therefore simply given by N.x, which does not depend on the evolution of past wages.

In Ireland, New Zealand and the United Kingdom there is a basic flat rate benefit based on either residence or contribution history, but in all cases the benefit is increased by the growth of earnings, thereby not affecting the future replacement rate. In fact, in the United Kingdom, there is a triple lock increase to pensions (the maximum of price inflation, nominal wage growth and $2.5 \%$ ) which amounts to wage growth according to the long-term assumptions in the OECD pension model, implying an unchanged replacement rate provided that nominal wage growth is assumed to exceed $2.5 \%$ per year on average. In total ten OECD countries are unaffected by variations in annual real wage growth between $0.5 \%$ and $2 \%$ (Austria, Germany, Hungary, Ireland, Japan, Luxembourg, the Netherlands, New Zealand, Slovenia and the United Kingdom) (Figure 4.2).

\section{Figure 4.2. Gross replacement rate for average earners with different wage growth} Percentage of earnings

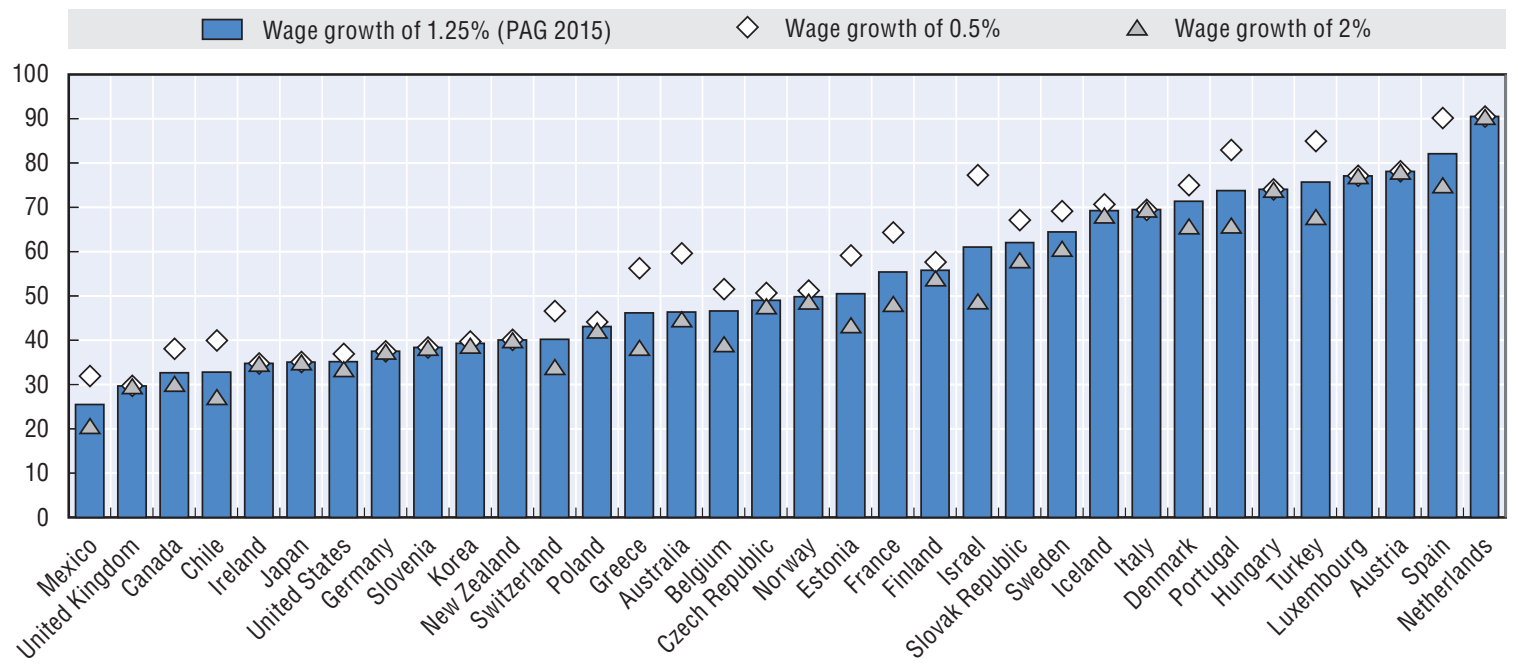

Source: OECD pension models.

Of those countries affected by variations in real-wage growth trends holding the other parameters constant, there is considerable variation in the impact due to the systems design. In Australia, Israel, Mexico and Chile, as shown in Figure 4.2, where the impact is largest, the main pension component is defined contribution. With an assumed constant rate of return in these schemes, a higher wage growth affects more the denominator of the replacement rates (wages) than the numerator (accumulated assets), and the replacement rates decrease as a result. Conversely, replacement rates increase when wage growth is lower. Mandatory defined contribution schemes also exist in Denmark, Estonia, Norway, the Slovak Republic and Sweden. Although they represent a smaller component of the overall pension system they contribute to the variation in these countries.

Additionally the value of any pension component that is indexed to prices will vary in relative terms depending on real-wage growth rates. For example, the basic pensions in Canada and Iceland are both indexed to prices, which means that the value of the benefit relative to wages is declining when real wages grow faster, thus clearly affecting the replacement rate for future retirees. Finally, a 
number of countries, among them Belgium and France, uprate previous earnings according to prices and so, as with the basic pensions above, all else being equal the replacement rate is negatively affected by higher real-wage growth.

In four countries, Denmark, Italy, Poland and Turkey, pension benefits depend on real-GDP growth. By definition, real GDP is equal to labour productivity times labour input. Hence, the OECD pension model assumes that real-GDP growth is equal to real-wage growth plus the change in the working-age population. This means that for a common wage growth rate across countries, differences in GDP growth rate across countries are driven by demographics. In both Italy and Poland, as in many other countries, the projected size of the population aged 20-64 is set to decline over the next 50 years. This results in the assumed level of annual GDP growth in both countries being set at 0.5 percentage points below annual wage growth. Conversely, the working-age population is projected to increase in both Denmark and Turkey, and their respective GDP growth rate are 0.2 and 0.3 percentage points per year above the wage growth rate.

This real-GDP growth effect, which is taken into account in Figure 4.2, has an impact on replacement rates in three of these four countries. The exception is Italy, where the relevant factor is the difference between wage growth and GDP, which only depends on demographics and is equal to 0.5 percentage points across all the scenarios based on the same mortality tables. In Denmark, the basic and targeted components are indexed to real GDP growth minus $0.3 \%$. This limits the impact of changing wage-growth assumptions, which directly affects the denominator of the replacement rate. Yet, overall, the replacement rate increases in Denmark by around 7 percentage points across the earnings levels when the annual wage-growth rate falls from $1.25 \%$ to $0.5 \%$ and falls by 6 percentage points when the wage-growth rate increases from the baseline to 2. In Turkey, the earnings-related component is indexed to $30 \%$ of the GDP change, and the replacement rate increases by 9 percentage points and decreases by 8 percentage points as the wage growth rate rises and falls by 0.75 percentage points, respectively. Finally, in Poland the sub-account system is indexed to GDP, but as it is a small component of the overall pension system the replacement rate only changes by 1 percentage point either way under the same scenarios as above.

\subsection{How changes in the rate of return affect future replacement rates}

The rate of return, or more accurately the difference between the rate of return and the rate of wage growth, is the most important indicator for replacement rates in defined-contribution schemes. With at least 45 years of contributions assumed in many countries for full-career workers, the level of the capital accumulated over this period varies considerably with even small changes to the rate of return. The default value for Pensions at a Glance 2015 is 3\% per year on average in real terms and the variant cases shown in Figure 4.3 are $2 \%$ and $4 \%$.

Only nine OECD countries have mandatory defined-contribution schemes, and are therefore affected by changes in the rate of return assumption. There are a number of countries with sizeable voluntary defined-contribution components, as shown in Chapter 6 (see Figure 6.3), but only mandatory schemes are examined herein. Of these nine countries the contribution rates to the defined-contribution scheme range from a low of $2 \%$ in Norway to a high of $15 \%$ in Israel (Chapter 5, Table 5.6), which is a prime driver of the magnitude of the sensitivity of replacement rates to rate-of-return assumptions (Figure 4.3). In Israel, for example, the gross replacement rate is 11 percentage points lower with the $2 \%$ rate of return, and 15 percentage points higher with a $4 \%$ rate of return, in comparison with the default 3\% level. By contrast the replacement rate for Norway is only 1.3 percentage points lower with the $2 \%$ rate of return and 1.9 percentage points higher at the $4 \%$ rate. 
Figure 4.3. Gross replacement rate for average earners with differing rates of return

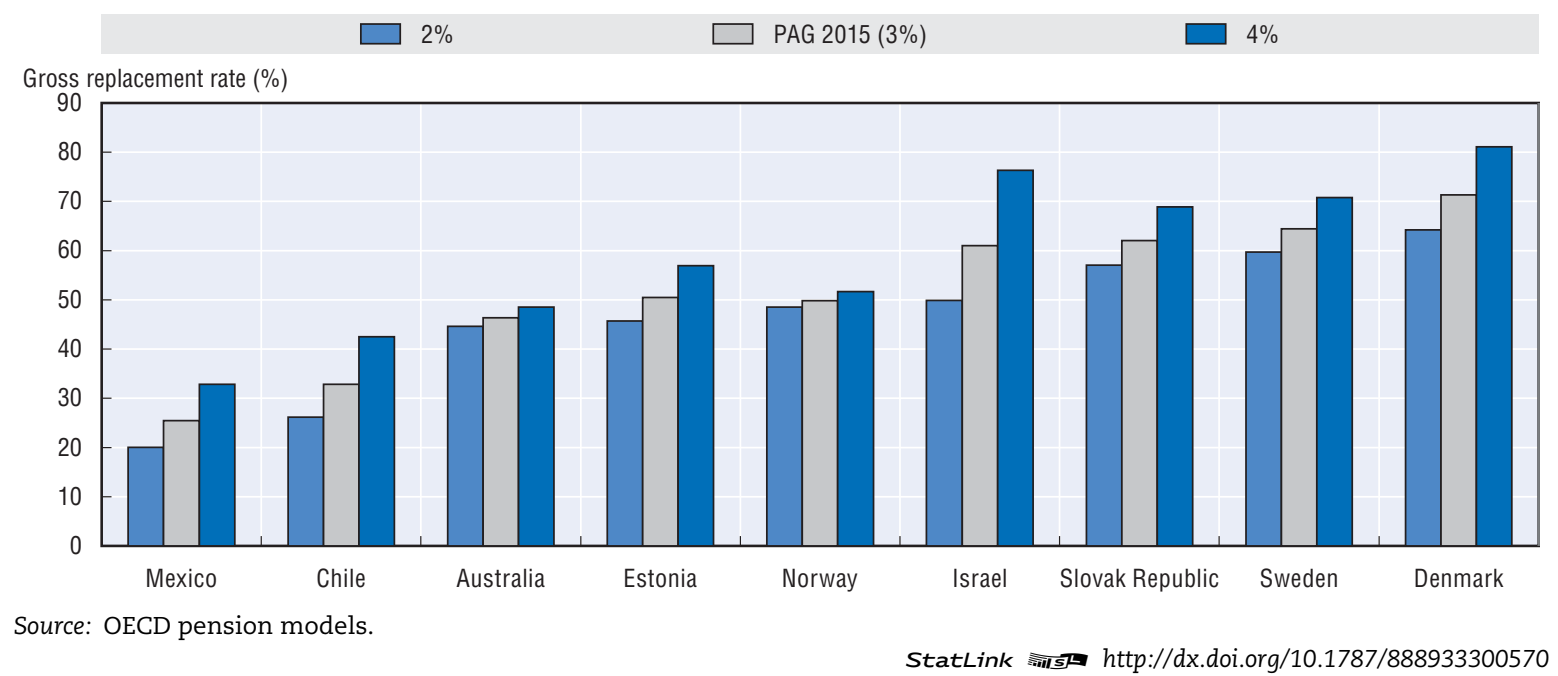

Figure 4.4. Gross replacement rate for average earners with $3 \%$ rate of return and variable conversion factor

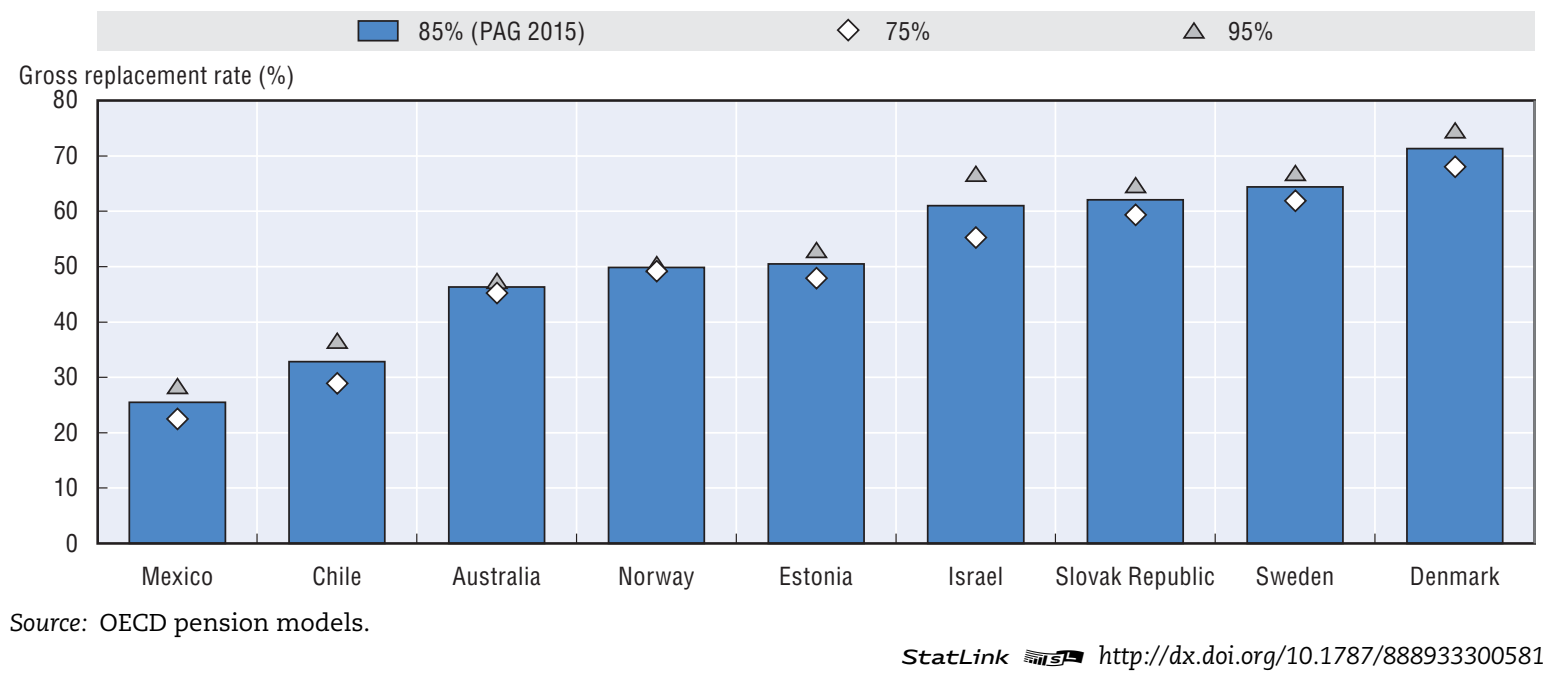

As the defined contribution scheme is not the only component of the overall pension in many countries, the system design is also important. In Australia, for example, the defined-contribution superannuation guarantee is offset by the means-tested Age Pension. Therefore, when the level of return either increases or decreases the capital value of the Superannuation before annuitisation varies accordingly. When the resulting annual payment falls the loss is partially recovered from the Age Pension and vice versa when the annual annuity increases. Therefore, despite having a high contribution rate of $9.5 \%$, increasing to $12 \%$ by 2025 , there is little variation in the replacement rate in Australia with varying rates of return, in comparison to Israel, because of the Age Pension.

Another important factor is the conversion factor applied to defined-contribution assets used to compute annuities, which by default is $85 \%$. This factor has been implemented to account for fees and charges and to reward risk-taking especially linked to mortality uncertainties at the time of annuitisation; the research on this topic suggests that this factor could be as low as 70\% (St. John, 2004) or as high as $90 \%$ (Brown et al., 1999). For comparison purposes the conversion factor has been increased and decreased by 10 percentage points from its baseline level of $85 \%$. 
The sensitivity of the replacement rate to the conversion factor is shown in Figure 4.4. Overall, the impact is not large. For example, in both Australia and Norway, there is very little variation depending on the conversion factor; however, there are two different factors at play. Firstly, in Norway, the contribution level is low at $2 \%$ and the defined-contribution component is a small proportion of the overall pension. Secondly, in Australia, for the same reason as mentioned above, the offsetting of the defined-contribution superannuation guarantee with the Age Pension partially reduces the impact of any reduction in the conversion factor. As with the previous findings in Figure 4.3, the biggest absolute change is found in Israel at $+/-6$ percentage points, but the largest percentage changes are found in Chile and Mexico, both at $+/-12 \%$.

\subsection{How changes in the discount rate affect replacement rates}

The discount rate has no impact on the value of pensions in defined-benefit schemes. In contrast, varying the discount rate directly affects annuities for a given level of accumulated assets in definedcontribution schemes. With a lower discount rate, future flows have a higher net present value all other things equal. Hence, a given level of accumulated assets will be able to finance a lower pension benefit, and the replacement rate will be lower. It is the opposite when discount rates increase.

Figure 4.5 compares the value of the future pension replacement rates when the real discount rate is assumed to equal 1\%, 2\% (the baseline assumption in Pensions at a Glance 2015) and 3\%. The nine OECD countries affected by this change are those that have a mandatory defined-contribution (DC) scheme. The impact of the change depends on the absolute size of the DC scheme, measured for example by the mandatory contribution rates, the relative importance of the DC scheme in the pension system taken into account in the computation of replacement rates, and on other parameters such as the retirement age. The largest absolute change is found in Israel at $+/-6$ percentage points for a 1 percentage point difference in the discount rate. However, when the baseline replacement-rate level is taken into account, both Chile and Mexico record the largest (relative) change, at around $+/-11 \%$, which is larger than Israel at $+/-9 \%$ and Australia at $+/-8 \%$. Smaller variations are found in Denmark, Estonia, Norway, the Slovak Republic and Sweden as the defined contribution component accounts for a smaller proportion of the overall pension system.

\section{Figure 4.5. Gross replacement rate, for average earners, by discount rate} Percentage of earnings

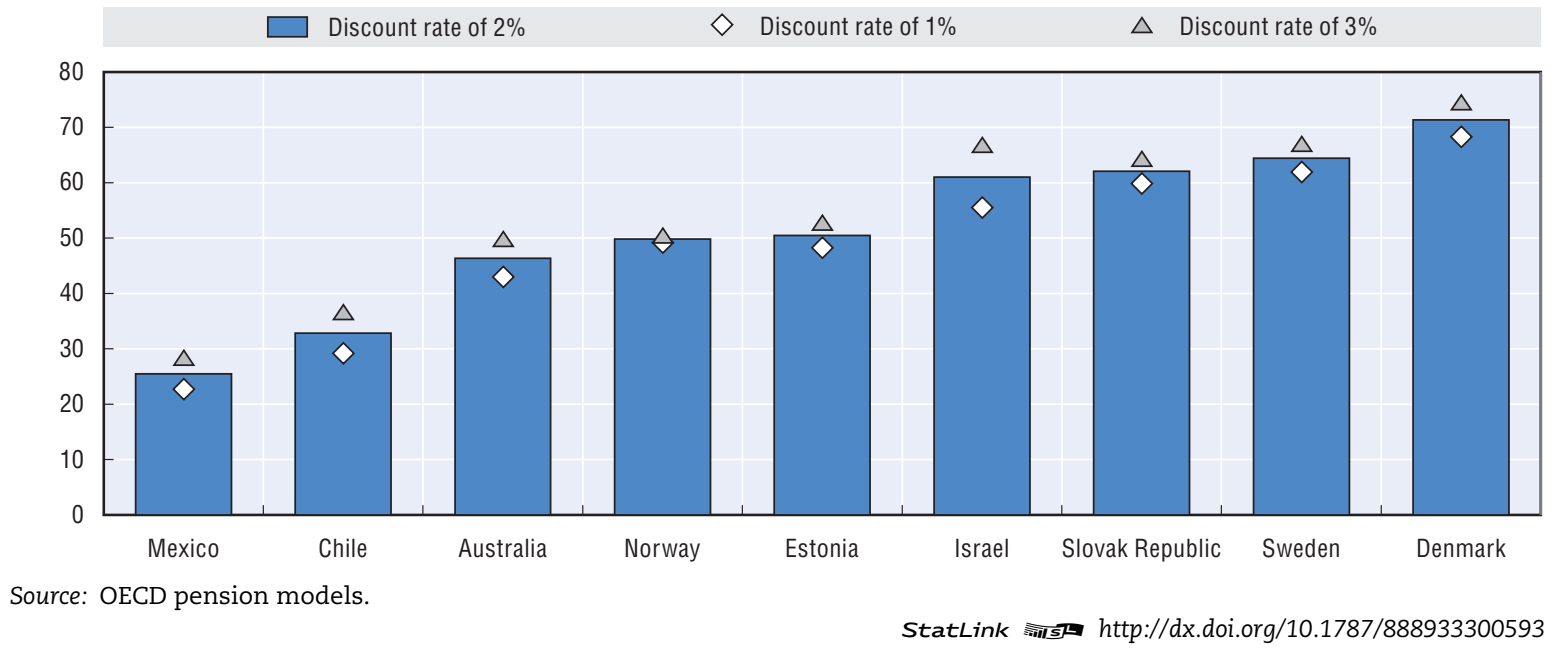




\subsection{Impact of mortality rates}

The final component directly affecting replacement rates in defined-contribution schemes is the mortality rates used to calculate the annuity factor, which links annuities to accumulated assets. However, varying mortality rates also affects the pension wealth - the total value of the lifetime flow of retirement incomes - within defined-benefit schemes, as although the replacement rate is unaffected, the duration of future payment will change. For this analysis, the available mortality data has been both reduced and increased by $10 \%$ to provide a clear assessment of the full impact. This has the effect of increasing and decreasing the life expectancy at age 65 by around one year on average across countries.

On top of the nine countries discussed in Sections 4.5 and 4.6, replacement rates are also affected in Italy and Poland, which have a notional account but no DC scheme. In addition, Norway and Sweden have both, which increases the sensitivity to mortality rates beyond that recorded in the defined-contribution scheme. Increasing life expectancy lowers the replacement rate, as the period of payment is longer. The overall impact is virtually identical across countries, which is unsurprising as the change in mortality levels is the same. However, the countries with NDC schemes show more sensitivity as the level of contribution is considerably higher (Figure 4.6). For example in Italy $33 \%$ of earnings is paid towards the NDC scheme.

Figure 4.6. Gross replacement rate, for average earners, by mortality level Percentage of earnings

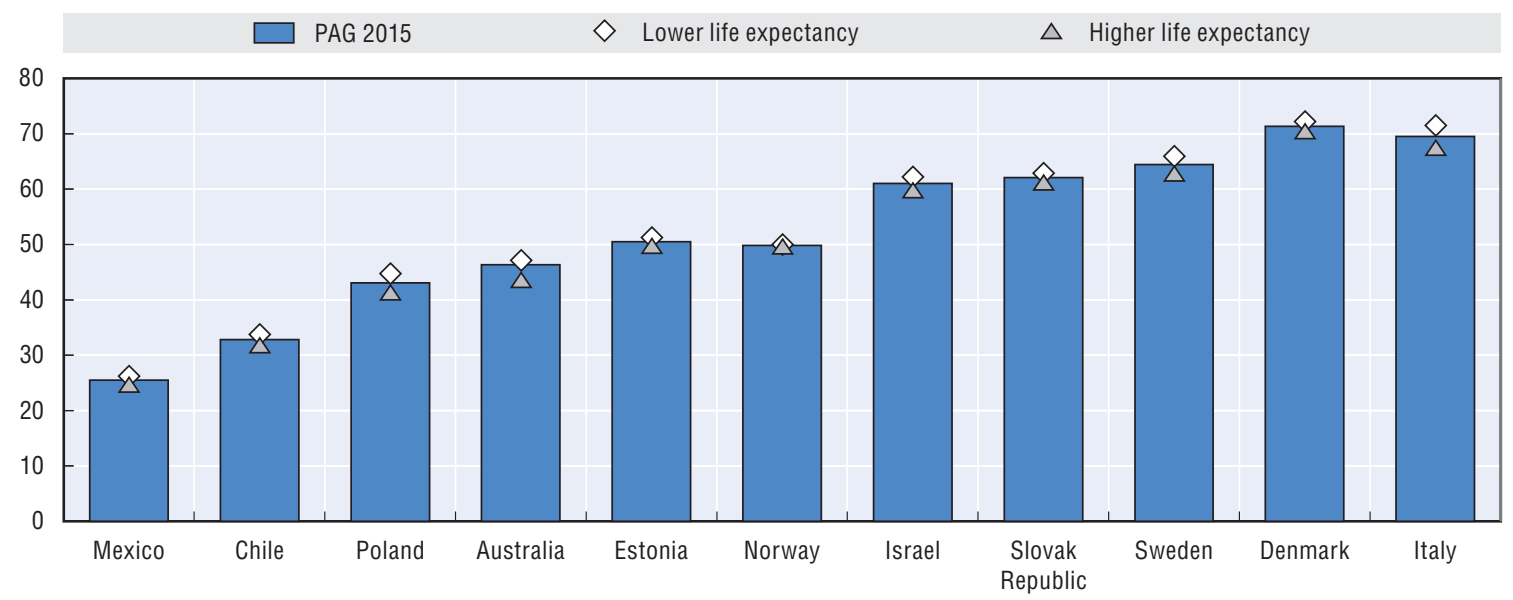

Source: OECD pension models.

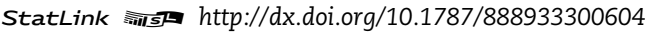

\subsection{Country-specific economic assumptions}

All of the above analysis has taken a common set of economic assumptions for all OECD countries. This section concentrates on country specific assumptions where every country is estimated to have different levels of price inflation, real-wage growth, and real interest rates depending on the level of economic development measured by the GDP per capita level. Country-specific values are based on estimations presented in Box 4.1 with the full country-specific results presented in Table 4.2. Estimations confirm that a higher level of economic development measured by GDP per capita is associated with higher inflation, higher real-wage growth and higher real interest rates, with some non-linearity identified for the first two variables. 


\section{Box 4.1. Calculation of country-specific economic parameters}

For every key parameter, several models were estimated, and the one with the lowest root mean square error (RMSE) was selected.

Inflation rate regressions: The dependent variable is the inflation rate over the period 2000-13. Annual inflation rates were capped at $20 \%$ to limit the influence of outliers. Despite this, Turkey turned out to be a clear outlier overall and was excluded from the regressions. The first regression includes a constant term and the difference (in logs) between the volume of GDP per capita in PPP in 1995 and its average across countries in 1995. Over this period, less developed countries recorded higher inflation rates on average. As the negative relation with GDP per capita may hold for less developed countries but not for the most developed, non-linearity was introduced in the second regression, by including the previous difference only for countries having had a below average level of GDP per capita in 1995. In the third regression, the constant term from the second regression was restricted to match the Pensions at a Glance assumption of $2 \%$. In the fourth regression, the regressor was the same as for the second regression but the threshold was allowed to vary instead of being set at the GDP-per capita average, and the value of that thereshold which led to the lowest RMSE was chosen. In the fifth regression, only a constant term was included, and in the last model the previous constant term was set to match the Pensions at a Glance assumption of $2 \%$. The first and fifth regressions were estimated by Ordinary Least Squares (OLS) while the second, third and fourth ones were estimated by Non-linear Least Squares (NLS).

The best model fit, in terms of lowest RMSE $(=1.00)$, was achieved by the second model whose parameter estimates (with robust standard errors in brackets) are shown below. An above-average increase of $10 \%$ in real GDP-per capita (up to a threshold equal to the average) is associated with a medium-term decrease of 0.23 percentage points in the inflation rate.

$$
\text { Inflation rate }=2.187-2.285^{*} \min \{(\log \text { GDP pc }- \text { Log Average GDP pc }), 0\}
$$

$$
\text { [0.213] [0.501] }
$$

Real-wage growth regressions: The dependent variable is the real wage growth rate over the period 1989-2013. Estonia turned out to be a clear outlier and was excluded from the regressions. Again the same models were used with the Pensions at a Glance assumption of $1.25 \%$. The best model fit, in terms of lowest RMSE $(=0.73)$, was achieved by the second and fourth models. The second approach was chosen and the parameter estimates (with robust standard errors in brackets) are shown below. An above-average increase of $10 \%$ in real GDP per capita (up to a threshold level equal to the average) is associated with a medium-term decrease of 0.19 percentage points in the real wage growth rate.

Wage growth rate $=0.762-1.860 * \min \{($ Log GDP pc - Log Average GDP pc $), 0\}$

[0.152] [0.413]

Real GDP growth: Country-specific values for the real-GDP growth rate are obtained from the rate of real-wage growth and demographics, as explained in Section 4.4.

Real discount rate regressions: The dependent variable is the annual ten-year real government yield over the period 2000-13. Annual real interest rates are capped at 10\%. The same models were estimates as above using the Pensions at a Glance assumption of $2 \%$. The lowest RMSE $(=0.84)$ is achieved by the first model. This highlights the negative relationship with economic development but rejects the assumption that a better fit could be obtained by non linearities. Estimated parameters (with robust standard errors in brackets) are shown below. An above-average increase of $10 \%$ in real GDP per capita is associated with a medium-term decrease of 0.10 percentage points in the real interest rate:

$$
\text { Real interest rate }=2.195-0.989 *(\log \text { GDP pc }- \text { Log Average GDP pc })
$$

$$
\text { [0.123] [0.481] }
$$

The forecasted values were calculated for each country by using the corresponding parameter estimates and GDP per capita data in 2014. All forecasted country values (Table 4.2) have been rescaled so that the overall OECD average matches the Pensions at a Glance 2015 assumptions.

Real rate of return: There is no comprehensive and available historical data on rates of return on financial assets across countries. Country-specific rates of return were assumed to exceed real discount rate by 1 percentage in all countries. 
Table 4.2. Country-specific economic parameters

\begin{tabular}{|c|c|c|c|c|}
\hline & Price inflation & Real earnings growth & Discount rate & Rate of return \\
\hline Australia & 1.62 & 0.94 & 1.78 & 2.78 \\
\hline Austria & 1.62 & 0.94 & 1.79 & 2.79 \\
\hline Belgium & 1.62 & 0.94 & 1.85 & 2.85 \\
\hline Canada & 1.62 & 0.94 & 1.82 & 2.82 \\
\hline Chile & 2.90 & 1.98 & 2.49 & 3.49 \\
\hline Czech Republic & 2.24 & 1.44 & 2.21 & 3.21 \\
\hline Denmark & 1.62 & 0.94 & 1.81 & 2.81 \\
\hline Estonia & 2.48 & 1.64 & 2.31 & 3.31 \\
\hline Finland & 1.62 & 0.94 & 1.92 & 2.92 \\
\hline France & 1.68 & 0.99 & 1.97 & 2.97 \\
\hline Germany & 1.62 & 0.94 & 1.82 & 2.82 \\
\hline Greece & 2.54 & 1.69 & 2.34 & 3.34 \\
\hline Hungary & 2.66 & 1.79 & 2.39 & 3.39 \\
\hline Iceland & 1.62 & 0.94 & 1.81 & 2.81 \\
\hline Ireland & 1.62 & 0.94 & 1.72 & 2.72 \\
\hline Israel & 1.98 & 1.24 & 2.10 & 3.10 \\
\hline Italy & 1.86 & 1.14 & 2.05 & 3.05 \\
\hline Japan & 1.76 & 1.06 & 2.00 & 3.00 \\
\hline Korea & 1.91 & 1.18 & 2.07 & 3.07 \\
\hline Luxembourg & 1.62 & 0.94 & 1.08 & 2.08 \\
\hline Mexico & 3.50 & 2.47 & 2.75 & 3.75 \\
\hline Netherlands & 1.62 & 0.94 & 1.76 & 2.76 \\
\hline New Zealand & 1.72 & 1.02 & 1.98 & 2.98 \\
\hline Norway & 1.62 & 0.94 & 1.41 & 2.41 \\
\hline Poland & 2.67 & 1.80 & 2.40 & 3.40 \\
\hline Portugal & 2.35 & 1.54 & 2.26 & 3.26 \\
\hline Slovak Republic & 2.43 & 1.60 & 2.29 & 3.29 \\
\hline Slovenia & 2.23 & 1.43 & 2.20 & 3.20 \\
\hline Spain & 1.95 & 1.21 & 2.08 & 3.08 \\
\hline Sweden & 1.62 & 0.94 & 1.79 & 2.79 \\
\hline Switzerland & 1.62 & 0.94 & 1.55 & 2.55 \\
\hline Turkey & 3.23 & 2.26 & 2.64 & 3.64 \\
\hline United Kingdom & 1.62 & 0.94 & 1.93 & 2.93 \\
\hline United States & 1.62 & 0.94 & 1.61 & 2.61 \\
\hline Average & 2.00 & 1.25 & 2.00 & 3.00 \\
\hline Minimum & 1.62 & 0.94 & 1.08 & 2.08 \\
\hline Maximum & 3.50 & 2.47 & 2.75 & 3.75 \\
\hline
\end{tabular}

Source: OECD calculations.

The results for the gross replacement rate are shown in Figure 4.7 in comparison with the Pensions at a Glance 2015 baseline.

Overall, there is very little change in the replacement rates based on Pensions at a Glance 2015 and the country-specific assumptions shown in Table 4.2. The different assumptions have no impact on replacement rate in some countries. For example, the pensions in Ireland, New Zealand and the United Kingdom are effectively flat-rate and so the changes in the economic parameters do not alter the replacement rates as the benefits are uprated in line with wage increase. This means that the expected benefits effectively remain constant relative to past wages. The results for Austria, Germany, Japan, Luxembourg, the Netherlands and Slovenia are also constant under both scenarios, as in these countries all the applicable components of the pension system are indexed to wages. 


\section{Figure 4.7. Future gross replacement results for male average earners under Pensions at a Glance 2015 and country-specific assumptions}

Percentage of earnings

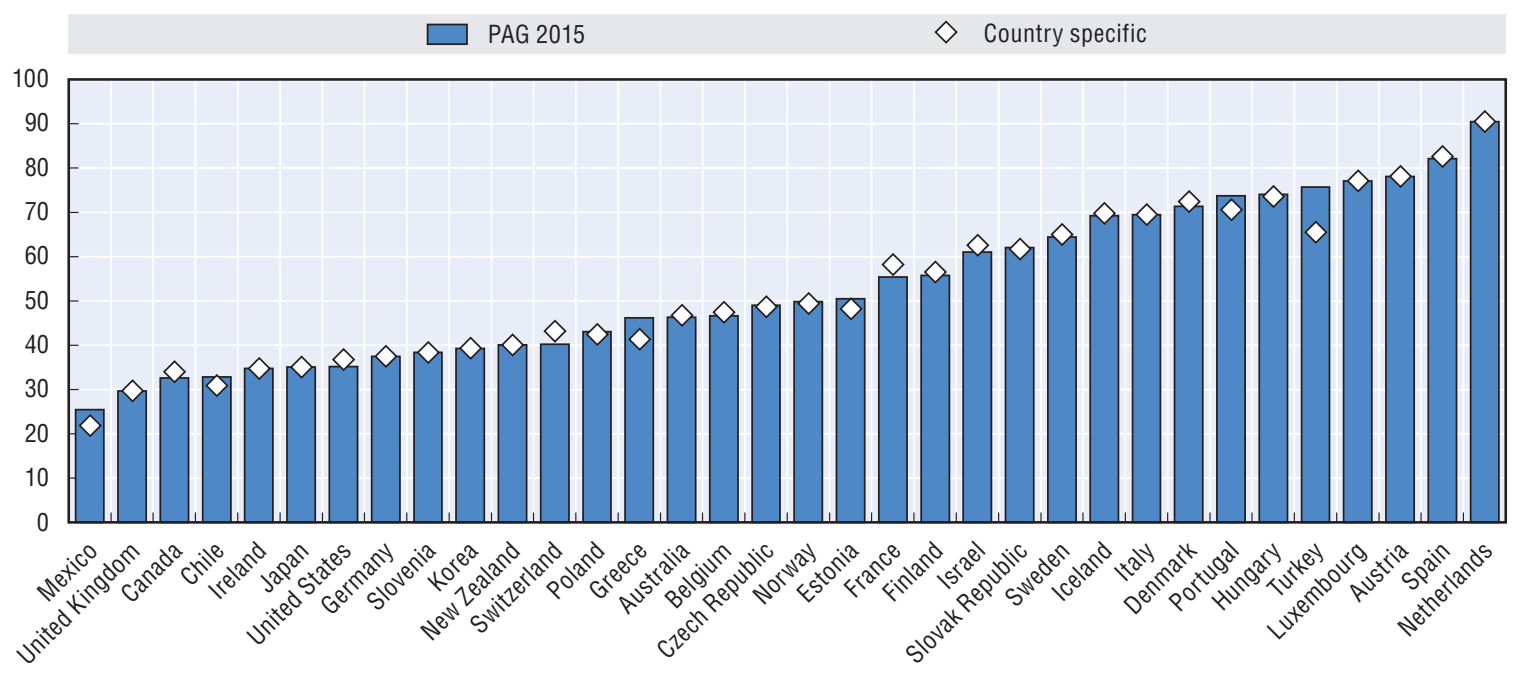

Source: Author calculations using OECD pension model.

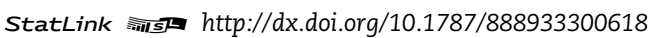

The biggest increase obtained by moving to country-specific assumption are in France and Switzerland at around 3 percentage points. This change comes mostly from the lower assumptions for real-wage growth (and the sensitivity to this parameter as discussed in Section 4.4). At the other end of the scale the largest fall in replacement rates are found in Turkey (10 percentage points), Greece (5 percentage points) and Mexico (4 precentage points). In Turkey and Greece this is caused by the considerably higher level of wage growth, at $2.26 \%$ and $1.69 \%$, respectively, rather than the common $1.25 \%$ in the baseline. In Mexico the difference between the rate of return and wage growth is only $1.28 \%$ as opposed to $1.75 \%$ under Pensions at a Glance 2015 , so the value of the capital upon retirement is much lower relative to earnings.

\section{References}

Brown, J.R., O.S. Mitchell and J.M. Poterba (1999), “The Role of Real Annuities and Indexed Bonds in an Individual Accounts Retirement Program", NBER Working Paper, No. 7005, Cambridge, United States.

St. John, S. (2004), “The Annuities Market in New Zealand”, University of Auckland Business School, Retirement Policy and Research Centre. 


\section{Chapter 5}

\section{Design of pension systems}

The five indicators in this section look in detail at the design of national retirement income systems in OECD countries and other major economies. The first indicator sets out the taxonomy of the different kinds of retirement-income programmes found around the world. It uses this framework to describe the architecture of 42 countries' pension systems.

The next four indicators set out the parameters and rules of the pension systems. The description begins with the second indicator covering "Basic, targeted and minimum pensions", showing the values and coverage of these systems. The third indicators look at the "Earnings-related pensions" systems. It shows how benefits are determined in these schemes and the range of earnings that are covered. The fourth indicator presents the "Current retirement ages" by pension scheme for an individual entering the labour market at age 20 and retiring in 2014. The last indicator looks at the "Future retirement ages" for an individual entering the labour market at age 20 in 2014 and retiring in the future.

The statistical data for Israel are supplied by and under the responsibility of the relevant Israeli authorities. The use of such data by the OECD is without prejudice to the status of the Golan Heights, East Jerusalem and Israeli settlements in the West Bank under the terms of international law. 


\section{Key results}

Retirement-income regimes are diverse and often involve a number of different programmes. Classifying pension systems and different retirement-income schemes is consequently difficult. The taxonomy of pensions used here consists of two mandatory "tiers": an adequacy part and an earnings-related part. Voluntary provision, be it individual or employer-provided, makes up a third tier.

The framework, shown in the figure, is based on the role and objective of each part of the system. The first tier comprises programmes designed to ensure pensioners achieve some absolute, minimum standard of living. The second-tier, earnings-related components are designed to achieve some target standard of living in retirement compared with that when working. Within these tiers, schemes are classified further by provider (public or private) and the way benefits are determined. Pensions at $a$ Glance focuses mainly on these mandatory components although information is also provided on some voluntary, private schemes.

Using this framework, the architecture of national schemes is shown in the table. Programmes aimed to prevent poverty in old age - first-tier schemes - are provided by the public sector and are of three main types.

Basic pensions can take two different forms: a benefit paid to everyone irrespective of any contributions made, although beneficiaries might have to meet some residence criteria. In some countries residence-based benefits are potentially offset against other pension income; or a benefit paid solely on the basis of the number of years of contributions, i.e. independently of earnings. Some 18 OECD countries have a basic pension scheme or other provisions with a similar effect.

Minimum pensions can refer to either the minimum of a specific contributory scheme or of all schemes combined. They are found in 13 OECD countries. The value of entitlements takes account only of pension income: unlike meanstested schemes, it is not affected by income from savings, etc. Minimum pension credits in earnings-related secondtier schemes, such as those in Belgium and France, also have a redistributive effect and benefits workers with very low earnings since the pension credits are calculated as if the worker had earned pension credits at a higher level.

Social assistance plans pay a higher benefit to poorer pensioners and reduced benefits to better-off retirees. In these plans, the value of benefits depends either on income from other sources or on both income and assets. All countries have general social safety-nets of this type. Rather than having every country marked in the table, only seven OECD countries are marked in this column; full-career workers with low earnings ( $30 \%$ of the average) would be entitled to resource-tested benefits in these countries.

Only Ireland and New Zealand in the OECD do not have mandatory, second-tier provision. In the other 32 countries, there are four kinds of scheme.

Defined benefit (DB) plans are provided by the public sector in 18 OECD countries. Private (occupational) schemes are mandatory or quasi-mandatory in three OECD countries (Iceland, the Netherlands and Switzerland). Retirement income depends on the number of years of contributions and individual earnings

There are points schemes in four OECD countries: French occupational plans (operated by the public sector) and the Estonian, German and Slovak public schemes. Workers earn pension points based on their earnings each year. At retirement, the sum of pension points is multiplied by a pension-point value to convert them into a regular pension payment.

Defined contribution (DC) plans are compulsory in nine OECD countries. In these schemes, contributions flow into an individual account. The accumulation of contributions and investment returns is usually converted into a pensionincome stream at retirement. In Denmark and Sweden, there are quasi-mandatory, occupational DC schemes in addition to smaller compulsory plans.

There are notional-accounts schemes in four OECD countries (Italy, Norway, Poland and Sweden). These record contributions in an individual account and apply a rate of return to the balances. The accounts are "notional" in that the balances exist only on the books of the managing institution. At retirement, the accumulated notional capital is converted into a stream of pension payments using a formula based on life expectancy. Since this is designed to mimic DC schemes, they are often called notional defined contribution plans (NDC). 


\subsection{Taxonomy: Different types of retirement-income provision}

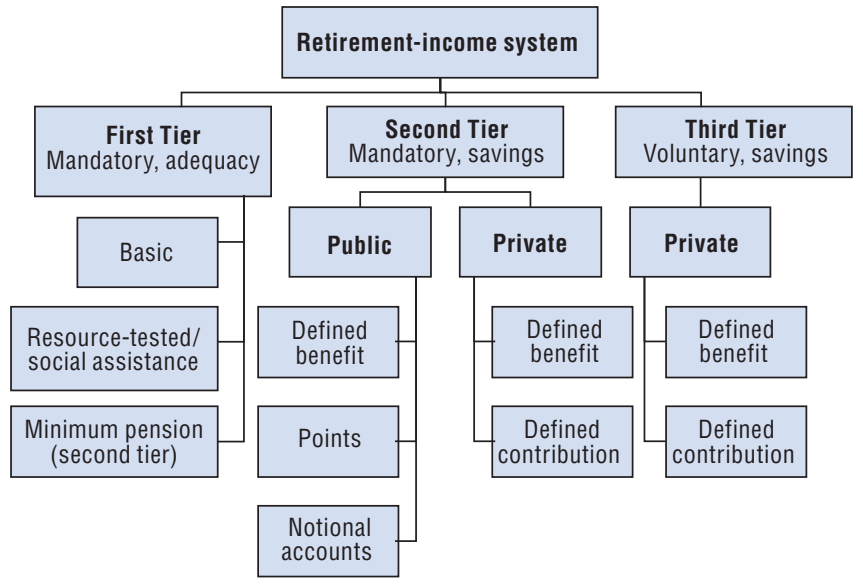

\subsection{Structure of retirement-income provision}

\begin{tabular}{|c|c|c|c|c|c|c|c|c|c|c|c|}
\hline & \multirow{2}{*}{ Basic } & \multirow{2}{*}{ Minimum } & \multirow{2}{*}{$\begin{array}{c}\text { Social } \\
\text { assistance }\end{array}$} & Public & Private & & \multirow{2}{*}{ Basic } & \multirow{2}{*}{ Minimum } & \multirow{2}{*}{$\begin{array}{c}\text { Social } \\
\text { assistance }\end{array}$} & \multirow{2}{*}{$\begin{array}{c}\text { Public } \\
\text { Type }\end{array}$} & \multirow{2}{*}{$\frac{\text { Private }}{\text { Type }}$} \\
\hline & & & & Type & Type & & & & & & \\
\hline OECD members & & & & & & OECD members (cont.) & & & & & \\
\hline Australia & $\checkmark$ & & & & DC & New Zealand & $\checkmark$ & & & & \\
\hline Austria & & & & DB & & Norway & $\checkmark$ & & & NDC & DC \\
\hline Belgium & & $\checkmark$ & $\checkmark$ & DB & & Poland & & $\checkmark$ & & NDC & \\
\hline Canada & $\checkmark$ & & $\checkmark$ & DB & & Portugal & & $\checkmark$ & & $\mathrm{DB}$ & \\
\hline Chile & $\checkmark$ & & $\checkmark$ & & DC & Slovak Republic & & & & Points & DC \\
\hline Czech Republic & $\checkmark$ & $\checkmark$ & & DB & & Slovenia & & $\checkmark$ & & $\mathrm{DB}$ & \\
\hline Denmark & $\checkmark$ & & $\checkmark$ & & DC & Spain & & $\checkmark$ & & $\mathrm{DB}$ & \\
\hline Estonia & $\checkmark$ & & & Points & DC & Sweden & $\checkmark$ & & & NDC & DC \\
\hline Finland & $\checkmark$ & & $\checkmark$ & DB & & Switzerland & & $\checkmark$ & & $\mathrm{DB}$ & DB \\
\hline France & & $\checkmark$ & & $\mathrm{DB}+$ points & & Turkey & & $\checkmark$ & & DB & \\
\hline Germany & & & & Points & & United Kingdom & $\checkmark$ & & & DB & \\
\hline Greece & $\checkmark$ & & & DB & & United States & & & & DB & \\
\hline Hungary & & $\checkmark$ & & DB & & & & & & & \\
\hline Iceland & $\checkmark$ & & $\checkmark$ & & DB & Other major economies & & & & & \\
\hline Ireland & $\checkmark$ & & & & & Argentina & $\checkmark$ & $\checkmark$ & & DB & \\
\hline Israel & $\checkmark$ & & & & DC & Brazil & & $\checkmark$ & & $\mathrm{DB}$ & \\
\hline Italy & & $\checkmark$ & & NDC & & China & & $\checkmark$ & & NDC/DC & \\
\hline Japan & $\checkmark$ & & & $\mathrm{DB}$ & & India & & $\checkmark$ & & $\mathrm{DB}+\mathrm{DC}$ & \\
\hline Korea & & & $\checkmark$ & DB & & Indonesia & & & & DC & \\
\hline Luxembourg & $\checkmark$ & $\checkmark$ & & DB & & Russian Federation & $\checkmark$ & & & NDC & $D C$ \\
\hline Mexico & & $\checkmark$ & & & DC & Saudi Arabia & & $\checkmark$ & & $\mathrm{DB}$ & \\
\hline Netherlands & $\checkmark$ & & & & DB & South Africa & $\checkmark$ & & & & \\
\hline
\end{tabular}

Note: $\mathrm{DB}=$ Defined benefit; $\mathrm{DC}=$ Defined contribution; NDC = Notional accounts. In Iceland and Switzerland, the government sets contribution rates, minimum rates of return and the annuity rate at which the accumulation is converted into a pension for mandatory occupational plans. These schemes are therefore implicitly defined benefit.

Source: See "Country profiles" in Chapter 11 of this report. 


\section{Key results}

Basic and minimum pensions along with social assistance are designed to ensure adequacy of old-age incomes and make up the first tier of the OECD's taxonomy of pension systems, which was set out in the previous indicator of the "Architecture of national pension systems".

Basic pensions exist in 18 OECD countries and are worth $20.1 \%$ of average worker earnings. 26 OECD countries provide a social assistance benefit equivalent to $18.9 \%$ of average worker earnings. Furthermore, 13 OECD countries provide a minimum pension benefit, most often above the basic or social assistance level. For a full-career worker, the average minimum pension is $24.8 \%$ of average worker earnings.

About three out of ten older people receive some support from basic, minimum pensions or social assistance on average.

There are three main ways in which OECD countries might provide retirement incomes to meet a minimum standard of living in old age. The left-hand part of the table shows the value of benefits provided under these different types of scheme and Chapter 2 provides additional details. Values are presented in absolute terms - national currency units - to allow a direct link with the detailed information in the "Country profiles" in Chapter 11 of this report. They are also given in relative terms - as a percentage of economy-wide average earnings - to facilitate comparisons between countries. (See the indicator of "Average worker earnings" in Chapter 8.)

Benefit values are shown for a single person. In some cases - usually with minimum contributory pensions each partner in a couple receives an individual entitlement. In other cases - especially for targeted schemes - the couple is treated as the unit of assessment and generally receives less than twice the entitlement of a single person.

The analysis of benefit values is complicated by the existence of multiple programmes in many countries. In some cases, benefits under these schemes are additive. In others, there is a degree of substitution between them. Basic and minimum pension values are therefore summarised in Figure 5.4. The dark bars show the overall value of the basic benefit. This can be seen as the absolute minimum, safety-net income based on either residence or contributions. The lighter bars show minimum contributory benefits. The entitlements shown are the maximum for a worker contributing for each year from age 20 until the standard national pension age. These can be seen as the minimum income of a low-earning, full-career worker.

There are only five countries in the OECD that do not have either a basic or minimum pension within their system
(Austria, Germany, Korea, the Slovak Republic and the United States). In the other 29 countries, basic benefits are present in 18 including cases where basic pensions are residency-tested, such as the Netherlands and New Zealand. In Canada, Denmark and Iceland amongst others, entitlements are a mix of basic and resource-tested benefits (see Chapter 2 for more details).

In 13 countries, there is a minimum pension, with only the Czech Republic and Luxembourg having both a basic and minimum. The value of these benefits varies between a low of $11 \%$ of average earnings in Hungary to $41 \%$ in Turkey, with an average of $25 \%$ across the 13 countries.

\section{Coverage}

The percentage of over 65s receiving first-tier benefits is shown in the final two columns of the table and in Figure 5.5. Data are presented just for non-contributory safety-net benefits (not including the pure residency based basic pensions with no income test, e.g. New Zealand) and contributory minimum pensions. The importance of these benefits varies enormously. In Denmark $88 \%$ receive at least a partial payment from the safety-net, with a further $78 \%$ receiving an element of the basic pension in Australia. At the other end of the spectrum, $3 \%$ or fewer of pensioners receive safety-net benefits in Germany, Japan and the Slovak Republic.

Minimum pensions are received by nearly $60 \%$ of the over 65 s in Portugal and $47 \%$ in Finland. Levels are around $30 \%$ in France, Italy, Luxembourg and Spain, but account for fewer than $1 \%$ of the over $65 \mathrm{~s}$ in Hungary. 


\subsection{Basic, targeted and minimum pensions, 2014}

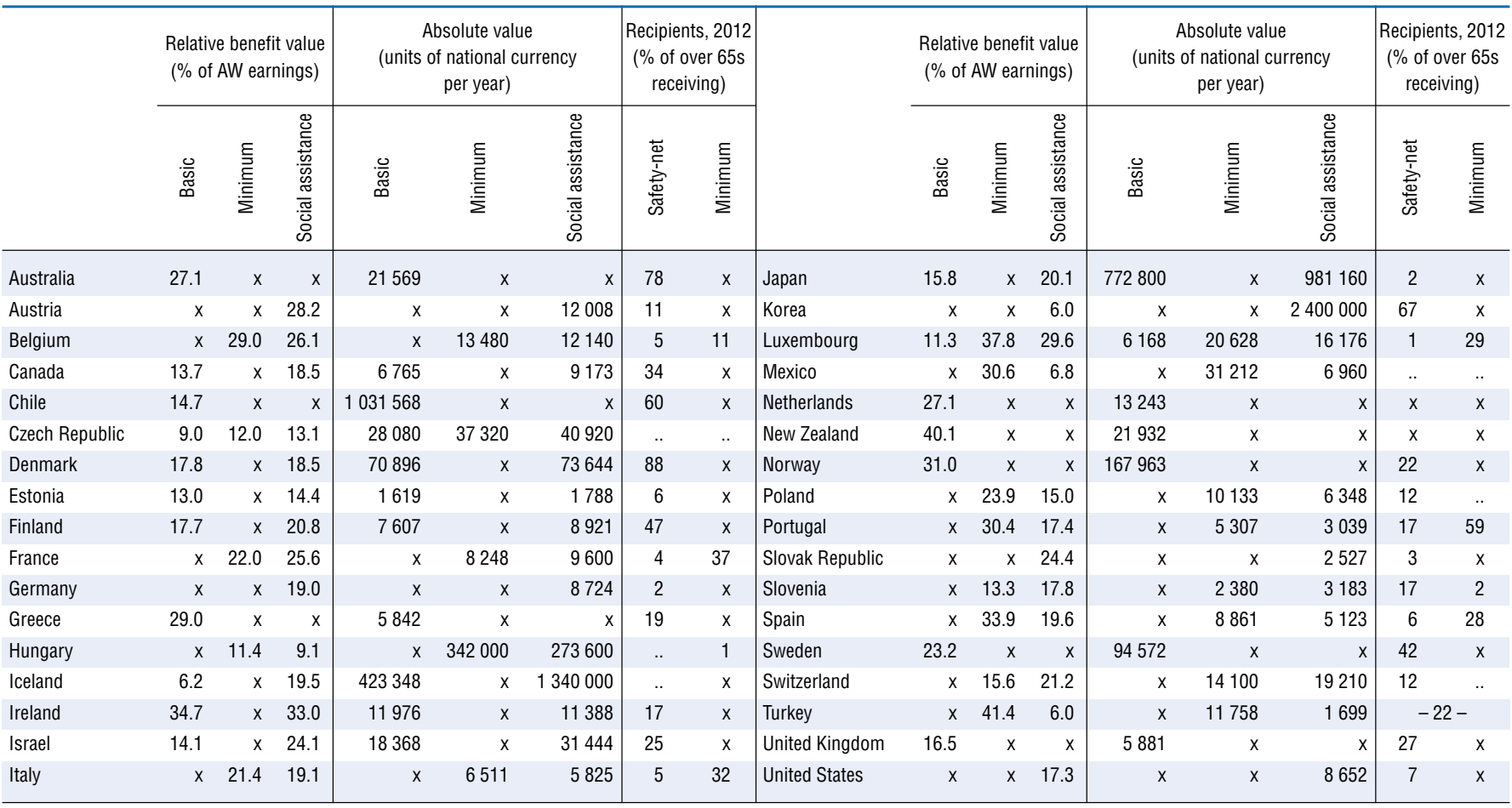

Note: .. = Data are not available; $\mathrm{x}=$ Not applicable.

StatLink त्राड़ी http://dx.doi.org/10.1787/888933301062

\subsection{Value of basic and minimum pensions}

Percentage of economy-wide average earnings

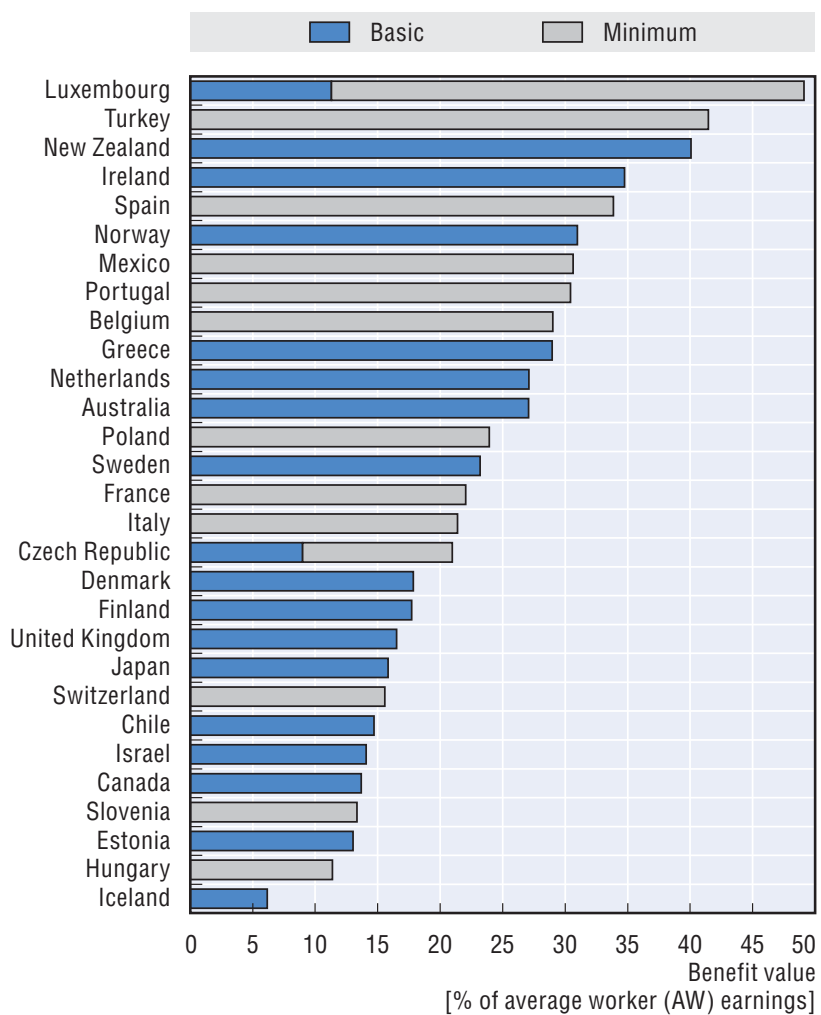

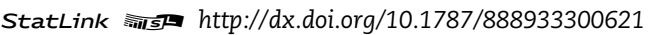

\subsection{Recipients of safety-nets and minimum pensions}

Percentage of individuals 65 and over

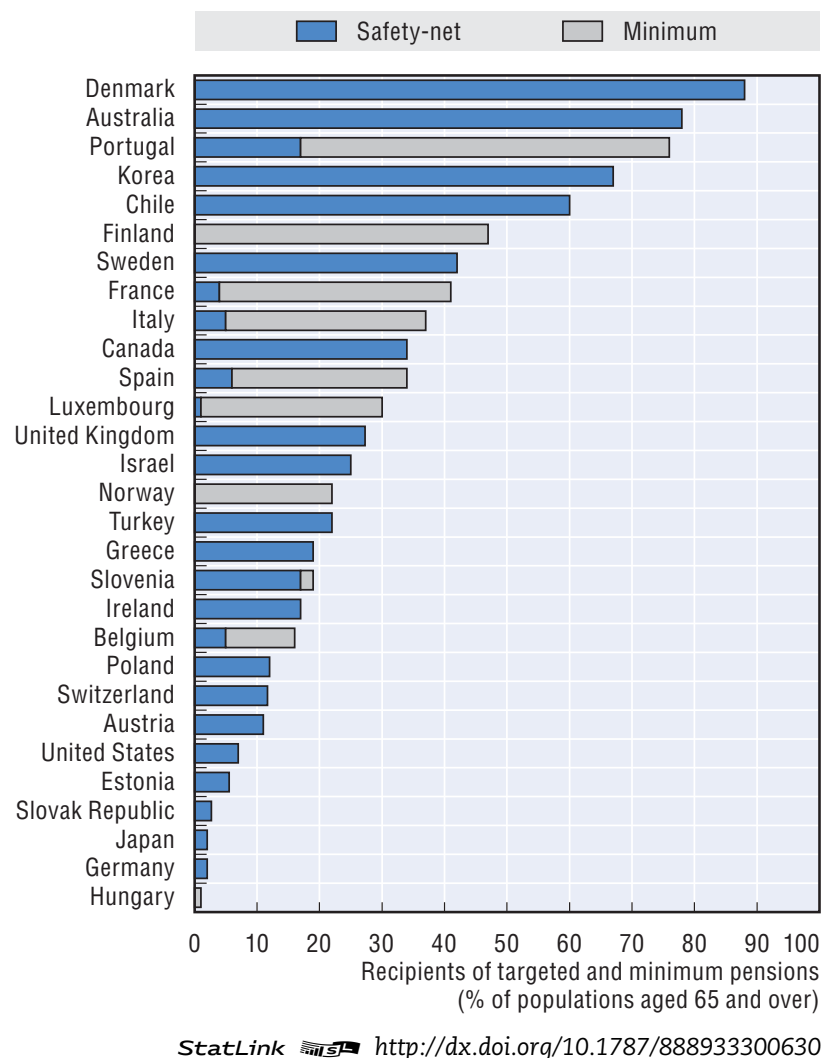




\section{Key results}

The second tier of the OECD's taxonomy of retirement-income provision comprises earnings-related pensions. Key parameters and rules of these schemes determine the value of entitlements, including the long-term effect of pension reforms that have already been legislated.

Earnings-related schemes can be of four different types: defined benefit (DB), defined contribution (DC), points or notional accounts (NDC). The accrual rate shows the rate at hich benefit entitlements build up for each year of coverage. The accrual rate is expressed as a percentage of the earnings that are "covered" by the pension scheme.

For points systems, the effective accrual rate is calculated as the ratio of the value of a pension point to the pension-point cost. In notional-accounts schemes, the effective accrual rate is calculated in a similar way; it depends on the contribution rate, notional interest rate and annuity factors.

In a little under half of the countries with earningsrelated plans, accrual rates are constant; i.e. do not depend on the level of earnings. Elsewhere, the benefit earned for each year of coverage varies, either with individual earnings, age or years of contributions.

Among the eight cases where accrual rates vary with earnings, the public schemes of the Czech Republic, Portugal, Switzerland and the United States are "progressive"; they pay higher replacement rates to lower earners. The occupational plans of France and Sweden offset the public scheme's redistribution, paying a higher replacement rate to high earners on their pay above the ceiling of the public plan. In occupational plans in Finland and Switzerland, accrual rates increase with age.

Accrual rates vary with service in two countries; in Luxembourg, increasing with a longer contribution history. Spain does the reverse: the highest accruals for the first few years of coverage and lower later on.

Earnings measures used to calculate benefits also differ. Some 22 OECD countries use lifetime earnings to calculate benefits and in Canada and the United States, the great majority of careers (34-35 years) are used. Spain uses the final 25 years, while public benefits in France and all benefits in Slovenia are based on the best 25 years' of earnings and best 24 years, respectively.

Closely linked with the earnings measure is valorisation, whereby past earnings are adjusted to take account of changes in living standards between the time pension rights accrued and the time they are claimed (sometimes called pre-retirement indexation). The uprating of the pensionpoint value and the notional interest rate in points and notional-accounts systems, respectively are the exact corollaries of valorisation in DB plans. The most common practice is to revalue earlier years' pay with the growth of average earnings. Belgium, France and Spain, revalue earnings only with price inflation and 25 years enters the benefit formula in the French and Spanish defined-benefit scheme compared with lifetime average in Belgium and the French occupational plans. Estonia, Finland and Portugal revalue earlier years' earnings to a mix of price and wage inflation and for Turkey it is a mix of price inflation and GDP growth.

The key parameter for defined contribution (DC) plans is the proportion of earnings that must be paid into the individual account. The average contribution rate for the ten countries shown, including quasi-mandatory DC occupational schemes in Denmark and Sweden, is 7.9\%.

Most countries set a limit on the earnings used to calculate both contribution liabilities and pension benefits. The average ceiling on public pensions for 19 countries is $184 \%$ of average economy-wide earnings, excluding four countries with no ceiling on public pensions. Ceilings are typically higher for mandatory private pensions.

Indexation refers to the uprating of pensions in payment. Price indexation is most common, but five countries uprate benefits with a mix of inflation and wage growth. A further two have a combination of prices and GDP, with another two increasing by wages with a set deduction. Some countries have progressive indexation, giving larger increases to low pensions. 


\subsection{Future parameters and rules of earnings-related pensions}

\begin{tabular}{|c|c|c|c|c|c|c|c|c|}
\hline & \multicolumn{5}{|c|}{ Earnings-related schemes (DB, points, NDC) } & \multirow{2}{*}{$\begin{array}{c}\text { DC schemes } \\
\begin{array}{c}\text { Contribution rate } \\
(\%)\end{array}\end{array}$} & \multicolumn{2}{|c|}{$\begin{array}{l}\text { Ceilings on pensionable earnings } \\
\text { ( } \% \text { of ave. earnings) }\end{array}$} \\
\hline & Type & $\begin{array}{c}\text { Accrual rate } \\
(\%)\end{array}$ & Earnings measure & Valorisation & Indexation & & Public & Private \\
\hline Australia & None & & & & & $9.5-12.0$ & & 241 \\
\hline Austria & DB & 1.78 & $26-40$ & $w^{1}$ & $d$ & & 149 & \\
\hline Belgium & $\mathrm{DB}$ & 1.33 & L & $p$ & $p$ & & 114 & \\
\hline Canada & $\mathrm{DB}$ & 0.64 & $L(83 \% b)$ & w & $\mathrm{p}[\mathrm{c}]$ & & 108 & \\
\hline Chile & None & & & & & 10.0 & & 305 \\
\hline Czech Republic & $\mathrm{DB}$ & $1.5-1.02$ & $L$ & w & $33 w / 67 p$ & & None & \\
\hline Denmark & None & & & & & $12.0^{2}$ & & \\
\hline Estonia & Points & 0.41 & $\mathrm{~L}$ & $50 w / 50 p$ & $80 w / 20 p$ & 6.0 & None & None \\
\hline Finland & DB & $1.5-4.5$ & $\mathrm{~L}$ & $80 w / 20 p$ & $20 w / 80 p$ & & None & \\
\hline France & DB/points & $1.16 / 0.51$ & $\mathrm{~b} 25 / \mathrm{L}$ & $\mathrm{p} / \mathrm{p}$ & $p / p$ & & $100 / 284^{3}$ & \\
\hline Germany & Points & 0.97 & L & $w[c]$ & $w[c]$ & & 151 & \\
\hline Greece & DB & $0.8-1.5$ & $L$ & $p$ & 50p/50 GDP & & $379^{4}$ & \\
\hline Hungary & $\mathrm{DB}$ & 1.64 & $\mathrm{~L}$ & w & $p$ & & & \\
\hline Iceland & $\mathrm{DB}$ & 1.47 & $L$ & $\mathrm{fr}$ & $p$ & & & None \\
\hline Ireland & None & & & & & & & \\
\hline Israel & None & & & & & 15.0 & & 416 \\
\hline Italy & NDC & 1.46 & $L$ & GDP & $p^{5}$ & & 328 & \\
\hline Japan & $\mathrm{DB}$ & 0.55 & $L$ & w & $w / p^{6}$ & & 192 & \\
\hline Korea & DB & 0.87 & $\mathrm{~L}$ & w & $p$ & & 123 & \\
\hline Luxembourg & $\mathrm{DB}$ & $1.92[y]$ & $\mathrm{L}$ & w & $\mathrm{p} / \mathrm{w}$ & & 174 & \\
\hline Mexico & None & & & & & 6.5 & & 587 \\
\hline Netherlands & $\mathrm{DB}$ & 1.85 & $L$ & $\mathrm{w}[\mathrm{c}]$ & $w[c]$ & & & None \\
\hline New Zealand & None & & & & & & & \\
\hline Norway & NDC & 0.94 & $\mathrm{~L}$ & w & $w-0.75$ & 2.0 & 104 & \\
\hline Poland & NDC & 0.91 & $\mathrm{~L}$ & $w^{7}$ & $p^{7}$ & 2.92 & 265 & \\
\hline Portugal & $\mathrm{DB}$ & $2.3-2[w]$ & $\mathrm{L}$ & $25 w / 75 p$ & $\mathrm{p} / \mathrm{GDP}^{8}$ & & None & \\
\hline Slovak Republic & Points & 0.55 & $\mathrm{~L}$ & w & $50 w / 50 p$ & 6.0 & 206 & \\
\hline Slovenia & DB & 0.96 & b24 & w (d) & w & & 205 & \\
\hline Spain & DB & $1.82[y]$ & $\mathrm{f} 25$ & $p$ & $p$ & & 165 & \\
\hline Sweden & NDC & $0.95[w]$ & $\mathrm{L}$ & w & $w-1.6[c]$ & $2.5+4.5^{9}$ & 105 & $113 /$ none $^{8}$ \\
\hline Switzerland & $\mathrm{DB}$ & [w/a] & $\mathrm{L}$ & $\mathrm{fr}$ & $50 w / 50 p$ & & 93 & 93 \\
\hline Turkey & DB & $1.68[w]$ & $\mathrm{L}$ & $p+30 \%$ GDP & $p$ & & 311 & \\
\hline United Kingdom & $\mathrm{DB}$ & & & & & & & \\
\hline United States & $\mathrm{DB}$ & $0.75[w]$ & b35 & $w^{10}$ & $p$ & & 233 & \\
\hline
\end{tabular}

Note: Parameters are for 2014 but include all legislated changes that take effect in the future: for example, some countries are extending the period of earnings covered for calculating benefits. Empty cells indicate that the parameter is not relevant. [a] = Varies with age; $b=$ Number of best years; $[c]=$ Valorisation/indexation conditional on financial sustainability; $d=$ Discretionary indexation; $D B=$ Defined benefit; DC = Defined contribution; $\mathrm{f}=$ Number of final years; $\mathrm{fr}=$ Fixed rate valorisation; GDP $=$ Growth of gross domestic product; $\mathrm{L}=$ Lifetime average; NDC = Notional accounts; $\mathrm{p}=$ Valorisation/indexation with prices; $\mathrm{w}=$ Valorisation/indexation with average earnings; $[\mathrm{w}]=$ Varies with earnings; $[\mathrm{y}]=$ Varies with years of service.

1. Austria: valorisation assumed to move to earnings as the averaging period for the earnings measure is extended.

2. Denmark: typical contribution rate for quasi-mandatory occupational plans.

3. France: the first ceiling relates to the national pension scheme, the second to the mandatory occupational plan modelled here (ARRCO).

4. Greece: effective ceiling calculated from maximum pension.

5. Italy: indexation is fully to prices for low pensions, $90 \%$ of prices or $75 \%$ of prices for higher pensions.

6. Japan: indexation is to wages until age 67 and to prices after age 68 .

7. Poland: valorisation to real wage bill growth but at least price inflation.

8. Portugal: indexation will be higher relative to prices for low pensions and vice versa. Indexation will be more generous the higher is GDP growth.

9. Sweden: the contribution rate is $2.5 \%$ for personal plans up to the ceiling for the public scheme. For quasi-mandatory occupational plans the contribution rates are $4.5 \%$ on a lower slice of earnings and $30 \%$ on an upper slice with no ceiling (in the largest scheme for private-sector workers)

10. United States: earnings valorisation to age 60; no adjustment from 60 to 62; prices valorisation from 62 to 67. 


\section{Key results}

The rules for eligibility to retire and withdraw a pension benefit are very complex and often reflect conflicting government objectives. This is all mirrored in the different criteria for pension benefit withdrawal in different schemes. In 2014 the OECD average normal pension age was equal to 64.0 years for men and 63.1 years for women across all schemes for an individual retiring in 2014 and assuming labour market entry at age 20.

The table shows the rules for normal and early retirement by pension benefit scheme for a person entering the labour force at age 20. Assuming the same entry age for current retirement ages enables a comparison over time between the current retirement ages presented here and the future retirement ages presented in the following section and in the OECD pensions modelling. In 2014 the OECD average normal pension age in 2014 was equal to 64.0 years for men and 63.1 years for women across all schemes and countries. These averages should however be interpreted with caution as they do not say anything about how individuals actually react to these ages in either the schemes or countries.

\section{Normal pension age}

The lowest normal pension ages equal 58 for women in Turkey and 58.7 for men in Slovenia (Figure 5.8). Iceland, Israel (for men only) and Norway have the highest normal pension age at 67.

In 11 out of the 34 countries the pension ages still differ between men and women. In these countries the average pension age for men equalled 63.6 years and 60.9 for women. However, except for Chile, Israel and Switzerland these gender differences in the pension rules are being phased out.

In 21 of the 34 countries, different rules apply to different components of the overall retirement-income package and so these are shown separately. In these 21 countries there is no easy answer to what the normal retirement age is as it differs across pension schemes.

\section{Early age}

Early pension withdrawal before age 60 is often possible in occupational and private pension plans. However, some countries will not allow early retirement in any mandatory part of the pension system such as Denmark, Ireland, Israel, the Netherlands, New Zealand, Poland, Turkey and the United Kingdom. In other cases, early retirement is restricted to certain schemes: in Australia, Chile and Iceland to mandatory private pensions; and in Canada and Sweden, there is no early retirement under basic or targeted programmes but early withdrawal is possible for the earnings-related systems.

In most defined benefit and points schemes, the adjustment is simply a parameter of the pension system: the benefit is permanently reduced by $x \%$ for each year of early retirement.

In defined contribution systems the size of the annual benefit varies and depends on the age of benefit withdrawals through the size of the annuity divisor. The annuity divisor is calculated as a function of expected remaining life expectancy and discount rates. In these type of systems there is only an age of early pension withdrawal. In Ireland for example occupational pensions are available from the age of 50 , however, it is not possible to withdraw the basic pension before the age of 66. In a similar manner it is possible to withdraw the NDC/DC pensions in a flexible manner in Sweden from the age of 61, however, if you are eligible for the minimum top-up pension you have to wait until 65. As a consequence the normal pension age not only differs between gender but it also differs across earnings levels, eligibility criteria and type of pension system and obviously how important income from these schemes are for the individual to finance retirement. 


\subsection{Early and normal retirement ages for an individual retiring in 2014 by type of pension scheme}

\begin{tabular}{|c|c|c|c|c|c|c|c|c|c|}
\hline & & Scheme & Early age & Normal & & & Scheme & Early age & Normal \\
\hline \multirow[t]{2}{*}{ Australia } & & $\mathrm{T}$ & .. & 65 & Italy & Men & NDC & .. & 62.5 \\
\hline & & DC & 55 & .. & & Women & NDC & .. & 62 \\
\hline \multirow[t]{2}{*}{ Austria } & Men & $\mathrm{DB}(\mathrm{ER})$ & 64.25 & 65 & Japan & & Basic/DB & 60 & 65 \\
\hline & Women & $\mathrm{DB}(\mathrm{ER})$ & 59.25 & 60 & Korea & & DB & 56 & 61 \\
\hline \multirow[t]{2}{*}{ Belgium } & & DB (ER) & 60 & & Luxembourg & & $\mathrm{DB}$ & 57 & 60 \\
\hline & & Min. & .. & 65 & Mexico & & $\mathrm{T}$ & .. & 65 \\
\hline \multirow[t]{2}{*}{ Canada } & & Basic/T + DB & 60 (DB only) & 65 & & & $\mathrm{DC}$ & Any age/60 & 65 \\
\hline & & DB (ER) & 60 & .. & Netherlands & & Basic &.. & 65.2 \\
\hline \multirow[t]{3}{*}{ Chile } & & Basic/T & .. & 65 & & & $\mathrm{DB}(\mathrm{Occ})$ & & 65 \\
\hline & Men & DC & Any age & 65 & New Zealand & & Basic &.. & 65 \\
\hline & Women & $\mathrm{DC}$ & Any age & 60 & & & $\mathrm{DC}$ & Flexible & \\
\hline \multirow[t]{2}{*}{ Czech Republic } & Men & $\mathrm{DB}$ & 60 & 62.67 & Norway & & Min. & 67 & 67 \\
\hline & Women & $\mathrm{DB}$ & 60 & 61.33 & & & NDC/DB & 62 & 67 \\
\hline \multirow[t]{3}{*}{ Denmark } & & Basic/T & .. & 65 & Poland & Men & NDC/min. & .. & 65.25 \\
\hline & & DC (ATP) & .. & 65 & & Women & NDC/min. & .. & 60.25 \\
\hline & & $\mathrm{DC}(\mathrm{Occ})$ & & 65 & Portugal & & DB & 65 & 66 \\
\hline \multirow[t]{3}{*}{ Estonia } & Men & Points & 60 & 63 & & & Min. & .. & 66 \\
\hline & Women & Points & 60 & 62 & Slovak Republic & Men & $\mathrm{DB}$ & Subsistance level & 62 \\
\hline & & DC & 62 & .. & & Women & $\mathrm{DB}$ & Subsistance level & $62-57.5^{1}$ \\
\hline \multirow[t]{2}{*}{ Finland } & & Min. & 63 & 65 & Slovenia & Men & $\mathrm{DB}$ & .. & 58.7 \\
\hline & & $\mathrm{DB}$ & 63 & 65 & & Women & $\mathrm{DB}$ & .. & 58.3 \\
\hline \multirow[t]{2}{*}{ France } & & $\mathrm{DB}$ & 61.2 & 61.2 & Spain & & DB & 61 & 65 \\
\hline & & Points & 60.0 & 61.2 & Sweden & & GARP & .. & 65 \\
\hline Germany & & Points & 63 & 65 & & & NDC/DC & 61 & .. \\
\hline Greece & & DB & 62 & 62 & Switzerland & Men & DB & 63 & 65 \\
\hline \multirow[t]{2}{*}{ Hungary } & Men & $\mathrm{DB}$ &.. & 62.5 & & Women & $\mathrm{DB}$ & 62 & 64 \\
\hline & Women & DB & Any with 40 years & 62.5 & Turkey & Men & $\mathrm{DB}$ & .. & 60 \\
\hline \multirow[t]{2}{*}{ Iceland } & & Basic/T & .. & 67 & & Women & $\mathrm{DB}$ & .. & 58 \\
\hline & & $\mathrm{DB}(\mathrm{Occ})$ & 65 & 67 & United Kingdom & Men & Basic (SP) & .. & 65 \\
\hline \multirow[t]{2}{*}{ Ireland } & & Basic/T & .. & 66 & & Women & Basic (SP) & .. & 62.5 \\
\hline & & $\mathrm{DC}(\mathrm{Occ})$ & 50 & .. & & & $\mathrm{T}(\mathrm{PC})$ & .. & 65 \\
\hline \multirow[t]{3}{*}{ Israel } & Men & Basic/T & .. & 67 & & & DC & 55 & .. \\
\hline & Women & Basic/T & .. & 62 & United States & & $\mathrm{DB}$ & 62 & 66 \\
\hline & & & & & & & $T$ & & 65 \\
\hline
\end{tabular}

Note: The normal retirement age is calculated assuming labour market entry at age 20 . DB = Defined benefit; DC = Defined contribution; .. = Early retirement or deferral of pension is not available; Occ = Occupational; $\mathrm{T}=$ Targeted. Where pension ages for men and women differ they are shown as men/women. - = Benefits automatically adjusted for early and late retirement in DC schemes.

1. Slovak Republic: For women with children the pension age is reduced.

Source: See "Country profiles" in Chapter 11 of this report.

\subsection{Current retirement age in $\mathbf{2} 014$ for a person who entered the labour force at age 20}

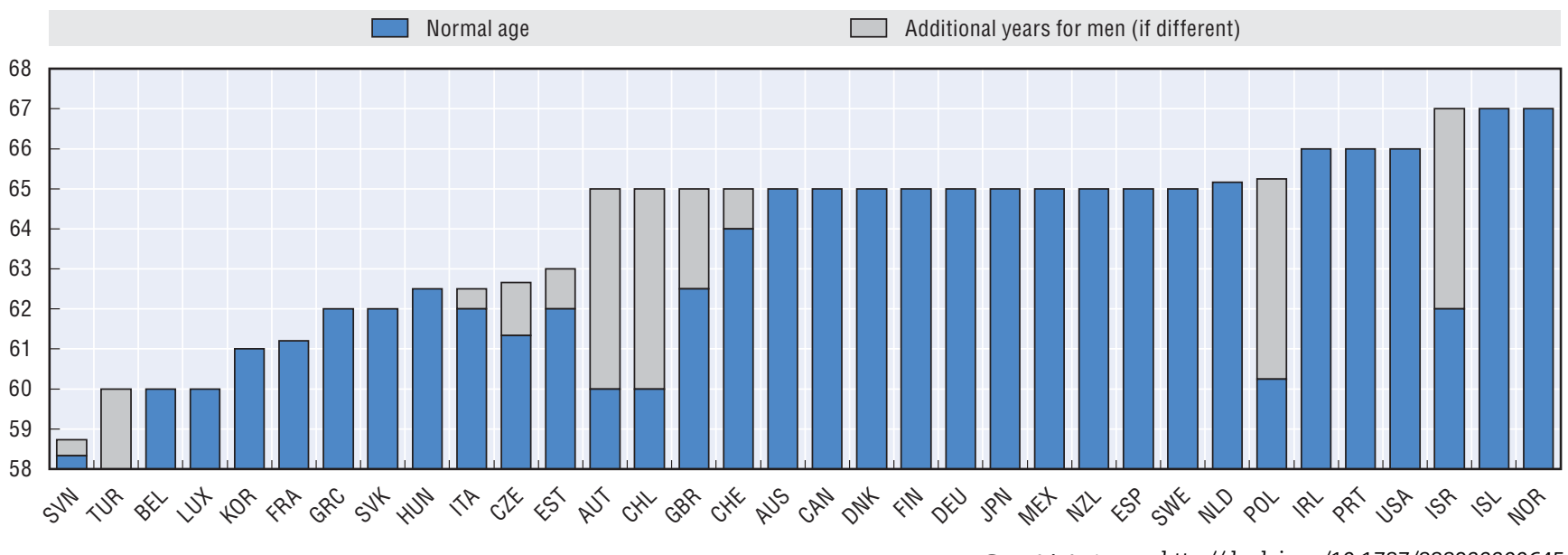




\section{Key results}

Future normal and early retirement ages have been increasing. Following the changes presented herein and assuming labour market entry at age 20 in 2014 the normal retirement age will increase to 65.5 for men and 65.4 for women on average across all OECD countries against 64.0 and 63.1 years respectively in 2014.

The table shows the future long-term rules for normal and early retirement by pension benefit scheme for a person entering the labour force at age 20. Across all schemes and countries and genders the average normal pension age in 2014 was equal to 64.0 for men and 63.1 years for women and by 2054 - this age will increase to 65.5 years for men and 65.4 years for women across all OECD countries. This average shoud however be interpreted with caution as it does not say anything about how individuals react to these ages in neither the schemes nor the countries. However, it does give some insight in the averages across schemes modelled currently.

\section{Normal pension age}

The normal retirement age will increase in 18 out of 34 OECD countries for people entering at age 20. In the countries were the normal pension age is increasing the average increase is almost 3 years from the pension age of today. The highest increase in the pension age will happen in the Czech Republic were the normal pension age is increasing from 62.7 currently to 68 years in the period after 2054 . Two other countries that are rapidly increasing their normal pension age are Italy from 62.5 to 67 and the Slovak Republic from 62 years currently to 67 years in the future. Normal retimement ages are also set to increase above 65. In 2014 eight of 34 countries had retirement ages above 65 . By 2054 - this share will change to 15 out of 34 OECD countries.

In 2054 the lowest normal retirement age will be equal to 60 in Luxembourg and Slovenia. Although in Slovenia it will by this time have increased from 58.7 currently. Other countries with low normal retirement ages in the future are Greece at 62 years and France at 63 years.

In 2014 retirement age gender gaps existed in two out of the 34 OECD countries. In these countries the average pension age for men equals 63.4 and 61.0 for women. However, by 2054 and beyond most retirement age gender gaps will have been phased out everywhere except for in Chile, Israel and Switzerland.

\section{Current and future retirement-age gap between men and women entering the labour market at age $\mathbf{2 0}$}

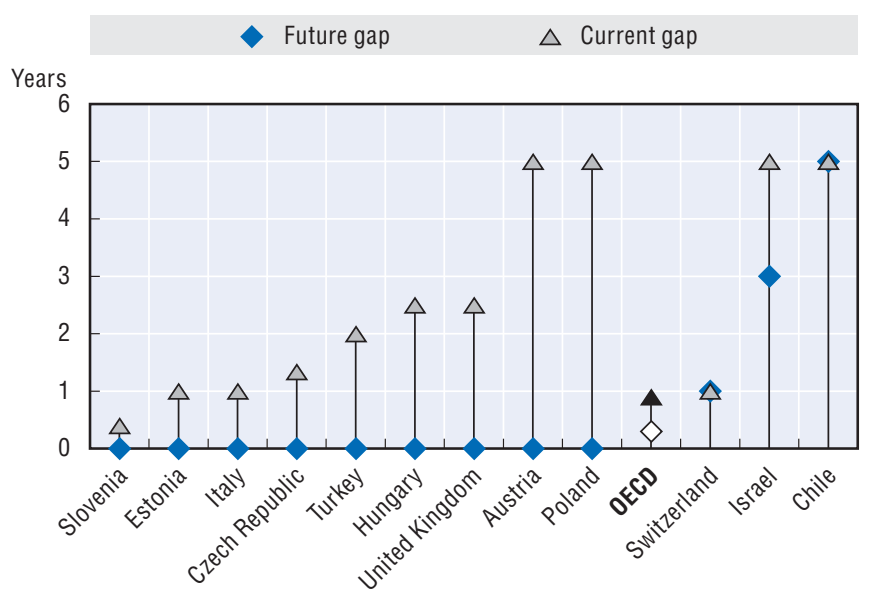

Source: See Chapter 1 on "Recent pension reforms". StatLink 제매 http://dx.doi.org/10.1787/888933300266

\section{Early retirement age}

Early pension benefit withdrawal will still be possible in a large number of OECD countries and in some cases benefit withdrawal will still be possible before age 60. Most often this option is available in defined contribution systems that are either occupational and/or private pension plans. In the United Kingdom for example defined contribution pension pots will be eligible for withdrawal 10 years before the normal retirement age. In defined contribution systems benefits are automatically actuarially adjusted. In defined benefit systems pension benefits for early retirees are usually cut to reflect the longer durations in retirement. Increasing penalties for early withdrawal has been one of the most widely used reforms to increase economic incentives to defer pension benefit receipt (see Table 5.9 for the adjustments made to DB systems). 


\subsection{Early and normal retirement ages by type of scheme in the long-term for a person entering} the labour force at age 20 in 2014

\begin{tabular}{|c|c|c|c|c|c|c|c|c|c|c|c|c|c|}
\hline & & Scheme & Early age & $\begin{array}{l}\text { Reduction } \\
\quad(\%)\end{array}$ & Normal & $\begin{array}{c}\text { Increase } \\
(\%)\end{array}$ & & & Scheme & Early age & $\begin{array}{l}\text { Reduction } \\
(\%)\end{array}$ & Normal & $\begin{array}{c}\text { Increase } \\
(\%)\end{array}$ \\
\hline \multirow[t]{2}{*}{ Australia } & & $\mathrm{T}$ & .. & & 67 & & Italy & & NDC & 62 & & 67 & \\
\hline & & DC & 55 & &.. & & Japan & & Basic/DB & 60 & 6.0 & 65 & 8.4 \\
\hline Austria & & $\mathrm{DB}(\mathrm{ER})$ & 62 & 5.1 & 65 & 4.2 & Korea & & DB & 60 & & 65 & 7.2 \\
\hline \multirow[t]{2}{*}{ Belgium } & & $\mathrm{DB}(\mathrm{ER})$ & 62 & & 65 & & Luxembourg & & $\mathrm{DB}$ & 60 & & 60 &.. \\
\hline & & Min &.. & & 65 & & Mexico & & $\mathrm{T}$ & .. & & 65 & \\
\hline \multirow[t]{2}{*}{ Canada } & & Basic/T + DB & 60 (DB only) & & 67 (Basic/T) & 7.2 (Basic/T) & & & DC & Any age/60 & - & 65 & - \\
\hline & & DB (ER) & 60 & 7.2 & 65 & 8.4 & Netherlands & & Basic & .. & & 67 & .. \\
\hline \multirow[t]{3}{*}{ Chile } & & Basic/T &.. & & 65 & & & & $\mathrm{DB}(\mathrm{Occ})$ & & & 65 & \\
\hline & Men & DC & Any age & & 65 & & New Zealand & & Basic &.. & & 65 & \\
\hline & Women & $\mathrm{DC}$ & Any age & & 60 & & & & DC & Flexible & & & \\
\hline Czech Republic & & DB & 65 & $3.6-5.6$ & 68 & 6.0 & Norway & & Min. & 67 & & 67 & \\
\hline \multirow[t]{3}{*}{ Denmark } & & Basic/T & .. & & 67 & 5.8 & & & $\mathrm{NDC} / \mathrm{DB}$ & 62 & & .. & \\
\hline & & DC (ATP) & .. & & 67 & & & & $\mathrm{DC}(\mathrm{Occ})$ & 62 & & .. & \\
\hline & & $\mathrm{DC}(\mathrm{Occ})$ & & & 65 & & Poland & & NDC/min. & .. & & 67 & \\
\hline \multirow[t]{2}{*}{ Estonia } & & Points & 62 & 4.8 & 65 & 10.8 & Portugal & & DB & 55 & 6.0 & 66 & \\
\hline & & DC & 62 & &.. & & & & Min. & .. & & 66 & \\
\hline \multirow[t]{2}{*}{ Finland } & & Min. & 63 & 4.8 & 65 & $7.2^{1}$ & Slovak Republic & & DB & 65 & 6.5 & 67 & 6.0 \\
\hline & & $\mathrm{DB}$ & 63 & & 65 & 4.8 & & & $\mathrm{DC}$ & 62 & & 67 & \\
\hline \multirow[t]{2}{*}{ France } & & DB & 62 & 5.0 & 63 & 5.0 & Slovenia & & $\mathrm{DB}$ & .. & & 60 & $4-12$ \\
\hline & & Points & 62 & $4.0-7.0$ & 63 & & Spain & & DB & 61 & & 65 & \\
\hline Germany & & Points & 63 & 3.6 & 65 & 6.0 & Sweden & & GARP & .. & & 65 & \\
\hline Greece & & DB & 62 & & 62 & & & & NDC/DC & 61 & & .. & \\
\hline Hungary & & DB & .. & & 65 & 6.0 & & & $\mathrm{DC}(\mathrm{Occ})$ & 55 & & 65 & \\
\hline \multirow[t]{2}{*}{ Iceland } & & Basic/T & .. & & 67 & & Switzerland & Men & DB & 63 & 6.8 & 65 & $5.2-6.3$ \\
\hline & & $\mathrm{DB}(0 \mathrm{cc})$ & 65 & 7.0 & 67 & 6.0 & & Women & $\mathrm{DB}$ & 62 & $6.35-7.1$ & 64 & $4.5-5$ \\
\hline \multirow[t]{2}{*}{ Ireland } & & Basic/T & .. & & 68 &.. & Turkey & & DB & .. & & 65 & \\
\hline & & $\mathrm{DC}(\mathrm{Occ})$ & 50 & &.. & & United Kingdom & & Basic & .. & & 68 & 10.4 \\
\hline \multirow[t]{3}{*}{ Israel } & Men & Basic/T & .. & & 67 & 5.0 & & & $\mathrm{DC}(\mathrm{Occ})$ & 58 & & .. & \\
\hline & Women & Basic/T &.. & & 64 & & United States & & DB & 62 & $5.0 / 6.7$ & 67 & 8.0 \\
\hline & & DC & & & 67 & & & & & & & & \\
\hline
\end{tabular}

Note: $\mathrm{DB}=$ Defined benefit; $\mathrm{DC}=$ Defined contribution; .. = Early retirement or deferral of pension is not available; Occ = Occupational; $\mathrm{T}=$ Targeted . Where pension ages for men and women differ they are shown as M/F. - = Benefits automatically adjusted for early and late retirement in DC schemes. Data rounded to one decimal place. The reference retirement age used in the modelling has been bolded.

1. Finland: The increase comes only after 68.

Source: See "Country profiles" in Chapter 11 of this report. 
5.10. Current and future retirement ages for a man entering the labour market at age 20

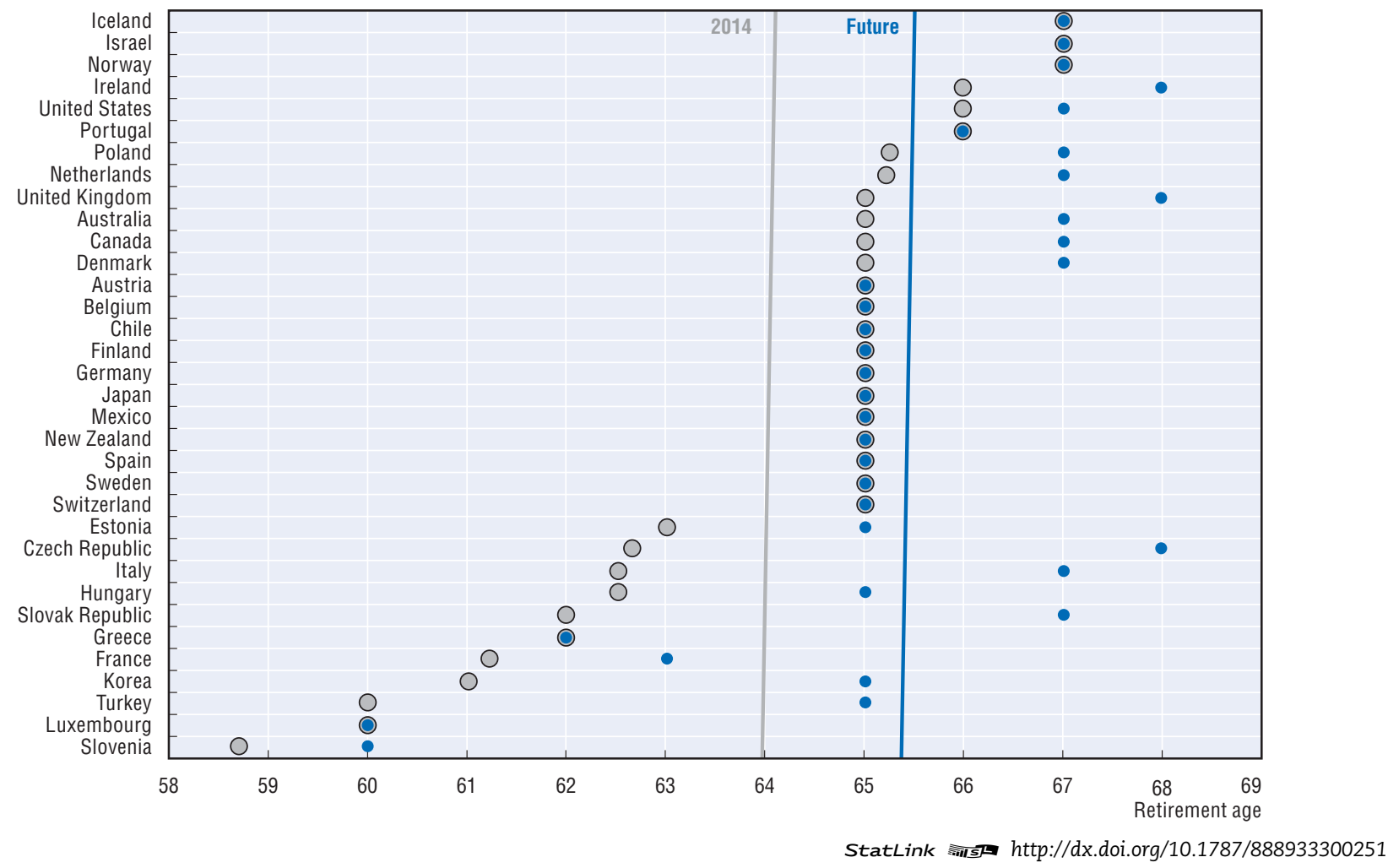




\section{Chapter 6}

\section{Pension entitlements}

Pension entitlements are calculated using the OECD pension models. The theoretical calculations are based on national parameters and rules that apply in 2014. They relate to workers entering the labour market in 2014 at the age of 20 and include the full impact of pension reforms that have been legislated and are being phased in. A note on the methodology used and assumptions made precedes the pension indicators.

The indicators begin with the gross replacement rate in mandatory pension schemes: the ratio of pensions to individual earnings. The second shows the replacement rates for mandatory and voluntary pension schemes where these schemes have broad coverage. Thereafter follows an analysis of the tax treatment of pensions and pensioners. The fourth and fifth indicator shows the net replacement rates, taking account of taxes and contributions. After this follows two indicators of pension wealth: the lifetime discounted value of the flow of retirement benefits. This indicator also takes into account the retirement age, indexation of benefits, and life expectancy. The pension wealth indicator is presented in gross and net terms. The net pension wealth is based on the after tax flow of retirement benefits.

The statistical data for Israel are supplied by and under the responsibility of the relevant Israeli authorities. The use of such data by the OECD is without prejudice to the status of the Golan Heights, East Jerusalem and Israeli settlements in the West Bank under the terms of international law. 


\section{Introduction}

The indicators of pension entitlements that follow here in Chapter 6 use the OECD cohort based pension models. The methodology and assumptions are common to the analysis of all countries, allowing the design of pension systems to be compared directly. This enables the comparison of future entitlements under today's parameters and rules.

The pension entitlements that are presented are those that are currently legislated in OECD countries. Reforms that have been legislated before June 2015 are included where sufficient information is available. Changes that have already been legislated and are being phased-in gradually and yearly are modelled from the year that they are implemented and onwards.

The values of all pension-system parameters reflect the situation in the year 2014 and onwards. The calculations show the pension benefits of a worker who enters the system today at ag 20 and retires after a full career. The main results are shown for a single person. All indexation and valorisation rules follow what is legislated in the baseline scenario.

\section{Career length}

A full career is defined here as entering the labour market at age of 20 and working until the normal pension age defined by this entry age (see indicator on "Future retirement ages" in Chapter 5). The implication is that the length of career varies with the statutory retirement age: 40 years for retirement at 60,45 with retirement age at 65 , etc.

People often spend periods out of paid work in unemployment, full-time education, caring for children, disabled or elderly relatives, etc. However, most OECD countries have mechanisms in place to protect the pension entitlements for such periods. The impact of interrupted careers is shown in Chapter 3: "How incomplete careers affect pension entitlements".

Rules for periods of unemployment and caring for children, which are often very complex, are set out in the "Country profiles" towards the end of this report.

\section{Coverage}

The pension models presented here include all mandatory pension schemes for private-sector workers, regardless of whether they are public (i.e. they involve payments from government or from social security institutions, as defined in the System of National Accounts) or private. For each country, the main national scheme for private-sector employees is modelled. Schemes for civil servants, public-sector workers and special professional groups are excluded.

Schemes with near-universal coverage are also included, provided that they cover at least $85 \%$ of employees. Such plans are called "quasi-mandatory" in this report. They are particularly significant in Denmark, the Netherlands and Sweden.
An increasing number of OECD countries have broad coverage of voluntary, occupational pensions and these play an important role in providing retirement incomes. For these countries, a second set of results for replacement rates is shown with entitlements from these voluntary pension plans.

Resource-tested benefits for which retired people may be eligible are also modelled. These can be means-tested, where both assets and income are taken into account, purely income-tested or withdrawn only against pension income. The calculations assume that all entitled pensioners take up these benefits. Where there are broader means tests, taking account also of assets, the income test is taken as binding. It is assumed that the whole of income during retirement comes from the mandatory pension scheme (or from the mandatory plus voluntary pension schemes in those countries where the latter are modelled).

Pension entitlements are compared for workers with a range of different earnings levels: between 0.5 and three times the average worker earnings (AW). This range permits an analysis of future retirement benefits of both the poorest and richest workers.

\section{Economic variables}

The comparisons are based on a single set of economic assumptions for all the OECD countries and other major economies analysed. In practice, the level of pensions will be affected by economic growth, rate of return on financial assets, real wage growth, the discount rate and inflation, and these will vary across countries. A single set of assumptions, however, ensures that the outcomes of the different pension regimes are not affected by different economic conditions. In this way, differences across countries in pension levels reflect differences in pension systems and policies alone. The baseline assumptions are set out below.

Price inflation is assumed to be $2 \%$ per year. Real earnings are assumed to grow by $1.25 \%$ per year on average (given the assumption for price inflation, this implies nominal wage growth of $3.275 \%$ ). Individual earnings are assumed to grow in line with the economy-wide average. This means that the individual is assumed to remain at the same point in the earnings distribution, earning the same percentage of average earnings in every year of the working life. The real rate of return on funded, defined-contribution pensions is assumed to be $3 \%$ per year. Administrative charges, fee structures and the cost of buying an annuity are assumed to result in a defined contribution conversion factor of $85 \%$ applied to the accumulated defined contribution wealth when calculating the annuity. The real discount rate (for actuarial calculations) is assumed to be $2 \%$ per year. 
The baseline modelling uses country-specific projections of mortality rate from the United Nations population database for every year from 2014 to 2080.

Changes in these baseline assumptions will obviously affect the resulting pension entitlements. The impact of variations in the economic variables is shown in the Chapter 4: "Sensitivity of replacement rates to the model parameters".

The calculations assume that benefits from definedcontribution plans are paid in the form of a price-indexed life annuity at an actuarially fair price assuming perfect foresight. This is calculated from the mortality projections once the conversion factor is taken into account. If people withdraw the money in alternative ways, the capital sum at the time of retirement is the same: it is only the way that the benefits are spread that is changed. Similarly, the notional annuity rate in notional accounts schemes is (in most cases) calculated from mortality data using the indexation rules and discounting assumptions employed by the respective country.

\section{Legislated policy versus constant policy}

In some schemes, the safety-net in the pension system may be tied to some general index that is different than that of average wages (most often consumer price index or a mixture of the two). Discrepancies to the income distribution (current wage level) may therefore occur over long simulation periods (such as 40 years). In these cases an alternative scenario assuming full-wage indexation of safety nets is produced. The alternative scenario is only presented if relevant in the country chapter. The aim here is to emphasise the importance of indexation in the longerterm. The results should therefore not be seen as an attempt to forecast what policies will be implemented in practice in the future but rather as a prospective comparison of the current legislation and a constant policy scenario.

\section{Taxes and social security contributions}

Information on personal income tax and social security contributions paid by pensioners, which were used to calculate pension entitlements, are available in the on-line

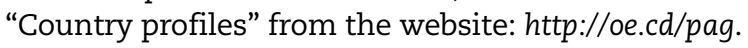

The modelling assumes that tax systems and socialsecurity contributions remain unchanged in the future. This constant policy assumption implicitly means that "value" parameters, such as tax allowances or contribution ceilings, are adjusted annually in line with average worker earnings, while "rate" parameters, such as the personal income tax schedule and social security contribution rates, remain unchanged.

General provisions and the tax treatment of workers for 2014 can be found in the OECD's Taxing Wages report. The conventions used in that report, such as which payments are considered taxes, are followed here.

\section{Further reading}

OECD (2015), Taxing Wages 2015, OECD Publishing, Paris, http://dx.doi.org/10.1787/tax_wages-2015-en. 


\section{Key results}

The future gross replacement rate shows the level of pension benefits in retirement from mandatory public and private pension schemes relative to earnings when working. For workers with average worker earnings (AW), the future gross replacement rate averages $53 \%$ for both men and women in the 34 OECD countries, with substantial cross-country variation. At the bottom of the range, Mexico and the United Kingdom offer future replacement rates of around $20-25 \%$ of average earnings to people starting work today. The Netherlands, at the top of the range, offers replacement rates of slightly more than $90 \%$.

Most OECD countries protect low-income workers (here defined as workers earning half of average worker earnings) from old-age poverty by providing higher replacement rates for them than for average worker earners. Lowincome workers would receive gross replacement rates averaging around $65 \%$, compared with $53 \%$ for averagewage workers. However, projected replacement rates in nine countries are the same at average and half-average pay: Austria, Finland, Germany, Hungary, Italy, Poland, Spain, Sweden and Turkey.

At the top of the range, low earners in Denmark receive a replacement rate of $107 \%$ : retirement benefits are thus higher than their earnings when working. At the other end of the scale, Mexico offers replacement rates of $35 \%$ to low-income earners. Some countries, such as Ireland, pay relatively small benefits to average earners, but are closer to average for low-income workers. On average in the 34 OECD countries, the gross replacement rate at 1.5 times average earnings (here called "high earnings") is $48 \%$, somewhat below the $53 \%$ figure for average earners. Replacement rates equal $89 \%$ in the Netherlands, while at the other end of the spectrum, the United Kingdom offers a replacement rate of around 15\%.

Gross pension replacement rates differ for women (due to a lower pension eligibility age for women than for men and the use of sex specific mortality rates to compute annuities or due to gender specific accrual rates) in six countries: Australia, Chile, Israel, Mexico, Slovenia and Switzerland. Differences between the sexes are substantial in Australia, Chile and Israel, with replacement rates for women between $88 \%$ and $95 \%$ of the value for men. In Slovenia the replacement rates for women are $105 \%$ of that for men due to a higher accrual rate for women. This difference is being phased out by 2023. For the non-OECD countries there is a wide range in the replacement rate calculations, with South Africa around $11 \%$ and India at $97 \%$ for average earners.

Gross pension replacement rates fall with age from $53 \%$ on average at the time of retirement across all OECD countries to $46 \%$ at age of 80 . This difference is due to the indexation of pension benefits in payment, which do not follow wages in many countries. Austria, Spain, Sweden and Turkey have the biggest drop around 13-14 percentage points between the retirement age and age 80 . Countries were the indexation of pension benefits follow wages have the same replacement rate at age 80 .

\section{Definition and measurement}

The old-age pension replacement rate measures how effectively a pension system provides a retirement income to replace earnings, the main source of income before retirement. The gross replacement rate is defined as gross pension entitlement divided by gross pre-retirement earnings.

Often, the replacement rate is expressed as the ratio of the pension to final earnings (just before retirement). Here, however, pension benefits are shown as a share of individual lifetime average earnings (revalued in line with economy-wide earnings growth). Under the baseline assumptions, workers earn the same percentage of average worker earnings throughout their career. If people move up the earnings distribution as they get older, then their earnings just before retirement will be higher than they were on average over their lifetime and replacement rates calculated on individual final earnings would be lower. 


\subsection{Gross pension replacement rates by earnings}

\begin{tabular}{|c|c|c|c|c|c|c|c|c|c|}
\hline & \multicolumn{4}{|c|}{ Individual earnings, multiple of mean for men (women where different) } & & \multicolumn{4}{|c|}{ Individual earnings, multiple of mean for men (women where different) } \\
\hline & Pension age & 0.5 & 1.0 & 1.5 & & Pension age & 0.5 & 1.0 & 1.5 \\
\hline OECD members & & & & & OECD members (cont.) & & & & \\
\hline Australia & 67 & $79.3(75.7)$ & 44.5 (40.9) & 32.9 (29.3) & Norway & 67 & 62.8 & 49.8 & 38.9 \\
\hline Austria & 65 & 78.1 & 78.1 & 77.6 & Poland & 67 & 43.1 & 43.1 & 43.1 \\
\hline Belgium & 65 & 47.6 & 46.6 & 35.3 & Portugal & 66 & 75.1 & 73.8 & 72.5 \\
\hline Canada & 67 & 50.1 & 36.7 & 25.1 & Slovak Republic & 67 & 70.4 & 62.1 & 59.3 \\
\hline Chile & 65 & 39.4 (36.7) & 32.8 (28.8) & 32.9 (28.9) & Slovenia & 60 & 44.4 (46.8) & 38.4 (40.4) & $36.0 \quad(37.9)$ \\
\hline Czech Republic & 68 & 78.9 & 49.0 & 39.1 & Spain & 65 & 82.1 & 82.1 & 82.1 \\
\hline Denmark & 67 & 107.4 & 67.8 & 55.1 & Sweden & 65 & 56.0 & 56.0 & 65.2 \\
\hline Estonia & 65 & 62.1 & 50.5 & 46.6 & Switzerland & 65 (64) & 55.7 (55.1) & 40.2 (39.9) & 26.8 (26.6) \\
\hline Finland & 65 & 55.8 & 55.8 & 55.8 & Turkey & 65 & 75.7 & 75.7 & 75.7 \\
\hline France & 63 & 56.8 & 55.4 & 48.2 & United Kingdom & 68 & 43.3 & 21.6 & 14.4 \\
\hline Germany & 65 & 37.5 & 37.5 & 37.5 & United States & 67 & 44.4 & 35.2 & 29.1 \\
\hline Greece & 62 & 79.4 & 66.7 & 62.3 & OECD34 & 65.5 (65.4) & 64.5 (64.2) & 52.9 (52.5) & 47.8 (47.4) \\
\hline Hungary & 65 & 58.7 & 58.7 & 58.7 & & & & & \\
\hline Iceland & 67 & 82.6 & 69.2 & 68.1 & Other major economies & & & & \\
\hline Ireland & 68 & 69.5 & 34.7 & 23.2 & Argentina & 65 (60) & 81.8 (88.2) & 71.6 (71.5) & 68.3 (65.9) \\
\hline Israel & 67 (64) & 82.7 (74.7) & $61.0(54.1)$ & $40.7(36.0)$ & Brazil & $55 \quad(50)$ & 97.5 & 69.5 (52.9) & 62.5 (52.9) \\
\hline Italy & 67 & 69.5 & 69.5 & 69.5 & China & 60 & 94.0 (86.5) & $74.0 \quad(69.0)$ & 67.4 (63.2) \\
\hline Japan & 65 & 48.8 & 35.1 & 30.5 & India & 58 & 96.5 (91.3) & 96.5 (91.3) & 96.5 (91.3) \\
\hline Korea & 65 & 58.5 & 39.3 & 29.3 & Indonesia & 55 & 13.0 (11.8) & 13.0 (11.8) & 13.0 \\
\hline Luxembourg & 60 & 89.5 & 76.8 & 72.5 & Russian Federation & 60 & 75.2 (64.1) & 75.2 (64.1) & $75.2(64.1)$ \\
\hline Mexico & 65 & 35.0 & 25.5 (23.6) & 24.2 (22.4) & Saudi Arabia & 45 & 59.6 & 59.6 & 59.6 \\
\hline Netherlands & 67 & 94.0 & 90.5 & 89.3 & South Africa & 60 & 20.9 & 10.5 & 7.0 \\
\hline New Zealand & 65 & 80.1 & 40.1 & 26.7 & EU28 & 65.2 & 69.9 (69.7) & 59.0 (58.8) & $54.4 \quad(54.2)$ \\
\hline
\end{tabular}

Source: OECD pension models.

StatLink त्नाIS http://dx.doi.org/10.1787/888933301102

\subsection{Gross pension replacement rates: Average earners at retirement age and age 80}

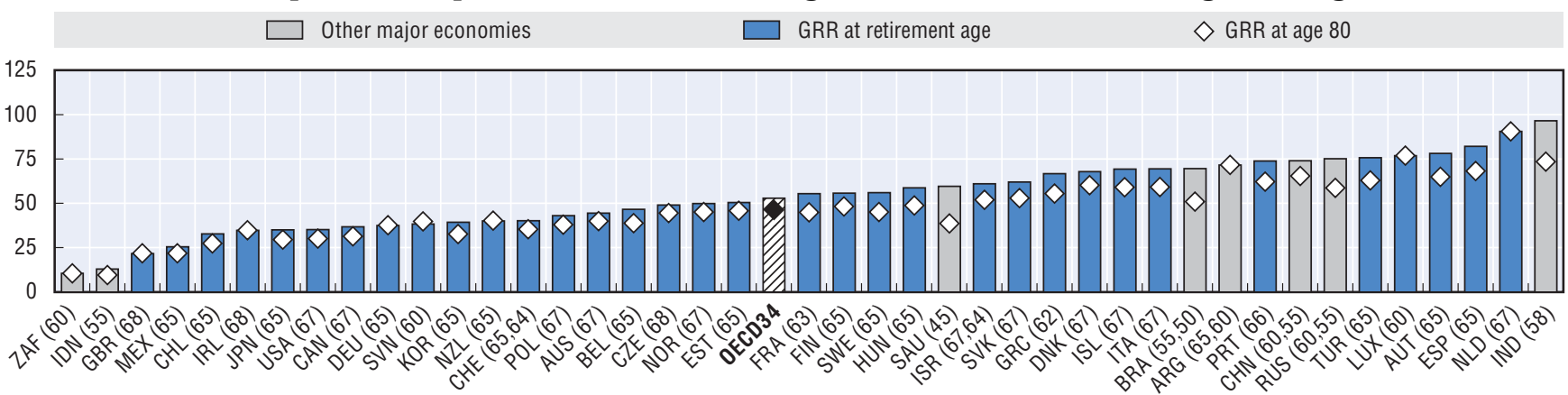

Source: OECD pension models.

StatLink न्तार्य http://dx.doi.org/10.1787/888933300676

\subsection{Gross pension replacement rates: Low and high earners}

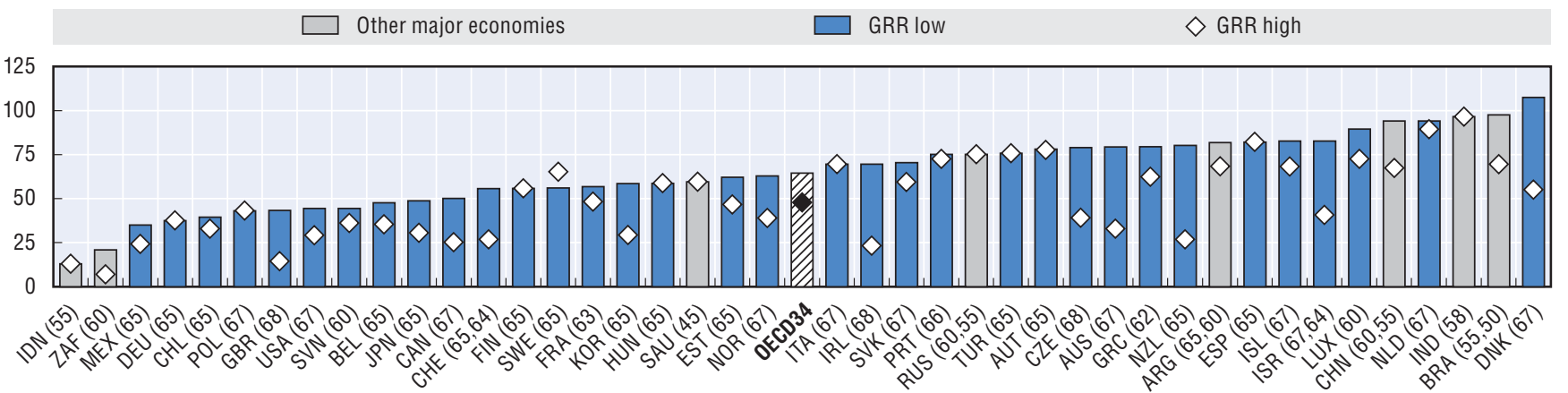

Source: OECD pension models. 


\section{Key results}

Private pensions play a large and growing role in providing incomes for old age. The OECD average for gross replacement rates of an average earner from public schemes alone is $41 \%$, compared with $53 \%$ with mandatory private pensions included. When voluntary private pensions are taken into account the OECD average increases to $58 \%$. For the seven OECD countries where voluntary private pensions are widespread the average replacement rate is $59 \%$ for an average earner compared with $36 \%$ when only mandatory schemes are considered.

Table 6.4 shows the interplay between mandatory public, mandatory private and voluntary pension schemes. For the 15 OECD countries where the calculations of entitlements only cover mandatory public pensions, the average replacement rate for an average worker earner is $60 \%$. For the 12 OECD countries with both public and mandatory private provision, the average replacement rate is $54 \%$. For all 34 OECD countries, including public, mandatory private and voluntary private pensions, the average replacement rate for the average-wage worker is $58 \%$.

Australia, Denmark, Iceland and Israel have highly targeted public programmes, where public replacement rates for middle and high earners are often topped up with mandatory private pension provisions. In Chile, Mexico, the Slovak Republic and Sweden, part of the public provision has been replaced as a result of reforms within mandatory private pensions. Canada, Ireland, the United Kingdom and the United States have long had relatively low public pensions and widespread voluntary provision.

Of the other major economies public pensions are mandatory in Argentina, Brazil, China, India, the Russian Federation and Saudi Arabia. South Africa has voluntary private schemes, with the public pension being withdrawn for average earners and above, because of its means-tested component. Indonesia's system is entirely mandatory private with no public component.

\section{Mandatory private pensions}

Mandatory private pensions exist in 12 countries. Private pensions that have near- universal coverage are described as "quasi-mandatory" (Denmark, the Netherlands and Sweden).

In Iceland, the Netherlands and Switzerland, private pensions are defined benefit while in the other countries, they are defined contribution. Replacement rates from mandatory private schemes range from $22 \%$ to $33 \%$ in six of the 12 countries. They are significantly above this range in Denmark, Iceland, Israel and the Netherlands, lower in Switzerland and much lower in Norway. However, some countries have private pensions designed to cover earnings above the ceiling of the public scheme. This is why replacement rates from private plans increase with earnings in the Netherlands and Sweden, and to a lesser extent in Norway.

\section{Voluntary private pensions}

Voluntary private pensions are shown for seven countries where voluntary private pensions are widespread (see the indicator of "Coverage of private pensions" in Chapter 10). It is assumed that workers with voluntary private pensions spend a full career in the scheme. Voluntary private pensions include both voluntary occupational and voluntary personal. In all seven countries, a definedcontribution plan is modelled.

When voluntary private pension are taken into account for Belgium, Canada, Germany, Ireland, New Zealand, the United Kingdom and the United States the average replacement, for these seven countries, is $59 \%$ for an average earner compared with $36 \%$ when only mandatory schemes are considered.

In general, the defined-contribution schemes pay a constant replacement rate with earnings. (Data on actual contribution rates by earnings are not available for most countries, and so an average or typical rate is assumed across the earnings range). It is also assumed that individuals participate fully, irrespective of their earnings gradient. Belgium and Germany are the exceptions due to a ceiling on pensionable earnings that qualify for tax incentives and a ceiling equal to $151 \%$ of average worker earnings, respectively. 


\subsection{Gross pension replacement rates from mandatory public, mandatory private} and voluntary private pension schemes

\begin{tabular}{|c|c|c|c|c|c|c|c|c|c|c|c|c|c|c|c|}
\hline & \multicolumn{3}{|c|}{ Mandatory public } & \multicolumn{3}{|c|}{ Mandatory private (DB and DC) } & \multicolumn{3}{|c|}{ Total mandatory } & \multicolumn{3}{|c|}{ Voluntary DC } & \multicolumn{3}{|c|}{ Total with voluntary } \\
\hline & 0.5 & 1.0 & 1.5 & 0.5 & 1.0 & 1.5 & 0.5 & 1.0 & 1.5 & 0.5 & 1.0 & 1.5 & 0.5 & 1.0 & 1.5 \\
\hline \multicolumn{16}{|l|}{ OECD members } \\
\hline Australia & 48.4 & 13.5 & 1.9 & 30.9 & 30.9 & 30.9 & 79.3 & 44.5 & 32.9 & & & & 79.3 & 44.5 & 32.9 \\
\hline Austria & 78.1 & 78.1 & 77.6 & & & & 78.1 & 78.1 & 77.6 & & & & 78.1 & 78.1 & 77.6 \\
\hline Belgium & 47.6 & 46.6 & 35.3 & & & & 47.6 & 46.6 & 35.3 & 13.3 & 13.3 & 10.1 & 60.9 & 59.9 & 45.5 \\
\hline Canada & 44.3 & 36.7 & 25.1 & & & & 44.3 & 36.7 & 25.1 & 29.3 & 29.3 & 29.3 & 73.5 & 66.0 & 54.4 \\
\hline Chile & 6.8 & 0.0 & 0.0 & 32.7 & 32.8 & 32.9 & 39.4 & 32.8 & 32.9 & & & & 39.4 & 32.8 & 32.9 \\
\hline Czech Republic & 78.9 & 49.0 & 39.1 & & & & 78.9 & 49.0 & 39.1 & & & & 78.9 & 49.0 & 39.1 \\
\hline Denmark & 56.2 & 21.5 & 10.3 & 51.3 & 46.3 & 44.7 & 107.4 & 67.8 & 55.1 & & & & 107.4 & 67.8 & 55.1 \\
\hline Estonia & 40.1 & 28.5 & 24.6 & 22.0 & 22.0 & 22.0 & 62.1 & 50.5 & 46.6 & & & & 62.1 & 50.5 & 46.6 \\
\hline Finland & 55.8 & 55.8 & 55.8 & & & & 55.8 & 55.8 & 55.8 & & & & 55.8 & 55.8 & 55.8 \\
\hline France & 56.8 & 55.4 & 48.2 & & & & 56.8 & 55.4 & 48.2 & & & & 56.8 & 55.4 & 48.2 \\
\hline Germany & 37.5 & 37.5 & 37.5 & & & & 37.5 & 37.5 & 37.5 & 12.5 & 12.5 & 12.5 & 50.0 & 50.0 & 50.0 \\
\hline Greece & 79.4 & 66.7 & 62.3 & & & & 79.4 & 66.7 & 62.3 & & & & 79.4 & 66.7 & 62.3 \\
\hline Hungary & 58.7 & 58.7 & 58.7 & & & & 58.7 & 58.7 & 58.7 & & & & 58.7 & 58.7 & 58.7 \\
\hline Iceland & 16.8 & 3.4 & 2.3 & 65.8 & 65.8 & 65.8 & 82.6 & 69.2 & 68.1 & & & & 82.6 & 69.2 & 68.1 \\
\hline Ireland & 69.5 & 34.7 & 23.2 & & & & 69.5 & 34.7 & 23.2 & 30.3 & 30.3 & 30.3 & 99.8 & 65.1 & 53.5 \\
\hline Israel & 23.5 & 11.8 & 7.8 & 59.2 & 49.3 & 32.8 & 82.7 & 61.0 & 40.7 & & & & 82.7 & 61.0 & 40.7 \\
\hline Italy & 69.5 & 69.5 & 69.5 & & & & 69.5 & 69.5 & 69.5 & & & & 69.5 & 69.5 & 69.5 \\
\hline Japan & 48.8 & 35.1 & 30.5 & & & & 48.8 & 35.1 & 30.5 & & & & 48.8 & 35.1 & 30.5 \\
\hline Korea & 58.5 & 39.3 & 29.3 & & & & 58.5 & 39.3 & 29.3 & & & & 58.5 & 39.3 & 29.3 \\
\hline Luxembourg & 89.5 & 76.8 & 72.5 & & & & 89.5 & 76.8 & 72.5 & & & & 89.5 & 76.8 & 72.5 \\
\hline Mexico & 13.5 & 3.9 & 2.6 & 21.6 & 21.6 & 21.6 & 35.0 & 25.5 & 24.2 & & & & 35.0 & 25.5 & 24.2 \\
\hline Netherlands & 54.2 & 27.1 & 18.1 & 39.8 & 63.4 & 71.2 & 94.0 & 90.5 & 89.3 & & & & 94.0 & 90.5 & 89.3 \\
\hline New Zealand & 80.1 & 40.1 & 26.7 & & & & 80.1 & 40.1 & 26.7 & 12.4 & 12.4 & 12.4 & 92.5 & 52.5 & 39.1 \\
\hline Norway & 58.0 & 44.0 & 32.7 & 4.8 & 5.9 & 6.2 & 62.8 & 49.8 & 38.9 & & & & 62.8 & 49.8 & 38.9 \\
\hline Poland & 43.1 & 43.1 & 43.1 & & & & 43.1 & 43.1 & 43.1 & & & & 43.1 & 43.1 & 43.1 \\
\hline Portugal & 75.1 & 73.8 & 72.5 & & & & 75.1 & 73.8 & 72.5 & & & & 75.1 & 73.8 & 72.5 \\
\hline Slovak Republic & 47.3 & 38.9 & 36.2 & 23.1 & 23.1 & 23.1 & 70.4 & 62.1 & 59.3 & & & & 70.4 & 62.1 & 59.3 \\
\hline Slovenia & 44.4 & 38.4 & 36.0 & & & & 44.4 & 38.4 & 36.0 & & & & 44.4 & 38.4 & 36.0 \\
\hline Spain & 82.1 & 82.1 & 82.1 & & & & 82.1 & 82.1 & 82.1 & & & & 82.1 & 82.1 & 82.1 \\
\hline Sweden & 37.0 & 37.0 & 27.4 & 19.0 & 19.0 & 37.8 & 56.0 & 56.0 & 65.2 & & & & 56.0 & 56.0 & 65.2 \\
\hline Switzerland & 35.6 & 23.3 & 15.6 & 20.1 & 16.9 & 11.2 & 55.7 & 40.2 & 26.8 & & & & 55.7 & 40.2 & 26.8 \\
\hline Turkey & 75.7 & 75.7 & 75.7 & & & & 75.7 & 75.7 & 75.7 & & & & 75.7 & 75.7 & 75.7 \\
\hline United Kingdom & 43.3 & 21.6 & 14.4 & & & & 43.3 & 21.6 & 14.4 & 29.8 & 29.8 & 29.8 & 73.1 & 51.4 & 44.2 \\
\hline United States & 44.4 & 35.2 & 29.1 & & & & 44.4 & 35.2 & 29.1 & 32.6 & 32.6 & 32.6 & 77.0 & 67.8 & 61.7 \\
\hline OECD34 & 52.9 & 41.3 & 36.0 & & & & 64.5 & 52.9 & 47.8 & & & & 69.1 & 57.6 & 52.4 \\
\hline \multicolumn{16}{|c|}{ Other major economies } \\
\hline Argentina & 81.8 & 71.6 & 68.3 & & & & 81.8 & 71.6 & 68.3 & & & & 81.8 & 71.6 & 68.3 \\
\hline Brazil & 97.5 & 69.5 & 69.5 & & & & 97.5 & 69.5 & 69.5 & & & & 97.5 & 69.5 & 69.5 \\
\hline China & 94.0 & 74.0 & 67.4 & & & & 94.0 & 74.0 & 67.4 & & & & 94.0 & 74.0 & 67.4 \\
\hline India & 96.5 & 96.5 & 96.5 & & & & 96.5 & 96.5 & 96.5 & & & & 96.5 & 96.5 & 96.5 \\
\hline Indonesia & & & & 13.0 & 13.0 & 13.0 & 13.0 & 13.0 & 13.0 & & & & 13.0 & 13.0 & 13.0 \\
\hline Russian Federation & 33.7 & 33.7 & 33.7 & 41.5 & 41.5 & 41.5 & 75.2 & 75.2 & 75.2 & & & & 75.2 & 75.2 & 75.2 \\
\hline Saudi Arabia & 59.6 & 59.6 & 59.6 & & & & 59.6 & 59.6 & 59.6 & & & & 59.6 & 59.6 & 59.6 \\
\hline South Africa & 20.9 & 0.0 & 0.0 & & & & 20.9 & 0.0 & 0.0 & 48.7 & 48.7 & 48.7 & 69.6 & 48.7 & 48.7 \\
\hline EU28 & 60.8 & 49.3 & 43.7 & & & & 69.9 & 59.0 & 54.4 & & & & 73.0 & 62.1 & 57.4 \\
\hline
\end{tabular}

Note: $\mathrm{DC}=$ Defined contribution; $\mathrm{DB}=$ Defined benefit.

Source: OECD pension models. 


\section{Key results}

The personal tax system plays an important role in old-age support. Pensioners often do not pay social security contributions. Personal income taxes are progressive and pension entitlements are usually lower than earnings before retirement, so the average tax rate on pension income is typically less than the tax rate on earned income. In addition, most income tax systems give preferential treatment either to pension incomes or to pensioners, through additional allowances or credits to older people.

Slightly more than half (19 out of 34) OECD countries provide older people with additional basic relief under the personal income tax. Generally, this takes the form of an extra tax allowance or tax credit. In many cases - Canada and the United Kingdom, for example - this additional relief is phased out for older people with higher incomes.

A significant number of countries offer tax relief for particular sources of retirement income. Relief from income tax for public pensions, either full or partial, is available in 14 OECD countries. For example, between $15 \%$ and $50 \%$ of income from public pensions (social security) in the United States is not taxed, depending on the total income of the pensioner. In Australia, for example, benefits derived from pension contributions and investment returns that have been taxed are not taxable in payment for over 60s. This therefore applies to the mandatory defined-contribution scheme and voluntary contributions to such plans.

In contrast some countries such as Denmark, Iceland, the Netherlands and Sweden tax earned income from work less than pensions.

Overall, 26 OECD countries have some concession for older people or pension income under their personal income taxes. In only eight is the tax treatment of pensions and pensioners the same as it is for people of working age.

Virtually all OECD countries levy employee social security contributions on workers: Australia and New Zealand are the only exceptions. In addition to these two countries, a further 17 do not levy social security contributions on pensioners. The rate of contributions in the 15 countries that do levy social security contributions on retirees is always lower than the rate charged on workers. Typically, older people do not pay contributions for pensions or unemployment (for obvious reasons). However, pensioners can be subject to levies to pay for health or long-term care and, in some cases, are liable for "solidarity" contributions to finance a broad range of benefits.

\section{Empirical results}

The figure shows the percentage of income paid in taxes and contribution by workers and pensioners.
Starting with workers, countries have been ranked by the proportion of income paid in tax at an average earner level. This is then compared to the replacement rate that an average earner would see in retirement (as set out in the indicator of "Gross pension replacement rates"). In seven OECD countries and six other major economies, such a pensioner would not pay any income tax in retirement. In some cases, such as the Slovak Republic and Turkey, this is because pensions are not taxable. In Ireland it is because the pension income would be less than the basic incometax relief offered to older people. Pensioners with the gross replacement rate for an average earner would pay $12 \%$ of their income in taxes and contributions on average across the OECD.

The figure aims to show directly the impact of different tax and contribution treatment of earnings and pensions. The amount of taxes and contributions paid by a worker with average earnings averages $27 \%$ in OECD countries and $11 \%$ in other major economies.

The last comparison shows how much a pensioner would pay with the same income: that is, a pension worth the same as average earnings. This averages $18 \%$ in OECD countries, some nine percentage points lower than workers' pay with the same level of income.

The difference between this $18 \%$ rate for pensioners with an income equal to average earnings and the $12 \%$ paid in taxes and contributions paid on incomes equal to the gross replacement rate for an average earner illustrates the impact of progressivity in income-tax systems.

\section{Further reading}

Keenay, G. and E.R. Whitehouse (2003), "The Role of the Personal Tax System in Old-age Support: A Survey of 15 Countries", Fiscal Studies, Vol. 24, No. 1, pp. 1-21. 
6.5. Treatment of pensions and pensioners under personal income tax and social security contributions

\begin{tabular}{|c|c|c|c|c|c|c|c|c|c|}
\hline & \multirow{2}{*}{$\begin{array}{c}\text { Extra tax } \\
\text { Allowance/credit }\end{array}$} & \multicolumn{2}{|c|}{$\begin{array}{l}\text { Full or partial relief } \\
\text { for pension income }\end{array}$} & \multirow{2}{*}{$\begin{array}{c}\begin{array}{c}\text { Social security } \\
\text { contributions }\end{array} \\
\text { Pensions }\end{array}$} & & \multirow{2}{*}{$\begin{array}{c}\text { Extra tax } \\
\text { Allowance/credit }\end{array}$} & \multicolumn{2}{|c|}{$\begin{array}{l}\text { Full or partial relief } \\
\text { for pension income }\end{array}$} & \multirow{2}{*}{$\begin{array}{r}\begin{array}{r}\text { Social security } \\
\text { contributions }\end{array} \\
\text { Pensions }\end{array}$} \\
\hline & & Public scheme & Private scheme & & & & Public scheme & Private scheme & \\
\hline OECD members & & & & & OECD members (cont.) & & & & \\
\hline Australia & $\checkmark$ & 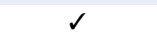 & $\checkmark$ & None & New Zealand & & & & None \\
\hline Austria & & & & Low & Norway & $\checkmark$ & $\checkmark$ & & Low \\
\hline Belgium & & $\checkmark$ & & Low & Poland & & & & Low \\
\hline Canada & $\checkmark$ & $\checkmark$ & $\checkmark$ & None & Portugal & $\checkmark$ & & & None \\
\hline Chile & $\checkmark$ & & & None & Slovak Republic & & $\checkmark$ & & None \\
\hline Czech Republic & $\checkmark$ & $\checkmark$ & & None & Slovenia & $s$ & & & Low \\
\hline Denmark & & & & None & Spain & & $\checkmark$ & & None \\
\hline Estonia & $\checkmark$ & & & None & Sweden & 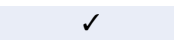 & & & None \\
\hline Finland & & $s$ & & Low & Switzerland & & & & Low \\
\hline France & & & & Low & Turkey & & $d$ & & None \\
\hline Germany & & $\checkmark$ & $\checkmark$ & Low & United Kingdom & $\checkmark$ & & & None \\
\hline Greece & & & & Low & United States & $\checkmark$ & $\checkmark$ & & None \\
\hline Hungary & & $s$ & $\checkmark$ & None & & & & & \\
\hline Iceland & & & & None & Other major economies & & & & \\
\hline Ireland & $\checkmark$ & & & Low & Argentina & & $\checkmark$ & & Low \\
\hline Israel & $\checkmark$ & & & Low & Brazil & & $\checkmark$ & & None \\
\hline Italy & $\checkmark$ & & $\checkmark$ & None & China & & & & None \\
\hline Japan & $\checkmark$ & $\checkmark$ & $\checkmark$ & Low & India & $\checkmark$ & & & None \\
\hline Korea & $\checkmark$ & $\checkmark$ & & None & Indonesia & & & & None \\
\hline Luxembourg & $\checkmark$ & & & Low & Russian Federation & & & & Low \\
\hline Mexico & $\checkmark$ & & & None & Saudi Arabia & & & & Low \\
\hline Netherlands & $\checkmark$ & & & Low & South Africa & $\checkmark$ & & & None \\
\hline
\end{tabular}

Source: On-line "Country profiles" available at www.oecd.org/els/social/pensions/PAG.

\subsection{Personal income taxes and social security contributions paid by pensioners and workers}

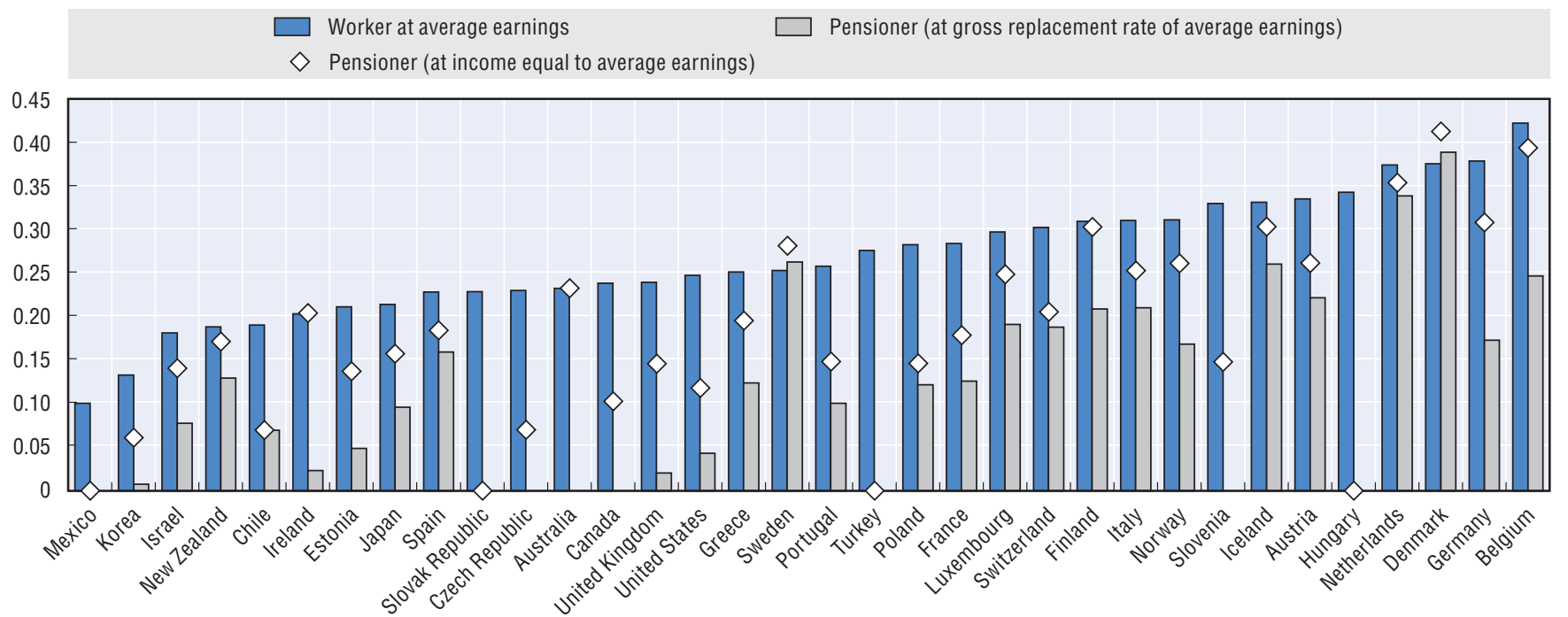

Source: OECD pension models; OECD tax and benefit models. 


\section{Key results}

For average earners, the net replacement rate from mandatory pension schemes averages $63 \%$ across the OECD, which is 10 percentage points higher than the average gross replacement rate. This reflects the higher effective tax and contribution rates that people pay on their earnings than on their pensions in retirement. Net replacement rates vary across a large range, from less than $30 \%$ in Mexico and the United Kingdom to 105\% in Turkey for average-wage workers. For low earners (with half of average worker earnings), the average net replacement rate across OECD countries is $74 \%$. For high earners ( $150 \%$ of average worker earnings) the average net replacement rate is $59 \%$, lower than for low earners. The differences across earnings levels reflect the progressive features of pension systems, such as minimum benefits and ceilings on pensionable earnings, the progressivity of the tax system and various tax measures that favour pension income.

The previous indicator of the "Tax treatment of pensions and pensioners" showed the important role that the personal tax and social security contribution systems play in old-age income support. Pensioners often do not pay social security contributions and receive preferential treatment under the income tax. Tax expenditures, progressivity of income taxes coupled with gross replacement rates of less than $100 \%$ also mean that pensioners have a lower income tax rate than workers. As a result, net replacement rates are generally higher than gross replacement rates.

For average earners, the net replacement rate across the OECD averages $63 \%$ for mandatory schemes. Moreover, the pattern of replacement rates across countries is different on a net rather than a gross basis. For example, the Belgian and German pension systems have considerably higher net replacement rates than gross. This is due, first, to favourable treatment of pension income under social security contributions. Second, because both replacement rates are relatively low compared with the OECD average and personal income taxes are strongly progressive in these countries, people pay much less in income tax when retired than they did when working. This is despite the fact that the very generous tax treatment of pension income in Germany is gradually being withdrawn. In the case of Slovenia the difference between gross and net is a consequence of the pension formula; pension benefits are calculated in net terms directly.

For low earners, the effect of taxes and contributions on net replacement rates is more muted than for workers higher up the earnings scale. This is because low income workers typically pay less in taxes and contributions relative to average earners. In many cases, their retirement incomes are below the level of the standard reliefs in the personal income tax (allowances, credits, etc.). Thus, they are often unable to benefit fully from any additional concessions granted to pensions or pensioners under their personal income tax.
The difference between gross and net replacement rates for low earners is 10 percentage points on average. Belgium, Germany, Norway, Slovenia and Turkey have much higher replacement rates for low earners on a net basis than in gross terms. The net replacement rate for workers earning $150 \%$ of the average is highest in Turkey. The lowest replacement rates for high earners are found in Canada, Ireland, Mexico, New Zealand, Switzerland and the United Kingdom where workers earning $150 \%$ of the average will receive pensions that amount to less than one-third of their net earnings when working. In Sweden, high income earners have a higher replacement rate than others due to the distributional design of the occupational pension system. Net replacement rates are furthermore affected by the fact that pension income and work income are taxed differently and at different rates.

For non-OECD countries, there is very little variation in net replacement rates within countries across the earnings range. However, there is considerable difference between countries, ranging from $12 \%$ for average earners in South Africa to $110 \%$ in India. As with the gross rates, the EU28 average net replacement rate for average earners is $71 \%$, markedly higher than the OECD34 figure.

\section{Definition and measurement}

The net replacement rate is defined as the individual net pension entitlement divided by net pre-retirement earnings, taking account of personal income taxes and social security contributions paid by workers and pensioners. Otherwise, the definition and measurement of the net replacement rates are the same as for the gross replacement rate (see the previous indicator). Details of the rules that national tax systems apply to pensioners can be found in the on-line "Country profiles" www.oecd.org/ pensions/pensionsataglance.htm. 


\subsection{Net pension replacement rates by earnings}

\begin{tabular}{|c|c|c|c|c|c|c|c|c|c|}
\hline \multirow{3}{*}{ OECD members } & \multicolumn{4}{|c|}{ Individual earnings, multiple of mean for men (women where different) } & & \multicolumn{4}{|c|}{ Individual earnings, multiple of mean for men (women where different) } \\
\hline & \multirow[t]{2}{*}{ Pension age } & 0.5 & 1.0 & 1.5 & & Pension age & 0.5 & 1.0 & 1.5 \\
\hline & & & & & OECD members (cont.) & & & & \\
\hline Australia & 67 & 88.6 (84.6) & 58.0 (53.4) & 45.9 (40.9) & Norway & 67 & 80.1 & 60.2 & 48.6 \\
\hline Austria & 65 & 92.1 & 91.6 & 88.9 & Poland & 67 & 54.0 & 52.8 & 52.4 \\
\hline Belgium & 65 & 64.2 & 60.9 & 49.1 & Portugal & 66 & 87.7 & 89.5 & 88.4 \\
\hline Canada & 67 & 58.5 & 47.9 & 34.1 & Slovak Republic & 67 & 84.0 & 80.6 & 79.4 \\
\hline Chile & 65 & 48.7 (45.3) & 37.7 (33.1) & 38.0 (33.4) & Slovenia & 60 & 57.6 (60.6) & 57.4 (60.4) & 55.1 (57.6) \\
\hline Czech Republic & 68 & 93.1 & 63.8 & 51.9 & Spain & 65 & 89.1 & 89.5 & 89.3 \\
\hline Denmark & 67 & 103.2 & 66.4 & 57.2 & Sweden & 65 & 56.7 & 55.8 & 70.1 \\
\hline Estonia & 65 & 76.1 & 59.8 & 53.5 & Switzerland & 65 (64) & 61.4 (60.7) & 46.9 (46.5) & 31.5 (31.2) \\
\hline Finland & 65 & 66.6 & 63.5 & 65.0 & Turkey & 65 & 98.0 & 104.8 & 109.9 \\
\hline France & 63 & 66.9 & 67.7 & 62.0 & United Kingdom & 68 & 51.7 & 28.5 & 20.3 \\
\hline Germany & 65 & 53.4 & 50.0 & 49.0 & United States & 67 & 54.3 & 44.8 & 38.9 \\
\hline Greece & 62 & 82.9 & 72.9 & 73.3 & OECD34 & 65.5 (65.4) & 74.1 (73.7) & 63.2 (62.7) & 58.5 (58.0) \\
\hline Hungary & 65 & 89.6 & 89.6 & 89.6 & & & & & \\
\hline Iceland & 67 & 90.5 & 76.7 & 76.3 & Other major economies & & & & \\
\hline Ireland & 68 & 70.1 & 42.2 & 32.5 & Argentina & $65(60)$ & 96.4 (104.0) & 87.5 (87.3) & 80.8 (78.4) \\
\hline Israel & 67 (64) & 85.7 (77.4) & 68.8 (61.9) & $50.3(45.2)$ & Brazil & $55 \quad(50)$ & 105.9 & 76.4 (58.1) & 76.4 (58.1) \\
\hline Italy & 67 & 82.2 & 79.7 & 81.6 & China & 60 & $102.2(94.0)$ & 80.5 (75.0) & $73.6 \quad(69.0)$ \\
\hline Japan & 65 & 53.3 & 40.4 & 35.5 & India & 58 & 109.7 (103.8) & 109.7 (103.8) & 109.7 (103.8) \\
\hline Korea & 65 & 64.3 & 45.0 & 34.4 & Indonesia & 55 & 13.8 (12.5) & 13.8 (12.5) & 13.9 (12.6) \\
\hline Luxembourg & 60 & 98.4 & 88.6 & 83.7 & Russian Federation & 60 (55) & 86.4 (73.7) & 86.4 (73.7) & 86.4 (73.7) \\
\hline Mexico & 65 & 35.5 & 28.4 (26.2) & 28.1 (26.0) & Saudi Arabia & 45 & 65.4 & 65.4 & 65.4 \\
\hline Netherlands & 67 & 101.3 & 95.7 & 94.1 & South Africa & 60 & 21.7 & 11.8 & 8.3 \\
\hline New Zealand & 65 & 80.8 & 43.0 & 30.4 & EU28 & 65.2 (65) & 80.7 (80.4) & 70.9 (70.7) & 66.4 (66.2) \\
\hline
\end{tabular}

Source: OECD pension models.

\subsection{Net pension replacement rates: Average earners}

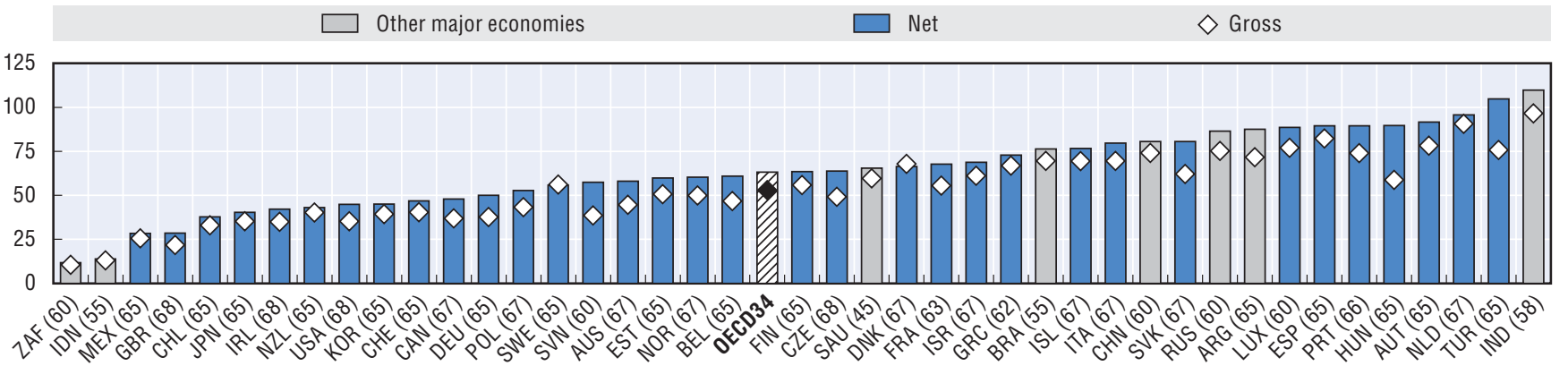

Source: OECD pension models.

StatLink त्ञाज http://dx.doi.org/10.1787/888933300704

\subsection{Net pension replacement rates: Low and high earners}

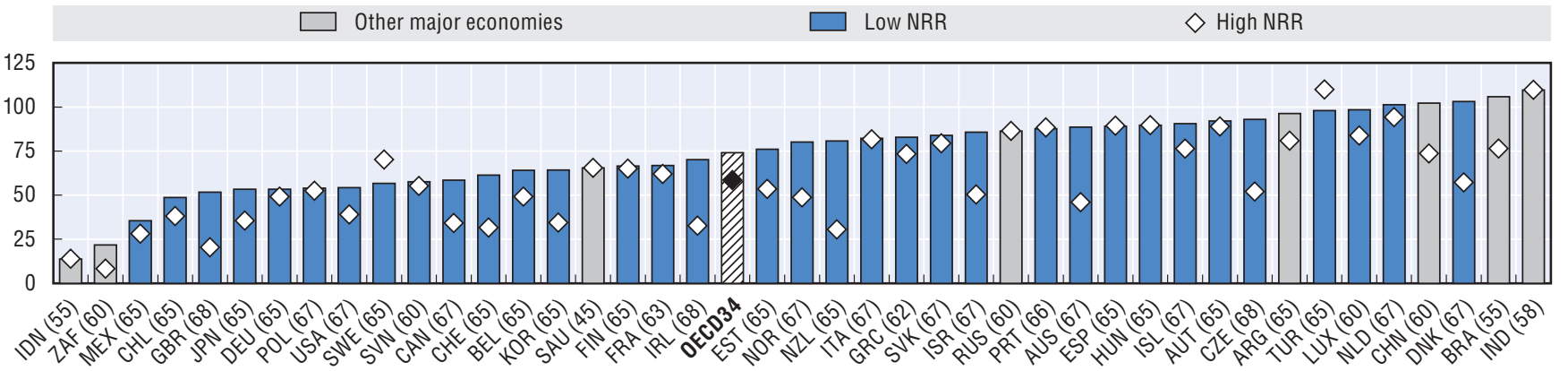

Source: OECD pension models. 


\section{Key results}

Since gross mandatory and voluntary pension systems are playing an increasing role in providing income for old age it also is equally important to look at the net replacement rate. The OECD average for net replacement rates of an average earner from public and mandatory private schemes alone is $63 \%$. When voluntary private pensions, are added, the average net replacement rate is $68 \%$ for an average earner. When voluntary private pensions are taken into account, for the seven OECD countries where voluntary private pensions are widespread the average net replacement rate for these seven countries is $71 \%$ compared with $59 \%$ in gross terms.

The personal tax system plays an important role in old-age support. Pensioners often do not pay social security contributions and, as personal income taxes are progressive and pension entitlements are usually lower than earnings before retirement, the average tax rate on pension income is typically less than the tax rate on earned income. In addition, most income tax systems give preferential treatment either to pension incomes or to pensioners, by giving additional allowances or credits to older people. Therefore, net replacement rates are usually higher than gross replacement rates.

For the 15 OECD countries where the calculations cover only public pensions, the replacement rate for an average earner is $73 \%$ on average. For the 12 OECD countries with data for public and mandatory private provision, the average replacement rate is $61 \%$. In the seven countries where voluntary pensions are modelled the average replacement rate reaches $71 \%$.

For all 34 OECD countries, including public, mandatory private and voluntary private pensions, the average replacement rate is $68 \%$. Overall net replacement rates are on average 10 percentage-points higher than the corresponding gross replacement rate figures.

For the other major economies there is a wide variation between country and across earnings level.

\section{Mandatory private pensions}

The first group of 12 countries have mandatory private pensions or private pensions that have near-universal coverage and so are described as "quasi-mandatory" (Denmark, the Netherlands and Sweden).

In Iceland, the Netherlands and Switzerland, private pensions are defined benefit while in other countries, they are defined contribution. Net replacement rates from mandatory private schemes for average earners range from $22 \%$ to $38 \%$ in six of the 12 countries. But they are significantly above this range in Denmark, Iceland, Israel and the
Netherlands, lower in Switzerland and much lower in Norway.

Between the combination of some countries having private pensions designed to cover earnings above the ceiling of the public scheme and the tax system in place no country has the same replacement rate across the earnings levels. This is the reason that replacement rates from private plans increase with earnings across the range in Australia, Chile, Mexico, the Netherlands, Norway and the Slovak Republic. It also explains why replacement rates from mandatory private schemes for workers on $150 \%$ of average earnings are more than double that of average workers in Sweden.

\section{Voluntary private pensions}

Replacement rates are shown for seven countries where voluntary private pensions are widespread (see the indicator of "Coverage of private pensions" in Chapter 10). The only country with a comparable proportion of the workforce in voluntary private pensions is Japan, but information is not available on typical rules. It is assumed that workers with voluntary private pensions spend a full career in the scheme.

The rules that have been modelled are in the "Country profiles" in Chapter 11. In all nine countries, a defined contribution plan is modelled.

In general, the defined contribution schemes pay a constant replacement rate with earnings. (Data on actual contribution rates by earnings are not available for most countries, and so an average or typical rate is assumed across the earnings range.) However the difference in taxation rules means that the net replacement rate differs across the earnings range, but generally increases as earnings increase. Belgium is the exception due to ceilings on pensionable earnings that qualify for tax incentives. Germany also falls into this category but the ceiling is just above $151 \%$ of average earnings. 


\subsection{Net pension replacement rates from mandatory public, mandatory private and voluntary private pension schemes}

Percentage of individual earnings

\begin{tabular}{|c|c|c|c|c|c|c|c|c|c|c|c|c|}
\hline & \multicolumn{3}{|c|}{ Gross mandatory public and private } & \multicolumn{3}{|c|}{ Net mandatory public and private } & \multicolumn{3}{|c|}{ Total gross with voluntary } & \multicolumn{3}{|c|}{ Total net with voluntary } \\
\hline & 0.5 & 1.0 & 1.5 & 0.5 & 1.0 & 1.5 & 0.5 & 1.0 & 1.5 & 0.5 & 1.0 & 1.5 \\
\hline \multicolumn{13}{|l|}{ OECD members } \\
\hline Australia & 79.3 & 44.5 & 32.9 & 88.6 & 58.0 & 45.9 & 79.3 & 44.5 & 32.9 & 88.6 & 58.0 & 45.9 \\
\hline Austria & 78.1 & 78.1 & 77.6 & 92.1 & 91.6 & 88.9 & 78.1 & 78.1 & 77.6 & 92.1 & 91.6 & 88.9 \\
\hline Belgium & 47.6 & 46.6 & 35.3 & 64.2 & 60.9 & 49.1 & 60.9 & 59.9 & 45.5 & 80.6 & 72.1 & 58.6 \\
\hline Canada & 50.1 & 36.7 & 25.1 & 58.5 & 47.9 & 34.1 & 73.5 & 66.0 & 54.4 & 86.0 & 96.1 & 73.8 \\
\hline Chile & 39.4 & 32.8 & 32.9 & 48.7 & 37.7 & 38.0 & 39.4 & 32.8 & 32.9 & 48.7 & 37.7 & 38.0 \\
\hline Czech Republic & 78.9 & 49.0 & 39.1 & 93.1 & 63.8 & 51.9 & 78.9 & 49.0 & 39.1 & 93.1 & 63.8 & 51.9 \\
\hline Denmark & 107.4 & 67.8 & 55.1 & 103.2 & 66.4 & 57.2 & 107.4 & 67.8 & 55.1 & 103.2 & 66.4 & 57.2 \\
\hline Estonia & 62.1 & 50.5 & 46.6 & 76.1 & 59.8 & 53.5 & 62.1 & 50.5 & 46.6 & 76.1 & 59.8 & 53.5 \\
\hline Finland & 55.8 & 55.8 & 55.8 & 66.6 & 63.5 & 65.0 & 55.8 & 55.8 & 55.8 & 66.6 & 63.5 & 65.0 \\
\hline France & 56.8 & 55.4 & 48.2 & 66.9 & 67.7 & 62.0 & 56.8 & 55.4 & 48.2 & 66.9 & 67.7 & 62.0 \\
\hline Germany & 37.5 & 37.5 & 37.5 & 53.4 & 50.0 & 49.0 & 50.0 & 50.0 & 50.0 & 65.6 & 64.7 & 63.7 \\
\hline Greece & 79.4 & 66.7 & 62.3 & 82.9 & 72.9 & 73.3 & 79.4 & 66.7 & 62.3 & 82.9 & 72.9 & 73.3 \\
\hline Hungary & 58.7 & 58.7 & 58.7 & 89.6 & 89.6 & 89.6 & 58.7 & 58.7 & 58.7 & 89.6 & 89.6 & 89.6 \\
\hline Iceland & 82.6 & 69.2 & 68.1 & 90.5 & 76.7 & 76.3 & 82.6 & 69.2 & 68.1 & 90.5 & 76.7 & 76.3 \\
\hline Ireland & 69.5 & 34.7 & 23.2 & 70.1 & 42.2 & 32.5 & 99.8 & 65.1 & 53.5 & 100.7 & 72.1 & 63.8 \\
\hline Israel & 82.7 & 61.0 & 40.7 & 85.7 & 68.8 & 50.3 & 82.7 & 61.0 & 40.7 & 85.7 & 68.8 & 50.3 \\
\hline Italy & 69.5 & 69.5 & 69.5 & 82.2 & 79.7 & 81.6 & 69.5 & 69.5 & 69.5 & 82.2 & 79.7 & 81.6 \\
\hline Japan & 48.8 & 35.1 & 30.5 & 53.3 & 40.4 & 35.5 & 48.8 & 35.1 & 30.5 & 53.3 & 40.4 & 35.5 \\
\hline Korea & 58.5 & 39.3 & 29.3 & 64.3 & 45.0 & 34.4 & 58.6 & 39.3 & 29.3 & 64.3 & 45.0 & 34.4 \\
\hline Luxembourg & 89.5 & 76.8 & 72.5 & 98.4 & 88.6 & 83.7 & 89.5 & 76.8 & 72.5 & 98.4 & 88.6 & 83.7 \\
\hline Mexico & 35.0 & 25.5 & 24.2 & 35.5 & 28.4 & 28.1 & 35.0 & 25.5 & 24.2 & 35.5 & 28.4 & 28.1 \\
\hline Netherlands & 94.0 & 90.5 & 89.3 & 101.3 & 95.7 & 94.1 & 94.0 & 90.5 & 89.3 & 101.3 & 95.7 & 94.1 \\
\hline New Zealand & 80.1 & 40.1 & 26.7 & 80.8 & 43.0 & 30.4 & 92.5 & 52.5 & 39.1 & 94.8 & 56.8 & 44.6 \\
\hline Norway & 62.8 & 49.8 & 38.9 & 80.1 & 60.2 & 48.6 & 62.8 & 49.8 & 38.9 & 80.1 & 60.2 & 48.6 \\
\hline Poland & 43.1 & 43.1 & 43.1 & 54.0 & 52.8 & 52.4 & 43.1 & 43.1 & 43.1 & 54.0 & 52.8 & 52.4 \\
\hline Portugal & 75.1 & 73.8 & 72.5 & 87.7 & 89.5 & 88.4 & 75.1 & 73.8 & 72.5 & 87.7 & 89.5 & 88.4 \\
\hline Slovak Republic & 70.4 & 62.1 & 59.3 & 84.0 & 80.6 & 79.4 & 70.4 & 62.1 & 59.3 & 84.0 & 80.6 & 79.4 \\
\hline Slovenia & 44.4 & 38.4 & 36.0 & 57.6 & 57.4 & 55.1 & 44.4 & 38.4 & 36.0 & 57.6 & 57.4 & 55.1 \\
\hline Spain & 82.1 & 82.1 & 82.1 & 89.1 & 89.5 & 89.3 & 82.1 & 82.1 & 82.1 & 89.1 & 89.5 & 89.3 \\
\hline Sweden & 56.0 & 56.0 & 65.2 & 56.7 & 55.8 & 70.1 & 56.0 & 56.0 & 65.2 & 56.7 & 55.8 & 70.1 \\
\hline Switzerland & 55.7 & 40.2 & 26.8 & 61.4 & 46.9 & 31.5 & 55.7 & 40.2 & 26.8 & 61.4 & 46.9 & 31.5 \\
\hline Turkey & 75.7 & 75.7 & 75.7 & 98.0 & 104.8 & 109.9 & 75.7 & 75.7 & 75.7 & 98.0 & 104.8 & 109.9 \\
\hline United Kingdom & 43.3 & 21.6 & 14.4 & 51.7 & 28.5 & 20.3 & 73.1 & 51.4 & 44.2 & 82.4 & 61.2 & 54.8 \\
\hline United States & 44.4 & 35.2 & 29.1 & 54.3 & 44.8 & 38.9 & 88.8 & 70.3 & 58.3 & 90.5 & 81.9 & 78.3 \\
\hline 0ECD34 & 64.5 & 52.9 & 47.8 & 74.1 & 63.2 & 58.5 & 69.1 & 57.6 & 52.4 & 79.1 & 68.4 & 63.9 \\
\hline \multicolumn{13}{|c|}{ Other major economies } \\
\hline Argentina & 81.8 & 71.6 & 68.3 & 96.4 & 87.5 & 80.8 & 81.8 & 71.6 & 68.3 & 96.4 & 87.5 & 80.8 \\
\hline Brazil & 97.5 & 69.5 & 69.5 & 105.9 & 76.4 & 76.4 & 97.5 & 69.5 & 69.5 & 105.9 & 76.4 & 76.4 \\
\hline China & 94.0 & 74.0 & 67.4 & 102.2 & 80.5 & 73.6 & 94.0 & 74.0 & 67.4 & 102.2 & 80.5 & 73.6 \\
\hline India & 96.5 & 96.5 & 96.5 & 109.7 & 109.7 & 109.7 & 96.5 & 96.5 & 96.5 & 109.7 & 109.7 & 109.7 \\
\hline Indonesia & 13.0 & 13.0 & 13.0 & 13.8 & 13.8 & 13.8 & 13.0 & 13.0 & 13.0 & 13.8 & 13.8 & 13.8 \\
\hline Russian Federation & 75.2 & 75.2 & 75.2 & 86.4 & 86.4 & 86.4 & 75.2 & 75.2 & 75.2 & 86.4 & 86.4 & 86.4 \\
\hline Saudi Arabia & 59.6 & 59.6 & 59.6 & 65.4 & 65.4 & 65.4 & 59.6 & 59.6 & 59.6 & 65.4 & 65.4 & 65.4 \\
\hline South Africa & 20.9 & 10.5 & 7.0 & 21.7 & 11.8 & 8.3 & 69.6 & 48.7 & 48.7 & 100.6 & 54.8 & 56.1 \\
\hline EU28 & 69.9 & 59.0 & 54.4 & 80.7 & 70.9 & 66.4 & 73.0 & 62.1 & 57.4 & 83.0 & 73.4 & 68.5 \\
\hline
\end{tabular}

Source: OECD pension models. 


\section{Key results}

Pension wealth relative to individual earnings measures the total discounted value of the lifetime flow of all retirement incomes in mandatory pension schemes at the point of retirement age. For average earners, pension wealth for men is 9.6 times and for women 10.9 times annual individual earnings on average in OECD countries. Gross pension wealth relative to annual individual earnings is higher for women because of their longer life expectancy.

Replacement rates give an indication of the pension promise relative to individual earnings, but they are not comprehensive measures; they look only at the benefit level relative to individual earnings at the point of retirement. For a full picture, life expectancy, retirement age and indexation of pension benefits must also be taken into account. Together, these determine for how long the pension benefit is paid, and how its value evolves over time. Pension wealth - a measure of the stock of future flows of pension benefits takes account of these factors. It can be thought of as the lump-sum needed to buy an annuity giving the same flow of pension payments as that promised by mandatory retirement-income schemes relative to individual earnings.

In defined benefit systems there is often no or a weak link between the replacement rate and the expected duration of benefit withdrawal. As a result pension wealth increases with longevity gains when retirement ages are held constant. In defined contributions systems there is a more direct link between the size of the benefit and the expected duration of benefit withdrawals. In these systems the pension wealth measure is equal to the accumulated assets and therefore independent of longevity increases as these automatically reduce the benefits. Gross pension wealth at individual earnings equal to average worker earnings is highest in Luxembourg at 17.8 for men and 20.4 times for women. It is only slightly lower in the Netherlands at 17.2 for men and 19.6 for women. The lowest pension wealth is found in the United Kingdom at around 4 times (annual) individual earnings for both men and women, due to relatively low replacement rates.

Higher individual replacement rates mean that pension wealth relative to individual earnings tends to be higher for low earners than for average earners as well, at least when abstracting from differences in life expectancy across income levels. For men with individual earnings equal to half-average earnings, pension wealth is 11.7 times their earnings on average, compared with 9.6 times the individuals' earnings of average wage workers. Similarly, for women with low earnings, pension wealth of 13.3 compares with 10.9 times individual earnings for average earners. In the countries where pension wealth for low earners is highest (Denmark, Luxembourg and the Netherlands), its value is between 18 and 21 times individual earnings for men and slightly above 20 to 24 times individual earnings for women.

\section{Impact of life expectancy}

In countries where the duration in retirement is shorter and where pension benefits are defined benefit, such as Hungary, the Slovak Republic and Turkey, the individual pension wealth is smaller. The effect is the opposite in Switzerland and some of the Nordic countries (in DB systems), where life expectancies are high. Similarly, since women's life expectancy is longer than men's, pension wealth for women is higher in all countries that use unisex mortality tables or that have defined benefit systems. This is simply because in that case the same level of pension benefits can be expected to be paid over a longer retirement period. In addition, some countries still have lower retirement ages for women; this extends the payment period even further. Pension wealth is also affected by pension ages. A low retirement age in a defined benefit system such as in Luxembourg increases the pension wealth at a given level of benefit.

\section{Impact of indexation}

Pension wealth might be affected by indexation rules. Although most OECD countries now index pensions in payment to prices, there are exceptions: Germany, Ireland, Luxembourg and the United Kingdom for example link their defined benefit or point's systems to average earnings. Since earnings tend to grow faster than prices pension wealth is higher with generous indexation procedures, for a given level of replacement rate. For the non-OECD countries there is great variation with South Africa at only 1.4 and 1.8 times individual earnings for average earners for men and women compared to 17.3 for men in Brazil and 16.9 for women in India.

\section{Definition and measurement}

The calculation of pension wealth uses a uniform real discount rate of $2 \%$. Since the comparisons refer to prospective pension entitlements, the calculations use countryspecific mortality rates by age and sex at the year of retirement. Pension wealth is expressed as a multiple of gross annual individual earnings. 


\subsection{Gross pension wealth by earnings}

\begin{tabular}{|c|c|c|c|c|c|c|c|c|c|c|c|c|c|}
\hline & \multicolumn{6}{|c|}{ Individual earnings, multiple of mean } & & \multicolumn{6}{|c|}{ Individual earnings, multiple of mean } \\
\hline & \multicolumn{3}{|c|}{ Men } & \multicolumn{3}{|c|}{ Women } & & \multicolumn{3}{|c|}{ Men } & \multicolumn{3}{|c|}{ Women } \\
\hline & 0.5 & 1.0 & 1.5 & 0.5 & 1.0 & 1.5 & & 0.5 & 1.0 & 1.5 & 0.5 & 1.0 & 1.5 \\
\hline OECD members & & & & & & & OECD members (cont.) & & & & & & \\
\hline Australia & 14.0 & 7.8 & 5.8 & 15.1 & 8.2 & 5.8 & Norway & 11.9 & 9.4 & 7.3 & 13.8 & 10.8 & 8.4 \\
\hline Austria & 13.8 & 13.8 & 13.7 & 15.8 & 15.8 & 15.7 & Poland & 6.5 & 6.5 & 6.5 & 7.7 & 7.7 & 7.7 \\
\hline Belgium & 8.3 & 8.1 & 6.1 & 9.5 & 9.3 & 7.1 & Portugal & 12.7 & 11.8 & 11.6 & 14.8 & 13.6 & 13.4 \\
\hline Canada & 8.5 & 6.2 & 4.3 & 9.6 & 7.0 & 4.8 & Slovak Republic & 9.8 & 8.6 & 8.2 & 11.6 & 10.2 & 9.8 \\
\hline Chile & 6.9 & 5.8 & 5.8 & 7.4 & 5.8 & 5.8 & Slovenia & 9.8 & 8.5 & 7.9 & 12.2 & 10.6 & 9.9 \\
\hline Czech Republic & 12.1 & 7.5 & 6.0 & 14.0 & 8.7 & 6.9 & Spain & 14.6 & 14.6 & 14.6 & 17.2 & 17.2 & 17.2 \\
\hline Denmark & 18.3 & 11.3 & 9.1 & 20.4 & 12.6 & 10.1 & Sweden & 9.7 & 9.7 & 11.4 & 10.9 & 10.9 & 12.9 \\
\hline Estonia & 8.9 & 7.2 & 6.7 & 11.0 & 8.9 & 8.3 & Switzerland & 10.7 & 7.7 & 5.1 & 12.5 & 9.0 & 6.0 \\
\hline Finland & 9.8 & 9.8 & 9.8 & 11.7 & 11.7 & 11.7 & Turkey & 12.3 & 12.3 & 12.3 & 14.3 & 14.3 & 14.3 \\
\hline France & 10.7 & 10.4 & 9.1 & 12.6 & 12.3 & 10.7 & United Kingdom & 7.1 & 3.6 & 2.4 & 7.8 & 3.9 & 2.6 \\
\hline Germany & 14.5 & 14.5 & 14.5 & 15.7 & 15.7 & 15.7 & United States & 7.2 & 5.7 & 4.7 & 8.0 & 6.4 & 5.3 \\
\hline Greece & 15.1 & 12.7 & 11.9 & 16.8 & 14.1 & 13.2 & OECD34 & 11.7 & 9.6 & 8.6 & 13.3 & 10.9 & 9.9 \\
\hline Hungary & 8.5 & 8.5 & 8.5 & 10.1 & 10.1 & 10.1 & & & & & & & \\
\hline Iceland & 14.8 & 12.1 & 11.9 & 16.4 & 13.4 & 13.2 & Other major economies & & & & & & \\
\hline Ireland & 12.9 & 6.5 & 4.3 & 14.7 & 7.3 & 4.9 & Argentina & 12.9 & 11.3 & 10.7 & 18.4 & 14.9 & 13.7 \\
\hline Israel & 14.5 & 10.7 & 7.1 & 15.3 & 11.1 & 7.4 & Brazil & 24.2 & 17.3 & 17.3 & 26.7 & 14.5 & 14.5 \\
\hline Italy & 12.2 & 12.2 & 12.2 & 14.0 & 14.0 & 14.0 & China & 17.3 & 13.7 & 12.4 & 20.3 & 16.2 & 14.8 \\
\hline Japan & 9.1 & 6.6 & 5.7 & 10.7 & 7.7 & 6.7 & India & 16.0 & 16.0 & 16.0 & 16.9 & 16.9 & 16.9 \\
\hline Korea & 10.7 & 7.2 & 5.3 & 12.6 & 8.4 & 6.3 & Indonesia & 2.3 & 2.3 & 2.3 & 2.3 & 2.3 & 2.3 \\
\hline Luxembourg & 20.8 & 17.8 & 16.8 & 23.8 & 20.4 & 19.3 & Russian Federation & 9.6 & 9.6 & 9.6 & 12.8 & 12.8 & 12.8 \\
\hline Mexico & 6.1 & 4.5 & 4.2 & 6.6 & 4.5 & 4.2 & Saudi Arabia & 14.8 & 14.8 & 14.8 & 15.6 & 15.6 & 15.6 \\
\hline Netherlands & 17.8 & 17.2 & 16.9 & 20.4 & 19.6 & 19.4 & South Africa & 2.9 & 1.4 & 1.0 & 3.6 & 1.8 & 1.2 \\
\hline New Zealand & 16.6 & 8.3 & 5.5 & 18.5 & 9.3 & 6.2 & EU28 & 12.3 & 10.4 & 9.5 & 14.1 & 11.9 & 11.0 \\
\hline
\end{tabular}

Source: OECD pension models.

StatLink 젶ㄴ $h t t p: / / d x . d o i . o r g / 10.1787 / 888933301153$

\subsection{Gross pension wealth for lower earners by gender}

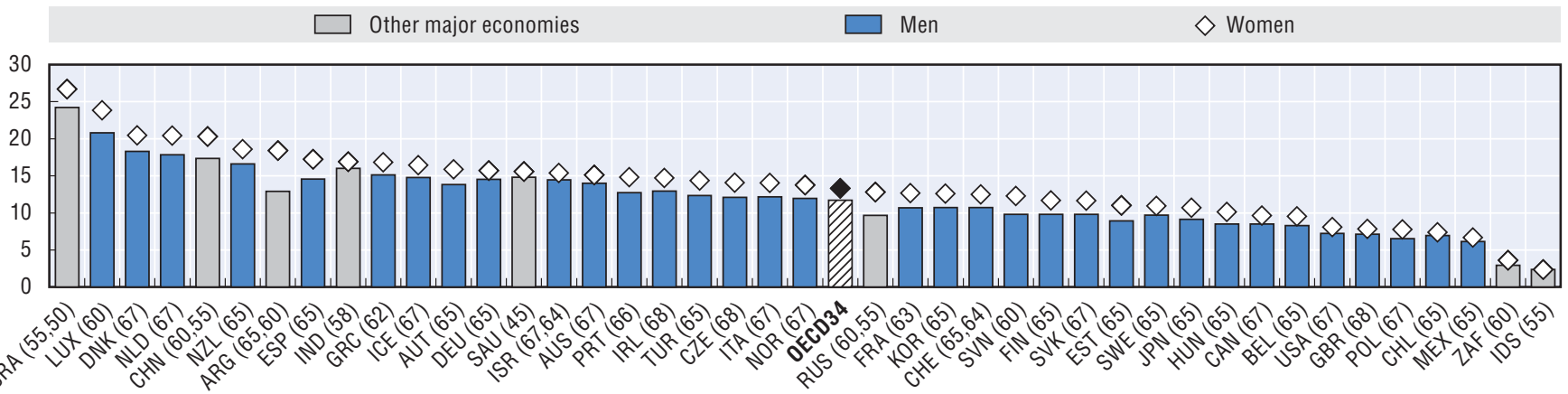

Source: OECD pension models.

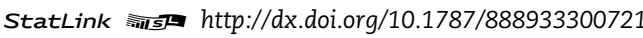

\subsection{Gross pension wealth for average earners by gender}

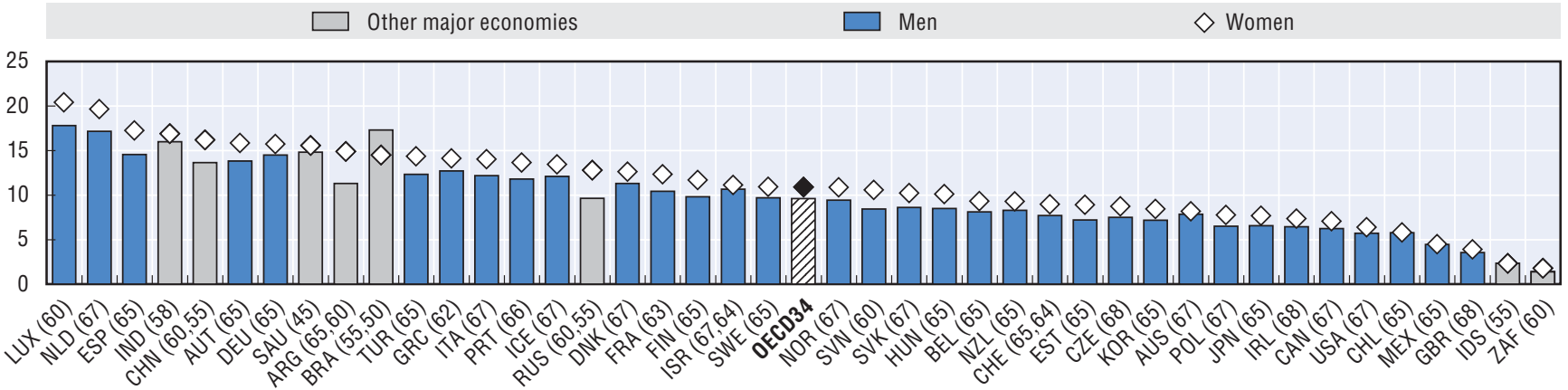

Source: OECD pension models. 


\section{Key results}

Net pension wealth, like the equivalent indicator in gross terms, shows the present value of the lifetime flow of pension benefits in mandatory pension schemes. But it also takes account of taxes and contribution paid on retirement incomes. Both figures for pension wealth are expressed as a multiple of individual gross earnings.

For average earners, net pension wealth for OECD countries averages 8.2 times gross individual earnings for men and 9.4 for women. Values are higher for women than men, due mainly to differences in life expectancy between the sexes.

Because net pension wealth is expressed as a multiple of individual gross earnings, it is less than gross pension wealth (if there is some tax liability during retirement) or the same (if pensions are not taxed or pension income is below tax thresholds). This is clear in the two figures opposite. For example, pension wealth is the same, in both net and gross terms, in the Slovak Republic and Turkey because pensions are not taxable.

The levels of pension wealth change significantly when measured on a net rather than a gross basis as do the country rankings. For example, Denmark has an above average OECD ranking in gross pension wealth compared with below OECD average ranking measured on a net basis. The net to gross pension wealth ratio in Denmark is 61\%. The situation is similar in the other four Nordic countries, as well as in Austria, Italy, Luxembourg and the Netherlands, where retirees face a substantial tax burden. In part, this reflects the high level of the gross replacement rate from the mandatory system. But it also results from the levels of taxation in the economy as whole. As a result the differences in net pension wealth levels are much smaller than the differences in gross pension wealth between countries.

\section{Impact of individual earnings}

Low earners would not be liable for taxes or pay less than $1 \%$ in tax and contributions in fourteen OECD countries. In eleven countries there is no or very low tax liability on pensions for average earners.

For high earners there is less variation in the results, with the majority of countries showing net pension wealth in the range of four to nine times annual earnings. The main exception to this is Luxembourg at 12.4 times earnings for men and 14.2 for women. The lowest figure is for the United Kingdom: 2.4 times earnings for men and 2.6 for women.
For the non-OECD economies, net and gross pension wealth are the same in Brazil, China, India, Indonesia, the Russian Federation, Saudi Arabia and South Africa. As with the gross pension wealth calculation, there is a wide range among these countries, with South Africa at 1.4 and 1.8 times average earnings for men and women respectively and Brazil with the highest of any country at 17.3 for men and India with 16.9 for women.

It is important to note that these calculations look at the benefit side of the pension system only. The impact of taxes and contributions paid by people of working age on living standards during retirement relative to when working work are discussed above in the indicator of "Net pension replacement rates".

\section{Definition and measurement}

Net pension wealth is the present value of the flow of pension benefits, taking account of the taxes and social security contributions that retirees have to pay on their pensions. It is measured and expressed as a multiple of gross annual individual earnings in the respective country. The reason for using gross earnings as the comparator is to isolate the effects of taxes and contributions paid in retirement from those paid when working. This definition means that gross and net pension wealth are the same where people are not liable for contributions and income taxes on their pensions.

Taxes and contributions paid by pensioners are calculated conditional on the mandatory pension benefit to which individuals are entitled at different levels of earnings. The calculations take account of all standard tax allowances and tax reliefs as well as concessions granted either to pension income or to people of pension age.

Details of the rules that national tax systems apply to pensioners can be found in the on-line "Country profiles" at http://oe.cd/pag. 


\subsection{Net pension wealth by earnings}

\begin{tabular}{|c|c|c|c|c|c|c|c|c|c|c|c|c|c|}
\hline & \multicolumn{6}{|c|}{ Multiple of individual annual gross earnings } & & \multicolumn{6}{|c|}{ Multiple of individual annual gross earnings } \\
\hline & \multicolumn{3}{|c|}{ Men } & \multicolumn{3}{|c|}{ Women } & & \multicolumn{3}{|c|}{ Men } & \multicolumn{3}{|c|}{ Women } \\
\hline & 0.5 & 1.0 & 1.5 & 0.5 & 1.0 & 1.5 & & 0.5 & 1.0 & 1.5 & 0.5 & 1.0 & 1.5 \\
\hline OECD members & & & & & & & OECD members (cont.) & & & & & & \\
\hline Australia & 14.0 & 7.8 & 5.8 & 15.1 & 8.2 & 5.8 & Norway & 11.6 & 7.8 & 5.8 & 13.3 & 9.0 & 6.7 \\
\hline Austria & 12.6 & 10.7 & 9.8 & 14.4 & 12.3 & 11.3 & Poland & 6.0 & 5.7 & 5.6 & 7.1 & 6.8 & 6.7 \\
\hline Belgium & 8.1 & 6.1 & 4.4 & 9.4 & 7.0 & 5.1 & Portugal & 12.4 & 10.6 & 9.7 & 14.5 & 12.3 & 11.2 \\
\hline Canada & 8.5 & 6.2 & 4.3 & 9.6 & 7.0 & 4.8 & Slovak Republic & 9.8 & 8.6 & 8.2 & 11.6 & 10.2 & 9.8 \\
\hline Chile & 6.9 & 5.4 & 5.4 & 7.4 & 5.4 & 5.4 & Slovenia & 9.8 & 8.5 & 7.7 & 12.2 & 10.6 & 9.6 \\
\hline Czech Republic & 12.1 & 7.5 & 5.9 & 14.0 & 8.7 & 6.8 & Spain & 13.6 & 12.2 & 11.5 & 16.1 & 14.5 & 13.7 \\
\hline Denmark & 11.4 & 6.9 & 5.4 & 12.8 & 7.7 & 6.0 & Sweden & 7.8 & 7.2 & 8.2 & 8.8 & 8.1 & 9.2 \\
\hline Estonia & 8.9 & 6.7 & 6.0 & 11.0 & 8.3 & 7.4 & Switzerland & 8.5 & 6.2 & 4.2 & 9.8 & 7.3 & 4.8 \\
\hline Finland & 9.7 & 7.9 & 7.4 & 11.5 & 9.4 & 8.8 & Turkey & 12.3 & 12.3 & 12.3 & 14.3 & 14.3 & 14.3 \\
\hline France & 9.9 & 9.1 & 7.8 & 11.7 & 10.8 & 9.2 & United Kingdom & 7.1 & 3.6 & 2.4 & 7.8 & 3.9 & 2.6 \\
\hline Germany & 14.5 & 12.0 & 11.1 & 15.7 & 13.0 & 12.0 & United States & 7.1 & 5.5 & 4.4 & 7.9 & 6.1 & 5.0 \\
\hline Greece & 13.6 & 10.6 & 9.6 & 15.1 & 11.8 & 10.7 & 0ECD34 & 10.8 & 8.2 & 7.1 & 12.3 & 9.4 & 8.1 \\
\hline Hungary & 8.5 & 8.5 & 8.5 & 10.1 & 10.1 & 10.1 & & & & & & & \\
\hline Iceland & 12.3 & 8.9 & 8.2 & 13.7 & 9.9 & 9.1 & Other major economies & & & & & & \\
\hline Ireland & 12.6 & 6.3 & 4.2 & 14.3 & 7.2 & 4.8 & Argentina & 12.5 & 10.3 & 9.3 & 17.8 & 13.6 & 11.9 \\
\hline Israel & 14.0 & 9.8 & 6.6 & 14.9 & 10.4 & 6.9 & Brazil & 24.2 & 17.3 & 17.3 & 27.7 & 22.6 & 22.6 \\
\hline Italy & 11.0 & 9.6 & 9.0 & 12.7 & 11.1 & 10.3 & China & 17.3 & 13.7 & 12.3 & 20.3 & 16.2 & 14.8 \\
\hline Japan & 8.1 & 5.9 & 5.0 & 9.4 & 6.9 & 5.8 & India & 16.0 & 16.0 & 16.0 & 16.9 & 16.9 & 16.9 \\
\hline Korea & 10.7 & 7.1 & 5.3 & 12.5 & 8.4 & 6.2 & Indonesia & 2.3 & 2.3 & 2.3 & 2.3 & 2.3 & 2.3 \\
\hline Luxembourg & 18.9 & 14.4 & 12.4 & 21.7 & 16.5 & 14.2 & Russian Federation & 9.6 & 9.6 & 9.6 & 12.8 & 12.8 & 12.8 \\
\hline Mexico & 6.1 & 4.5 & 4.2 & 6.6 & 4.5 & 4.2 & Saudi Arabia & 14.8 & 14.8 & 14.8 & 15.6 & 15.6 & 15.6 \\
\hline Netherlands & 13.6 & 11.3 & 10.1 & 15.6 & 12.9 & 11.6 & South Africa & 2.9 & 1.4 & 1.0 & 3.6 & 1.8 & 1.2 \\
\hline New Zealand & 14.4 & 7.2 & 4.8 & 16.1 & 8.1 & 5.4 & EU28 & 11.4 & 8.9 & 7.8 & 13.0 & 10.3 & 9.0 \\
\hline
\end{tabular}

Source: OECD pension models.

\subsection{Gross versus net pension wealth, men, average earner}

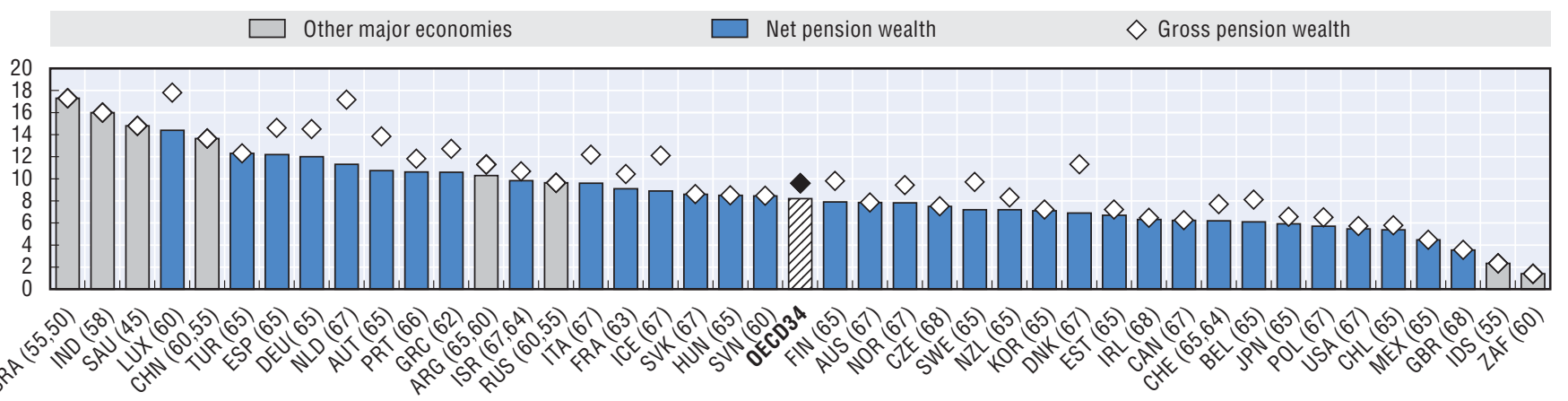

Source: OECD pension models.

\subsection{Gross versus net pension wealth, women, average earner}

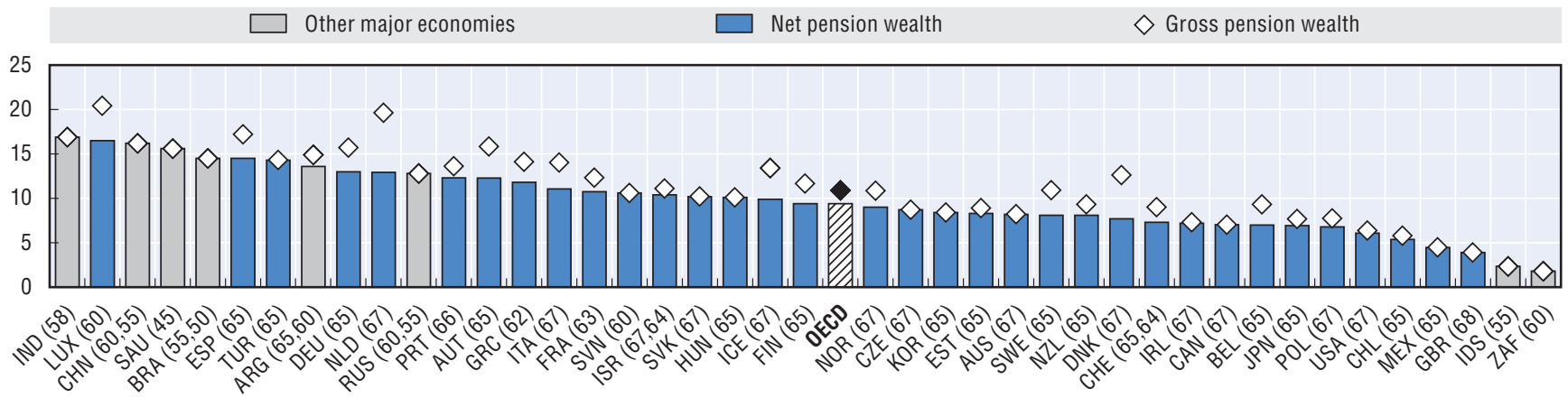

Source: OECD pension models. 



\section{Chapter 7}

\section{Demographic and economic context}

Population ageing has been one of the main driving forces behind changes in pension policies and reforms. Ageing is the result of two demographic changes.

The first indicator looks into the number of births and the development over the last fifty years. The second driver of population ageing is increasing life expectancy. Changes in life expectancy - at birth and at age 65 are show as the second indicator. There is also a brief discussion about how this might change in the future. The third indicators looks into the degree of ageing measured as the demographic dependency ratio. The number of people ages 65 and above relative to the number of people of working age. The fourth indicator takes a look at the employment rates of older workers. The fifth indicator presents calculations for the age that people leave the labour market - the "Effective age of labour market exit". The last indicator that measures the "Expected years in retirement" combines life expectancy with effective age of labour maker exit.

The statistical data for Israel are supplied by and under the responsibility of the relevant Israeli authorities. The use of such data by the OECD is without prejudice to the status of the Golan Heights, East Jerusalem and Israeli settlements in the West Bank under the terms of international law. 


\section{Key results}

The total fertility rate is below the replacement level of about 2.1 - the number of children needed to keep the total population constant - in 32 out of 34 OECD countries in 2013. The exceptions to this are Israel with a total fertility rate of 3.0 and Mexico at 2.2. In two-thirds of OECD countries fertility rates have slightly increased since the early 2000s. Fertility rates have a profound implication for pension systems because they, along with life expectancy, are the drivers of population ageing.

Fertility rates averaged 1.67 across OECD countries in 2013, well below the level that ensures population replacement. The trend to fewer children has been going on since the 1960s. The fall in fertility rates reflects changes in individuals' lifestyle preferences, in family formation, and in the constraints of everyday living, such as those driven by labour-market insecurity, difficulties in finding suitable housing and unaffordable childcare.

The positive (and widening) gap between the number of children women declare that they want and the number that they actually have shows at least in part the influence of these constraints.

Another effect might come from changes in women's aspiration regarding partnership and childbearing norms, especially in countries such as Japan and Korea where there is a strong link between marriage and maternity. The link is also significant in several European countries, such as Greece, Italy, Poland and Switzerland. However, the childbearing patterns of unmarried men and women have also changed. For example, half or more of births now occur outside of marriage in France, Iceland, Norway and Sweden. The average proportion of births outside marriage in OECD countries is now one-third of the total.

The recent increase in fertility rates is assumed to continue, albeit very slowly, and it is forecasted to average 1.9 across OECD countries by 2060 according to the United Nations Population Prospects.

Low fertility rates have wider social and economic consequences. First, the decline in population can become self-reinforcing, as the number of women of childbearing age falls by each generation. Secondly, there is a growing tax burden on people of working age to finance pensions and health care for older people. Finally, the workforce will also age and so might be less adaptable to technological change, thereby reducing productivity and economic growth.

Among the other major economies, Argentina, India, Indonesia, Saudi Arabia and South Africa all currently have fertility rates well above the replacement level of 2.1. Nevertheless, the trend follows that of the OECD countries.

\section{Definition and measurement}

The total fertility rate is the number of children that would be born to each woman if she were to live to the end of her child-bearing years and if the likelihood of her giving birth to children at each age was the currently prevailing age-specific fertility rates. It is generally computed by summing up the age-specific fertility rates defined over a five-year interval. A total fertility rate of 2.1 (i.e. the replacement level) children per women ensures broad stability of the population, on the assumptions of no migration flows and unchanged mortality rates.

\section{Further reading}

D'Addio, A.C. and M. Mira d'Ercole (2005), “Trends and Determinants of Fertility Rates: The Role of Polies", OECD Social, Employment and Migration Working Papers, No. 27, OECD Publishing, Paris, http://dx.doi.org/ $10.1787 / 880242325663$.

OECD (2014), Society at a Glance 2014: OECD Social Indicators, OECD Publishing, Paris, http://dx.doi.org/10.1787/ soc_glance-2014-en. 
7.1. Total fertility rates, $\mathbf{1 9 6 0 - 2 0 6 0}$

\begin{tabular}{|c|c|c|c|c|c|c|c|c|c|}
\hline & 1960 & 1970 & 1980 & 1990 & 2000 & 2010 & 2013 & 2020 & 2060 \\
\hline \multicolumn{10}{|l|}{ OECD members } \\
\hline Australia & 3.45 & 2.86 & 1.89 & 1.90 & 1.76 & 1.95 & 1.88 & 1.87 & 1.86 \\
\hline Austria & 2.69 & 2.29 & 1.65 & 1.46 & 1.36 & 1.44 & 1.44 & 1.57 & 1.79 \\
\hline Belgium & 2.54 & 2.25 & 1.68 & 1.62 & 1.64 & 1.84 & 1.76 & 1.89 & 1.95 \\
\hline Canada & 3.90 & 2.33 & 1.68 & 1.71 & 1.49 & 1.63 & 1.61 & 1.74 & 1.86 \\
\hline Chile & .. & 3.95 & 2.72 & 2.59 & 2.05 & 1.89 & 1.80 & 1.77 & 1.82 \\
\hline Czech Republic & 2.11 & 1.91 & 2.10 & 1.89 & 1.14 & 1.49 & 1.46 & 1.71 & 1.91 \\
\hline Denmark & 2.54 & 1.95 & 1.55 & 1.67 & 1.77 & 1.87 & 1.67 & 1.91 & 1.95 \\
\hline Estonia & .. & .. & 2.02 & 2.05 & 1.36 & 1.72 & 1.52 & 1.71 & 1.88 \\
\hline Finland & 2.71 & 1.83 & 1.63 & 1.79 & 1.73 & 1.87 & 1.75 & 1.87 & 1.90 \\
\hline France & 2.74 & 2.48 & 1.95 & 1.78 & 1.87 & 2.02 & 1.98 & 1.98 & 1.99 \\
\hline Germany & 2.37 & 2.03 & 1.56 & 1.45 & 1.38 & 1.39 & 1.41 & 1.50 & 1.69 \\
\hline Greece & 2.23 & 2.40 & 2.23 & 1.40 & 1.27 & 1.47 & 1.30 & 1.61 & 1.80 \\
\hline Hungary & 2.02 & 1.97 & 1.92 & 1.84 & 1.33 & 1.26 & 1.34 & 1.53 & 1.77 \\
\hline Iceland & 4.27 & 2.81 & 2.48 & 2.31 & 2.08 & 2.20 & 1.93 & 2.00 & 1.87 \\
\hline Ireland & 3.76 & 3.87 & 3.23 & 2.12 & 1.90 & 2.06 & 1.96 & 1.99 & 1.97 \\
\hline Israel & .. & .. & 3.14 & 3.02 & 2.95 & 3.03 & 3.03 & 2.69 & 2.08 \\
\hline Italy & 2.41 & 2.43 & 1.68 & 1.36 & 1.26 & 1.41 & 1.39 & 1.61 & 1.83 \\
\hline Japan & 2.00 & 2.13 & 1.75 & 1.54 & 1.36 & 1.39 & 1.43 & 1.54 & 1.78 \\
\hline Korea & 6.00 & 4.53 & 2.82 & 1.57 & 1.47 & 1.23 & 1.19 & 1.46 & 1.75 \\
\hline Luxembourg & 2.28 & 1.98 & 1.50 & 1.62 & 1.78 & 1.63 & 1.55 & 1.74 & 1.85 \\
\hline Mexico & 6.78 & 6.72 & 4.71 & 3.36 & 2.65 & 2.28 & 2.22 & 1.94 & 1.76 \\
\hline Netherlands & 3.12 & 2.57 & 1.60 & 1.62 & 1.72 & 1.80 & 1.68 & 1.81 & 1.88 \\
\hline New Zealand & 4.24 & 3.17 & 2.03 & 2.18 & 1.98 & 2.17 & 2.01 & 1.94 & 1.83 \\
\hline Norway & 2.91 & 2.50 & 1.72 & 1.93 & 1.85 & 1.95 & 1.78 & 1.93 & 1.94 \\
\hline Poland & 2.98 & 2.20 & 2.28 & 1.99 & 1.37 & 1.38 & 1.26 & 1.53 & 1.77 \\
\hline Portugal & 3.10 & 2.83 & 2.18 & 1.56 & 1.56 & 1.39 & 1.21 & 1.38 & 1.71 \\
\hline Slovak Republic & 3.07 & 2.40 & 2.31 & 2.09 & 1.29 & 1.40 & 1.34 & 1.52 & 1.77 \\
\hline Slovenia & 2.18 & 2.21 & 2.11 & 1.46 & 1.26 & 1.57 & 1.55 & 1.60 & 1.80 \\
\hline Spain & 2.86 & 2.90 & 2.22 & 1.36 & 1.23 & 1.37 & 1.27 & 1.63 & 1.83 \\
\hline Sweden & 2.20 & 1.94 & 1.68 & 2.14 & 1.55 & 1.98 & 1.89 & 1.95 & 1.99 \\
\hline Switzerland & 2.44 & 2.10 & 1.55 & 1.59 & 1.50 & 1.54 & 1.52 & 1.62 & 1.80 \\
\hline Turkey & 6.40 & 5.00 & 4.63 & 3.07 & 2.27 & 2.06 & 2.07 & 1.89 & 1.77 \\
\hline United Kingdom & 2.72 & 2.43 & 1.90 & 1.83 & 1.64 & 1.92 & 1.83 & 1.89 & 1.90 \\
\hline United States & 3.65 & 2.48 & 1.84 & 2.08 & 2.06 & 1.93 & 1.86 & 1.98 & 1.99 \\
\hline OECD34 & 3.18 & 2.73 & 2.17 & 1.91 & 1.67 & 1.75 & 1.67 & 1.77 & 1.85 \\
\hline \multicolumn{10}{|c|}{ Other major economies } \\
\hline Argentina & 3.11 & 3.07 & 3.33 & 2.99 & 2.48 & 2.21 & 2.18 & 2.06 & 1.86 \\
\hline Brazil & 6.21 & 5.02 & 4.07 & 2.81 & 2.36 & 1.84 & 1.81 & 1.71 & 1.75 \\
\hline China & 5.76 & 5.47 & 2.71 & 2.51 & 1.51 & 1.65 & 1.66 & 1.72 & 1.84 \\
\hline India & 5.87 & 5.49 & 4.68 & 3.88 & 3.15 & 2.56 & 2.51 & 2.25 & 1.85 \\
\hline Indonesia & 5.67 & 5.47 & 4.43 & 3.12 & 2.48 & 2.43 & 2.37 & 2.12 & 1.84 \\
\hline Russian Federation & 2.42 & 2.01 & 1.90 & 1.89 & 1.20 & 1.57 & 1.69 & 1.66 & 1.85 \\
\hline Saudi Arabia & 7.22 & 7.28 & 7.21 & 5.84 & 3.99 & 2.83 & 2.70 & 2.24 & 1.73 \\
\hline South Africa & 6.17 & 5.59 & 4.79 & 3.66 & 2.87 & 2.50 & 2.70 & 2.18 & 1.82 \\
\hline EU28 & 2.75 & 2.43 & 2.01 & 1.78 & 1.48 & 1.59 & 1.56 & 1.68 & 1.84 \\
\hline
\end{tabular}

Source: OECD (2014), Society at a Glance 2014: OECD Social Indicators; United Nations, World Population Prospects - 2012 Revision (forecasts). 


\section{Key results}

The remarkable increase in life expectancy is one of the greatest achievements of the last century. Lives continue to get longer, and this trend is predicted to continue. In 2010-15, life expectancy at birth averaged 77.2 years for men and 82.7 years for women. Among women, the figure was highest in Japan (86.9 years), followed by Spain, France, Italy and Switzerland. For men, life expectancy at birth was highest in Iceland (80.2 years) followed by Australia, Switzerland, Japan and Israel.

Life expectancy at older ages is especially important for the finances of retirement-income systems. In 2010-15, on average in OECD countries, women aged 65 could expect to live an additional 20.8 years, which is forecast to increase to 25.8 years by $2060-65$. Men of the same age could expect to live 17.4 more years in $2010-15$, with a projected increase of 4.5 years by 2060-65 to reach 21.9 years. Gender gaps in the longevity of older people are expected to remain broadly constant in relative terms but increase in absolute terms (from 3.4 to 3.9 years on average in OECD countries).

There is considerable variation between OECD countries in life expectancy at older ages. Women in Japan are predicted to live another 29.7 years on reaching age 65 in 2060-65. In contrast, women in the Slovak Republic are expected to live an extra 21.9 years at age 65 . The figures for Japan and Korea (29.5) are the highest. France displays the third highest life expectancy at age 65 amounting at 28.3 years.

For men there is less variation between countries than there is for women. Japan would again have the longest life expectancy at age 65 in 2060-65 (24.1 years), followed by Korea (23.8 years). By contrast, men in Estonia could expect to live just another 17.5 years at the age of 65 .

The gender gap in life-expectancy at age 65 is predicted to be between three and five years in favour of women in nearly all OECD countries in 2060-65. Larger gender gaps of nearly six years are observed in France, Japan and Korea. The smallest gender gaps (close to 2 years) are instead observed in Mexico and the United Kingdom.

Given this trend, many OECD countries have increased or plan to increase their pension ages: see Chapter 1 on "Pension Reforms". Others have introduced elements into their retirement-income provision that will automatically adjust the level of pensions as people live longer.
Overall longevity gains are due to rising living standards, but also greater access to quality health services.

Turning to the non-OECD major economies, life expectancy is generally lower. Life expectancy at birth is by far the lowest in South Africa at 55 years for men and 59 years for women. The highest life expectancy at birth is found in Argentina for women at 80 years and in China for men at 74 years. Life expectancy at 65 is the lowest for Indian women (at 14.5) and it is lowest among men in South Africa at 10.9 years.

\section{Definition and measurement}

Life expectancy is defined as the average number of years that people of a particular age could expect to live if they experienced the age- and sex-specific mortality rates prevalent in a given country in a particular year: in this case, 2010-15 and 2060-65. Since the determinants of longevity change slowly, life expectancy is best analysed over a long time horizon.

\section{Further reading}

Whitehouse, E.R. (2007), "Life-Expectancy Risk and Pensions: Who Bears the Burden?", OECD Social, Employment and Migration Working Paper, No. 60, OECD Publishing, Paris, http://dx.doi.org/10.1787/060025254440.

Whitehouse, E.R. and A. Zaidi (2008), "Socio-Economic Differences in Mortality: Implications for Pension Policy", OECD Social, Employment and Migration Working Paper, No. 71, OECD Publishing, Paris, http://dx.doi.org/ $10.1787 / 231747416062$. 
7.2. Life expectancy at birth, in years, men and women, born in $\mathbf{2 0 1 0 - 1 5}$

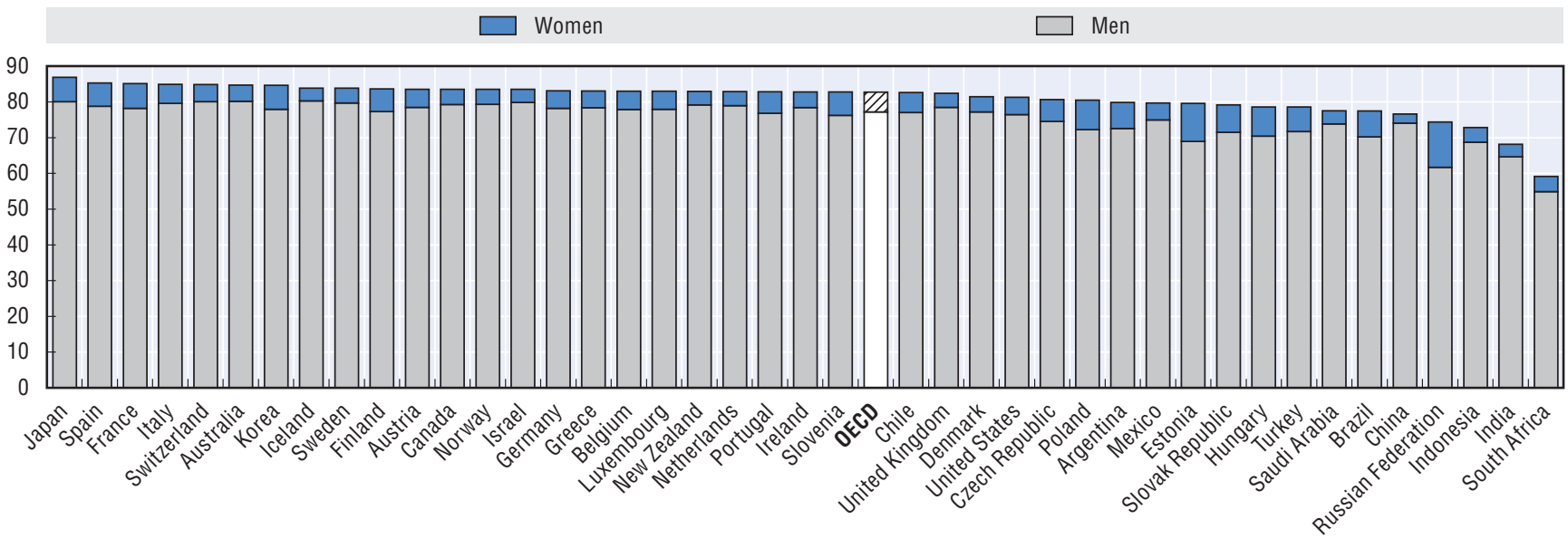

Source: United Nations, World Population Prospects - 2012 Revision.

\subsection{Expected remaining life expectancy at age 65, in years for women in 2010-15 and 2060-65}

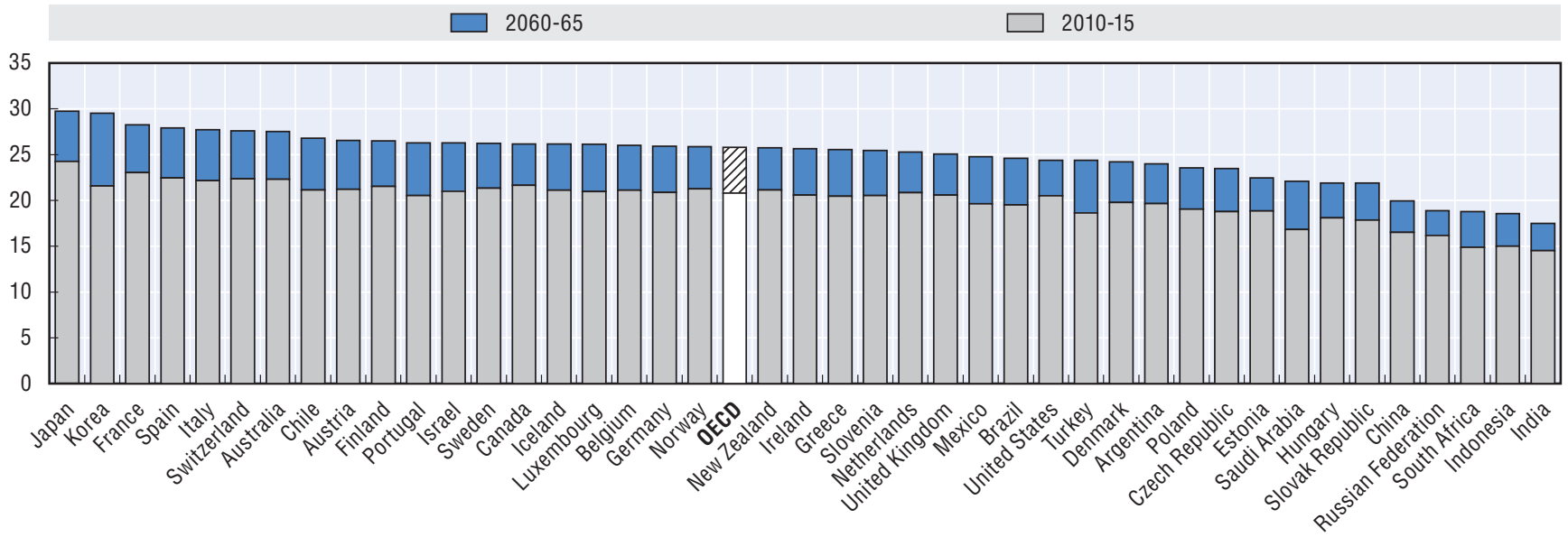

Source: United Nations, World Population Prospects - 2012 Revision.

\subsection{Expected remaining life expectancy at age 65, in years for men in 2010-15 and 2060-65}

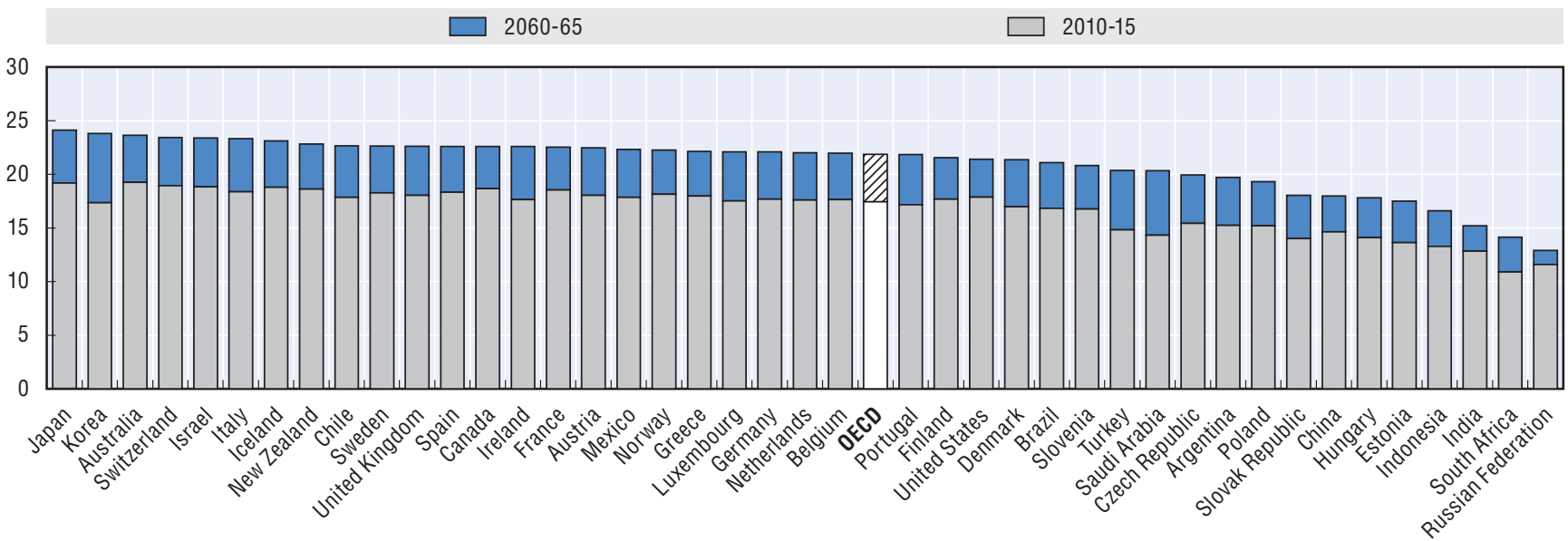




\section{Key results}

The demographic old-age dependency ratio will double by 2075 compared to today keeping age thresholds constant. Population ageing has been one of the main driving forces behind the wave of pension reforms in recent years. At the moment, there are 28 individuals aged 65 and over for every 100 persons of working age (ages 20 to 64) on average across all OECD countries. In 1950 the demographic dependency ratio was equal to 14, and has increased to 28 in 2015. The demographic dependency ratio is expected to continue to increase and to reach 35 in 2025, 51 in 2050 and 55 by 2075 .

In 2015, the demographically oldest OECD country was Japan, with a demographic dependency ratio equal to 47 (meaning 47 indivdiuals aged 65 and over for 100 persons of working age). Germany and Italy also had high dependency ratios equal to 35 and 37 respectively. By 2075 the dependency ratio will reach 80 in Korea , 77 in Japan, 76 in Portugal and 66 in Germany.

In contrast, Mexico and Turkey are the youngest countries, with dependency ratios of 12 and 13 respectively, followed by Chile, at 17 . By 2075 , their dependency ratios will be larger than the OECD average, reaching 63 in Chile, 59 in Mexico and 55 in Turkey.

Four of the six main English-speaking OECD countries - Australia, Canada, Ireland and the United States - have relatively low dependency ratios, between 21 and 26. This is partly due to inward migration of workers, Ireland and the United States have fertility rates currently just below replacement level. Other countries that currently have a younger population are the Slovak Republic and Poland, with dependency ratios of 21 and 24 respectively. As both countries will age quickly in the future, their dependency ratio will be very close to the OECD average by 2075 .

The evolution of dependency ratios depends on mortality, fertility rates and migration. OECD countries have seen prolonged increases in life expectancy, which most analysts project to continue in the future implying an increasing number of older people and most likely the number of pensioners too.

There have also been substantial declines in fertility, which, of course, will eventually reduce the number of workers entering the labour market. For example, fertility rates fell below the replacement level on average in OECD countries around 1980, implying shrinking generations. In the future, however, there is a great deal of uncertainty over how fertility rates will evolve.
For the OECD as a whole, the increase in the dependency ratio is projected to continue in the future. There is, however, a considerable predicted convergence among OECD countries, with demographically younger countries ageing more rapidly.

By far the most rapid population ageing among OECD countries will be in Korea. The dependency ratio would increase from 6 in 1950 to 80 by 2075 and Korea will move from being currently the fourth youngest country in the OECD to the oldest in 2075.

The pattern for the EU28 broadly follows the OECD average. European countries are already older than the OECD average: a dependency ratio of 29 for the EU28 in 2015 compares with an OECD figure of 28. By 2075, the dependency ratio for the European Union is projected to reach 55.

All of the other non-OECD major economies have dependency ratios below the OECD average. However, many will face rapid population ageing in the coming decades. In Brazil and China, for example, the dependency ratio will increase from around 13 and 14 currently to 60 and 51 in 2075, respectively. By the end of the projection horizon, only South Africa will be demographically younger than the OECD average today, with a dependency ratio of 28 , followed by India with the second lowest at 33 .

\section{Definition and measurement}

The demographic old-age dependency ratio is defined as the number of individuals aged 65 and over per 100 people of working age defined as those aged between 20 and 64 .

The projections for old-age dependency ratios used here are based on the most recent "medium-variant" population projections. They are drawn from the United Nation, World Population Prospects - 2012 Revision. 
7.5. Demographic old-age dependency ratios: Historical and projected values, $1950-2075$

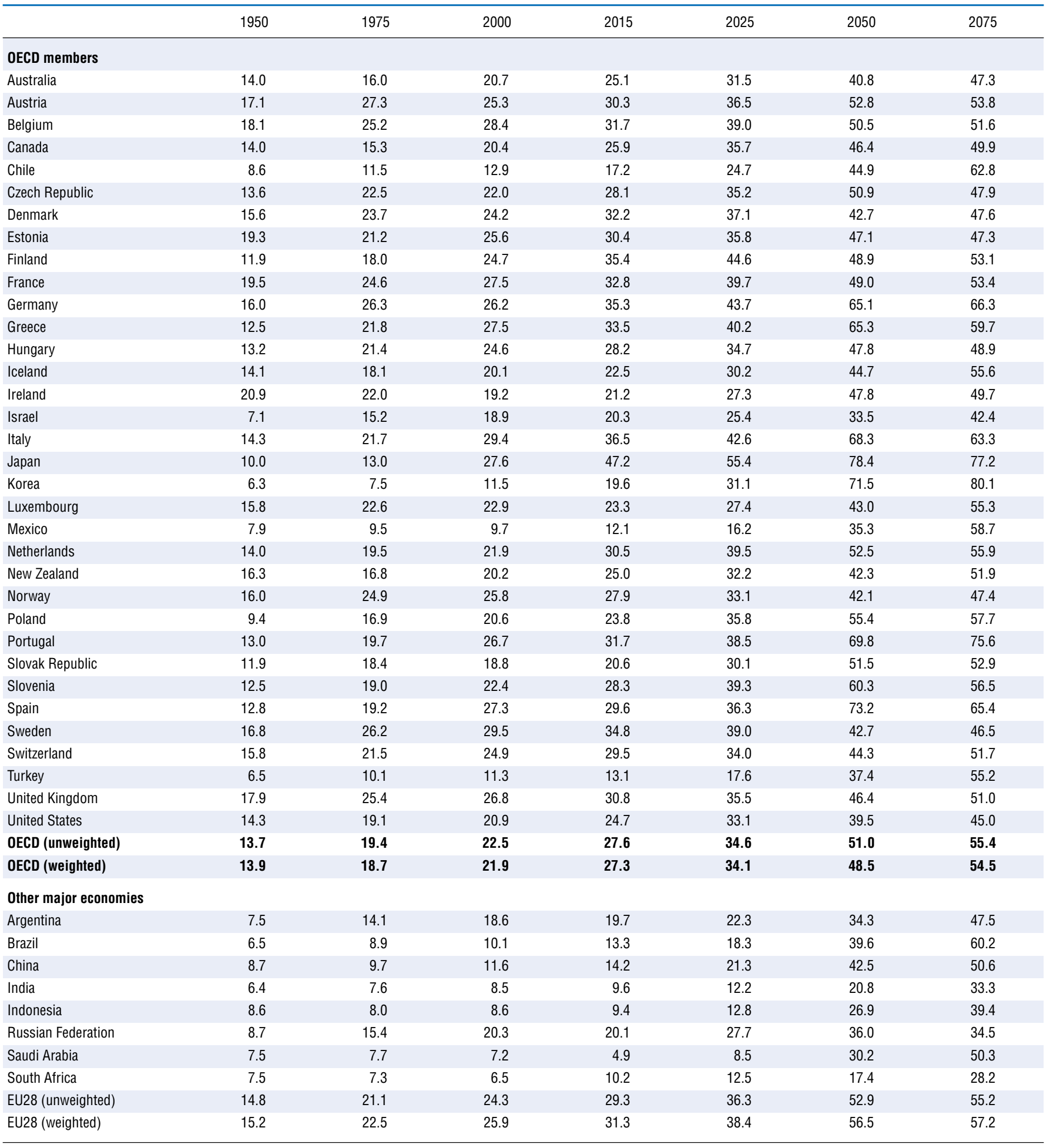

Note: The demographic old-age dependency ratio is defined as the number of individuals aged 65 and over per 100 people of working age defined as those aged between 20 and 64 .

Source: United Nations, World Population Prospects - 2012 Revision. 


\section{Key results}

The employment rate falls with age in all OECD countries. For individuals of age 55 to 59 the average employment rate across all OECD countries was equal to $67 \%$ in 2014 against $44 \%$ for the $60-64$ age group and $20 \%$ for the $65-69$ s. In 14 OECD countries the employment rates were above the OECD average for all age groups, by contrast it was below average for all age groups in 13 OECD countries. Employment rates of people aged 55-64 have improved over the past decade in most OECD countries, from $48 \%$ in 2004 to $56 \%$ in 2014.

There are large cross-country variations in the employment rates of people aged 55 to 69 in the OECD. In 2014, Iceland displayed the highest rates at $86 \%$ for the $55-59 \mathrm{~s}$ and at above $82 \%$ for individuals aged between 60 and 64 . Employment rates of individuals aged 65-69 were just above $53 \%$. By contrast the lowest employment rates were found in Slovenia, Greece and Turkey where employment rates for people aged 55-59 were at the most 50\%. In Denmark, Finland and Germany the employment rates are well above the OECD average (67\%) for individuals aged 55-59 at around 75-80\%. However they fall quickly with age and are below the OECD average for individuals aged between 65 and 69. In France the employment rates are close to the OECD average for the 55-59s, but they fall steeply and are well below the average for the over $60 \mathrm{~s}$. In contrast, the employment rates in Mexico are below the OECD average for the 55-59s but above average in the age-groups 60-64 and 65-69.

In a large number of European OECD countries the employment rates are below the OECD average for all age groups considered: Austria, Belgium, Hungary, Ireland, Italy, Luxembourg, Poland, the Slovak Republic, Slovenia and Spain are among these.

Employment rates of people aged between 55 and 64 have improved in most OECD countries over the last decade. On average, they have increased by 8 percentage points passing from $48 \%$ in 2004 to $56 \%$ in 2014 . The greatest increase has occurred in Germany from a relatively low level of $42 \%$ in 2004 to $66 \%$ in 2014 . Mainly as a result of the economic crisis, in Greece and Portugal the employment rates of the 55-64s have declined and in 2014 they were lower than in 2004.

\section{Definition and measurement}

Employment - Persons in civilian employment include all those people employed above a specified age who during a specified brief period, either one week or one day, were in the following categories: i) paid employment; ii) employers and self-employed; and iii) unpaid family workers; unpaid family workers at work should be considered as being selfemployed irrespective of the number of hours worked during the reference period. For operational purposes, the notion of some work may be interpreted as work for at least one hour. Total employment is defined as the sum of civilian employment and members of the armed forces.

\section{Further reading}

OECD Reviews on Ageing and Employment Policies: Working Better with Age, reports on Denmark, France, the Netherlands, Norway, Poland and Switzerland, www.oecd.org/els/employment/olderworkers.

OECD (2015), OECD Employment Outlook 2015, OECD Publishing, Paris http://dx.doi.org/10.1787/empl_outlook2015-en.

Sonnet, A., H. Olsen and T. Manfredi (2014), “Towards More Inclusive Ageing and Employment Policies: The Lessons from France, The Netherlands, Norway and Switzerland", De Economist, Vol. 162, December. 


\subsection{Employment rates of workers aged 55 to 59, 60 to 64 and 65 to 69 in 2014}

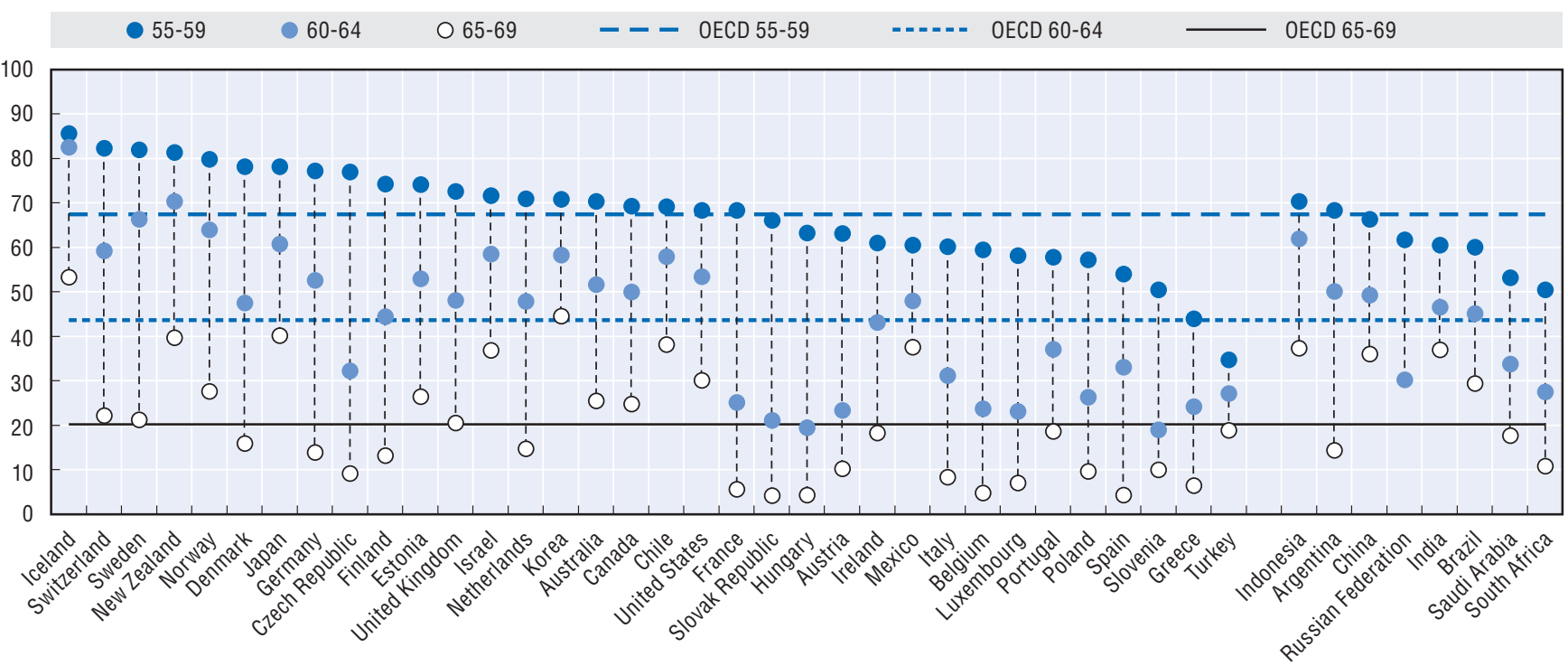

Source: OECD (2015), OECD Employment Outlook 2015.

\subsection{Changes in employment rate of older workers 2004 to 2014}

Percentage points difference in employment rates of older workers aged 55-64, 2004-14

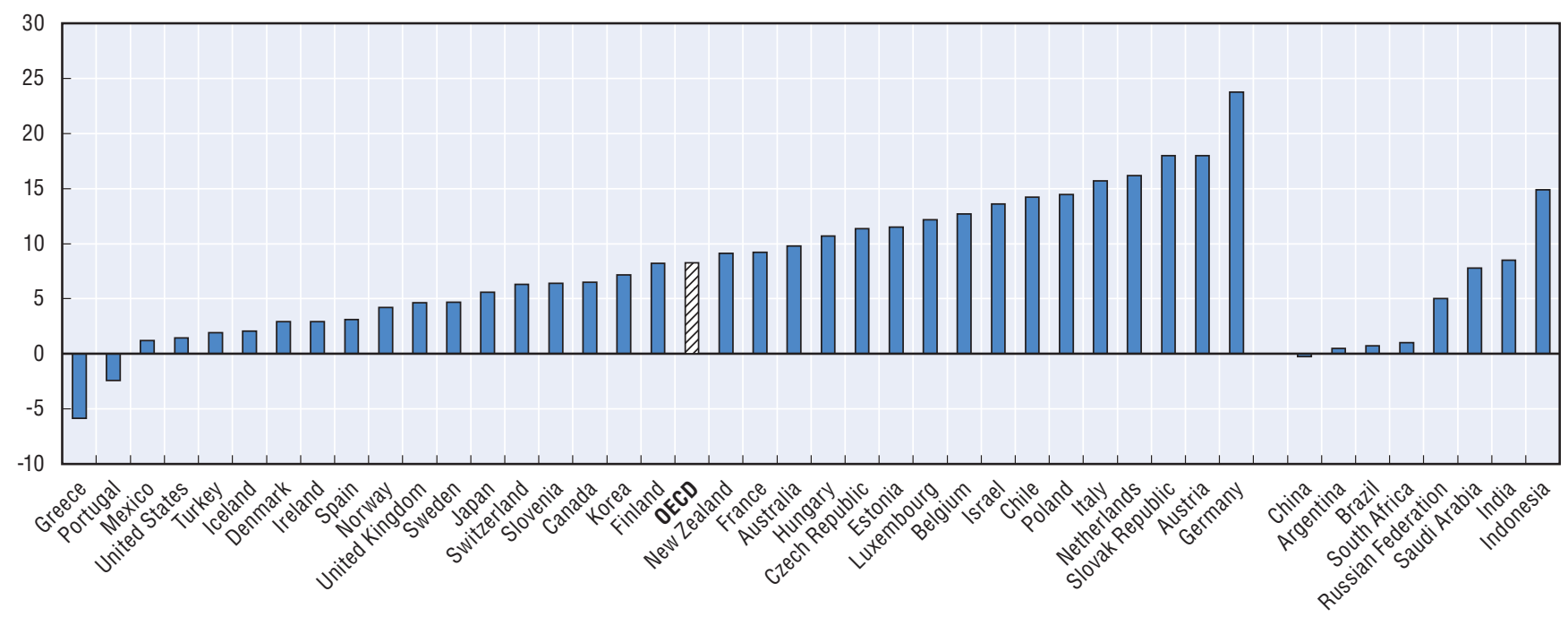

Source: OECD (2015), OECD Employment Outlook 2015. 


\section{Key results}

The average effective age of labour market exit was 64.6 for men and 63.1 for women across OECD countries in 2014 . Across all OECD countries, the average effective age of labour market exit is six months higher than the average normal retirement age for men and equal to the average normal retirement age for women. The lowest effective exit age is found in France for men and in the Slovak Republic for women at 59.4 and 58.2 years, respectively. On the other range of the scale, Korea displayed the highest figures, at 72.9 years for men and 70.6 years for women, respectively.

On average across the OECD, the retirement age is 0.6 years lower for men than the effective age of labour market exit age, for women it is the same. However, there is considerable variation between OECD countries. The effective age of exit is three years lower than the retirement in Poland for men and four years lower than the retirement age for women in Denmark. In contrast, the effective labour market exit age is considerably higher than the official retirement age in Korea at 12 years for men and ten years for women.

The normal retirement age for a person entering the labour market at age 20 was equal to 64.0 for men and 63.1 for women in 2014. The effective age of labour market exit is lower than official retirement age in the majority of OECD countries. It is lower for both men and women in 16 out of the 34 OECD countries.

However, there is considerable variation between OECD countries. The effective age of exit is almost three years lower for both men and women in Finland. In contrast, the effective labour market exit age is considerably higher than the official retirement age in 15 countries. The highest difference is found in Korea at 12 years for men and almost 10 years for women.

Gender gaps in the official retirement ages exist in 11 OECD countries. The effect on the exit age varies substantially across countries. In Chile for example women work until the age of almost 67 on average although the retirement age is only 60 . In Italy, women retire at age 61 despite the retirement age being 62 assuming labour market entry at age 20 . In most of these countries, the retirement age of women will align in the future to that of men and the only countries that will maintain a lower age for women are Chile, Israel and Switzerland.
Only in Spain, Finland and France is the effective age of labour market exit higher for women relative to men. In Finland and France they leave the labour market half a year after men, while in Spain they leave nearly 11 months after men. In all the other OECD countries men exit the labour market after women, with the largest difference observed in Mexico (3.9 years).

Over time there was a downward trend to the effective exit age until the early 2000s. In 1970 the effective exit age was 68.4 years for men and 66.4 years for women. In contrast, the effective age of labour market exit averaged 63.2 years for men and 61.1 years for women in 2000 with substantial cross-country variations: with a low for men of 58.3 years in Hungary and a high of 75.0 years in Mexico. For women, the average effective age of labour market exit ranges between 55.8 years and 69.8 years in Hungary and Mexico, respectively. By 2014 the average had come up again to 64.6 year for men and 63.1 for women.

\section{Definition and measurement}

The average effective age of retirement is defined as the average age of exit from the labour force for workers initially aged 40 and over. In order to abstract from compositional effects in the age structure of the population, labour force withdrawals are estimated using changes in labour force participation rates rather than labour force levels. These changes are calculated for each (synthetic) cohort divided into five-year age groups.

The normal retirement age is defined here as the current normal pension ages in 2014 assuming labour market entry at age 20. This age corresponds to the indicator "Current retirement ages" in Chapter 5). 


\subsection{Average effective age of labour-market exit and normal pensionable age in 2014}

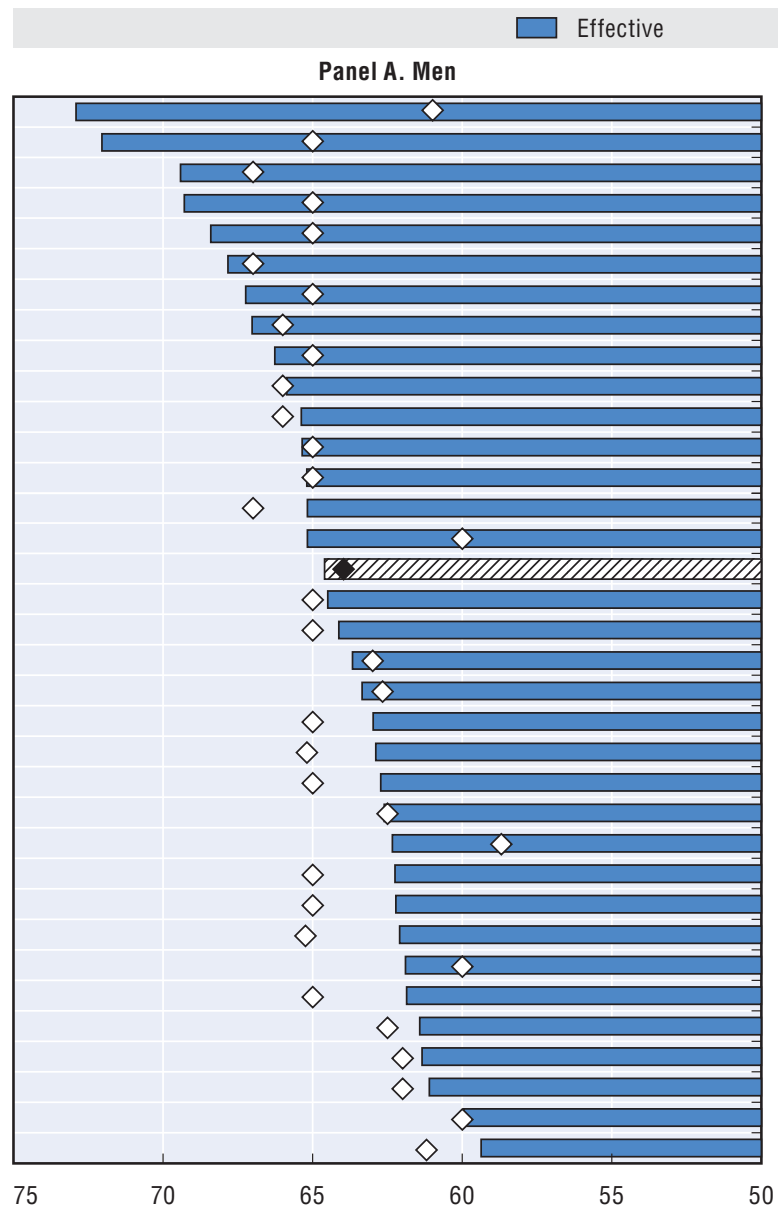

Korea
Mexico
Iceland
Japan
Chile
Israel
New Zealand
Portugal
Switzerland
United States
Ireland
Australia
Sweden
Norway
Turkey
OECD
Canada
United Kingdom
Estonia
Czech Republic
Denmark
Netherlands
Germany
Hungary
Slovenia
Austria
Spain
Poland
Luxembourg
Finland
Italy
Greece
Slovak Republic
Belgium
France

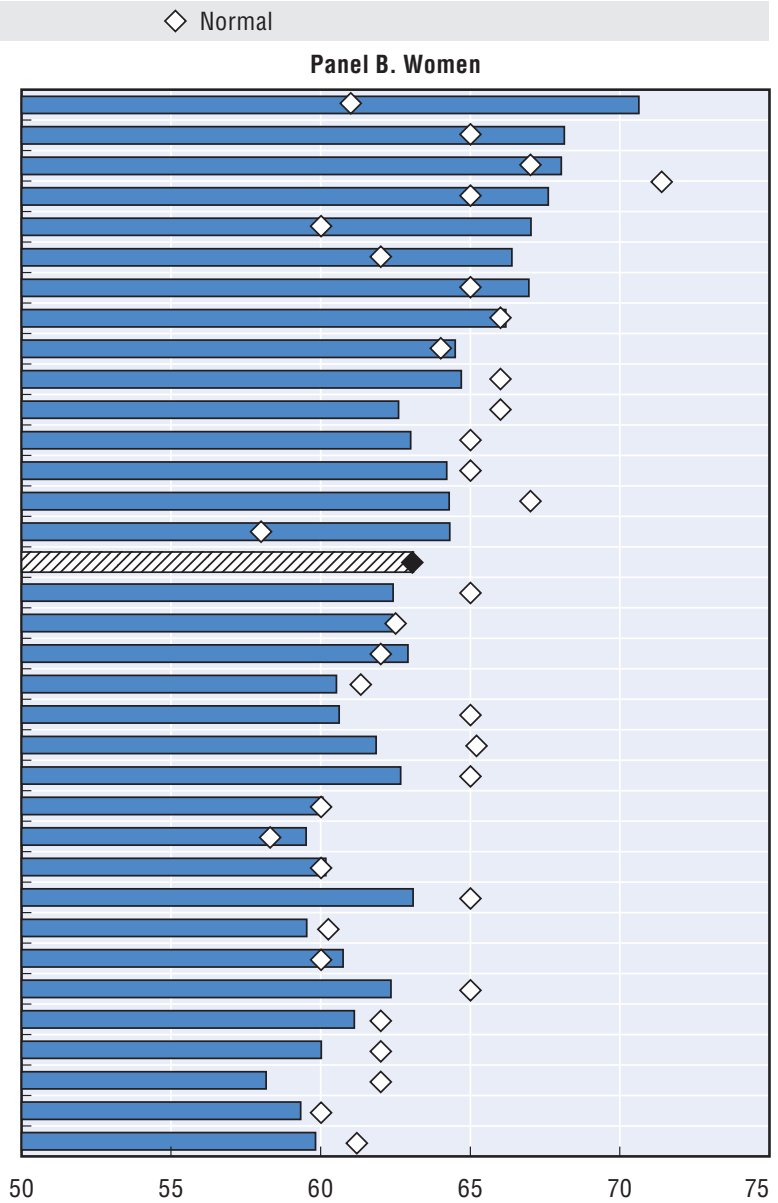

Note: Effective retirement age shown is for five year period 2009-14. Pensionable age is shown for individuals retiring in 2014 and assuming labour market entry at age 20 .

Source: OECD estimates based on the results of national labour force surveys and the European Union Labour Force Survey (EU-LFS).

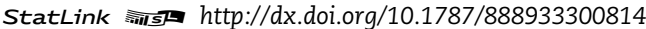

\subsection{Average labour market exit age in OECD countries, 1970-2014}

Average effective age of labour market exit Panel A. Men

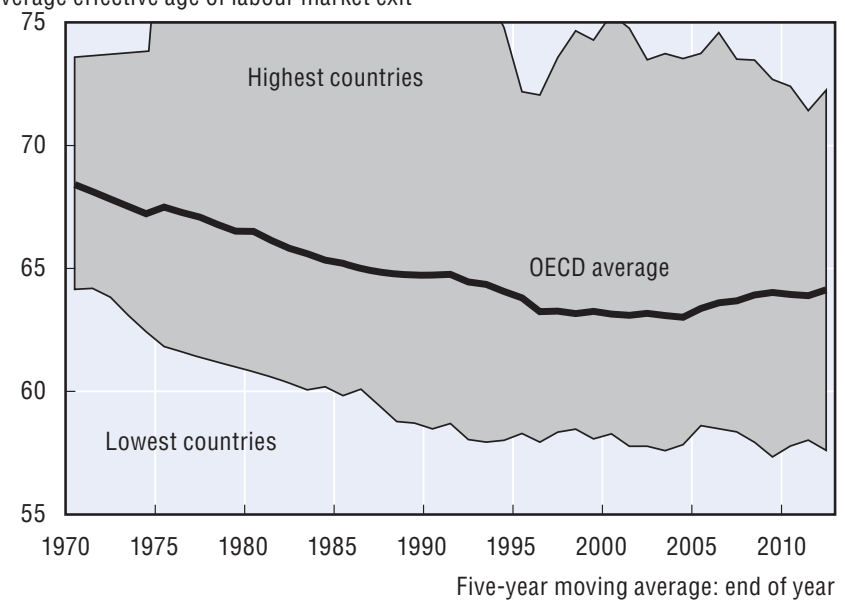

Panel B. Women

Average effective age of labour market exi

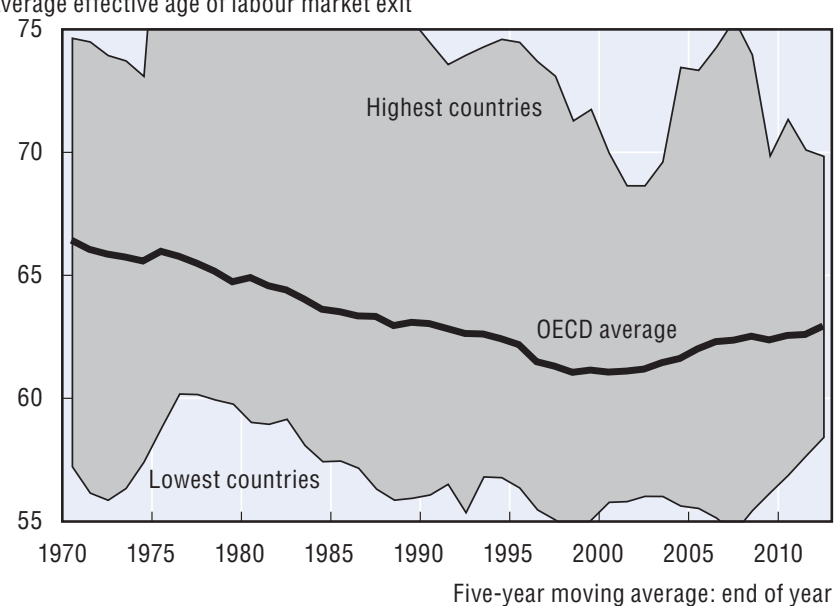

Source: OECD estimates based on the results of national labour force surveys, the European Union Labour Force Survey (EU-LFS) and, for earlier years in some countries, national censuses. 


\section{Key results}

The expected years in retirement indicator measures the length of expected remaining life expectancy from the time of average labour market exit by gender. In 2014 the OECD average for the number of expected years in retirement was 17.6 years for men and 22.3 years for women. France had the highest expected time in retirement, where it was equal to 23.0 years for men 27.2 years for women. Korea had the lowest expected years in retirement and here it was 11.4 years for men and 16.6 years for women. The average duration of expected years in retirement across OECD countries has increased over time. In 1970 men in the OECD countries spent on average 11 years in retirement, and women 15. By 2014 this had increased to 18 and 22 years respectively.

The expected years in retirement illustrates the length of the expected remaining life expectancy from the time of average labour market exit. Men typically can expect to spend fewer years in retirement than women: 4.7 years less than women on average in the OECD (Figure 7.10). Women can expect to spend more than 25 years in retirement in Austria, Belgium, France, Italy, Luxembourg and Slovenia (Figure 7.10, Panel A). Similarly, men can expect to spend more 20 years in retirement in Belgium, Finland, France, Greece, Italy and Spain (Figure 7.10, Panel B). Women's expected duration of retirement measured at the average age of labour market exit was below 20 years in Chile, Iceland, Korea, Mexico, New Zealand, Portugal, Turkey, and below 15 years, for men, in Korea, Mexico and Turkey.

In Poland, the Slovak Republic and Slovenia the gender gap in the expected duration of retirement was seven years or more. Longer periods in retirement expose women to old-age income poverty, as in some countries price indexation magnifies the impact of gender pay gaps, observed in all OECD countries, on pension benefits and of longer life expectancies.

The duration of expected years in retirement for women in emerging countries varies from 20 years in China to 16 years in South Africa. For men it varies from 13 years in Brazil to 9.6 years in South Africa.

The average length of retirement measured at labour market exit has increased over time. In 1970 men in the
OECD countries spent on average 11 years in retirement and by 2014 they could expect an average duration of retirement of 18 years (Figure 7.11, Panel B). Women who could expect to stay in retirement for 15 years on average in 1970, would enjoy a duration of retirement equal to 22 years in 2014 (Figure 7.11, Panel A). The increase in the expected duration of retirement from 1970 to 2014 is due both to a drop in the effective exit age from the labour force and to increased longevity.

The expected years in retirement increased gradually from 1970 to the late 1990s from a gradual decrease in the effective labour market exit age. After some relatively stable years, that average effective labour market exit age started to increase slowly form 2004. Life at the effective exit age has increased substantially during this period, particularly for women, and over the last two decades for men as well. Over the past few years, this increase has been roughly equal to that of the exit age and the expected years in retirement have stabilised.

\section{Definition and measurement}

Expected years in retirement is life expectancy measured at the age of effective labour market exit for men and women. Estimates of remaining life expectancy are calculated based from the UN World Population Prospects, the 2012 revision dataset. 


\title{
7.10. Expected years in retirement by gender in 2014
}

Panel A. Expected years in retirement, women (১), 2014

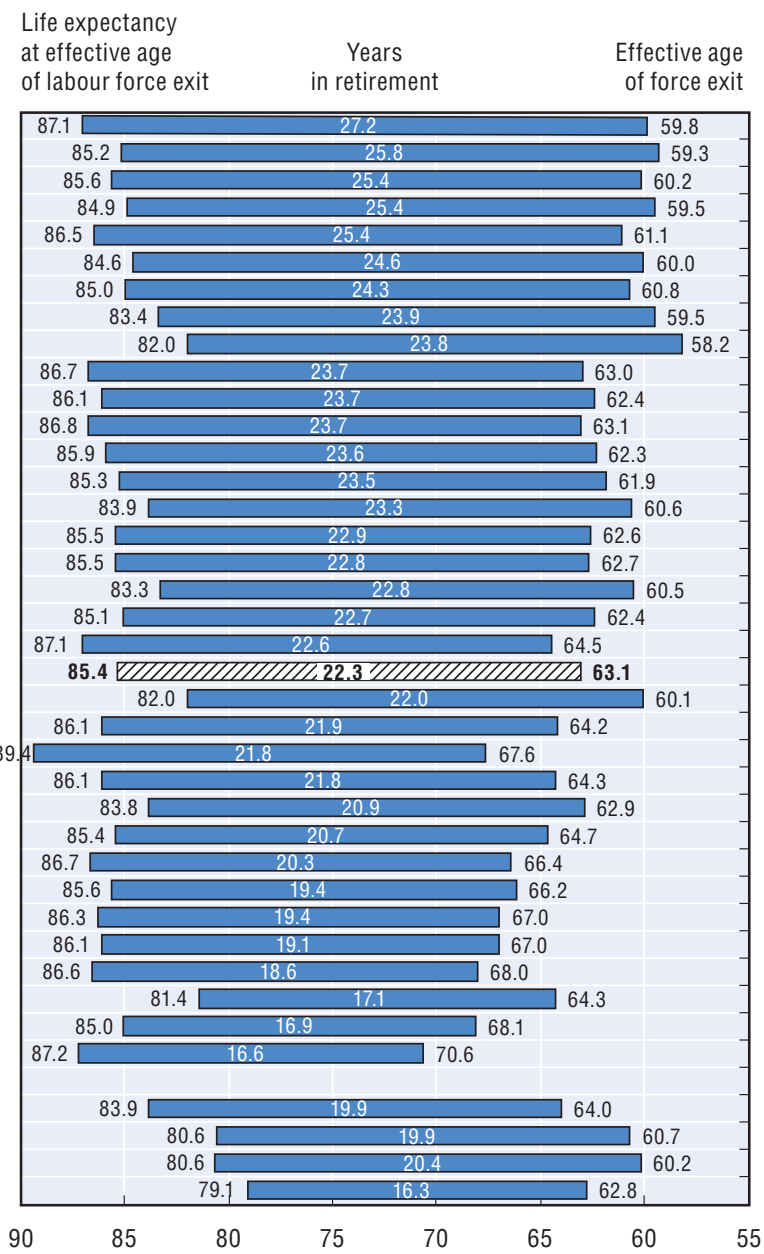

Panel B. Expected years in retirement, men, 2014

\begin{tabular}{|c|c|}
\hline & \\
\hline $\begin{array}{l}\text { Effective age } \\
\text { of force exit }\end{array}$ & $\begin{array}{c}\text { Years } \\
\text { in retirement }\end{array}$ \\
\hline
\end{tabular}

France
Belgium
Austria
Slovenia
Italy
Greece
Luxembourg
Poland
ovak Republic
Australia
Canada
Spain
Finland
Netherlands
Denmark
Ireland
Germany
zech Republic
ited Kingdom
Switzerland
OECD
Hungary
Sweden
Japan
Norway
Estonia
United States
Israel
Portugal
New Zealand
Chile
Iceland
Turkey
Mexico
Korea
Brazil
China
South Africa
sian Fedderation
Sula

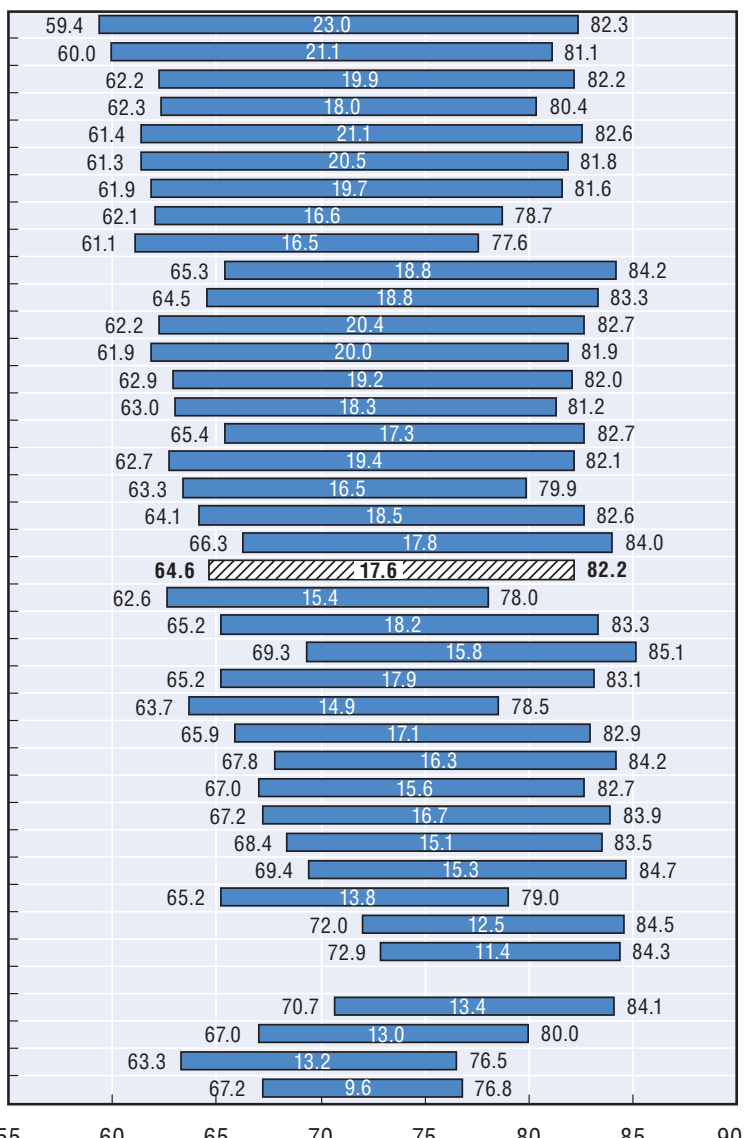

Note: Effective retirement age shown is for five year period 2007-12; data for Israel is 2011. Pensionable age is shown for 2014.

Source: OECD estimates based on the results of national labour force surveys and the European Union Labour Force Survey (EU-LFS).

StatLink הiाst $h t t p: / / d x$.doi.org/10.1787/888933300832

\subsection{Average years in retirement across all OECD countries, 1970-2014}

Panel A. Women

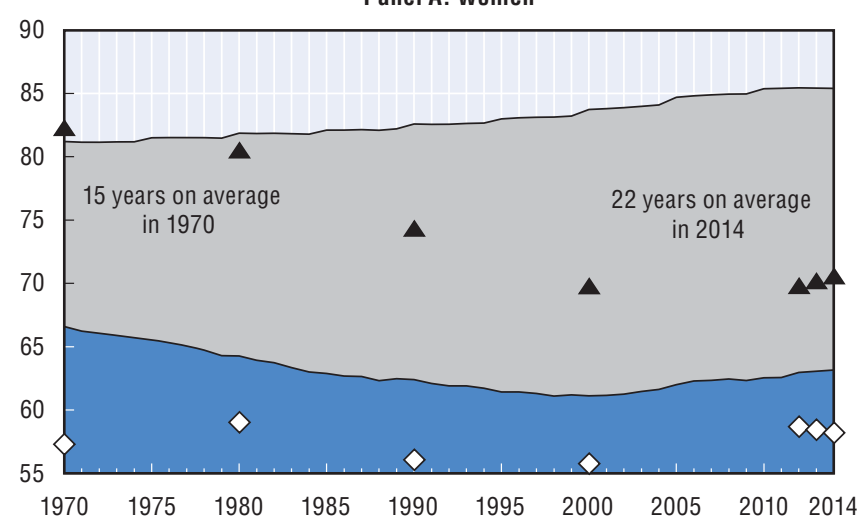

Panel B. Men

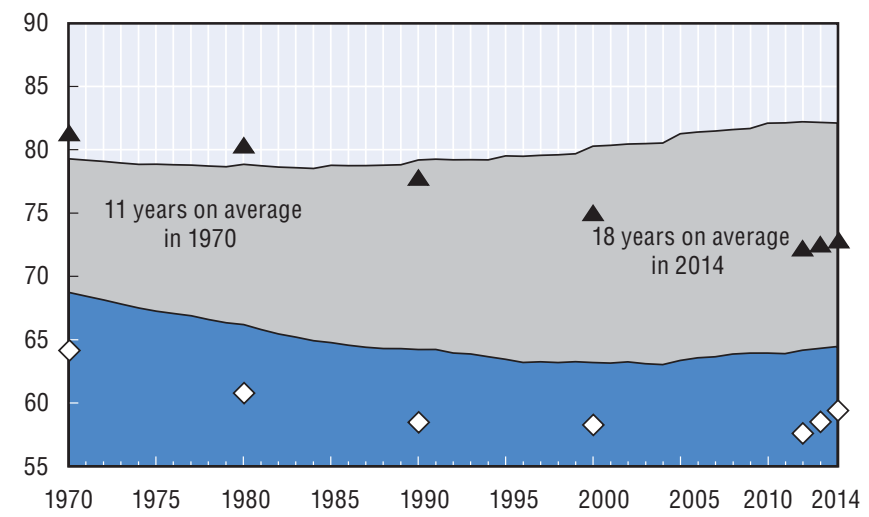

Source: OECD estimates based on the results of national labour force surveys, the European Union Labour Force Survey (EU-LFS) and, for earlier years in some countries, national censuses. 



\section{Chapter 8}

\section{Incomes and poverty of older people}

These three sets of indicators look at the economic situation of older people in recent years. The first indicator examines the income of older people, comparing them with the population as a whole. It also shows the income sources of older people whether the incomes sources come from publicly provided benefits, earnings or private pensions and on other savings.

The second indicator looks at poverty of older people. It shows the proportion of older people living on incomes of less than half the national median income. It also compares the poverty rates of older people with poverty rates of the population as a whole.

The final indicator presents the "Average worker earnings" that underpin all pension modelling. These data are used widely in the report and many values for parameters and all modelling results for pension entitlements are reported as percentages of national average worker earnings.

The statistical data for Israel are supplied by and under the responsibility of the relevant Israeli authorities. The use of such data by the OECD is without prejudice to the status of the Golan Heights, East Jerusalem and Israeli settlements in the West Bank under the terms of international law. 


\section{Key results}

Incomes of older people are on average lower than those of the population, even when differences in household size are taken into account. The incomes of the over 65 s had incomes of $87 \%$ of the total population's in $2012-13$. The incomes of the people aged between 66 and 75 equalled 92\% of the total population's while the over $75 \mathrm{~s}$ had income equal to $80 \%$ of the total population's. In most OECD countries, public transfers provide the bulk of income in old age.

People over 65 had incomes amounting to $87 \%$ of population incomes, on average, in 2012 and where data are available (Table 8.1). Older people fared best in France and Luxembourg where incomes for the over-65s were equal or higher than for the total population at $100 \%$ and $106 \%$ respectively. Older people also had relatively high incomes in Greece, Israel, Italy, Mexico, Portugal and Spain with incomes above $95 \%$ of the national average. In Australia and Korea, by contrast, older people's incomes stood at just $67 \%$ and $60 \%$ respectively.

People aged 66-75 have higher relative incomes, on average, than those aged over 75 : $92 \%$ and $80 \%$ of population incomes, respectively. Lower incomes for older retirees are partly explained by cohort effects such as the growth of real earnings. Over time this translate to higher earnings for each successive cohort of retirees. This in turn leads to higher pensions income for each generation. Indexation principles of pension benefits in payment therefore play a large role in protecting the income of the elderly over longer periods of time. The has a particular effect on older women who tend to have both lower wages while active and also have longer life expectancies compared to men and are over-represented among the oldest-old.

\section{Income sources}

Of the four main sources of income on which older people draw, public transfers (earnings-related pensions, resource-tested benefits, etc.) and occupational transfers are the most important (Figure 8.2). They account for $56 \%$ and $13 \%$ of older people's incomes on average respectively. The over-65s who are most reliant on public transfers live in Hungary and Belgium: $89 \%$ and $85 \%$ respectively of their incomes come from that source. Public transfers represent a small share in Mexico being 6\% of all income. Occupational transfers are of particular importance in 13 OECD countries. France and Finland have the highest levels at $70 \%$ and $72 \%$.

Work accounts for $21 \%$ and income from capital for about $10 \%$ of older people's incomes on average in the OECD. Work is especially important in Mexico where it accounts for more than $60 \%$ of old-age income. Work is also very important in New Zealand, Turkey, the United States and Israel where it accounts for more than $30 \%$ of older people's income. Several factors are behind these values. In some countries, such as Israel and the United States, the normal pension age is higher than age 65. And in others, people keep on working to fill gaps in contribution histories or to obtain better incomes over retirement. Also, as incomes are measured for households, older people are assumed to draw on the earnings of younger family member with whom they may live. Work is likely to be a more important income source for older people where many of them live in multi-generational households.

Capital, mostly private pensions, represents $40 \%$ of all income sources of older people in Canada. In Australia, Denmark, France and the United States, capital represents around $20 \%$ of all income.

\section{Definition and measurement}

Incomes of older people groups all incomes from employment, self-employment, capital and public transfers. The data shown are for disposable incomes (i.e. net of personal income tax and social security contributions). Incomes are measured on a household basis and equivalised with the square root equivalence scale to adjust for differences in household size. See In It Together: Why Less Inequality Benefits All (OECD, 2015) for more details on definitions and data sources. The special chapter on "Incomes and poverty of older people" in Pensions at a Glance 2013 provides a more detailed analysis.

\section{Further reading}

OECD (2015), In It Together: Why Less Inequality Benefits All, OECD Publishing, Paris, http://dx.doi.org/10.1787/ 9789264235120-en.

OECD (2013), Pensions at a Glance 2013: OECD and G20 Indicators, OECD Publishing, Paris, http://dx.doi.org/10.1787/ pension_glance-2013-en. 


\subsection{Incomes of older people, 2012 (or latest available)}

\begin{tabular}{|c|c|c|c|c|c|c|c|c|c|}
\hline & \multicolumn{3}{|c|}{ Incomes of people aged over $65, \%$ of population incomes } & & & \multicolumn{3}{|c|}{ Incomes of people aged over $65, \%$ of population incomes } & \\
\hline & All aged over 65 & Age $66-75$ & Aged over 75 & & & All aged over 65 & Age 66-75 & Aged over 75 & \\
\hline Australia & 67.1 & 70.8 & 61.9 & 2012 & Korea & 60.1 & 62.0 & 56.4 & 2013 \\
\hline Austria & 89.8 & 93.2 & 84.6 & 2012 & Luxembourg & 106.0 & 103.2 & 110.8 & 2012 \\
\hline Belgium & 77.2 & 80.5 & 73.4 & 2012 & Mexico & 96.2 & 102.6 & 85.5 & 2012 \\
\hline Canada & 91.6 & 94.0 & 88.4 & 2011 & Netherlands & 87.3 & 99.2 & 78.3 & 2013 \\
\hline Czech Republic & 81.1 & 84.0 & 76.5 & 2012 & New Zealand & 83.3 & 93.5 & 68.2 & 2012 \\
\hline Denmark & 77.1 & 82.4 & 69.1 & 2012 & Norway & 89.4 & 99.6 & 75.2 & 2012 \\
\hline Estonia & 68.9 & 72.9 & 63.6 & 2012 & Poland & 90.3 & 89.7 & 91.0 & 2012 \\
\hline Finland & 83.6 & 93.2 & 70.6 & 2012 & Portugal & 96.3 & 102.2 & 89.8 & 2012 \\
\hline France & 100.4 & 107.3 & 93.3 & 2013 & Slovak Republic & 83.9 & 84.9 & 81.9 & 2012 \\
\hline Germany & 86.9 & 90.5 & 80.0 & 2012 & Slovenia & 86.3 & 90.5 & 80.6 & 2012 \\
\hline Greece & 97.5 & 103.5 & 90.2 & 2012 & Spain & 95.9 & 100.8 & 90.9 & 2012 \\
\hline Hungary & 84.1 & 92.9 & 82.3 & 2012 & Sweden & 85.7 & 97.6 & 67.9 & 2012 \\
\hline Iceland & 92.7 & 96.9 & 86.8 & 2012 & Switzerland & 75.6 & 80.8 & 67.7 & 2012 \\
\hline Ireland & 87.9 & 96.6 & 74.8 & 2012 & Turkey & 89.5 & 94.4 & 81.6 & 2012 \\
\hline Israel & 96.5 & 106.4 & 83.0 & 2012 & United Kingdom & 82.3 & 88.7 & 74.3 & 2012 \\
\hline \multirow[t]{2}{*}{ Italy } & 95.6 & 101.2 & 89.6 & 2013 & United States & 92.1 & 102.9 & 76.8 & 2013 \\
\hline & & & & & OECD32 & 86.8 & 92.5 & 79.5 & \\
\hline
\end{tabular}

Source: OECD Income Distribution Database, www.oecd.org/social/income-distribution-database.htm.

\subsection{Income sources of old people, 2012 or latest available}

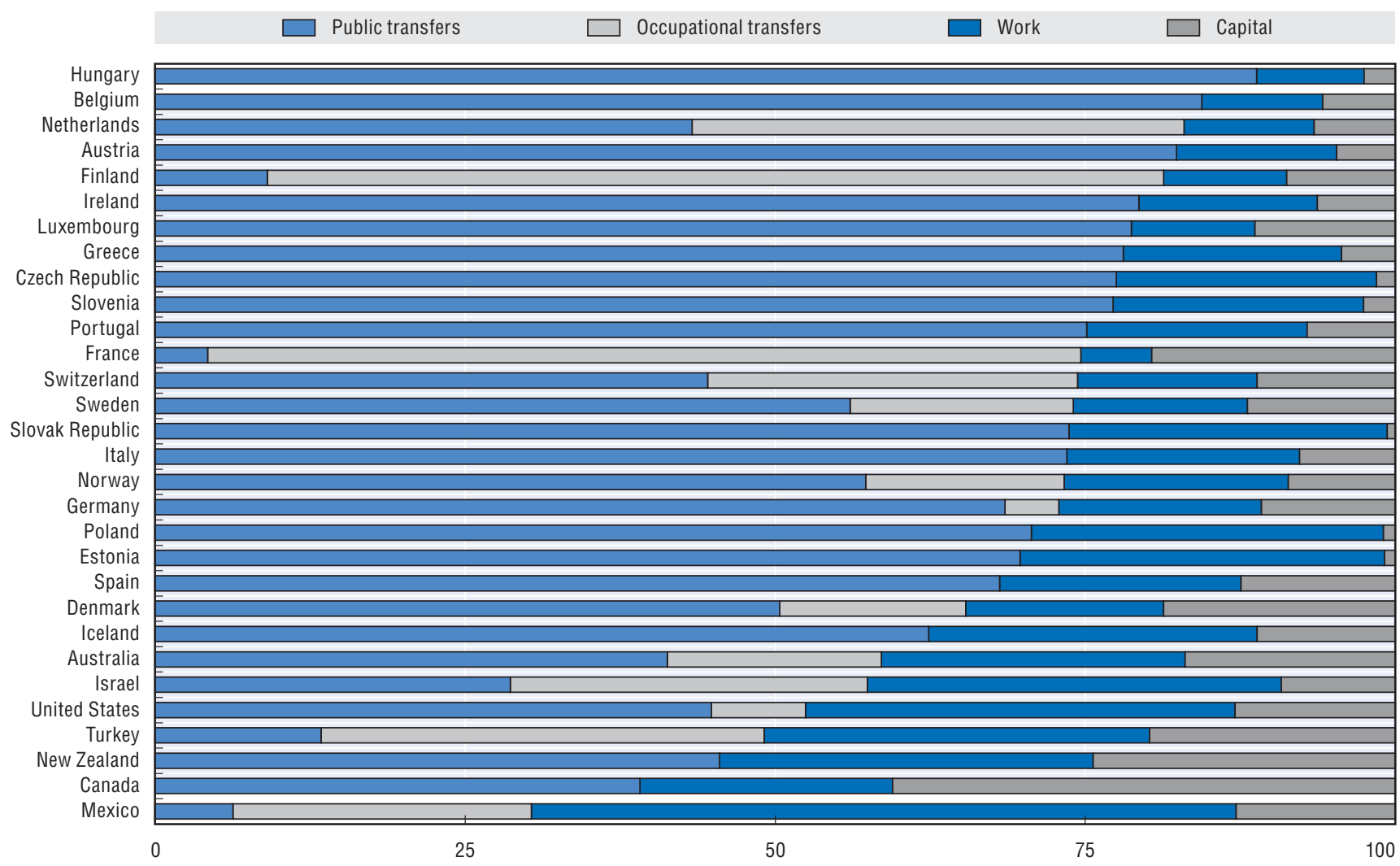

Note: Income from work includes both earnings (employment income) and income from self-employment. Capital income includes private pensions as well as income from the returns on non-pension savings. Chile, Japan, Korea and the United Kingdom missing. Source: OECD Income Distribution Database, www.oecd.org/social/income-distribution-database.htm. 


\section{Key results}

On average in the OECD, $12.6 \%$ of individuals aged over 65 live in relative income poverty, defined as an income below half the national median equivalised household income. There is large variation between countries. Poverty rates are higher for older people than for the population as a whole, which averages $11.3 \%$. However, this result is driven by a handful of countries. In 19 out of 34 OECD countries, old-age income poverty is lower than for the population as a whole.

According to the latest available figures, poverty rates of people aged over 65 were very high in Korea (50\%), Australia (34\%), and Mexico (27\%). In contrast, the Netherlands and the Czech Republic have the lowest poverty rates: $2 \%$ and $3 \%$ respectively. Poverty rates are close to the OECD average of $12.4 \%$ in Austria, Belgium, Estonia, and the United Kingdom.

\section{Poverty among older age groups}

Poverty among the "younger old" (aged 66-75) is less frequent than among the "older old" (aged 75 and over); the average poverty rates are $10.9 \%$ and $14.7 \%$, respectively. The difference between the two is in double digits in Israel, Slovenia, Switzerland and the United States. There are many explanations for this pattern. Most significantly, as real earnings have tended to grow over time, each successive cohort of retirees has a higher starting benefit. Also, women predominate among the old. Nevertheless, in two countries - Luxembourg and Poland - the over 75s fare slightly better than their younger counterparts.

One important factor that explains the varying incidence of old-age poverty is the level at which safety-net retirement benefits are set. (See the indicator on "Basic, targeted and minimum pensions" in Chapter 5.)

\section{Poverty and gender}

Older women are at greater risk of poverty than older men in all countries where breakdowns are available. The average poverty rate for men equals $8.4 \%$ and $12.4 \%$ for women. The smallest poverty gender gaps (less than $0.1 \%$ points) are observed in Ireland and Luxembourg. Differences are also small around 1 percentage point in France, Iceland and the Netherlands.

The largest gender poverty gaps are in Estonia, Slovenia and the United States where the poverty rates among women are between 8 and 12 percentage points higher than among men. But there are also significant differences between 6 and 7 percentage points, in Germany, Hungary, Poland and Switzerland.

\section{Poverty and age}

In 15 out of 34 countries, older people are more likely to be income poor than the population (Table 8.5). The largest differences between the two are found in Australia, Korea and Switzerland where older people have poverty rates that are 14 to 35 percentage points higher than the total population. In Korea, the reason for this is that the pension system has not fully matured, while in both Australia and Switzerland this is due to the fact that many pensioners take their accumulated pensions as lump sums rather than annuitising them to provide income streams. In the 15 OECD countries with old age poverty higher than total population's, old-age poverty rates average $20 \%$. Older people are relatively less likely to be poor than the total population in another 19 countries. Most notably among these are Canada, Greece and Spain, where the old-age poverty rate is between 5 and 8 percentage points lower than the overall rate. In this group of countries the old age poverty equals $7 \%$ while the population poverty is $10 \%$.

\section{Definition and measurement}

For international comparisons, the OECD treats poverty as a "relative" concept. The yardstick for poverty depends on the median household income in a particular country at a particular point in time. Here, the poverty threshold is set at $50 \%$ of median, equivalised household disposable income. See OECD (2015) for more details on definitions and data sources.

\section{Further reading}

OECD (2015), In It Together: Why Less Inequality Benefits All, OECD Publishing, Paris, http://dx.doi.org/10.1787/ 9789264235120-en. 


\subsection{Income poverty rates by age and gender}

Percentage with incomes less than $50 \%$ of median household disposable income

\begin{tabular}{|c|c|c|c|c|c|c|c|c|c|c|c|c|c|}
\hline & \multicolumn{6}{|c|}{2012 or latest available } & & \multicolumn{6}{|c|}{2012 or latest available } \\
\hline & \multicolumn{5}{|c|}{ Older people (aged over 65) } & \multirow{3}{*}{$\begin{array}{c}\text { Whole } \\
\text { population }\end{array}$} & & \multicolumn{5}{|c|}{ Older people (aged over 65) } & \multirow{3}{*}{$\begin{array}{c}\text { Whole } \\
\text { population }\end{array}$} \\
\hline & \multicolumn{3}{|c|}{ By age } & \multicolumn{2}{|c|}{ By gender } & & & & By age & & & nder & \\
\hline & All 65+ & $66-75$ & $76+$ & Men & Women & & & All 65+ & $66-75$ & $76+$ & Men & Women & \\
\hline Australia & 33.5 & 30.5 & 37.8 & 31.0 & 35.7 & 14.0 & Korea & 49.6 & 46.1 & & & & 14.6 \\
\hline Austria & 11.4 & 11.2 & 11.6 & 9.0 & 13.2 & 9.6 & Luxembourg & 3.0 & 3.2 & 2.7 & 3.0 & 3.1 & 8.4 \\
\hline Belgium & 10.7 & 10.2 & 11.4 & 9.7 & 11.5 & 10.2 & Mexico & 27.0 & 25.3 & 30.0 & 26.0 & 27.9 & 18.9 \\
\hline Canada & 6.7 & 6.6 & 6.9 & 4.9 & 8.2 & 11.8 & Netherlands & 2.0 & 1.8 & 2.3 & 1.7 & 2.3 & 7.9 \\
\hline Chile & 18.4 & 17.7 & 19.3 & & & 16.3 & New Zealand & 8.2 & 8.0 & 8.5 & 5.5 & 10.5 & 9.9 \\
\hline Czech Republic & 2.8 & 2.7 & 3.0 & 1.5 & 3.8 & 5.3 & Norway & 4.1 & 2.2 & 6.9 & 1.8 & 6.0 & 8.1 \\
\hline Denmark & 4.6 & 2.7 & 7.4 & 3.1 & 5.8 & 5.4 & Poland & 8.2 & 10.4 & 5.6 & 4.4 & 10.5 & 10.2 \\
\hline Estonia & 12.1 & 12.3 & 11.8 & 6.9 & 14.6 & 12.3 & Portugal & 8.1 & 6.4 & 10.0 & 6.8 & 9.0 & 13.0 \\
\hline Finland & 7.8 & 4.1 & 12.7 & 5.1 & 9.7 & 7.1 & Slovak Republic & 3.6 & 3.2 & 4.3 & 0.7 & 5.3 & 8.4 \\
\hline France & 3.8 & 2.7 & 5.0 & 3.0 & 4.4 & 8.1 & Slovenia & 15.8 & 11.7 & 21.3 & 8.7 & 20.7 & 9.4 \\
\hline Germany & 9.4 & 8.1 & 10.8 & 6.3 & 12.3 & 8.4 & Spain & 6.7 & 6.4 & 7.1 & 5.7 & 7.6 & 14.0 \\
\hline Greece & 6.9 & 5.9 & 8.1 & 5.6 & 8.0 & 15.1 & Sweden & 9.3 & 6.6 & 13.5 & 6.6 & 11.6 & 9.0 \\
\hline Hungary & 8.6 & 7.8 & 9.9 & 5.0 & 10.6 & 10.1 & Switzerland & 23.4 & 18.8 & 30.5 & 19.8 & 26.4 & 9.1 \\
\hline Iceland & 2.8 & 2.8 & 2.8 & 2.5 & 3.0 & 6.3 & Turkey & 17.2 & 15.9 & 19.3 & 15.9 & 18.3 & 17.8 \\
\hline Ireland & 6.9 & 6.5 & 7.5 & 6.9 & 7.0 & 8.4 & United Kingdom & 13.4 & 10.9 & 16.6 & 10.9 & 15.5 & 10.5 \\
\hline Israel & 24.1 & 19.7 & 30.0 & 21.2 & 26.4 & 18.6 & United States & 21.5 & 17.5 & 27.2 & 16.5 & 25.6 & 17.6 \\
\hline Italy & 9.4 & 9.5 & 9.2 & 6.4 & 11.5 & 12.7 & OECD & 12.4 & 10.9 & 14.7 & 8.4 & 12.4 & 11.3 \\
\hline Japan & 19.4 & 16.6 & 22.8 & & & 16.0 & & & & & & & \\
\hline
\end{tabular}

Source: OECD Income Distribution Database, www.oecd.org/social/income-distribution-database.htm; 2013 for Chile, Finland, Hungary, Israel, the Netherlands and the United States. Korea 2009 and Turkey 2011.

\subsection{Income poverty rates by age}

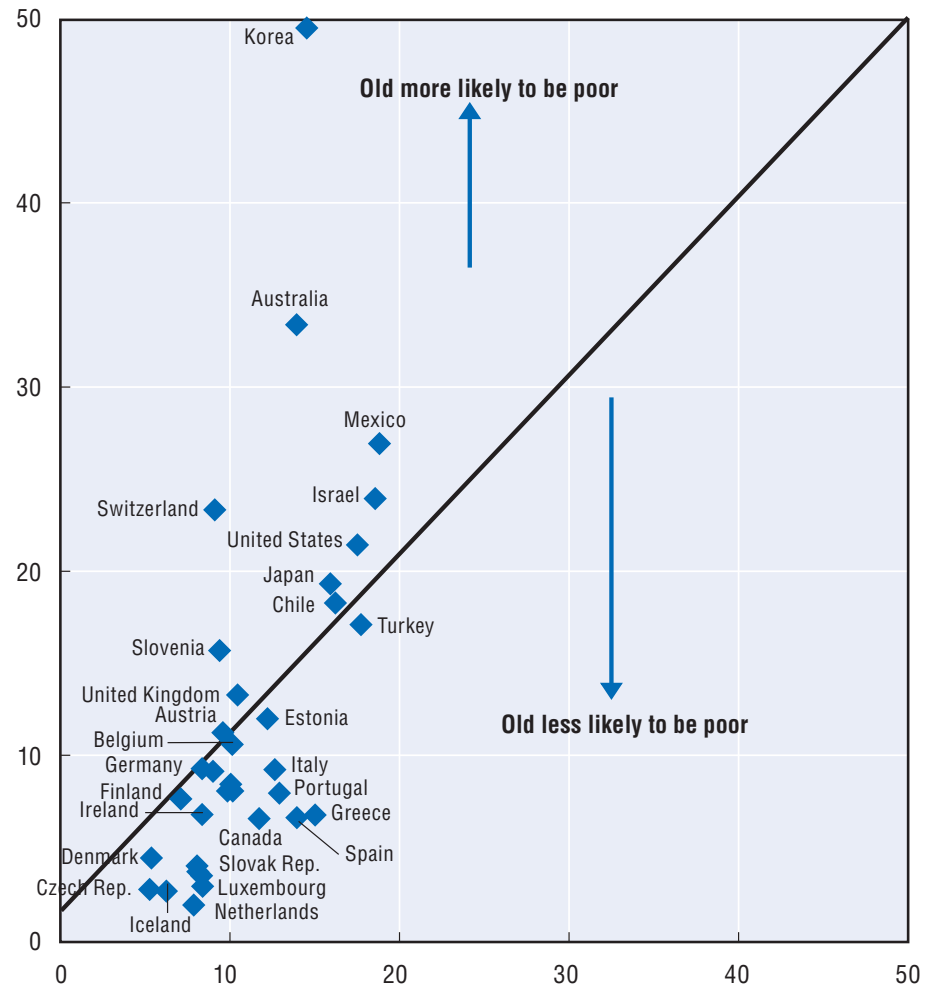

Source: OECD Income Distribution Database, www.oecd.org/social/income-distribution-database.htm. 


\section{Key results}

"Average worker earnings (AW)" is an important metric as all pension modelling results are presented as multiples of this measure. The average worker earnings for all OECD countries averaged USD 40007 in 2014.

Table 8.5 reports average worker earnings levels according to the OECD's average worker wage (AW) measure for the year 2014. Earnings are defined as gross wages before deductions of any kind (including personal income taxes and social security contributions), but including overtime pay and other cash supplements paid to employees.

Average worker earnings are displayed in national currencies and in US dollars (both at market exchange rates and at purchasing power parities, PPP). The PPP exchange rate adjusts for the fact that the purchasing power of a dollar varies between countries: it allows for differences in the price of a basket of goods and services between countries. The Economist regularly produces a popular and easy-to-understand version of PPP - the "Big-Mac" index which shows how currencies differ from the level that would mean the burger cost the same worldwide (see www.economist.com/content/big-mac-index?fsrc=PS/cemea/ggl/ gen/big-mac-index).

Average worker earnings across the OECD countries averaged USD 40007 in 2014 at market exchange rates. At PPP average earnings averaged USD 40 548. The higher figure for PPP earnings suggests that many OECD countries exchange rates with the US dollar were lower than the rate that would equalise the cost of a standard basket of goods and services.

Average earnings for the other major economy countries are not based on the average worker earnings definition or another consistent basis as such a series is unfortunately not available. Data have been collected from national sources and thus vary between average individual income, average covered wage and average wage for a particular group of workers as available.

\section{Definition and measurement}

The "average worker" earnings series (AW) was adopted from the second edition of Pensions at a Glance (OECD, 2007). This concept is broader than the previous benchmark of the "average manual production worker" (APW) because it covers more economic sectors and includes both manual and non-manual workers. The new AW measure was introduced in the OECD report Taxing Wages and also serves as benchmark for Benefits and Wages. The third edition of Pensions at a Glance (OECD, 2009) also included a comparison of replacement rates under the old and new measures of earnings for eight countries where the results were significantly different.

\section{Further reading}

D'Addio, A.C. and H. Immervoll (2010), "Earnings of Men and Women Working in the Private Sector: Enriched Data for Pensions and Tax-Benefit Modelling", OECD Social, Employment and Migration Working Paper, No. 108, OECD Publishing, Paris, http://dx.doi.org/10.1787/ $5 \mathrm{~km} 7 \mathrm{sm} t 2 \mathrm{r} 7 \mathrm{~d} 2$-en. 


\subsection{Average worker earnings (AW), 2014}

National currency and USD at market price and purchasing-power-parity exchange rates

\begin{tabular}{|c|c|c|c|c|c|}
\hline & \multicolumn{3}{|c|}{ OECD measures of average earnings } & \multicolumn{2}{|c|}{ Exchange rate with USD } \\
\hline & National currency & USD, market exchange rate & USD, PPP & Market rate & PPP \\
\hline \multicolumn{6}{|l|}{ OECD members } \\
\hline Australia & 79689 & 65195 & 51746 & 1.22 & 1.54 \\
\hline Austria & 42573 & 51557 & 50986 & 0.83 & 0.84 \\
\hline Belgium & 46464 & 56269 & 55447 & 0.83 & 0.84 \\
\hline Canada & 49481 & 42689 & 39270 & 1.16 & 1.26 \\
\hline Chile & 7018884 & 11588 & 18919 & 605.69 & 371.00 \\
\hline Czech Republic & 312084 & 13637 & 23465 & 22.89 & 13.30 \\
\hline Denmark & 397484 & 64654 & 52369 & 6.15 & 7.59 \\
\hline Estonia & 12436 & 15060 & 22050 & 0.83 & 0.56 \\
\hline Finland & 42910 & 51965 & 45697 & 0.83 & 0.94 \\
\hline France & 37427 & 45325 & 45148 & 0.83 & 0.83 \\
\hline Germany & 45952 & 55649 & 58389 & 0.83 & 0.79 \\
\hline Greece & 20168 & 24424 & 32217 & 0.83 & 0.63 \\
\hline Hungary & 3009284 & 11526 & 22798 & 261.10 & 132.00 \\
\hline Iceland & 6856100 & 53779 & 48972 & 127.49 & 140.00 \\
\hline Ireland & 34466 & 41739 & 40982 & 0.83 & 0.84 \\
\hline Israel & 130605 & 33466 & 32570 & 3.90 & 4.01 \\
\hline Italy & 30463 & 36891 & 40188 & 0.83 & 0.76 \\
\hline Japan & 4881994 & 40765 & 46495 & 119.76 & 105.00 \\
\hline Korea & 39800000 & 36457 & 46441 & 1091.70 & 857.00 \\
\hline Luxembourg & 54560 & 66074 & 60623 & 0.83 & 0.90 \\
\hline Mexico & 101904 & 6912 & 12706 & 14.74 & 8.02 \\
\hline Netherlands & 48856 & 59165 & 59219 & 0.83 & 0.83 \\
\hline New Zealand & 54733 & 42718 & 37233 & 1.28 & 1.47 \\
\hline Norway & 542386 & 72602 & 57395 & 7.47 & 9.45 \\
\hline Poland & 42360 & 11978 & 23148 & 3.54 & 1.83 \\
\hline Portugal & 17436 & 21115 & 29653 & 0.83 & 0.59 \\
\hline Slovak Republic & 10342 & 12525 & 20561 & 0.83 & 0.50 \\
\hline Slovenia & 17851 & 21618 & 29555 & 0.83 & 0.60 \\
\hline Spain & 26162 & 31683 & 38701 & 0.83 & 0.68 \\
\hline Sweden & 407974 & 52272 & 45584 & 7.80 & 8.95 \\
\hline Switzerland & 90522 & 91179 & 66074 & 0.99 & 1.37 \\
\hline Turkey & 28370 & 12164 & 23642 & 2.33 & 1.20 \\
\hline United Kingdom & 35633 & 55539 & 50329 & 0.64 & 0.71 \\
\hline United States & 50075 & 50075 & 50075 & 1.00 & 1.00 \\
\hline OECD34 & & 40007 & 40548 & & \\
\hline \multicolumn{6}{|c|}{ Other major economies } \\
\hline Argentina & 135492 & 16006 & & 8.47 & \\
\hline Brazil & 19312 & 7267 & 11564 & 2.66 & 1.67 \\
\hline China & 56339 & 9077 & 15393 & 6.21 & 3.66 \\
\hline India & 80338 & 1271 & 4539 & 63.19 & 17.70 \\
\hline Indonesia & 17200000 & 1385 & 4363 & 12422 & 3942.00 \\
\hline Russian Federation & 391920 & 6691 & 20519 & 58.57 & 19.10 \\
\hline Saudi Arabia & 183989 & 49020 & & 3.75 & \\
\hline South Africa & 144627 & 12525 & 27084 & 11.55 & 5.34 \\
\hline
\end{tabular}

Note: AW = Average worker wage; PPP = Purchasing power parity. Average earnings are rounded to the nearest 100 and exchange rates rounded to decimal places. The market exchange rate used is from the 31-12-2014. 



\section{Chapter 9}

\section{Finances of retirement-income systems}

The indicators in this chapter look at the finances of retirement-income system. The first indicator presents an overview of the "Mandatory pension contributions" that workers have to pay towards their pension entitlements.

The second indicator looks at the "Public expenditure on pensions" systems. It shows how much of gross domestic product is allocated towards national public pensions and the overall share of public pensions in the government budget. The third indicator focuses on private pension spending and looks at the total benefit spending on mandatory, quasi-mandatory and voluntary private schemes.

The final indicator presents long-term projections of pension spending and in particular the evolution of public expenditure on pensions in the period 2013-15 to 2050 .

The statistical data for Israel are supplied by and under the responsibility of the relevant Israeli authorities. The use of such data by the OECD is without prejudice to the status of the Golan Heights, East Jerusalem and Israeli settlements in the West Bank under the terms of international law. 


\section{Key results}

Mandatory social insurance contributions and mandatory private pension contribution rates for employees and employers for a private sector worker at average earnings average equals $24 \%$ for 13 OECD countries. The average mandatory employers and employees pension contributions for the other 21 OECD countries where this is applicable averaged $18 \%$ in 2014.

Most of the measures presented in Pensions at a Glance look at the benefits side of the pension system. These indicators look at the contribution side and the aim here is to try to map out how much the average workers contributed towards their pension in 2014. Tax financed pension benefits are not covered here.

Since different pension components in a country can be financed through different income sources mapping out the pension's contribution terrain is very important but it can also be difficult. This presentation aims to give a broad picture of the pension schemes modelled herein and where data are available. Importantly the contributions included here only refer to pensions contributions that reflect the pensions modelling. This might be different than the total contributions made by either employees and employers or the total social insurance or tax that apply to wage cost. For this, readers are referred to the OECD Taxing Wages publication.

The upper table presents the 19 OECD countries for where the pension contributions are mandatory public and private. Countries that belong to this group have pension systems where the contribution rate paid is more directly linked to the pensions system. The average contribution rate in this group equalled $18 \%$ in 2014 . The highest total mandatory contribution rate is found in Italy at 33\%.

The lower table looks at the mandatory private and mandatory social insurance contribution rates that apply for a private sector worker. In this group it is difficult to separate the pension contributions paid by the employee and employer to pension benefits from the other parts of social insurance such as survivor's benefits, disability benefits, unemployment, etc. In addition individuals cannot choose which systems to belong to and they therefore have to contribute fully to all parts. The average contribution rate in this group is $24 \%$ for an average worker (AW) in 2014. The highest mandatory private and social insurance contributions are found in Hungary at $47 \%$ and the lowest in the United States at $12 \%$.

Countries with higher pension contribution rates often have above average pension benefits (as in the case of Iceland and the Netherlands) or longer duration in retirement through lower retirement age as is the case in France or in Italy. Higher mandatory pension contribution rates might lower overall employment and increase informality.

New Zealand has the lowest mandatory contribution rates which equals $6 \%$. Other countries which also have low levels of mandatory contributions are Australia with a total mandatory contribution rate equal to $9.5 \%$, Canada at $9.9 \%$ and Korea at $9 \%$ respectively.

\section{Further reading}

OECD (2015), Taxing Wages 2015, OECD Publishing, Paris, http://dx.doi.org/10.1787/tax_wages-2015-en. 
9.1. Mandatory pension contribution rates for an average worker in 2014

\begin{tabular}{|c|c|c|c|c|c|}
\hline & \multicolumn{2}{|c|}{ Public } & \multicolumn{2}{|c|}{ Private } & \multirow{2}{*}{ Total } \\
\hline & Employee & Employer & Employee & Employer & \\
\hline Australia & & 9.5 & & & 9.5 \\
\hline Belgium & 7.5 & 8.86 & & & 16.4 \\
\hline Canada & 4.95 & 4.95 & & & 9.9 \\
\hline Chile & & & 11.2 & 1.15 & 12.3 \\
\hline Denmark & 0.54 & 0.82 & & 12 & 13.4 \\
\hline Finland & 7.05 & 17.75 & & & 24.8 \\
\hline France & 6.8 & 8.45 & 3.0 & 3.0 & 21.25 \\
\hline Germany & 9.5 & 9.5 & & & 18.9 \\
\hline Iceland & & 7.79 & 4 & 8 & 19.8 \\
\hline Israel & 3.75 & 3.75 & 5.5 & 12.0 & 25.0 \\
\hline Italy & 9.19 & 23.81 & & & 33.0 \\
\hline Japan & 8.737 & 8.737 & & & 17.5 \\
\hline Korea & 4.5 & 4.5 & & & 9.0 \\
\hline Luxembourg & 8.0 & 8.0 & & & 16.0 \\
\hline Mexico & & & 1.125 & 5.15 & 6.275 \\
\hline Netherlands & 4.9 & & & & 20.9 \\
\hline New Zealand & & & 3 & 3 & 6 \\
\hline Poland & 9.76 & 9.76 & & & 19.5 \\
\hline Sweden & 7.0 & 11.4 & & 4.5 & 22.9 \\
\hline Switzerland & 4.2 & 4.2 & 7.7 & 10.4 & 26.6 \\
\hline Turkey & 9.0 & 11.0 & & & 20.0 \\
\hline
\end{tabular}

Note: In some cases, pension contribution revenues have been calculated assuming that the revenues are split between different social security programmes in the same proportion as the contribution rates. The total contribution includes payments from people who are not employed (principally the self-employed). In Denmark the ATP contribution is expressed as percentages of AW earnings DNK 397484.

Source: OECD (various years), Taxing Wages; OECD (2013), Revenue Statistics; Social Security Administration, United States (various years), Social Security Programs throughout the World; OECD pension and tax models.

StatLink Aitlst http://dx.doi.org/10.1787/888933301228

\subsection{Social insurance contribution and mandatory private contribution rates for an average worker in 2014}

\begin{tabular}{|c|c|c|c|c|c|}
\hline & \multicolumn{2}{|c|}{ Public } & \multicolumn{2}{|c|}{ Private } & \multirow{2}{*}{ Total } \\
\hline & Employee & Employer & Employee & Employer & \\
\hline Austria & 10.25 & 12.55 & & & 22.8 \\
\hline Czech Republic & 6.5 & 21.5 & & & 28.0 \\
\hline Estonia & & 16.0 & 2.0 & 4.0 & 20.0 \\
\hline Greece & 6.67 & 13.3 & & & 20.0 \\
\hline Hungary & 18.5 & 28.5 & & & 47.0 \\
\hline Ireland & 4 & 10.75 & & & 14.75 \\
\hline Norway & 8.2 & 14.1 & & & 22.3 \\
\hline Portugal & 6.4 & 13.8 & & & 20.2 \\
\hline Slovak Republic & 7.0 & 20.0 & & & 27.0 \\
\hline Slovenia & 15.5 & 8.85 & & & 24.4 \\
\hline Spain & 4.7 & 23.6 & & & 28.3 \\
\hline United Kingdom & 9.05 & 11.9 & & & 20.95 \\
\hline United States & 6.2 & 6.2 & & & 12.4 \\
\hline
\end{tabular}

Note: In some cases, pension contribution revenues have been calculated assuming that the revenues are split between different social security programmes in the same proportion as the contribution rates. The total contribution includes payments from people who are not employed (principally the self-employed).

Source: OECD (various years), Taxing Wages; OECD (2013), Revenue Statistics; Social Security Administration, United States (various years), Social Security Programs throughout the World; OECD pension and tax models. 


\section{Key results}

Public spending on cash old-age pensions and survivors' benefits in the OECD increased 28\% faster than domestic output between 1990 and 2011, from an average of $6.2 \%$ of gross domestic product (GDP) to $7.9 \%$. Public pensions are often the largest single item of social expenditure, accounting for $18 \%$ of total government spending on average.

Italy spent the largest proportion of national income on public pensions among OECD countries in 2011: $15.8 \%$ of GDP. Other countries with high gross public pension spending are also found in continental Europe, with Austria, France, Greece and Portugal at about $13 \%$ to $14 \%$ of GDP and Germany, Poland and Slovenia at about 11\%. Public pensions generally account for between $23 \%$ and $30 \%$ of total public expenditure in these countries.

Iceland and Mexico spent $2.1 \%$ and $1.8 \%$ of GDP on public pensions respectively. Korea is also a low spender at $2.2 \%$ of GDP. Iceland and Mexico are countries with relative young populations and Korea's pension system is not mature yet: the public, earnings-related scheme was only established in 1988 and the new targeted basic pension was introduced only in 2014. In Mexico, low spending also reflects relatively narrow coverage of pensions (only around $35 \%$ of employees). In Iceland, much of retirement income is provided by compulsory occupational schemes (see the next indicator of "Pension-benefit expenditures: Public and private"), leaving a lesser role for the public sector in providing old-age income. In addition the retirement age is high at age 67.

Spending also tends to be low in countries with favourable demographics, such as Australia, Canada, Ireland and New Zealand. However, this is not always the case: Turkey spends $7.5 \%$ of GDP on public pensions despite being the second youngest OECD country in demographic terms. This is more than Denmark, the Netherlands, the United Kingdom and the United States, despite the fact that these countries have a higher share of people aged over 65 as a share of the population as in Turkey.

\section{Trends}

Public pension spending was fairly stable as a proportion of GDP over the period 1990-2011 in six countries: Canada, Iceland, Ireland, Luxembourg, Norway and Sweden.
In another two countries, the Netherlands and New Zealand, public pension spending grew markedly more slowly than national income. In the Netherlands this change reflects the growing importance of occupational pension which reduces the reliance on targeted public pensions. In New Zealand, the decline of around $30 \%$ reflects two policies: freezing the value of the basic pension in 1992-94 and increasing pension age from 60 to 65 years. Often reductions in public pension expenditure are met by increases in private and occupational pension expenditure.

Public pension expenditure more than doubled relative to national income in six OECD countries. In Korea, Mexico and (to a lesser degree) Turkey, this reflected the low starting point in 1990. But Poland and Portugal moved from spending below the OECD average to well above. The change in Japan results from rapid ageing.

\section{Gross and net spending}

The penultimate column of the tables shows public spending in net terms: after taxes and contributions paid on benefits. Net spending is significantly below gross spending in Austria, Belgium, France, Italy, Poland and the Nordic countries, due to relatively high taxes on pension benefits. Gross and net spending are similar where pensions are not taxable such as the Slovak Republic or where public benefits are generally below basic tax reliefs (Australia, the Czech Republic, Ireland and the United Kingdom).

\section{Non-cash benefits}

The final column of the table shows total gross public spending on older people, including non-cash benefits. In three countries, such benefits exceed $2 \%$ of GDP. The most important in Denmark, Norway and Sweden are housing benefits. These are defined as "non-cash benefits" because they are contingent on particular expenditure by individuals. Australia, Finland, Japan and the Netherlands also record high figures for non-cash benefits. 


\subsection{Public expenditure on old-age and survivors benefits}

\begin{tabular}{|c|c|c|c|c|c|c|c|c|c|c|}
\hline & \multicolumn{9}{|c|}{ Public expenditure on cash benefits for old-age and survivors } & \multirow{3}{*}{$\begin{array}{r}\text { Total inc. } \\
\text { non-cash } \\
(\% \text { of GDP }) \\
2011\end{array}$} \\
\hline & \multicolumn{5}{|c|}{ Level (\% of GDP) } & \multirow{2}{*}{$\begin{array}{l}\text { Change (\%) } \\
1990-2011\end{array}$} & \multicolumn{2}{|c|}{$\begin{array}{c}\text { Level (\% of total } \\
\text { government spending) }\end{array}$} & \multirow{2}{*}{$\begin{array}{c}\begin{array}{c}\text { Level in net } \\
\text { terms } \\
\text { (\% of GDP) }\end{array} \\
2011\end{array}$} & \\
\hline & 1990 & 1995 & 2000 & 2005 & 2011 & & 1990 & 2011 & & \\
\hline Australia & 3.1 & 3.6 & 3.8 & 3.3 & 3.5 & 14.0 & 8.5 & 9.7 & 3.4 & 5.2 \\
\hline Austria & 11.4 & 12.3 & 12.2 & 12.4 & 13.2 & 16.3 & 22.1 & 26.1 & 11.5 & 13.9 \\
\hline Belgium & 9.1 & 9.3 & 8.9 & 9.0 & 10.2 & 11.7 & 17.4 & 19.0 & 9.0 & 10.4 \\
\hline Canada & 4.2 & 4.6 & 4.2 & 4.0 & 4.3 & 2.7 & 8.7 & 10.5 & 4.1 & 4.3 \\
\hline Chile & & 6.7 & 7.3 & 3.7 & 3.2 & & & & 3.2 & 3.3 \\
\hline Czech Republic & 5.8 & 6.1 & 7.2 & 7.0 & 8.9 & 53.8 & & 20.5 & 8.9 & 9.1 \\
\hline Denmark & 5.1 & 6.2 & 5.3 & 5.4 & 6.2 & 21.4 & 9.2 & 10.8 & 4.6 & 8.5 \\
\hline Estonia & & & 6.0 & 5.3 & 6.9 & & & 18.3 & 6.8 & 7.0 \\
\hline Finland & 7.3 & 8.8 & 7.6 & 8.4 & 10.3 & 41.0 & 15.1 & 18.7 & 8.5 & 11.4 \\
\hline France & 10.6 & 12.0 & 11.8 & 12.4 & 13.8 & 29.5 & 21.4 & 24.6 & 12.7 & 14.2 \\
\hline Germany & 9.5 & 10.5 & 11.2 & 11.5 & 10.6 & 11.6 & & 23.4 & 10.2 & 10.6 \\
\hline Greece & 9.9 & 9.7 & 10.8 & 11.8 & 14.5 & 46.3 & & 28.0 & 14.5 & 14.7 \\
\hline Hungary & & & 7.6 & 8.5 & 10.0 & & & 19.9 & 10.0 & 10.5 \\
\hline Iceland & 2.2 & 2.4 & 2.2 & 2.0 & 2.1 & -3.9 & & 4.5 & 1.8 & 2.6 \\
\hline Ireland & 4.8 & 4.3 & 3.1 & 3.4 & 5.3 & 8.5 & 11.5 & 11.2 & 5.0 & 5.8 \\
\hline Israel & & 4.5 & 4.7 & 4.9 & 4.8 & & & 11.4 & 4.7 & 4.9 \\
\hline Italy & 11.7 & 13.2 & 13.7 & 14.0 & 15.8 & 35.3 & 22.2 & 31.9 & 13.8 & 16.0 \\
\hline Japan & 4.8 & 6.1 & 7.3 & 8.5 & 10.2 & 112.1 & & 24.4 & 9.7 & 11.9 \\
\hline Korea & 0.7 & 1.2 & 1.4 & 1.5 & 2.2 & 205.7 & 3.7 & 7.4 & 2.2 & 2.4 \\
\hline Luxembourg & 8.2 & 8.8 & 7.5 & 7.2 & 7.7 & -5.3 & 21.6 & 18.1 & 7.0 & 7.7 \\
\hline Mexico & 0.4 & 0.7 & 0.8 & 1.2 & 1.8 & 308.5 & & 7.9 & 1.8 & 1.8 \\
\hline Netherlands & 6.7 & 5.8 & 5.0 & 5.0 & 5.5 & -18.8 & 12.2 & 10.9 & 5.0 & 6.4 \\
\hline New Zealand & 7.3 & 5.6 & 4.9 & 4.2 & 4.9 & -33.6 & 14.0 & 11.1 & 4.2 & 4.9 \\
\hline Norway & 5.6 & 5.5 & 4.8 & 4.8 & 5.4 & -3.7 & & 12.4 & 4.4 & 7.4 \\
\hline Poland & 5.1 & 9.4 & 10.5 & 11.4 & 10.8 & 110.3 & & 24.9 & 9.8 & 10.9 \\
\hline Portugal & 4.9 & 7.2 & 7.9 & 10.3 & 13.0 & 166.7 & & 26.4 & 12.2 & 13.1 \\
\hline Slovak Republic & & 6.3 & 6.3 & 6.2 & 7.0 & & & 17.9 & 7.0 & 7.3 \\
\hline Slovenia & & & 10.5 & 9.9 & 11.4 & & & 22.8 & 11.4 & 11.6 \\
\hline Spain & 7.9 & 9.0 & 8.6 & 8.1 & 10.5 & 32.4 & & 22.9 & 10.1 & 11.2 \\
\hline Sweden & 7.6 & 8.2 & 7.2 & 7.6 & 7.4 & -2.6 & & 14.3 & 5.7 & 9.8 \\
\hline Switzerland & 5.5 & 6.5 & 6.5 & 6.6 & 6.6 & 19.3 & 18.5 & 19.5 & 6.6 & 6.9 \\
\hline Turkey & 2.4 & 2.7 & 4.9 & 5.9 & 7.5 & 219.4 & & 20.2 & 7.5 & 7.6 \\
\hline United Kingdom & 4.8 & 5.3 & 5.3 & 5.5 & 5.6 & 17.0 & 11.6 & 11.7 & 5.4 & 6.1 \\
\hline United States & 5.8 & 6.0 & 5.6 & 5.7 & 6.7 & 15.3 & 15.8 & 16.1 & 6.3 & 6.7 \\
\hline OECD & 6.2 & 6.7 & 6.8 & 7.0 & 7.9 & 27.8 & & 17.5 & 7.3 & 8.4 \\
\hline
\end{tabular}

Note: See Adema, W. and M. Ladaique (2009), "How Expensive is the Welfare State? Gross and Net Indicators in the OECD Social Expenditure Database (SOCX)", OECD Social, Employment and Migration Working Paper, No. 92, OECD Publishing, Paris, http://dx.doi.org/10.1787/220615515052 for more details on the data, sources and methodology.

Source: OECD Social Expenditures Database (SOCX), www.oecd.org/social/expenditure.htm; OECD Main Economic Indicators Database, http://stats.oecd.org/mei/.

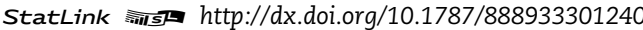




\section{Key results}

Payments from private pension schemes were worth $1.6 \%$ of gross domestic product (GDP) on average in 2011 in the 26 OECD countries for which data are available. This is equivalent to one-fifth of average public spending on retirement benefits. Private-pension payments increased 38\% faster than GDP between 1990 and 2011 on average, which is faster than public pension spending.

Private pensions are mandatory or achieve nearuniversal coverage through industrial relations agreements ("quasi-mandatory") in less than half of the 34 OECD countries. In others, voluntary private pensions - either individual ("personal") or employer-provided ("occupational") have broad coverage.

The biggest flow of private-pension payments is in the Netherlands: $5.8 \%$ of GDP in 2011. Added to public spending, total benefits are $11.2 \%$ of GDP. Switzerland has the next highest figure for private-pension benefits: $5.0 \%$ of GDP. Swiss occupational plans are compulsory, although the data on private-pension payments include benefits above the statutory minimum level.

The next five countries - Canada, Denmark, Iceland, the United Kingdom and the United States - record privatepension payments of between $3.3 \%$ and $4.7 \%$ of GDP. With the exception of Denmark and Iceland private pensions here are voluntary, but both occupational and personal plans have broad coverage. Japan (where private pensions are voluntary) also has high levels of expenditure on private pensions, at $2.7 \%$ of GDP. Iceland has the highest share of private in total pension expenditure at $64 \%$.

Many countries introduced compulsory private pensions in the 1990s: Australia, Estonia, Mexico, Poland, the Slovak Republic and Sweden. In some cases - particularly in Central and Eastern Europe - these new schemes were mainly taken up by younger workers. Many of them have yet to begin paying benefits. Much of the private benefit payouts recorded in Australia and Sweden relate to voluntary and quasi-mandatory (respectively) schemes that were already in place before private pensions were made compulsory. In all these cases, it will be some decades before all retirees have spent a full career in compulsory private pension plans.

\section{Trends}

The countries with the fastest growth in privatepension payments tended to start from a low base, below $0.5 \%$ of GDP. But there are exceptions, such as Denmark, Iceland, Sweden and Switzerland. In the latter, occupational pensions became compulsory in 1985, which extended coverage significantly. This is now being reflected in the rapid growth in private pension entitlements as each successive generation of retirees has spent longer on average covered by private pensions.

\section{Tax breaks}

Many OECD countries offer favourable tax treatment to retirement savings made through private pension plans. Often, individual contributions are fully or partially deductible from income-tax liabilities and investment returns are fully or partially relieved from tax. Some countries offer tax relief on pension payments (see "Tax treatment of pensions and pensioners" in Chapter 6).

The cost of these fiscal incentives is measured in many OECD countries using the concept of "tax expenditures", developed in the 1960s. This attempts to quantify the value of the preferential tax treatment relative to a benchmark tax treatment. The idea is that this is the amount the government would have to provide as a subsidy (a direct expenditure) to achieve the same effect.

Data on tax expenditures for retirement savings are available for 21 OECD countries. More than half of these figures are $0.2 \%$ of GDP or less. And in only four countries - Australia, Canada, Ireland and the United Kingdom - are reported tax expenditures worth $1 \%$ of GDP or more.

Tax expenditure figures come with important caveats: they are not comparable between countries because of differences in the benchmark tax system chosen. Despite their name, they are not equivalent to direct expenditures and so should not be added to numbers for public pension spending.

\section{Further reading}

Adema, W. and M. Ladaique (2009), "How Expensive is the Welfare State? Gross and Net Indicators in the OECD Social Expenditure Database (SOCX)", Social, Employment and Migration Working Paper, No. 92, OECD Publishing, Paris, http://dx.doi.org/10.1787/220615515052.

OECD (2010), Tax Expenditures in OECD Countries, OECD Publishing, Paris, http://dx.doi.org/10.1787/9789264076907-en. 


\subsection{Pension-benefit expenditures: Public and private}

\begin{tabular}{|c|c|c|c|c|c|c|c|c|c|}
\hline & \multirow{3}{*}{ Scheme type } & \multicolumn{6}{|c|}{ Benefit expenditure of private pension schemes } & \multirow{3}{*}{$\begin{array}{c}\begin{array}{c}\text { Public and private } \\
\text { benefit spending } \\
\text { (\% of GDP) }\end{array} \\
2011\end{array}$} & \multirow{3}{*}{$\begin{array}{l}\text { Tax breaks for private } \\
\text { pensions ( } \% \text { of GDP) } \\
2011\end{array}$} \\
\hline & & \multicolumn{5}{|c|}{ Level ( $\%$ of GDP) } & \multirow{2}{*}{$\begin{array}{c}\text { Change (\%) } \\
1990-2011\end{array}$} & & \\
\hline & & 1990 & 1995 & 2000 & 2005 & 2011 & & & \\
\hline Australia & v & & 1.8 & 2.9 & 1.9 & 2.1 & & 5.6 & 1.9 \\
\hline Austria & v & 0.4 & 0.4 & 0.5 & 0.5 & 0.7 & 56.6 & 13.9 & 0.0 \\
\hline Belgium & v & 1.0 & 1.7 & 1.4 & 1.5 & 1.2 & 15.7 & 11.4 & 0.2 \\
\hline Canada & v & 2.5 & 3.4 & 3.9 & 4.2 & 3.3 & 29.3 & 7.6 & 1.5 \\
\hline Chile & $\mathrm{m}$ & & 0.9 & 1.1 & 1.2 & 1.4 & & 4.6 & \\
\hline \multirow[t]{2}{*}{ Czech Republic } & $\mathrm{m}$ & $\mathrm{a}$ & $a$ & 0.2 & 0.2 & 0.5 & & \multirow[t]{2}{*}{9.4} & \multirow[t]{2}{*}{0.0} \\
\hline & v & a & 0.0 & 0.0 & 0.0 & 0.1 & & & \\
\hline Denmark & $q / m$ & 1.5 & 1.8 & 2.0 & 2.3 & 4.7 & 202.2 & 10.9 & \\
\hline Estonia & & & & & & & & 6.9 & \\
\hline Finland & v & 0.1 & 0.4 & 0.3 & 0.2 & 0.3 & 173.6 & 10.5 & 0.1 \\
\hline \multirow[t]{2}{*}{ France } & $\mathrm{m}$ & 0.2 & 0.1 & 0.2 & 0.2 & 0.2 & -18.7 & \multirow[t]{2}{*}{14.1} & \multirow[t]{2}{*}{0.0} \\
\hline & v & 0.1 & 0.1 & 0.1 & 0.1 & 0.2 & 233.0 & & \\
\hline Germany & v & 0.7 & 0.7 & 0.8 & 0.8 & 0.8 & 18.1 & 11.4 & 0.9 \\
\hline Greece & v & 0.4 & 0.4 & 0.5 & 0.5 & 0.4 & 0.5 & 14.9 & \\
\hline Hungary & & & & & & & & 10.0 & \\
\hline Iceland & v & 1.4 & 1.8 & 2.3 & 2.8 & 3.7 & 167.1 & 5.9 & 0.0 \\
\hline Ireland & v & 0.9 & 1.0 & 0.8 & 0.9 & 0.8 & -4.3 & 6.1 & 1.1 \\
\hline Israel & & & & & & & & 4.8 & \\
\hline \multirow[t]{2}{*}{ Italy } & $\mathrm{m}$ & $a$ & a & $a$ & $a$ & $a$ & $a$ & \multirow[t]{2}{*}{16.2} & \multirow[t]{2}{*}{0.0} \\
\hline & v & 0.1 & 0.3 & 0.3 & 0.3 & 0.4 & 159.0 & & \\
\hline \multirow[t]{2}{*}{ Japan } & $\mathrm{m}$ & 0.2 & 0.3 & 0.5 & 0.4 & 0.6 & & \multirow[t]{2}{*}{13.0} & \multirow[t]{2}{*}{0.0} \\
\hline & v & $a$ & $a$ & 2.9 & 2.2 & 2.7 & & & \\
\hline Korea & v & $\mathrm{m}$ & 0.0 & 0.0 & 0.0 & 0.1 & & 2.3 & \\
\hline Luxembourg & v & a & $a$ & $a$ & 0.6 & 0.6 & & 8.3 & 0.0 \\
\hline Mexico & & & & & & & & 1.8 & 0.3 \\
\hline \multirow[t]{2}{*}{ Netherlands } & $\mathrm{m}$ & $a$ & 0.0 & 0.0 & 0.0 & 0.0 & & \multirow[t]{2}{*}{11.2} & \\
\hline & $q$ & 3.9 & 4.7 & 4.8 & 5.2 & 5.8 & 48.5 & & \\
\hline New Zealand & & & & & & & & 4.9 & \\
\hline Norway & v & 0.6 & 0.6 & 0.6 & 0.6 & 0.6 & 15.9 & 6.1 & 0.5 \\
\hline Poland & & & & & & & & 10.8 & 0.0 \\
\hline Portugal & v & 0.3 & 0.3 & 0.4 & 0.6 & 0.6 & 95.0 & 13.6 & 0.1 \\
\hline Slovak Republic & v & $\mathrm{a}$ & 0.1 & 0.2 & 0.4 & 0.3 & & 7.3 & 0.1 \\
\hline Slovenia & & & & & & & & 11.4 & \\
\hline Spain & & & & & & & & 10.5 & 0.2 \\
\hline Sweden & $q / m$ & 1.2 & 1.9 & 1.8 & 2.1 & 2.6 & 112.5 & 9.9 & \\
\hline \multirow[t]{2}{*}{ Switzerland } & $\mathrm{m}$ & 2.3 & 3.3 & 4.2 & 4.7 & 5.0 & \multirow[t]{2}{*}{113.3} & 11.5 & \\
\hline & v & 0.0 & 0.0 & 0.0 & 0.0 & 0.0 & & & \\
\hline Turkey & & & & & & & & 7.5 & \\
\hline United Kingdom & $\mathrm{v} / \mathrm{m}$ & 4.2 & 5.1 & 6.0 & 4.7 & 4.6 & 7.4 & 10.2 & 1.5 \\
\hline United States & v & 2.6 & 3.0 & 3.6 & 3.6 & 4.5 & 72.5 & 11.2 & 0.8 \\
\hline OECD & & 1.2 & 1.3 & 1.5 & 1.4 & 1.6 & 37.9 & 9.3 & 0.4 \\
\hline
\end{tabular}

Note: $\mathrm{a}$ = Legend; $\mathrm{m}$ = Mandatory private scheme; $\mathrm{q}=$ Quasi mandatory; and $\mathrm{v}=$ Voluntary.

Source: OECD Social Expenditures Database (SOCX), www.oecd.org/social/expenditure.htm; OECD Main Economic Indicators Database, http://stats.oecd.org/mei/. See Adema and Ladaique (2009) for more details on the data, sources and methodology. 


\section{Key results}

Public spending on pensions has been on the rise in most OECD countries for the past decades, as shown by the previous two indicators. Long-term projections show that pension spending is expected to go on growing in 20 OECD countries and fall in 13 OECD countries where data are available. On average pension expenditure is forecast to grow from around 9.0\% of gross domestic product (GDP) in 2010-15 to 10.1\% of GDP in 2050.

The main driver of growing pension expenditures is demographic change. The projections shown opposite are derived either from the European Commission's The 2015 Ageing Report - which covers the EU28 members plus Norway - or from national projections or from Standard and Poor's Global Ageing 2013 report. In the main table, data are presented forwards to 2060 for those countries where the figures are available. However, since the horizon is 2050 for ten OECD countries and all the other major economies this is the main comparison in the table. In the case of Australia the latest projections are made until 2055.

Long-term projections are a crucial tool in planning pension policy: there is often a long time lag between when a pension reform occurs and when it begins to affect public pension expenditure. There are some differences in the range of different programmes covered in the forecasts, reflecting the complexity and diversity of national retirement-income provision. For example, data for a number of countries do not include special schemes for public-sector workers while in others they are included. Similarly, projections can either include or exclude spending on resourcetested benefits for retirees. The coverage of the data also differs from the OECD Social Expenditures Database (SOCX), from which the data on past spending trends in the previous two indicators were drawn. The numbers for 2010-15 may differ between the SOCX database and the sources used here because of the different range of benefits covered and the definitions used.

Nevertheless, the figures do reveal broad trends. Pension spending is projected to grow from $9 \%$ of GDP to $10 \%$ of GDP by 2050 on average across all OECD countries. In the EU28 it is projected to remain stable around $11-12 \%$ throughout the entire period. This would be a significant achievement given the demographic change throughout the time period. The indicator of the "Old-age dependency ratio" in Chapter 7 shows an $80 \%$ increase in the demographic dependency ratio, the number of people above the age 65 per 100 people aged between 20 and 64 from today until 2050. Cuts in benefits for future retirees, through lowered indexation and valorisation or benefit formulae, together and with increases in the age at which individuals first can claim pension benefits, will reduce growth in public pension expenditure.

Public pension expenditure is expected to increase in 22 OECD countries by 2050 . In two countries, Turkey and Korea, pension spending would increase considerably, by more than 10 percentage points of GDP by 2050. However, the increase is from a low base. In the case of Korea this rapid increase reflects both the ageing process and the relative immaturity of the pension system. In Belgium, public spending is projected to rise further: from above the OECD average at $12 \%$ of GDP, to $15 \%$ of GDP by 2050 . In Slovenia, spending will increase from $12 \%$ of GDP in $2010-15$ to $16 \%$ in 2050 .

As in the OECD, long-term public pension spending is expected to increase significantly in all major economies but India. Most notably in Brazil where pension expenditure will grow from 9\% currently and reach 17\% of GDP by 2050 .

\section{Further reading}

European Commission (2015), The 2015 Ageing Report: Economic and budgetary projections for the $28 \mathrm{EU}$ Member States (2013-2060), Publications Office of the European Union, Luxembourg.

Standard and Poor's (2013), Global Aging 2013: Rising To The Challenge. 


\subsection{Projections of public expenditure on pensions, 2013-60}

\begin{tabular}{|c|c|c|c|c|c|c|c|c|c|c|}
\hline & $2010-15$ & 2020 & 2025 & 2030 & 2035 & 2040 & 2045 & 2050 & 2055 & 2060 \\
\hline \multicolumn{11}{|l|}{ OECD members } \\
\hline Australia & 2.9 & & 2.5 & & 2.5 & & 2.6 & & 2.7 & \\
\hline Austria & 13.9 & 13.9 & 14.1 & 14.4 & 14.7 & 14.7 & 14.7 & 14.6 & 14.6 & 14.4 \\
\hline Belgium & 11.8 & 12.7 & 13.8 & 14.7 & 15.2 & 15.2 & 15.1 & 15.0 & 15.1 & 15.1 \\
\hline Canada & 4.9 & & & & & & & 6.3 & & \\
\hline Chile & 5.5 & & & & & & & 3.8 & & \\
\hline Czech Republic & 9.0 & 9.0 & 9.1 & 9.0 & 8.8 & 9.0 & 9.3 & 9.6 & 9.8 & 9.7 \\
\hline Denmark & 10.3 & 8.7 & 8.4 & 8.3 & 8.2 & 8.0 & 7.7 & 7.5 & 7.3 & 7.2 \\
\hline Estonia & 7.6 & 7.6 & 7.3 & 7.1 & 7.0 & 6.9 & 6.8 & 6.7 & 6.6 & 6.3 \\
\hline Finland & 12.9 & 14.2 & 14.9 & 15.0 & 14.4 & 13.6 & 13.0 & 12.8 & 12.8 & 12.9 \\
\hline France & 14.9 & 14.6 & 14.9 & 14.7 & 14.2 & 13.8 & 13.3 & 12.8 & 12.3 & 12.1 \\
\hline Germany & 10.0 & 10.3 & 10.9 & 11.6 & 12.1 & 12.2 & 12.3 & 12.5 & 12.6 & 12.7 \\
\hline Greece & 16.2 & 15.5 & 15.0 & 14.4 & 14.1 & 14.1 & 14.1 & 14.4 & 14.2 & 14.3 \\
\hline Hungary & 11.5 & 9.8 & 9.3 & 8.9 & 9.1 & 9.6 & 10.4 & 10.7 & 11.0 & 11.4 \\
\hline Iceland & 3.3 & & & & & & & 3.5 & & \\
\hline Ireland & 7.4 & 8.0 & 8.7 & 9.1 & 9.6 & 10.0 & 10.2 & 10.0 & 9.3 & 8.4 \\
\hline \multicolumn{11}{|l|}{ Israel } \\
\hline Italy & 15.7 & 15.3 & 15.5 & 15.7 & 15.8 & 15.8 & 15.5 & 14.8 & 14.2 & 13.8 \\
\hline Japan & 11.2 & 10.5 & 9.9 & & & & & & & \\
\hline Korea & 1.7 & & & & & & & 12.5 & & \\
\hline Luxembourg & 9.4 & 10.6 & 11.2 & 11.9 & 12.4 & 12.7 & 12.7 & 12.5 & 12.4 & 13.4 \\
\hline Mexico & 1.5 & & & & & & & 1.3 & & \\
\hline Netherlands & 6.9 & 7.1 & 7.4 & 7.7 & 8.1 & 8.3 & 8.3 & 8.1 & 7.9 & 7.8 \\
\hline New Zealand & 5.5 & & & & & & & 7.3 & & \\
\hline Norway & 9.9 & 10.7 & 11.1 & 11.3 & 11.4 & 11.4 & 11.4 & 11.6 & 11.9 & 12.4 \\
\hline Poland & 11.3 & 10.6 & 10.5 & 10.4 & 10.1 & 10.0 & 10.1 & 10.4 & 10.7 & 10.7 \\
\hline Portugal & 13.8 & 14.6 & 14.9 & 15.0 & 15.0 & 14.8 & 14.6 & 14.4 & 13.8 & 13.1 \\
\hline Slovak Republic & 8.1 & 8.0 & 7.9 & 7.6 & 7.7 & 8.1 & 8.6 & 9.1 & 9.7 & 10.2 \\
\hline Slovenia & 11.8 & 11.1 & 11.4 & 12.3 & 13.3 & 14.3 & 15.1 & 15.6 & 15.6 & 15.3 \\
\hline Spain & 11.8 & 11.8 & 11.4 & 11.2 & 11.5 & 11.9 & 12.5 & 12.3 & 11.4 & 11.0 \\
\hline Sweden & 8.9 & 8.3 & 8.1 & 7.9 & 7.8 & 7.5 & 7.3 & 7.2 & 7.4 & 7.5 \\
\hline Switzerland & 9.6 & & & & & & & 10.7 & & \\
\hline Turkey & 6.3 & & & & & & & 17.0 & & \\
\hline United Kingdom & 7.7 & 7.4 & 7.8 & 7.9 & 8.2 & 8.4 & 8.1 & 8.1 & 8.3 & 8.4 \\
\hline United States & 4.9 & & & & & & & 6.1 & & \\
\hline OECD & 9.0 & & & & & & & 10.1 & & 11.3 \\
\hline \multicolumn{11}{|c|}{ Other major economies } \\
\hline Argentina & 7.4 & & & & & & & 11.9 & & \\
\hline Brazil & 9.1 & & & & & & & 16.8 & & \\
\hline China & 3.4 & & & & & & & 9.2 & & \\
\hline India & 1.0 & & & & & & & 0.7 & & \\
\hline Indonesia & 0.7 & & & & & & & 1.6 & & \\
\hline Russian Federation & 8.1 & & & & & & & 14.9 & & \\
\hline Saudi Arabia & 2.2 & & & & & & & 8.1 & & \\
\hline South Africa & 1.9 & & & & & & & 3.5 & & \\
\hline EU28 & 11.3 & 11.2 & 11.4 & 11.6 & 11.7 & 11.7 & 11.6 & 11.4 & 11.3 & 11.2 \\
\hline
\end{tabular}

Note: OECD28 figure shows only countries for which complete data between 2010-15 and 2050 are available. EU28 figure is a simple average of member states (not the weighted average published by the European Commission). Pension schemes for civil servants and other public-sector workers are generally included in the calculations for EU member states: see European Commission, The 2015 Ageing Report.

Source: European Commission (2015), The 2015 Ageing Report; Australia: Commonwealth of Australia (2015), 2015 Intergenerational Report: Australia in 2055; Working Group on Public Pensions, Social Security Council (2013), Ministry of Health and Welfare, Japan; Standard and Poor's (2013), Global Aging 2013: Rising To The Challenge: Argentina, Brazil, Canada, China, Iceland, India, Indonesia, Korea, Mexico, Saudi Arabia and the United States. 



\section{Chapter 10}

\section{Private pensions and public pension reserve funds}

The range of indicators of private pensions and public pension reserves follows the format of the last edition of Pensions at a Glance.

The first of these seven indicators looks at the proportion of the working-age population covered by private pensions. It distinguishes between mandatory, quasimandatory and voluntary schemes and between occupational provision, through an employer-provided or industry-wide scheme, and personal provision, arranged by an individual with a pension provider.

The institutional structure of private pensions is examined next. This shows the type of vehicle that is used to provide pensions, distinguishing between pension funds, book reserves and insurance contracts. This indicator also examines pension types, split between defined benefit, defined contribution and mixed or hybrid schemes.

The third indicator reports assets in private pensions and public pension reserves for 2013. The way these assets are invested is explored in the fourth indicator. There then follows an analysis of the investment performance of private pensions and public pension reserves in 2012 and 2013.

The sixth indicator looks at operating expenses of private pension schemes and the fees charged to pension members in selected defined contribution plans.

The final indicator focuses on defined benefit funding ratios, which are presented for 2012 and 2013.

The statistical data for Israel are supplied by and under the responsibility of the relevant Israeli authorities. The use of such data by the OECD is without prejudice to the status of the Golan Heights, East Jerusalem and Israeli settlements in the West Bank under the terms of international law. 


\section{Key results}

Private pension arrangements have been growing in importance in recent years as pension reforms have reduced public pension entitlements. In 17 OECD countries, private pensions were mandatory or quasi-mandatory in 2013 (that is, they achieve near-universal coverage of employees through collective bargaining agreements). In eight OECD countries, voluntary private pensions (occupational and personal) cover more than $40 \%$ of the working-age population.

In 2013, seventeen of the thirty four OECD countries had some form of mandatory or quasi-mandatory private pension system in place, ensuring a high coverage of the working-age population. In Finland, Iceland, Norway, and Switzerland, occupational pensions are mandatory and cover almost or more than $70 \%$ of the working-age population: employers must operate a scheme and contribution rates are set by the government. Iceland is one of the countries with the highest coverage rate of any OECD country, reaching $87.9 \%$ of the working-age population. Other occupational pension systems can be classified as quasi-mandatory: through industry-wide or nation-wide collective bargaining agreements, employers establish schemes that employees must join. As not all sectors may be covered by such agreements, these systems are not classified as mandatory. Examples include the occupational pension systems in Denmark, the Netherlands, and Sweden. In these countries, the coverage is close to the one in countries with mandatory systems, with $60 \%$ or more of the working-age population covered.

Mandatory personal accounts systems are prevalent in Latin America and Central and Eastern Europe where they have partly replaced social security benefits. Such plans can be found in Chile, Estonia, Mexico, the Slovak Republic, and until recently in Poland, where contributions to personal accounts in open pension funds became voluntary in 2014. Other OECD countries with such mandatory personal pensions include Denmark, Israel and Sweden. While coverage is nearly universal in Denmark, Estonia, Israel and Sweden, it is still not the case in the other countries, where older workers tend not to be covered by the new systems. The coverage rate of around $40-60 \%$ will therefore continue increasing over time as new workers join personal pensions. Some of these countries also have a high incidence of informal employment which limits coverage levels.

Coverage of voluntary occupational pension plans varies across countries. These plans are called voluntary in the sense that employers, in some countries jointly with employees, are free to set up an occupational plan. Personal pension plans are voluntary when individuals can freely decide whether to join them or not. The coverage of voluntary pension plans (occupational or personal) is above $50 \%$ in Belgium, the Czech Republic, Germany, Iceland and New Zealand and close to $50 \%$ in the United States. On the other hand, the coverage of voluntary pension plans is very low (below 5\%) in countries such as Greece and Portugal. In these countries the generosity of public pensions may explain the low private pension coverage. Coverage of voluntary pensions is also low in Mexico (1.7\%) which has a mandatory private pension system.

Three countries, Italy, New Zealand and the United Kingdom, have introduced automatic enrolment (with an opt-out clause) into private pension plans at the national level. The results have been mixed. New Zealand has achieved a coverage rate of $73 \%$ in the "KiwiSaver" scheme (introduced in 2007). In Italy, since 2007 the severance pay provision (so called Trattamento di Fine Rapporto - TFR) of private sector employees is automatically paid into an occupational pension plan unless the employee makes an explicit choice to remain in the TFR regime. Despite this rule, only $16 \%$ of the working-age population is covered by a voluntary pension plan in Italy. For the United Kingdom, the data shown still reflect the situation before the reform, but preliminary 2013 data on employees' coverage by workplace pension schemes exhibit the first increase since 2006. Automatic enrolment is also encouraged by regulation in Canada and the United States.

\section{Definition and measurement}

Several measures of private pension coverage coexist. Individuals can be considered as covered by a private pension plan either if they have assets in a private pension plan, they contribute to a plan, or contributions are being made on their behalf. To be a member of a private pension plan from the perspective proposed here, an individual must have assets or have accrued benefits in a plan. Hence, an individual who does not contribute (for various reasons, including unemployment) or on behalf of whom contributions are not made during a year would still be considered as a plan member if he/she has assets or has accrued benefits in the plan. A large difference between the two measures of coverage arises in countries with large informal sectors.

Counting individuals more than once may arise when using administrative data as individuals can be members of both occupational and personal voluntary pension plans. Therefore total voluntary pension plan coverage cannot be obtained by summing occupational and personal coverage data. For example, in the case of the United States, $41.6 \%$ of the working-age population is member of occupational plans and $22.0 \%$ has personal pensions, while overall voluntary pension coverage is $47.1 \%$. This implies that $40 \%$ of people with occupational pension plans also have a personal plan. 
10.1. Coverage of private pension schemes by type of plan, 2013

As a percentage of working-age population (15-64 years)

\begin{tabular}{|c|c|c|c|c|}
\hline & \multirow{2}{*}{ Mandatory/quasi-mandatory } & \multicolumn{3}{|c|}{ Voluntary } \\
\hline & & Occupational & Personal & Total \\
\hline Australia & 68.5 & $x$ & 19.9 & 19.9 \\
\hline Austria & $x$ & 15.1 & 18.0 & .. \\
\hline Belgium & $x$ & 57.3 & .. & .. \\
\hline Canada & $\mathrm{x}$ & 25.7 & 24.7 & .. \\
\hline Chile & 78.9 & .. & .. & .. \\
\hline Czech Republic & $x$ & $x$ & 66.2 & 66.2 \\
\hline Denmark & $\begin{array}{l}\text { ATP: } 83.3 \\
\text { QM0: } 62.3\end{array}$ & $\mathrm{x}$ & 22.4 & 22.4 \\
\hline Estonia & 74.3 & $\mathrm{x}$ & 5.1 & 5.1 \\
\hline Finland & 84.1 & 9.2 & 20.9 & 29.1 \\
\hline France & $x$ & 20.2 & 5.3 & .. \\
\hline Germany & $x$ & 56.4 & 35.2 & 71.3 \\
\hline Greece & $x$ & 0.2 & .. & .. \\
\hline Hungary & $x$ & .. & 18.5 & .. \\
\hline Iceland & 87.9 & $x$ & 52.2 & 52.2 \\
\hline Ireland & $x$ & 31.0 & 12.0 & 41.3 \\
\hline Israel & 94.2 & $x$ & $x$ & $\mathrm{x}$ \\
\hline Italy & $x$ & 7.4 & 8.9 & 15.7 \\
\hline Japan & .. & .. & .. & .. \\
\hline Korea & 13.9 & $x$ & 23.4 & 23.4 \\
\hline Luxembourg & $x$ & 5.2 & .. & .. \\
\hline Mexico & 57.8 & 1.7 & $x$ & 1.7 \\
\hline Netherlands & 88.0 & $\mathrm{x}$ & 28.3 & 28.3 \\
\hline New Zealand & $x$ & 7.2 & 72.9 & .. \\
\hline Norway & 68.6 & .. & 22.3 & .. \\
\hline Poland & 60.3 & 1.4 & .. & .. \\
\hline Portugal & $x$ & 3.2 & 4.0 & .. \\
\hline Slovak Republic & 55.3 & $x$ & .. & .. \\
\hline Slovenia & $x$ & .. & .. & 36.3 \\
\hline Spain & $x$ & 3.3 & 15.7 & 18.6 \\
\hline Sweden & $\begin{array}{l}\text { PPS: 100 } \\
\text { QMO: 90 }\end{array}$ & $x$ & 36.0 & 36.0 \\
\hline Switzerland & 72.6 & $x$ & .. & .. \\
\hline Turkey & 1.4 & 0.5 & 6.9 & .. \\
\hline United Kingdom & $x$ & 30.0 & 11.1 & 43.3 \\
\hline United States & $x$ & 41.6 & 22.0 & 47.1 \\
\hline
\end{tabular}

Note: QMO = Quasi-mandatory occupational; PPS = Premium Pension System; .. = Not available; $\mathrm{x}=$ Not applicable. Coverage rates are provided with respect to the total working-age population (i.e. individual aged 15 to 64 years old) for all countries except Germany, Ireland and Sweden for which coverage rates are provided with respect to employees subject to social insurance contributions for Germany and to total employment for Ireland and Sweden.

Source: Estimates from OECD Global Pension Statistics and OECD calculations using survey data.

StatLink त्नाज्ञ http://dx.doi.org/10.1787/888933301275 


\section{Key results}

Private pension plans can be funded through various financing vehicles. In 2013, for OECD countries for which data are available, on average, $75 \%$ of OECD private pension assets was held by pension funds, $20 \%$ was held in pension insurance contracts run by life and pension insurance companies, $4 \%$ was held in retirement products provided by banks or investment management companies, and $1 \%$ were book reserves.

Within pension funds, DC plans are playing an increasing role, even if DB plans still dominate pension fund assets in some countries, largely due to their historical prominence as the favoured arrangement for occupational (workplace) pensions in many countries.

Occupational pensions are overwhelmingly funded through pension funds in most OECD countries, the main exception being countries such as Belgium, Denmark, France, Korea, Norway and Sweden where pension insurance contracts play a larger role, and Germany and Austria where book reserves - provisions on sponsoring employers' balance sheets - are the main type of financing vehicle for occupational pension plans. Personal pension plans are often funded through pension insurance contracts or financial products provided by banks and asset managers. The main exceptions to this general trend are the mandatory personal pension plans established in countries such as Chile, Estonia, Mexico and the Slovak Republic. These systems can only be financed via pension funds during the asset accumulation stage (before retirement). At retirement, the accumulated assets may (or in some cases have to) be converted into an annuity, which is classified as a pension insurance product.

In 2013, for countries for which data are available, on average, $75 \%$ of OECD private pension markets was held by pension funds, $20 \%$ was held in pension insurance contracts run by life and pension insurance companies, $4 \%$ was held in retirement products provided by banks or investment management companies, and $1 \%$ were book reserves.

In broad terms, and depending on how pension benefits are calculated and who bears the inherent risk, pension plans can either be defined benefit (DB) or defined contribution (DC) in nature. In DC plans, participants bear the brunt of risk, while in traditional DB plans sponsoring employers assume most of the risks. Employers in some countries have introduced hybrid and mixed DB plans, which come in different forms, but effectively involve some degree of risk sharing between employers and employees. In certain types of hybrid DB plans in countries such as Canada and the Netherlands, benefit levels (either fully or partially) are conditional on the fund's funding status. Cash balance plans (another type of hybrid DB plan) provide benefits based on a fixed contribution rate and a guaranteed rate of return (the guarantee is provided by the sponsoring employer, hence these plans are classified as DB). Such plans are part of the pension landscape in Belgium (where by law, employers must provide a minimum return guarantee), Germany, Japan and the United States. Mixed plans are those where the plan has two separate DB and DC components which are treated as part of the same plan. For instance, the plan may calculate benefits under a DC formula up to a certain age before retirement and apply a DB formula thereafter. There are also DC plans such as those in Denmark and Sweden which offer guaranteed benefits or returns and in which risks are borne collectively by plan members. They are classified as DC as whenever there is no recourse to the sponsoring employer in case of underfunding. Such plans, however, provide a degree of predictability over future benefits similar to that of DB plans.

Occupational pension plans in OECD countries have traditionally been DB. However, in recent years, occupational pension plan sponsors have in many countries shown a growing interest in DC plans, as demonstrated by the number of employers that have closed DB plans to new entrants and encouraged employees to join DC plans (and in some cases also frozen benefit accruals for existing employees). DB plans, however, still play an important role, largely due to their historical prominence as the favoured arrangement for occupational (workplace) pensions in many countries. In 2013, traditional DB assets accounted for most of pension funds' assets in countries like Canada, Finland, Germany, Ireland, Israel, Korea, Luxembourg, Norway, Portugal, Switzerland, Turkey and the United States, where public sector pension funds remain overwhelmingly DB. At the other extreme, all pension funds are classified as DC in Chile, the Czech Republic, Estonia, France, Greece, Hungary, Poland, the Slovak Republic and Slovenia. In other OECD countries, the DB-DC split varies.

\section{Definition and measurement}

The OECD has established a set of guidelines for classifying private pensions (see OECD, 2005). The analysis uses this framework. Data is readily available for pension funds. On the other hand, not all countries collect and report information on pension insurance contracts or retirement saving products offered by banks or investment management companies. Information on book reserves, which refer to pension provisions made by plan sponsors on their balance sheets (without legal separation of assets), is also only available for a few countries. The split by type of plan is therefore only presented for pension funds.

\section{Further reading}

OECD (2005), Private Pensions: OECD Classification and Glossary, OECD Publishing, Paris, www.oecd.org/dataoecd/0/49/ 38356329.pdf. 
10.2. Private pension assets by type of financing vehicle in selected OECD countries, 2013

As a percentage of total assets

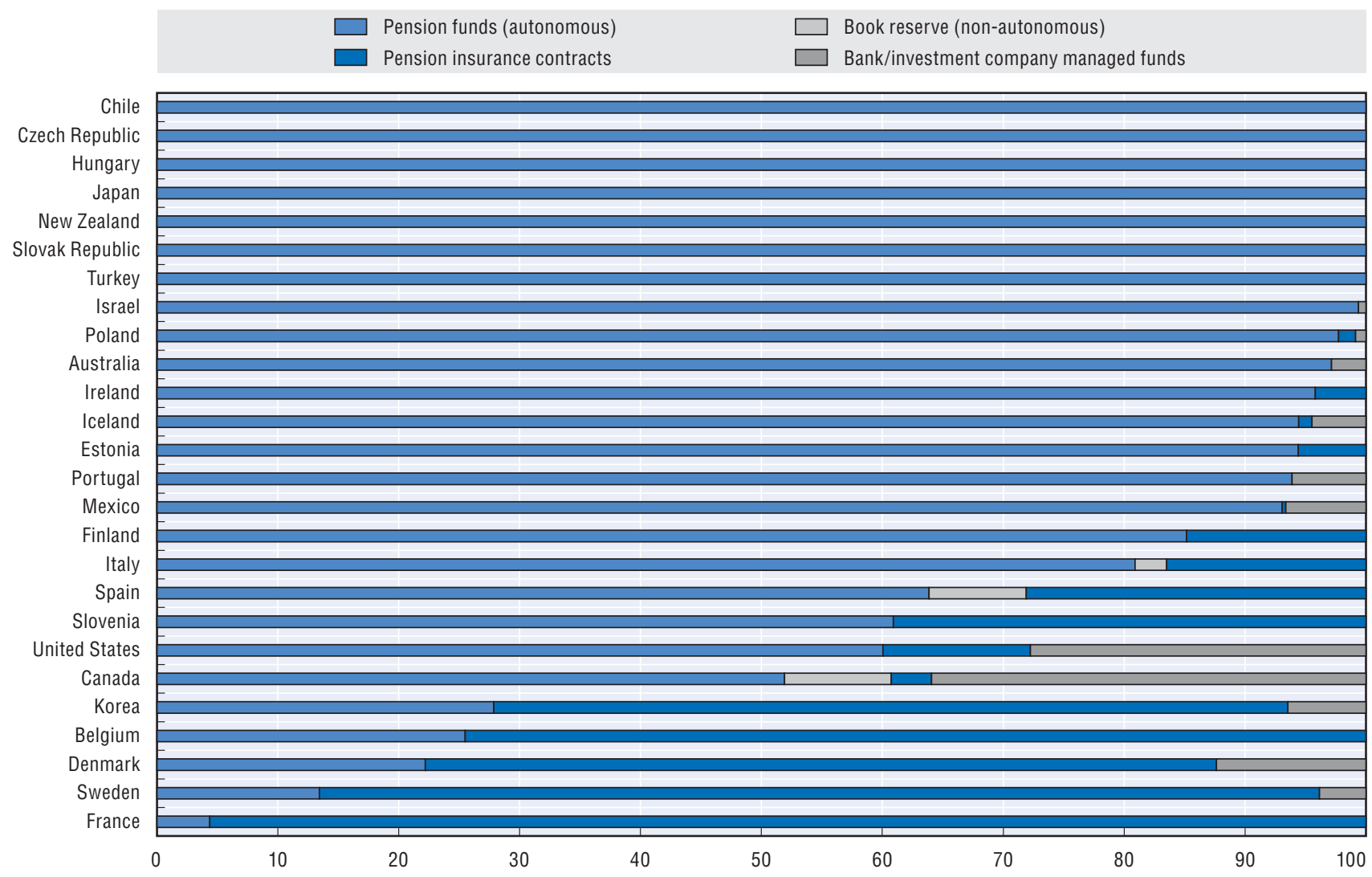

Source: OECD Global Pension Statistics.

\subsection{Relative shares of DB, DC and hybrid pension fund assets in selected OECD countries, 2013}

As a percentage of total assets

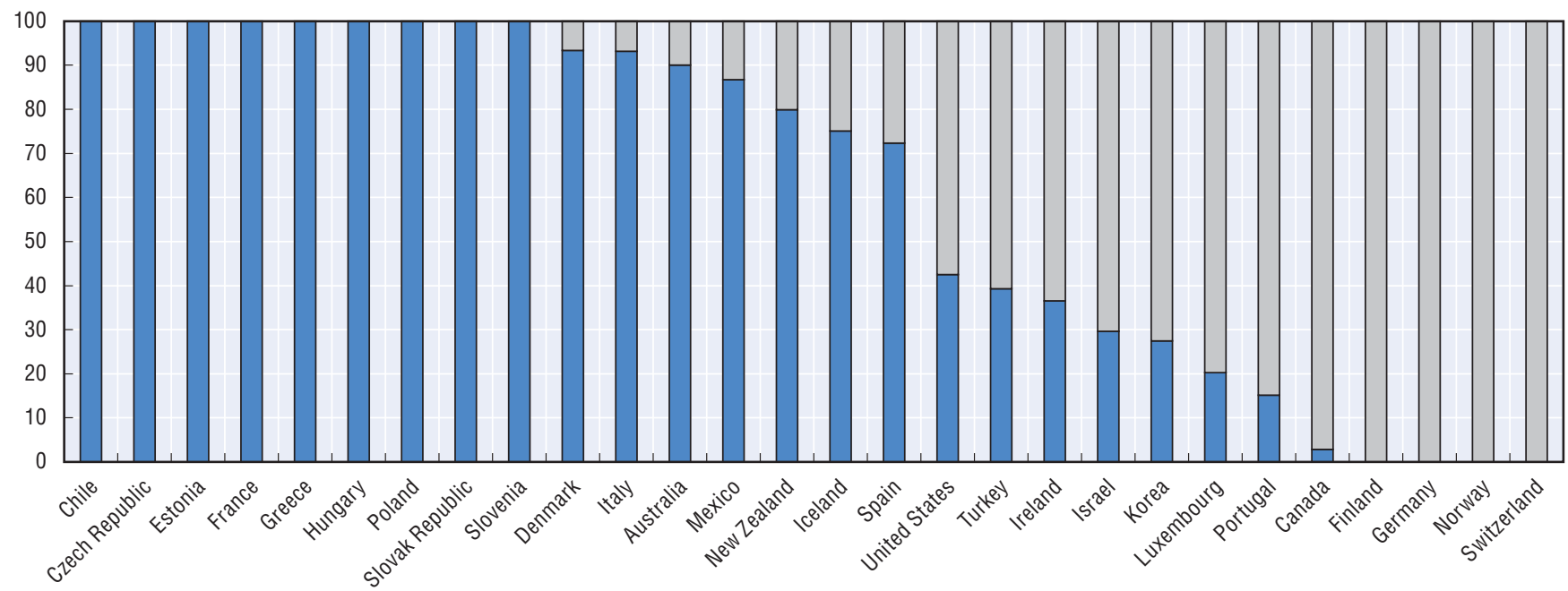

Source: OECD Global Pension Statistics. 


\section{Key results}

Substantial assets have been accumulated in most OECD countries to help meet future pension liabilities. The weighted average of OECD pension funds' assets was equal to $83 \%$ of gross domestic product (GDP) in 2013. Sixteen OECD countries have also built up public pension reserves to help pay for state pensions. For these countries, public pension reserves were worth nearly $20 \%$ of GDP on average.

OECD pension fund assets reached USD 24.8 trillion in 2013. The United States had the largest pension fund market within the OECD member countries with assets worth USD 13.9 trillion, representing $56.2 \%$ of the OECD total. Other OECD countries with large pension fund systems include the United Kingdom with assets worth USD 2.8 trillion and a $11.3 \%$ share of OECD pension fund market in 2013; Australia, USD 1.4 trillion and 5.8\%; the Netherlands, USD 1.3 trillion and 5.4\%; Japan, USD 1.3 trillion, 5.4\%; and Canada, USD 1.3 trillion and 5.1\%.

In 2013, only four countries achieved asset-to-GDP ratios higher than $100 \%$ - the Netherlands (148.7\%), Iceland (141.2\%), Switzerland (113.4\%) and Australia (102.2\%). In addition to these countries, the United Kingdom (99.6\%) and the United States (83.2\%) exceeded the OECD weighted average asset-to-GDP ratio of $82.8 \%$. In such countries, funded pensions have been in place for a long time, and with the exception of the United Kingdom and the United States, have mandatory or quasi-mandatory private pension systems. Pension fund assets were of varying importance relative to GDP in the other countries.

Only 13 out of 34 countries had asset-to-GDP ratios above $20 \%$. Other countries have introduced mandatory funded pension systems in recent years. Of these, Chile has the longest history and has accumulated assets not much below the OECD average (62.3\%). Growth prospects are also very positive in countries like Estonia and Mexico, countries that introduced mandatory private pensions in the late 1990s and early 2000s. Assets have grown rapidly since that point, reaching between $9 \%$ and 15\% of GDP respectively. These figures will continue growing over coming years and decades as more people join the new retirement-income system and existing members make further contributions.

Some prefunding also occurs in state pension systems, which are normally financed on a pay-as-you go basis. Public pension reserve funds (PPFRs) are expected to play a major role in the future financing of some public pension systems, alleviating the impact of population ageing on the public purse. By the end of 2013, the total amounts of PPRFs assets were equivalent to USD 5.3 trillion for the 16 OECD countries for which data are available. The largest reserve was held by the US social security trust fund at USD 2.8 trillion, accounting for $52.4 \%$ of total OECD assets, although the assets consist of non-tradable IOUs issued by the US Treasury to the social security trust. Japan's Government Pension Investment Fund was second at USD 1.2 trillion $-23.2 \%$ of the OECD total. Of the remaining countries, Korea, Canada and Sweden had also accumulated large reserves, respectively accounting for $7.7 \%$, $5.8 \%$ and $3.1 \%$ of the total.

In terms of total assets relative to the national economy, on average, PPRF assets accounted for $19.7 \%$ of GDP in the OECD area in 2013. The highest ratio was observed in the Korean National Pension Fund with $29.9 \%$ of GDP. Other countries where the ratio was of a significant size included Sweden with $28.0 \%$ and Japan with $26.8 \%$. PPRFs in Australia, Belgium, Chile, New Zealand and Poland have been established relatively recently (between 2002 and 2006), explaining the low level of assets accumulated up to now. The expansion of this pool of assets should continue over the coming years, although some countries such as France and Spain have already started withdrawing some of the savings to cover social security deficits. The French Pension Reserve Fund and the Irish National Pension Reserve Fund do not qualify anymore as public pension reserve funds as their mandate now goes beyond financing pay-as-you-go pension plans.

\section{Definition and measurement}

A pension fund is a pool of assets forming an independent legal entity that are bought with the contributions to a pension plan for the exclusive purpose of financing pension plan benefits. The plan/fund members have a legal or beneficial right or some other contractual claim against the assets of the pension fund.

PPRFs are reserves established by governments or social security institutions to support public pension systems, which are otherwise financed on a pay-as-you-go basis. The assets in such reserve funds form part of the government sector, broadly defined. 


\subsection{Assets in pension funds and public pension reserve funds in OECD countries and other major economies, 2013}

As a percentage of GDP and in millions of USD

\begin{tabular}{|c|c|c|c|c|}
\hline & \multicolumn{2}{|c|}{ Pension funds } & \multicolumn{2}{|c|}{ Public pension reserve funds } \\
\hline & $\%$ of GDP & USD millions & $\%$ of GDP & USD millions \\
\hline \multicolumn{5}{|l|}{ OECD members } \\
\hline Australia & 102.2 & 1440898 & 6.1 & 85597 \\
\hline Austria & 5.7 & 25173 & $x$ & $\mathrm{x}$ \\
\hline Belgium & 5.0 & 27213 & 5.1 & 27531 \\
\hline Canada & 70.8 & 1260157 & 17.2 & 307370 \\
\hline Chile & 62.3 & 162988 & 2.8 & 7335 \\
\hline Czech Republic & 7.3 & 14951 & $x$ & $x$ \\
\hline Denmark & 42.1 & 146700 & $x$ & $x$ \\
\hline Estonia & 9.5 & 2443 & $x$ & $x$ \\
\hline Finland & 48.7 & 135651 & 27.0 & 75211 \\
\hline France & 0.4 & 11860 & 2.5 & 71575 \\
\hline Germany & 6.1 & 236932 & $x$ & $x$ \\
\hline Greece & 0.1 & 136 & $x$ & $x$ \\
\hline Hungary & 4.0 & 5506 & $x$ & $x$ \\
\hline Iceland & 141.2 & 22986 & $x$ & $x$ \\
\hline Ireland & 52.3 & 126188 & $x$ & $x$ \\
\hline Israel & 50.5 & 152679 & $x$ & $x$ \\
\hline Italy & 6.0 & 132168 & $x$ & $x$ \\
\hline Japan & 29.2 & 1331231 & 26.8 & 1223863 \\
\hline Korea & 6.0 & 81555 & 29.9 & 404543 \\
\hline Luxembourg & 2.1 & 1323 & $x$ & $\mathrm{x}$ \\
\hline Mexico & 14.7 & 181255 & 0.1 & 1716 \\
\hline Netherlands & 148.7 & 1335092 & $x$ & $\mathrm{x}$ \\
\hline New Zealand & 18.8 & 33831 & 10.4 & 20629 \\
\hline Norway & 8.1 & 40908 & 5.7 & 28862 \\
\hline Poland & 18.2 & 100563 & 1.1 & 5856 \\
\hline Portugal & 8.9 & 20904 & 6.9 & 16134 \\
\hline Slovak Republic & 9.8 & 9926 & $x$ & $x$ \\
\hline Slovenia & 3.9 & 1954 & $x$ & $x$ \\
\hline Spain & 8.8 & 127478 & 5.1 & 74118 \\
\hline Sweden & 9.1 & 53767 & 28.0 & 164650 \\
\hline Switzerland & 113.4 & 807893 & $x$ & $x$ \\
\hline Turkey & 4.8 & 35543 & $x$ & $x$ \\
\hline United Kingdom & 99.6 & 2810564 & $x$ & $x$ \\
\hline United States & 83.2 & 13946142 & 16.5 & 2764431 \\
\hline OECD34 & 82.8 & 24824555 & 19.7 & 5279423 \\
\hline \multicolumn{5}{|c|}{ Other major economies } \\
\hline Argentina & 0.0 & 0 & 9.9 & 50680 \\
\hline Brazil & 13.3 & 273965 & $x$ & $\mathrm{x}$ \\
\hline EU28 & 94.3 & 5351027 &.. &.. \\
\hline China & 1.0 & 98896 & .. & .. \\
\hline India & 0.4 & 6819 & 6.1 & 116229 \\
\hline Indonesia & 1.8 & 15058 & 1.7 & 12303 \\
\hline Russian Federation & 5.7 & 117180 & $x$ & $\mathrm{x}$ \\
\hline Saudi Arabia &.. & .. &.. &.. \\
\hline South Africa & 94.8 & 306107 & $x$ & $x$ \\
\hline
\end{tabular}

Note: OECD34 and EU28 represent the weighted average of funds' assets as a \% of GDP or total funds' assets in millions of USD for countries in the area for which data are available.

.. = Not available; $\mathrm{x}=$ Not applicable.

Source: OECD Global Pension Statistics and Annual Survey of Public Pension Reserve Funds. 


\section{Key results}

At the end of 2013, traditional asset classes (primarily bonds and equities) were still the most common kind of investment in pension fund and public pension reserve fund portfolios. Proportions of equities and bonds vary considerably across countries but there is, generally, a greater preference for bonds.

In most OECD countries for which 2013 data were available, bonds and equities remain the two most important asset classes, accounting for over $80 \%$ of total pension funds' portfolio at the end of 2013 in 15 OECD countries. In Belgium, for example, $42.0 \%$ of total pension funds' assets were invested in bonds, while $39.0 \%$ were in equities, giving Belgian pension funds an aggregate weighting of $81.0 \%$ in equities and bonds. The combined proportion of bonds and equities relative to the total pension funds' portfolio in 2013 was $99.0 \%$ for Mexico, $93.2 \%$ for Poland, $92.7 \%$ for Norway, 90.6\% for Sweden, 90.2\% for Luxembourg, 89.3\% for Hungary, $88.9 \%$ for Chile, $86.9 \%$ for the Czech Republic, $83.0 \%$ for Turkey, $82.5 \%$ for Austria, $82.5 \%$ for Estonia, $81.8 \%$ for Denmark, $80.4 \%$ for the Netherlands and $80.0 \%$ for Israel. At the other extreme, this combined proportion was below or close to $50 \%$ for a few countries, including Korea (9.0\%) and the United Kingdom (53.8\%).

Proportions of equities and bonds vary considerably in pension funds' portfolio across countries. Although there is, in general, at the end of 2013, a greater preference for bonds, the reverse is true in some OECD countries, namely Australia, where equities outweigh bonds by $48.9 \%$ to $8.6 \%$; Finland by $38.2 \%$ to $31.1 \%$; and the United States by $49.4 \%$ to $20.9 \%$.

Within the "bonds" category, public sector bonds, as opposed to corporate bonds, comprise a significant share of the combined direct (i.e. excluding investment via mutual funds) bond holdings of pension funds in many countries. For example, public sector bonds comprise $92.4 \%$ of total direct bond holdings in Hungary, 89.8\% in Iceland, 86.5\% in Israel, $85.6 \%$ in the Czech Republic, and $85.5 \%$ in Turkey, but only $39.4 \%$ in Luxembourg, 26.3\% in Norway, and 9.9\% in Korea.

Cash and deposits also account for a significant share of pension funds' portfolio in some OECD countries. For example, the proportion of cash and deposits in total portfolio in 2013 was as high as $23.1 \%$ for the Slovak Republic, $24.6 \%$ for Greece, and 56.5\% for Korea.
In most OECD countries, loans, real estate (land and buildings), unallocated insurance contracts and private investment funds (shown as "other" in the figure) only account for relatively small amounts of pension funds' assets although some exceptions exist. Real estate, for example, is a significant component of pension fund portfolios (directly or indirectly through collective investments schemes) in Australia, Canada, Finland, Portugal and Switzerland (in the range of 5 to $20 \%$ of total assets). Anecdotal evidence shows that pressure to decreased DB funding gaps and raise returns is driving a move into alternative investments with pension funds increasingly using derivatives to hedge risks and as an alternative to direct investment in the underlying markets.

Fixed income and equities were also the predominant asset classes within PPRF portfolios at the end of 2013. There was also a strong equity bias in some reserve funds, which reflects their long-term investment outlook and generally greater investment autonomy. For example, in 2013, Norway's Government Pension Fund invested $59.7 \%$ of its assets in equities and $36.5 \%$ in fixed income, while the figures for Sweden AP funds were around 50\% and 30\% (AP1, AP2, AP3 and AP4 funds), and $44.9 \%$ and $20.7 \%$ for the Quebec Pension Plan. The reserves in the main Canadian reserve fund, Canada Pension Plan Investment Board (CPPIB), were roughly evenly split between equities (32.1\%) and fixed income $(33.0 \%)$. On the other hand, reserve funds in Chile, Japan, Portugal and Poland for instance invested much more in bonds than equities in 2013.

The extreme cases are those of the Belgian, Spanish and US PPRFs, which are by law fully invested in government bonds.

Some PPRFs also started to invest in real estate and non-traditional asset classes like private equity and hedge funds. For example, the funds with the highest allocation to private equity and hedge funds were those in Mexico (54.3\% in total in 2013) and Australia (22.3\%). 
10.5. Pension funds' asset allocation for selected investment categories in selected OECD countries, 2013 As a percentage of total investment

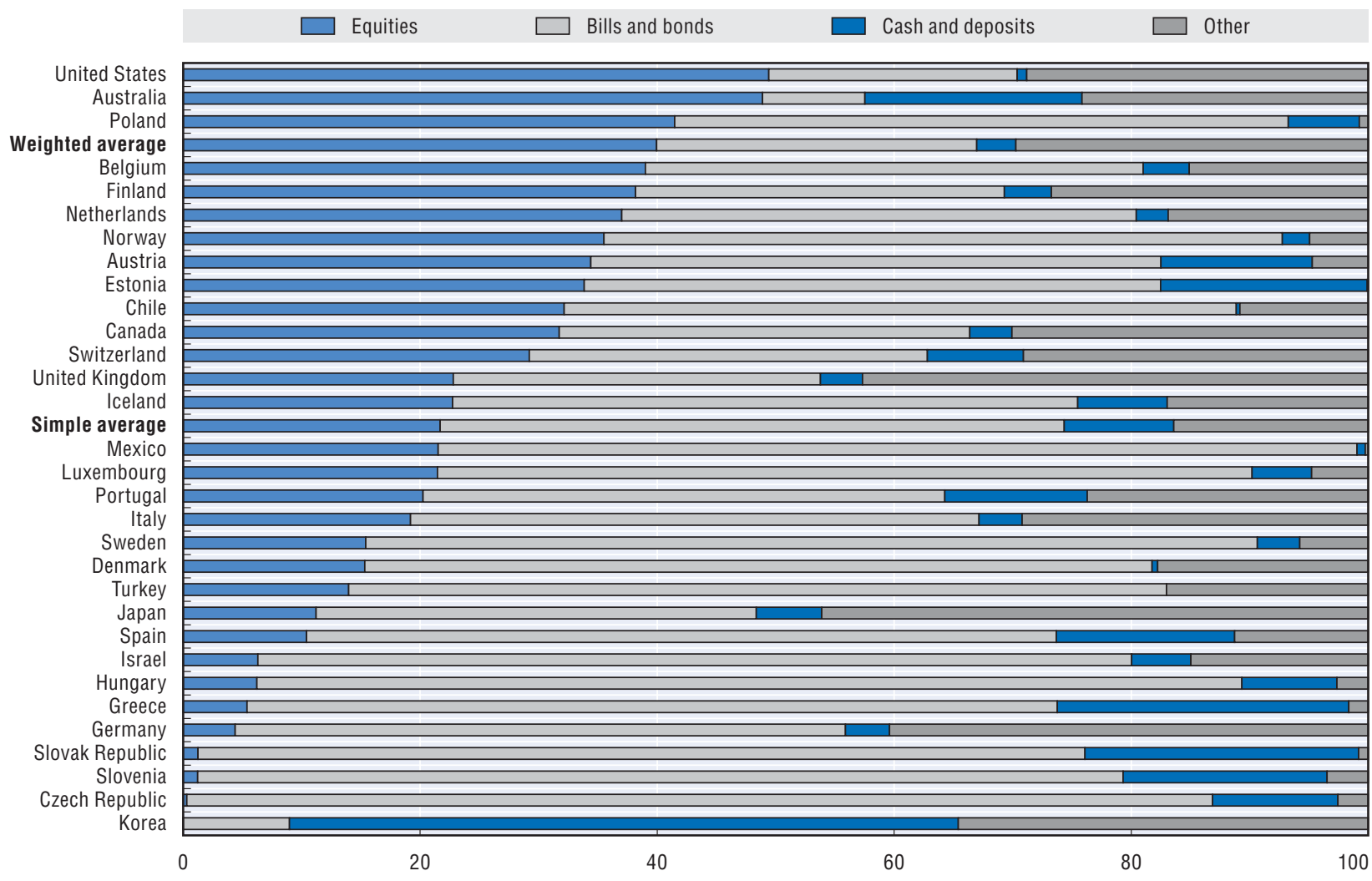

Source: OECD Global Pension Statistics.

\subsection{Public pension reserve funds' asset allocation for selected investment categories} in selected OECD countries, 2013

As a percentage of total investment

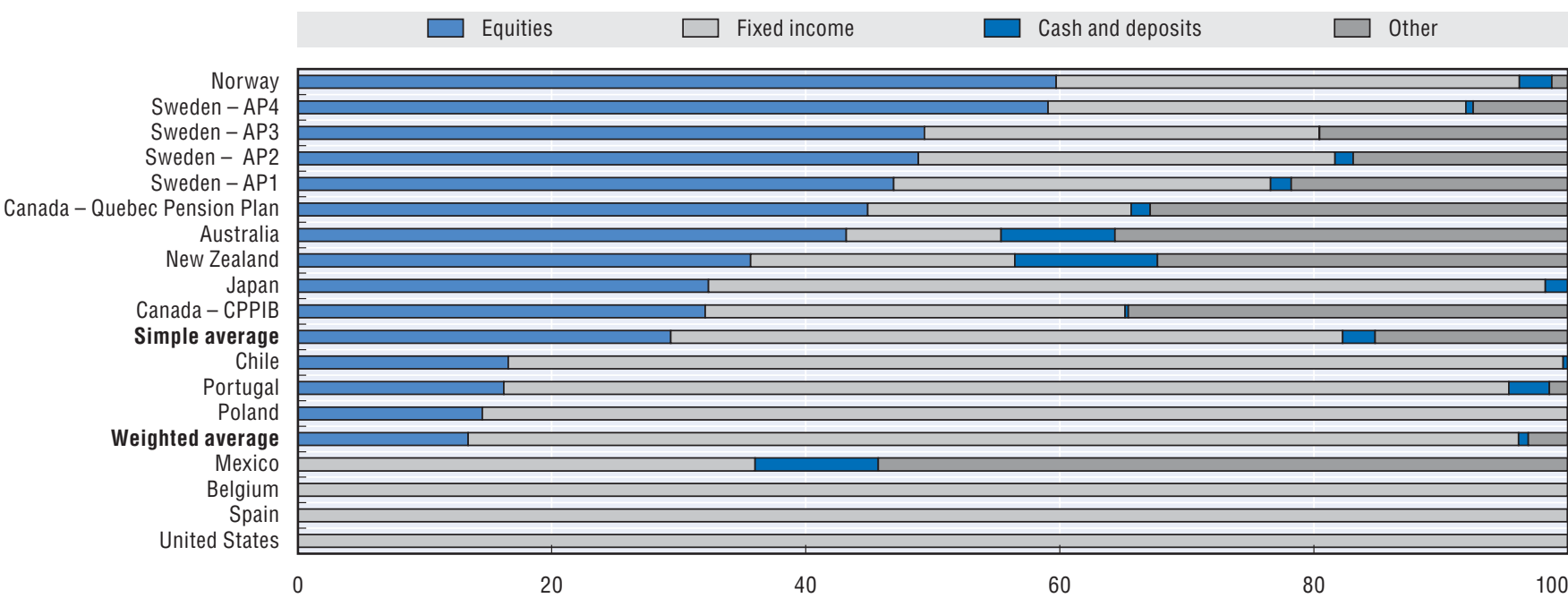

Source: OECD Annual Survey of Public Pension Reserve Funds. 


\section{Key results}

Despite uncertainties in the world economy and volatility in financial markets, pension funds experienced positive rates of return in most OECD countries in 2012 and 2013. During 2013, pension funds recorded high real investment rates of return, with an OECD weighted average at $9.7 \%$. Public pension reserve funds experienced the same trend, with strong returns both in 2012 and 2013 on average.

After a gloomy year in 2011, good performance in stock markets and gains from bonds brought pension funds back on track to achieve positive returns in 2012 and 2013.

In 2012, OECD pension funds experienced on average a positive return of $5.7 \%$ in real terms. The best performing pension funds amongst OECD countries in 2012 were in Mexico (9.7\%), Turkey (9.6\%), the Netherlands (9.5\%) and Belgium (9.3\%). None of the reporting OECD countries had a negative real return in 2012.

The net investment rate of return varied considerably across national markets in 2013. On the basis of the weighted average across OECD countries, for the countries for which information is available, pension funds experienced an annual, real rate of investment return of $9.7 \%$, ranging from $11.5 \%$ for the highest performer (the United States) to $-7.6 \%$ for the lowest (Turkey). After the United States, the highest returns in 2013 were in Australia (10.3\%), Canada (9.8\%), New Zealand (9.5\%) and Japan (8.9\%). On the other hand, in only three countries, pension funds experienced negative investment returns in 2013 in real terms: Mexico (-1.5\%), Denmark (-4.6\%) and Turkey $(-7.6 \%)$. As the real net investment return is the combination of the nominal performance of pension funds and inflation, a low figure can be accounted for by either low gains and income or inflation. In the case of Denmark, pension funds had a negative real return in 2013, due to negative contributions from hedging instruments.
All PPRFs except one performed positively in 2012 and 2013, with an average (weighted by the assets managed at the end of the year) net investment rate of return of $5.1 \%$ and $7.0 \%$ in real terms respectively. Only Chile's Pension Reserve Fund experienced a negative return in $2012(-4.8 \%)$. The highest performers in 2012 were in Portugal (21.0\%), New Zealand (18.1\%) and Sweden (13.4\% for AP2).

2013 has also been a year of strong returns on average for PPRFs in real terms. Returns were positive in the 20 funds for which information was available. Real rate of investment return ranked from $0.6 \%$ in Mexico to $24.1 \%$ in New Zealand.

\section{Definition and measurement}

Real (after inflation) returns are calculated in local currency after investment management expenses.

The average nominal net investment returns for pension funds are the results of a calculation using a common formula for all countries, except for Austria (2012), Israel, Korea, Sweden and Turkey (2013), for which the nominal returns have been provided by the countries, using their own formula. The common formula corresponds to the ratio between the net investment income at the end of the year and the average level of assets during the year.

For PPRFs, nominal returns have been provided by the funds directly, using their own formula and methodology. 


\subsection{Pension funds' real net investment return in selected OECD countries, 2012-13}

In percentage

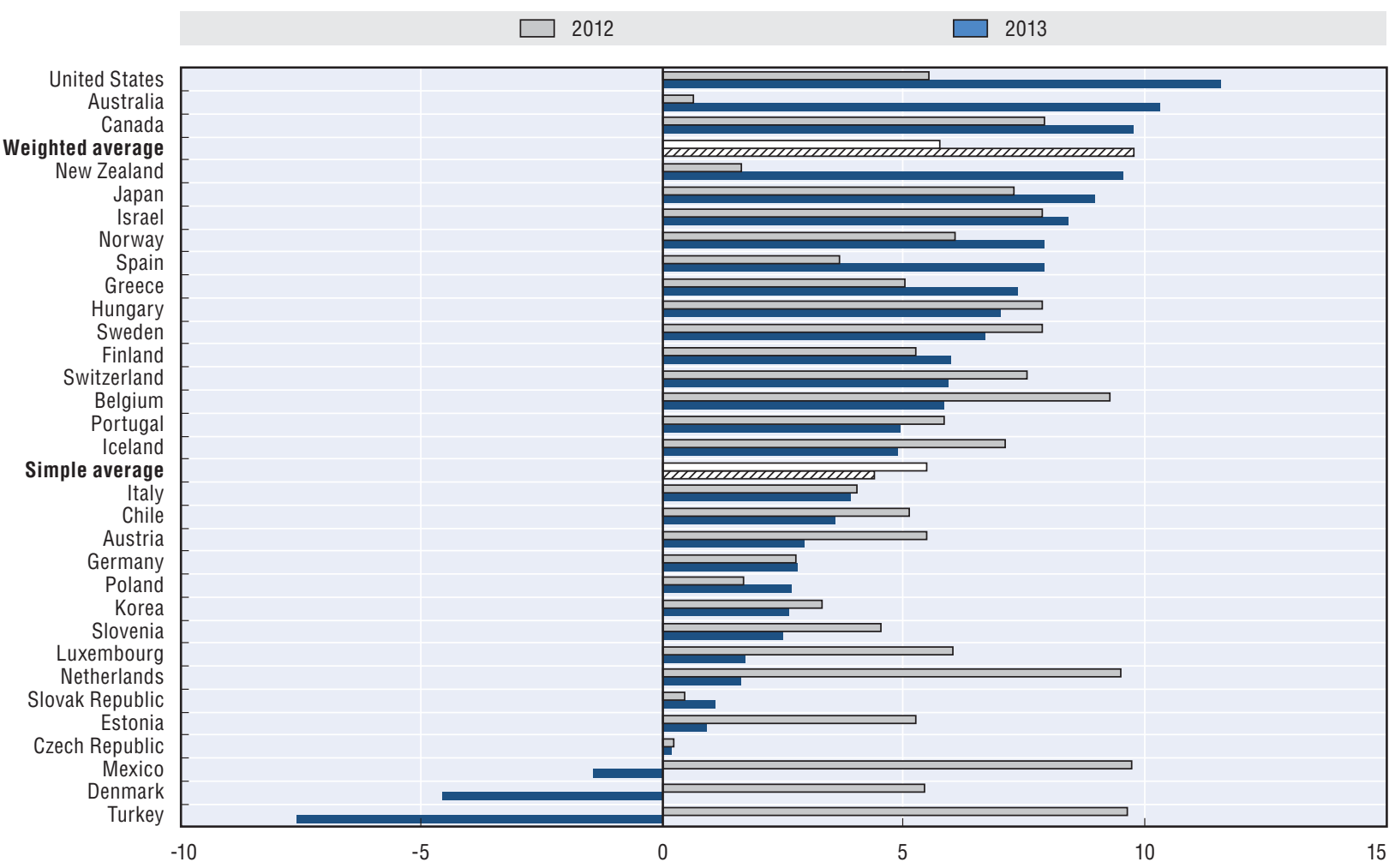

Source: OECD Global Pension Statistics.

10.8. PPRFs' real net investment return in selected OECD countries, 2012-13

In percentage

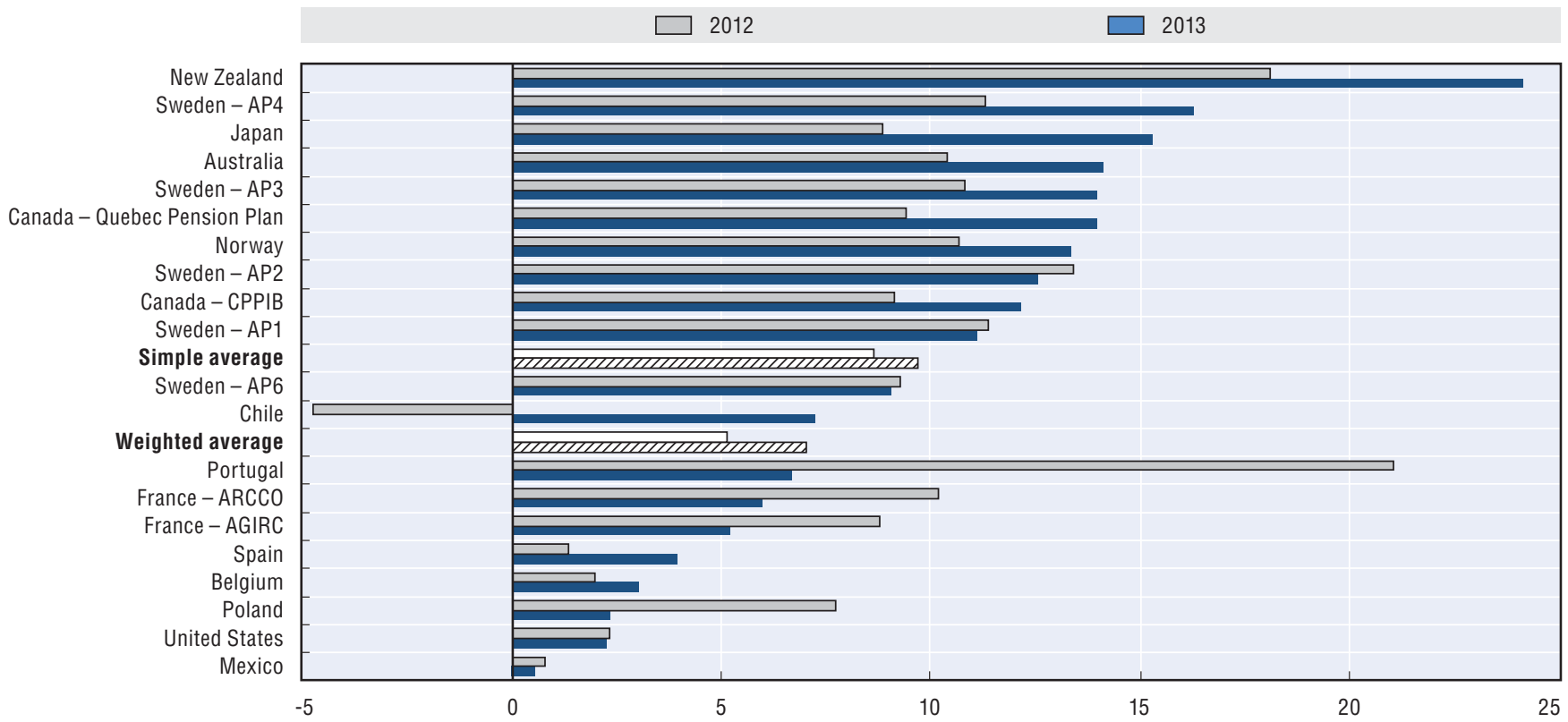

Source: OECD Annual Survey of Public Pension Reserve Funds. 


\section{Key results}

Private pension systems efficiency, as measured by the total operating costs in relation to assets managed, varies considerably between countries, ranking from $0.1 \%$ of assets under management annually to $1.5 \%$. Fees charged to plan members to cover these costs also vary considerably in structure and level across countries.

The efficiency of private pension systems can be judged by looking at the total operating costs in relation to assets managed. The total operating costs of private pension systems include all costs of administration and investment management involved in the process of transforming pension contributions into retirement benefits.

The figure shows the operating costs of the pension fund industry reported by OECD countries in 2013. In general, countries with defined contribution systems and those with large numbers of small funds appear to have higher operating costs than countries with only a few funds offering defined benefit, hybrid, or collective defined contribution pension arrangements. For instance, operating costs accounted for $1.5 \%$ of assets under management in the Czech Republic, 1.4\% in Estonia, 1.2\% in Spain and Slovenia, $1.0 \%$ in Hungary, $0.8 \%$ in the Slovak Republic and Australia, and $0.7 \%$ in Mexico and Turkey. On the other hand, they accounted for less than $0.3 \%$ of total assets in Norway $(0.3 \%)$, Iceland $(0.2 \%)$, the United Kingdom (0.2\%), Portugal $(0.2 \%)$, Germany $(0.2 \%)$, the Netherlands $(0.1 \%)$, Denmark (0.1\%) and Finland (0.1\%).

In defined contribution private pension systems, providers cover their operating costs through the fees they charge to plan members. The structure of charges across countries is fairly complex. The analysis considers fees in selected DC systems only. While there is a tendency for countries from the same region (e.g. Latin America, Central and Eastern Europe) to have similar fee structures, they can vary greatly across wider geographical regions.

Variable fees on contributions can be expressed as percentages of salaries or as percentages of contributions. They can be found in Chile, Israel, Poland, the Slovak Republic and Turkey for instance. In Chile, fees are expressed as percentages of salary. Such fees on contributions are not charged in Estonia, Mexico and Spain. In Mexico, as of March 2008, Afores may only charge a fee on assets, while before that date they could charge fees both on assets and on contributions.

A variable fee on the stock of funds can be levied either on the value of the fund or on returns. Such fees may encourage pension companies to seek higher investment returns. Fees on assets can be found in all countries presented in the table, except in Chile. Most countries only charge fees on assets, while the Czech Republic, Poland and the Slovak Republic charge fees both on assets and on returns.

\section{Definition and measurement}

Operating costs include marketing the plan to potential participants, collecting contributions, sending contributions to investment fund managers, keeping records of accounts, sending reports to participants, investing the assets, converting account balances to annuities, and paying annuities.

Some costs may not be fully reported. For example, in Chile pension funds that invest in international mutual funds deduct management costs directly from the fund. These costs are reported separately by each pension fund administrator to the Superintendence of Pensions. However, they are not included in the fees charged to members and thus not included in the operating expenses.

Fees can either be fixed or variable. Fixed fees are characterised by the fact that their levels depend neither on salaries nor on funds. A variable fee may take the form of a percentage of the inflow of contributions, of the amount of assets managed, or of the investment return on the assets under management. The table only reports variable fees. 
10.9. Pension funds' operating expenses as a share of total investments in selected OECD countries, 2013 As a percentage of total investment

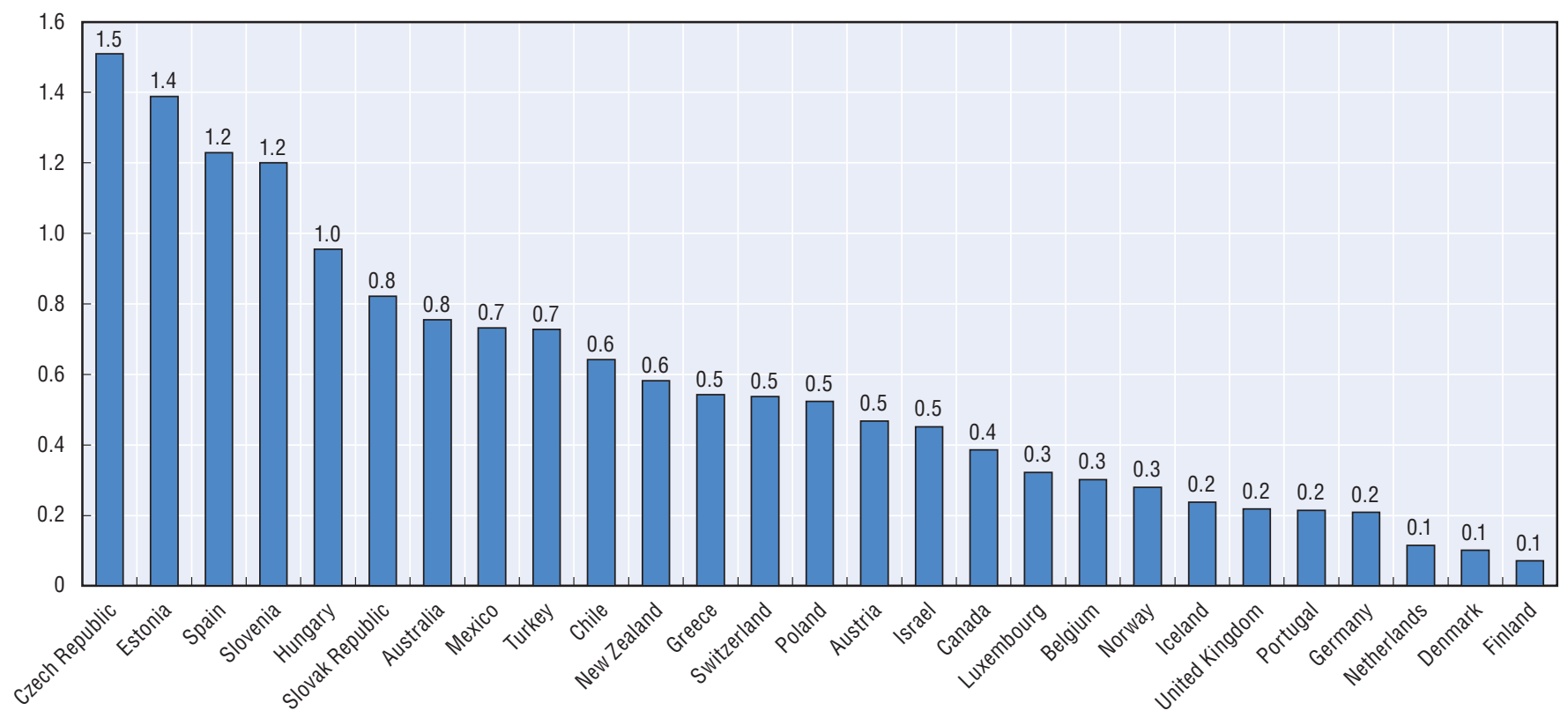

Source: OECD Global Pension Statistics.

10.10. Total fees or commissions charged by pension funds or their administrators/managers to members, by type of fee, in selected OECD countries, 2013

As a percentage of total investment

\begin{tabular}{|c|c|c|c|c|c|}
\hline & Fee on contributions & Fee on assets & Fee on return/performance & $\begin{array}{l}\text { Other fees (e.g. exit fees, } \\
\text { entry fees, switching fees) }\end{array}$ & Total \\
\hline Chile & 0.6 & - & - & - & 0.6 \\
\hline Czech Republic &.. & 0.6 & 0.3 &.. & .. \\
\hline Estonia & - & 1.3 & - & 0.0 & 1.4 \\
\hline Hungary &.. & 0.5 & - & .. & .. \\
\hline Israel & 0.1 & 0.1 & .. & .. & .. \\
\hline Mexico & - & 1.0 & - & - & 1.0 \\
\hline Poland & 0.1 & 0.4 & 0.0 & - & 0.5 \\
\hline Slovak Republic & 0.1 & 0.6 & 0.2 & 0.1 & 0.9 \\
\hline Slovenia & .. & 0.9 & - & 2.2 & .. \\
\hline Spain & - & 1.0 & - & - & 1.0 \\
\hline Turkey & 0.1 & 0.6 & - & 0.2 & 0.9 \\
\hline
\end{tabular}

Note: .. = Not available; - = Nil.

Source: OECD Global Pension Statistics. 


\section{Key results}

Average funding ratios of defined benefit pension plans varied greatly across countries at the end of 2013. For the countries that report such data to the OECD, funding levels improved in 2013 relative to 2012, with the exception of Germany where pension funds' overfunding position slightly declined. Funding levels are calculated using national (regulatory) valuation methodologies and hence cannot be compared across countries.

A significant part of OECD pension assets is still in defined benefit and other plans which offer return or benefit guarantees. Funding levels reflect very different situations in a selection of OECD countries at the end of 2013. Pension funds in Belgium, Finland, Germany, the Netherlands, Norway, Portugal and Spain were overfunded that year, with an average funding ratio around or above $110 \%$. In contrast, pension funds were underfunded at the end of 2013 in Canada, Iceland, Ireland and the United States. For Iceland, the very low funding ratio of $46 \%$ refers to pension funds for public sector workers. Since the start of the global financial crisis, the Icelandic government has not made additional contributions to these plans.

Funding levels remained stable between 2012 and 2013 in Finland, Norway, Portugal and Spain. In Belgium, the Netherlands and the United States, pension funds have improved their funding position, increasing the average funding ratio by 6 percentage points in Belgium (from 129\% to $135 \%$ ), by 8 percentage points in the Netherlands (from $102 \%$ to $110 \%$ ) and by 7 percentage points in the United States (from $65 \%$ to $72 \%$ ). The opposite trend can be observed in Germany, where pension funds saw their overfunding position slightly decline between 2012 and 2013 by 4 percentage points (from $119 \%$ to $115 \%$ ).

Funding levels are calculated using national (regulatory) valuation methodologies and hence cannot be compared across countries. Differences in methodology are substantial as some countries like Germany and Spain use fixed discount rates while others like the Netherlands and Sweden use market rates. Discount rates have a major impact on funding levels, a $1 \%$ decline in the discount rate causing a roughly $20 \%$ increase in a pension fund liabilities. Since 2012, the Netherlands and Sweden apply a new methodology for setting the discount rate. Pension funds in the Netherlands can use an ultimate forward rate (UFR) for long maturities as the discount rate, based on long-term assumptions about growth and inflation. In Sweden, the regulator sets a floor on discount rate.

\section{Definition and measurement}

The level of funding, that is, the ratio of pension plan assets to liabilities, is estimated using country-specific methodologies. Methodologies differ across countries with respect to the formula used, the discount rate (e.g. a market discount rate, or a fixed discount rate), or with the way future salaries are accounted for (e.g. liabilities can be based on current salaries or on salaries projected to the future date that participants are expected to retire). In addition, some countries calculate a funding ratio for each pension funds and calculate an average (simple or weighted) thereafter, while other countries only calculate an aggregate funding ratio for the whole pension fund industry. 
10.11. Average funding ratio of DB pension plans in selected OECD countries, 2012-13 In percentage

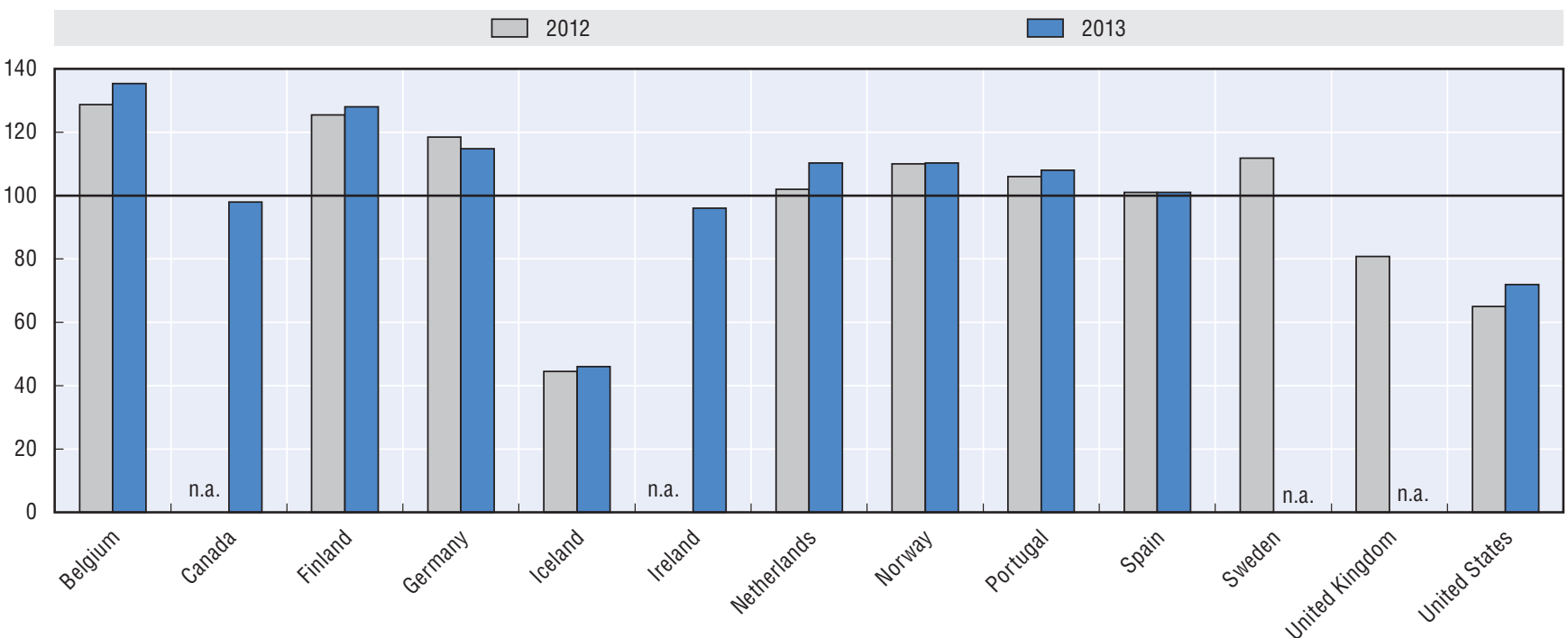

Note: n.a. $=$ Not available

Source: OECD Global Pension Statistics.

StatLink त्ताजी http://dx.doi.org/10.1787/888933300942 



\section{Chapter 11}

\section{Pensions at a Glance 2015: Country profiles}

This part of Pensions at a Glance presents "Country profiles" of national pension systems. Each country profile summarises the architecture of the national pension system and provides key indicators on demographics, public pensions spending and average worker earnings. It then goes on to provide the technical details of parameters and rules of the pension system in 2014 and explains the calculation of pension entitlements and benefits. Each profile ends with the main country-specific results. 


\section{Guide to the country profiles}

The "Country profiles" use a common framework. First, there is a brief summary of the national retirement-income system and a table of key indicators. This background table comprises average worker earnings, public pension expenditures, life expectancy and the dependency ratio (the number of pensioners for every 100 workers). Data both for the country in question and the average for the OECD as a whole are presented.

Secondly, there is a detailed description of the rules and parameters of the pension schemes that make up each country's retirement-income system. These are structured as follows.

- Qualifying conditions: pension eligibility (or "retirement") age and years of contributions required to receive a pension.

- Benefit calculation: the rules for each schemes making up the pension system, such as basic, resourcetested and minimum pensions as well as public, earnings-related and mandatory private plans.

- Voluntary private pensions: the parameters of typical voluntary plans are provided for the countries for which replacement rates under these schemes were modelled in the indicator of "Gross pension replacement rates: Mandatory and voluntary schemes" in Chapter 6.

- Variant careers 1: the rules and conditions under which workers can retire early or continue to work beyond the standard retirement age and the impact on pension entitlements.

- Variant careers 2: rules for protecting pensions for people who are out of paid work due to caring for children or unemployment.

The treatment of pensioners under the personal income tax and social security contributions is not described in this edition, for reasons of space. However, the on-line version of the "Country profiles", available at www.oecd.org/pensions/oecd-pensions-at-a-glance-19991363.htm, do include this information. For details on the taxes and social security contributions paid by workers, see OECD (2015), Taxing Wages.

Values of all pension parameters and other relevant figures such as minimum wages are given in national currencies and as a proportion of average earnings. (See the indicator of "Average worker earnings" in Chapter 8.)

In each country profile, a table gives expected relative pension values, replacement rates and pension wealth at different individual levels of earnings for mandatory pension schemes. (See Chapter 6 of this report for definition and measurement of the different indicators.) These are given in both gross and net terms (the latter taking account of taxes and contributions paid when working and when drawing the pension). They are also provided based on full wage indexation and legislated indexation if different. 
Summary figures show the breakdown of the gross relative pension value into the different components of the pension scheme (the first row of the figures). As far as possible, the same terminology is used to describe these schemes. The particular national scheme that is described can be found in the text of the country profile. Some standard abbreviations are used in the legends of the figures:

- SA: social assistance.

- Targeted: separate resource-tested schemes for older people.

- Minimum: a minimum pension within an earnings related scheme.

- Basic: a pension based only on number of years of coverage or residency.

- Earnings-related: all public earnings-related programmes, including notional accounts and points schemes as well as traditional defined-benefit plans.

- DC: defined-contribution, mandatory private plans.

- Occupational: mandatory or quasi-mandatory pensions, which can be provided by employers, industry-wide schemes (Netherlands), profession-based schemes (Sweden) or publicly (Finland, France).

The second row of country figures shows the effect of personal income taxes and social security contributions on relative pension values and replacement rates, giving the gross and net values.

The figures use a standard scale to ease comparisons between countries: the scale for replacement rates runs to $125 \%$ while that for relative pension values runs to 2.5 times average earnings. The figures show pension entitlements for people earning between $50 \%$ and $200 \%$ of average worker earnings (AW). 


\section{Argentina}

\section{Argentina: Pension system in 2014}

The pension system has two main components: a basic component and an additional social insurance component. For those aged 70 and above there is also an additional age-related social insurance component, as well as a social assistance component.
Key indicators: Argentina

\begin{tabular}{|c|c|c|c|}
\hline & & Argentina & OECD \\
\hline \multirow[t]{2}{*}{ Average worker earnings (AW) } & ARS & 135492 & 338672 \\
\hline & USD & 16006 & 40007 \\
\hline Public pension spending & $\%$ of GDP & & 7.9 \\
\hline \multirow[t]{2}{*}{ Life expectancy } & At birth & 76.2 & 80.0 \\
\hline & At age 65 & 17.6 & 19.3 \\
\hline Population over age 65 & $\%$ of population & 11.2 & 16.2 \\
\hline
\end{tabular}

\section{Qualifying conditions}

Retirement age for the basic pension is 65 for men and 60 for women with at least 30 years of service. To meet the contribution qualifying condition, the insured may substitute two years of age after the retirement age for one year of missing contributions.

Additional pension (social insurance): Age 65 (men) or age 60 (women) with at least 30 years of service.

Advanced old-age pension (social insurance): Aged 70 or older with at least ten years of service, with contributions paid while employed or self-employed, including at least five of the last eight years before leaving employment. A self-employed person must have been insured for at least five years.

Non-contributory old-age pension (social assistance): Needy persons aged 70 or older residing in Argentina.

\section{Benefit calculation}

\section{Old-age basic pension}

The monthly pension is ARS 1805.53 (as of March 2015).

\section{Additional pension (social insurance)}

The monthly pension is $1.5 \%$ of the insured's average adjusted monthly earnings in the last ten years (weighted average adjusted amounts for all periods for self-employed persons) for each year of lifetime service.

\section{Advanced-age old-age pension}

The monthly pension is $70 \%$ of the basic old-age pension, plus the additional pension.

The combined minimum monthly old-age pension (the sum of all contributory pensions) is ARS 3821.73 (as of March 2015).

The maximum monthly old-age pension (sum of the basic and social insurance pensions) is ARS 27998.79 (as of March 2015).

Pensions are paid monthly with a 13th payment equal to the regular monthly payment divided in half and paid in June and December. Benefits are adjusted automatically in March and September based on changes in tax revenue, wage indexes, and revenue of the National Social Security Administration. 


\section{Non-contributory old-age pension (social assistance)}

The monthly pension was ARS 1601.04 (around 70\% of the minimum pension in September 2013). 
Pension modelling results: Argentina in 2059, retirement at age 65 (men)
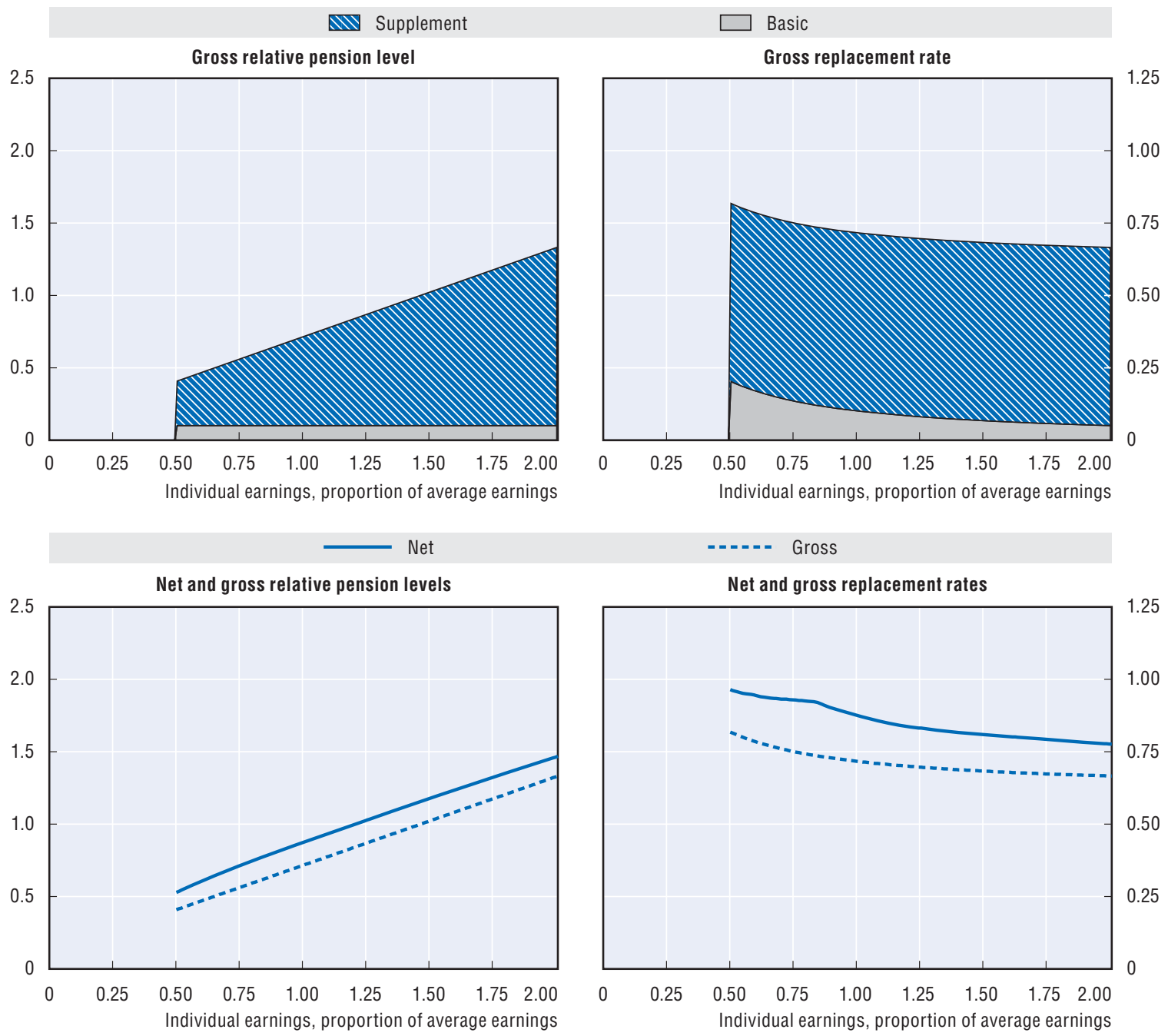

\begin{tabular}{|c|c|c|c|c|c|c|}
\hline \multicolumn{7}{|c|}{ Baseline scenario: Legislation scenario (wage indexation of safety-nets schemes) } \\
\hline \multirow{2}{*}{$\begin{array}{l}\text { Men } \\
\text { Women (where different) }\end{array}$} & \multicolumn{6}{|c|}{ Individual earnings, multiple of average } \\
\hline & 0.5 & 0.75 & 1 & 1.5 & 2 & 3 \\
\hline Gross relative pension level & 40.9 & 56.3 & 71.6 & 102.4 & 133.2 & 194.7 \\
\hline (\% average gross earnings) & 44.1 & 57.8 & 71.5 & 98.8 & 126.1 & 180.8 \\
\hline Net relative pension level & 52.8 & 71.3 & 87.5 & 117.9 & 146.7 & 200.0 \\
\hline (\% net average earnings) & 56.9 & 73.0 & 87.3 & 114.4 & 140.3 & 188.1 \\
\hline Gross replacement rate & 81.8 & 75.0 & 71.6 & 68.3 & 66.6 & 64.9 \\
\hline (\% individual gross earnings) & 88.2 & 77.0 & 71.5 & 65.9 & 63.1 & 60.3 \\
\hline Net replacement rate & 96.4 & 92.8 & 87.5 & 80.8 & 77.6 & 72.6 \\
\hline (\% individual net earnings) & 104.0 & 95.0 & 87.3 & 78.4 & 74.2 & 68.2 \\
\hline Gross pension wealth & 12.9 & 11.8 & 11.3 & 10.7 & 10.5 & 10.2 \\
\hline (multiple of individual gross earnings) & 18.4 & 16.0 & 14.9 & 13.7 & 13.1 & 12.5 \\
\hline Net pension wealth & 12.5 & 11.2 & 10.3 & 9.3 & 8.7 & 7.9 \\
\hline (multiple of individual gross earnings) & 17.8 & 15.2 & 13.6 & 11.9 & 11.0 & 9.8 \\
\hline
\end{tabular}

Assumptions: Real rate of return $3 \%$, real earnings growth $1.25 \%$, inflation $2 \%$, and real discount rate $2 \%$. All systems are modelled and indexed according to what is legislated. Transitional rules apply where relevant. DC conversion rate equal $85 \%$. Labour market entry occurs at age 20 in 2014. Tax system latest available: 2013. 


\section{Australia}

\section{Australia: Pension system in 2014}

Australia's retirement income system has three components: a means-tested Age Pension funded through general taxation revenue; the superannuation guarantee, a compulsory employer contribution to private superannuation savings; and voluntary superannuation contributions and other private savings. Superannuation savings are encouraged through taxation concessions.
Key indicators: Australia

\begin{tabular}{llrr}
\hline & & Australia & OECD \\
\hline \multirow{2}{*}{ Average worker earnings (AW) } & AUD & 79689 & 48901 \\
& USD & 65195 & 40007 \\
Public pension spending & \% of GDP & 3.5 & 7.9 \\
Life expectancy & At birth & 82.4 & 80.0 \\
\multirow{2}{*}{ Population over age 65 } & At age 65 & 20.8 & 19.3 \\
& \% of population & 15.0 & 16.2 \\
\hline
\end{tabular}

StatLink intst http://dx.doi.org/10.1787/888933301736

\section{Qualifying conditions}

The Age Pension is payable from age 65 for men and women. Pension age will increase by six months every two years from 2017 until it reaches 67 by 2023. The minimum age for withdrawing superannuation benefits is 55 years for people born before 1 July 1960, but increases gradually for people born after that date, so that the minimum age is 60 for people born after 30 June 1964 .

\section{Benefit calculation}

\section{Defined contribution}

The superannuation guarantee was introduced in 1992. It consists of a mandatory employer contribution to an employee's superannuation fund (a private pension plan). Superannuation funds may be operated by employers, industry associations and financial service companies or even by individuals themselves. The mandatory contribution rate has been $9 \%$ of employee ordinary time earnings from 1 July 2002 until 30 June 2013. On 1 July 2013, the rate increased to $9.25 \%$, before increasing again on 1 July 2014 , to $9.5 \%$. The government has announced that the superannuation guarantee rate will remain at $9.5 \%$ until 30 June 2021 . After this, the rate will increase by 0.5 percentage points each year until it reaches 12\% on 1 July 2025.

Employers need not contribute for workers earning less than AUD 450 a month, but they can choose to contribute for these workers (this minimum has not been increased in the past). There is also a ceiling to the earnings covered by the superannuation guarantee. Employers need not contribute for employees' pay above this ceiling. For each quarter of the financial year 2013-14 this amount was AUD 48040 (AUD 192160 annually).

Low to middle-income earners who make personal after-tax (non-concessional) contributions to their superannuation fund may be eligible for the government to make a matching 50\% co-contribution, up to a maximum of AUD 500 in 2013-14. Contributors with incomes less than AUD 33516 in 2013-14 were eligible for the full co-contribution. For each dollar of income earned above AUD 33 516, the maximum co-contribution is reduced by 3.333 cents, up to a higher income threshold of AUD 48 516, above which no co-contribution was payable. If the co-contribution payable for an eligible contributor was less than AUD 20 the amount was increased to AUD 20. 
The withdrawal stage of the superannuation guarantee complicates the calculations. Although there are some defined-benefit occupational plans, most employees are members of definedcontribution schemes. Members can withdraw the accumulated capital as a lump sum or as an income stream. Currently, most people choose to take some or all of their benefits as a lump sum. For comparison with other countries, the capital from the superannuation guarantee is assumed to be converted to a price-indexed annuity.

\section{Basic (targeted safety net)}

The Age Pension is designed to provide a safety net for those unable to save enough through their working life and to supplement the retirement savings of others. An income test and an assets test (means tests) are used to target Age Pension payments. In addition to the Age Pension, seniors can be eligible for a comprehensive system of concessions and assistance for health, rent assistance, pharmaceuticals and other living expenses.

In March 2014, the maximum single rate of pension with the Pension Supplement and Energy Supplement was AUD 843 a fortnight equal to an annual entitlement of AUD 21570.

The value of the Age Pension is adjusted biannually. The Age Pension's value is increased in line with the consumer price index (CPI) or the Pensioner and Beneficiary Living Cost Index (PBLCI), whichever is the greater. If necessary further increases ensure that the combined couple rate does not fall below $41.8 \%$ of national pre-tax Male Total Average Weekly Earnings. The single maximum basic rate of pension, excluding supplements, is $66.33 \%$ of the combined couple rate.

The Age Pension is reduced if annual income from other sources exceeds a threshold known as the "income free area". This is adjusted annually in July. In 2013-14, the fortnightly income free areas were AUD 156 for a single pensioner and AUD 138 for couples (or AUD 276 for a couple combined).

The Age Pension has a "Work Bonus" income test concession designed to encourage people of pension age to continue to work. It allows pensioners to earn up to AUD 250 a fortnight without it being assessed as income under the income test. Pensioners who earn less than AUD 250 in a fortnight can accrue the unused amount of fortnightly concession up to AUD 6500 to offset future employment income. The combination of the Work Bonus and the pension income free area, allows a single pensioner with no other income to earn up to around AUD 10450 each year without it affecting their pension.

An assets test also applies. Almost $41 \%$ of all pensioners have their benefits reduced by the means test and are therefore on part-rate Age Pension. Within this group 59\% have their pension reduced as a result of the income test and $41 \%$ as a result of the assets test. About $59 \%$ of pensioners are on the maximum rate Age Pension.

In 2013-14, the pension asset test thresholds for homeowners were AUD 196750 for a single pensioner and AUD 279000 for a couple combined. For non-homeowners the thresholds were AUD 339250 for a single pensioner and AUD 421500 for a couple combined. Assets above these amounts reduce the pension by AUD 1.50 per fortnight for every AUD 1000 above the amount, for a single pensioner and for a couple combined. The family home is exempted from the asset test.

Rent Assistance is available for private renters whose rent exceeds a specified amount. It is paid as part of the pension payment and may be reduced by income and asset tests along with that payment. The value of the Rent Assistance is adjusted biannually in line with growth in the CPI and is paid fortnightly. In March 2014, the maximum single rate of Rent Assistance was AUD 126 a fortnight. This gives an accrued maximum annual entitlement of AUD 3245. 
Rent thresholds below which Rent Assistance is not payable are also adjusted biannually. In March 2014, the minimum rent for which Rent Assistance was payable was AUD 112 a fortnight. Rent Assistance is paid at a rate of 75 cents for each dollar of rent paid above the rent threshold until the maximum rate is reached.

Rent Assistance is not payable to people renting from a government housing authority, or to residents of Australian Government funded nursing homes or hostels.

\section{Variant careers}

\section{Early retirement}

Superannuation benefits can be withdrawn from age 55. The earliest age at which superannuation benefits can be withdrawn is increasing for all individuals born on or after 1 July 1960 (see the table below). Individuals who are still working can also access their benefits from preservation age, but only in the form of a non-commutable income stream. The Age Pension is not paid before the qualifying age.

\begin{tabular}{cc}
\hline Date of birth & Preservation age \\
\hline Before 1 July 1960 & 55 \\
1 July 1960-30 June 1961 & 56 \\
1 July 1961-30 June 1962 & 57 \\
1 July 1962-30 June 1963 & 58 \\
1 July 1963-30 June 1964 & 59 \\
\hline After 30 June 1964 & 60 \\
\hline
\end{tabular}

\section{Late retirement}

It is possible to defer claiming superannuation until after 65 years of age. Employers are required to make superannuation contributions under the superannuation guarantee arrangements for their eligible employees regardless of age. In addition, the Age Pension has a "Work Bonus" income test concession designed to encourage people of pension age to continue to work.

\section{Childcare}

There is no specific protection for periods out of work in the superannuation guarantee system. Voluntary contributions are possible during periods without paid work.

\section{Unemployment}

There are no credits in the superannuation guarantee system for periods of unemployment. Voluntary contributions are possible during periods without paid work. 
Pension modelling results: Australia in 2061, retirement at age 67
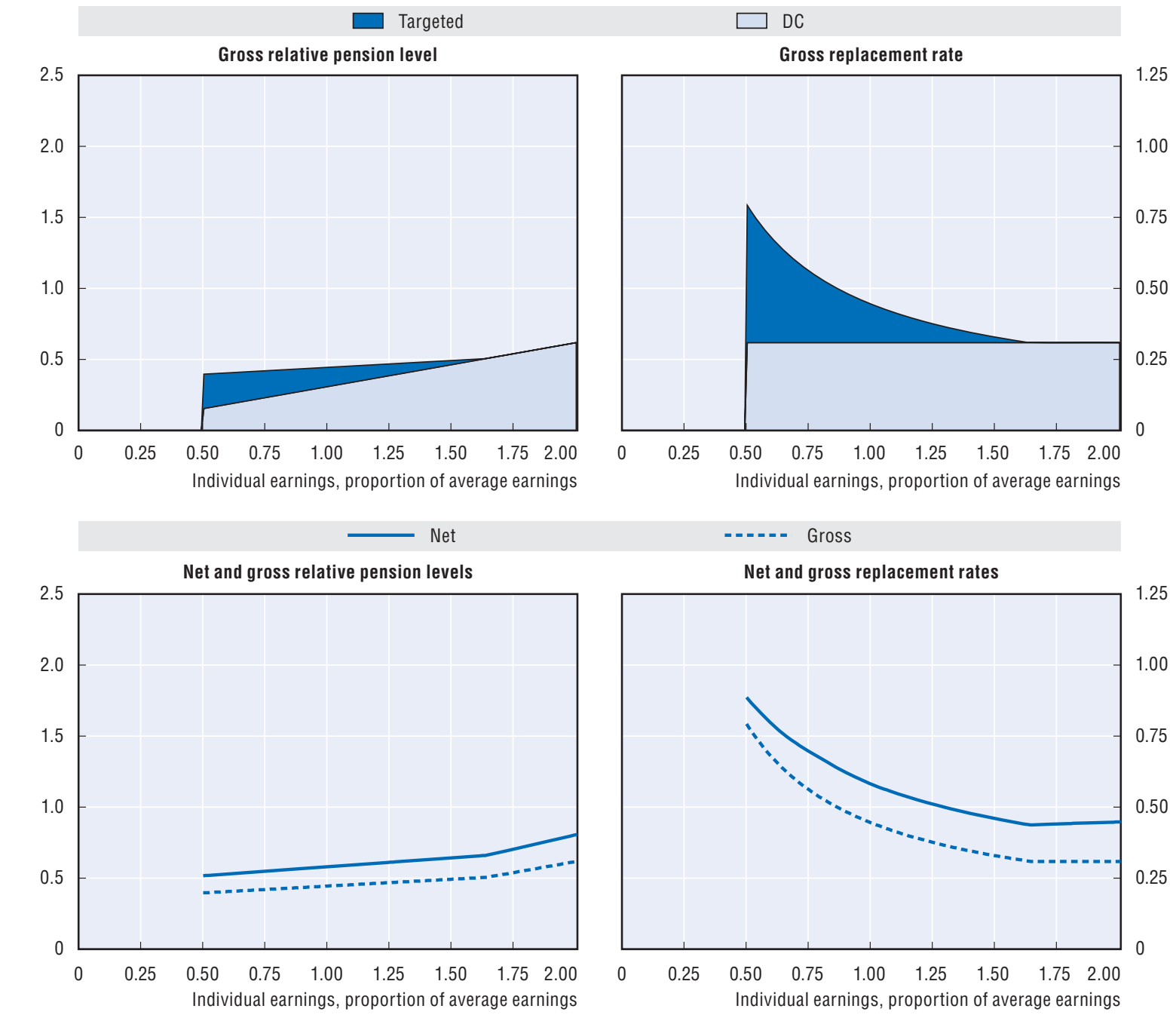

\begin{tabular}{|c|c|c|c|c|c|c|}
\hline \multicolumn{7}{|c|}{ Baseline scenario: Legislation scenario (current policy indexation of safety-net schemes) } \\
\hline \multirow{2}{*}{$\begin{array}{l}\text { Men } \\
\text { Women (where different) }\end{array}$} & \multicolumn{6}{|c|}{ Individual earnings, multiple of average } \\
\hline & 0.5 & 0.75 & 1 & 1.5 & 2 & 3 \\
\hline Gross relative pension level & 39.6 & 42.1 & 44.5 & 49.3 & 61.9 & 74.6 \\
\hline (\% average gross earnings) & 37.9 & 39.4 & 40.9 & 43.9 & 54.7 & 65.9 \\
\hline Net relative pension level & 51.8 & 54.9 & 58.0 & 64.3 & 80.7 & 97.3 \\
\hline (\% net average earnings) & 49.4 & 51.4 & 53.4 & 57.3 & 71.4 & 86.1 \\
\hline Gross replacement rate & 79.3 & 56.1 & 44.5 & 32.9 & 30.9 & 24.9 \\
\hline (\% individual gross earnings) & 75.7 & 52.5 & 40.9 & 29.3 & 27.3 & 22.0 \\
\hline Net replacement rate & 88.6 & 69.6 & 58.0 & 45.9 & 44.8 & 38.5 \\
\hline (\% individual net earnings) & 84.6 & 65.1 & 53.4 & 40.9 & 39.6 & 34.0 \\
\hline Gross pension wealth & 14.0 & 9.9 & 7.8 & 5.8 & 5.5 & 4.4 \\
\hline (multiple of individual gross earnings) & 15.1 & 10.5 & 8.2 & 5.8 & 5.5 & 4.4 \\
\hline Net pension wealth & 14.0 & 9.9 & 7.8 & 5.8 & 5.5 & 4.4 \\
\hline (multiple of individual gross earnings) & 15.1 & 10.5 & 8.2 & 5.8 & 5.5 & 4.4 \\
\hline
\end{tabular}

Assumptions: Real rate of return $3 \%$, real earnings growth $1.25 \%$, inflation $2 \%$, and real discount rate $2 \%$. All systems are modelled and indexed according to what is legislated. Transitional rules apply where relevant. DC conversion rate equal $85 \%$. Labour market entry occurs at age 20 in 2014. Tax system latest available: 2013. 
Pension modelling results: Australia in 2061, retirement at age 67 (cont.)

\begin{tabular}{|c|c|c|c|c|c|c|}
\hline \multicolumn{7}{|c|}{ Alternative scenario: Full wage scenario (wage indexation of safety-net schemes) } \\
\hline \multirow{2}{*}{$\begin{array}{l}\text { Men } \\
\text { Women (where different) }\end{array}$} & \multicolumn{6}{|c|}{ Individual earnings, multiple of average } \\
\hline & 0.5 & 0.75 & 1 & 1.5 & 2 & 3 \\
\hline Gross relative pension level & 41.5 & 43.9 & 46.3 & 51.2 & 61.9 & 74.6 \\
\hline \multicolumn{7}{|l|}{ (\% average gross earnings) } \\
\hline Net relative pension level & 54.2 & 57.3 & 60.5 & 66.8 & 80.7 & 97.3 \\
\hline \multicolumn{7}{|l|}{ (\% net average earnings) } \\
\hline Gross replacement rate & 83.0 & 58.6 & 46.3 & 34.1 & 30.9 & 24.9 \\
\hline \multicolumn{7}{|l|}{ (\% individual gross earnings) } \\
\hline Net replacement rate & 92.8 & 72.7 & 60.5 & 47.7 & 44.8 & 38.5 \\
\hline \multicolumn{7}{|l|}{ (\% individual net earnings) } \\
\hline Gross pension wealth & 14.7 & 10.3 & 8.2 & 6.0 & 5.5 & 4.4 \\
\hline (multiple of individual gross earnings) & 15.9 & 11.0 & 8.5 & 6.1 & 5.5 & 4.4 \\
\hline Net pension wealth & 14.7 & 10.3 & 8.2 & 6.0 & 5.5 & 4.4 \\
\hline (multiple of individual gross earnings) & 15.9 & 11.0 & 8.5 & 6.1 & 5.5 & 4.4 \\
\hline
\end{tabular}

Assumptions: Real rate of return 3\%, real earnings growth $1.25 \%$, inflation $2 \%$, and real discount rate $2 \%$. All systems are modelled and indexed according to what is legislated. Transitional rules apply where relevant. DC conversion rate equal $85 \%$. Labour market entry occurs at age 20 in 2014. Tax system latest available: 2013. 


\section{Austria}

\section{Austria: Pension system in 2014}

The pension system consists of a definedbenefit public scheme with an incometested top-up for low-income pensioners.

\section{Qualifying conditions}

\section{Key indicators: Austria}

\begin{tabular}{llcc}
\hline & & Austria & OECD \\
\hline \multirow{2}{*}{ Average worker earnings (AW) } & EUR & 42573 & 33036 \\
& USD & 51557 & 40007 \\
Public pension spending & \% of GDP & 13.2 & 7.9 \\
Life expectancy & At birth & 81.0 & 80.0 \\
\multirow{2}{*}{ Population over age 65 } & At age 65 & 19.8 & 19.3 \\
& \% of population & 18.7 & 16.2 \\
\hline
\end{tabular}

The normal pension age is currently 65 for men and 60 years for women. The retirement age for women will increase from 60 to 65 between 2024 and 2033. There is a coverage condition: 180 months (15 years) in the last 30 years or 300 months (25 years) during the full lifetime. Alternatively, 180 months of contributions actually paid (as opposed to coverage alone) are sufficient. Insured months are either contributory months (from employment or voluntary contributions) or supplementary (i.e. credited months, known as Teilversicherungszeiten) for which only limited contributions are paid. Within the 2005 pension reform the number of contribution years due to gainful employment required for old-age-pension was reduced from 15 to 7 years. The remaining minimum insurance period of eight years can be reached, e.g. by child raising periods.

\section{Benefit calculation}

\section{Earnings-related}

The pension benefit currently accrues at $1.78 \%$. The earnings measure is currently the best 26 years' of revalued earnings. The averaging period is being extended and it will reach 40 years in 2028. Past earnings are valorised in line with earnings growth except for the last two years before retirement. Contributions are payable up to a ceiling of EUR 63420 in 2014. The yearly adjustment for pensions in payment is basically in line with CPI. In 2014, pensions were valorised at $1.6 \%$. This is $0.8 \%$ below the consumer price index.

\section{Targeted}

Retirees with low earning-related benefits also receive a means-tested top-up (Ausgleichszulage) equal to EUR 857.73 per month for a single person household (EUR 1286.03 for couples). There are 14 annual payments and adjustment of the safety-net income is discretionary.

\section{Means tested minimum income scheme (bedarfsorientierte Mindestsicherung)}

The means-tested minimum income scheme (bedarfsorientierte Mindestsicherung) is the modernised version of the former social assistance scheme (Sozialhilfe) which was reformed in 2011. The aim of the means-tested minimum income scheme is to provide a decent standard of living for individuals who are not able to meet their daily living costs or those of their dependant family members. The assistance scheme is not specifically designed for older people. However older people may apply only when there are no other resources (i.e. pension, etc.) available. The means-tested minimum income scheme is a general residency based non-contributory system. Several groups are assimilated to Austrian citizens, 
including EEA citizens, third-country nationals with specific residence permits (notably "permanent resident - EU") and recognised refugees. The Länder (Landesgesetzgebung) are responsible for the means-tested minimum income scheme.

The monthly threshold is EUR 814 for single persons (EUR 1221 for couples). Before applying for any means-tested minimum income scheme all individual resources have to be used up to a threshold of EUR 4069.95 in 2014. House or flat ownership is possible, but the authorities might include it in the deeds (Grundbuch) after some time.

\section{Additional benefit}

Any additional needs which are not covered by the minimum standard (for instance expenses for appropriate accommodation and heating) can be covered by an additional supplementary benefit.

These benefits are very diverse and vary between a flat-rate allowance and the coverage of the actual appropriate costs for dwelling. The additional benefits are provided by the Länder, who may grant housing allowances (Wohnbeihilfe) as a supplement to guaranteed minimum resources or as an independent benefit. Any person who does not have sickness insurance and receives means-tested minimum income scheme, is registered by the competent institutions with the statutory sickness insurance.

\section{Variant careers}

\section{Early retirement}

Early retirement is currently possible on the grounds of:

1. Long-term insurance periods (Vorzeitige Alterspension bei langer Versicherungsdauer), currently an insurance period of at least 38.5 insurance years or at least 36 contribution years is necessary. This pension is being phased out in 2017: retirement age in July 2014: 64 years and three months for men, 59 years and three months for women, and rising further to 65 for men and 60 for women in 2017.

2. Long-term insurance contributions (Langzeitversichertenpension - Hacklerregelung), currently a contribution period of 40 (women)/45 (men) contributory years or more is required (with increasingly aggravated access as from 2014; current retirement age: 60 for men, 55 for women; as from 2014: 62 for men, 57 for women, stepwise to 62 (deduction per year: $4.2 \%$ ).

3. Physically hard work (Schwerarbeitspension) a contribution period of 45 insurance years or more is required, additionally within the last 20 years there have to be at least 10 years of physically hard work.

4. Physically hard work combined with long-term insurance periods of 45 insurance years or more (Langzeitversicherungspension mit Schwerarbeit), retirement age: 60 for men, 55 for women (deduction per year: 1.8\%). Only possible for men born after 31 December 1953 and before 1 January 1959 and women born after 31 December 1958 and before 1 December 1964.

5. Corridor-pension (Korridorpension) at the age of 62 for both sexes, when having 38.5 insurance years or more (deduction per year: $5.1 \%$ ).

6. Disability: Reform of the disability pension scheme on the basis of the philosophy "Rehabilitation and Prevention before Pension"; for those who were born 1964 or later; medical or occupational rehabilitation instead of a temporary disability pension from 2014 onwards.

\section{Late retirement}

For retirement between the ages of 65 and 68 the pension is increased by $4.2 \%$ per year and there is no such increment after 68 . Workers who defer their pension continue to pay contributions thereby increasing their pension entitlements. 
Combining work and pensions is possible but there is an earnings limit. If pensioners below the age of 65 earn more than EUR 386.80 (2014) the pension is fully withdrawn. After age 65, unlimited earnings from work and pension receipt are permitted.

\section{Childcare}

Periods spent out of paid work for childcare are taken into account in two different ways. Childcare periods of up to four years per child are credited on the basis of a fictitious pensionable salary of EUR 1649.84 (2014) per month But only two years per child are covered years and count towards the qualifying period for pension entitlement (four years for those who were born after 1955 - see above, section "Qualifying conditions").

\section{Unemployment}

Periods of receiving unemployment insurance benefits and unemployment assistance $($ at $70 \%$ of the assessment basis) count as contribution years. 


\section{Pension modelling results: Austria in 2059, retirement at age 65}

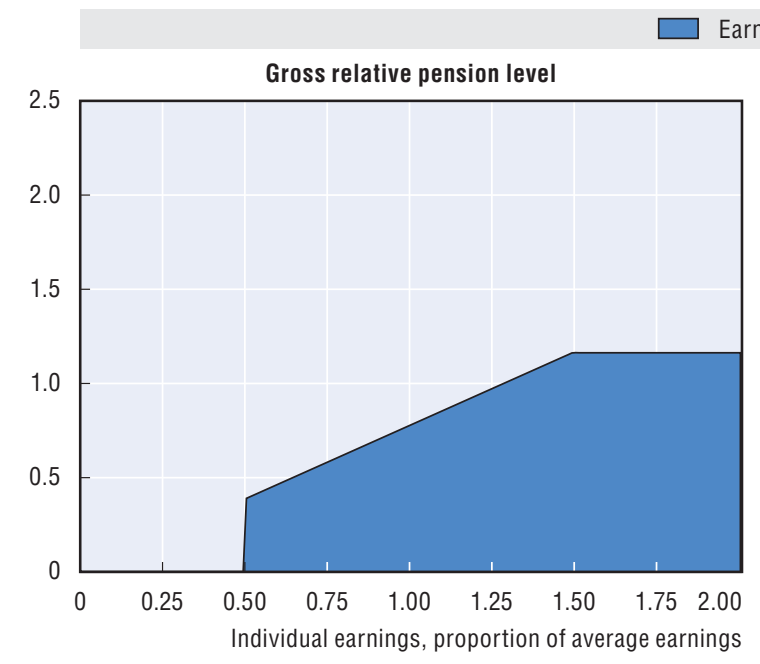

Earnings-related
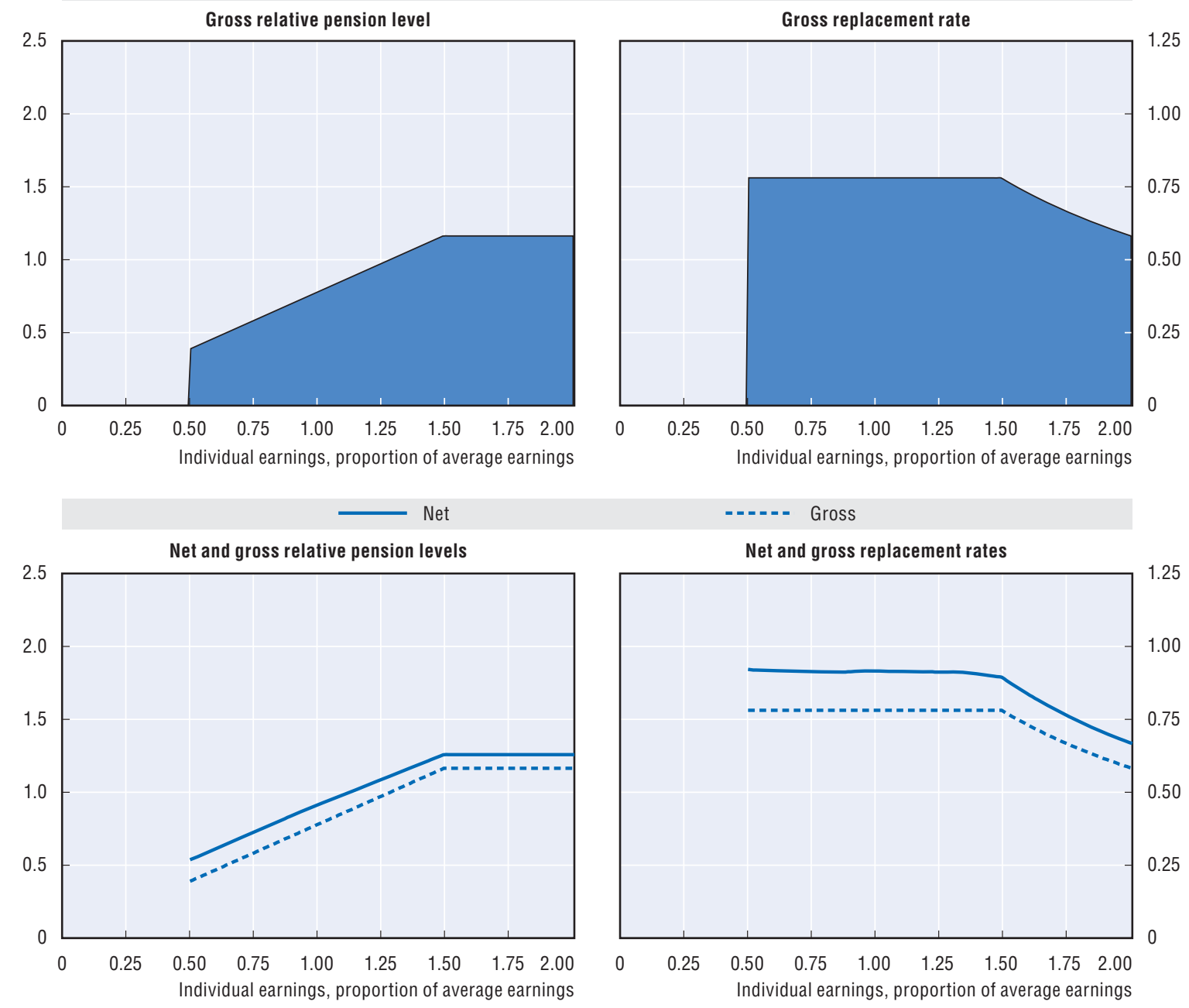

\begin{tabular}{|c|c|c|c|c|c|c|}
\hline \multicolumn{7}{|c|}{ Baseline scenario: Legislation scenario (current policy indexation of safety-nets schemes) } \\
\hline \multirow{2}{*}{$\begin{array}{l}\text { Men } \\
\text { Women (where different) }\end{array}$} & \multicolumn{6}{|c|}{ Individual earnings, multiple of average } \\
\hline & 0.5 & 0.75 & 1 & 1.5 & 2 & 3 \\
\hline Gross relative pension level & 39.0 & 58.6 & 78.1 & 116.3 & 116.3 & 116.3 \\
\hline \multicolumn{7}{|l|}{ (\% average gross earnings) } \\
\hline Net relative pension level & 53.8 & 72.8 & 91.6 & 125.8 & 125.8 & 125.8 \\
\hline \multicolumn{7}{|l|}{ (\% net average earnings) } \\
\hline Gross replacement rate & 78.1 & 78.1 & 78.1 & 77.6 & 58.2 & 38.8 \\
\hline \multicolumn{7}{|l|}{ (\% individual gross earnings) } \\
\hline Net replacement rate & 92.1 & 91.4 & 91.6 & 88.9 & 66.7 & 45.8 \\
\hline \multicolumn{7}{|l|}{ (\% individual net earnings) } \\
\hline Gross pension wealth & 13.8 & 13.8 & 13.8 & 13.7 & 10.3 & 6.9 \\
\hline (multiple of individual gross earnings) & 15.8 & 15.8 & 15.8 & 15.7 & 11.8 & 7.9 \\
\hline Net pension wealth & 12.6 & 11.4 & 10.7 & 9.8 & 7.4 & 4.9 \\
\hline (multiple of individual gross earnings) & 14.4 & 13.0 & 12.3 & 11.3 & 8.4 & 5.6 \\
\hline
\end{tabular}

Assumptions: Real rate of return $3 \%$, real earnings growth $1.25 \%$, inflation $2 \%$, and real discount rate $2 \%$. All systems are modelled and indexed according to what is legislated. Transitional rules apply where relevant. DC conversion rate equal $85 \%$. Labour market entry occurs at age 20 in 2014. Tax system latest available: 2013. 


\section{Belgium}

\section{Belgium: Pension system in 2014}

The pension system has two components: an earnings-related public scheme with a minimum pension and a means-tested safety net.
Key indicators: Belgium

\begin{tabular}{|c|c|c|c|}
\hline & & Belgium & OECD \\
\hline \multirow[t]{2}{*}{ Average worker earnings (AW) } & EUR & 46464 & 33036 \\
\hline & USD & 56269 & 40007 \\
\hline Public pension spending & $\%$ of GDP & 10.2 & 7.9 \\
\hline \multirow[t]{2}{*}{ Life expectancy } & At birth & 80.4 & 80.0 \\
\hline & At age 65 & 19.5 & 19.3 \\
\hline Population over age 65 & $\%$ of population & 18.6 & 16.2 \\
\hline
\end{tabular}

\section{Qualifying conditions}

Normal pensionable age is 65 for all. A full pension benefit requires 45 years of contributions.

\section{Benefit calculation}

\section{Earnings-related}

The rate for the calculation of the pension for a single pensioner is $60 \%$ and for those with a dependent spouse, $75 \%$ (if the sum of the individual pension rights at $60 \%$ for both spouses is less advantageous). The estimated annual accrual rate is therefore $60 \% / 45=1.33 \%$ for a single pension. The earnings measure is average lifetime pay (under the modelling simplifying assumptions). Earlier years' earnings are revalued in line with prices and at the same time a revaluation coefficient is applied in order to revalue elderly wages in line with the increase of living standards (different coefficient for each year). The application of these revaluations of elderly wages used for the calculation of the retirement pension is not modelled.

The full pension is paid provided the qualifying conditions above are met. For shorter contribution histories, the pension is calculated on the lower number of career years.

For the calculation, a ceiling to yearly pensionable earnings is applied. This ceiling is EUR 52972.54 for 2014.

Pensions in payment are uprated in line with a consumer price index (so-called "health index" that excludes some goods). There have also been discretionary increases in real terms (called "adaptations to well-being"). However, these increments have recently been more targeted to the lowest or the longest-running pensions. Since 2008, legislation obliges the government to make decisions on uprating of pensions every two years, based on advice of the social partners.

There are additional payments ("holiday" and "supplementary" allowances), payable once a year. These are equal to the value of the monthly pension up to a ceiling of EUR 668.65 for a single person and EUR 835.81 for pensioners with a dependent spouse (amounts payable in May 2014).

\section{Minimum}

\section{Minimum annual credit}

In cases of pensioners with low earnings or part-time work throughout their career, there is a minimum annual credit designed to increase their attributed pension entitlements. Annual earnings of less than EUR 22466.73 (amount applicable 1 September 2013) are inflated to this level. To qualify for the minimum credits, at least 15 years' insurance is necessary, for an equivalent of at least one-third of a full-time employment (this gives an effective minimum pension for a full-career 
worker for a single person with a 45 year contribution history raised to this level for each year of the career). The application of this minimum annual credit cannot lead to the attribution of a pension superior to EUR 17866.12 for a pension at "family pension" rate or EUR 14292.89 for a pension at "isolated person" rate. If the pension calculation should result in such a pension, the "minimum annual credit" application will not be applied for all eligible career years, until the pension passes under this ceiling.

\section{Minimum earnings-related pension}

There is also a minimum earnings-related pension which corresponds to EUR 13480.03 for pensioners meeting the full contribution condition (45 years) for a single person or EUR 16844.72 with a dependent spouse. The benefit will be a proportion of this minimum in the case of less-than-full careers, if the beneficiary has contributed at least two-thirds of the full number of years. With lower contributions, the benefit value result from the application of the benefit formula (there will be no "levelling up" of the benefit in line with the minimum pensions).

The minimum pension is indexed to prices, excluding certain goods. Benefits are increased by $2 \%$ each time cumulative inflation exceeds a certain threshold $(2 \%)$ since the last adjustment.

Pensioners will receive the higher of the minimum pension described here and the pension calculated (eventually with application of the "minimum annual credit" for those career years fulfilling the conditions).

\section{Pension bonus}

For pensions starting from 1 January 2007 onwards and before 2014, work after the age of 62 to maximally the normal legal retirement age or beyond 44 years of contributions will be credited with a bonus [EUR 2.2974 (amount on 1 January 2013)] for each day worked (indexed to prices), limited to EUR 716.78 for each full year of work, following the "generation pact". The government has taken the decision to reform this system from 1 January 2014 onwards, making the pension bonus progressive in function of how much longer one works (from EUR 1.5 per day up to EUR 2.5 per day when working six years longer). Form 1 January 2015 this "pension bonus" is abolished for the new entrants in the system, with exception made for the already acquired rights.

Working after normal retirement age can also be used to plug career gaps to obtain a full pension or can improve the pension amount, since only the 45 last years are used in the calculation.

\section{Safety-net income: Targeted}

In the case of elderly people, who have no pension rights based on a professional activity or whose pension rights are very low, a means-tested safety-net income can be attributed. This so-called GRAPA (Garantie de revenu aux personnes âgées) is a part of the social assistance measures, which are complementary to the social security provisions (e.g. legal pension for workers of the private sector as modelled).

The means-tested safety-net income for the elderly is EUR 1011.70 a month for a pensioner living alone and EUR 674.46 a month for an older person living with others. Indexation is again to prices excluding certain goods. For the means test, "normal" pension revenue is taken into account for only $90 \%$ of its real amount.

Age limit is 65, without possibility for early take-up.

\section{Voluntary private pensions}

A scheme of sectoral complementary pensions was introduced in 2003 to further extend the second pillar pension system. The contribution rates are fixed through (sectoral) collective labour agreements, and can vary between economic sectors (the modelled contribution rate is $4.25 \%$ ). 


\section{Variant careers}

\section{Early retirement}

Since 1 January 2014, early retirement is possible from age 61, subject to 39 years contributions. This will gradually increase to age 62 with 40 years contribution by 1 January 2016 (see table below). For very long careers (more than 40 years), early retirement will still be possible before the "normal" early retirement age. There is no actuarial reduction in the pension calculation in the scheme of wage-earners. The pension however, can be incomplete, due to the possible incompleteness of the career (less than 45 years). There is an earnings test limiting the opportunity to combine an early retirement pension with work. This is stricter than the earnings test applied after normal pension age.

\begin{tabular}{lccc}
\hline Starting date & Early retirement age & Career length & Exceptions \\
\hline 1 January 2013 & 60.5 & 38 & Age 60 and 40 years career \\
1 January 2014 & 61 & 39 & Age 60 and 40 years career \\
1 January 2015 & 61.5 & 40 & Age 60 and 41 years career \\
1 January 2016 & 62 & 40 & Age 60 and 42 years career or age 61 and 41 years career \\
\hline
\end{tabular}

A further increase in the early retirement age to 63 with 42 years of seniority by 1 January 2019 has been announced in the agreement of the new government.

\section{Late retirement}

It is possible to defer pension after the normal retirement age. For people who continue working after normal retirement age, this can permit to plug career gaps to obtain a full(er) pension or can improve the pension amount, since only the last 45 years are used in the calculation of the pension benefit.

Otherwise, it is possible to combine pensions and earnings (after normal pension age) within limits. For annual earnings under EUR 22509 (single) or EUR 27379 (with a dependent child), the pensions will not be reduced. Above this ceiling, the pension will be reduced by the amount that earnings surpass these limits. If actual earnings are $25 \%$ above the limits then the pension will be completely withdrawn (for as long as the earnings surpass the ceiling). Since 2013 further reforms are applicable, so that for a retiree older than 65 with a career of at least 42 years the ceiling is lifted entirely and the combination between pension and earnings is unlimited. The new government has announced to lift further all restrictions on combining earnings and pensions above the age of 65 .

Before the legal (normal) pension age, the limits for cumulating pensions and earnings are limited to EUR 7793 or EUR 11689 respectively, with the same 25\% earnings restriction.

\section{Childcare}

A maximum of three years in total caring for children may count as gainful employment, if the person benefits from the so-called "tijdskrediet". Tijdskrediet is a right for all employees in the private sector and they could benefit from a full suspension of labour activities or of a half-time reduction of labour time if they had worked more than three-quarters of full time for at least 12 months preceding the start of tijdskrediet. They also need to have worked for the same employer for more than a year, during the 15 months before the application for the start of the tijdskrediet period. When a person withdraws totally from the labour market, no compensation is made. These years count in the numerator of the benefit formula. The value for earnings in the formula is the last earnings before the labour-market absence. 


\section{Unemployment}

Periods on unemployment insurance benefits are credited under the pension system. The unemployment years count in the numerator of the benefit formula, and until 2012 earnings prior to the period of unemployment are used in the calculation base for the entire unemployment period.

For those who became involuntarily unemployed since 1 November 2012 the crediting of unemployment periods has changed for the unemployed aged less than 55 . For them, the crediting of the unemployment period starting with the so called "3rd period" (from the moment the unemployment benefit will be calculated as a lump sum/day and no longer based on a percentage of the lost wage - starting after maximum 48 months of unemployment) will be done on the basis of the "minimum annual credit" instead of the lost wage. For those unemployed aged 55 or more on 1 November 2012 and entering the "3rd period" of unemployment, further crediting will take place on the basis of the lost wage. For those who became unemployed after their 50th birthday, the crediting of the "3rd period" after they reached the age of 55 will also be further credited on the basis of the lost wage.

Since 2012, for those unemployed in the system of the "unemployment benefit with supplement of the employer", the crediting of the unemployment period after their 59th birthday will be on the basis of the lost wage. The periods falling before the 59th birthday will be credited at the "minimum annual credit" (except for those already in the system before 28 November 2012 - crediting on the basis of the lost wage).

There is no limit to the number of years credited, but the total career length after crediting cannot be longer than 45 years. 
Pension modelling results: Belgium in 2059, retirement at age 65

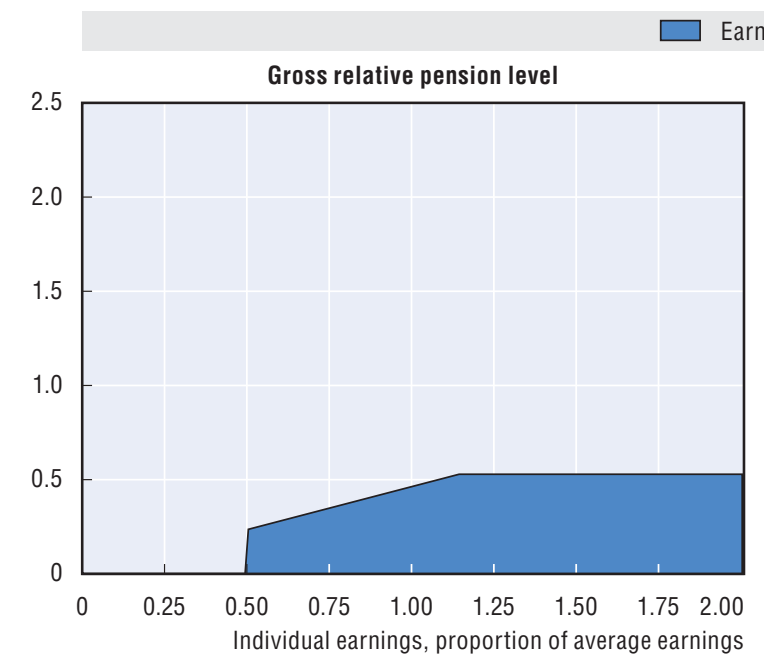

Earnings-related
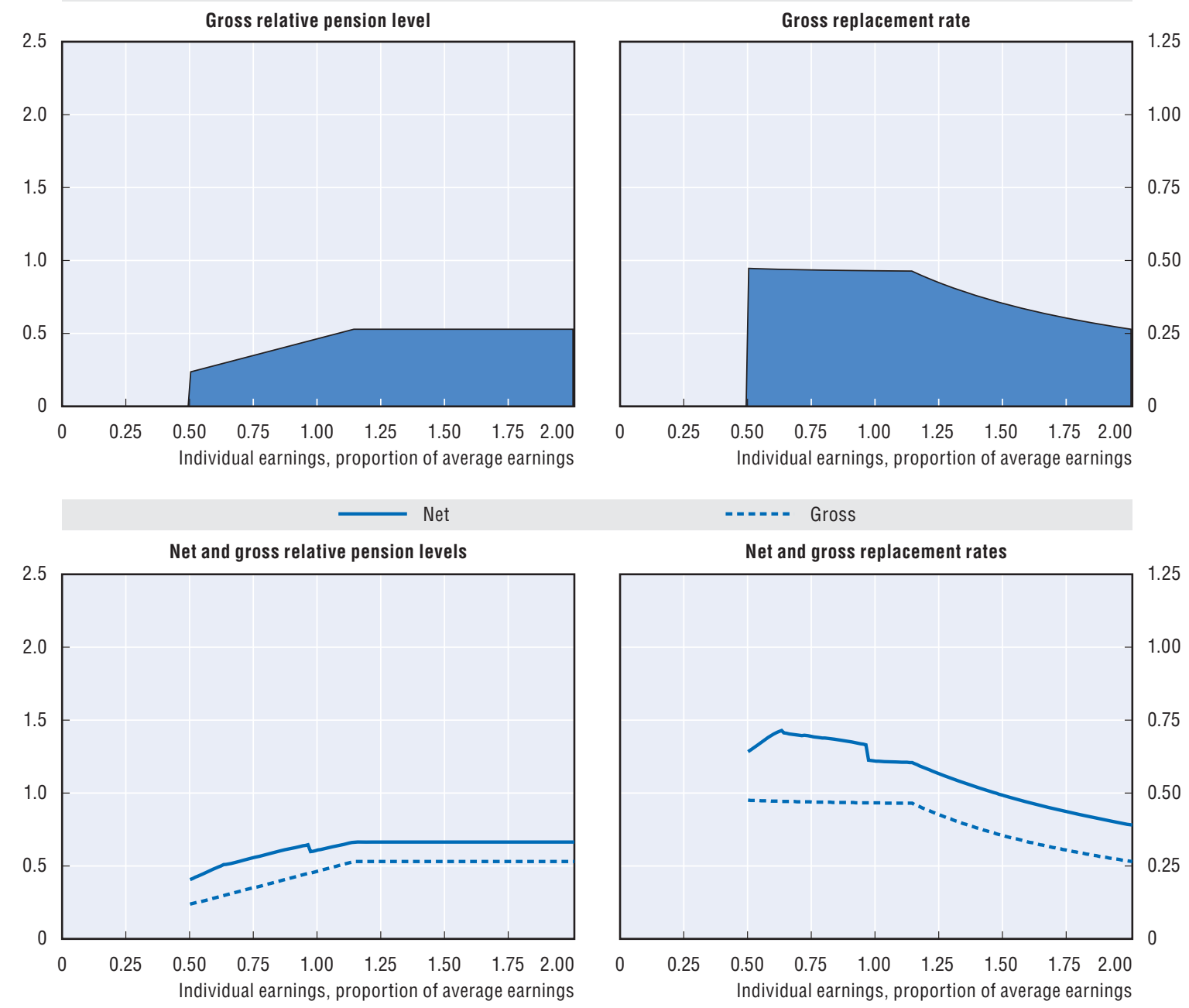

\begin{tabular}{|c|c|c|c|c|c|c|}
\hline \multicolumn{7}{|c|}{ Baseline scenario: Legislation scenario (price indexation of safety nets) } \\
\hline \multirow{2}{*}{$\begin{array}{l}\text { Men } \\
\text { Women (where different) }\end{array}$} & \multicolumn{6}{|c|}{ Individual earnings, multiple of average } \\
\hline & 0.5 & 0.75 & 1 & 1.5 & 2 & 3 \\
\hline Gross relative pension level & 23.8 & 35.2 & 46.6 & 53.0 & 53.0 & 53.0 \\
\hline \multicolumn{7}{|l|}{ (\% average gross earnings) } \\
\hline Net relative pension level & 40.7 & 55.8 & 60.9 & 66.4 & 66.4 & 66.4 \\
\hline \multicolumn{7}{|l|}{ (\% net average earnings) } \\
\hline Gross replacement rate & 47.6 & 46.9 & 46.6 & 35.3 & 26.5 & 17.7 \\
\hline \multicolumn{7}{|l|}{ (\% individual gross earnings) } \\
\hline Net replacement rate & 64.2 & 69.4 & 60.9 & 49.1 & 39.0 & 27.7 \\
\hline \multicolumn{7}{|l|}{ (\% individual net earnings) } \\
\hline Gross pension wealth & 8.3 & 8.2 & 8.1 & 6.1 & 4.6 & 3.1 \\
\hline (multiple of individual gross earnings) & 9.5 & 9.4 & 9.3 & 7.1 & 5.3 & 3.5 \\
\hline Net pension wealth & 8.1 & 7.4 & 6.1 & 4.4 & 3.3 & 2.2 \\
\hline (multiple of individual gross earnings) & 9.4 & 8.5 & 7.0 & 5.1 & 3.8 & 2.5 \\
\hline
\end{tabular}

Assumptions: Real rate of return $3 \%$, real earnings growth $1.25 \%$, inflation $2 \%$, and real discount rate $2 \%$. All systems are modelled and indexed according to what is legislated. Transitional rules apply where relevant. DC conversion rate equal $85 \%$. Labour market entry occurs at age 20 in 2014. Tax system latest available: 2013. 
Pension modelling results: Belgium in 2059, retirement at age 65 (cont.)

\begin{tabular}{|c|c|c|c|c|c|c|}
\hline \multicolumn{7}{|c|}{ Alternative scenario: Full-wage indexation of safety-nets schemes } \\
\hline \multirow{2}{*}{$\begin{array}{l}\text { Men } \\
\text { Women (where different) }\end{array}$} & \multicolumn{6}{|c|}{ Individual earnings, multiple of average } \\
\hline & 0.5 & 0.75 & 1 & 1.5 & 2 & 3 \\
\hline Gross relative pension level & 29.1 & 35.8 & 47.2 & 53.6 & 53.6 & 53.6 \\
\hline \multicolumn{7}{|l|}{ (\% average gross earnings) } \\
\hline Net relative pension level & 49.9 & 56.4 & 61.5 & 67.0 & 67.0 & 67.0 \\
\hline \multicolumn{7}{|l|}{ (\% net average earnings) } \\
\hline Gross replacement rate & 58.3 & 47.8 & 47.2 & 35.8 & 26.8 & 17.9 \\
\hline \multicolumn{7}{|l|}{ (\% individual gross earnings) } \\
\hline Net replacement rate & 78.6 & 70.1 & 61.5 & 49.5 & 39.3 & 27.9 \\
\hline \multicolumn{7}{|l|}{ (\% individual net earnings) } \\
\hline Gross pension wealth & 10.1 & 8.3 & 8.2 & 6.2 & 4.7 & 3.1 \\
\hline (multiple of individual gross earnings) & 11.6 & 9.5 & 9.4 & 7.1 & 5.4 & 3.6 \\
\hline Net pension wealth & 10.0 & 7.5 & 6.1 & 4.5 & 3.3 & 2.2 \\
\hline (multiple of individual gross earnings) & 11.5 & 8.6 & 7.1 & 5.1 & 3.8 & 2.6 \\
\hline
\end{tabular}

Assumptions: Real rate of return 3\%, real earnings growth $1.25 \%$, inflation $2 \%$, and real discount rate $2 \%$. All systems are modelled and indexed according to what is legislated except for the safety-nets which follow real-wages. Transitional rules apply where relevant. DC conversion rate equal 85\%. Labour market entry occurs at age 20 in 2014. Tax system latest available: 2013.

StatLink 部声 http://dx.doi.org/10.1787/888933301339 


\section{Brazil}

\section{Brazil: Pension system in 2014}

The Regime Geral de Previdência Social (RGPS) covers the private sector workforce. It is financed through payroll taxes, shared by the employer and the employee, revenues from sales taxes and federal transfers that cover shortfalls of the system. It is a mandatory, pay-as-you-go financed single-pillar scheme, which is operated by the National Social Security Institute.

\section{Key indicators: Brazil}

\begin{tabular}{llrr}
\hline & & Brazil & OECD \\
\hline Average worker earnings (AW) & BRL & 19312 & 106417 \\
& USD & 7267 & 40007 \\
Public pension spending & \% of GDP & 7.4 & 7.9 \\
Life expectancy & At birth & 73.8 & 80.0 \\
\multirow{2}{*}{ Population over age 65 } & At age 65 & 18.3 & 19.3 \\
& \% of population & 8.0 & 16.2 \\
\hline
\end{tabular}

\section{Qualifying conditions}

Private-sector employees are entitled to retire with a full pension if they meet one of two conditions, retirement on the basis of length of contributions or on basis of age. Retirement on the basic of length of contribution, at any age, is possible after having contributed to social security for 35 years for men and 30 years for women. This option is the most common pathway to retirement for private-sector employees. Retirement on the basis of age is 65 for men and 60 for women with a minimum contribution record of at least 15 years.

Contributions vary by earnings level at $8 \%$ for monthly earnings up to BRL $1317.07,9 \%$ for earnings from BRL 1317.08 to BRL 2195.12 and 11\% for earnings from BRL 2195.13 to BRL 4 390.24.

\section{Benefit calculation}

\section{Earnings-related}

There are 13 payments a year with benefits adjusted annually.

Pensions that exceed the minimum level are adjusted according to changes in the consumer price index.

\section{Retirement on the basis of length of contribution}

The benefit is the average of the best $80 \%$ monthly earnings multiplied by the "Fator Previdenciário". The "Fator Previdenciário" is an actuarial coefficient based on the insured's contribution rate, contribution period, age, and life expectancy. For a man retiring on the basis of length of contribution, considering the minimum of 35 years, this multiplication reduces the benefit level when retiring before the age of 64 , while increasing it thereafter. The "Fator Previdenciário" is not applied to arduous work with 15, 20 or 25 years of contributions.

$$
f=\frac{T_{C} \times a}{E_{S}} \times\left[1+\frac{\left(I_{d}+T_{C} \times a\right)}{100}\right]
$$

$f=$ "Fator Previdenciário"

$\mathrm{T}_{\mathrm{C}}=$ Worker contribution period

$a=$ Contribution rate $31 \%$

$E_{S}=$ Worker's life expectancy upon retirement

$I_{d}=$ Worker's age at time of retirement 


\section{Retirement on the basis of age}

The benefit is the average of the best $80 \%$ monthly earnings multiplied by $70 \%$ plus 1 percentage point for each set of 12 months of contribution, capped at 100\%. This result is multiplied by the "Fator Previdenciário" only if this factor is higher than 1.0. The minimum and maximum monthly earnings for benefit calculation purposes are the same as in retirement based on length of contribution.

\section{Minimum}

The minimum monthly earnings for benefit calculation purposes are equal to the legal monthly minimum wage (BRL 724). The maximum monthly earnings for benefit calculation purposes are BRL 4 390.24. The minimum pension for minimum monthly contributions is equal to the legal monthly minimum wage. For the two-thirds of private-sector pensioners who receive the minimum pension amount, annual adjustments are equivalent to those of the minimum wage, which has been rising significantly faster than consumer prices over the past decade.

\section{Social assistance programmes for old-age population}

Pension-like assistance benefits are also available to those who do not qualify for a retirement benefit on the basis of the two conditions mentioned above. The BPC-LOAS was created to assist old-age people (65 years old and more, both male and female) or disabled people whose household income per capita is under one-quarter of the minimum wage (floor). They receive an amount equal to the minimum wage and their conditions are revised every two years. Beneficiaries cannot receive any other non-contributory benefit from the government, but social assistance received by another member of the household is not taken into account. However, regular pension benefits received by another member of the household are taken into account. The logistics is made by the INSS (medical certification and means-test), but the responsibility for the benefit is given to the Ministry of Social Development and Fight Against Hunger (MDS).

There is another benefit called Previdencia Rural (Rural Pension) for those males aged 60 and females aged 55 or older, who have completed at least 180 months of work in rural areas. The benefit is equal to the minimum wage.

\section{Variant careers}

\section{Early retirement}

Early retirement is allowed at age 53 with at least 30 years of contributions (men) or age 48 with at least 25 years of contributions (women). Pension deductions are applied in this case through the "Fator previdenciário". This rule applies only to workers who were contributing before 1998. The value of early retirement is proportional to its integral value and they must contribute during an additional length of period of at least five more years. This rule is about to be naturally extinct.

\section{Late retirement}

Pensions can be claimed along with employment, and there is therefore no incentive to delay benefit claim. 
Pension modelling results: Brazil in 2049 (2044) with retirement at age 55 men (and 50 for women)

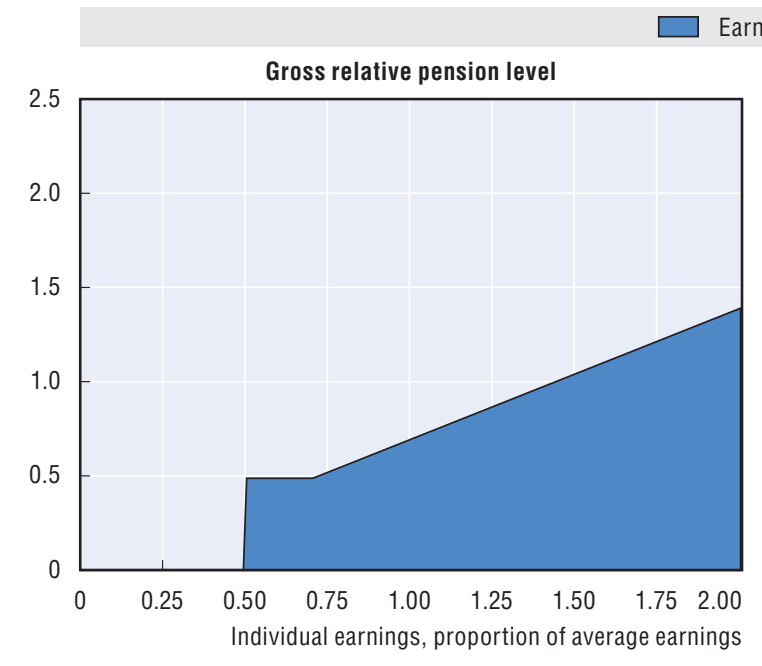

Earnings-related
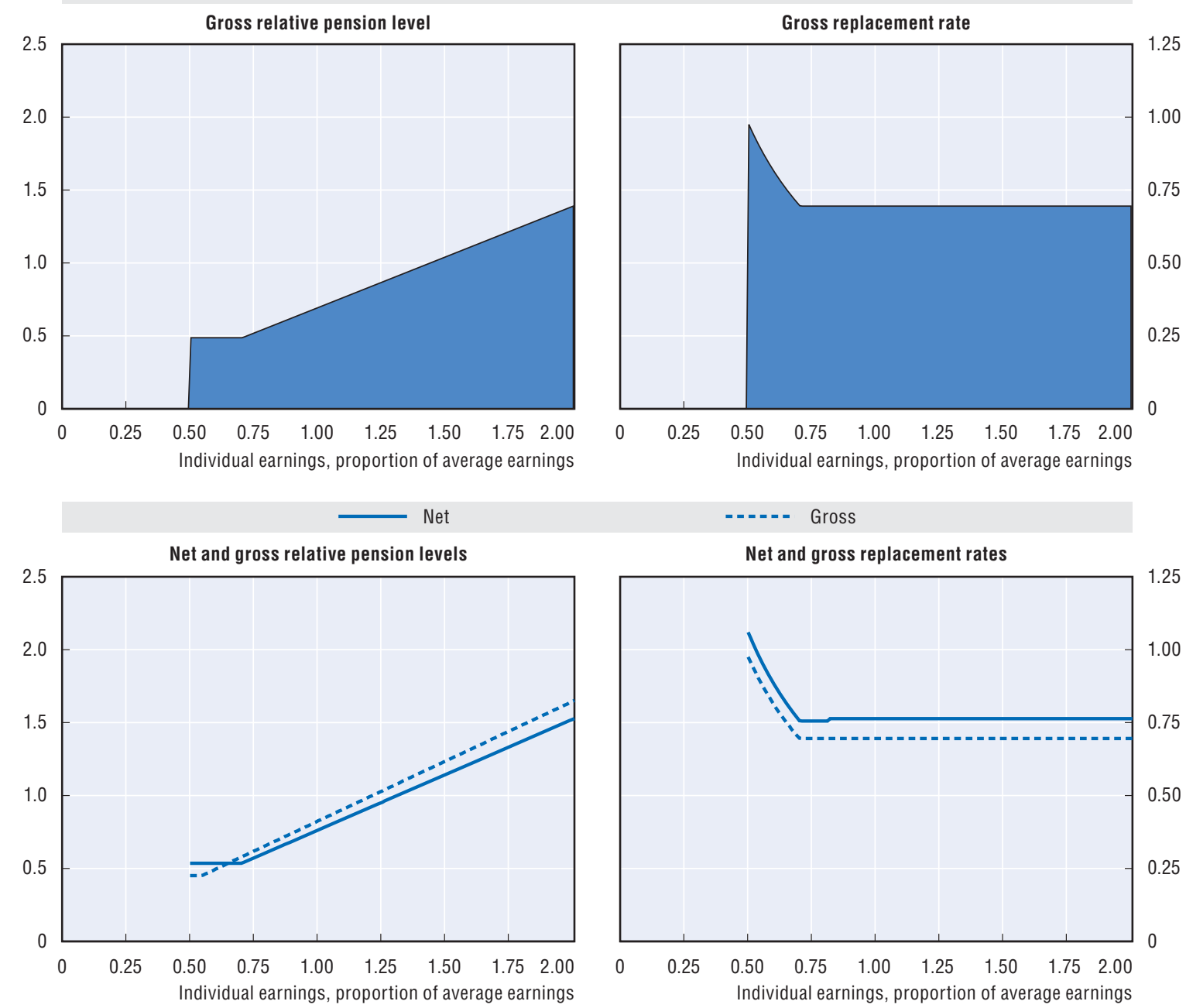

\begin{tabular}{|c|c|c|c|c|c|c|}
\hline \multicolumn{7}{|c|}{ Baseline scenario: Legislation scenario (wage indexation of minimum pension) } \\
\hline \multirow{2}{*}{$\begin{array}{l}\text { Men } \\
\text { Women (where different) }\end{array}$} & \multicolumn{6}{|c|}{ Individual earnings, multiple of average } \\
\hline & 0.5 & 0.75 & 1 & 1.5 & 2 & 3 \\
\hline Gross relative pension level & 48.7 & 52.1 & 69.5 & 104.2 & 139.0 & 189.6 \\
\hline (\% average gross earnings) & & 48.7 & 52.9 & 79.3 & 105.7 & 144.2 \\
\hline Net relative pension level & 53.6 & 57.3 & 76.4 & 114.6 & 152.7 & 208.3 \\
\hline (\% net average earnings) & & 53.6 & 58.1 & 87.1 & 116.2 & 158.5 \\
\hline Gross replacement rate & 97.5 & 69.5 & 69.5 & 69.5 & 69.5 & 63.2 \\
\hline (\% individual gross earnings) & & 65.0 & 52.9 & 52.9 & 52.9 & 48.1 \\
\hline Net replacement rate & 105.9 & 75.5 & 76.4 & 76.4 & 76.4 & 69.3 \\
\hline (\% individual net earnings) & & 70.6 & 58.1 & 58.1 & 58.1 & 52.7 \\
\hline Gross pension wealth & 24.2 & 17.3 & 17.3 & 17.3 & 17.3 & 15.7 \\
\hline (multiple of individual gross earnings) & 26.7 & 17.8 & 14.5 & 14.5 & 14.5 & 13.2 \\
\hline Net pension wealth & 24.2 & 17.3 & 17.3 & 17.3 & 17.3 & 15.7 \\
\hline (multiple of individual gross earnings) & 26.7 & 17.8 & 14.5 & 14.5 & 14.5 & 13.2 \\
\hline
\end{tabular}

Assumptions: Real rate of return $3 \%$, real earnings growth $1.25 \%$, inflation $2 \%$, and real discount rate $2 \%$. All systems are modelled and indexed according to what is legislated. Transitional rules apply where relevant. DC conversion rate equal $85 \%$. Labour market entry occurs at age 20 in 2014. Tax system latest available: 2014. 


\section{Canada}

\section{Canada: Pension system in 2014}

The pension system offers a flat-rate benefit, which can be topped up with an income-tested benefit, earnings-related public schemes and voluntary private pensions.

\section{Key indicators: Canada}

\begin{tabular}{llrr}
\hline & & Canada & OECD \\
\hline Average worker earnings (AW) & CAD & 49481 & 46373 \\
& USD & 42689 & 40007 \\
Public pension spending & \% of GDP & 4.3 & 7.9 \\
Life expectancy & At birth & 81.4 & 80.0 \\
\multirow{2}{*}{ Population over age 65 } & At age 65 & 20.3 & 19.3 \\
& \% of population & 16.0 & 16.2 \\
\hline
\end{tabular}

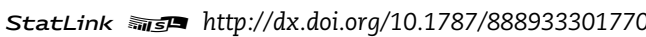

\section{Qualifying conditions}

The basic Old Age Security (OAS) pension is residence based. Each year of Canadian residence after age 18 up to a maximum of 40 years earns $2.5 \%$ of the maximum pension. A minimum of ten years' is required to receive a benefit. The OAS is currently payable from age 65.

Commencing in April 2023, the age of eligibility for the basic OAS pension and the Guaranteed Income Supplement (GIS) will gradually increase from 65 to 67, with full implementation expected by January 2029.

For the earnings-related scheme, the Canada Pension Plan (CPP), the normal pension eligibility age is 65 but an early pension can be claimed from age 60 and a late pension can be claimed up to the age of 70 .

\section{Benefit calculation}

\section{Basic}

The 2014 full pension level for the OAS pension was CAD 6 676.59. The value of the basic pension is price-indexed.

This pension is subject to an income test operated through the tax system (a "claw-back"). For income above CAD 71592 a year, the basic pension in 2014 was withdrawn at a $15 \%$ rate. It is also indexed to prices.

\section{Targeted}

The GIS is added to the basic OAS pension. The combination gave a maximum benefit of CAD 15729.69 in 2014 for a single pensioner.

The GIS is reduced against income other than the basic pension at a 50\% rate, however the first CAD 3500 of employment income is exempt. The target benefit level is price-indexed.

\section{Earnings-related}

Earnings-related pensions and benefits are provided by the CPP/Québec Pension Plan (QPP). The CPP and QPP offer broadly similar benefits. The scheme targets a replacement rate of $25 \%$ of earnings up to the Yearly Maximum Pensionable Earnings (YMPE), based on average lifetime salary (excluding the $17 \%$ of years with the lowest earnings). Earlier years' pay is re-valued in line with economy-wide earnings. A full benefit requires about 39 years' contributions with proportional reductions for shorter work histories. The maximum earnings-related retirement pension for 2014 was CAD 12780 . 
People earning less than CAD 3500 a year are not required to contribute. The ceiling, or YMPE, for contributions was CAD 52500 in 2014. The ceiling is indexed to increases in average earnings while the contribution floor is frozen in nominal terms. Earnings-related pension benefits are indexed with prices.

\section{Voluntary private pensions}

There is an additional voluntary pension which is assumed to be defined contribution. The contribution rate is assumed to be $8.5 \%$.

\section{Variant careers}

\section{Early retirement}

Early retirement beginning at age 60 is possible in the state earnings-related scheme subject to a benefit reduction that has gradually been increasing over a period of five years. The reduction was $6 \%$ per year in 2011 and is gradually being increased to 7.2\% in 2016. Early retirement is not possible in the other two public schemes (basic and means-tested).

\section{Late retirement}

Individuals have the option to defer the basic OAS pension for up to five years after age 65 . The deferred pension will be adjusted upward by $7.2 \%$ per year, up to a maximum of $36 \%$ at age 70 . The income-tested benefit cannot be deferred.

The earnings-related pension can be deferred, earning an increment for each year after age 65 - up to a maximum of five years. The increment was 8.4\% per year in 2014 .

\section{Childcare}

Years of caring for children under the age of seven are excluded from the averaging period in the pension calculation and these years are excluded from the contributory period under the earnings-related scheme.

\section{Unemployment}

Up to $17 \%$ of the contributory period may be excluded in calculating average earnings in the earnings-related scheme. This drop-out is intended to compensate for periods of unemployment, illness, schooling, etc. There are no additional credits for periods of unemployment. 


\section{Pension modelling results: Canada in 2061, retirement at age 67}
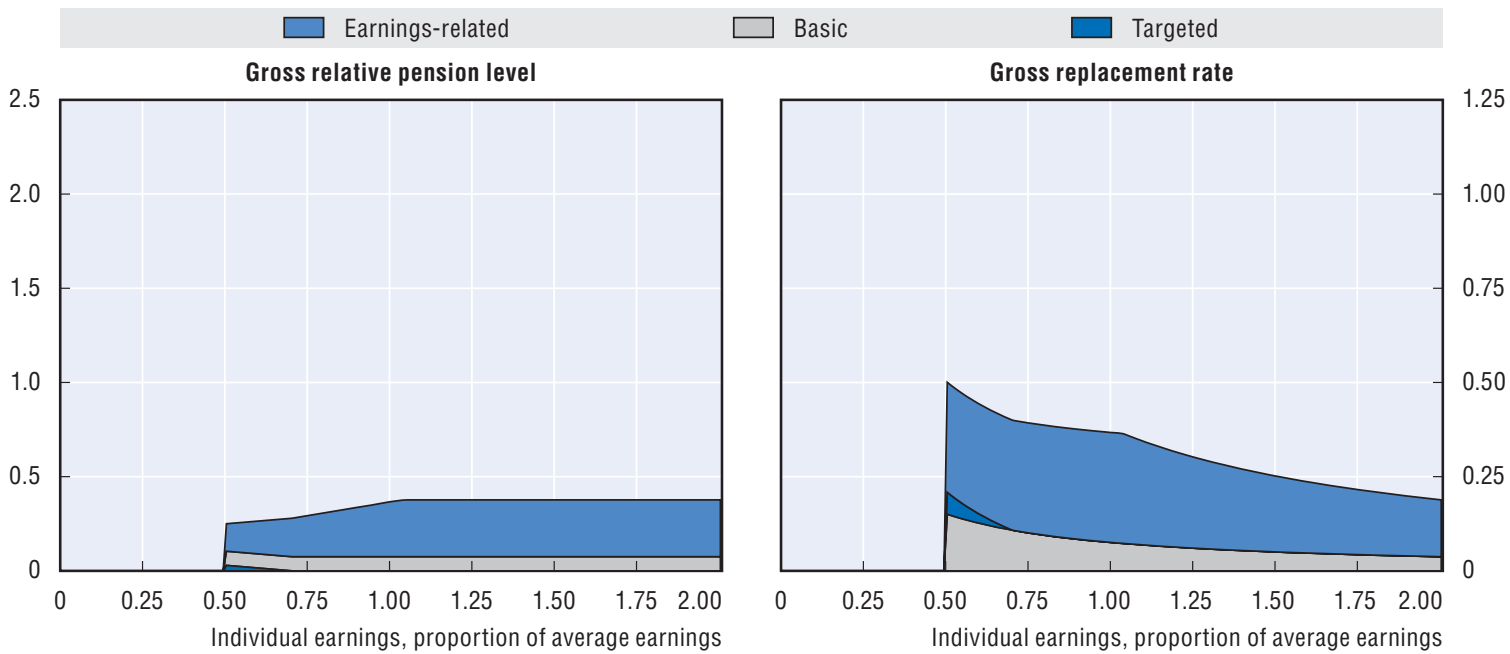

- - - - Gross

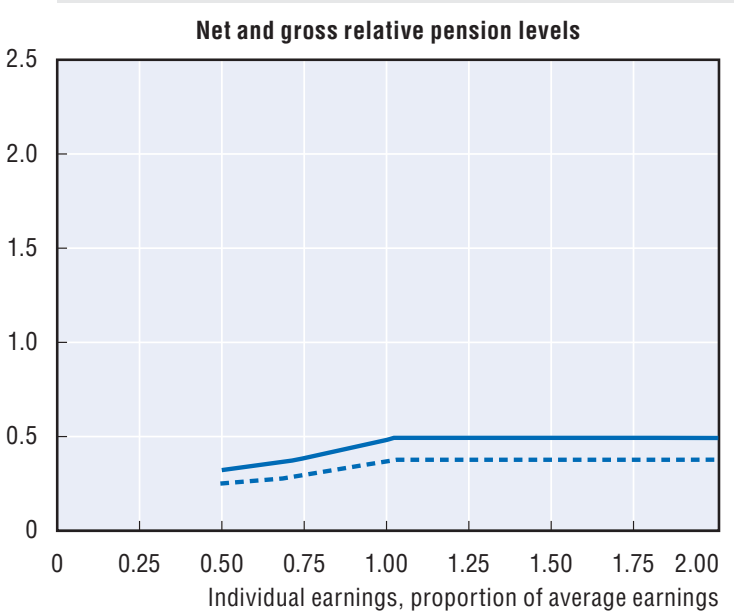

Net and gross replacement rates

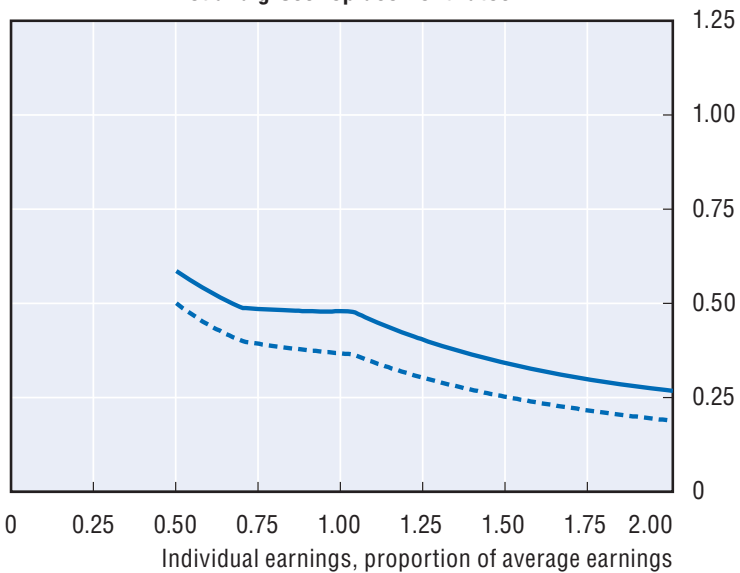

Baseline scenario: Legislation scenario (price indexation of targeted schemes)

\begin{tabular}{|c|c|c|c|c|c|c|}
\hline \multirow{2}{*}{$\begin{array}{l}\text { Men } \\
\text { Women (where different) }\end{array}$} & \multicolumn{6}{|c|}{ Individual earnings, multiple of average } \\
\hline & 0.5 & 0.75 & 1 & 1.5 & 2 & 3 \\
\hline Gross relative pension level & 25.0 & 29.4 & 36.7 & 37.7 & 37.7 & 37.7 \\
\hline \multicolumn{7}{|l|}{ (\% average gross earnings) } \\
\hline Net relative pension level & 32.7 & 38.4 & 47.9 & 49.2 & 49.2 & 49.2 \\
\hline \multicolumn{7}{|l|}{ (\% net average earnings) } \\
\hline Gross replacement rate & 50.1 & 39.2 & 36.7 & 25.1 & 18.8 & 12.6 \\
\hline \multicolumn{7}{|l|}{ (\% individual gross earnings) } \\
\hline Net replacement rate & 58.5 & 48.5 & 47.9 & 34.1 & 26.7 & 19.2 \\
\hline \multicolumn{7}{|l|}{ (\% individual net earnings) } \\
\hline Gross pension wealth & 8.5 & 6.7 & 6.2 & 4.3 & 3.2 & 2.1 \\
\hline (multiple of individual gross earnings) & 9.6 & 7.5 & 7.0 & 4.8 & 3.6 & 2.4 \\
\hline Net pension wealth & 8.5 & 6.7 & 6.2 & 4.3 & 3.2 & 2.1 \\
\hline (multiple of individual gross earnings) & 9.6 & 7.5 & 7.0 & 4.8 & 3.6 & 2.4 \\
\hline
\end{tabular}

Assumptions: Real rate of return 3\%, real earnings growth $1.25 \%$, inflation $2 \%$, and real discount rate $2 \%$. All systems are modelled and indexed according to what is legislated. Transitional rules apply where relevant. DC conversion rate equal $85 \%$. Labour market entry occurs at age 20 in 2014. Tax system latest available: 2013. 
Pension modelling results: Canada in 2061, retirement at age 67 (cont.)

\begin{tabular}{|c|c|c|c|c|c|c|}
\hline \multicolumn{7}{|c|}{ Alternative scenario: Full-wage indexation of targeted schemes } \\
\hline \multirow{2}{*}{$\begin{array}{l}\text { Men } \\
\text { Women (where different) }\end{array}$} & \multicolumn{6}{|c|}{ Individual earnings, multiple of average } \\
\hline & 0.5 & 0.75 & 1 & 1.5 & 2 & 3 \\
\hline Gross relative pension level & 39.1 & 42.7 & 46.4 & 46.9 & 46.9 & 46.9 \\
\hline \multicolumn{7}{|l|}{ (\% average gross earnings) } \\
\hline Net relative pension level & 51.0 & 55.8 & 60.4 & 60.9 & 60.9 & 60.9 \\
\hline \multicolumn{7}{|l|}{ (\% net average earnings) } \\
\hline Gross replacement rate & 78.2 & 57.0 & 46.4 & 31.2 & 23.4 & 15.6 \\
\hline \multicolumn{7}{|l|}{ (\% individual gross earnings) } \\
\hline Net replacement rate & 91.4 & 70.4 & 60.4 & 42.2 & 33.1 & 23.7 \\
\hline \multicolumn{7}{|l|}{ (\% individual net earnings) } \\
\hline Gross pension wealth & 13.3 & 9.7 & 7.9 & 5.3 & 4.0 & 2.7 \\
\hline (multiple of individual gross earnings) & 15.0 & 10.9 & 8.9 & 6.0 & 4.5 & 3.0 \\
\hline Net pension wealth & 13.3 & 9.7 & 7.9 & 5.3 & 4.0 & 2.6 \\
\hline (multiple of individual gross earnings) & 15.0 & 10.9 & 8.9 & 6.0 & 4.5 & 3.0 \\
\hline
\end{tabular}

Assumptions: Real rate of return $3 \%$, real earnings growth $1.25 \%$, inflation $2 \%$, and real discount rate $2 \%$. All systems are modelled and indexed according to what is legislated except for the safety-nets which follow real-wages. Transitional rules apply where relevant. DC conversion rate equal 85\%. Labour market entry occurs at age 20 in 2014. Tax system latest available: 2013.

StatLink +inisl http://dx.doi.org/10.1787/888933301359 


\section{Chile}

\section{Chile: Pension system in 2014}

The pension system has three components: a redistributive first tier, a second tier of mandatory individual accounts and a voluntary third tier. The individual accounts system was introduced in 1981 and is defined contribution.
Key indicators: Chile

\begin{tabular}{|c|c|c|c|}
\hline & & Chile & OECD \\
\hline \multirow[t]{2}{*}{ Average worker earnings (AW) } & CLP (million) & 7.02 & 24.2 \\
\hline & USD & 11588 & 40007 \\
\hline Public pension spending & $\%$ of GDP & 3.2 & 7.9 \\
\hline \multirow[t]{2}{*}{ Life expectancy } & At birth & 79.8 & 80.0 \\
\hline & At age 65 & 19.6 & 19.3 \\
\hline Population over age 65 & $\%$ of population & 10.6 & 16.2 \\
\hline
\end{tabular}

\section{Qualifying conditions}

\section{Defined contribution}

Normal retirement age is 65 years for men and 60 years for women. Pension benefits can be withdrawn at any point from that age. Individuals are not required to stop working to claim a pension benefit.

\section{Basic and supplementary schemes}

The basic solidarity pension (PBS) is an entitlement for individuals without other pensions. The PBS is payable from the age of 65 to the poorest $60 \%$ of the population. Benefit receipt is conditional on at least 20 years of residency and on residency in at least four of the five years prior to the claim. There is also a supplementary welfare pension named Solidarity Pension Payment (APS) which is targeted to individuals with low pensions. The benefit is paid when the defined contribution pension is less than a specified amount: the maximum welfare pension threshold (PMAS). The qualifying conditions for this benefit are the same as the qualifying conditions to the PBS.

\section{Benefit calculation}

\section{Defined contribution}

The contribution rate for the individual accounts scheme equals $10 \%$ of earnings. Administrative fees are levied on top of the contribution rate. There is a ceiling on contributions, which in December 2014 was set at 72.3 "Unidades de Fomento" (UF), which was CLP 1780539 per month (equal to 7.9 times the minimum wage in December 2014). The ceiling is indexed to real earnings growth.

At retirement, the accumulated capital can be used to buy an immediate life annuity, to get a temporary income with a deferred life annuity, to take programmed withdrawals, or to buy an immediate life annuity with programmed withdrawals. An amount of 15 UFs are withdrawn from the individual account to cover for funeral expenses. On purposes, replacement rates have been calculated assuming an actuarially fair annuity, using sex-specific annuity rates.

\section{Basic}

The basic solidarity pension (PBS) was CLP 85964 in December 2014. The PBS is indexed to prices. The 2008 reform also introduced a pension-income-tested supplement as a replacement for the previous minimum pension, named Solidarity Pension Payment (APS). The objective of this new supplementary pension is to improve the living standards of low-income workers when they move into retirement. 
In general terms, the supplementary benefit is defined as the value of the basic pension (PBS) minus the ratio of PBS to the value of the maximum welfare pension (PMAS) multiplied by the value of the defined contribution pension. The PMAS value in December 2014 was CLP 279 427. The key withdrawal ratio of PBS to PMAS is $30.7 \%$.

\section{Variant careers}

\section{Early retirement}

Early retirement is allowed at any age in the defined contribution scheme as long as the capital accumulated in the account is sufficient to finance a pension above particular thresholds. The first condition is that the benefit must be at least worth $80 \%$ of the PMAS. The second condition is that a minimum $70 \%$ replacement rate is reached, relative to earnings and incomes in the ten years prior to drawing the pension.

The normal retirement age is reduced by one or two years for each five years of work under arduous conditions in specified occupations. The maximum reduction of the normal retirement age is ten years.

\section{Late retirement}

It is possible to defer pension claiming after normal retirement age.

\section{Childcare}

There is a parental leave for working mothers with earnings replacement for a maximum of 24 weeks. Of these 24 weeks, the first 18 are exclusively for mothers. For weeks 19 to 24 , the mother has the chance to transfer the benefit to the father. The replaced earnings are calculated over the average salary in the last three months before the birth, with the same ceiling as for pension contributions. The benefit does not vary with the number of children. During this period, the mandatory $10 \%$ contributions to the pension system are paid from the parental leave benefit. This benefit does not lower the retirement age but does increase pensions as it increases savings.

Finally, when a child aged less than one year has a serious illness, the mother is entitled to take medical leave for the time the physician considered sufficient to take care of the baby. The medical leave allows the mother (or father, in the case that the mother set that) to receive her wage and increase pensions via the mandatory contributions for the child's sick leave.

In addition, a pension voucher is given to women for each child born alive that they have had. This benefit is claimable when they reach 65 years of age. The voucher is equivalent to $10 \%$ of 18 months' minimum wages at the time of birth, plus the average net rate of return on defined contribution pension plans from the birth until the pension claim. The average interest rate is calculated for "fund C" of the private pensions: the middle one in terms of the risk-return trade-off. This is transformed into a pension flow when the woman claims her pension.

\section{Unemployment}

No pension credits are given. 
Pension modelling results: Chile in 2059, retirement at age 65
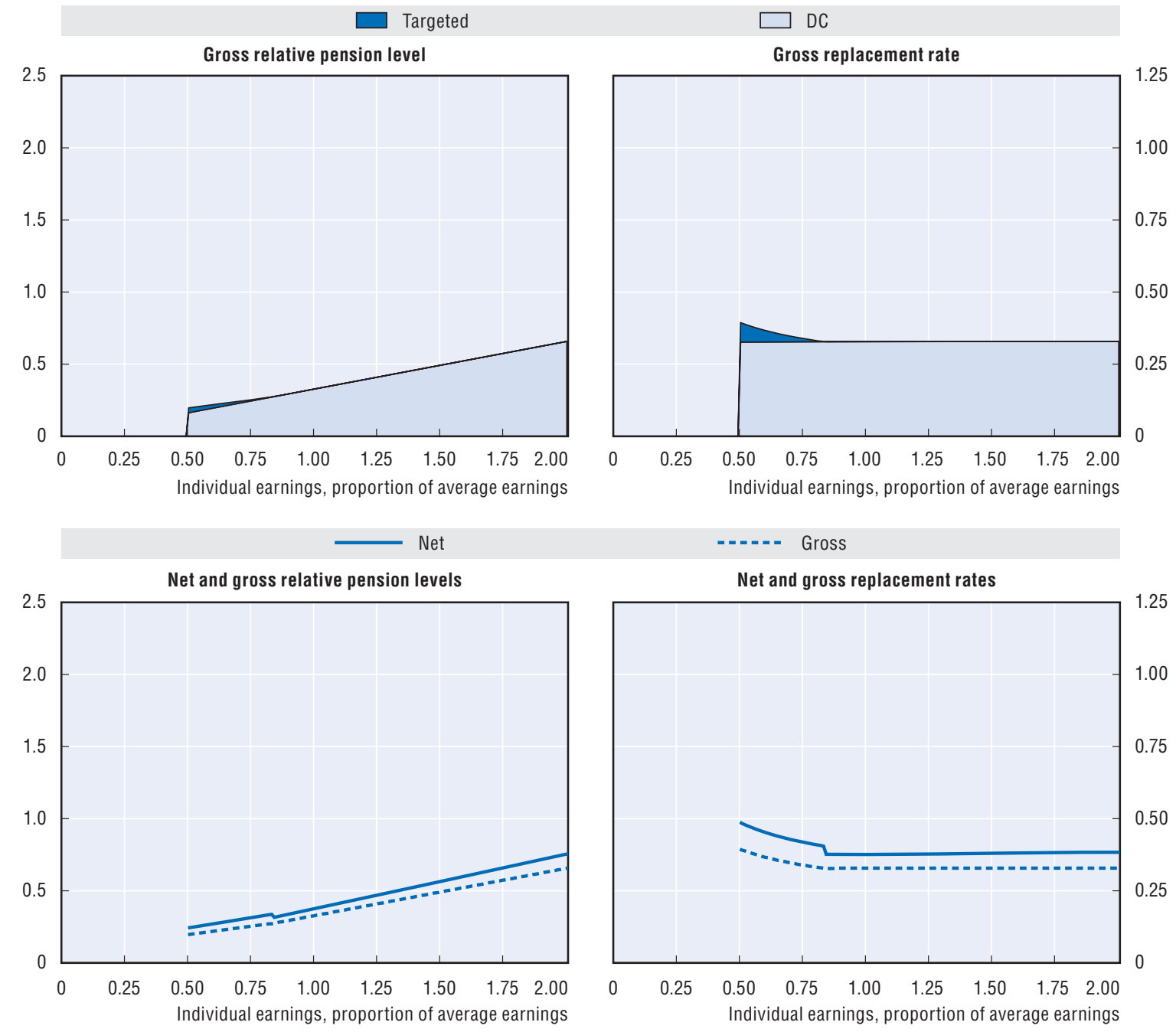

\begin{tabular}{|c|c|c|c|c|c|c|}
\hline \multicolumn{7}{|c|}{ Baseline scenario: Legislation scenario (price indexation of targeted schemes) } \\
\hline \multirow{2}{*}{$\begin{array}{l}\text { Men } \\
\text { Women (where different) }\end{array}$} & \multicolumn{6}{|c|}{ Individual earnings, multiple of average } \\
\hline & 0.5 & 0.75 & 1 & 1.5 & 2 & 3 \\
\hline Gross relative pension level & 19.7 & 25.4 & 32.8 & 49.3 & 65.8 & 98.8 \\
\hline (\% average gross earnings) & 18.3 & 23.4 & 28.8 & 43.3 & 57.8 & 86.8 \\
\hline Net relative pension level & 24.3 & 31.4 & 37.7 & 56.6 & 75.6 & 113.4 \\
\hline (\% net average earnings) & 22.6 & 28.8 & 33.1 & 49.7 & 66.4 & 99.7 \\
\hline Gross replacement rate & 39.4 & 33.9 & 32.8 & 32.9 & 32.9 & 32.9 \\
\hline (\% individual gross earnings) & 36.7 & 31.1 & 28.8 & 28.9 & 28.9 & 28.9 \\
\hline Net replacement rate & 48.7 & 41.8 & 37.7 & 38.0 & 38.4 & 37.9 \\
\hline (\% individual net earnings) & 45.3 & 38.4 & 33.1 & 33.4 & 34.7 & 33.3 \\
\hline Gross pension wealth & 6.9 & 6.0 & 5.8 & 5.8 & 5.8 & 5.8 \\
\hline (multiple of individual gross earnings) & 7.4 & 6.2 & 5.8 & 5.8 & 5.8 & 5.8 \\
\hline Net pension wealth & 6.9 & 6.0 & 5.4 & 5.4 & 5.4 & 5.4 \\
\hline (multiple of individual gross earnings) & 7.4 & 6.2 & 5.4 & 5.4 & 5.4 & 5.4 \\
\hline
\end{tabular}

Assumptions: Real rate of return $3 \%$, real earnings growth $1.25 \%$, inflation $2 \%$, and real discount rate $2 \%$. All systems are modelled and indexed according to what is legislated. Transitional rules apply where relevant. DC conversion rate equal $85 \%$. Labour market entry occurs at age 20 in 2014. Tax system latest available: 2014. 
Pension modelling results: Chile in 2059, retirement at age 65 (cont.)

\begin{tabular}{|c|c|c|c|c|c|c|}
\hline \multicolumn{7}{|c|}{ Alternative scenario: Full-wage indexation of targeted schemes } \\
\hline \multirow{2}{*}{$\begin{array}{l}\text { Men } \\
\text { Women (where different) }\end{array}$} & \multicolumn{6}{|c|}{ Individual earnings, multiple of average } \\
\hline & 0.5 & 0.75 & 1 & 1.5 & 2 & 3 \\
\hline Gross relative pension level & 25.9 & 31.6 & 37.3 & 49.2 & 65.7 & 98.7 \\
\hline (\% average gross earnings) & 24.5 & 29.6 & 34.6 & 44.6 & 57.7 & 86.7 \\
\hline Net relative pension level & 32.0 & 39.0 & 46.1 & 56.5 & 75.4 & 113.3 \\
\hline (\% net average earnings) & 30.3 & 36.5 & 42.7 & 55.1 & 66.3 & 99.5 \\
\hline Gross replacement rate & 51.8 & 42.2 & 37.3 & 32.8 & 32.8 & 32.9 \\
\hline (\% individual gross earnings) & 49.1 & 39.4 & 34.6 & 29.7 & 28.9 & 28.9 \\
\hline Net replacement rate & 64.0 & 52.1 & 46.1 & 37.9 & 38.3 & 37.8 \\
\hline (\% individual net earnings) & 60.6 & 48.7 & 42.7 & 37.0 & 33.6 & 33.2 \\
\hline Gross pension wealth & 9.1 & 7.4 & 6.6 & 5.8 & 5.8 & 5.8 \\
\hline (multiple of individual gross earnings) & 9.8 & 7.9 & 6.9 & 6.0 & 5.8 & 5.8 \\
\hline Net pension wealth & 9.1 & 7.4 & 6.6 & 5.4 & 5.4 & 5.4 \\
\hline (multiple of individual gross earnings) & 9.8 & 7.9 & 6.9 & 6.0 & 5.4 & 5.4 \\
\hline
\end{tabular}

Assumptions: Real rate of return 3\%, real earnings growth $1.25 \%$, inflation $2 \%$, and real discount rate $2 \%$. All systems are modelled and indexed according to what is legislated except for the safety-nets which follow real-wages. Transitional rules apply where relevant. DC conversion rate equal 85\%. Labour market entry occurs at age 20 in 2014. Tax system latest available: 2014.

StatLink 啇Is http://dx.doi.org/10.1787/888933301360 


\section{China}

\section{China: Pension system in 2014}

China has a two-tier pension system, consisting of a basic pension and a mandatory employee contribution to a second-tier plan. This system, which was introduced in 1998, was significantly revised in 2006. It covers urban workers and many of the parameters depend on province-wide (rather than national) average earnings.

\section{Key indicators: China}

\begin{tabular}{llrr}
\hline & & China & OECD \\
\hline \multirow{2}{*}{ Average worker earnings (AW) } & CNY & 56339 & 248313 \\
& USD & 7267 & 40007 \\
Public pension spending & \% of GDP & 3.4 & 7.9 \\
Life expectancy & At birth & 75.2 & 80.0 \\
\multirow{2}{*}{ Population over age 65 } & At age 65 & 15.6 & 19.3 \\
& \% of population & 9.5 & 16.2 \\
\hline
\end{tabular}

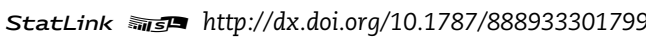

\section{Qualifying conditions}

Normal pension age is 60 years for men and 50 years for blue collar women and 55 years for white collar women.

\section{Benefit calculation}

\section{Basic}

The basic pension pays $1 \%$ of the average of the indexed individual wage and the province-wide average earnings for each year of coverage, subject to a minimum of 15 years of contributions. The pension in payment is indexed to a mix of wages and prices, which has been about $10 \%$ in recent years instead. The modelling assumes $50 \%$ indexation to wages.

\section{Defined contribution (funded or notional accounts)}

The second-tier system comprises individual accounts. In addition to the north-eastern provinces (Liaoning, Jilin and Heilongjiang), a further eight have funded individual account systems. In other cases, the accounts are largely notional and are credited with a notional interest rate.

Employees pay $8 \%$ of wages to the individual account system. The accumulated balance in the fund or the notional account is converted into a stream of pension payments at the time of retirement by dividing the balance by a government-determined annuity factor, depending on individual retirement age and average national life expectancy. In all provinces, these annuity factors for both males and females (for monthly benefits) are:

\begin{tabular}{|c|c|c|c|c|c|c|c|}
\hline Age & 40 & 45 & 50 & 55 & 60 & 65 & 70 \\
\hline Factor & 233 & 216 & 195 & 170 & 139 & 101 & 56 \\
\hline
\end{tabular}

\section{Variant careers}

\section{Early retirement}

It is possible to claim a pension benefit from the age of 55 years for men and 50 years for women if the individual engaged in physical work in certain industries or posts.

\section{Late retirement}

It is possible to defer pension payments until after normal pension age, but the pension benefit is not valorised. 


\section{Pension modelling results: China in 2054, retirement at age 60 (men)}
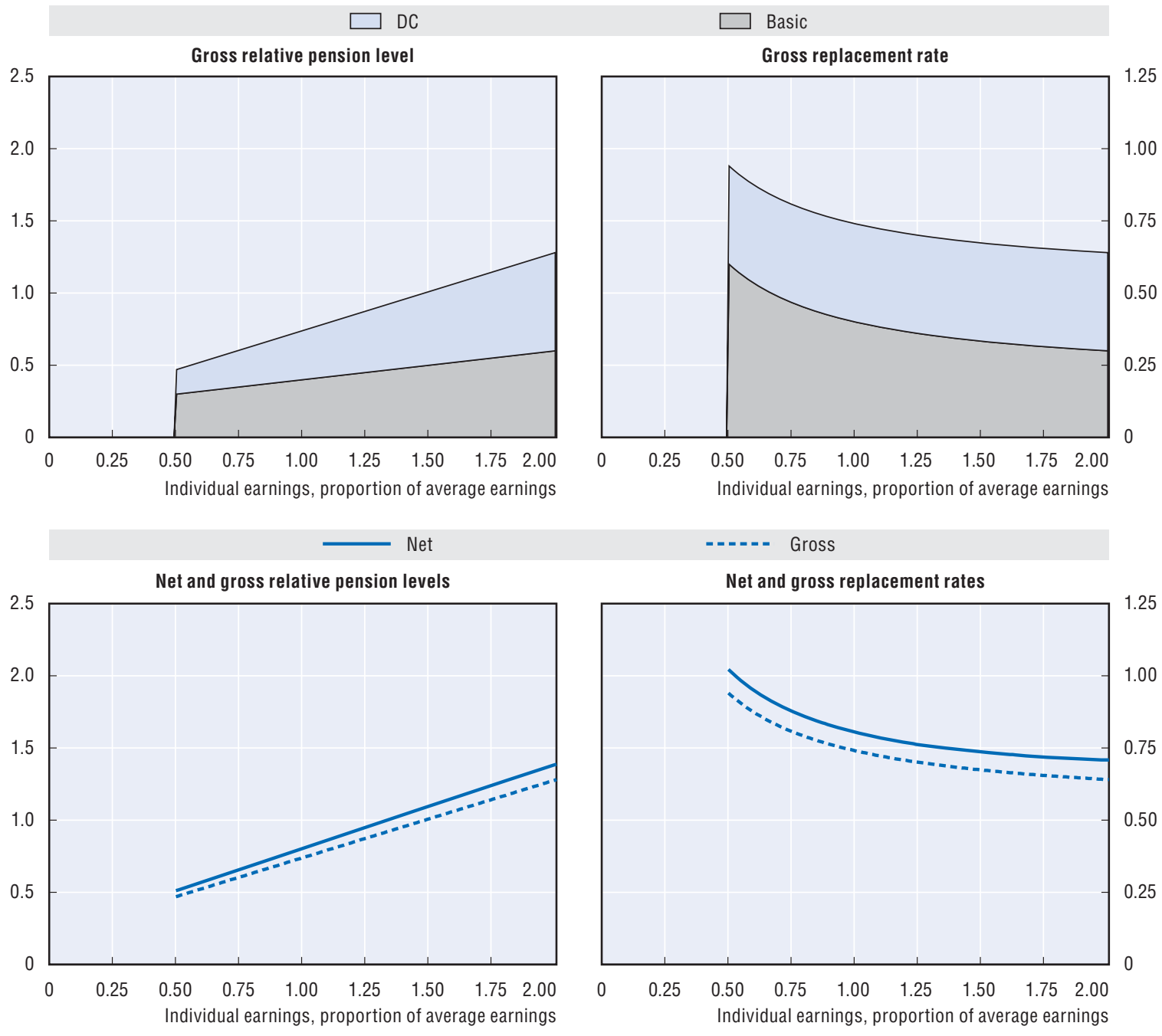

\begin{tabular}{|c|c|c|c|c|c|c|}
\hline \multicolumn{7}{|c|}{ Baseline scenario: Legislation scenario } \\
\hline \multirow{2}{*}{$\begin{array}{l}\text { Men } \\
\text { Women (where different) }\end{array}$} & \multicolumn{6}{|c|}{ Individual earnings, multiple of average } \\
\hline & 0.5 & 0.75 & 1 & 1.5 & 2 & 3 \\
\hline Gross relative pension level & 47.0 & 60.5 & 74.0 & 101.0 & 128.0 & 182.1 \\
\hline (\% average gross earnings) & 43.3 & 56.1 & 69.0 & 94.8 & 120.5 & 172.1 \\
\hline Net relative pension level & 51.1 & 65.8 & 80.5 & 109.8 & 138.8 & 194.4 \\
\hline (\% net average earnings) & 47.0 & 61.0 & 75.0 & 103.0 & 130.9 & 184.6 \\
\hline Gross replacement rate & 94.0 & 80.7 & 74.0 & 67.4 & 64.0 & 60.7 \\
\hline (\% individual gross earnings) & 86.5 & 74.9 & 69.0 & 63.2 & 60.3 & 57.4 \\
\hline Net replacement rate & 102.2 & 87.7 & 80.5 & 73.6 & 70.7 & 68.2 \\
\hline (\% individual net earnings) & 94.0 & 81.4 & 75.0 & 69.0 & 66.7 & 64.8 \\
\hline Gross pension wealth & 17.3 & 14.9 & 13.7 & 12.4 & 11.8 & 11.0 \\
\hline (multiple of individual gross earnings) & 20.3 & 17.5 & 16.2 & 14.8 & 14.1 & 13.3 \\
\hline Net pension wealth & 17.3 & 14.9 & 13.7 & 12.4 & 11.8 & 11.0 \\
\hline (multiple of individual gross earnings) & 20.3 & 17.5 & 16.2 & 14.8 & 14.1 & 13.3 \\
\hline
\end{tabular}

Assumptions: Real rate of return $3 \%$, real earnings growth $1.25 \%$, inflation $2 \%$, and real discount rate $2 \%$. All systems are modelled and indexed according to what is legislated. Transitional rules apply where relevant. DC conversion rate equal $85 \%$. Labour market entry occurs at age 20 in 2014. Tax system latest available: 2014. 


\section{Czech Republic}

\section{Czech Republic: Pension system} in 2014

The Czech pension system consists of a public pension scheme and a mandatory funded private scheme with voluntary entry.

The public pension scheme has a basic element and an earnings-related part calculated according to a progressive formula.
Key indicators: Czech Republic

\begin{tabular}{|c|c|c|c|}
\hline & & Czech Republic & OECD \\
\hline \multirow[t]{2}{*}{ Average worker earnings (AW) } & CZK & 312084 & 915586 \\
\hline & USD & 13637 & 40007 \\
\hline Public pension spending & $\%$ of GDP & 8.9 & 7.9 \\
\hline \multirow[t]{2}{*}{ Life expectancy } & At birth & 77.6 & 80.0 \\
\hline & At age 65 & 17.3 & 19.3 \\
\hline Population over age 65 & $\%$ of population & 17.6 & 16.2 \\
\hline
\end{tabular}

\section{Qualifying conditions}

The standard retirement age is currently 62 years and eight months for men and 61 years four months for women. The standard retirement age is gradually increasing by two months per birth cohort without any upper limit. The pension age for women is increasing by four months and from 2019 by six months in order to be unified with that of men. This will occur for all individuals born in 1975 and at the age of 66 years and eight months. The minimum years of required coverage will gradually increase from 25 years to 35 years (or 30 years without non-contributory periods). Individuals with 15 years of pension coverage (gradually increasing to 20 years or 15 years without non-contributory periods) can receive a pension benefit five years later than the standard retirement age for males of the same birth cohort.

\section{Benefit calculation}

\section{Basic}

The value of the basic pension is equal to $9 \%$ of the legislated average wage. In 2014 this translated into an annual benefit equal to CZK 28080.

\section{Earnings-related}

The earnings-related pension gives $1.5 \%$ of earnings for each service year. The earnings measure currently averages across all years starting from 1986, but it will gradually reach lifetime average. Earlier years' earnings are indexed by the growth of economy-wide average earnings.

There is a progressive benefit formula, under which income thresholds are applied to reduce average career earnings into the calculation basis. In the final state the first threshold is $44 \%$ of average wage and the second $400 \%$ of average wage [due to a five-year transition period, the figures effective in 2014 are different from those which apply to a future pensioner (after the transition period), but in terms of wages and prices of 2014]. The first reduction threshold is equal to CZK 11415 and the second is CZK 103768 in 2014. Up to the first threshold the earnings will be replaced by 100\% and between the first and second by $26 \%$. Earnings over the second threshold will not be taken into account.

There will be a statutory indexation requirement for the earnings-related pension component in payment to reach the state that the combined total average pension benefit (flat-rate and earnings-related components) is increased by $100 \%$ of price inflation (only one-third of price inflation in 2013-14) plus one-third of real wage growth. 


\section{Minimum}

The total value of the minimum monthly newly granted public pension benefit is CZK 3110 , which is made up of a minimum earnings-related pension of CZK 770 plus the basic component of CZK 2340.

\section{Social assistance}

The living minimum is composed of one component and created by living minimum ensuring subsistence and other basic personal needs. The living minimum of individual (and therefore also living-alone pensioner) amounted to CZK 3410 per month. The social protection in housing is solved within the framework of the state social benefit system, providing housing benefits and in the system of assistance in material need by surcharge for housing.

\section{Voluntary private pension}

As of January 2013 every insured person can voluntarily opt into a privately managed funded define-contribution pension system. Participation in the funded system cannot be revoked. The mandatory fully funded scheme is financed by contributions of $5 \%$ of gross earnings. At the same time the individual's contribution rate to earnings-related public pension scheme is lowered by 3 percentage points (from $28 \%$ to $25 \%$ ). As a result the total contribution rate for participants increases to $30 \%$ of gross earnings. The lower contribution rate to public pension scheme affects the accrual rate of the earnings-related component of public pensions. The accrual rate is decreased to $1.2 \%$ annually (instead of $1.5 \%$ ) for each year the individual contributes to the funded scheme.

The contributions are accumulated in individual accounts managed by private pension companies and invested according to an individual investment strategy chosen by the participant as a combination of savings allocation in pension funds in time. Each pension company offers exactly four pension funds with different revenue-risk profiles.

After a pension from the public pension scheme is granted, the participant can start drawing his/her savings from the funded scheme. Three withdrawal options are available - a lifelong annuity, lifelong annuity with additional three year survivor pension or a temporary 20-year annuity.

There is an additional voluntary pension which is assumed to be defined contribution. The contribution rate is assumed to be $2.8 \%$.

The voluntary private pension systems are not modelled in the base case.

\section{Variant careers}

\section{Early retirement}

It is possible to retire three years (increasing to five years, but no earlier than age 60) before the standard retirement ages subject to 25 years' coverage, increasing in line with general qualification conditions to 35 years. The total accrual factor (i.e. number of years of contributions multiplied by the accrual rate) is permanently reduced by $0.9 \%$ for each 90 days of the first 360 days of early retirement (3.6\% per year), $1.2 \%$ for each 90 days between 361 and 720 days (4.8\% per year) and $1.5 \%$ for each 90 days thereafter (6\% per year). For a full-career worker, this is equivalent to a decrement in the pension level (rather than the replacement rate) for early retirement of 3.6/64.5 (1.5\% times 43 years) $=5.6 \%$.

\section{Late retirement}

It is possible to defer claiming the pension beyond the normal pension age. The total accrual factor is increased by $1.5 \%$ for each 90 -day period of deferral ( $6 \%$ per year). There is no additional pension accrual for deferred retirement. It is also possible to combine pension receipt while 
continuing to work (from 2010 granted pension (total accrual factor) has been increased by $0.4 \%$ for each 360 days of work while receiving full pension) and to receive half old-age pension. Combination of half old-age pension and work has increased total accrual factor by $1.5 \%$ for each 180 days of work.

\section{Childcare}

There are credits for labour-market absences during periods caring for children up to four years old (or older in case of severe disability). These years are then ignored in the calculation of earnings for pension purposes so that these absences do not reduce the assessment base. (This approach is used for all non-contributory periods.)

\section{Unemployment}

Periods on earnings-related unemployment insurance are credited in the pension system. The duration of unemployment insurance entitlement varies with age: five months up to age 50, eight months from 50 to 55 and 11 months for over 55s. In addition, up to three years spent unemployed without entitlement to unemployment insurance are also credited (but only one year of unemployment without benefits before the age of 55 is credited). The unemployment period used for the pension calculation is reduced to $80 \%$, meaning that if an individual had five years' unemployment over the career, this would count as four years for pension purposes. If the unemployment period is in the decisive (reference) period for the average assessment base calculation, this period is excluded from the calculation and only the income from which the premium is paid is used. 


\section{Pension modelling results: Czech Republic in 2062, retirement at age 68}
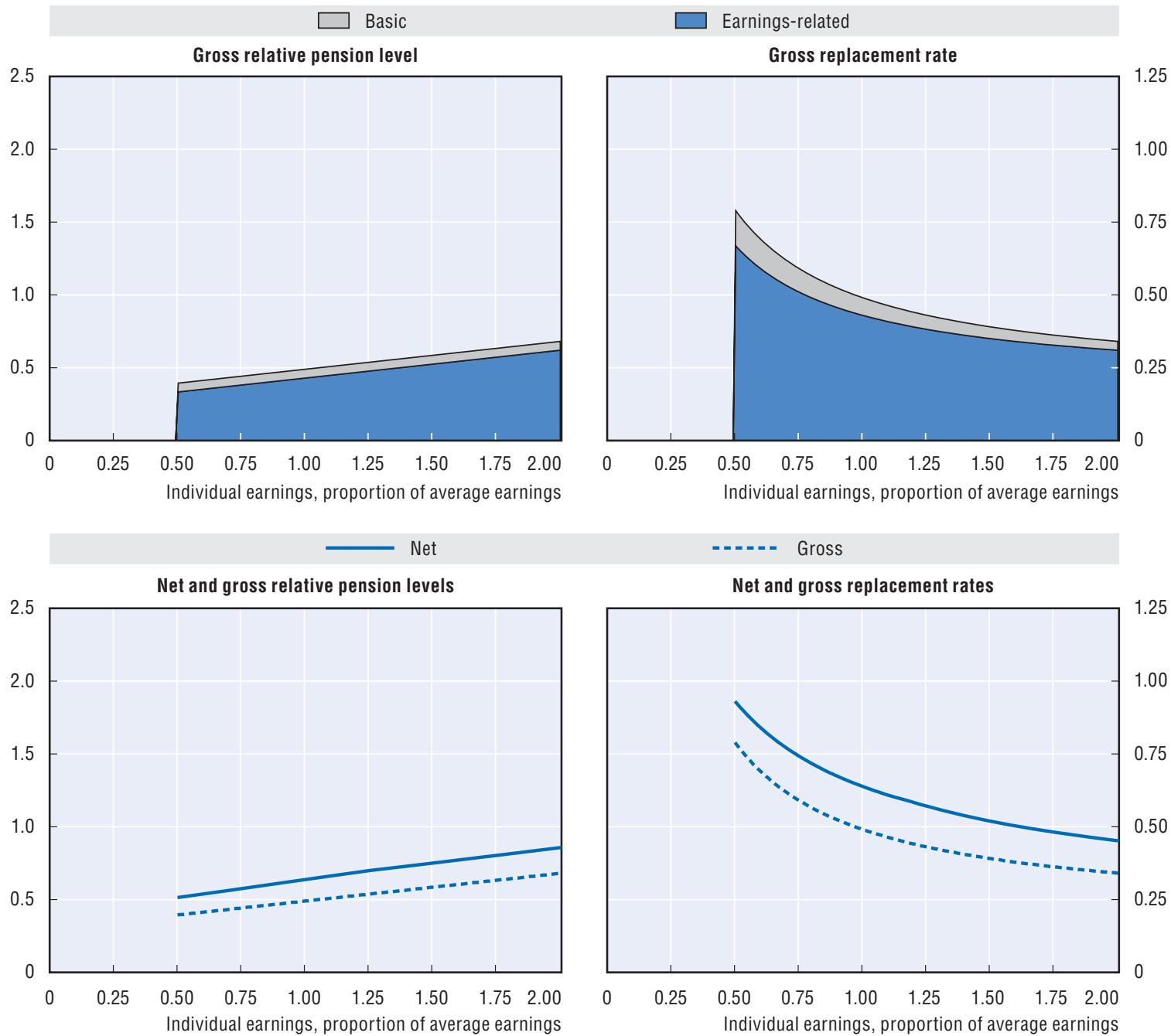

\begin{tabular}{|c|c|c|c|c|c|c|}
\hline \multicolumn{7}{|c|}{ Baseline scenario: Legislation scenario } \\
\hline \multirow{2}{*}{$\begin{array}{l}\text { Men } \\
\text { Women (where different) }\end{array}$} & \multicolumn{6}{|c|}{ Individual earnings, multiple of average } \\
\hline & 0.5 & 0.75 & 1 & 1.5 & 2 & 3 \\
\hline Gross relative pension level & 39.5 & 44.2 & 49.0 & 58.6 & 68.1 & 87.2 \\
\hline \multicolumn{7}{|l|}{ (\% average gross earnings) } \\
\hline Net relative pension level & 51.3 & 57.6 & 63.8 & 75.1 & 85.7 & 106.8 \\
\hline \multicolumn{7}{|l|}{ (\% net average earnings) } \\
\hline Gross replacement rate & 78.9 & 59.0 & 49.0 & 39.1 & 34.1 & 29.1 \\
\hline \multicolumn{7}{|l|}{ (\% individual gross earnings) } \\
\hline Net replacement rate & 93.1 & 74.2 & 63.8 & 51.9 & 45.2 & 38.3 \\
\hline \multicolumn{7}{|l|}{ (\% individual net earnings) } \\
\hline Gross pension wealth & 12.1 & 9.0 & 7.5 & 6.0 & 5.2 & 4.4 \\
\hline (multiple of individual gross earnings) & 14.0 & 10.5 & 8.7 & 6.9 & 6.1 & 5.2 \\
\hline Net pension wealth & 12.1 & 9.0 & 7.5 & 5.9 & 5.0 & 4.2 \\
\hline (multiple of individual gross earnings) & 14.0 & 10.5 & 8.7 & 6.8 & 5.9 & 4.9 \\
\hline
\end{tabular}

Assumptions: Real rate of return 3\%, real earnings growth $1.25 \%$, inflation $2 \%$, and real discount rate $2 \%$. All systems are modelled and indexed according to what is legislated. Transitional rules apply where relevant. DC conversion rate equal $85 \%$. Labour market entry occurs at age 20 in 2014. Tax system latest available: 2013. 
Pension modelling results: Czech Republic in 2062, retirement at age 68 (cont.)

\begin{tabular}{|c|c|c|c|c|c|c|}
\hline \multicolumn{7}{|c|}{ Alternative scenario: Full-wage indexation of targeted schemes } \\
\hline \multirow{2}{*}{$\begin{array}{l}\text { Men } \\
\text { Women (where different) }\end{array}$} & \multicolumn{6}{|c|}{ Individual earnings, multiple of average } \\
\hline & 0.5 & 0.75 & 1 & 1.5 & 2 & 3 \\
\hline Gross relative pension level & 42.4 & 47.2 & 52.0 & 61.5 & 71.1 & 90.2 \\
\hline \multicolumn{7}{|l|}{ (\% average gross earnings) } \\
\hline Net relative pension level & 55.2 & 61.4 & 67.6 & 78.4 & 89.0 & 110.1 \\
\hline \multicolumn{7}{|l|}{ (\% net average earnings) } \\
\hline Gross replacement rate & 84.9 & 62.9 & 52.0 & 41.0 & 35.5 & 30.1 \\
\hline \multicolumn{7}{|l|}{ (\% individual gross earnings) } \\
\hline Net replacement rate & 100.0 & 79.2 & 67.6 & 54.1 & 46.9 & 39.4 \\
\hline \multicolumn{7}{|l|}{ (\% individual net earnings) } \\
\hline Gross pension wealth & 13.0 & 9.6 & 7.9 & 6.3 & 5.4 & 4.6 \\
\hline (multiple of individual gross earnings) & 16.9 & 12.5 & 10.3 & 8.2 & 7.1 & 6.0 \\
\hline Net pension wealth & 13.0 & 9.6 & 7.9 & 6.1 & 5.2 & 4.3 \\
\hline (multiple of individual gross earnings) & 16.9 & 12.5 & 10.3 & 8.0 & 6.8 & 5.6 \\
\hline
\end{tabular}

Assumptions: Real rate of return $3 \%$, real earnings growth $1.25 \%$, inflation $2 \%$, and real discount rate $2 \%$. All systems are modelled and indexed according to what is legislated except for the safety-nets which follow real-wages. Transitional rules apply where relevant. DC conversion rate equal 85\%. Labour market entry occurs at age 20 in 2014. Tax system latest available: 2013.

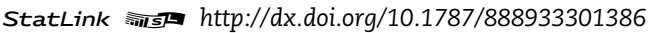




\section{Denmark}

\section{Denmark: Pension system in 2014}

There is a public basic scheme. A meanstested supplementary pension benefit is paid to the financially most disadvantaged pensioners. There is also a mandatory occupation pension scheme based on lump-sum contributions (ATP). In addition, compulsory occupational pension schemes negotiated as part of collective agreements or similar cover about $90 \%$ of the employed workforce.
Key indicators: Denmark

\begin{tabular}{llrr}
\hline & & Denmark & OECD \\
\hline \multirow{2}{*}{ Average worker earnings (AW) } & DKK & 397484 & 245962 \\
& USD & 64654 & 40007 \\
Public pension spending & \% of GDP & 6.2 & 7.9 \\
Life expectancy & At birth & 79.3 & 80.0 \\
\multirow{2}{*}{ Population over age 65 } & At age 65 & 18.5 & 19.3 \\
& \% of population & 18.6 & 16.2 \\
\hline
\end{tabular}

\section{Qualifying conditions}

The normal pension age is currently 65 years but will be increased gradually to 67 years in the period 2019-22. A full public old-age pension requires 40 years of residence. Shorter periods qualify for a pro-rated benefit.

Pension rights with ATP and with occupational pension schemes are accrued on a what-you-pay-is-what-you-get basis. The longer the working career, the higher the employment rate, the longer contribution record and the higher the contribution level, the greater the pensions benefit.

\section{Benefit calculation}

\section{Basic}

The full basic pension amount is DKK 5908 per month or DKK 70896 per year, equivalent to around $17 \%$ of average earnings. There is an individual earnings test which means that the basic pension will be reduced if earned income exceeds DKK 301200 (approximately 3/4 average earnings). The benefit is reduced at a rate of $30 \%$ against earned income above this level.

\section{Targeted}

The full pension supplement is DKK 6137 per month or DKK 73644 per year for single pensioners and DKK 35592 per year for married or cohabiting pensioners. The actual amounts are tested against all sources of personal income (including ATP and occupational pensions) apart from social pensions. The pension supplement is reduced by $30.9 \%$ of personal income exceeding DKK 66500 for single pensioners. For pensioners cohabiting with a spouse/partner who also receives a social pension the pension supplement is reduced by $16 \%$ of the couples total personal income exceeding DKK 133 400. If the spouse/partner does not receive a social pension the pension supplement is reduced by 32\% of the couples total personal income exceeding DKK 133400.

Public old-age pensioners may also receive a supplementary pension benefit of DKK 16200 . The supplementary pension benefit is taxable and paid once a year. The benefit is means-tested and targeted to the poorest pensioners without significant liquid assets (the liquid assets may not exceed DKK 80 300). 
The public old-age pension (the basic and pension supplement amounts plus the supplementary pension amount) is adjusted annually in line with average earnings. The adjustment is based on an index of wage increases during the two preceding years. If nominal earnings growth exceeds $2 \%$, a maximum of $0.3 \%$ of the excess increase is allocated to a social spending reserve. Thus, indexation of pensions and other social benefits is based upon wage increases less any allocation to the reserve.

Income from work up to DKK 60000 yearly is not taken into consideration when calculating (income-testing) the pension supplement and the supplementary pension benefit.

In addition to the targeted scheme public old-age pensioners are entitled to a number of supplementary benefits (particularly favourable housing benefits, heating benefits, health allowances, reduced tax on owner-occupied housing), most of which depend on objective criteria (rent, expenses, household income, household assets, etc.). Furthermore, particularly disadvantaged pensioners, e.g. pensioners not entitled to a full pension (less than 40 years of residence), may be granted a personal allowance following a specific, individual assessment of their needs. It should also be taken into consideration that pensioners and others are entitled to a number of free services, such as home-help services and hospital treatment.

The housing benefit to old-age pensioners (cf. above) is calculated as the difference between $75 \%$ of the (annual housing + DKK 6300 ) and 22.5\% of the household income exceeding DKK 149300 in 2014. The calculation in respect of one person includes the housing costs for a gross floor space of 65 square meters. For each additional member of the household the calculation includes the housing costs for additional 20 square meters. The maximum housing costs included in the calculations is DKK 83700 in 2014. The recipient shall as a minimum pay 11\% of the household income, and at least DKK 15800.

\section{Minimum social assistance}

An amount corresponding to the amount payable to a married old-age pensioner without any income other than the old-age pension will be granted to persons who do not qualify for social pensions due to the eligibility rules. The person is entitled to housing benefits although not the particularly favourable housing benefits to old-age pensioners. The housing benefit to non-pensioners is calculated as the difference between $60 \%$ of the annual housing, and $18 \%$ of the household income exceeding DKK 140500 in 2014. The calculation in respect of one person includes the housing costs for a gross floor space of 65 square meters. For each additional member of the household the calculation includes the housing costs for additional 20 square meters. The maximum housing costs included in the calculations is DKK 78800 in 2014. The housing allowance cannot exceed 15\% of the housing costs. The recipient shall as a minimum pay DKK 23700.

\section{ATP - Statutory savings based supplementary pension}

ATP (the Danish Labour Market Supplementary Pension) is a statutory, fully funded, collective insurance based, defined-contribution scheme. ATP provides a lifelong pension from the age of 65 and a survivors' lump sum benefit for dependents in the case of early death of an individual member. ATP covers all wage earners and almost all recipients of social security benefits. ATP membership is voluntary for the self-employed. ATP covers almost the entire population and comes close to absolute universality. 
Technically, the old age pension of ATP is a guaranteed deferred annuity. The contribution is a fixed amount - as opposed to a percentage of income - varied only against the number of hours worked. A full-time employee will pay DKK 3240 in 2014. Contributions are split, with two-thirds paid by the employer and one-third by the worker. The contribution schedule (the sum of employer and employee contribution) against hours worked is shown in the following table (for monthly paid workers). In order to compensate recipients of unemployment insurance benefits and sickness insurance benefits, for the loss of occupational pension contributions suffered during their absence from the labour market, doubled contributions are paid into the ATP pension scheme:

\begin{tabular}{lccc}
\hline Monthly hours & $<39$ & $39-77$ & $78-116$ \\
Contribution, DKK/month as from 2009 & 0 & 90 & 180
\end{tabular}

The contribution is adjusted if and when the social partners decide to do so as part of collective agreements. Over the past 20 years the contribution has been increased in steps more or less in line with average earnings. The latest adjustment came in 2009, and increased the contribution by approximately $10 \%$. A further increase of $5 \%$ will take effect by 2016 . The modelling assumes that the contribution will increase in line with average earnings.

Pension rights with ATP are accrued on a what-you-pay-is-what-you-get basis. In principle each generation finance their own rights and ATP is devoid of intergenerational transfers. Pension rights are guaranteed nominal lifelong rights paid from the statutory age of retirement. $80 \%$ of the contribution paid is used to purchase new individual pension rights with ATP based on a discount rate matching the long term interest hedgeable in the market place at the time of inception. Hence, the discount rate applied to new accruals will vary from year to year. The remaining $20 \%$ of the contribution is transferred to ATP's free reserves serving as an investment buffer and financing source for indexations and unexpected longevity increases.

The ATP scheme increases pensions in payment and pension rights alike if its' financial condition allows. This is done in the form of bonus allowances. Increases are guaranteed in line with earned rights.

The modelling assumes full indexation to price inflation.

\section{Occupational pensions}

The occupational pension schemes are fully funded defined-contribution schemes agreed between the social partners through collective agreements. Some $90 \%$ of the employed workforce is covered by such schemes and over time some $85-90 \%$ of the population will accrue rights - greater or smaller - with such schemes. The coverage ratio has increased from some $35 \%$ in the mid-1980s to the current level of around $90 \%$ due to the formation of new schemes covering blue collar workers. All public sector workers are enrolled in a collectively agreed fully funded defined contribution scheme, whereas around $75 \%$ of private sector workers are enrolled. Self-employed workers are not covered by such schemes. Contribution rates are set by the collective agreement and will be similar for all workers under the agreement. Contribution rates range between $12 \%$ and $18 \%$-generally low rates apply to low income and low education groups, while higher rates apply to higher income and higher education groups. Due to the flat rate nature of the basic pension and due to the fact that high education workers tend to enter the labour market later than low education workers do, a higher contribution rate is needed in order to obtain a reasonable replacement rate.

Since 2009, the percentage for the majority of Danish low income workers was raised to $12 \%$. The contribution rate used for the modelling is $12 \%$. 
Typically, occupational pension schemes will cover a variety of social risks and provide a range of benefits - disability, survivors' benefits, old-age benefits and critical illness benefits. While old-age benefits are fully funded insurance benefits, other benefits are insurance benefits financed from the current contribution. Typically schemes will spend $20-25 \%$ of the current contribution on other social risk coverage.

Occupational pension schemes are DC based insurance schemes. Pension rights are accrued on a what-you-pay-is-what-you-get basis. In principle each generation finance its' own rights and schemes are devoid of any intra- or intergenerational transfers other than those attributed to the insurance coverage.

Benefits are usually withdrawn as a lifelong annuity. Schemes may allow some choice for members to design their pay-out phase e.g. in order to front load the benefit payments. Some schemes offer the option of allocating some of the contribution into a lump sum savings policy.

The maximum allowed assumed interest rate when issuing guarantees is $1.5 \%$ for recent contributions or new schemes. However, the schemes operate on a "with-profit" basis, with pension increases depending on the return on assets and mortality experience of the fund. Since 2000, the annuity calculation must use unisex mortality tables and since 2010 insurers must comply with a mortality table benchmark issued by the FSA taking account of future longevity increases.

There are no vesting or portability issues related to Danish occupational pensions.

\section{Variant careers}

Spells of unemployment, maternities, periods with part time employment and other elements of variant careers will affect the accrual of private pensions and therefore the aggregate pension. However, the composition of the overall pension system moderates such effects quite significantly. Firstly, the public pension fraction is substantial for most workers meaning that variant career effects will only affect part of the overall pension. Secondly, the partial income test of the basic pension will further moderate adverse effects.

Other steps have been taken in order to address adverse pension effects stemming from variant labour careers.

\section{Late retirement}

It is possible to defer the public old age pension for up to ten years. The increment for deferring the pension for a year is the ratio of the period of deferral to average life expectancy at the time the pension is drawn. For example, if population projections show life expectancy for a 68 year old to be 17.1 years, the increment for deferring for a year from age 67 would be $1 / 17.1=5.8 \%$.

\section{Childcare}

For periods on maternity/paternity/parental benefits, double the amount of contributions is paid for ATP. The beneficiary will pay one-third of the contribution, with two-thirds being paid by the government/municipality. Maternity/paternity/parental benefits can be paid for up to 52 weeks in total. The four weeks prior to the birth and the first 14 weeks after the birth are reserved for the mother. The father is entitled to two weeks of leave during the first 14 weeks after the birth (paternity leave). The last 32 weeks can be divided or shared between the father and the mother (parental leave). Those out of the labour market caring for children beyond the maternity period typically switch to another scheme which also carries an ATP contribution. It is common for young parents to resume work when the leave period ends unless the child is e.g. ill or disabled in which cases there normally will be possibilities for drawing on some sort of public benefit with contribution to ATP. There are no credits or contributions for occupational pension schemes for periods out of paid work caring for children. 


\section{Unemployment}

During unemployment, the unemployment insurance (or municipality if not insured) take over the payment obligation of the employer, and ATP contributions are paid at the double rate when receiving benefit from the unemployment insurance (normal rate if social assistance benefit). The government pays two-thirds of the payment when unemployment insurance is exhausted and the individual is on unemployment/social assistance. There are no credits or contributions for occupational pension schemes for periods of unemployment.

There is also a voluntary early retirement programme linked with unemployment insurance, which pays benefits between age 60 (gradually increasing to age 62 between 2014 and 2017) and the normal pension age. To qualify, individuals must have been members of the unemployment insurance fund for at least 30 years and have paid voluntary early-retirement contributions during this period. They must also satisfy the conditions for entitlement to unemployment benefits in the event of unemployment at the time of transition to the voluntary early-retirement scheme. The benefit amount corresponds to the rate of unemployment benefits, subject to a limit of $91 \%$ of the maximum rate of unemployment benefit, equivalent to DKK 3710 per week for full-time workers and DKK 2470 for part-time workers in 2014. It is not possible to combine receipt of voluntary early-retirement benefits with the social pension.

People who defer the take up of voluntary early-retirement benefits for at least two years after they have become entitled to the benefit and are still working receive a higher rate of voluntary early-retirement benefit that is equivalent to the maximum rate of unemployment benefit (or DKK 4075 per week for full-time workers and DKK 2715 for part time workers in 2014). For three years' full-time work when an individual qualifies for voluntary early-retirement, a one-off tax-free lump-sum is paid up to a maximum of $72 \%$ of the yearly amount of maximum unemployment benefit. 


\section{Pension modelling results: Denmark in 2061, retirement at age 67}
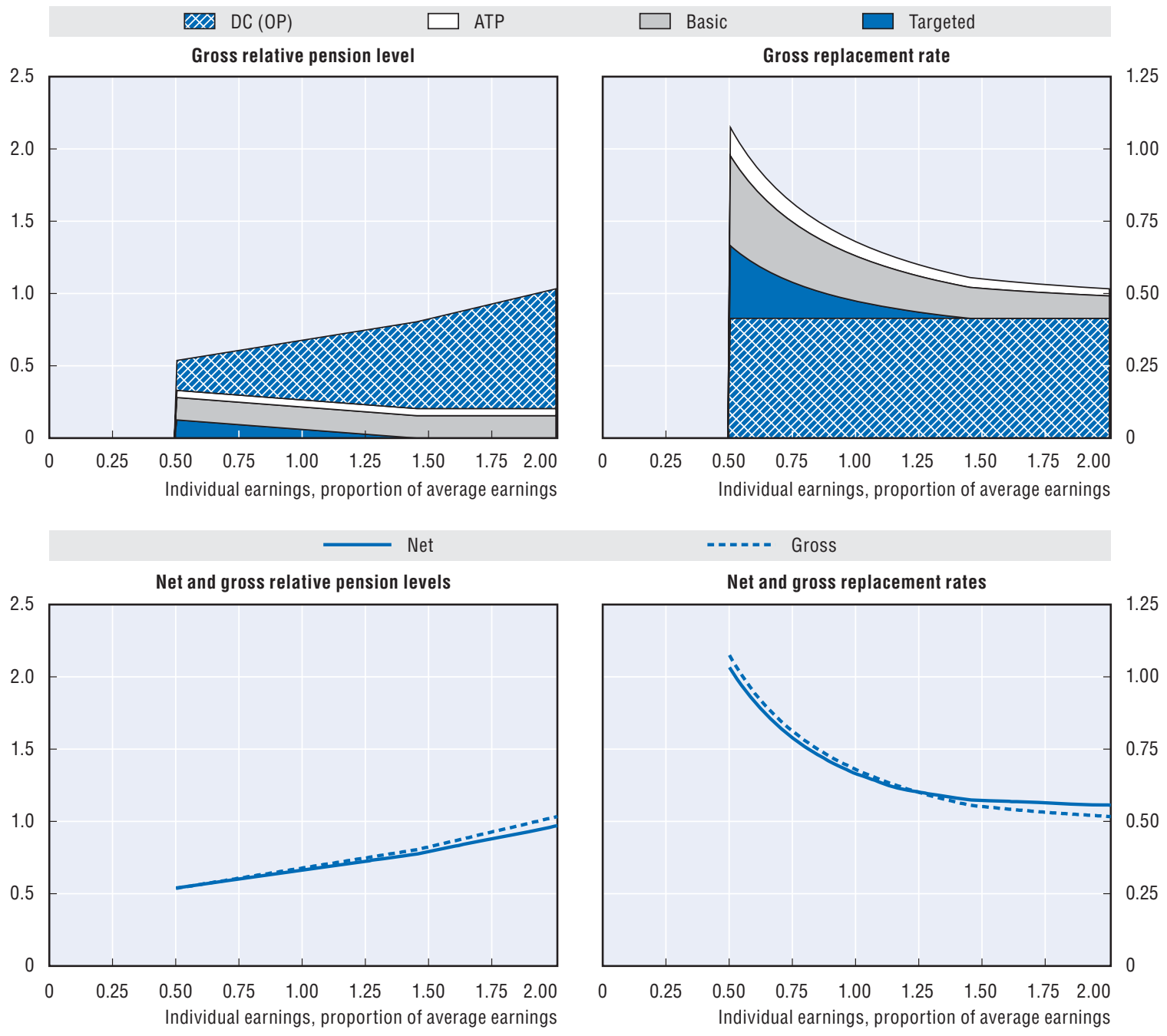

\begin{tabular}{|c|c|c|c|c|c|c|}
\hline \multicolumn{7}{|c|}{ Baseline scenario: Legislation scenario (wages $-0.3 \%$ indexation of basic and targeted schemes) } \\
\hline \multirow{2}{*}{$\begin{array}{l}\text { Men } \\
\text { Women (where different) }\end{array}$} & \multicolumn{6}{|c|}{ Individual earnings, multiple of average } \\
\hline & 0.5 & 0.75 & 1 & 1.5 & 2 & 3 \\
\hline Gross relative pension level & 53.7 & 60.8 & 67.8 & 82.6 & 103.3 & 144.7 \\
\hline \multicolumn{7}{|l|}{ (\% average gross earnings) } \\
\hline Net relative pension level & 54.0 & 60.2 & 66.4 & 79.3 & 96.9 & 123.9 \\
\hline \multicolumn{7}{|l|}{ (\% net average earnings) } \\
\hline Gross replacement rate & 107.4 & 81.0 & 67.8 & 55.1 & 51.6 & 48.2 \\
\hline \multicolumn{7}{|l|}{ (\% individual gross earnings) } \\
\hline Net replacement rate & 103.2 & 78.7 & 66.4 & 57.2 & 55.6 & 50.4 \\
\hline \multicolumn{7}{|l|}{ (\% individual net earnings) } \\
\hline Gross pension wealth & 18.3 & 13.6 & 11.3 & 9.1 & 8.5 & 7.9 \\
\hline (multiple of individual gross earnings) & 20.4 & 15.2 & 12.6 & 10.1 & 9.4 & 8.8 \\
\hline Net pension wealth & 11.4 & 8.4 & 6.9 & 5.4 & 4.9 & 4.2 \\
\hline (multiple of individual gross earnings) & 12.8 & 9.4 & 7.7 & 6.0 & 5.5 & 4.7 \\
\hline
\end{tabular}

Assumptions: Real rate of return 3\%, real earnings growth $1.25 \%$, inflation $2 \%$, and real discount rate $2 \%$. All systems are modelled and indexed according to what is legislated. Transitional rules apply where relevant. DC conversion rate equal $85 \%$. Labour market entry occurs at age 20 in 2014. Tax system latest available: 2013. Assumed pension contribution rate of $12 \%$. 
Pension modelling results: Denmark in 2061, retirement at age 67 (cont.)

\begin{tabular}{|c|c|c|c|c|c|c|}
\hline \multicolumn{7}{|c|}{ Alternative scenario: Wage indexation of basic and targeted schemes } \\
\hline \multirow{2}{*}{$\begin{array}{l}\text { Men } \\
\text { Women (where different) }\end{array}$} & \multicolumn{6}{|c|}{ Individual earnings, multiple of average } \\
\hline & 0.5 & 0.75 & 1 & 1.5 & 2 & 3 \\
\hline Gross relative pension level & 59.2 & 66.2 & 73.2 & 87.3 & 105.6 & 147.0 \\
\hline \multicolumn{7}{|l|}{ (\% average gross earnings) } \\
\hline Net relative pension level & 58.8 & 64.9 & 71.1 & 83.5 & 99.0 & 125.4 \\
\hline \multicolumn{7}{|l|}{ (\% net average earnings) } \\
\hline Gross replacement rate & 118.3 & 88.3 & 73.2 & 58.2 & 52.8 & 49.0 \\
\hline \multicolumn{7}{|l|}{ (\% individual gross earnings) } \\
\hline Net replacement rate & 112.3 & 84.9 & 71.1 & 60.2 & 56.8 & 51.0 \\
\hline \multicolumn{7}{|l|}{ (\% individual net earnings) } \\
\hline Gross pension wealth & 20.2 & 14.9 & 12.3 & 9.6 & 8.7 & 8.0 \\
\hline (multiple of individual gross earnings) & 22.6 & 16.7 & 13.7 & 10.7 & 9.7 & 8.9 \\
\hline Net pension wealth & 12.5 & 9.1 & 7.4 & 5.7 & 5.1 & 4.2 \\
\hline (multiple of individual gross earnings) & 14.0 & 10.2 & 8.3 & 6.4 & 5.6 & 4.7 \\
\hline
\end{tabular}

Assumptions: Real rate of return 3\%, real earnings growth $1.25 \%$, inflation $2 \%$, and real discount rate $2 \%$. All systems are modelled and indexed according to what is legislated. Transitional rules apply where relevant. DC conversion rate equal $85 \%$. Labour market entry occurs at age 20 in 2014. Tax system latest available: 2013. Assumed pension contribution rate of $12 \%$.

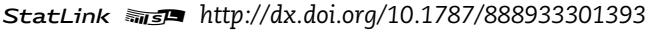




\section{Estonia}

\section{Estonia: Pension system in 2014}

The system combines an earnings-related public scheme with mandatory contributions to funded pensions. There is also a flat rate, basic element and a safety net, national pension.

\section{Key indicators: Estonia}

\begin{tabular}{llrr}
\hline & & Estonia & OECD \\
\hline \multirow{2}{*}{ Average worker earnings (AW) } & EUR & 12436 & 33036 \\
& USD & 15060 & 40007 \\
Public pension spending & \% of GDP & 6.9 & 7.9 \\
Life expectancy & At birth & 74.3 & 80.0 \\
\multirow{2}{*}{ Population over age 65 } & At age 65 & 16.8 & 19.3 \\
& \% of population & 18.4 & 16.2 \\
\hline
\end{tabular}

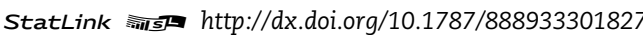

\section{Qualifying conditions}

The pension eligibility age is 63 year for men and will reach 63 years for women from 2016. After that, retirement age will increase gradually to 65 in 2026 for both men and women. The qualification period is at least 15 years of pensionable service.

\section{Benefit calculation}

\section{Basic}

The flat-rate base amount was EUR 134.91 per month in April 2014 and EUR 126.82 in 2013 and is only payable along with an earnings-related pension.

\section{Earnings-related}

Pension benefits are calculated on the amount of contributions paid on an individual's behalf relative to the average contribution paid. This is the annual pension-insurance coefficient of the person. The accumulation of those coefficients at retirement is multiplied by the value of a year of pensionable service to calculate pension entitlements. The value of a year of pensionable service was EUR 4.72 in July 2013 and EUR 4.96 in April 2014.

There is no ceiling to earnings for contribution or benefit purposes.

Pensions in payment are indexed to $20 \%$ consumer prices and $80 \%$ contribution revenues annually each April. This applies to the base amount, the value of a year of pensionable service in the earnings-related scheme and the value of the benefit under the targeted scheme.

\section{Targeted}

A minimum retirement-income guarantee is provided by the national pension. This was EUR 148.98 in April 2014.

National pension is granted to the following persons: Persons who have attained 63 years of age and who have not earned a pension qualifying period required for the grant of old-age pension and who have been permanent residents of Estonia or have resided in Estonia on the basis of a temporary residence permit or temporary right of residence for at least five years immediately before making a pension claim.

It is possible to also apply for a social assistance benefit, if the income is less than certain level. Benefit size depends on number of people in household, their income, housing costs, etc. It is granted by local governments. 


\section{Defined contribution}

Individuals choosing the funded option must make an additional contribution of $2 \%$ of earnings into their pension fund. Full contributions resumed from 2012 after paying only half in 2011 and nothing between June 2009 and 2011. Four per cent of the total social security contribution is then also diverted to this fund. New labour-market entrants (that is, those born in 1983 or after) are required to take the funded option. From 2011 only new entrants into the labour force can join the second pillar. Over 660000 people have taken out individual accounts.

Due to temporary suspension of second pillar contributions in 2009-11, about 280000 people will get higher contributions to second pillar (applications were voluntary) in 2014-17. Their state part of contributions will be increased from $4 \%$ to 6\%. In addition about 106000 people chose to increase individual contribution from $2 \%$ to $3 \%$.

\section{Variant careers}

\section{Early retirement}

The public pension can be claimed up to three years before the standard age (i.e. from age 62 in the long term) provided that the individual retires and if the condition of a 15-year qualification period is met. The pension is reduced by $4.8 \%$ for each year that an individual retires early.

\section{Late retirement}

The public pension can be deferred after the normal pension age. Deferring pension earns an increment of $10.8 \%$ per year. During the deferral period, the worker continues to contribute and earn extra entitlement. It is also possible to combine work and pension receipt. In this case, contributions are again paid and the pension is recalculated annually.

\section{Childcare}

The state pays the employer contribution on behalf of recipients of childcare allowance up to three years per child. This is 20\% on assumed earnings of minimum wage (EUR 355 in 2014).

From 2013 the system was improved. One parent will get monthly contributions equal to $4 \%$ of national average wage into the earnings related pension scheme for a maximum duration of three years per child for children born after 2013. In addition parents will get up to three pensionable service years per child for children born before 2013. This rule depends on the exact date of birth, since some parents already have extra pensionable service year per child due to old rules.

\section{Unemployment}

There are no credits for periods of unemployment. 


\section{Pension modelling results: Estonia in 2059, retirement at age 65}

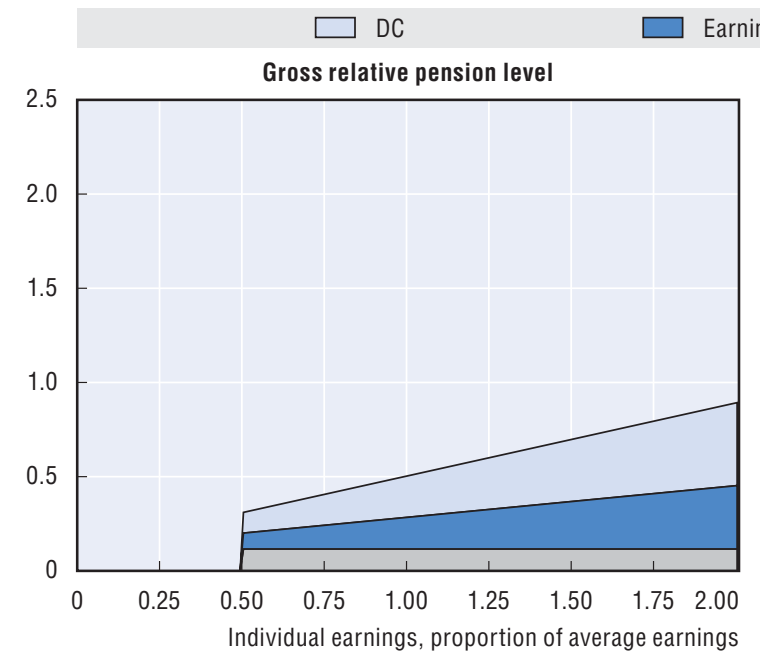

Earnings-related

Basic
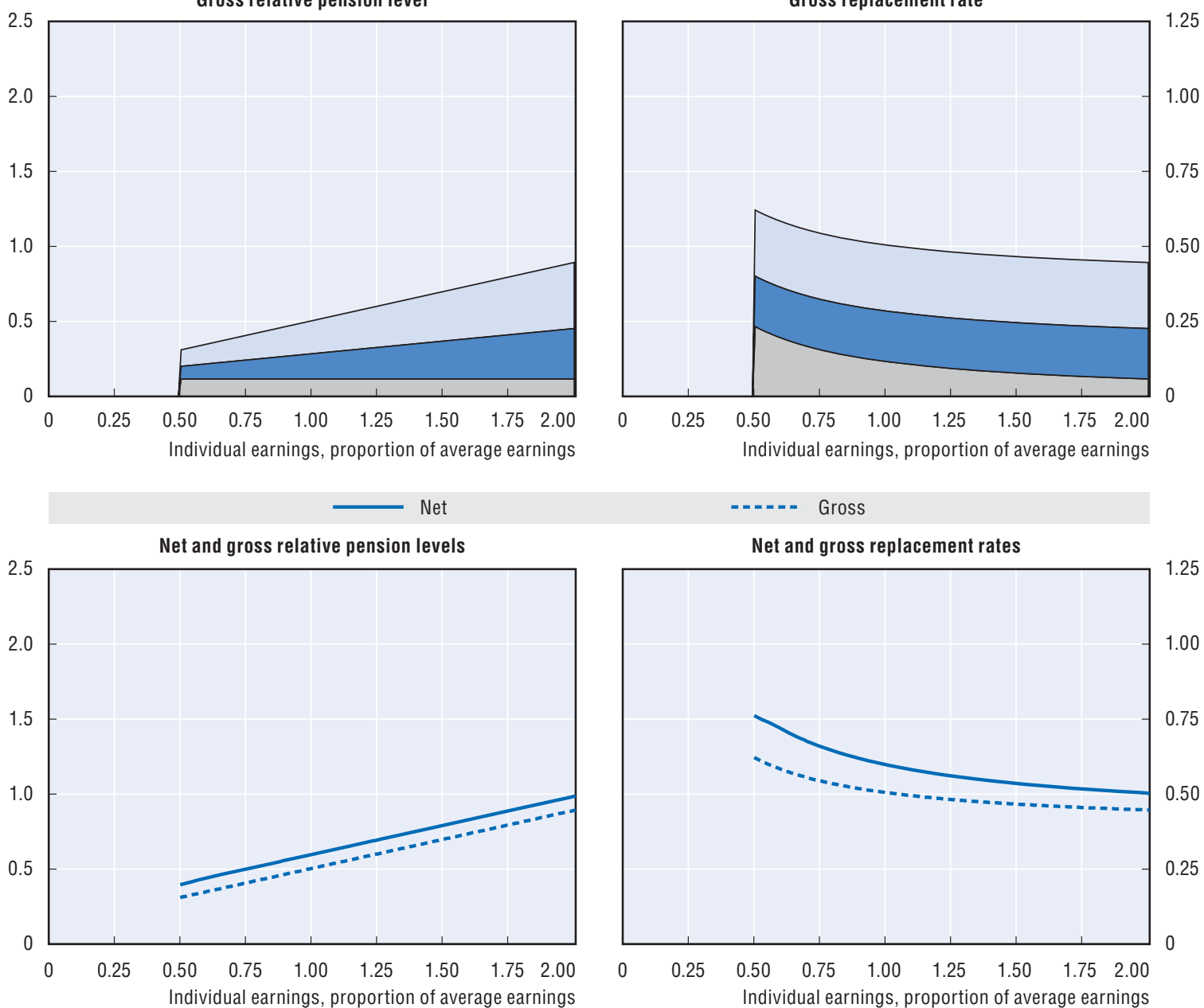

----- Gross

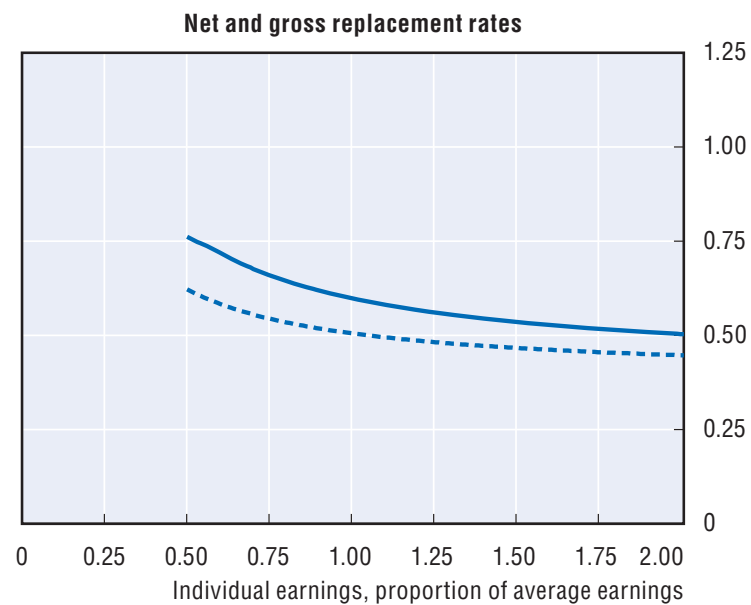

Baseline scenario: Legislation scenario (mixed-indexation of targeted schemes)

\begin{tabular}{|c|c|c|c|c|c|c|}
\hline \multirow{2}{*}{$\begin{array}{l}\text { Men } \\
\text { Women (where different) }\end{array}$} & \multicolumn{6}{|c|}{ Individual earnings, multiple of average } \\
\hline & 0.5 & 0.75 & 1 & 1.5 & 2 & 3 \\
\hline Gross relative pension level & 31.1 & 40.8 & 50.5 & 69.9 & 89.3 & 128.2 \\
\hline \multicolumn{7}{|l|}{ (\% average gross earnings) } \\
\hline Net relative pension level & 39.4 & 50.0 & 59.8 & 79.2 & 98.7 & 137.7 \\
\hline \multicolumn{7}{|l|}{ (\% net average earnings) } \\
\hline Gross replacement rate & 62.1 & 54.4 & 50.5 & 46.6 & 44.7 & 42.7 \\
\hline \multicolumn{7}{|l|}{ (\% individual gross earnings) } \\
\hline Net replacement rate & 76.1 & 65.9 & 59.8 & 53.5 & 50.3 & 47.1 \\
\hline \multicolumn{7}{|l|}{ (\% individual net earnings) } \\
\hline Gross pension wealth & 8.9 & 7.8 & 7.2 & 6.7 & 6.4 & 6.1 \\
\hline (multiple of individual gross earnings) & 11.0 & 9.6 & 8.9 & 8.3 & 7.9 & 7.6 \\
\hline Net pension wealth & 8.9 & 7.5 & 6.7 & 6.0 & 5.6 & 5.2 \\
\hline (multiple of individual gross earnings) & 11.0 & 9.3 & 8.3 & 7.4 & 6.9 & 6.4 \\
\hline
\end{tabular}

Assumptions: Real rate of return $3 \%$, real earnings growth $1.25 \%$, inflation $2 \%$, and real discount rate $2 \%$. All systems are modelled and indexed according to what is legislated. Transitional rules apply where relevant. DC conversion rate equal $85 \%$. Labour market entry occurs at age 20 in 2014. Tax system latest available: 2013. 
Pension modelling results: Estonia in 2059, retirement at age 65 (cont.)

\begin{tabular}{|c|c|c|c|c|c|c|}
\hline \multicolumn{7}{|c|}{ Alternative scenario: Full-wage indexation of targeted schemes } \\
\hline \multirow{2}{*}{$\begin{array}{l}\text { Men } \\
\text { Women (where different) }\end{array}$} & \multicolumn{6}{|c|}{ Individual earnings, multiple of average } \\
\hline & 0.5 & 0.75 & 1 & 1.5 & 2 & 3 \\
\hline Gross relative pension level & 32.5 & 42.2 & 51.9 & 71.4 & 90.8 & 129.7 \\
\hline \multicolumn{7}{|l|}{ (\% average gross earnings) } \\
\hline Net relative pension level & 41.2 & 51.7 & 61.4 & 80.9 & 100.4 & 139.4 \\
\hline \multicolumn{7}{|l|}{ (\% net average earnings) } \\
\hline Gross replacement rate & 65.0 & 56.3 & 51.9 & 47.6 & 45.4 & 43.3 \\
\hline \multicolumn{7}{|l|}{ (\% individual gross earnings) } \\
\hline Net replacement rate & 79.4 & 68.1 & 61.4 & 54.6 & 51.2 & 47.7 \\
\hline \multicolumn{7}{|l|}{ (\% individual net earnings) } \\
\hline Gross pension wealth & 9.3 & 8.1 & 7.4 & 6.8 & 6.5 & 6.2 \\
\hline (multiple of individual gross earnings) & 11.5 & 10.0 & 9.2 & 8.4 & 8.0 & 7.7 \\
\hline Net pension wealth & 9.3 & 7.8 & 6.9 & 6.1 & 5.7 & 5.2 \\
\hline (multiple of individual gross earnings) & 11.5 & 9.6 & 8.6 & 7.5 & 7.0 & 6.5 \\
\hline
\end{tabular}

Assumptions: Real rate of return 3\%, real earnings growth $1.25 \%$, inflation $2 \%$, and real discount rate $2 \%$. All systems are modelled and indexed according to what is legislated except for the safety nets which follow real-wages. Transitional rules apply where relevant. DC conversion rate equal 85\%. Labour market entry occurs at age 20 in 2014. Tax system latest available: 2013.

StatLink +inisl http://dx.doi.org/10.1787/888933301400 


\section{Finland}

\section{Finland: Pension system in 2014}

There is a targeted basic state pension (national pension and guarantee pension) which is pension income-tested, and a range of statutory earnings-related schemes, with very similar rules for different groups. Some of the schemes for private-sector employees are partially pre-funded while the publicsector schemes are pay-as-you-go financed (with buffer funds to even out future increases in pension contributions). Prefunding has no direct impact on the benefit level. In 2014 an agreement was reached on a substantial pension reform for 2017.
Key indicators: Finland

\begin{tabular}{llrr}
\hline & & Finland & OECD \\
\hline Average worker earnings (AW) & EUR & 42910 & 33036 \\
& USD & 51965 & 40007 \\
Public pension spending & \% of GDP & 10.3 & 7.9 \\
Life expectancy & At birth & 80.5 & 80.0 \\
\multirow{2}{*}{ Population over age 65 } & At age 65 & 19.8 & 19.3 \\
& \% of population & 20.4 & 16.2 \\
\hline
\end{tabular}

StatLink inlsts http://dx.doi.org/10.1787/888933301830

\section{Qualifying conditions}

The national pension is subject to a residency test (but no contribution requirements), withdrawn against pension income from the earnings-related schemes. The national old-age pension is payable from age 65 . The full old-age national pension benefit is payable with 40 years residence as an adult, with pro rata adjustments for shorter periods of residence. It is possible to retire to early old-age national pension between ages of 63 and 65. For those born before 1952 the earliest eligibility age to early old-age pension is 62 .

There are no waiting periods or euro limits to obtain a right to an earnings-related pension, even though there are minimum earning levels for pension insurance. Pension accrues, from age 18 to 68 , on the basis of every earned euro of the insured person. Old-age pension is payable from age 63 with an early old-age pension available at age 62 for those born before 1952 .

\section{Benefit calculation}

\section{Earnings-related}

Among different earnings-related schemes, the scheme for private sector employees (TyEL) is covered here. This scheme covers over $50 \%$ of employed people in Finland. The rules of other earnings-related pension schemes are very similar to TyEL.

From 2005 , the accrual rate is $1.5 \%$ of pensionable earnings at ages $18-52,1.9 \%$ at ages $53-62$ and $4.5 \%$ at ages $63-67$.

Pensionable earnings are, from 2005, based on average earnings of the whole career. However, as pension accrues differently in different age groups (see above), the earnings received by older workers have more weight in the total pension. When the pensionable earnings are calculated the amount corresponding to employee's pension contribution is deducted from the earnings. In 2014 the employee's pension contribution was $5.55 \%$ for employees under 53 years old and $7.05 \%$ for employees 53 years old or older. Note, however, that the replacement rates are shown relative to total average lifetime revalued gross earnings (for comparison with other countries) rather than this measure of pensionable earnings. 
Earlier years' earnings are re-valued in line with a mix of economy-wide earnings and prices. Wage growth has an $80 \%$ weight and price inflation, $20 \%$. After retirement, the earnings-related pension is uprated using a formula of $20 \%$ of earnings inflation and $80 \%$ of price inflation.

Since 2010 the level of new earnings-related pensions has been adjusted to take into account the changes in life expectancy after 2009. This is done by a mechanism called the life expectancy coefficient, which aims to stabilise the actuarial present value of new pensions, in a manner similar to notional defined contribution systems. The calculation of this coefficient uses unisex mortality statistics from the past five years and assumes a yearly discount rate of $2 \%$. By 2059, the Statistics Finland mortality projections imply an increase in life expectancy at age 63 to 27.8 years in comparison to 20.9 years in 2009. The life expectancy coefficient is projected to reduce benefits to $79.2 \%$ of their value under the pre-reform rules in 2060 . The life expectancy coefficient is calculated for each cohort at the age of 62 .

There is no contribution floor or ceiling to contributions or pensionable earnings. However, there are minimum earnings limits for pension insurance. Voluntary contributions are also possible for earnings below these limits.

The Finnish Centre for Pensions co-ordinates the schemes, resulting in a single pension payment even for people who have been members of different earnings-related pension schemes.

\section{Basic (national pension)}

The full basic monthly benefit for a single pensioner in 2014 was EUR 633.91. The national pension is reduced by $50 \%$ of the difference between other pension income and a small disregard which in 2014 was EUR 55.95 per month. No pension is payable once other pension income from Finland and other countries exceeds EUR 1310.30 or EUR 1166.96 per month.

\section{Targeted (guarantee pension)}

Since 2011 there is also a guarantee pension. The benefit guarantees a minimum pension level of EUR 743.38 per month to pensioners should the national and earnings-related pension together remain under the mentioned level. The earnings-related (employment) pension accrued after the age of 63 is disregarded when national pension entitlement is calculated.

The national and guarantee pension benefits, the parameters of the income test and pension payable are up-rated annually in line with prices.

\section{Variant careers}

If a person has time in his/her career when there is no work income, pension also accrues according to certain unpaid periods. If a benefit is based on previous salary, this salary is also used to calculate the pension accrual up to a certain percentage (this percentage varies according to the benefit). For child home-care allowance and periods of study a certain fixed salary base is used.

\section{Early retirement}

Early national old-age pension is available from the beginning of the month following one's 63rd birthday (62 for those born before 1952). Its amount is permanently reduced (in comparison with the ordinary old-age pension) by $0.4 \%$ for each month the pension is to be paid before the normal pensionable age of 65 years. The pension will not rise to its regular level when the recipient reaches the age of 65 .

Early retirement is possible at age 62 under the earnings-related scheme only for persons born before 1952, subject to a $0.6 \%$ benefit reduction per month of early retirement until the age of 63 . After the age of 63 there is no reduction in pension. However, there is more rapid accrual of earnings-related benefits after this age (see above). 


\section{Late retirement}

The national pension can be deferred after the age of 65 and the pension is then increased by $0.6 \%$ for each month by which retirement is postponed.

The increment for late retirement is $0.4 \%$ for each month ( $4.8 \%$ per year) in the earnings-related scheme after age 68. There is no adjustment between ages 63 and 68 because of the accelerated accrual of pension at those ages.

It is possible to combine receipt of pension and earnings from work. After taking the old-age pension, earnings accrue additional pension and the accrual rate is $1.5 \%$ per year until the age of 68 .

\section{Childcare}

From 2005 onwards, during periods of maternity, paternity and parent's allowance, the pension accrues based on 1.17 times the salary, on which the family benefit is based. The maximum paid parental leave period is 11 months.

For unpaid periods of childcare by either parent during which child home-care allowance is claimed, pensions accrue as if the person received a salary of EUR 706.87 per month in 2014, which is around a fifth of average earnings. This is the case until the child reaches the age of three.

People on parental leave are not liable for pension contributions. The pension accruing for paid parental leave is paid by the earnings-related pension system. The state finances the pension for periods of unpaid childcare leave.

The part of the pension that is based on unpaid periods of child care (and studies) is not included in the income test of the national pension.

\section{Unemployment}

Following the 2005 reform, earnings-related unemployment benefits accrue pension rights based on the proportion of the salary $(75 \%)$ on which the benefit is based. Only unemployment benefit received before the age of 63 generate a pension credit.

Unemployment-insurance benefits are paid for 500 days (around 23 months, with average 21.5 days per month). If an unemployed person reaches age 59 before the 500 days have accrued (age 60 for persons born in 1955 or after), earnings-related unemployment can be paid until age 65. Individuals receiving allowance after 500 days are entitled to choose claiming old-age pension from age 63 (62 possible for persons born before 1958, in which case there is no reduction for early retirement) and earnings-related unemployment benefits cease. After the period with earnings-related unemployment benefits, flat-rate or income-tested (under various conditions) unemployment assistance could be claimed but the period under these benefits are not credited for the pension entitlement. 


\section{Pension modelling results: Finland in 2059, retirement at age 65}

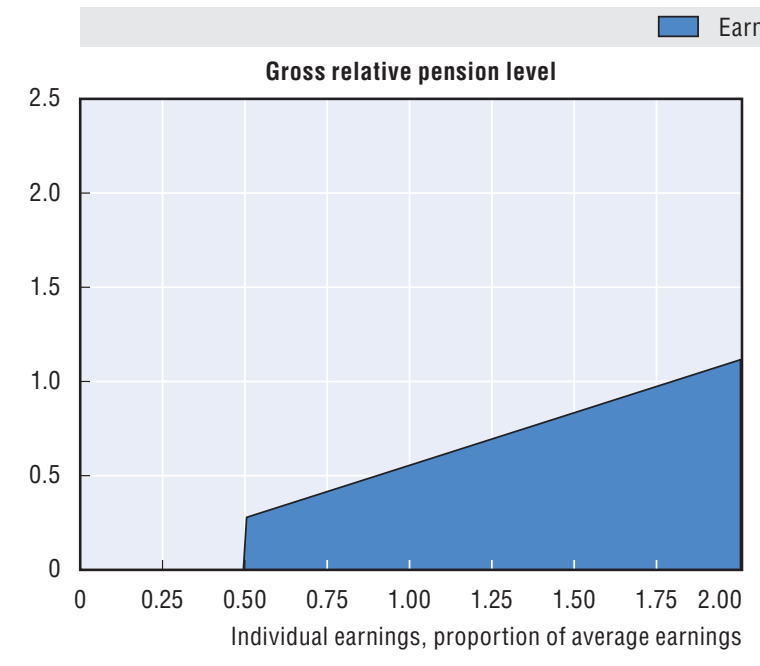

Earnings-related
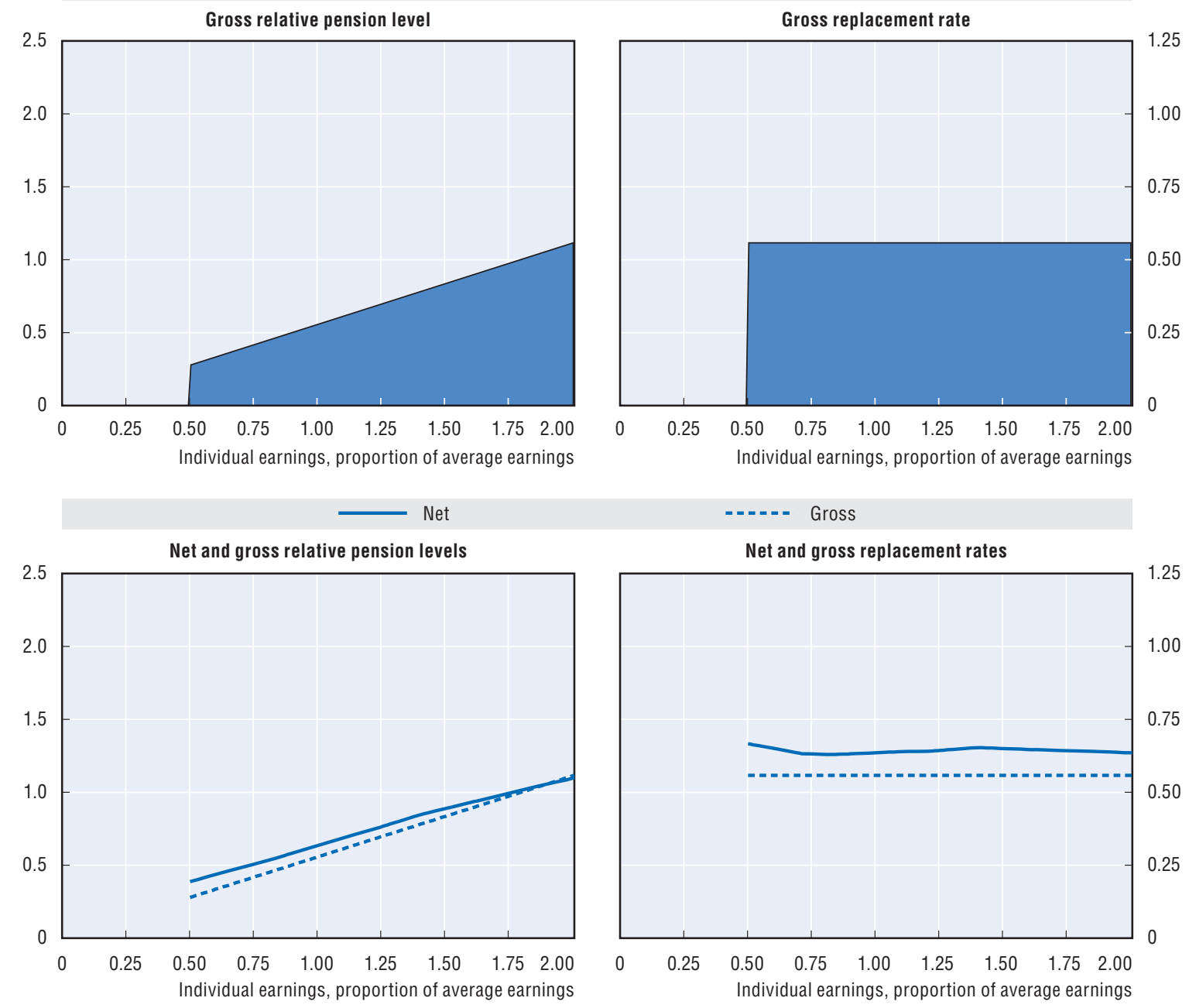

\begin{tabular}{|c|c|c|c|c|c|c|}
\hline \multicolumn{7}{|c|}{ Baseline scenario: Legislation scenario (price indexation of safety-nets schemes) } \\
\hline \multirow{2}{*}{$\begin{array}{l}\text { Men } \\
\text { Women (where different) }\end{array}$} & \multicolumn{6}{|c|}{ Individual earnings, multiple of average } \\
\hline & 0.5 & 0.75 & 1 & 1.5 & 2 & 3 \\
\hline Gross relative pension level & 27.9 & 41.8 & 55.8 & 83.7 & 111.6 & 167.4 \\
\hline \multicolumn{7}{|l|}{ (\% average gross earnings) } \\
\hline Net relative pension level & 38.8 & 50.7 & 63.5 & 88.9 & 109.9 & 155.2 \\
\hline \multicolumn{7}{|l|}{ (\% net average earnings) } \\
\hline Gross replacement rate & 55.8 & 55.8 & 55.8 & 55.8 & 55.8 & 55.8 \\
\hline \multicolumn{7}{|l|}{ (\% individual gross earnings) } \\
\hline Net replacement rate & 66.6 & 63.1 & 63.5 & 65.0 & 63.5 & 65.9 \\
\hline \multicolumn{7}{|l|}{ (\% individual net earnings) } \\
\hline Gross pension wealth & 9.8 & 9.8 & 9.8 & 9.8 & 9.8 & 9.8 \\
\hline (multiple of individual gross earnings) & 11.7 & 11.7 & 11.7 & 11.7 & 11.7 & 11.7 \\
\hline Net pension wealth & 9.7 & 8.4 & 7.9 & 7.4 & 6.8 & 6.5 \\
\hline (multiple of individual gross earnings) & 11.5 & 10.0 & 9.4 & 8.8 & 8.1 & 7.7 \\
\hline
\end{tabular}

Assumptions: Real rate of return $3 \%$, real earnings growth $1.25 \%$, inflation $2 \%$, and real discount rate $2 \%$. All systems are modelled and indexed according to what is legislated. Transitional rules apply where relevant. DC conversion rate equal $85 \%$. Labour market entry occurs at age 20 in 2014. Tax system latest available: 2013. 
Pension modelling results: Finland in 2059, retirement at age 65 (cont.)

\begin{tabular}{|c|c|c|c|c|c|c|}
\hline \multicolumn{7}{|c|}{ Alternative scenario: Full-wage indexation of targeted schemes } \\
\hline \multirow{2}{*}{$\begin{array}{l}\text { Men } \\
\text { Women (where different) }\end{array}$} & \multicolumn{6}{|c|}{ Individual earnings, multiple of average } \\
\hline & 0.5 & 0.75 & 1 & 1.5 & 2 & 3 \\
\hline Gross relative pension level & 35.2 & 42.1 & 55.8 & 83.7 & 111.6 & 167.4 \\
\hline \multicolumn{7}{|l|}{ (\% average gross earnings) } \\
\hline Net relative pension level & 77.2 & 63.4 & 63.5 & 65.0 & 63.5 & 65.9 \\
\hline \multicolumn{7}{|l|}{ (\% net average earnings) } \\
\hline Gross replacement rate & 70.3 & 56.2 & 55.8 & 55.8 & 55.8 & 55.8 \\
\hline \multicolumn{7}{|l|}{ (\% individual gross earnings) } \\
\hline Net replacement rate & 77.2 & 63.4 & 63.5 & 65.0 & 63.5 & 65.9 \\
\hline \multicolumn{7}{|l|}{ (\% individual net earnings) } \\
\hline Gross pension wealth & 12.3 & 9.9 & 9.8 & 9.8 & 9.8 & 9.8 \\
\hline (multiple of individual gross earnings) & 14.6 & 11.7 & 11.7 & 11.7 & 11.7 & 11.7 \\
\hline Net pension wealth & 11.2 & 8.5 & 7.9 & 7.4 & 6.8 & 6.5 \\
\hline (multiple of individual gross earnings) & 13.3 & 10.1 & 9.4 & 8.8 & 8.1 & 7.7 \\
\hline
\end{tabular}

Assumptions: Real rate of return $3 \%$, real earnings growth $1.25 \%$, inflation $2 \%$, and real discount rate $2 \%$. All systems are modelled and indexed according to what is legislated except for the safety-nets which follow real-wages. Transitional rules apply where relevant. DC conversion rate equal 85\%. Labour market entry occurs at age 20 in 2014. Tax system latest available: 2013.

StatLink iㅔs http://dx.doi.org/10.1787/888933301411 


\section{France}

\section{France: Pension system in 2014}

In the private sector, the pension system has two public mandatory tiers: a defined benefit pension and occupational schemes based on a points system. The definedbenefit scheme also has a means-tested minimum contributory pension (minimum contributif). In addition there is a targeted minimum income for the elderly (APSA).
Key indicators: France

\begin{tabular}{llrr}
\hline & & France & OECD \\
\hline Average worker earnings (AW) & EUR & 37427 & 33036 \\
& USD & 45325 & 40007 \\
Public pension spending & $\%$ of GDP & 13.8 & 7.9 \\
Life expectancy & At birth & 81.7 & 80.0 \\
& At age 65 & 21.0 & 19.3 \\
Population over age 65 & \% of population & 18.7 & 16.2 \\
\hline
\end{tabular}

StatLink त्ञात http://dx.doi.org/10.1787/888933301843

\section{Qualifying conditions}

A full-rate public pension requires to fulfil either both a minimum contributory record (41.25 years in 2014 for people born in 1953) and the minimum legal pension age (61 years and two months) or the age of 66 years and two months. According to the 2014 reform, the minimum contributory period is set to gradually increase from 165 quarters in 2014 to 172 in 2035.

The 2010 reform plans a gradual increase of the minimum pension age from age 60 to age 62 by 2017, depending on the birth year, and of the age of the full-rate pension from 65 to 67 , between 2016 and 2022.

The minimum contributory pension (minimum contributif) compensates the pension's level when the retiree reaches the legal conditions of the full-rate pension.

As the model assumes labour market entry at age 20 the long-term retirement age is 63 with 172 quarters of contribution.

\section{Benefit calculation}

\section{Earnings-related}

The main public pension scheme (regime général) has a payment rate of $50 \%$ after a full career (which length is increasing as described above). For each missing quarter, the pension is reduced by two means:

- The pension amount is reduced pro rata of the missing contributory period.

- In addition, the pension amount is reduced by $1.25 \%$ per missing quarter (or by $5 \%$ for each missing year) if the individual decides to retire before the full-rate pension age (but still after the minimum pension age); these rates ("décote") concern people born from 1953 up to the limit of $25 \%$.

The earnings reference is the average of the 25 best years, with past earnings valorised in line with price inflation.

Because of the threshold in the number of years included in the earnings measure for calculating pension benefits and the policy of valorisation in line with prices, the replacement rate in the French public system is sensitive to the time profile of earnings throughout the worker's career. There is a ceiling on eligible earnings, which/was EUR 37548 in 2014. Benefits in payment are indexed to prices. 


\section{Contributory minimum pension ("minimum contributif")}

There is an untargeted minimum pension in the "régime général" and in related schemes - regardless of the amount of pension received from other basic or supplementary schemes. To be eligible for this benefit, 41.25 years of contributions (for people born in 1953), or being aged 66 years and two months and over (planned to be extended to 67 from 2022) are needed. The minimum pension is pro-rated for shorter periods. In 2014, the annual amount was EUR 7 547.96. This amount is increased to EUR 8247.85 when the pensioner has contributed at least 120 quarters. The value of the minimum pension is indexed to prices.

\section{Mandatory occupational}

The ARRCO scheme covers private and agricultural sector employees ("non-cadres" and "cadres"). In addition, different rules apply to "cadres" (those in professional or managerial positions) under the AGIRC programme; the following regulations apply to "non-cadres".

Benefits are earned with a $6.2 \%$ contribution under the ceiling of the main public scheme ("régime général") and $16.2 \%$ between one and three times this ceiling. Thus, the ARRCO ceiling is three times that of the public pension scheme: EUR 112644 (the ceiling for the AGIRC scheme for cadres is eight times that of the main public pension scheme).

Each year, the number of points earned is the value of contributions divided by the cost of a pension point. At retirement, the accumulated number of points is converted into a pension benefit by multiplying them by the value of a pension point. The pension-point value was EUR 1.2513 from April 2013 to March 2015. The pension-point cost was EUR 15.2589 for calendar year 2014.

Uprating of the cost and value of pension points is agreed between the social partners. Since 2013, the agreement is to increase the cost of pension points in line with average earnings and the value of pension points in line with prices minus 1 p.p. The modelling assumes that this differential uprating (excluding the minus 1 p.p.) between the cost and value of a point will continue.

It is important to note that the uprating policy for these two parameters affects both the path of pensions in payment (here termed "indexation") and the change in value of pension entitlements between the time they were earned and the time they are withdrawn (akin to the process of "valorisation" in earnings-related schemes).

\section{Targeted minimum pension (Allocation de solidarité aux personnes âgées, APSA)}

There is a means-tested minimum income benefit for people reaching pension age worth EUR 9447.21 a year for a single person (EUR 14667.32 for a couple) from 1 April 2013 to 1 April 2014 (respectively EUR 9503.89 and EUR 14775.32 from 1 April 2014 to 1 October 2014, EUR 9600 and EUR 14904 since 1 October 2014). This benefit is adjusted in line with prices. Full-career workers will rarely be eligible for the old-age assistance programme, since the mandatory occupational pension supplements the main public pension benefit.

The elderly can benefit from housing benefits ("aides au logement"). The eligibility criteria depend on the level of income, the cost of housing, the number of dependants and the place of residence.

\section{Variant careers}

\section{Early retirement}

Early retirement, namely before the minimum legal retirement age, is allowed, from age 60, in the main public pension scheme, for people with full contributory periods who started their career before 20 . 
Under the occupational pension, early retirement is also possible, often subject to reductions related either to age of retirement or years of contributions or both. With less than the full contributory record, the pension is adjusted as shown in the table with the adjustment being that which is more favourable: that related to the retirement age or to the number of missing years. For retirement five years before the full pension retirement age, for example, the pension is reduced to $78 \%$ of the full value. However, if the individual retires missing only one year of contributions, the reduction is only to $96 \%$.

\begin{tabular}{lrrrr}
\hline Distance to full pension age, in years (increasing from 65 to 67) & 5 & 4 & 3 & 2 \\
Missing years to full contributory record & 5 & 4 & 3 & 1 \\
Coefficient & 0.78 & 0.83 & 0.88 & 0.92 \\
\hline
\end{tabular}

\section{Late retirement}

When people work after the minimum legal retirement age and have reached the qualifying contributory conditions for a full pension (which is 41 years and three months' coverage in 2014 for people born in 1953), each additional quarter increases the benefit under the public scheme by $1.25 \%$ ( $5 \%$ per year). For the period of deferred retirement, people continue to accumulate ARRCO points.

Work and pension receipt can be combined without limit when people have full rate pensions. If not, it is subject to some limits.

\section{Childcare}

For children born or adopted since 2010, a credit of four quarters is given to the mother for each of her children in the defined-benefit scheme, whether she continued to work or not during that time. Besides, another credit is given to one of the biologic parents for four years (a quarter per year of education). Both parents can receive a $10 \%$ increase in final pension pay-out in the defined-benefit plan if they have raised three or more children for at least nine years before age 16.

Periods out-of-work or working part time caring for a child are also credited in the public and occupational pension schemes (Assurance vieillesse des parents au foyer - AVPF). Credits are awarded as if the parent had earned the minimum wage. The three-year maximum applies to the first two children: credited periods are longer for subsequent children (qualifying conditions include entitlement to family benefits and earnings conditions). This credit can be cumulated with the two years credited per child in the public scheme.

\section{Unemployment}

Each period of involuntary unemployment is credited towards the state pension, in a limit of one year when people are under 55 years old (five years at 55 and more), when unemployment benefits are not received. When unemployment benefits are received each completed 50 days attributes one quarter of contributions, with a maximum of four quarters per year. These periods do not enter into the calculation of the average reference wage (salaire annuel moyen) based on the 25 best years of earnings and therefore not into the pension calculation.

There is also a credit for the first period of unemployment without unemployment payments to a maximum of one year (one year and a half for unemployment periods at the beginning of the working life). Subsequent periods of involuntary unemployment without unemployment payments are credited to a maximum of one year only if this follows a period of unemployment with unemployment benefits. 
In the mandatory occupational plans, periods of unemployment enable accumulation of pension points if the person had contributed to one of these plans before the beginning of unemployment. These points are calculated according to a "daily reference wage" (salaire journalier de référence) which is the last wage (on a year basis) divided by 365 . 


\section{Pension modelling results: France in 2057, retirement at age 63}
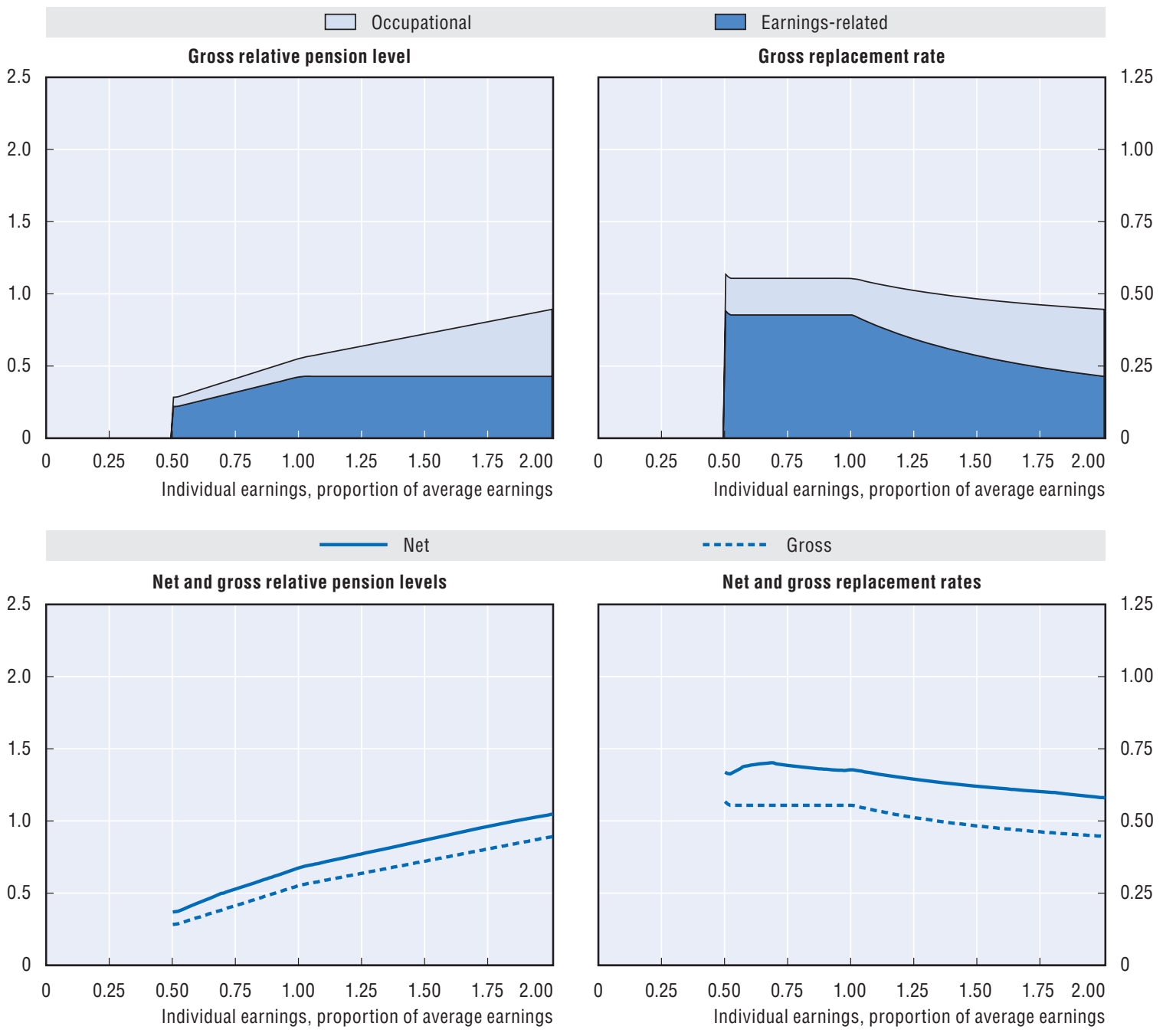

\begin{tabular}{|c|c|c|c|c|c|c|}
\hline \multicolumn{7}{|c|}{ Baseline scenario: Price indexation of targeted schemes } \\
\hline \multirow{2}{*}{$\begin{array}{l}\text { Men } \\
\text { Women (where different) }\end{array}$} & \multicolumn{6}{|c|}{ Individual earnings, multiple of average } \\
\hline & 0.5 & 0.75 & 1 & 1.5 & 2 & 3 \\
\hline Gross relative pension level & 28.4 & 41.5 & 55.4 & 72.4 & 89.3 & 123.1 \\
\hline \multicolumn{7}{|l|}{ (\% average gross earnings) } \\
\hline Net relative pension level & 36.9 & 53.0 & 67.7 & 87.0 & 104.8 & 136.5 \\
\hline \multicolumn{7}{|l|}{ (\% net average earnings) } \\
\hline Gross replacement rate & 56.8 & 55.4 & 55.4 & 48.2 & 44.6 & 41.0 \\
\hline \multicolumn{7}{|l|}{ (\% individual gross earnings) } \\
\hline Net replacement rate & 66.9 & 69.2 & 67.7 & 62.0 & 58.0 & 53.2 \\
\hline \multicolumn{7}{|l|}{ (\% individual net earnings) } \\
\hline Gross pension wealth & 10.7 & 10.4 & 10.4 & 9.1 & 8.4 & 7.7 \\
\hline (multiple of individual gross earnings) & 12.6 & 12.3 & 12.3 & 10.7 & 9.9 & 9.1 \\
\hline Net pension wealth & 9.9 & 9.5 & 9.1 & 7.8 & 7.0 & 6.1 \\
\hline (multiple of individual gross earnings) & 11.7 & 11.2 & 10.8 & 9.2 & 8.3 & 7.2 \\
\hline
\end{tabular}

Assumptions: Real rate of return $3 \%$, real earnings growth $1.25 \%$, inflation $2 \%$, and real discount rate $2 \%$. All systems are modelled and indexed according to what is legislated. Transitional rules apply where relevant. DC conversion rate equal $85 \%$. Labour market entry occurs at age 20 in 2014. Tax system latest available: 2013. 


\section{Germany}

\section{Germany: Pension system in 2014}

The statutory public pension system has a single tier and is an earnings related PAYG system. Calculation of pensions is based on pension points. If individual old-age provision from all income sources is not sufficient, additional means-tested benefits can be claimed from social assistance.
Key indicators: Germany

\begin{tabular}{|c|c|c|c|}
\hline & & Germany & OECD \\
\hline \multirow[t]{2}{*}{ Average worker earnings (AW) } & EUR & 45952 & 33036 \\
\hline & USD & 55649 & 40007 \\
\hline Public pension spending & $\%$ of GDP & 10.6 & 7.9 \\
\hline \multirow[t]{2}{*}{ Life expectancy } & At birth & 80.7 & 80.0 \\
\hline & At age 65 & 19.4 & 19.3 \\
\hline Population over age 65 & $\%$ of population & 21.4 & 16.2 \\
\hline
\end{tabular}

\section{Qualifying conditions}

At present the regular old-age pension is payable from age 65 and two months with at least five years' contributions. Less than five years' contributions earn no benefit. Starting with the year 2012 the statutory retirement age will be gradually increased to 67 during the next two decades. For those born 1964 or later, the statutory retirement age will be 67. As of July 2014 special length of service pension is paid at age 63 for workers with 45 years of contributions. From 2016 this age will increase until it reaches 65 in 2028.

\section{Benefit calculation}

\section{Earnings-related}

A year's contribution at the average earnings of contributors earns one pension point. The relevant average earning is approximately identical to the National Accounts average earnings (EUR 34857 in 2014). Contributions based on lower or higher income earn proportionately less or more pension points. Contributions are levied on annual earnings up to EUR 71400 in 2014.

At retirement, the pension points of every year are summed up. The sum of pension points is then multiplied by a "pension-point value", which was EUR 337.68 in 2014. The pension point value is valid for newly retired and already retired pensioners. The pension point value is adjusted annually in relation to the gross wage growth as a starting point. In addition, the "contribution factor" accounts for changes of the contribution rate to the statutory pension scheme and to the subsidised (voluntary) private pension schemes. An increase of contribution rates will reduce the adjustment of the pension point value. The "sustainability factor", that measures the change of the number of standardised contributors in relation to the number of standardised pensioners, links the adjustment of the pension point value to the changes in the statutory pension scheme's dependency ratio, the ratio of pensioners to contributors. These two factors in the indexation formula can alter the size of adjustment, resulting in an expected $14 \%$ lower growth of the pension point value in relation to gross wages per capita in the long run. Furthermore, the increase of the contribution rate will be limited from currently $18.9 \%$ to $22 \%$.

The relevant average earnings for calculating the pension points as well as the pension-point value are slightly different in the new Länder. This difference is assumed to disappear in the long run as wages will align. 


\section{Social assistance}

If individual old-age provision from all income sources is not sufficient, additional means-tested benefits can be claimed from social assistance. These benefits refer to the individual primary needs. Means-tested provision results from the difference between the individual need and the respective household income (including pension benefits). The average of these needs amounted to EUR 8724 per capita in 2012 for all who received means-tested old-age provision.

\section{Voluntary private pensions}

There is an additional voluntary and private pension which can be provided by banks, insurance companies or investment funds (so-called Riester pension). Riester pension is tax-promoted and subsidised by the government. The modelling assumes a contribution rate of $4 \%$.

\section{Variant careers}

\section{Early retirement}

Early retirement is possible at the age of 63 for persons with an insurance record of at least 35 years. However, the pension benefit will be reduced by a permanent deduction, which increases in line with the rise of the statutory retirement age. If retiring before the age of 67 , benefits are permanently reduced by $3.6 \%$ for each year pensioner's fall short of the statutory retirement age. In addition, retiring at age 63 compared to someone retiring at 67 , pension entitlements are significantly lower due to working four years less and not earning additional pension points.

Besides this, old-age pension for severely handicapped people can be claimed. People with an assessed degree of at least $50 \%$ handicap and at least 35 years of contribution can currently retire at age 60 and eight months with a maximum reduction of $10.8 \%$. The retirement age of this pension will be gradually increased from age 60 to 62 years.

Individuals can still retire at the age 63 without any pension penalties if they complete 45 years of insured time (employment, child care or from child-raising periods up to age 10 or periods of short-time unemployment (UB1) all count as insured time). Unemployment spells at the ages 61 or 62 does not count. The age will gradually increase to 65 until 2029.

\section{Late retirement}

Postponing the retirement age will yield a higher pension accrual of $0.5 \%$ for each month worked after the statutory retirement age.

\section{Childcare}

For children born in 1992 or later one parent is credited for a period of three years with one pension point per year (equal to contributions based on average earnings). For children born before 1992 two pension points are credited. These entitlements can be taken by either an employed or non-employed parent or can be shared between parents. There are also credits for periods caring for children up to age of 10 . These years count towards the number of years needed to qualify for a pension (Berücksichtigungszeit) and in addition have an effect on the pension entitlement. If people work while their children are under 10 or if at least two children under 10 are parented, they receive a bonus of up to 0.33 pension points per year. However, this cannot result in a total accrual exceeding one pension point per year. Those child related benefits in the public pension system are tax-financed. 


\section{Unemployment}

The unemployment insurance contributes to the pension scheme on behalf of the unemployed. During the first period of unemployment benefits (UB1, Arbeitslosengeld I), contributions are paid on the basis of $80 \%$ of previous gross earnings. The first period lasts between 6 and 24 months depending both on age and contribution years. Thereafter, the unemployed person moves to the second type of unemployment benefit (UB2, Arbeitslosengeld II), which is means-tested and paid at a lower rate. For this period, the unemployment insurance provides no financial contributions to the pension scheme. 


\section{Pension modelling results: Germany in 2059, retirement at age 65}

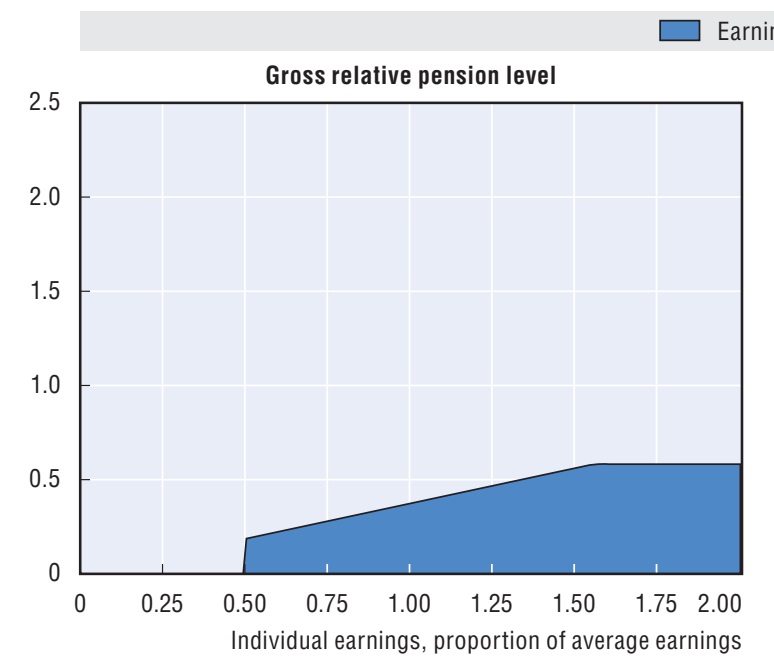

Earnings-related
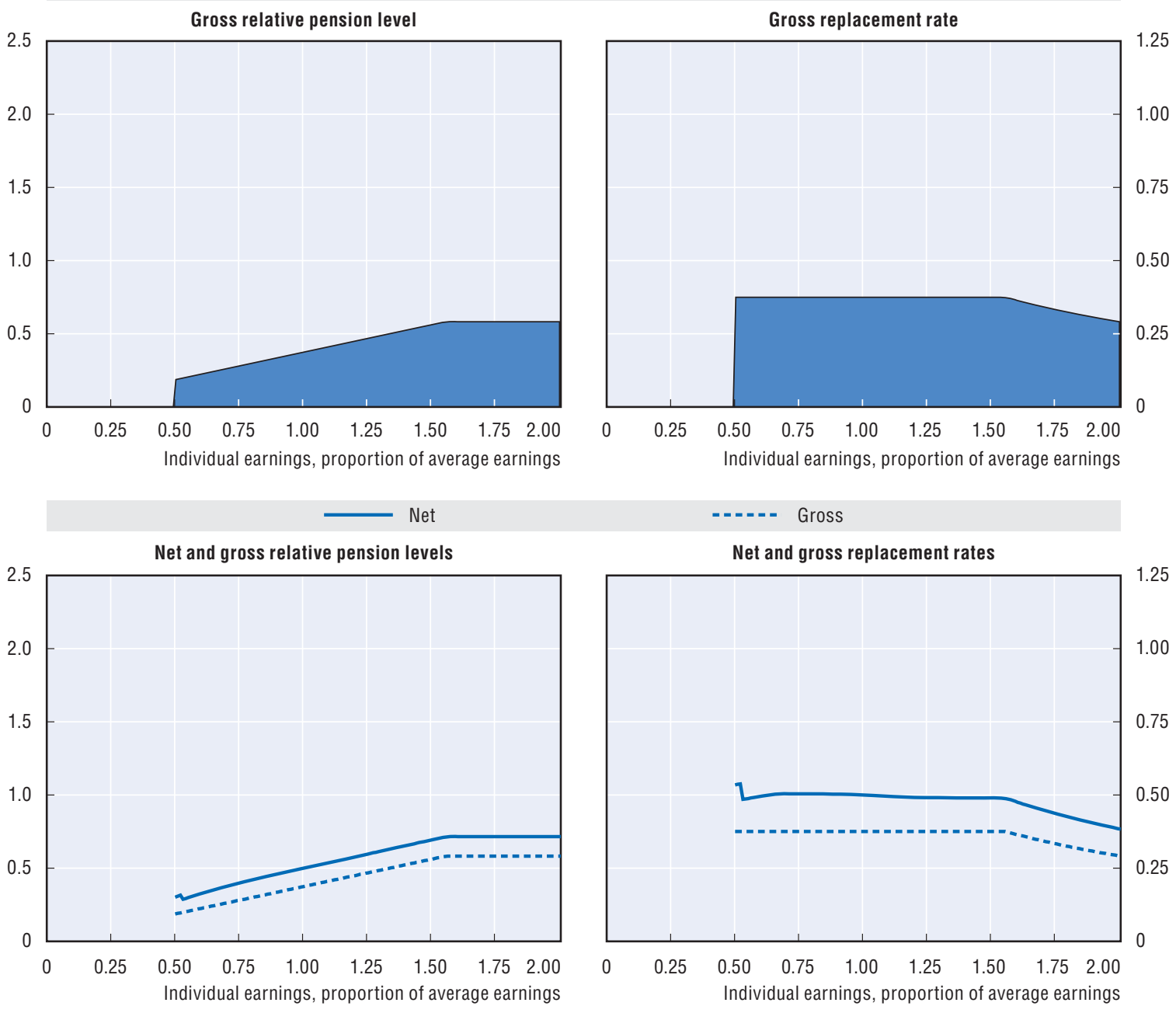

\begin{tabular}{|c|c|c|c|c|c|c|}
\hline \multicolumn{7}{|c|}{ Baseline scenario: Legislation scenario (wages indexation of targeted schemes) } \\
\hline \multirow{2}{*}{$\begin{array}{l}\text { Men } \\
\text { Women (where different) }\end{array}$} & \multicolumn{6}{|c|}{ Individual earnings, multiple of average } \\
\hline & 0.5 & 0.75 & 1 & 1.5 & 2 & 3 \\
\hline Gross relative pension level & 18.7 & 28.1 & 37.5 & 56.2 & 58.3 & 58.3 \\
\hline \multicolumn{7}{|l|}{ (\% average gross earnings) } \\
\hline Net relative pension level & 30.3 & 39.3 & 50.0 & 69.4 & 71.4 & 71.4 \\
\hline \multicolumn{7}{|l|}{ (\% net average earnings) } \\
\hline Gross replacement rate & 37.5 & 37.5 & 37.5 & 37.5 & 29.1 & 19.4 \\
\hline \multicolumn{7}{|l|}{ (\% individual gross earnings) } \\
\hline Net replacement rate & 53.4 & 50.4 & 50.0 & 49.0 & 38.3 & 25.9 \\
\hline \multicolumn{7}{|l|}{ (\% individual net earnings) } \\
\hline Gross pension wealth & 14.5 & 14.5 & 14.5 & 14.5 & 11.3 & 7.5 \\
\hline (multiple of individual gross earnings) & 15.7 & 15.7 & 15.7 & 15.7 & 12.2 & 8.1 \\
\hline Net pension wealth & 14.5 & 12.7 & 12.0 & 11.1 & 8.6 & 5.7 \\
\hline (multiple of individual gross earnings) & 15.7 & 13.8 & 13.0 & 12.0 & 9.3 & 6.2 \\
\hline
\end{tabular}

Assumptions: Real rate of return 3\%, real earnings growth $1.25 \%$, inflation $2 \%$, and real discount rate $2 \%$. All systems are modelled and indexed according to what is legislated. Transitional rules apply where relevant. DC conversion rate equal $85 \%$. Labour market entry occurs at age 20 in 2014. Tax system latest available: 2013. 


\section{Greece}

\section{Greece: Pension system in 2014}

Pensions are provided through an earnings-related public scheme and a basic pension.
Key indicators: Greece

\begin{tabular}{|c|c|c|c|}
\hline & & Greece & OECD \\
\hline \multirow[t]{2}{*}{ Average worker earnings (AW) } & EUR & 20168 & 33036 \\
\hline & USD & 24424 & 40007 \\
\hline Public pension spending & $\%$ of GDP & 14.5 & 7.9 \\
\hline \multirow[t]{2}{*}{ Life expectancy } & At birth & 80.7 & 80.0 \\
\hline & At age 65 & 19.3 & 19.3 \\
\hline Population over age 65 & $\%$ of population & 20.2 & 16.2 \\
\hline
\end{tabular}

\section{Qualifying conditions}

From 1 January 2013 the pension age is 67 for both men and women with less than 4500 days of contributions (equivalent to 15 years). Workers with a contribution record of 12000 working days (40 years) can retire with a full pension benefit at the age of 62 . There are concessions for people who work in arduous or unhygienic occupations and for women with dependant or disabled children. The minimum old-age pension requires 15 years' contributions.

\section{Benefit calculation}

\section{Earnings-related scheme: Main component}

The earnings-related pension accrual rate (from 1 January 2015) increases from $0.80 \%$ per year (for 300 days of insurance to 4500 days of insurance) up to 1.5\% per year (for wages from 11701 days of insurance to 15000 days of insurance).

There is a maximum old-age pension for all insured persons from 1 January 1993 and onwards. The maximum gross pension was equal to EUR 2773.40 in 2011.

From 1 January 2014, pensions are indexed by half the annual change of GDP growth and half the changes in Consumer's Price Index (CPI), with the annual change of CPI being the ceiling for adjustment.

\section{Basic pension}

From 1 January 2015 the basic pension will be granted by all Social Security Organisations provided that the beneficiaries are at least 67 years old and have had a permanent residency in Greece for at least 15 years and can fulfil some previous income criteria.

The basic pension is equal to EUR 486.84 per month for an unmarried person and a married person whose spouse is working or EUR 523.37 per month for a person with a non-working spouse is equal to EUR 486.84 per month or EUR 523.37 for a married person. For married individuals with non-working spouses and with one to three children the benefit is higher (EUR 547.76, EUR 571.99, or EUR 596.31). For unmarried individuals the benefit equals to EUR 511.23, EUR 535.46, or EUR 559.78 with one to three children, respectively.

There are 12 payments a year and all benefits are indexed with consumer prices. 


\section{Variant careers}

\section{Early retirement}

Early retirement is possible. This usually entails a penalty (1/200 per month) with the exemption of certain cases including, long careers (40 years - age 62) and employment at arduous and unhealthy occupations, where a full old-age pension is paid under favourable prerequisites.

\begin{tabular}{ccc}
\hline Number of years & Eligibility age & Conditions \\
\hline 15 & 67 & No reduction \\
15 & 62 & With reduction $(1 / 200)$ \\
40 & 62 & No reduction \\
\hline
\end{tabular}

\section{Late retirement}

Late retirement is possible and no compulsory retirement exists with the exception of employees in public sector.

\section{Childcare}

For mothers entitled to an old-age pension with the retirement conditions that applied until 31 December 2010, there is a credit towards the pension qualifying conditions of one year for the first child (300 days of insurance) and two years (600 days of insurance) for each subsequent child up to a maximum of three children, for children born after 1 January 2000.

For insured persons entitled to an old-age pension with the new retirement conditions that apply from 1 January 2011 and onwards, either parent may use credited insurance period due to the fact that they raised children (one year or 300 days for the first child, two years for the second and each subsequent child with a maximum of five years all together) in order to fulfil the required conditions for entitlement to a pension. From 2014, the maximum on any credited insurance period is seven years. All the credited periods taken into account in order to qualify for pension cannot exceed seven years, from 2014 onwards.

\section{Unemployment}

For insured persons entitled to an old-age pension based on the stricter requirements that came into force from 1 January 2011 and onwards and any period of (voluntary or involuntary) unemployment can be used as credited insurance period, towards the fulfilment of the minimum prerequisites for retirement. Note that subsidised unemployment cannot exceed one year or 300 days during the lifetime and that the maximum credited period of six years applies in 2013. All the credited periods taken into account in order to qualify for pension cannot exceed seven years, from 2014 onwards. 


\section{Pension modelling results: Greece in 2056, retirement at age 62}
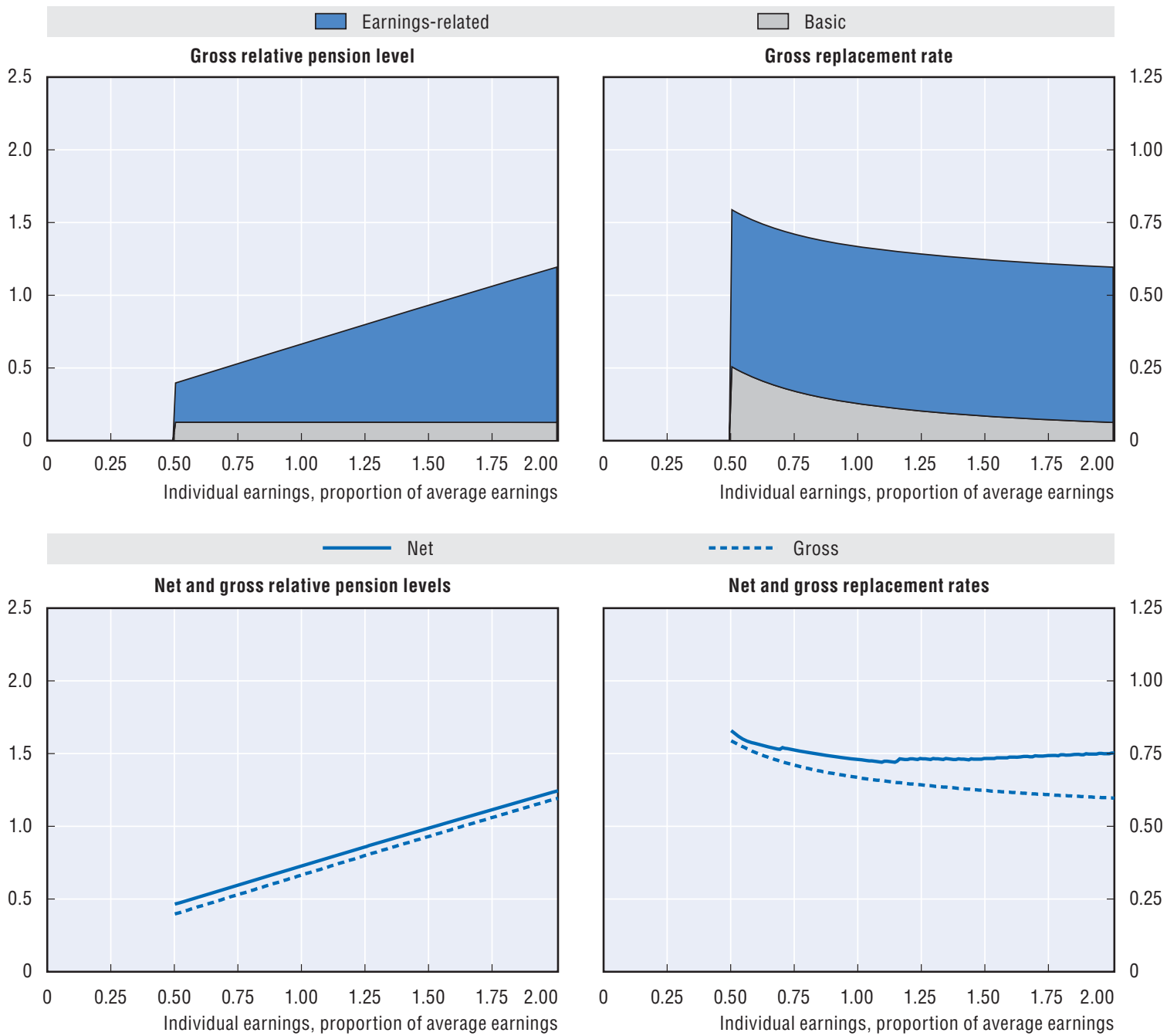

\begin{tabular}{|c|c|c|c|c|c|c|}
\hline \multicolumn{7}{|c|}{ Baseline scenario: Legislation scenario (price indexation of safety-nets schemes) } \\
\hline \multirow{2}{*}{$\begin{array}{l}\text { Men } \\
\text { Women (where different) }\end{array}$} & \multicolumn{6}{|c|}{ Individual earnings, multiple of average } \\
\hline & 0.5 & 0.75 & 1 & 1.5 & 2 & 3 \\
\hline Gross relative pension level & 39.7 & 53.2 & 66.7 & 93.4 & 119.4 & 137.6 \\
\hline \multicolumn{7}{|l|}{ (\% average gross earnings) } \\
\hline Net relative pension level & 46.5 & 59.7 & 72.9 & 99 & 124.5 & 142.3 \\
\hline \multicolumn{7}{|l|}{ (\% net average earnings) } \\
\hline Gross replacement rate & 79.4 & 71.0 & 66.7 & 62.3 & 59.7 & 45.9 \\
\hline \multicolumn{7}{|l|}{ (\% individual gross earnings) } \\
\hline Net replacement rate & 82.9 & 76.2 & 72.9 & 73.3 & 75.2 & 62.3 \\
\hline \multicolumn{7}{|l|}{ (\% individual net earnings) } \\
\hline Gross pension wealth & 15.1 & 13.5 & 12.7 & 11.9 & 11.4 & 8.7 \\
\hline (multiple of individual gross earnings) & 16.8 & 15.0 & 14.1 & 13.2 & 12.6 & 9.7 \\
\hline Net pension wealth & 13.6 & 11.6 & 10.6 & 9.6 & 9.1 & 6.9 \\
\hline (multiple of individual gross earnings) & 15.1 & 12.9 & 11.8 & 10.7 & 10.1 & 7.7 \\
\hline
\end{tabular}

Assumptions: Real rate of return $3 \%$, real earnings growth $1.25 \%$, inflation $2 \%$, and real discount rate $2 \%$. All systems are modelled and indexed according to what is legislated. Transitional rules apply where relevant. DC conversion rate equal $85 \%$. Labour market entry occurs at age 20 in 2014. Tax system latest available: 2013. 
Pension modelling results: Greece in 2056, retirement at age 62 (cont.)

\begin{tabular}{|c|c|c|c|c|c|c|}
\hline \multicolumn{7}{|c|}{ Alternative scenario: Full-wage indexation of targeted schemes } \\
\hline \multirow{2}{*}{$\begin{array}{l}\text { Men } \\
\text { Women (where different) }\end{array}$} & \multicolumn{6}{|c|}{ Individual earnings, multiple of average } \\
\hline & 0.5 & 0.75 & 1 & 1.5 & 2 & 3 \\
\hline Gross relative pension level & 48.4 & 61.9 & 75.4 & 101.8 & 127.6 & 145.8 \\
\hline \multicolumn{7}{|l|}{ (\% average gross earnings) } \\
\hline Net relative pension level & 55.4 & 68.6 & 81.8 & 107.6 & 132.9 & 150.7 \\
\hline \multicolumn{7}{|l|}{ (\% net average earnings) } \\
\hline Gross replacement rate & 96.8 & 82.6 & 75.4 & 67.9 & 63.8 & 48.6 \\
\hline \multicolumn{7}{|l|}{ (\% individual gross earnings) } \\
\hline Net replacement rate & 98.7 & 87.5 & 81.8 & 79.7 & 80.3 & 65.9 \\
\hline \multicolumn{7}{|l|}{ (\% individual net earnings) } \\
\hline Gross pension wealth & 18.4 & 15.7 & 14.4 & 12.9 & 12.2 & 9.3 \\
\hline (multiple of individual gross earnings) & 20.5 & 17.5 & 16.0 & 14.4 & 13.5 & 10.3 \\
\hline Net pension wealth & 16.1 & 13.3 & 11.9 & 10.5 & 9.7 & 7.3 \\
\hline (multiple of individual gross earnings) & 17.9 & 14.8 & 13.3 & 11.6 & 10.8 & 8.1 \\
\hline
\end{tabular}

Assumptions: Real rate of return 3\%, real earnings growth $1.25 \%$, inflation $2 \%$, and real discount rate $2 \%$. All systems are modelled and indexed according to what is legislated except for the safety-nets which follow real-wages. Transitional rules apply where relevant. DC conversion rate equal 85\%. Labour market entry occurs at age 20 in 2014. Tax system latest available: 2013.

StatLink +inisl http://dx.doi.org/10.1787/888933301448 


\section{Hungary}

\section{Hungary: Pension system in 2014}

The Hungarian pension system is a mandatory, uniform, defined benefit pay-as-you-go system with an earningsrelated public pension combined with a minimum pension.
Key indicators: Hungary

\begin{tabular}{llrr}
\hline & & Hungary & OECD \\
\hline Average worker earnings (AW) & HUF (million) & 3.01 & 10.4 \\
& USD & 11526 & 40007 \\
Public pension spending & \% of GDP & 10.0 & 7.9 \\
Life expectancy & At birth & 74.5 & 80.0 \\
\multirow{2}{*}{ Population over age 65 } & At age 65 & 16.4 & 19.3 \\
& \% of population & 17.6 & 16.2 \\
\hline
\end{tabular}

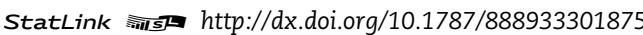

\section{Qualifying conditions}

The standard retirement age is currently 62 years and six months and is gradually increasing (by half a year for every age cohort) and will reach 65 in 2022. In addition, 20 years' service is required for both the earnings-related pension and the minimum amount of pension. 15 years' service is required to receive a partial pension without eligibility to minimum amount of pension.

The mandatory social insurance pension system was reformed in 2012. Early retirement pensions have been transformed into social benefits ("benefits prior to retirement age"). Pension benefit can only be awarded after reaching the standard retirement age.

\section{Benefit calculation}

\section{Earnings-related}

The earnings-related public pension system is a mandatory defined benefit system where the earnings-related pension is calculated as $33 \%$ of average earnings for the first ten years of coverage. Each additional year of coverage adds $2 \%$ from year 11 to $25,1 \%$ from year 26 to $36,1.5 \%$ from year 37 to year 40 and $2 \%$ thereafter.

The earnings base is net salary (i.e. gross wage less employee's contribution and taxes). Earlier years' earnings are valorised with economy-wide average earnings to the year preceding retirement. From 2012 pension benefits are adjusted to changes in consumer prices index.

\section{Minimum}

There is a minimum pension, which is worth HUF 28500 per month. The government decides upon the increases. The amount has remained unchanged since 2009.

\section{Means-tested safety net}

Those who have reached the standard retirement age, but are not eligible for social security pension and have no other source of sufficient income can apply for a means-tested old-age allowance. The allowance is tax-financed and a part of the social assistance system. 


\section{Reversal of mandatory private pension}

From 1 November 2010 to 31 December 2011 all payments to the mandatory funded defined contribution scheme were suspended, and all contributions were redirected to the public pension scheme. Members of the defined contribution scheme had to decide by 31 January 2011 whether to remain in the scheme or switch back to pay-as-you-go public pension system. The private pension fund members have the possibility to pay their personal account membership fee (but not contribution) to the private pension funds voluntarily. The second pillar has been completely dismantled.

Before the reversal approximately 3.1 million people (more than $70 \%$ of the labour force) were members of the mixed system (end of 2010). After the reversal only 102000 scheme members have decided to remain in the defined contribution scheme. From 31 December 2011 all of the social security contributions (employee's and employer's contribution) go to the Pension Insurance Fund. The private pension fund members have had the possibility of making voluntary contributions to their personal accounts. Members who previously opted out also had the possibility of returning to the public earnings related pension (until 31 March 2012). Approximately 23000 more private pension fund members returned to the social security system as the returning possibility was reopened. Currently 61498 (2014 Q4) members are in the pension funds. The accumulated amount in the defined contribution private pension scheme must be converted into an annuity on retirement. According to the current legislation the annuity must provide at least the same indexation of the pension in payment as the public pension scheme. Unisex life tables must be used to calculate annuity rates.

\section{Variant careers}

\section{Early retirement}

From 1 January 2011 a new early retirement option has been introduced with 40 years eligibility period for women. It is available for women regardless of age, who have at least 40 years of eligibility and cease gainful activity. Eligibility period includes periods gained with gainful activity or pregnancy-confinement benefit, child care fee, child home care allowance, and child raising support or nursing fee. At least 32 years of gainful activity is needed ( 30 years in case of nursing fee). The eligibility period is decreased by one year for each child in households with five or more children (a maximum of seven years is possible).

\section{Late retirement}

It is possible to defer the earnings-related pension. The pension is increased by $0.5 \%$ for each month of additional service time. The final pension may exceed the average monthly earnings if the insured person has sufficient service period and reached the legal retirement age.

\section{Childcare}

Since 1998 pension contributions have to be paid after the following benefits: pregnancy confinement benefit, child care fee, child care allowance and child raising support. Therefore these benefits will be taken into account for the pension base calculation in case the amounts of these benefits are favourable for the insured person. Pregnancy confinement benefit (terhességi gyermekágyi segély) is for women in the pregnancy period or giving birth, for 24 weeks (168 days). The benefit is $70 \%$ of the daily average gross earnings of the previous year. Child care fee (gyermekgondozási dij) can be claimed by one of the parents on the day after the expiry period of pregnancy confinement benefit and it is provided as long as the insurance period of the parent takes, but maximum to the age of two years of the child (maximum 84 weeks). The benefit amount is $70 \%$ of the daily average gross earnings of the previous year up to the maximum of twice of the minimum wage (HUF 142100 
in 2014). It is obligatory to pay the individual pension contribution rate, which was $10 \%$ in 2014 . Child home care allowance (gyermekgondozási segély) is for one of the parents who cares for the child until the child's third birthday (maximum 36 months), or in case of twin children until the end of the year they reach school age, or in case of a permanently ill or seriously disabled child until they are ten years of age (maximum 120 months). The monthly amount is equal to the minimum old-age pension of HUF 28500 as from January 2008 irrespective of the number of children in the family. In case of multiple births the amount is multiplied according to the number of children (for example doubled in case of twins, tripled in case of triplets, etc.). The child home care allowance can be paid for a maximum of two children if, after 1 January 2014 another infant is born into the family, after whom the parents are entitled to the said benefit again, or both of the children are born after 1 January 2014. Children born from the same pregnancy (e.g. twins) generate eligibility of allowance for one child when the next child will be born. In that case child home care allowance can be paid after the next child as well.

After the child's first birthday, also grandparents can claim the benefit. It's obligatory to pay the individual pension contribution which was 10\% in 2014. Child raising support (gyermeknevelési támogatás) for one of the parents who cares for the child and who raises three or more underage children for the period between the third and the eighth birthday of the youngest child (maximum 60 months). The monthly amount is equal to the minimum old-age pension, irrespective of the number of children.

The total amount of periods taken off work is not maximised and entitlements are not added up, though it depends on the age and number of the children and the composition of the family.

In 2014, pension contribution after child care benefits is paid by:

\begin{tabular}{lccc}
\hline & Individual & Employer & Government \\
\hline Pregnancy confinement benefit & - & - & - \\
Child care fee & $\mathrm{X}$ & - & \\
Child care allowance & $\mathrm{X}$ & - & \\
Child raising support & $\mathrm{X}$ & - & \\
\hline
\end{tabular}

\section{Unemployment}

The unemployed are covered by the earnings-related pension system. Generally, the periods of unemployment are qualified as pensionable service. The earnings measure for the period of unemployment is the most favourable of: i) the amount of unemployment benefits; or ii) the average of previous and subsequent earnings.

Older unemployed people can receive job-seeker aid before pension if they have received job-seeker insurance benefit for 45 days, and have exhausted their jobseeker benefit entitlement or their job-seeker benefit was terminated due to employment and they are not entitled again to job-seeker benefit will reach pensionable age within five years, and have contributed to the pension scheme for at least 20 years. 
Pension modelling results: Hungary in 2059, retirement at age 65

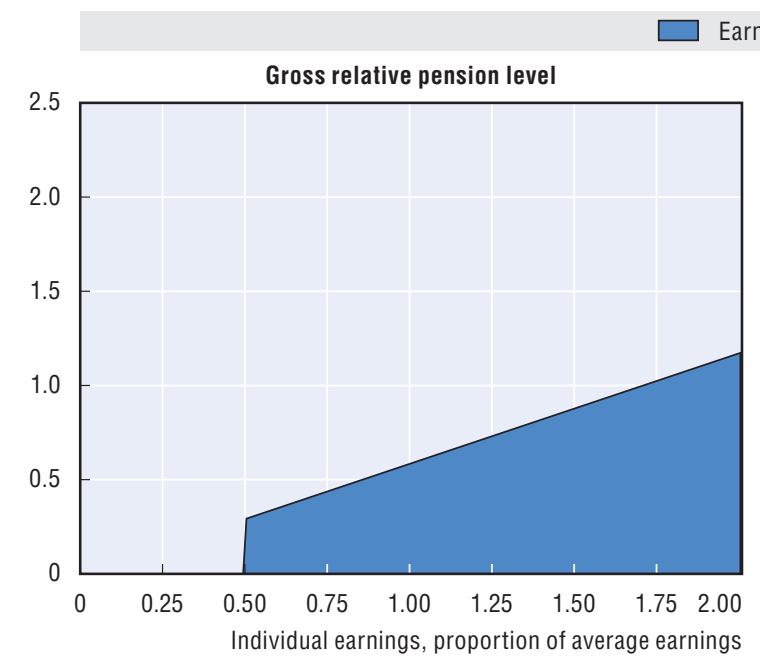

Earnings-related
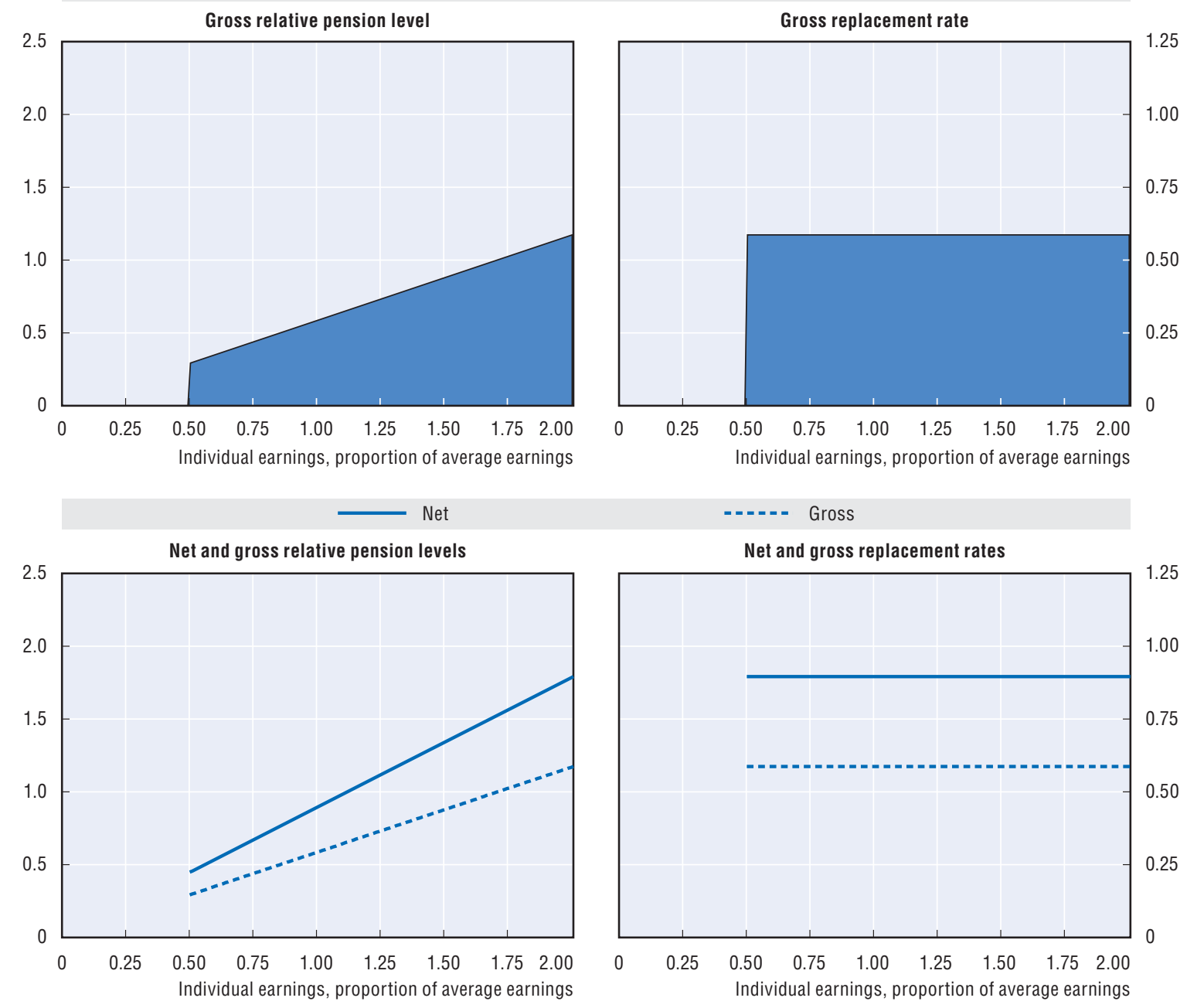

\begin{tabular}{|c|c|c|c|c|c|c|}
\hline \multicolumn{7}{|c|}{ Baseline scenario: Legislation scenario (price indexation of targeted schemes) } \\
\hline \multirow{2}{*}{$\begin{array}{l}\text { Men } \\
\text { Women (where different) }\end{array}$} & \multicolumn{6}{|c|}{ Individual earnings, multiple of average } \\
\hline & 0.5 & 0.75 & 1 & 1.5 & 2 & 3 \\
\hline Gross relative pension level & 29.3 & 44.0 & 58.7 & 88.0 & 117.4 & 176.0 \\
\hline \multicolumn{7}{|l|}{ (\% average gross earnings) } \\
\hline Net relative pension level & 44.8 & 67.2 & 89.6 & 134.4 & 179.2 & 268.7 \\
\hline \multicolumn{7}{|l|}{ (\% net average earnings) } \\
\hline Gross replacement rate & 58.7 & 58.7 & 58.7 & 58.7 & 58.7 & 58.7 \\
\hline \multicolumn{7}{|l|}{ (\% individual gross earnings) } \\
\hline Net replacement rate & 89.6 & 89.6 & 89.6 & 89.6 & 89.6 & 89.6 \\
\hline \multicolumn{7}{|l|}{ (\% individual net earnings) } \\
\hline Gross pension wealth & 8.5 & 8.5 & 8.5 & 8.5 & 8.5 & 8.5 \\
\hline (multiple of individual gross earnings) & 10.1 & 10.1 & 10.1 & 10.1 & 10.1 & 10.1 \\
\hline Net pension wealth & 8.5 & 8.5 & 8.5 & 8.5 & 8.5 & 8.5 \\
\hline (multiple of individual gross earnings) & 10.1 & 10.1 & 10.1 & 10.1 & 10.1 & 10.1 \\
\hline
\end{tabular}

Assumptions: Real rate of return $3 \%$, real earnings growth $1.25 \%$, inflation $2 \%$, and real discount rate $2 \%$. All systems are modelled and indexed according to what is legislated. Transitional rules apply where relevant. DC conversion rate equal $85 \%$. Labour market entry occurs at age 20 in 2014. Tax system latest available: 2013. 


\section{Iceland}

\section{Iceland: Pension system in 2014}

There is a basic state pension (national pension), which is income-tested. There are also mandatory occupational pensions.

\section{Qualifying conditions}

Key indicators: Iceland

\begin{tabular}{|c|c|c|c|}
\hline & & Iceland & OECD \\
\hline \multirow[t]{2}{*}{ Average worker earnings (AW) } & ISK (million) & 6.86 & 5.1 \\
\hline & USD & 53779 & 40007 \\
\hline Public pension spending & $\%$ of GDP & 2.1 & 7.9 \\
\hline \multirow[t]{2}{*}{ Life expectancy } & At birth & 82.0 & 80.0 \\
\hline & At age 65 & 20.0 & 19.3 \\
\hline Population over age 65 & $\%$ of population & 13.4 & 16.2 \\
\hline
\end{tabular}

The normal pension age is 67 . A full basic pension is earned with 40 years' residency. The pension is proportionally reduced for shorter periods of residency, with a minimum of three years required between the ages of 16 and 67 . The pension age is also 67 for members of private-sector occupational plans but is 60 for seamen who have been working in this occupation for at least 25 years. The social security system guarantees a minimum pension to everyone, even when very little, or nothing, has been paid into a pension fund. Pension payments are subject to income tax in the same way as earned income.

\section{Benefit calculation}

\section{Basic}

The full basic pension value is ISK 423348 per year, equivalent to $6 \%$ of average worker earnings. The national pension may be reduced when income is gained from other sources, or withdrawn if it exceeds a certain amount. Income in this respect does not include social security benefits, supplementary pension or social assistance. Withdrawal begins once income (from labour income or capital income) exceeds ISK 2.58 million or equivalent to $38 \%$ of average earnings, and ceases at ISK 4.27 million or equal to $62 \%$ of average earnings. The basic pension can be indexed to either prices or to wages. For the last two years the basic pension has been indexed to prices.

\section{Targeted}

A second element is the pension supplement. The maximum value of this benefit is ISK 1.34 million per year for a single person, some $20 \%$ of average earnings. This benefit is withdrawn against labour income above ISK 1.32 million per year (around 20\% of average earnings), supplementary pension above ISK 259200 and capital income above ISK 98 640. The withdrawal rate for the income-test in the pension supplement is $13.35 \%$ of the amount up to ISK 2.58 million and $38.35 \%$ above that amount.

According to the Social Assistance Act, various social assistance benefits may be granted in addition to the national pension in special circumstances or when it is shown that the beneficiary cannot support him- or herself without this assistance. These are for instance the household supplement for a single person, the special supplement for support and further supplements. 


\section{Mandatory occupational}

All working people are required to be members of a pension fund and pay to the fund a specific percentage of their wages. Employers pay a counter-contribution to these funds for each employee. Coverage is mandatory for people aged 16 to 70 . There is a minimum contribution to occupational schemes of $12 \%$ of earnings. The employee pays $4 \%$ of the total wages, while the employer pays $8 \%$. In the public sector and certain other sectors, the employer's contribution is higher. The law requires schemes to target a replacement rate of $56 \%$ with 40 years' contributions, giving an accrual rate of $1.4 \%$ for each year of service. The earnings base in this calculation is average lifetime salary for each year of membership. There is no ceiling to pensionable earnings. Past earnings are valorised in line with inflation plus $3.5 \%$ interest rate. In the modelling past earnings are valorised with earnings growth. Payment of pension is assumed to begin at the age of 67 years. The commencement of pension payments can be brought forward to the age of 65 years, and it can be delayed to the age of 70 years.

\section{Variant careers}

\section{Early retirement}

Under the mandatory occupational scheme, early retirement rules vary between funds, depending on the structure of fund membership. In the private sector, the normal retirement age is 67 and the pension can be claimed from 65 . In general, pensions are reduced by $7 \%$ for each year that pension is claimed early. It is not possible to claim the basic or targeted pensions before the normal pension age.

\section{Late retirement}

It is possible to defer the basic pension and the pension supplement (i.e. claim them at a later date) up to the age of 72 years. In this case, benefits are increased by $0.5 \%$ for each additional month. A maximum increase of $30 \%$ is possible. Under the mandatory occupational scheme, workers can defer receiving their pension up to the age of 70 . The amount of benefits increases by around $8 \%$ for each year pension payments are deferred.

\section{Childcare}

The government social assistance scheme contains benefits for parents who must take care of children with long-term illnesses or disabilities. There are three kinds of payments; payments to parents on the labour market, to parents who are engaged in studies and base payments, to parents who are neither working nor studying.

\section{Unemployment}

The contribution base, on which the minimum $10 \%$ contribution is levied, includes unemployment insurance benefits as well as earnings but excludes all other benefits. 
Pension modelling results: Iceland in 2061, retirement at age 67
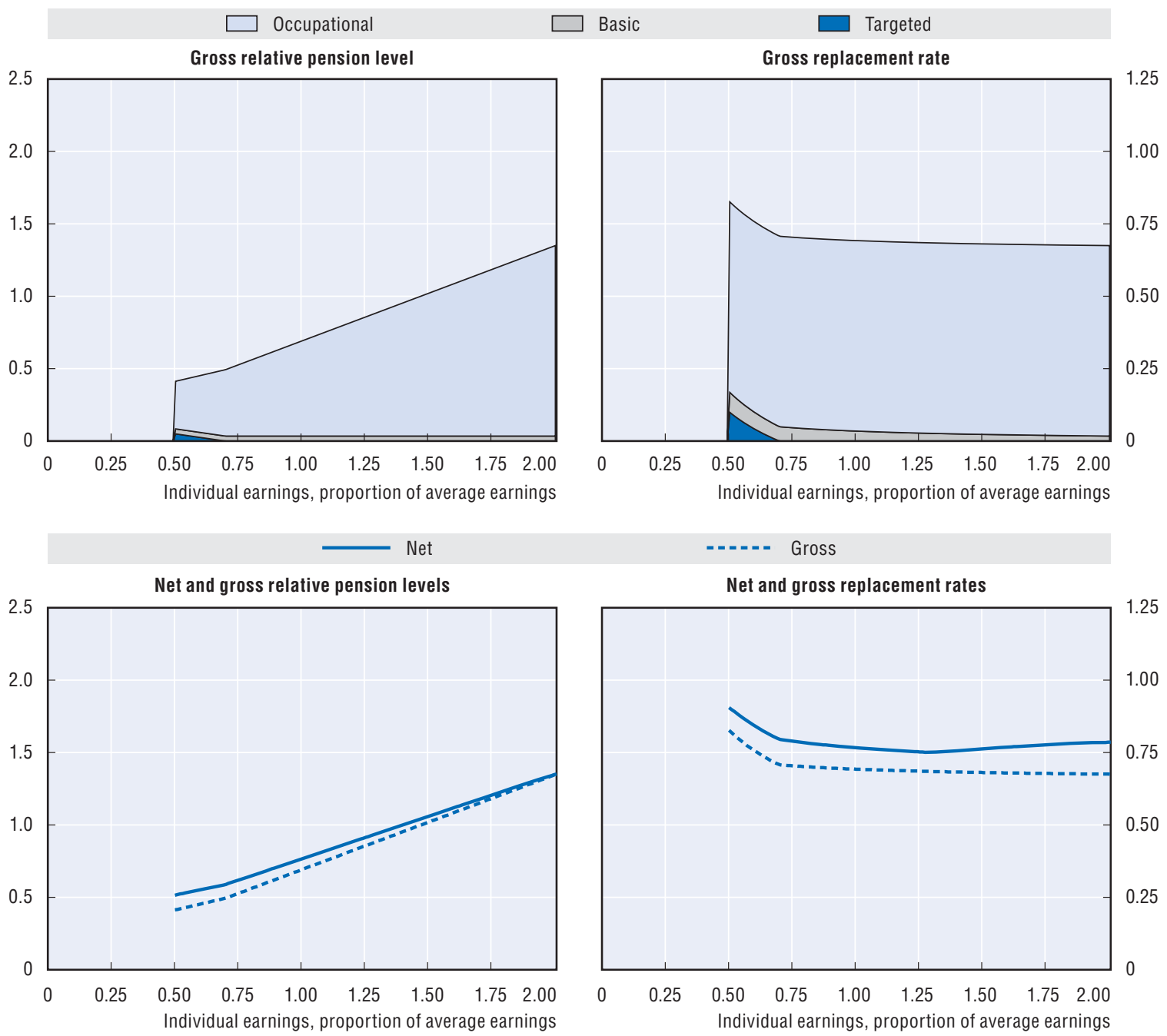

\begin{tabular}{|c|c|c|c|c|c|c|}
\hline \multicolumn{7}{|c|}{ Baseline scenario: Legislation scenario (price indexation of targeted schemes) } \\
\hline \multirow{2}{*}{$\begin{array}{l}\text { Men } \\
\text { Women (where different) }\end{array}$} & \multicolumn{6}{|c|}{ Individual earnings, multiple of average } \\
\hline & 0.5 & 0.75 & 1 & 1.5 & 2 & 3 \\
\hline Gross relative pension level & 41.3 & 52.8 & 69.2 & 102.1 & 135.0 & 200.8 \\
\hline \multicolumn{7}{|l|}{ (\% average gross earnings) } \\
\hline Net relative pension level & 51.6 & 61.9 & 76.7 & 106.1 & 135.1 & 188.2 \\
\hline \multicolumn{7}{|l|}{ (\% net average earnings) } \\
\hline Gross replacement rate & 82.6 & 70.4 & 69.2 & 68.1 & 67.5 & 66.9 \\
\hline \multicolumn{7}{|l|}{ (\% individual gross earnings) } \\
\hline Net replacement rate & 90.5 & 78.9 & 76.7 & 76.3 & 78.5 & 79.1 \\
\hline \multicolumn{7}{|l|}{ (\% individual net earnings) } \\
\hline Gross pension wealth & 14.8 & 12.3 & 12.1 & 11.9 & 11.7 & 11.6 \\
\hline (multiple of individual gross earnings) & 16.4 & 13.7 & 13.4 & 13.2 & 13.0 & 12.9 \\
\hline Net pension wealth & 12.3 & 9.6 & 8.9 & 8.2 & 7.8 & 7.3 \\
\hline (multiple of individual gross earnings) & 13.7 & 10.7 & 9.9 & 9.1 & 8.7 & 8.1 \\
\hline
\end{tabular}

Assumptions: Real rate of return $3 \%$, real earnings growth $1.25 \%$, inflation $2 \%$, and real discount rate $2 \%$. All systems are modelled and indexed according to what is legislated. Transitional rules apply where relevant. DC conversion rate equal $85 \%$. Labour market entry occurs at age 20 in 2014. Tax system latest available: 2013. 
Pension modelling results: Iceland in 2061, retirement at age 67 (cont.)

\begin{tabular}{|c|c|c|c|c|c|c|}
\hline \multicolumn{7}{|c|}{ Alternative scenario: Full-wage indexation of targeted schemes } \\
\hline \multirow{2}{*}{$\begin{array}{l}\text { Men } \\
\text { Women (where different) }\end{array}$} & \multicolumn{6}{|c|}{ Individual earnings, multiple of average } \\
\hline & 0.5 & 0.75 & 1 & 1.5 & 2 & 3 \\
\hline Gross relative pension level & 56.8 & 68.1 & 78.3 & 104.9 & 137.8 & 203.6 \\
\hline \multicolumn{7}{|l|}{ (\% average gross earnings) } \\
\hline Net relative pension level & 65.5 & 75.6 & 84.7 & 108.6 & 137.3 & 190.4 \\
\hline \multicolumn{7}{|l|}{ (\% net average earnings) } \\
\hline Gross replacement rate & 113.6 & 90.8 & 78.3 & 69.9 & 68.9 & 67.9 \\
\hline \multicolumn{7}{|l|}{ (\% individual gross earnings) } \\
\hline Net replacement rate & 115.0 & 96.4 & 84.7 & 78.0 & 79.8 & 80.0 \\
\hline \multicolumn{7}{|l|}{ (\% individual net earnings) } \\
\hline Gross pension wealth & 20.9 & 16.4 & 13.9 & 12.2 & 12.0 & 11.8 \\
\hline (multiple of individual gross earnings) & 23.3 & 18.2 & 15.4 & 13.6 & 13.3 & 13.1 \\
\hline Net pension wealth & 16.1 & 12.1 & 10.0 & 8.4 & 8.0 & 7.4 \\
\hline (multiple of individual gross earnings) & 17.9 & 13.5 & 11.1 & 9.4 & 8.9 & 8.2 \\
\hline
\end{tabular}

Assumptions: Real rate of return $3 \%$, real earnings growth $1.25 \%$, inflation $2 \%$, and real discount rate $2 \%$. All systems are modelled and indexed according to what is legislated except for the safety-nets which follow real-wages. Transitional rules apply where relevant. DC conversion rate equal 85\%. Labour market entry occurs at age 20 in 2014. Tax system latest available: 2013.

StatLink iㅔs http://dx.doi.org/10.1787/888933301460 


\section{India}

\section{India: Pension system in 2014}

Workers are covered under the earningsrelated employee pension scheme and defined contribution employee provident fund administered by the Employees Provident Fund Organization (EPFO) and other employer managed funds. Civil Employees of Central Government who have joined services on or after 1 January 2004 are covered under the Defined Contribution based New Pension System (NPS).

\section{Key indicators: India}

\begin{tabular}{|c|c|c|c|}
\hline & & India & OECD \\
\hline \multirow[t]{2}{*}{ Average worker earnings (AW) } & INR & 80338 & 2528029 \\
\hline & USD & 1271 & 40007 \\
\hline Public pension spending & $\%$ of GDP & 2.2 & 7.9 \\
\hline \multirow[t]{2}{*}{ Life expectancy } & At birth & 66.3 & 80.0 \\
\hline & At age 65 & 13.7 & 19.3 \\
\hline Population over age 65 & $\%$ of population & 5.5 & 16.2 \\
\hline
\end{tabular}

\section{Qualifying conditions}

The normal pension age for earnings-related pension benefits from the Employees' Pension Scheme is 58 years with a minimum of ten years of contributions. The pension age for the earnings-related Employees Provident Fund scheme is 55 years.

About $12 \%$ of the workforce (or approximately 58 million people) are covered under various pension systems according to the 2011 census. Covered individuals belong to the organised sectors and are employed by the government, government enterprises, public and private sector enterprises, which are mandatorily covered by the Employees Provident Fund Organization (EPFO). Employers with 20 or more employees are covered by EPFO. The remaining $88 \%$ of the workforce are mainly occupied in the unorganised sector (self-employed, daily wage workers, farmers, etc.) and some are in the organised sector, but are not mandatorily covered by the EPFO. For this share of the workforce the Public Provident Fund (PPF) and Postal Saving Schemes have traditionally been the main long-term savings instruments but these have only catered to a relatively small section of this population.

\section{Benefit calculation}

\section{Employees Provident Fund Schemes (EPF)}

For employees with basic wages less than or equal to INR 15000 per month, the employee contributes $12 \%$ of the monthly salary and the employer contributes $3.67 \%$ as employer's share towards this fund. This combined $15.67 \%$ accumulates as a lump-sum.

For employees with basic wages greater than INR 15000 per month, the employee contributes $12 \%$ of the monthly salary and the employer also contributes a matching amount as employer's share. This combined $24 \%$ accumulates as a lump-sum.

Prior to September 2014 employees with basic wages above the then wage ceiling (INR 6500 per month) got a lower employer contribution share at $3.67 \%$ as the balance $8.33 \%$ was diverted to the pension scheme.

There is no annuity and full accumulations are paid on retirement after attaining 55 years of age. For comparison with other countries, for replacement rate purposes the pension is shown as a price-indexed annuity based on sex-specific mortality rates. 


\section{Employees' Pension Scheme (EPS)}

Starting from September 2014 new members with basic wage above INR 15000 per month no longer have the option of contributing to the EPS. Existing participants who have until now been contributing over the earlier INR 6500 wage cap have an option to continue contributing over the increased wage cap of INR 15000 but they would also have to contribute the government subsidy of $1.16 \%$ on the excess amount.

For the existing and new subscribers who are within the new basic wage cap of INR 15000 , the employer contributes an amount equal to $8.33 \%$ of the basic wage to the EPS fund and the Central Government contributes a subsidy of $1.16 \%$ of the salary into the EPS. This accumulation is used to pay various pension benefits on retirement or early termination. The kind of pension a member gets under the scheme depends upon the age at which they retire and the number of years of eligible service.

$$
\text { Monthly pension }=(\text { pensionable salary } \times \text { pensionable service }) / 70
$$

Starting September 2014, the pensionable salary will be calculated on the average monthly pay for the contribution period of the last 60 months (as against 12 months earlier) preceding the date of exit from the membership.

The maximum possible replacement rate is roughly $50 \%$.

With effect from September 2014, a minimum pension level of INR 1000 per month has been provided under the scheme.

\section{Targeted social safety net}

There is no population wide social safety net.

\section{Variant careers}

\section{Early retirement}

The EPS can be claimed from age 50 with ten years of contribution and the benefits are reduced by $3 \%$ per year of early retirement. If a member leaves his job before rendering at least ten years of service, he is entitled to a withdrawal benefit. The amount he can withdraw is a proportion of his monthly salary at the date of exit from employment. This proportion depends on the number of years of eligible services he has rendered. No pension is payable in cases where there is a break in service before ten years.

In case of EPF, there are multiple scenarios, which allow for early access to the accumulation. Partial withdrawals relate to marriage, housing advance, financing life insurance policy, illness of members/family members, withdrawals are also permitted one year before retirement, etc. In addition to various permitted partial withdrawals, employees can close their account and withdraw the full corpus in case they move from one employer to another or decide to retire early. No gratuity can be claimed before five years of service.

\section{Late retirement}

It is not possible to delay claiming pension after normal pension age. 


\section{Pension modelling results: India in 2052, retirement at age 58}
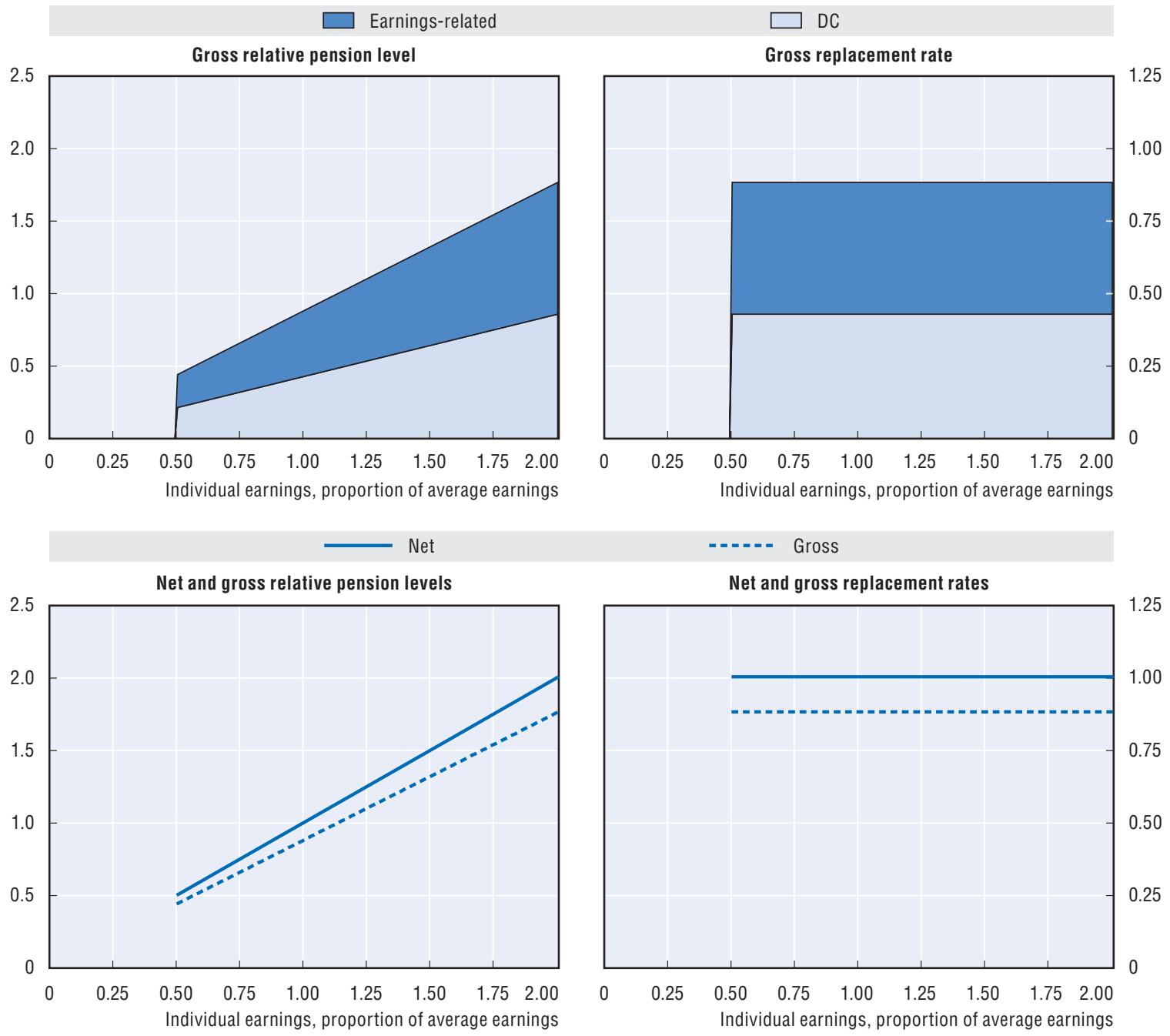

\begin{tabular}{|c|c|c|c|c|c|c|}
\hline \multicolumn{7}{|c|}{ Baseline scenario: Legislation scenario } \\
\hline \multirow{2}{*}{$\begin{array}{l}\text { Men } \\
\text { Women (where different) }\end{array}$} & \multicolumn{6}{|c|}{ Individual earnings, multiple of average } \\
\hline & 0.5 & 0.75 & 1 & 1.5 & 2 & 3 \\
\hline Gross relative pension level & 48.3 & 72.4 & 96.5 & 144.8 & 193.0 & 255.0 \\
\hline (\% average gross earnings) & 45.7 & 68.5 & 91.3 & 137.0 & 182.6 & 239.5 \\
\hline Net relative pension level & 54.8 & 82.3 & 109.7 & 164.5 & 219.4 & 289.8 \\
\hline (\% net average earnings) & 51.9 & 77.8 & 103.8 & 155.7 & 207.5 & 272.1 \\
\hline Gross replacement rate & 96.5 & 96.5 & 96.5 & 96.5 & 96.5 & 85.0 \\
\hline (\% individual gross earnings) & 91.3 & 91.3 & 91.3 & 91.3 & 91.3 & 79.8 \\
\hline Net replacement rate & 109.7 & 109.7 & 109.7 & 109.7 & 109.7 & 96.6 \\
\hline (\% individual net earnings) & 103.8 & 103.8 & 103.8 & 103.8 & 103.8 & 90.7 \\
\hline Gross pension wealth & 16.0 & 16.0 & 16.0 & 16.0 & 16.0 & 14.2 \\
\hline (multiple of individual gross earnings) & 16.9 & 16.9 & 16.9 & 16.9 & 16.9 & 14.8 \\
\hline Net pension wealth & 16.0 & 16.0 & 16.0 & 16.0 & 16.0 & 14.2 \\
\hline (multiple of individual gross earnings) & 16.9 & 16.9 & 16.9 & 16.9 & 16.9 & 14.8 \\
\hline
\end{tabular}

Assumptions: Real rate of return 3\%, real earnings growth $1.25 \%$, inflation $2 \%$, and real discount rate $2 \%$. All systems are modelled and indexed according to what is legislated. Transitional rules apply where relevant. DC conversion rate equal $85 \%$. Labour market entry occurs at age 20 in 2014. Tax system latest available: 2014. 


\section{Indonesia}

\section{Indonesia: Pension system in 2014}

Employees in private sectors are covered by a defined contribution plan.

\section{Qualifying conditions}

Key indicators: Indonesia

\begin{tabular}{|c|c|c|c|}
\hline & & Indonesia & OECD \\
\hline \multirow[t]{2}{*}{ Average worker earnings (AW) } & IDR (million) & 17.20 & 496.96 \\
\hline & USD & 1385 & 40007 \\
\hline Public pension spending & $\%$ of GDP & & 7.9 \\
\hline \multirow[t]{2}{*}{ Life expectancy } & At birth & 70.7 & 80.0 \\
\hline & At age 65 & 14.2 & 19.3 \\
\hline Population over age 65 & $\%$ of population & 5.4 & 16.2 \\
\hline
\end{tabular}

Normal pension age is 55 years. Retirement is not required and employees age 55 with 15 years of contributions are qualified for a periodical pension benefit while those having less than 15 years qualify for a lump-sum payment.

\section{Benefit calculation}

\section{Defined contribution}

Employees in private sectors are covered by defined contribution pension plans. During 1993 to 2013 this refers to one of the Employees Social Security Programmes (PT Jamsostek) and in this case the Jaminan Hari Tua (JHT) or Old Age Security (OAS). The total contribution rate is $5.7 \%$ of wages. The JHT is a compulsory programme for all employees and the retired may opt for a partly lump-sum, periodical until death and lump-sum payment. Employees contribute $2 \%$ of earnings and employers pay $3.7 \%$ of the payroll. Pension is paid in lump sum or payable monthly up to a maximum of five years if the balance is more than IDR 3 million. For comparison with other countries, for replacement rate purposes the pension is shown as a price-indexed annuity based on sex-specific mortality rates.

A new National Social Security System (NSSS) will be implemented on 1 July 2015 and PT Jamsostek will become a public body, named BPJS Ketenagakerjaan or BPJS Employee. The new social security pension will be a defined benefit scheme and complement the current defined contribution scheme. The total contribution rate in the new defined benefit scheme is proposed to be $8 \%$. The benefit calculation is still undecided and therefore this benefit is not modelled.

\section{NSSS Programme and contribution rates as of wages}

\begin{tabular}{|c|c|c|c|c|c|}
\hline \multirow{2}{*}{ No } & \multirow{2}{*}{ Programmes } & \multicolumn{3}{|c|}{ Shared contributions (\%) } & \multirow{2}{*}{ Remarks } \\
\hline & & Employer & Employee & Total & \\
\hline 1 & Health care & 3.0 & 2.0 & 5.0 & Proposed \\
\hline 2 & Work accident & $0.25-0.75$ & - & $0.25-0.75$ & \\
\hline 3 & Provident fund & 3.7 & 2.0 & 5.7 & Jamsostek \\
\hline 4 & Pension plan & 5.0 & 3.0 & 8.0 & Proposed \\
\hline \multirow[t]{2}{*}{5} & Death benefit & 0.3 & - & 0.3 & Jamsostek \\
\hline & Grand total & $12.25-12.75$ & 7.0 & $19.25-19.75$ & \\
\hline
\end{tabular}

Source: National Social Security Council (2012). 


\section{Variant careers}

Early retirement

It is possible to start claiming pension at any age with a minimum of five years of contribution.

\section{Late retirement}

It is not possible to start claiming pension after normal pension age. 


\section{Pension modelling results: Indonesia in 2049, retirement at age 55}
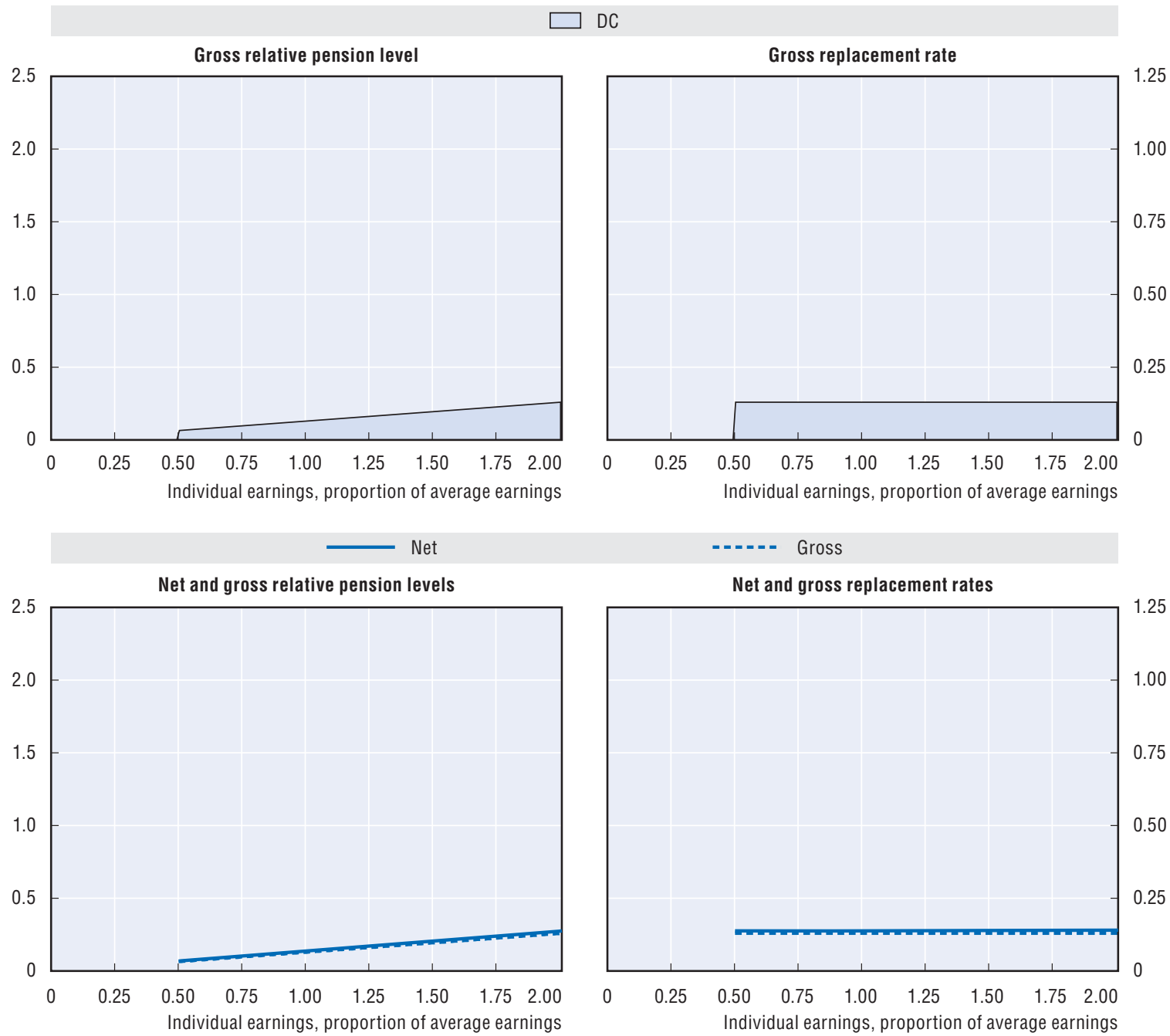

\begin{tabular}{|c|c|c|c|c|c|c|}
\hline \multicolumn{7}{|c|}{ Baseline scenario: Legislation scenario } \\
\hline \multirow{2}{*}{$\begin{array}{l}\text { Men } \\
\text { Women (where different) }\end{array}$} & \multicolumn{6}{|c|}{ Individual earnings, multiple of average } \\
\hline & 0.5 & 0.75 & 1 & 1.5 & 2 & 3 \\
\hline Gross relative pension level & 6.5 & 9.7 & 13.0 & 19.5 & 25.9 & 38.9 \\
\hline (\% average gross earnings) & 5.9 & 8.8 & 11.8 & 17.7 & 23.6 & 35.3 \\
\hline Net relative pension level & 6.9 & 10.3 & 13.8 & 20.6 & 27.5 & 41.3 \\
\hline (\% net average earnings) & 6.2 & 9.4 & 12.5 & 18.7 & 25.0 & 37.5 \\
\hline Gross replacement rate & 13.0 & 13.0 & 13.0 & 13.0 & 13.0 & 13.0 \\
\hline (\% individual gross earnings) & 11.8 & 11.8 & 11.8 & 11.8 & 11.8 & 11.8 \\
\hline Net replacement rate & 13.8 & 13.8 & 13.8 & 13.9 & 14.0 & 14.2 \\
\hline (\% individual net earnings) & 12.5 & 12.5 & 12.5 & 12.6 & 12.7 & 12.9 \\
\hline Gross pension wealth & 2.3 & 2.3 & 2.3 & 2.3 & 2.3 & 2.3 \\
\hline (multiple of individual gross earnings) & 2.3 & 2.3 & 2.3 & 2.3 & 2.3 & 2.3 \\
\hline Net pension wealth & 2.3 & 2.3 & 2.3 & 2.3 & 2.3 & 2.3 \\
\hline (multiple of individual gross earnings) & 2.3 & 2.3 & 2.3 & 2.3 & 2.3 & 2.3 \\
\hline
\end{tabular}

Assumptions: Real rate of return 3\%, real earnings growth $1.25 \%$, inflation $2 \%$, and real discount rate $2 \%$. All systems are modelled and indexed according to what is legislated. Transitional rules apply where relevant. DC conversion rate equal $85 \%$. Labour market entry occurs at age 20 in 2014. Tax system latest available: 2014. 


\section{Ireland}

\section{Ireland: Pension system in 2014}

The public pension is a basic scheme paying a flat rate to all who meet the contribution conditions. There is also a meanstested pension to provide a safety net for the low-income elderly. Voluntary occupational pension schemes have broad coverage: over half of employees.
Key indicators: Ireland

\begin{tabular}{|c|c|c|c|}
\hline & & Ireland & OECD \\
\hline \multirow[t]{2}{*}{ Average worker earnings (AW) } & EUR & 34466 & 33036 \\
\hline & USD & 41739 & 40007 \\
\hline Public pension spending & $\%$ of GDP & 5.3 & 7.9 \\
\hline \multirow[t]{2}{*}{ Life expectancy } & At birth & 80.6 & 80.0 \\
\hline & At age 65 & 19.2 & 19.3 \\
\hline Population over age 65 & $\%$ of population & 12.6 & 16.2 \\
\hline
\end{tabular}

\section{Qualifying conditions}

The State Pension (contributory) is payable from age 66. As the age for claiming State pension was standardised to age 66 from 2014 the State Pension (transition) was abolished from January 2014. State pension age is being increased to 67 in 2021 and 68 in 2028.

Full entitlement to the State pension (contributory) requires an average of 48 weeks contributions or credits per year throughout the working life. The pension value is reduced for incomplete contribution histories. It requires a minimum average of ten weeks' contributions per year. There is also a minimum total period of paid (as opposed to credited) contributions of 520 weeks (equivalent to ten years' full coverage).

A means-tested State (non-contributory) pension is payable from age 66.

\section{Benefit calculation}

\section{Basic}

The State Pension (contributory) benefit is EUR 230.30 per week and an additional EUR 10 a week is paid if the receiver is aged 80 or above. If the individual is aged 66 or older, is unmarried or living alone the addition is EUR 7.70 a week.

\section{Targeted}

The maximum value of the means-tested State pension (non-contributory) benefit is EUR 219 per week for a single person with an extra EUR 144.70 for an adult dependent aged under the age of 66 for 2014. Where the dependent is 66 or over, s/he may make a claim for this pension in his/her own right, and qualify for a payment of up to EUR 219 per week. There is a small weekly disregard of EUR 30 in the means test, and there is an additional earnings disregard of EUR 200: otherwise, the benefit is withdrawn at $100 \%$ of income. There is also an assets test, with capital of more than EUR 20000 being converted to income using a standard formula.

\section{Voluntary private pensions}

There is an additional voluntary private pension component which is assumed to be defined contribution. The contribution rate is assumed to be $10 \%$. 


\section{Variant careers}

\section{Early retirement}

The State pension (contributory) and the State Pension (non-contributory) can only be claimed from the age of 66 , and cannot be claimed before the normal eligibility age.

\section{Late retirement}

Unlike the State pension (transition), the State pension (contributory) does not require the pensioner to retire and is not subject to an earnings test, and so the abolition of the former in 2014 has removed a significant disincentive to working past pension age. There is no provision to defer claiming the pension.

\section{Childcare}

Eventual public pension entitlement is not affected by periods out of paid work for caring purposes, provided at least 520 weeks of contributions are paid over the course of working life, as such periods of caring for children and/or incapacitated adults (since 1994) are disregarded when calculating the average contributions used to determine pension entitlement.

\section{Unemployment}

Eventual public pension entitlement is not affected by periods of unemployment provided at least 520 weeks of contributions are paid over the course of working life, as contributions are credited in respect of such periods. 


\section{Pension modelling results: Ireland in 2062, retirement at age 68}
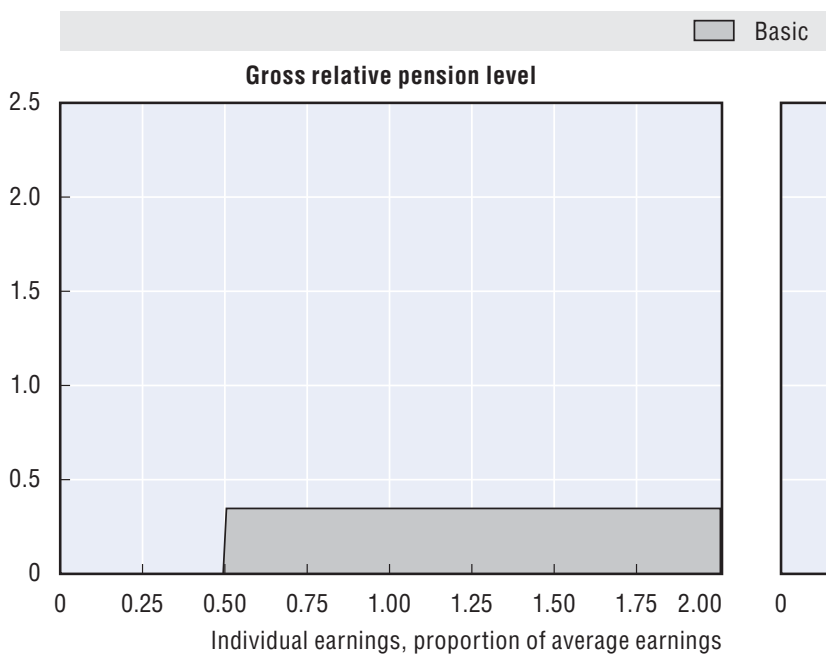

Gross replacement rate 1.25
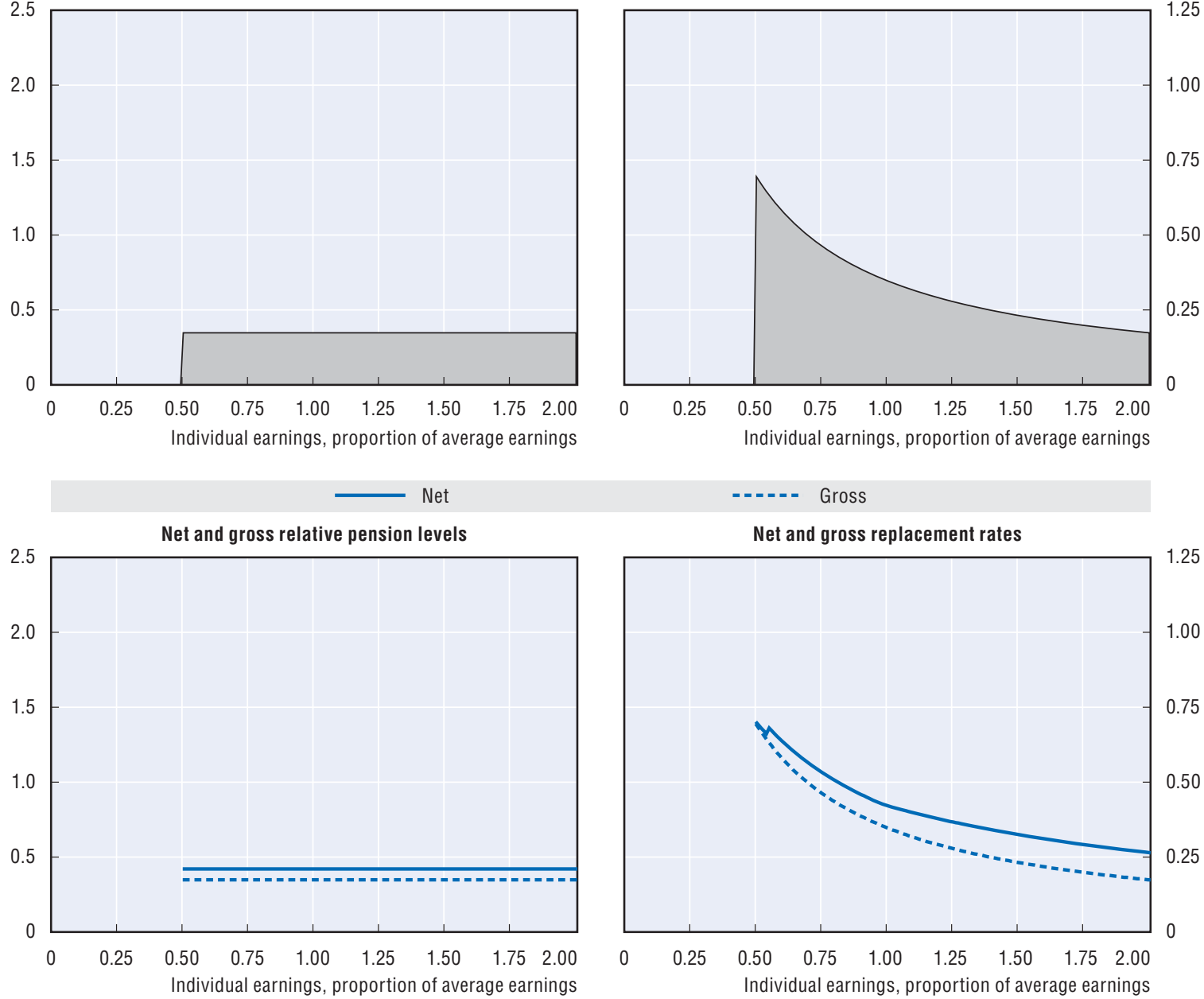

-n-n. Gross

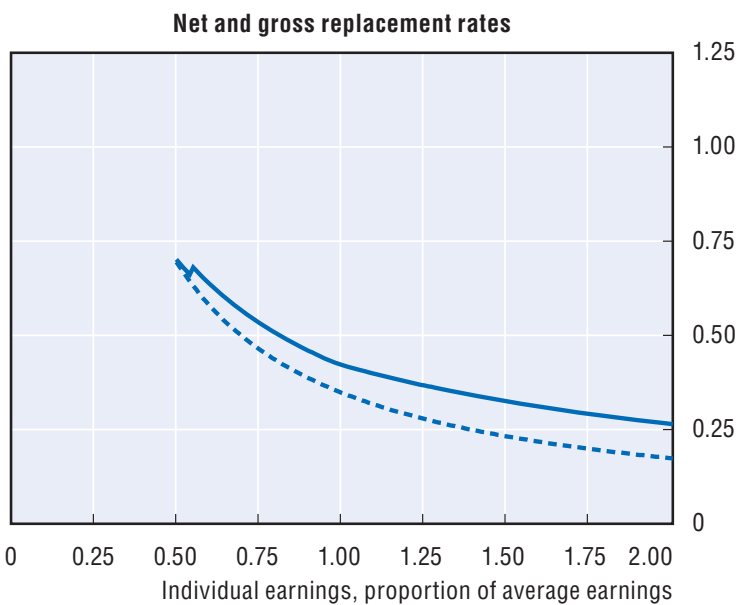

Baseline scenario: Legislation scenario (wage indexation of basic pension benefits)

\begin{tabular}{|c|c|c|c|c|c|c|}
\hline \multirow{2}{*}{$\begin{array}{l}\text { Men } \\
\text { Women (where different) }\end{array}$} & \multicolumn{6}{|c|}{ Individual earnings, multiple of average } \\
\hline & 0.5 & 0.75 & 1 & 1.5 & 2 & 3 \\
\hline Gross relative pension level & 34.7 & 34.7 & 34.7 & 34.7 & 34.7 & 34.7 \\
\hline \multicolumn{7}{|l|}{ (\% average gross earnings) } \\
\hline Net relative pension level & 42.2 & 42.2 & 42.2 & 42.2 & 42.2 & 42.2 \\
\hline \multicolumn{7}{|l|}{ (\% net average earnings) } \\
\hline Gross replacement rate & 69.5 & 46.3 & 34.8 & 23.2 & 17.4 & 11.6 \\
\hline \multicolumn{7}{|l|}{ (\% individual gross earnings) } \\
\hline Net replacement rate & 70.1 & 53.3 & 42.2 & 32.5 & 26.4 & 19.2 \\
\hline \multicolumn{7}{|l|}{ (\% individual net earnings) } \\
\hline Gross pension wealth & 12.9 & 8.6 & 6.5 & 4.3 & 3.2 & 2.2 \\
\hline (multiple of individual gross earnings) & 14.7 & 9.8 & 7.3 & 4.9 & 3.7 & 2.4 \\
\hline Net pension wealth & 12.6 & 8.4 & 6.3 & 4.2 & 3.2 & 2.1 \\
\hline (multiple of individual gross earnings) & 14.3 & 9.6 & 7.2 & 4.8 & 3.6 & 2.4 \\
\hline
\end{tabular}

Assumptions: Real rate of return $3 \%$, real earnings growth $1.25 \%$, inflation $2 \%$, and real discount rate $2 \%$. All systems are modelled and indexed according to what is legislated. Transitional rules apply where relevant. DC conversion rate equal $85 \%$. Labour market entry occurs at age 20 in 2014. Tax system latest available: 2013. 


\section{Israel}

\section{Israel: Pension system in 2014}

The state pension comprises a universal insurance pension combined with meanstested income support. Until 2008 voluntary contributions were common but as of 1 January 2008 mandatory contributions to defined contribution pension funds have been introduced.

\section{Key indicators: Israel}

\begin{tabular}{|c|c|c|c|}
\hline & & Israel & OECD \\
\hline \multirow[t]{2}{*}{ Average worker earnings (AW) } & ILS & 130605 & 156133 \\
\hline & USD & 33466 & 40007 \\
\hline Public pension spending & $\%$ of GDP & 4.8 & 7.9 \\
\hline \multirow[t]{2}{*}{ Life expectancy } & At birth & 81.7 & 80.0 \\
\hline & At age 65 & 20.0 & 19.3 \\
\hline Population over age 65 & $\%$ of population & 10.9 & 16.2 \\
\hline
\end{tabular}

\section{Qualifying conditions}

Residents are eligible for an old-age pension from the National Insurance Institute when they reach the pension age. Men's retirement age reached 67 years in 2010 while women's is currently 62 and will reach 64 years, subject to legislation, by 2017. There are limits on the earnings from work for pensioners until age 70 for men and as of 2009 until age 67 for women, but this age will increase to 70 years for women as well.

\section{Benefit calculation}

\section{Basic pension}

Individuals contribute $0.22 \%$ of earnings below, $60 \%$ of the national average wage, which was ILS 9089 in January 2014, plus 3.85\% of earnings above that threshold.

The minimum earnings for contribution purposes are ILS 4300 , equal to the minimum wage. Anyone earning less than this amount pays contributions as if earning the minimum.

The maximum earnings for contribution purposes are five times the national average wage in 1 January 2014. The basic pension benefit is indexed with prices.

The annual basic pension is ILS 18368 for a single pensioner equal to $17.7 \%$ of the old-age reference amount whereas a couple receives ILS 27612 . The old-age monthly reference amount is ILS 8648 in 2014. The basic pension for those aged 80 or older is ILS 19404 for a single pensioner or ILS 28644 for a couple.

In addition there is a seniority increment where the pension is increased by $2 \%$ for each year of insurance coverage exceeding ten years, up to a maximum equal to $50 \%$ of the pension.

\section{Safety net}

An income supplement is paid if income, including the pension, is less than the minimum subsistence level. The size of the benefit depends on the age of the individual, marital status and the size of the household. Rates vary between $30.3 \%$ and $63.4 \%$ of the old-age reference amount, depending on marital status and the number of children. The resulting amount is increased by an additional $7 \%$. Income Support is withdrawn at a rate of $60 \%$ in the presence of income from defined contribution pensions.

The statistical data for Israel are supplied by and under the responsibility of the relevant Israeli authorities. The use of such data by the OECD is without prejudice to the status of the Golan Heights, East Jerusalem and Israeli settlements in the West Bank under the terms of international law. 
In addition the elderly may benefit from the heating grant if they fullfil the required conditions. Residents not covered by old-age insurance receive a special benefit.

\section{Defined contribution}

Mandatory contributions have applied to earnings up to the average wage for all employees since January 2008. Initially the rates were modest with a total contribution of $2.5 \%$ but increased to $15 \%$ (5\% from employees and 10\% from employers) by 2013. In 2014 the contribution rate increased a bit further to $17.5 \%$. Half of the employers' contribution also provides severance insurance which, if utilised, diminishes the pension.

\section{Variant careers}

\section{Early retirement}

It is not possible to receive a pension prior to the normal pension age.

\section{Late retirement}

The pension is increased by $5 \%$ for each year of deferred retirement.

\section{Childcare}

A woman who worked before birth is entitled to a 14-week Birth Allowance. This paid period is taken into account in the qualifying period for old age pension. There is no specific credit for periods of childcare.

\section{Unemployment}

An unemployed person has to pay a minimum premium to be entitled to old age pension (first pillar). Please note that old-age pension is a fixed amount and not a function of wages. All persons who accumulated the same qualifying period will receive the same benefit (not employment status related). 
Pension modelling results: Israel in 2061 (2058), retirement at age 67 (age 64)
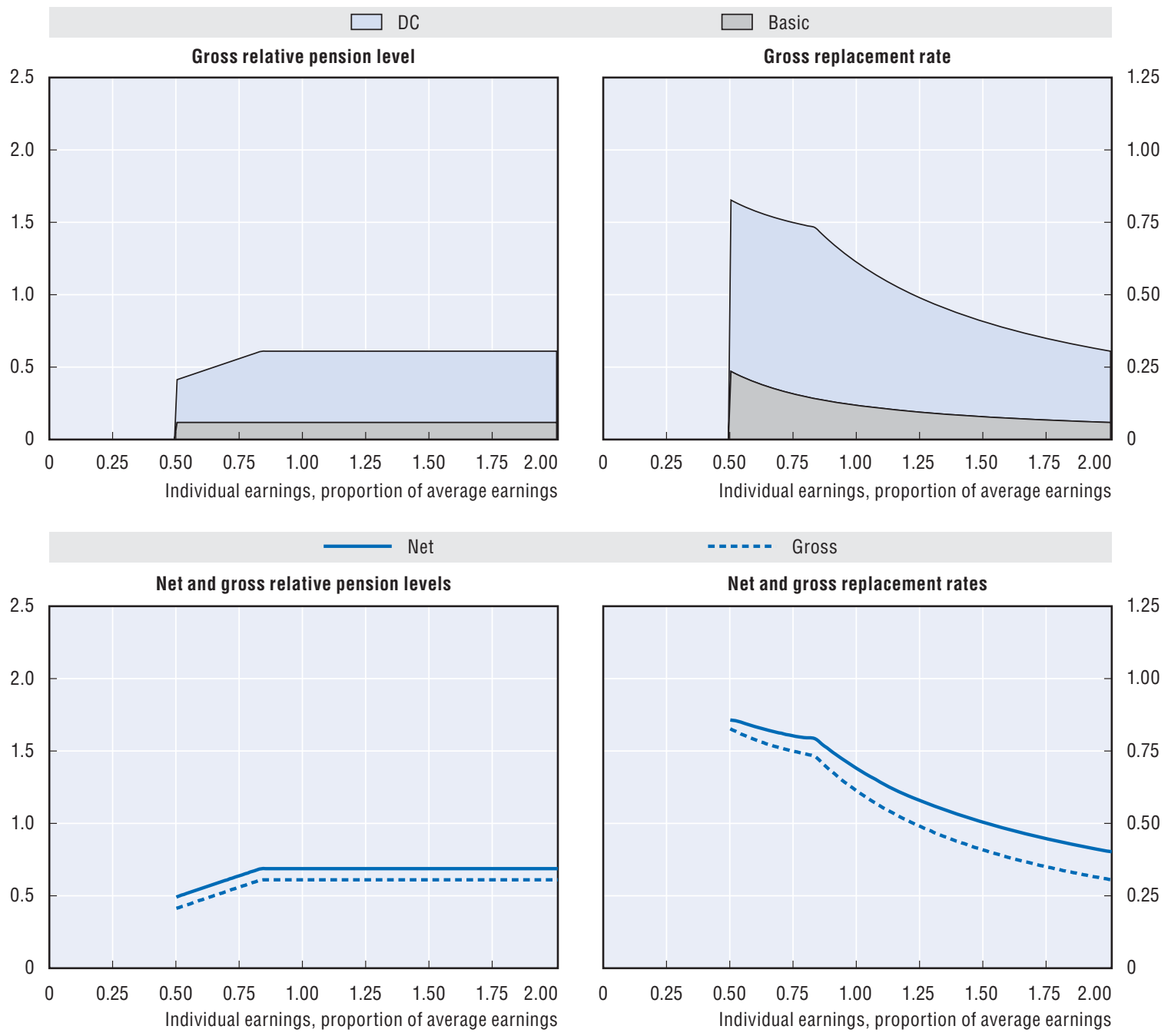

\begin{tabular}{|c|c|c|c|c|c|c|}
\hline \multicolumn{7}{|c|}{ Baseline scenario: Legislation scenario (price indexation of targeted schemes) } \\
\hline \multirow{2}{*}{$\begin{array}{l}\text { Men } \\
\text { Women (where different) }\end{array}$} & \multicolumn{6}{|c|}{ Individual earnings, multiple of average } \\
\hline & 0.5 & 0.75 & 1 & 1.5 & 2 & 3 \\
\hline Gross relative pension level & 41.4 & 56.1 & 61.0 & 61.0 & 61.0 & 61.0 \\
\hline (\% average gross earnings) & 37.3 & 49.9 & 54.1 & 54.1 & 54.1 & 54.1 \\
\hline Net relative pension level & 49.0 & 64.0 & 68.8 & 68.8 & 68.8 & 68.8 \\
\hline (\% net average earnings) & 44.3 & 57.8 & 61.9 & 61.9 & 61.9 & 61.9 \\
\hline Gross replacement rate & 82.7 & 74.9 & 61.0 & 40.7 & 30.5 & 20.3 \\
\hline (\% individual gross earnings) & 74.7 & 66.5 & 54.1 & 36.0 & 27.0 & 18.0 \\
\hline Net replacement rate & 85.7 & 80.2 & 68.8 & 50.3 & 40.2 & 28.9 \\
\hline (\% individual net earnings) & 77.4 & 72.4 & 61.9 & 45.2 & 36.2 & 26.0 \\
\hline Gross pension wealth & 14.5 & 13.1 & 10.7 & 7.1 & 5.3 & 3.6 \\
\hline (multiple of individual gross earnings) & 15.3 & 13.7 & 11.1 & 7.4 & 5.6 & 3.7 \\
\hline Net pension wealth & 14.0 & 12.2 & 9.8 & 6.6 & 4.9 & 3.3 \\
\hline (multiple of individual gross earnings) & 14.9 & 12.9 & 10.4 & 6.9 & 5.2 & 3.5 \\
\hline
\end{tabular}

Assumptions: Real rate of return $3 \%$, real earnings growth $1.25 \%$, inflation $2 \%$, and real discount rate $2 \%$. All systems are modelled and indexed according to what is legislated. Transitional rules apply where relevant. DC conversion rate equal $85 \%$. Labour market entry occurs at age 20 in 2014. Tax system latest available: 2013. 
Pension modelling results: Israel in 2061 (2058), retirement at age 67 (age 64) (cont.)

\begin{tabular}{lrrrrrr}
\hline \multicolumn{1}{c}{ Alternative scenario: Full-wage indexation of targeted schemes } \\
\hline Men & \multicolumn{3}{c}{ Individual earnings, multiple of average } \\
\cline { 2 - 7 } Women (where different) & 0.5 & 0.75 & 1 & 1.5 & 2 & 3 \\
\hline Gross relative pension level & 50.7 & 65.5 & 70.4 & 70.4 & 70.4 & 70.4 \\
(\% average gross earnings) & 46.2 & 58.8 & 62.9 & 62.9 & 62.9 & 62.9 \\
Net relative pension level & 58.6 & 73.2 & 78.1 & 78.1 & 78.1 & 78.1 \\
(\% net average earnings) & 54.2 & 66.6 & 70.7 & 70.7 & 70.7 & 70.7 \\
Gross replacement rate & 101.4 & 87.3 & 70.4 & 46.9 & 35.2 & 23.5 \\
(\% individual gross earnings) & 92.5 & 78.4 & 62.9 & 42.0 & 31.5 & 21.0 \\
Net replacement rate & 102.4 & 91.8 & 78.1 & 57.0 & 45.6 & 32.7 \\
(\% individual net earnings) & 94.7 & 83.5 & 70.7 & 51.6 & 41.3 & 29.7 \\
Gross pension wealth & 17.7 & 15.3 & 12.3 & 8.2 & 6.1 & 4.1 \\
(multiple of individual gross earnings) & 19.0 & 16.1 & 12.9 & 8.6 & 6.5 & 4.3 \\
Net pension wealth & 16.7 & 14.0 & 11.2 & 7.4 & 5.6 & 3.7 \\
(multiple of individual gross earnings) & 18.2 & 14.9 & 11.9 & 7.9 & 5.9 & 4.0 \\
\hline
\end{tabular}

Assumptions: Real rate of return $3 \%$, real earnings growth $1.25 \%$, inflation $2 \%$, and real discount rate $2 \%$. All systems are modelled and indexed according to what is legislated except for the safety-nets which follow real-wages. Transitional rules apply where relevant. DC conversion rate equal 85\%. Labour market entry occurs at age 20 in 2014. Tax system latest available: 2013.

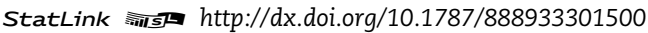




\section{Italy}

\section{Italy: Pension system in 2014}

The pension system is based on notional accounts. Contributions earn a rate of return related to real GDP growth. At retirement, the accumulated notional capital is converted into an annuity taking into account average life expectancy at retirement.
Key indicators: Italy

\begin{tabular}{|c|c|c|c|}
\hline & & Italy & OECD \\
\hline \multirow{2}{*}{ Average worker earnings (AW) } & EUR & 30463 & 33036 \\
\hline & USD & 36891 & 40007 \\
\hline Public pension spending & $\%$ of GDP & 15.8 & 7.9 \\
\hline \multirow[t]{2}{*}{ Life expectancy } & At birth & 82.3 & 80.0 \\
\hline & At age 65 & 20.4 & 19.3 \\
\hline Population over age 65 & $\%$ of population & 21.7 & 16.2 \\
\hline
\end{tabular}

\section{Qualifying conditions}

The normal pension age under the new system will increase gradually for men and women. The pension age will increase automatically in line with life expectancy at 65, every three years up to 2019 and every two years as of 2021 (the next revision is to add four months in 2016). The retirement age will be 67 for both men and women by 2019. In 2014 the retirement age was 63 years and nine months for women employed in the private sector gradually rising to 66 years and seven months in 2018 with 20 years of contributions. The pension age was 66 years and three months for men and women in the public sector in 2014. Only 15 years of contributions is necessary if the contributions are made before December 1992. The 2011 pension reform has introduced a flexible window of retirement between 62 and 70 years of age. Old-age pensions can be obtained with a minimum length of 20 years of contributions and whether the pension claimed is not lower than 1.5 times the old age social allowance in 2012, indexed with the five-year average of nominal GDP growth.

\section{Benefit calculation}

\section{Earnings-related scheme}

The notional accounts system has a contribution rate of $33 \%$, of which about one-third is paid by the employee and two-thirds by the employer. At retirement the pension benefit is calculated by applying the transformation coefficient to the accumulated lifelong contributions valorised with the nominal GDP growth rate (as a five-year moving-average). The transformation coefficient is a function based on the probabilities of death, the probabilities of leaving a widow or widower behind and the expected duration of years that a survivor's benefit will be withdrawn. 
The transformation coefficients are reviewed every three years. The transformation coefficients are available for the ages 62 to 70 . The latest available coefficients, applicable from the 1 January 2013 to 31 December 2015 are as follows:

\begin{tabular}{lll}
\hline Age & Divisor & Value (\%) \\
\hline 57 & 23.236 & 4.304 \\
58 & 22.647 & 4.416 \\
59 & 22.053 & 4.535 \\
60 & 21.457 & 4.661 \\
61 & 20.852 & 4.796 \\
62 & 20.242 & 4.940 \\
63 & 19.629 & 5.094 \\
64 & 19.014 & 5.259 \\
65 & 18.398 & 5.435 \\
66 & 17.782 & 5.624 \\
67 & 17.163 & 5.826 \\
68 & 16.541 & 6.046 \\
69 & 15.917 & 6.283 \\
70 & 15.288 & 6.541 \\
Discount rate $=1.5 \%$ & & \\
\hline
\end{tabular}

Source: Gazzetta Ufficiale, 24 May 2012.

In 2014 the minimum pay for contribution purposes was EUR 200.35 per week $(40 \%$ of the minimum pension). Maximum earnings for benefits were EUR 100123 per year under the new scheme, or just over $199 \%$ of the minimum pension.

The indexation of pensions in payment is progressive and lower pensions are indexed more generously than higher pensions. The indexation of pension benefits according ISTAT "cost-of-life" index was suspended in 2012 and 2013. In 2012 the suspension concerned pension benefits higher than EUR 1400 a month and in 2013 it concerned pension benefits higher than EUR 935 a month. The rule has since January 2009 been to index benefits above five times the minimum pension with prices above the threshold, pensions in payment have been up rated with 75\% of price inflation. In 2014-16 the new indexation rule for pensions in payment is: $100 \%$ of the "cost-of-life" index for treatments up to three times the minimum pension (EUR 1486.29 ); 95\% of the "cost-of-life" index for pensions up to four times the minimum pension (EUR 1981.72 ); 75\% of the "cost-of-life" index for pensions up to five times the minimum pension (EUR 2477.15 ); 50\% of the "cost-of-life" index for pensions up to six times the minimum pension (EUR 2 972.58); no indexation for pensions higher than the maximum threshold but a fixed benefit of EUR 13.08.

\section{Social assistance}

Under the old DB pension system contributions, people with a contributory pension below a minimum level (EUR 500.88 a month in 2014) could benefit of social payments (Minimum Pension Supplement) to reach EUR 6511.44 of pension income per year. In the notional account pension system, individuals without a contributory pension benefit can claim a means-tested tax-exempted social assistance benefit from the age of 65 years: the assegno sociale (old age social allowance). From 2013 this age increased to 65 years and three months which will increase in line with life expectancy. The assegno sociale for a single person was EUR 5813.15 annually in 2014 with 13 payments per year. In 2015 the benefit will increase to EUR 5824.83 per year. Beneficiaries of the assegno sociale aged 70 or over receive an additional monthly pension for up to EUR 190.15 which brings the benefit up to EUR 8285.16 a year. 


\section{Variant careers}

\section{Early retirement}

Early retirement is possible without penalty from age 62 if contributions have been paid for at least 42 years and six months for men and 41 years and six months for women. These requirements will increase in line with life expectancy. The next increase will be an additional four months to be added in 2016. For every year of early pension withdrawal pension entitlements are reduced by one percentage point. This reduction increases to two percentage points for each additional year if the age of departure is two years below the minimum of 62. The penalty, however, does not apply to workers who will meet the contribution requirement by 2017. For people under the contributive or mixed system, early retirement is possible only if the person fulfils the contribution requirement, without penalties due to age. Alternatively, these workers can retire at age 63 years and three months given the condition that they have paid contributions for at least 20 years and that the pension amount is not lower that 2.8 times the old age social allowance in 2012, indexed with the five-year average of nominal GDP.

\section{Late retirement}

It is possible to defer retirement and a higher transformation coefficient will be used.

\section{Childcare}

Mothers receive a more generous transformation coefficient than women without children. Women with one or two children receive a more favorable transformation coefficient used to calculate the pension benefit. The age that is used is the actual retirement age plus one year. For women with three or more children this age is equal to the actual age plus two years.

\section{Unemployment}

For businesses facing situations of distress, public assistance intervenes to grant earnings to workers through the Cassa Integrazione Guadagni (CIG). The CIG is payable to all employees excluding executives, trainees/apprentices and home workers. The length of the coverage varies, but the benefit is generally offered for up to 12 or 24 months. The allowance is equivalent to $80 \%$ of the last salary, but there are ceilings. In 2014 the maximum benefit was of EUR 969.77 per month for workers with a working salary up to EUR 2098.04 per month or EUR 25176.48 per year. For higher earnings the allowance equal EUR 1165.58 per month. The payment is subject to a reduction of $5.84 \%$ for social contributions and the maximum monthly net benefits were EUR 913.14 and EUR 1097.51 respectively. Benefits are subject to income tax.

For individuals in unintentional unemployment there is a monthly allowance for up to eight months if the worker is aged below 50 years or up to 12 months if the worker is aged 50 year to 55 years and up to 14 months otherwise. Entitlement to such benefit requires a minimum of one year of full contribution in the two years before the dismissal. Lower requirements apply to trainees/ apprentices or employees in the construction or agricultural sector. The unemployment allowance has been reformed and new rules apply gradually from 1 January 2013 to 31 December 2015, to be fully adopted from 1 January 2016. 
The benefit is equivalent to:

- $75 \%$ of the monthly average salary in the last two years before the dismissal, if the average salary is lower than a fixed threshold (equal to EUR 1192.98 in 2014) indexed with inflation.

- 75\% of EUR 1192.98 in 2014 and 25\% of the difference between the monthly average salary and the threshold in other cases.

In 2014 the benefit ceiling was equal to EUR 1165.58 per month.

After six months of unemployment the monthly allowance is lowered by $15 \%$ and after 12 months the benefit decreases by an additional 15\%. 
Pension modelling results: Italy in 2061, retirement at age 67

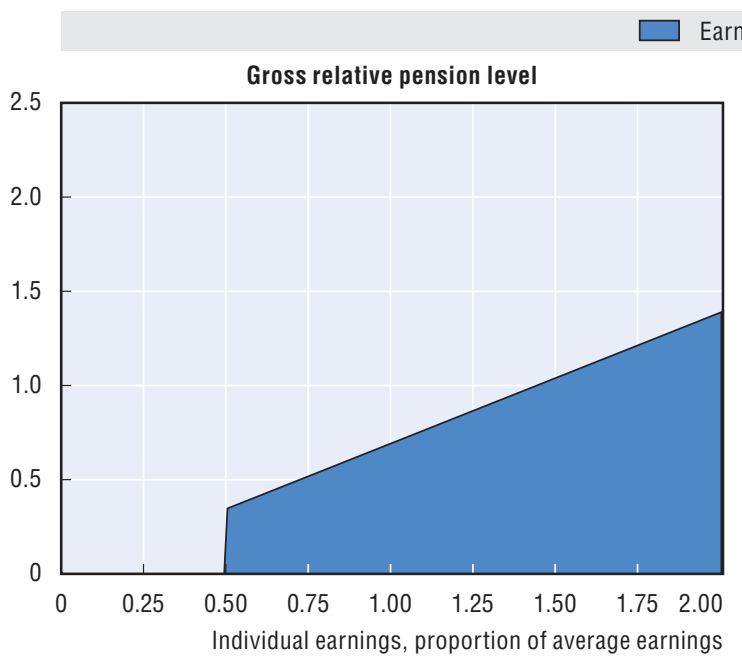

Earnings-related
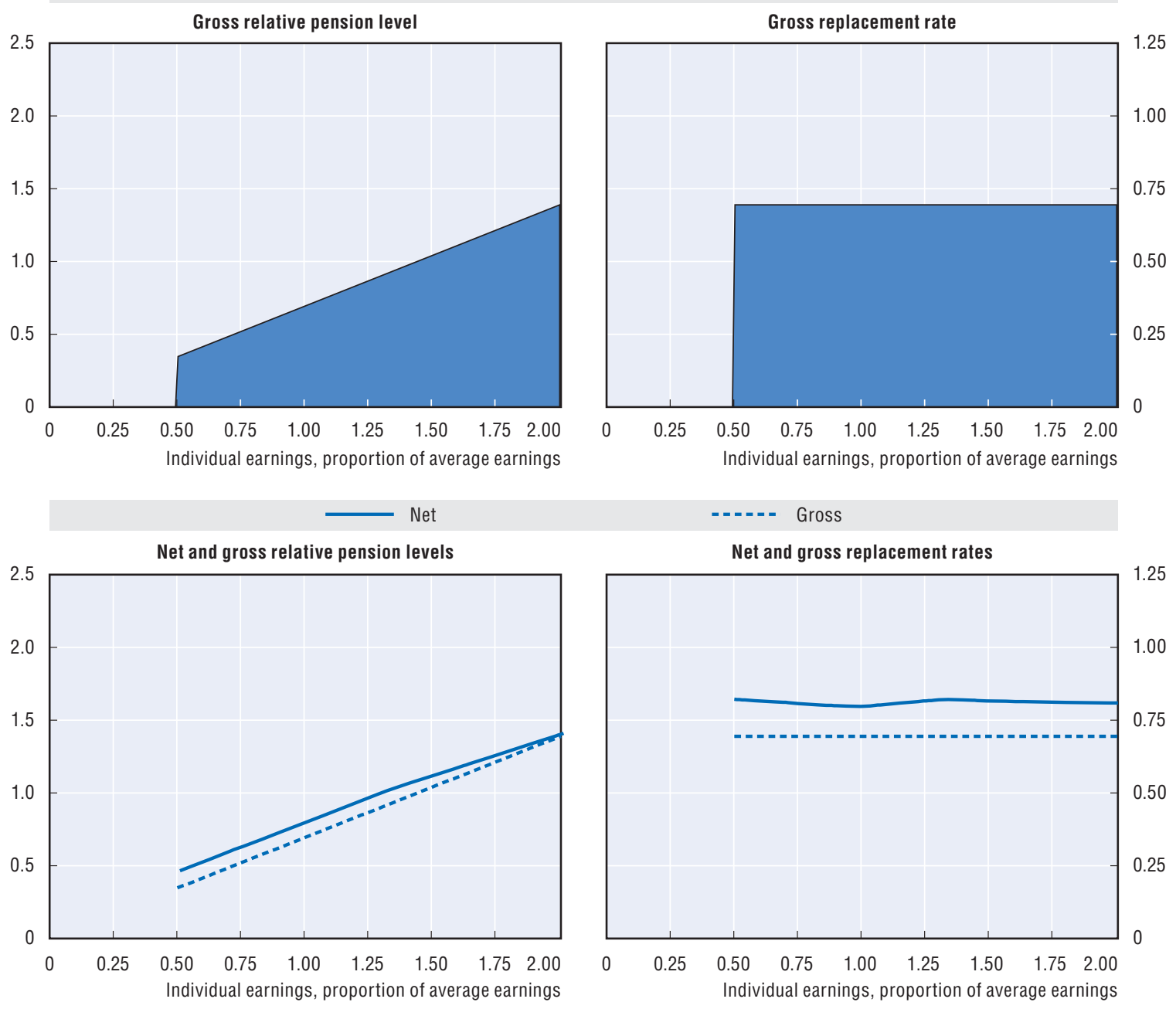

\begin{tabular}{|c|c|c|c|c|c|c|}
\hline \multicolumn{7}{|c|}{ Baseline scenario: Legislation scenario (price indexation of minimum and targeted pension benefits) } \\
\hline \multirow{2}{*}{$\begin{array}{l}\text { Men } \\
\text { Women (where different) }\end{array}$} & \multicolumn{6}{|c|}{ Individual earnings, multiple of average } \\
\hline & 0.5 & 0.75 & 1 & 1.5 & 2 & 3 \\
\hline Gross relative pension level & 34.7 & 52.1 & 69.5 & 104.2 & 139.0 & 208.5 \\
\hline \multicolumn{7}{|l|}{ (\% average gross earnings) } \\
\hline Net relative pension level & 45.8 & 62.8 & 79.7 & 111.8 & 140.2 & 196.3 \\
\hline \multicolumn{7}{|l|}{ (\% net average earnings) } \\
\hline Gross replacement rate & 69.5 & 69.5 & 69.5 & 69.5 & 69.5 & 69.5 \\
\hline \multicolumn{7}{|l|}{ (\% individual gross earnings) } \\
\hline Net replacement rate & 82.2 & 80.7 & 79.7 & 81.6 & 80.9 & 79.8 \\
\hline \multicolumn{7}{|l|}{ (\% individual net earnings) } \\
\hline Gross pension wealth & 12.2 & 12.2 & 12.2 & 12.2 & 12.2 & 12.2 \\
\hline (multiple of individual gross earnings) & 14.0 & 14.0 & 14.0 & 14.0 & 14.0 & 14.0 \\
\hline Net pension wealth & 11.0 & 10.1 & 9.6 & 9.0 & 8.4 & 7.9 \\
\hline (multiple of individual gross earnings) & 12.7 & 11.6 & 11.1 & 10.3 & 9.7 & 9.1 \\
\hline
\end{tabular}

Assumptions: Real rate of return $3 \%$, real earnings growth $1.25 \%$, inflation $2 \%$, and real discount rate $2 \%$. All systems are modelled and indexed according to what is legislated. Transitional rules apply where relevant. DC conversion rate equal $85 \%$. Labour market entry occurs at age 20 in 2014. Tax system latest available: 2014. 


\section{Japan}

\section{Japan: Pension system in 2014}

The public pension system has two tiers: a basic, flat-rate scheme and an earningsrelated plan (employees' pension scheme).
Key indicators: Japan

\begin{tabular}{|c|c|c|c|}
\hline & & Japan & OECD \\
\hline \multirow[t]{2}{*}{ Average worker earnings (AW) } & JPY (million) & 4.88 & 4.79 \\
\hline & USD & 40765 & 40007 \\
\hline Public pension spending & $\%$ of GDP & 10.2 & 7.9 \\
\hline \multirow[t]{2}{*}{ Life expectancy } & At birth & 83.5 & 80.0 \\
\hline & At age 65 & 21.9 & 19.3 \\
\hline Population over age 65 & $\%$ of population & 26.4 & 16.2 \\
\hline
\end{tabular}

\section{Qualifying conditions}

The basic old-age pension age is 65 years with a minimum of 25 years' of contributions. From 1 April 2017 the basic old-age pension benefit will require a minimum of ten years' of contributions. A full basic pension requires 40 years of contributions and benefits are adjusted proportionally for shorter or longer contribution periods.

The employees' pension is paid from age 65. The employees' pension is paid in addition to the basic pension with a minimum contribution period equal to one month and provided the pensioner is entitled to the basic pension. A "specially provided" employees' pension benefit is currently being phased out and the pension age for this benefit is gradually being raised. For the flat-rate component the pension age increased to 65 years for men in 2013 and will reach this level for women in 2018. The earnings-related pension age is also increasing from 60 to 65 years between 2013 and 2025 for men and between 2018 and 2030 for women.

\section{Benefit calculation}

\section{Basic}

The full annual basic pension benefit for 2014 was equal to JPY 772800 , corresponding to $16 \%$ of average worker earnings. The basic pension is indexed to net average wages until the pensioner reaches age 67 and price indexed after age 68.

\section{Social assistance}

In addition social assistance complements the pension system. The social assistance benefit for an individual aged 60 to 69 living in Tokyo in 2014 was JPY 981160 per year excluding housing benefit and other relevant benefit.

\section{Earnings-related}

The earnings-related pension benefit depends on both the remuneration and length of contributions. ${ }^{1}$ There is a ceiling to contributions of JPY 620000 a month equivalent to $152 \%$ of average worker earnings.

Until 2025, a "specially provided" employees' pension is partially available for individuals between 60 and 64 years of age. The "specially provided" employees' pension has a flat-rate and earnings-related component. The flat-rate benefit depends on year of birth. ${ }^{2}$ The "specially provided" employees' pension has been phased out from 2013 for men and will be so from 2018 for women. 
The employees' pension benefit in payment is indexed to net average earnings until the pensioner reaches age 67 and price-indexed after age 68 .

\section{Contracting out}

Employers who have at least 1000 employees may "contract out" from the earnings-related scheme if they cover their employees themselves. Around $15 \%$ of employees participate in these schemes. Contracting-out requires that employers offer at least $150 \%$ of the benefit that the public earnings-related scheme would have provided. The calculation of the pension required for contracting out is based on lifetime average nominal earnings. Indexation of pensions in payment and valorisation of past earnings is financed by the government.

The contribution rate in contracted-out schemes is determined by the government depending on the age structure of the covered employees and an actuarial assumption. Since 2005, the rate ranges between $2.4 \%$ and $5 \%$ of total remuneration.

Since 2001 the government has been promoting defined contribution pension schemes and defined benefit occupational pension schemes to replace earnings-related pensions schemes. From April 2014 the establishment of new earnings-related pension schemes is not possible.

\section{Variant careers}

\section{Early retirement}

Early retirement at a reduced benefit is possible in both the basic and earnings-related schemes. The benefit is reduced by $0.5 \%$ per month of early retirement, i.e. $6 \%$ per year. Individuals can claim the flat-rate component of the employees' pension between 60 and 65 . The pension in payment is indexed to net average earnings until the pensioner reaches age 67 and price-indexed after age 68 .

\section{Late retirement}

Late retirement is possible and deferral increases the pension benefit by $0.7 \%$ per month, i.e. $8.4 \%$ per year. Pension rights continue to accrue for each year of contributions.

Since 2004 it is possible to combine work and pension receipt after the age 65 of provided that the total income (from earnings and pension) does not exceed JPY 460000 . Above this limit, half of the excess will be reduced from the full earnings-related pension payment but basic pension will be paid in full. Workers over 70 do not need to pay contributions.

\section{Childcare}

Periods spent out of paid work for childcare are credited in the earnings-related scheme up to three years for each child and until when the last child becomes three years old. During this period contributions are considered to be made on the last earnings before the child care period. Qualifying conditions for the entire period is credited. In cases of part-time work the contribution will be based on the current earnings but the pension benefits will be calculated based on their full-time previous earnings. From 2014 maternity leave are exempt from social insurance premiums.

\section{Unemployment}

Unemployed or individuals whose income is below a certain level do not need to contribute to the earnings-related scheme; however they need to contribute to the basic scheme. Unemployed may be exempted from paying all, three-quarters, a half or one-quarter of contributions, depending on the household income level. A single person with previous year's income less than JPY 570000 is exempted from paying any contributions. People with income less than JPY 930000 are entitled to one-quarter of contributions, those with income lower than JPY 1410000 pay one-half and those with income less than JPY 1890000 pay three-quarters of contributions. 
For the periods of full exemption individuals are entitled to one-half of the basic pension and for the period with one-quarter of contribution five-eighths of the basic pension. For the periods with one-half contribution individuals gain three-quarters of the basic pension and for the period with three-quarters of contribution seven-eighths of the basic pension is credited. The exempted period is counted as full contribution period in assessing the qualifying conditions. It is possible to make up for contributions until 10 years later to receive higher pension after retirement.

\section{Notes}

1. Monthly amount of average pensionable remuneration $\times 0.7125 \% \times$ (the period of contributions until March 2003) + (amount of average pensionable remuneration including bonuses) $\times 0.5481 \% \times$ (the period of contributions after April 2003).

2. JPN $1676 \times$ (rate in accordance with the date of birth) $\times$ (the period of contributions) $\times 0.961$. 
Pension modelling results: Japan in 2059, retirement at age 65
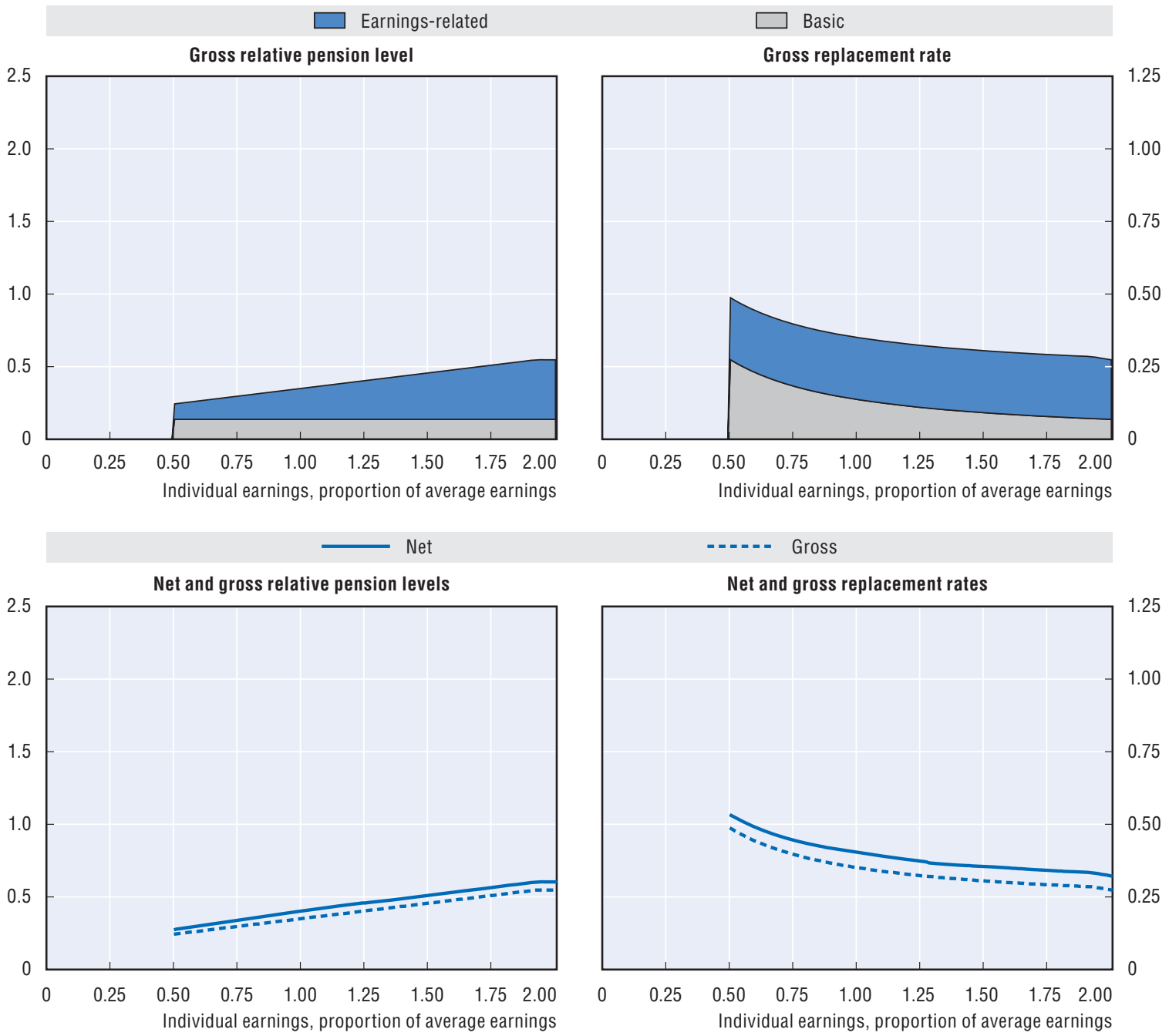

\begin{tabular}{|c|c|c|c|c|c|c|}
\hline \multicolumn{7}{|c|}{ Baseline scenario: Full-wage indexation of targeted schemes } \\
\hline \multirow{2}{*}{$\begin{array}{l}\text { Men } \\
\text { Women (where different) }\end{array}$} & \multicolumn{6}{|c|}{ Individual earnings, multiple of average } \\
\hline & 0.5 & 0.75 & 1 & 1.5 & 2 & 3 \\
\hline Gross relative pension level & 24.4 & 29.7 & 35.1 & 45.7 & 54.7 & 54.7 \\
\hline \multicolumn{7}{|l|}{ (\% average gross earnings) } \\
\hline Net relative pension level & 27.5 & 33.9 & 40.4 & 51.1 & 60.4 & 60.4 \\
\hline \multicolumn{7}{|l|}{ (\% net average earnings) } \\
\hline Gross replacement rate & 48.8 & 39.6 & 35.1 & 30.5 & 27.4 & 18.2 \\
\hline \multicolumn{7}{|l|}{ (\% individual gross earnings) } \\
\hline Net replacement rate & 53.3 & 44.5 & 40.4 & 35.5 & 32.1 & 22.6 \\
\hline \multicolumn{7}{|l|}{ (\% individual net earnings) } \\
\hline Gross pension wealth & 9.1 & 7.4 & 6.6 & 5.7 & 5.1 & 3.4 \\
\hline (multiple of individual gross earnings) & 10.7 & 8.7 & 7.7 & 6.7 & 6.0 & 4.0 \\
\hline Net pension wealth & 8.1 & 6.6 & 5.9 & 5.0 & 4.4 & 3.0 \\
\hline (multiple of individual gross earnings) & 9.4 & 7.8 & 6.9 & 5.8 & 5.2 & 3.5 \\
\hline
\end{tabular}

Assumptions: Real rate of return $3 \%$, real earnings growth $1.25 \%$, inflation $2 \%$, and real discount rate $2 \%$. All systems are modelled and indexed according to what is legislated except for the safety-nets which follow real-wages. Transitional rules apply where relevant. DC conversion rate equal 85\%. Labour market entry occurs at age 20 in 2014. Tax system latest available: 2013.

StatLink ains http://dx.doi.org/10.1787/888933301523 


\section{Korea}

\section{Korea: Pension system in 2014}

The Korean public pension scheme was introduced relatively recently. It is an earnings-related scheme with a progressive formula, since benefits are based on both individual earnings and the average earnings of the insured as a whole.
Key indicators: Korea

\begin{tabular}{|c|c|c|c|}
\hline & & Korea & OECD \\
\hline \multirow[t]{2}{*}{ Average worker earnings (AW) } & KRW (million) & 39.8 & 43.7 \\
\hline & USD & 36457 & 40007 \\
\hline Public pension spending & $\%$ of GDP & 2.2 & 7.9 \\
\hline \multirow[t]{2}{*}{ Life expectancy } & At birth & 81.4 & 80.0 \\
\hline & At age 65 & 19.7 & 19.3 \\
\hline Population over age 65 & $\%$ of population & 13.0 & 16.2 \\
\hline
\end{tabular}

\section{Qualifying conditions}

The pension age is currently 61 with at least ten years of contributions. A reduced early pension can be withdrawn from the age of 56 years.

The normal pension age is gradually being increased reaching 65 from 2033 and the early pension age will also increase from 55 years to 60 years.

\section{Benefit calculation}

\section{Earnings-related}

The earnings-related targeted replacement rate after 40 years of contributions is $47 \%$ in 2014 and is being reduced by 0.5 percentage points for every year from 2008 until reaching $40 \%$ in 2028 . The pension benefit is calculated as half of the targeted rate times the individual's lifetime average earnings valorised in line with nominal wage growth and half of the average earnings of the insured measured over the previous three years and valorised in line with prices (A value). There is a ceiling of pensionable earnings equal to KRW 4.08 million per month, equivalent to $206 \%$ of the A value in 2014. The A value was equal to KRW 1981975 in 2014.

The highest possible pension benefit is equal to $100 \%$ of individual earnings. The benefits in payment are indexed to prices. People above the age of 60 do not pay contributions and benefits do not accrue after this age.

\section{Basic age pension}

Some $70 \%$ of those aged 65 and over can get "Basic Pension". The Basic pension benefit replaced the Basic Old Age Pension in 1 July 2014. The maximum benefit is equal to KRW 200000 which is about $10 \%$ of the three-year average earnings of the insured of the National Pension (A value). Seniors receiving no or less than KRW 300000 per month from their National Pension get an additional KRW 200000 per month. The remaining seniors receive the following in below formula.

(KRW $200000-2 / 3 *$ A value of the National Pension) + KRW 100000

Couple rate is $80 \%$ of single rate each.

\section{Social assistance}

There are two criteria for the Basic Livelihood Security (social assistance). First the recognised income of a recipient's household should be less than the minimum cost of living per household. Second, a recipient should have no person under obligation to support. If a recipient has a person under obligation to support, he/she should not have capacity to support the recipient; or a recipient should be unable to be supported. 
There are seven forms of Livelihood benefits: housing benefits, self-sufficiency benefits, education benefits, childbirth benefits, funeral benefits, and medical benefits.

\section{Variant careers}

\section{Early retirement}

The early retirement age is increasing form 55 years to 60 years in 2033. The early retirement pension decreases the pension benefit with 6 percentage points for every year below the normal retirement age. The early retirement benefit is equal to $70 \%$ of the old-age pension if the benefit is withdrawn five years earlier. An individual retiring at the age of 60 in 2014 will be entitled to an early retirement benefit equal to $94 \%$ of the full old-age pension benefit.

\section{Late retirement}

Pension's deferral is possible and increases the pension benefit with $7.2 \%$ for every year above the normal retirement age. The pension benefit can be deferred for a maximum of five years. Pensioners above age 61 with higher earnings than the average insured will receive $50 \%$ of the full age-age pension and see the benefit increase by $10 \%$ according to the age increase. This is known as the "active old-age pension". Pensioners between ages 61 and 65 and that are working can chose either the "deferred pension" or the active "old-age pension".

\section{Childcare}

A person who is not on the labour market due to childcare can apply for exemptions from pension contributions and be exempted from payment of contributions during the period requested. Individuals are able to increase their insurance period by paying additional contributions by themselves after resuming work.

Pension credits are given to insured women who give birth, except for the first child. The credits are given to 12 months up to a maximum of 50 months depending on the number of children.

\section{Unemployment}

Unemployed individuals can apply for contribution exemption and be exempted from paying pension contributions during the period requested. They are able to increase the insured period by paying the exempted contributions themselves after resuming work. 
Pension modelling results: Korea in 2059, retirement at age 65
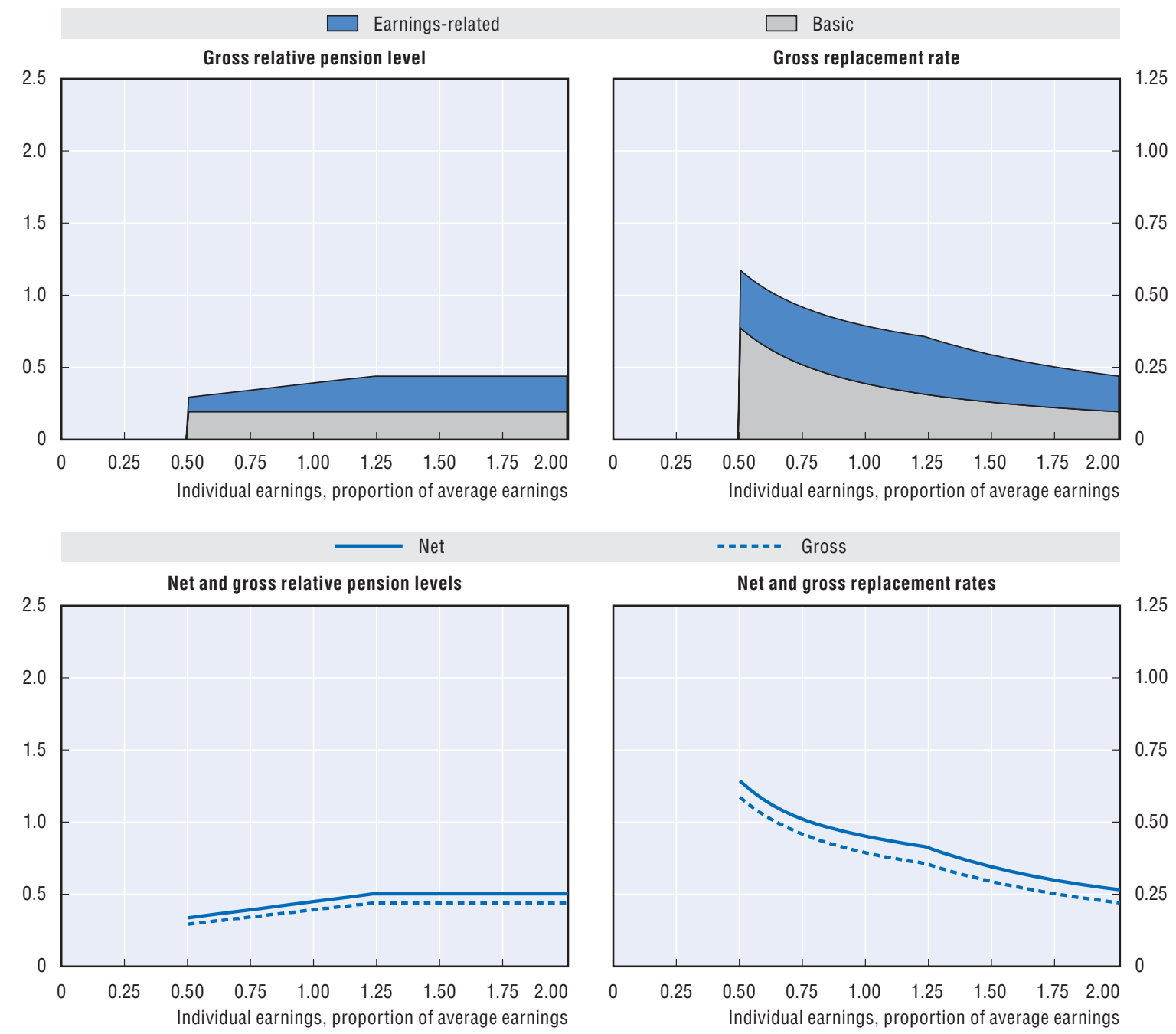

\begin{tabular}{|c|c|c|c|c|c|c|}
\hline \multicolumn{7}{|c|}{ Baseline scenario: Legislation scenario (price indexation of targeted schemes) } \\
\hline \multirow{2}{*}{$\begin{array}{l}\text { Men } \\
\text { Women (where different) }\end{array}$} & \multicolumn{6}{|c|}{ Individual earnings, multiple of average } \\
\hline & 0.5 & 0.75 & 1 & 1.5 & 2 & 3 \\
\hline Gross relative pension level & 29.3 & 34.3 & 39.3 & 43.9 & 43.9 & 43.9 \\
\hline \multicolumn{7}{|l|}{ (\% average gross earnings) } \\
\hline Net relative pension level & 33.7 & 39.4 & 45.0 & 50.2 & 50.2 & 50.2 \\
\hline \multicolumn{7}{|l|}{ (\% net average earnings) } \\
\hline Gross replacement rate & 58.6 & 45.7 & 39.3 & 29.3 & 22.0 & 14.6 \\
\hline \multicolumn{7}{|l|}{ (\% individual gross earnings) } \\
\hline Net replacement rate & 64.3 & 50.9 & 45.0 & 34.4 & 26.5 & 18.6 \\
\hline \multicolumn{7}{|l|}{ (\% individual net earnings) } \\
\hline Gross pension wealth & 10.7 & 8.4 & 7.2 & 5.3 & 4.0 & 2.7 \\
\hline (multiple of individual gross earnings) & 12.6 & 9.8 & 8.4 & 6.3 & 4.7 & 3.1 \\
\hline Net pension wealth & 10.7 & 8.3 & 7.1 & 5.3 & 4.0 & 2.6 \\
\hline (multiple of individual gross earnings) & 12.5 & 9.8 & 8.4 & 6.2 & 4.7 & 3.1 \\
\hline
\end{tabular}

Assumptions: Real rate of return $3 \%$, real earnings growth $1.25 \%$, inflation $2 \%$, and real discount rate $2 \%$. All systems are modelled and indexed according to what is legislated. Transitional rules apply where relevant. DC conversion rate equal $85 \%$. Labour market entry occurs at age 20 in 2014. Tax system latest available: 2013. 


\section{Luxembourg}

\section{Luxembourg: Pension system in 2014}

The public pension scheme has a basic and an earnings-related part. There is also a minimum pension.

\begin{tabular}{|c|c|c|c|}
\hline & & Luxembourg & OECD \\
\hline \multirow[t]{2}{*}{ Average worker earnings (AW) } & EUR & 54560 & 33036 \\
\hline & USD & 66074 & 40007 \\
\hline Public pension spending & $\%$ of GDP & 7.7 & 7.9 \\
\hline \multirow[t]{2}{*}{ Life expectancy } & At birth & 80.5 & 80.0 \\
\hline & At age 65 & 19.4 & 19.3 \\
\hline Population over age 65 & $\%$ of population & 14.4 & 16.2 \\
\hline
\end{tabular}

\section{Qualifying conditions}

An early pension is payable from age 57 with 40 years' of compulsory or voluntary contributions. With 40 years' coverage of compulsory, voluntary or credited contributions, the pension can be paid from age 60. Otherwise, the normal pension age is 65 (subject to at least ten years' contributions).

\section{Benefit calculation}

\section{Basic}

The basic pension benefit equalled EUR 453 per month in 2014, subject to 40 years of coverage. For incomplete insurance periods the benefit is reduced proportionally. Formally, the basic pension corresponds to a fixed annual percentage parameter of a reference amount, which amounted to $23.725 \%$ and EUR 1910 , respectively, in 2014.

There is also an "end-of-year allowance", which adds EUR 61 per month to the pension for 40 years' contributions. Just as for the basic pension, it is proportionally reduced for shorter insurance periods, implying around EUR 1.53 per month for each year covered. The end-of-year allowance is indexed to nominal earnings.

\section{Earnings-related}

The accrual rate for the earnings-related pension benefit corresponds to a fixed annual percentage parameter and is equal to $1.838 \%$. The earnings measure used in the formula to calculate the benefit is lifetime average pay re-valued in line with nominal earnings growth.

The accrual rate is higher for older workers and those with longer contribution periods. For each year above 93, the sum of the individual's age and years of contributions, the accrual rate is increased by 0.011 percentage points. Both parameters represent the values that apply in 2014 and will change over time. The maximum accrual rate is equal to $2.05 \%$ per year.

The maximum pension in 2014 was EUR 7958 per month (formally specified as $25 / 6$ of the reference amount).

Benefits are automatically indexed to changes in the cost of living (if cumulative inflation is at least 2.5\%). In addition, adjustments to increases in real wages must be considered every year. From 1 January 2013 adjustments of pensions to wages are only possible as long as annual income from contributions exceeds pension expenditure. 


\section{Minimum}

The minimum pension benefit is equal to EUR 1719 per month (defined as 90\% of the reference amount) and conditional to 40 years' coverage. The benefit is proportionally reduced for shorter periods subject to a minimum of 20 years of compulsory, voluntary or credited contributions.

\section{Social assistance}

The social-assistance safety-net level is EUR 1348 per month for a single person and EUR 2022 per month for a domestic community of two adults in 2014. In order to be eligible an individual has to be 25 years of age and a legal residence.

\section{Variant careers}

\section{Early retirement}

Early retirement is possible at age 57 with 40 years' of paid contributions, and at 60 with 40 years' paid or credited contributions. Early retirees may work provided that the earnings and the premium benefit do not exceed the average of the five best yearly incomes of the career so far. There is no further actuarial adjustment to benefits for early retirement.

In addition, there are a number of pre-retirement programmes. Relevant here are the preretirement solidarity and pre-retirement adaptation schemes. The pre-retirement solidary scheme allows early retirement given that the employer hires a job seeker assigned by the employment administration. The Pre-retirement adaption scheme allows for early retirement for older workers losing their jobs due to restructuring or bankruptcy. Both schemes are available from the age of 57 years, provided that conditions for early retirement from age 60 are satisfied within the following three years. The pre-retirement benefit is equal to $85 \%$ of past earnings in the first year, $80 \%$ in the second year, and $75 \%$ in the third. The earnings measure is pay in the preceding three months.

\section{Late retirement}

The pension benefit has to be claimed at age of 65 . However, it is possible to combine work and pension benefits receipt without reductions in the pension benefit.

\section{Childcare}

Parental leave benefits and periods are credited and enter into the pension benefit formula. Parental leave is equal to six months of full-time or 12 months of part-time parental leave per child are granted upon request if a parent satisfies the qualifying conditions. During this period, a monthly allowance equal to EUR 1778 (EUR 889 for part-time leave) is paid. These earnings are pensionable, and the period is relevant for eligibility, thus entering into the flat rate component of the pension formula.

Childcare periods ("baby years") equal to two years for one and four years for two children are credited as insured time. Pensionable earnings are based on income immediately before the baby years are claimed. The period counts as qualifying conditions and enters in the flat rate component of the pension formula.

Employees with insufficient contributory years to claim baby-years have the right to a special monthly allowance at retirement equal to EUR 109 per child.

Non-contributory periods for bringing up children under age six count towards the qualifying conditions. 


\section{Unemployment}

Unemployment benefits and periods are credited. The pension contributions from the benefits are paid by state (two-thirds) and beneficiary (one-third). The unemployment period counts towards the qualifying conditions and enters in the earnings-related component of the pension formula. For this period, unemployment benefit is used as a base for pension calculation. 


\section{Pension modelling results: Luxembourg in 2054, retirement at age 60}
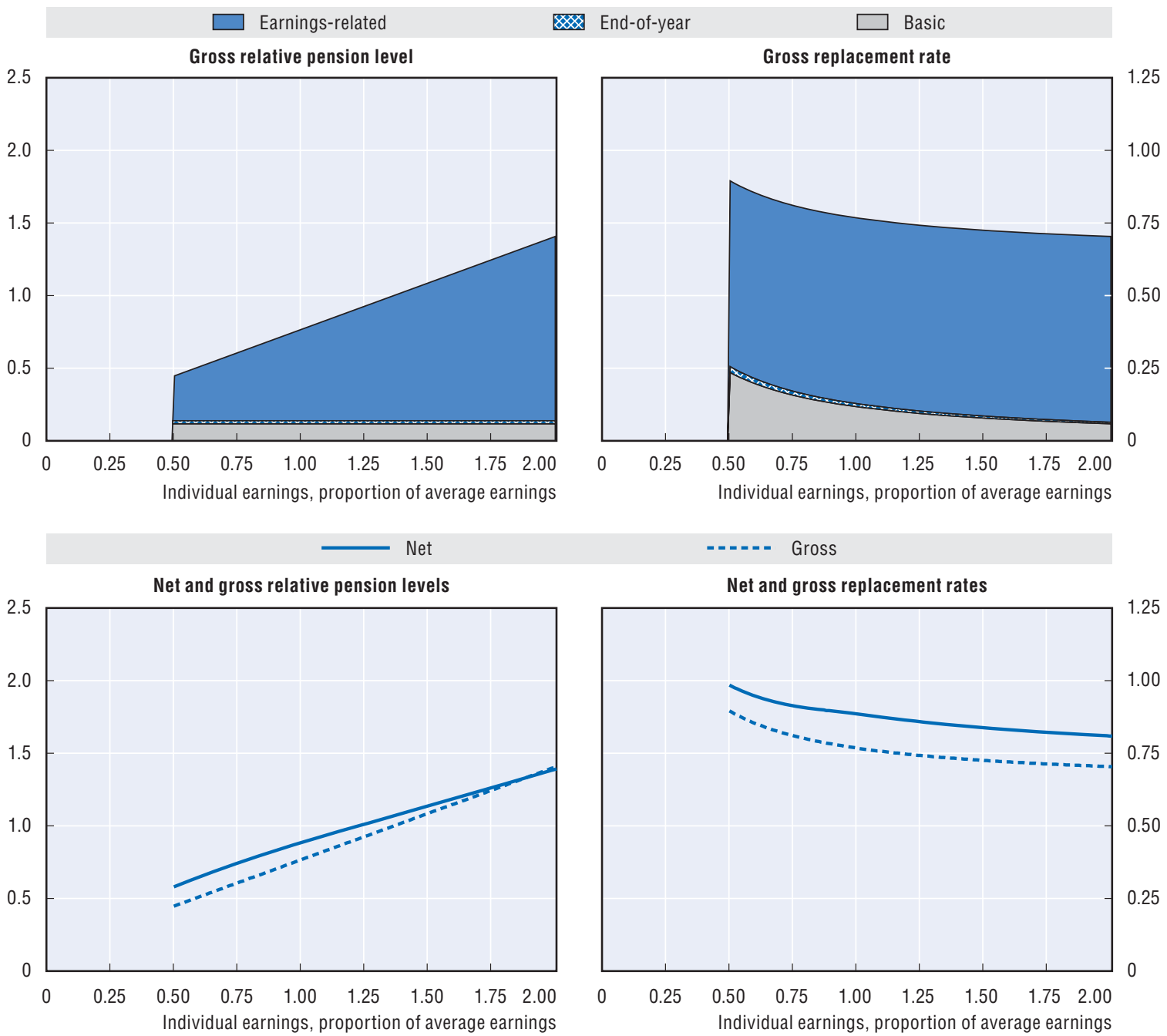

\begin{tabular}{|c|c|c|c|c|c|c|}
\hline \multicolumn{7}{|c|}{ Baseline scenario: Legislation scenario (wage indexation of targeted schemes) } \\
\hline \multirow{2}{*}{$\begin{array}{l}\text { Men } \\
\text { Women (where different) }\end{array}$} & \multicolumn{6}{|c|}{ Individual earnings, multiple of average } \\
\hline & 0.5 & 0.75 & 1 & 1.5 & 2 & 3 \\
\hline Gross relative pension level & 44.8 & 60.8 & 76.8 & 108.8 & 140.8 & 187.8 \\
\hline \multicolumn{7}{|l|}{ (\% average gross earnings) } \\
\hline Net relative pension level & 58.1 & 74.4 & 88.6 & 113.9 & 139.1 & 176.2 \\
\hline \multicolumn{7}{|l|}{ (\% net average earnings) } \\
\hline Gross replacement rate & 89.5 & 81.0 & 76.8 & 72.5 & 70.4 & 62.6 \\
\hline \multicolumn{7}{|l|}{ (\% individual gross earnings) } \\
\hline Net replacement rate & 98.4 & 91.3 & 88.6 & 83.7 & 80.9 & 70.9 \\
\hline \multicolumn{7}{|l|}{ (\% individual net earnings) } \\
\hline Gross pension wealth & 20.8 & 18.8 & 17.8 & 16.8 & 16.3 & 14.5 \\
\hline (multiple of individual gross earnings) & 23.8 & 21.6 & 20.4 & 19.3 & 18.7 & 16.7 \\
\hline Net pension wealth & 18.9 & 16.1 & 14.4 & 12.4 & 11.3 & 9.6 \\
\hline (multiple of individual gross earnings) & 21.7 & 18.5 & 16.5 & 14.2 & 13.0 & 11.0 \\
\hline
\end{tabular}

Assumptions: Real rate of return $3 \%$, real earnings growth $1.25 \%$, inflation $2 \%$, and real discount rate $2 \%$. All systems are modelled and indexed according to what is legislated. Transitional rules apply where relevant. DC conversion rate equal $85 \%$. Labour market entry occurs at age 20 in 2014. Tax system latest available: 2013. 


\section{Mexico}

\section{Mexico: Pension system in 2014}

Mexico's retirement income system has three components: a means-tested age pension called 65+; two mandatory defined contribution systems one for private workers and other for public servants with a minimum pension; and other individual and occupational private plans. In addition States, local authorities and public universities have their own independent pension systems.
Key indicators: Mexico

\begin{tabular}{|c|c|c|c|}
\hline & & Mexico & OECD \\
\hline \multirow[t]{2}{*}{ Average worker earnings (AW) } & MXN & 101904 & 589793 \\
\hline & USD & 6912 & 40007 \\
\hline Public pension spending & $\%$ of GDP & 1.8 & 7.9 \\
\hline \multirow[t]{2}{*}{ Life expectancy } & At birth & 77.4 & 80.0 \\
\hline & At age 60 & 18.8 & 19.3 \\
\hline Population over age 65 & $\%$ of population & 6.8 & 16.2 \\
\hline
\end{tabular}

\section{Qualifying conditions}

Normal retirement age is 65 for men and women, subject to 1250 weeks (around 24 years) of contribution in the private sector and 25 years for public servants.

\section{Defined contribution}

Out of the total contribution of $6.5 \%$ of individual earnings to an individual account, workers contribute $1.125 \%$, employers contribute $5.150 \%$, and the government contributes $0.225 \%$. An additional $5 \%$ contribution is made by the employer to an individual housing sub-account (a scheme known as INFONAVIT) which reverts to the retirement account when it is not used. There is a ceiling on contributions of $6.5 \%$ of 25 times the minimum wage.

In addition, the government contributes a progressive amount into individual retirement accounts per day of contribution called cuota social or social fee. As of December 2014 the social fees were as follows: for workers who earn up to one minimum wage, the social fee is MXN 4.78130; for those who earn between 1.01 and four times the minimum wage, MXN 4.58208; for those in the 4.01 to seven times the minimum wage bracket, MXN 4.38286; for those in the 7.01 to ten times the minimum wage bracket, MXN 4.18364 and finally, for those who earn between 10.01 and 15 times the minimum wage, MXN 3.98442. For higher wage earners there is no social fee contribution. The social fee is indexed to inflation every three months.

\section{Benefit calculation}

At retirement, the individual converts the accumulated account balance (discounting the premium for survivors' benefits insurance) into a price-indexed annuity or a programmed withdrawal. Annuity rates are sex-specific.

The pensioner, who opts for the alternative of programmed withdrawals, can purchase a life annuity at any time if the monthly life annuity value is greater than the guaranteed pension.

\section{Minimum pension}

At retirement, if a worker is aged 65 and has contributed to at least 1250 weeks (around 24 years), but the assets accumulated in their account are not enough to at least buy an annuity equivalent to the minimum pension, then their assets are transferred to the government and they are entitled to the minimum pension (paid by the government). 
The minimum (guaranteed) pension is equivalent to MXN 31211.52 annually (December 2014) and is indexed to inflation every year.

\section{Negative statement (Negativa de pension)}

At retirement, if the individual has contributed for less than 1250 weeks he is not entitled to a pension and gets a negative statement "negativa de pension". Then, he gets a lump sum of the resources accumulated in his account.

\section{Non-contributory means tested old age pension or safety net 65+}

There is an old-age pension (PAM) targeted to all individuals that have reached the age of 65 and do not have a pension from a social security institute. The monthly amount paid to each beneficiary is MXN 580.

\section{Variant careers}

\section{Early retirement}

Early retirement is possible from age 60 up to 64 for men and women if they are not employed and have made at least 1250 weekly contributions.

Members may retire at any age prior to 60 years old if the accumulated balance in their account allows them to buy a life annuity that is at least $30 \%$ higher than the minimum guaranteed pension, provided they have contributed for at least 1250 weeks.

\section{Late retirement}

It is not mandatory to retire at 65 . It is possible to defer the pension after age 65 for both private and public sector workers.

\section{Unemployment}

There is no specific credit mechanisms for periods of unemployment. When a worker is unemployed, he/she will have the right to withdraw some money from his/her old-age/retirement sub-account once every five years. Unemployed members may withdraw the lower of the equivalent of 90 days of their average salary during the last 250 weeks in which he/she paid contributions or $11.5 \%$ of their account balance. The benefit may be distributed in a maximum of six monthly instalments. Unemployed members whose individual account were opened at least three years in advance to the unemployment spell and have paid at least two years of contributions may withdraw, in only one instalment, up to 30 days of their salary with a limit of ten minimum monthly wages.

\section{Childcare}

There is no specific credit for periods spent caring for children. 
Pension modelling results: Mexico in 2059, retirement at age 65
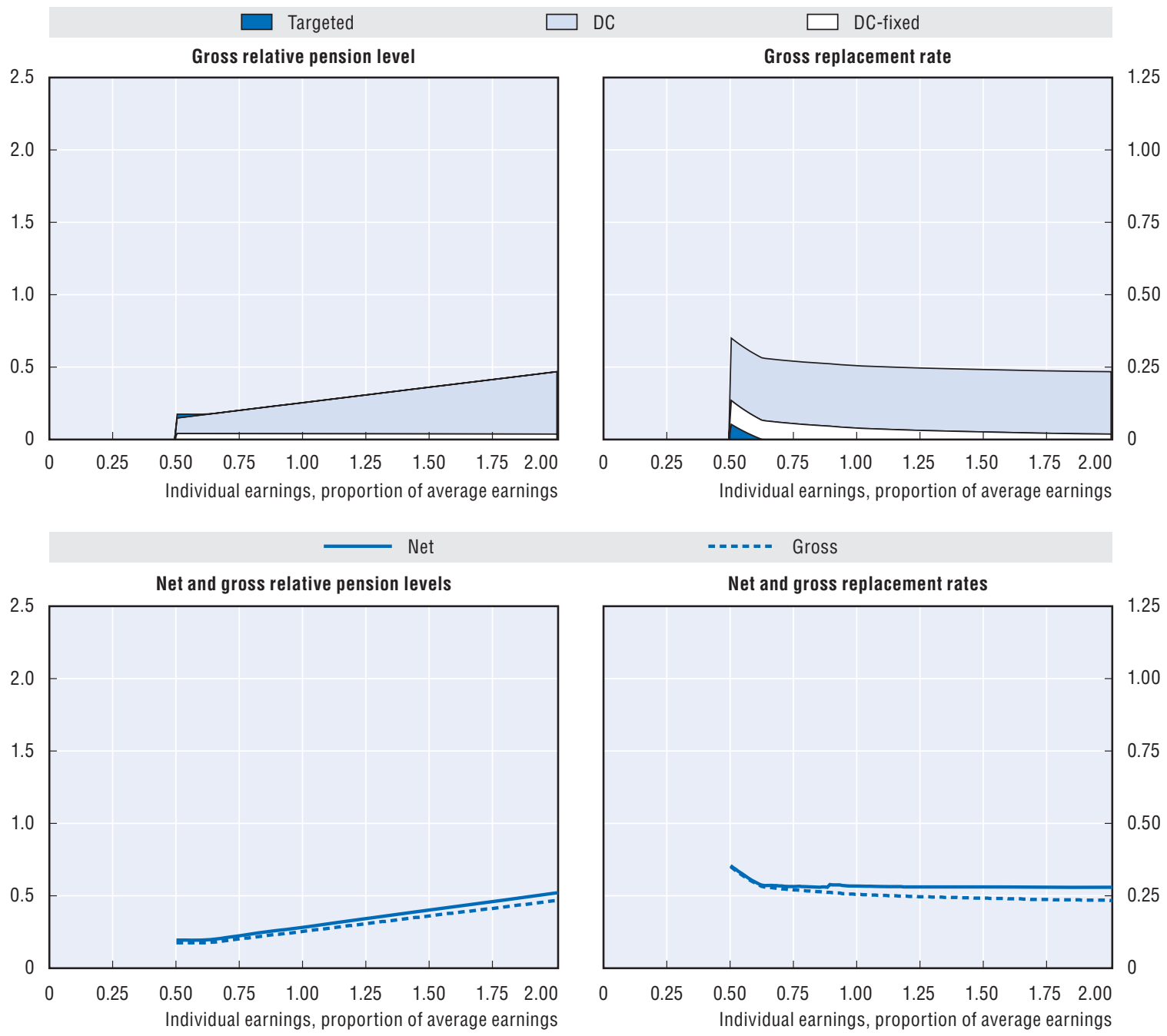

\begin{tabular}{|c|c|c|c|c|c|c|}
\hline \multicolumn{7}{|c|}{ Baseline scenario: Legislation scenario (price indexation of targeted schemes) } \\
\hline \multirow{2}{*}{$\begin{array}{l}\text { Men } \\
\text { Women (where different) }\end{array}$} & \multicolumn{6}{|c|}{ Individual earnings, multiple of average } \\
\hline & 0.5 & 0.75 & 1 & 1.5 & 2 & 3 \\
\hline Gross relative pension level & 17.5 & 20.3 & 25.5 & 36.3 & 46.9 & 68.0 \\
\hline (\% average gross earnings) & & 18.8 & 23.6 & 33.6 & 43.4 & 62.9 \\
\hline Net relative pension level & 19.5 & 22.6 & 28.4 & 40.3 & 52.1 & 75.7 \\
\hline (\% net average earnings) & & 20.9 & 26.2 & 37.3 & 48.3 & 70.0 \\
\hline Gross replacement rate & 35.0 & 27.0 & 25.5 & 24.2 & 23.4 & 22.7 \\
\hline (\% individual gross earnings) & & 25.0 & 23.6 & 22.4 & 21.7 & 21.0 \\
\hline Net replacement rate & 35.5 & 28.1 & 28.4 & 28.1 & 27.9 & 27.9 \\
\hline (\% individual net earnings) & & 26.1 & 26.2 & 26.0 & 25.8 & 25.8 \\
\hline Gross pension wealth & 6.1 & 4.7 & 4.5 & 4.2 & 4.1 & 4.0 \\
\hline (multiple of individual gross earnings) & 6.6 & 4.7 & 4.5 & 4.2 & 4.1 & 4.0 \\
\hline Net pension wealth & 6.1 & 4.7 & 4.5 & 4.2 & 4.1 & 4.0 \\
\hline (multiple of individual gross earnings) & 6.6 & 4.7 & 4.5 & 4.2 & 4.1 & 4.0 \\
\hline
\end{tabular}

Assumptions: Real rate of return $3 \%$, real earnings growth $1.25 \%$, inflation $2 \%$, and real discount rate $2 \%$. All systems are modelled and indexed according to what is legislated. Transitional rules apply where relevant. DC conversion rate equal $85 \%$. Labour market entry occurs at age 20 in 2014. Tax system latest available: 2014. 
Pension modelling results: Mexico in 2059, retirement at age 65 (cont.)

\begin{tabular}{|c|c|c|c|c|c|c|}
\hline \multicolumn{7}{|c|}{ Alternative scenario: Full-wage indexation of targeted schemes } \\
\hline \multirow{2}{*}{$\begin{array}{l}\text { Men } \\
\text { Women (where different) }\end{array}$} & \multicolumn{6}{|c|}{ Individual earnings, multiple of average } \\
\hline & 0.5 & 0.75 & 1 & 1.5 & 2 & 3 \\
\hline Gross relative pension level & 30.6 & 30.6 & 30.6 & 36.3 & 46.9 & 68.0 \\
\hline (\% average gross earnings) & & & & 33.6 & 43.4 & 62.9 \\
\hline Net relative pension level & 34.1 & 34.1 & 34.1 & 40.3 & 52.1 & 75.7 \\
\hline (\% net average earnings) & & & & 37.3 & 48.3 & 70.0 \\
\hline Gross replacement rate & 61.3 & 40.8 & 30.6 & 24.2 & 23.4 & 22.7 \\
\hline (\% individual gross earnings) & & & & 22.4 & 21.7 & 21.0 \\
\hline Net replacement rate & 62.0 & 42.5 & 34.1 & 28.1 & 27.9 & 27.9 \\
\hline (\% individual net earnings) & & & & 26.0 & 25.8 & 25.8 \\
\hline Gross pension wealth & 10.7 & 7.2 & 5.4 & 4.2 & 4.1 & 4.0 \\
\hline (multiple of individual gross earnings) & 11.6 & 7.7 & 5.8 & 4.2 & 4.1 & 4.0 \\
\hline Net pension wealth & 10.7 & 7.2 & 5.4 & 4.2 & 4.1 & 4.0 \\
\hline (multiple of individual gross earnings) & 11.6 & 7.7 & 5.8 & 4.2 & 4.1 & 4.0 \\
\hline
\end{tabular}

Assumptions: Real rate of return $3 \%$, real earnings growth $1.25 \%$, inflation $2 \%$, and real discount rate $2 \%$. All systems are modelled and indexed according to what is legislated except for the safety-nets which follow real-wages. Transitional rules apply where relevant. DC conversion rate equal 85\%. Labour market entry occurs at age 20 in 2014. Tax system latest available: 2014.

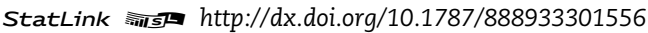




\section{Netherlands}

\section{Netherlands: Pension system in 2014}

The pension system has three main pillars: a flat-rate state pension (AOW) related to minimum wages and financed via payroll taxes, funded occupational pension schemes, and individual saving schemes. Although there is no statutory obligation for employers to offer a pension scheme to their employees, industrial-relation agreements mean that $91 \%$ of employees are covered. These schemes are therefore best thought of as quasimandatory.
Key indicators: Netherlands

\begin{tabular}{|c|c|c|c|}
\hline & & Netherlands & OECD \\
\hline \multirow[t]{2}{*}{ Average worker earnings (AW) } & EUR & 48856 & 33036 \\
\hline & USD & 59165 & 40007 \\
\hline Public pension spending & $\%$ of GDP & 5.5 & 7.9 \\
\hline \multirow[t]{2}{*}{ Life expectancy } & At birth & 80.9 & 80.0 \\
\hline & At age 65 & 19.3 & 19.3 \\
\hline Population over age 65 & $\%$ of population & 18.1 & 16.2 \\
\hline
\end{tabular}

\section{Qualifying conditions}

The basic old-age pension was payable from age 65 and two months in 2014. All residents are eligible for this benefit. The normal retirement age is typically also 65 in occupational plans. The statutory pension age is gradually increasing to 66 in 2018 and 67 in 2021. Thereafter, the standard retirement age will be linked to gains in life expectancy.

\section{Benefit calculation}

\section{Basic}

The basic pension benefit for a single person equalled EUR 1099.37 per month in 2014. There is an additional holiday allowance of EUR 50.11 per person in 2014. This gives a total of EUR 1149.48 for singles and EUR 1619.29 for couples. The benefit value is linked to changes in the net minimum wage which is uprated biannually.

The basic benefit accrues at $2 \%$ of the full value for each year an individual who resides or works in the Netherlands. For older people and/or households with less than 50 years of Dutch residency and with no other means of support or no assets there is also a means tested social-assistance scheme available. It supplements the available benefits from basic and occupational schemes to a maximum value equal to the net basic pension.

\section{Occupational schemes}

The Netherlands also has an occupational private pension system with broad coverage. The system consisted of 544 pension funds at the beginning of 2012 and 414 at the end of the year; 74 of these funds concern industry-wide schemes. Under certain conditions Dutch companies which are part of an industry with its own pension scheme may opt out of these plans if they offer their own scheme with equivalent benefits. Furthermore, there are 327 single-employer plans, and another 40818 schemes (end of 2011) belonging to mainly smaller employers offer schemes operated by insurance companies.

Approximately $94 \%$ of covered employees (beginning of 2012) have a defined benefit scheme. The remaining employees are covered by a defined contribution scheme. 
Almost $98 \%$ of participants in defined benefit schemes have an earnings measure for benefit calculation purposes based on lifetime average earnings whereas less than $1 \%$ use the final salary. The remainder it is either a combination of the two or a fixed amount.

Most final-salary schemes have an accrual rate of $1.75 \%$ of earnings for each year of service. This equals a target replacement rate of $70 \%$ after 40 years. In most average salary schemes the accrual rate varies from $1.75 \%$ to $2.25 \%$ per year of service. From 2014 the maximum allowed EET accrual rates (paid for with tax exempt contributions) will be lowered from $2.0 \%$ to $1.9 \%$ for final-salary schemes, and from $2.25 \%$ to $2.15 \%$ for average salary schemes. As of 2015 maximum average salary accrual rates have been reduced further to $1.875 \%$ and only cover earnings up to EUR 100000 . Pension contributions for higher earnings are now paid with taxable contributions. The retirement age is also increasing from 65 to 67 together with the lower accrual right for building up new pension rights.

There are no legal requirements for valorisation of earlier years' pay and practice varies between schemes according to rules agreed upon by the social partners. For approximately $90 \%$ of the participants in average wage schemes, past earnings are valorised in line with growth of average earnings while for $10 \%$ the aim is to follow prices. Although there is no legal uprating requirement, most pensions in payment are raised on an annual basis as well. Nearly $55 \%$ of the pensions in payment are aiming to follow wage growth in each respective industry, while some $42 \%$ of the pensions are indexed to prices and 3\% aim for a mixture of wage and price growth.

Pension rights are fully transferable when individuals change jobs. There is a legal requirement to index pension rights of people leaving a scheme before retirement in exactly the same way as pensions in payment are indexed. Vesting periods are very short. Occupational pensions are integrated with the public pension system. The current tax rules allow a maximum benefit of $100 \%$ of final pay at 65 from both public and private systems. Most schemes have a target total replacement rate of $70 \%$ of final pay, so private benefits are reduced by a franchise amount equal to the basic state pension.

\section{Variant careers}

\section{Early retirement}

The basic pension is not payable before age 65. It is possible to withdraw the occupation pension earlier however the benefits are adjusted.

\section{Late retirement}

It is not possible to defer the basic old-age pension scheme after 65 (gradually increasing to 67 in 2021). It is possible to combine the basic pension benefit receipt and work.

The rules on pension deferral vary between occupational plans. It is possible to combine the occupational pension scheme and work. Indeed, some schemes allow a member to withdraw a pension and continue to work with the same employer.

\section{Childcare}

In the basic old-age pension scheme, periods out of paid work are automatically covered. In the occupational schemes, there are no credits for childcare periods during which people are out of paid work but the accrual of pension rights continues over remaining working years. However, many schemes allow voluntary contributions to cover the aforementioned periods of absence.

\section{Unemployment}

There are no credits in the occupational plans for periods of unemployment. Again, the basic old-age scheme covers such periods automatically. In addition, the social partners administer a fund (FVP) which makes it possible for older workers to extend their pension accrual for a certain period during unemployment. The government has no formal relationship with this fund. The FVP fund is in liquidation now and does not take up any new cases. 


\section{Pension modelling results: Netherlands in 2061, retirement at age 67}
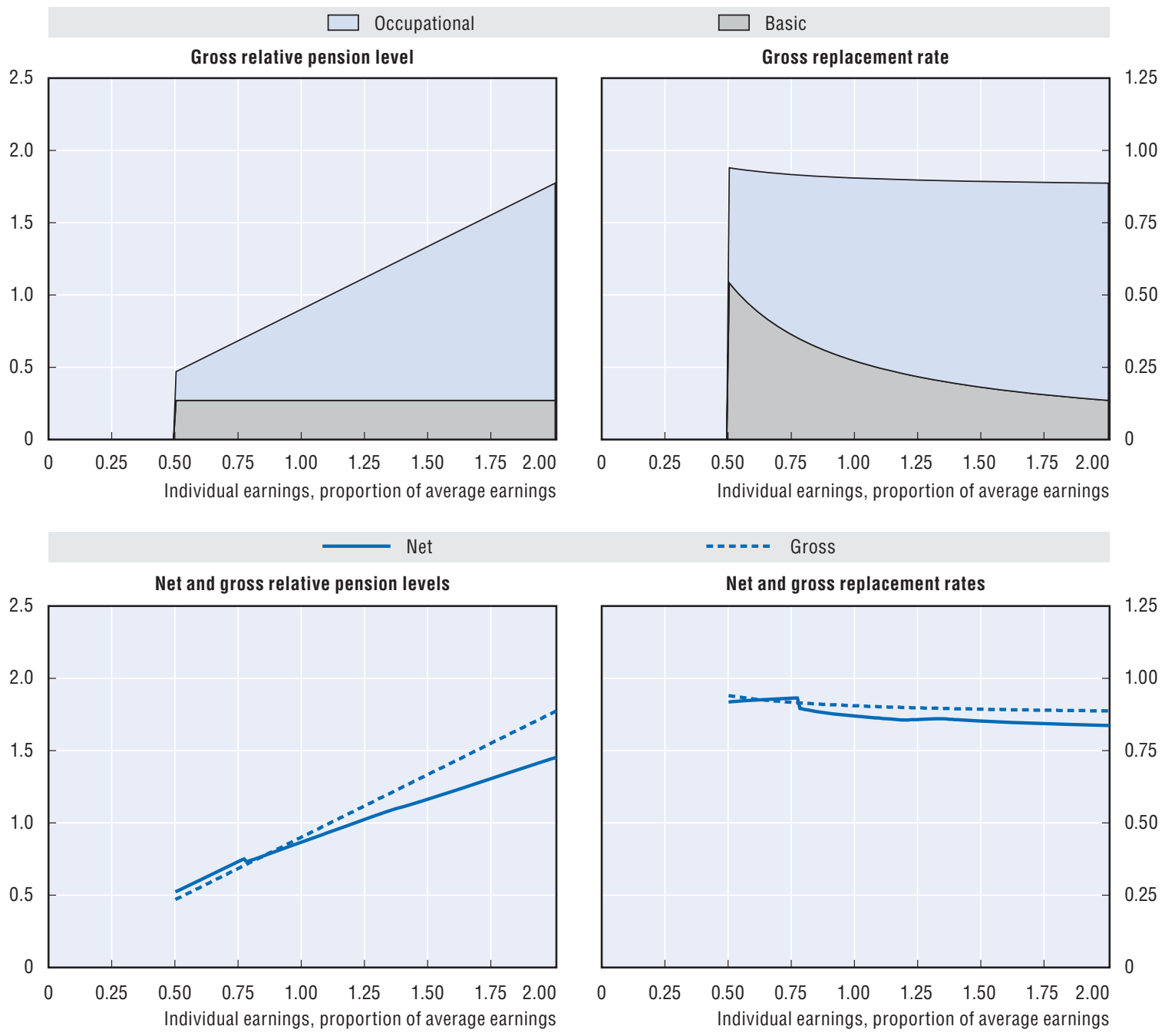

\begin{tabular}{|c|c|c|c|c|c|c|}
\hline \multicolumn{7}{|c|}{ Baseline scenario: Legislation scenario (wage indexation of basic scheme) } \\
\hline \multirow{2}{*}{$\begin{array}{l}\text { Men } \\
\text { Women (where different) }\end{array}$} & \multicolumn{6}{|c|}{ Individual earnings, multiple of average } \\
\hline & 0.5 & 0.75 & 1 & 1.5 & 2 & 3 \\
\hline Gross relative pension level & 47.0 & 68.7 & 90.5 & 134.0 & 177.4 & 264.4 \\
\hline \multicolumn{7}{|l|}{ (\% average gross earnings) } \\
\hline Net relative pension level & 57.6 & 80.9 & 95.7 & 128.4 & 160.1 & 223.5 \\
\hline \multicolumn{7}{|l|}{ (\% net average earnings) } \\
\hline Gross replacement rate & 94.0 & 91.7 & 90.5 & 89.3 & 88.7 & 88.1 \\
\hline \multicolumn{7}{|l|}{ (\% individual gross earnings) } \\
\hline Net replacement rate & 101.3 & 102.6 & 95.7 & 94.1 & 92.6 & 90.9 \\
\hline \multicolumn{7}{|l|}{ (\% individual net earnings) } \\
\hline Gross pension wealth & 17.8 & 17.4 & 17.2 & 16.9 & 16.8 & 16.7 \\
\hline (multiple of individual gross earnings) & 20.4 & 19.9 & 19.6 & 19.4 & 19.2 & 19.1 \\
\hline Net pension wealth & 13.6 & 12.8 & 11.3 & 10.1 & 9.5 & 8.8 \\
\hline (multiple of individual gross earnings) & 15.6 & 14.6 & 12.9 & 11.6 & 10.8 & 10.1 \\
\hline
\end{tabular}

Assumptions: Real rate of return 3\%, real earnings growth $1.25 \%$, inflation $2 \%$, and real discount rate $2 \%$. All systems are modelled and indexed according to what is legislated. Transitional rules apply where relevant. DC conversion rate equal $85 \%$. Labour market entry occurs at age 20 in 2014. Tax system latest available: 2013. 


\section{New Zealand}

\section{New Zealand: Pension system} in 2014

The public pension is flat-rate based on a residency test. Coverage of occupational pension plans continues to diminish. Coverage of the Kiwisaver voluntary workplace savings scheme continues to grow.
Key indicators: New Zealand

\begin{tabular}{|c|c|c|c|}
\hline & & New Zealand & OECD \\
\hline \multirow[t]{2}{*}{ Average worker earnings (AW) } & NZD & 54733 & 51260 \\
\hline & USD & 42718 & 40007 \\
\hline Public pension spending & $\%$ of GDP & 4.9 & 7.9 \\
\hline \multirow[t]{2}{*}{ Life expectancy } & At birth & 81.0 & 80.0 \\
\hline & At age 65 & 19.9 & 19.3 \\
\hline Population over age 65 & $\%$ of population & 14.7 & 16.2 \\
\hline
\end{tabular}

\section{Qualifying conditions}

Ten years' residency since the age of 20 (including five years after age 50) entitles people to the public pension from 65 years of age.

\section{Benefit calculation}

\section{Basic}

The pension for a single person living alone was NZD 421.76 gross per week from 1 April 2014. For 2013/14, the rate was NZD 410.32. The increase is due in part to the normal annual adjustment process, outlined below and in part to a government commitment, also outlined below. This gives a total pension of NZD 21 932, equivalent to around 40\% of gross average earnings.

State pension entitlements from other countries are taken into account in calculating the total public pension that is payable.

The rate of public pension is adjusted annually by the movement in the Consumer Price Index, but it must also maintain a relationship with the average net-of-tax weekly wage. For a couple, the governing legislation requires that the net-of-tax rate at each 1 April must be not less than $65 \%$ and not more than $72.5 \%$ of a net-of-tax surveyed weekly earnings measure. The net-of-tax rates for single people are set at $65 \%$ (living alone) and 60\% (sharing accommodation) of the net-of-tax couple rate. If movements in prices remain consistently below movements in the net-of-tax surveyed weekly earnings, effectively the latter becomes the index.

The current government has made a commitment that the net-of-tax rate at each 1 April is to be a minimum of $66 \%$ rather than $65 \%$ of the net-of-tax earnings measure.

Older people with limited assets and income may also access the Accommodation Supplement. The Accommodation Supplement subsidises $70 \%$ of housing expenses over a certain threshold (this threshold was NZD 92 per week at 1 April 2014 for a single pensioner living alone), up to a limit that varies by region and household composition.

\section{Voluntary private pensions}

Coverage of occupational pension plans has been falling for some time. The ratio of those in total employer sponsored schemes as a percentage of the employed workforce fell from $13.89 \%$ in 2003 to $9.98 \%$ in 2012. These plans are not government-subsidised through the tax system or otherwise. 
KiwiSaver is a government-subsidised voluntary retirement saving scheme introduced on 1 July 2007. At 30 June 2014, approximately $67 \%$ of New Zealanders aged 18-64 were active or provisional KiwiSaver members. The default minimum contribution rate for this scheme increased on 1 April 2013 from $4 \%$ to $6 \%$ of earnings, divided equally between employees and employers. Employees are able to select a higher personal contribution rate of $4 \%$ or $8 \%$.

Government subsidies are available to eligible savers to a maximum of NZD 521 per year. Members also receive a NZD 1000 contribution when they join. KiwiSaver entitles members to a lump sum, not a pension, on withdrawal at age 65 or over. While funds are generally "locked-in" until age 65, there are provisions to withdraw some funds earlier to assist with the purchase of a first home.

\section{Variant careers}

\section{Early retirement}

There is no compulsory retirement age. However, it is not possible for persons to claim the pension in their own right before the normal eligibility age of 65. People aged 65 years and over can include a non-qualifying partner in their pension, subject to income-testing against the couple's total income.

\section{Late retirement}

Receipt of the public pension is not dependent on retirement. It is therefore possible to combine pension and employment. Around $21 \%$ of people aged 65 or over are currently engaged in some paid work.

While people are not obliged to claim the public pension on reaching the qualifying age, there is no advantage in deferring a claim and retrospective claims are not allowed.

\section{Childcare}

Eventual public pension entitlement is not affected by periods out of paid work for caring purposes.

\section{Unemployment}

Eventual public pension entitlement is not affected by periods of unemployment. 
Pension modelling results: New Zealand in 2059, retirement at age 65
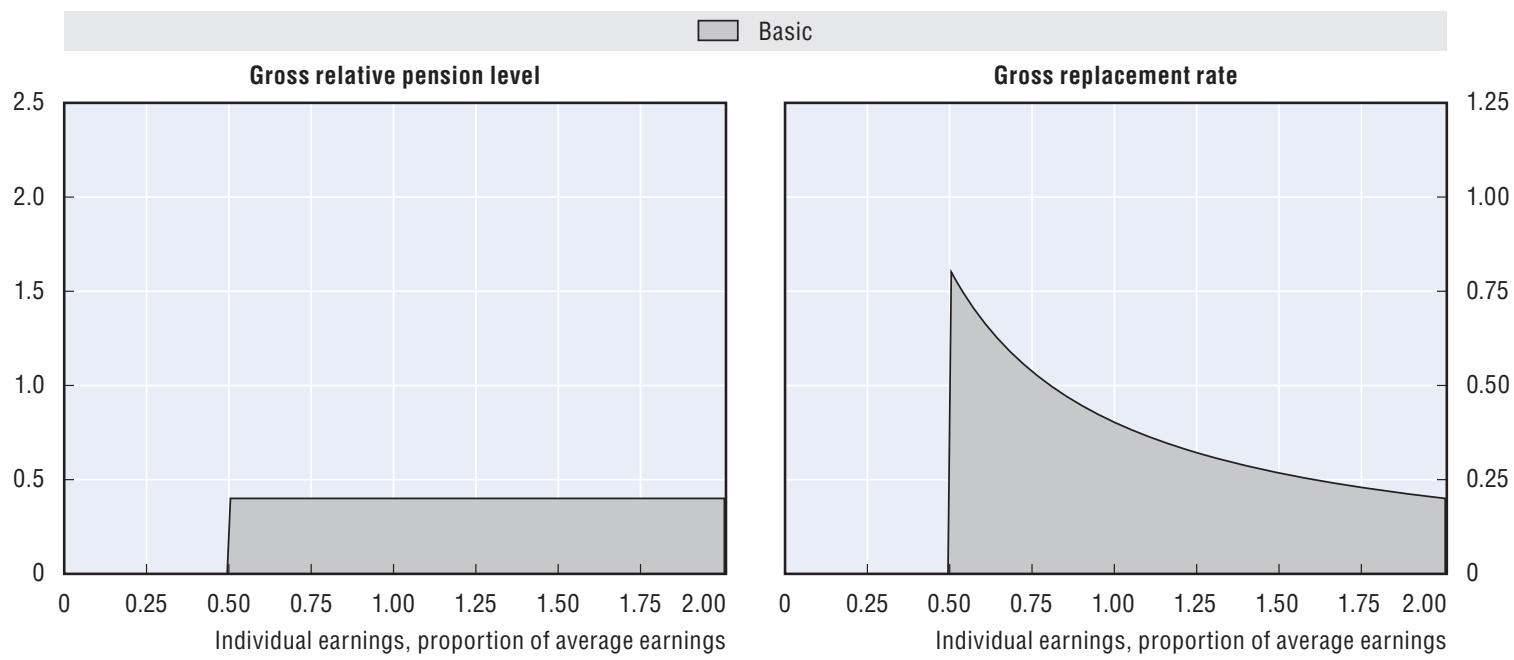

$-1,-1$ Gross

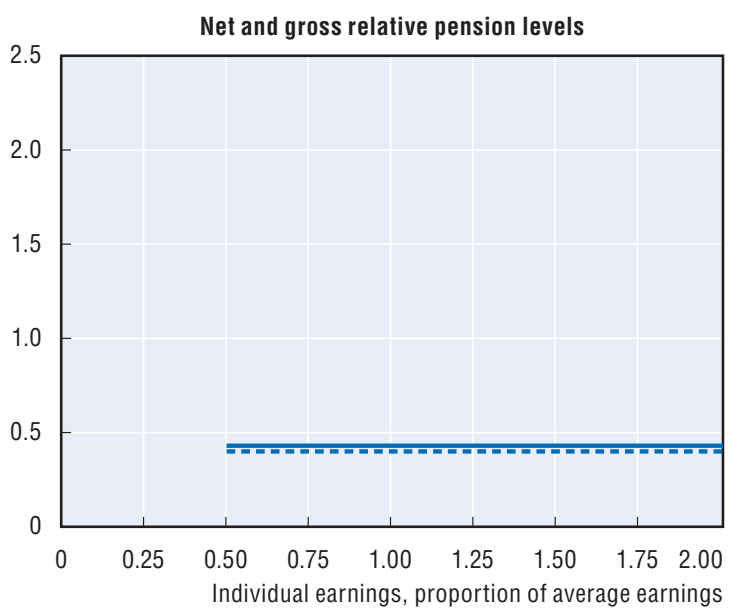

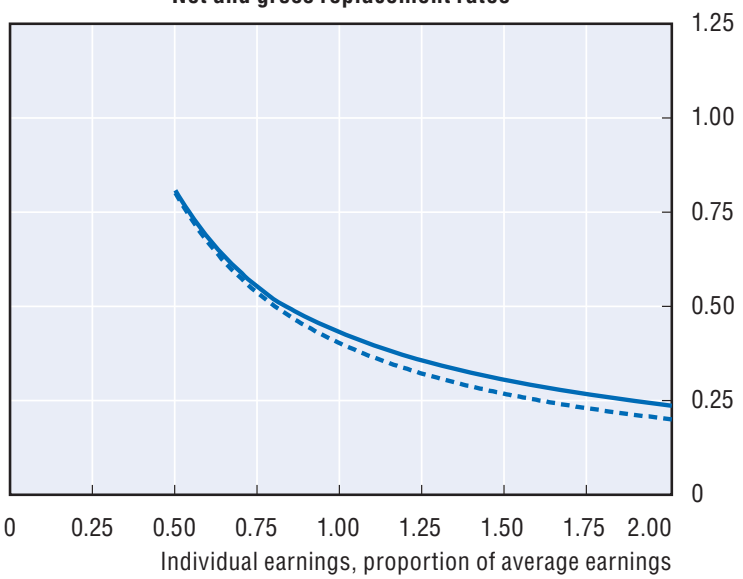

Net and gross replacement rates

Baseline scenario: Legislation scenario (full-wage indexation)

\begin{tabular}{|c|c|c|c|c|c|c|}
\hline \multirow{2}{*}{$\begin{array}{l}\text { Men } \\
\text { Women (where different) }\end{array}$} & \multicolumn{6}{|c|}{ Individual earnings, multiple of average } \\
\hline & 0.5 & 0.75 & 1 & 1.5 & 2 & 3 \\
\hline Gross relative pension level & 40.1 & 40.1 & 40.1 & 40.1 & 40.1 & 40.1 \\
\hline \multicolumn{7}{|l|}{ (\% average gross earnings) } \\
\hline Net relative pension level & 42.5 & 42.5 & 42.5 & 42.5 & 42.5 & 42.5 \\
\hline \multicolumn{7}{|l|}{ (\% net average earnings) } \\
\hline Gross replacement rate & 80.1 & 53.4 & 40.1 & 26.7 & 20.0 & 13.4 \\
\hline \multicolumn{7}{|l|}{ (\% individual gross earnings) } \\
\hline Net replacement rate & 80.8 & 55.0 & 43.0 & 30.4 & 23.7 & 16.4 \\
\hline \multicolumn{7}{|l|}{ (\% individual net earnings) } \\
\hline Gross pension wealth & 16.6 & 11.1 & 8.3 & 5.5 & 4.2 & 2.8 \\
\hline (multiple of individual gross earnings) & 18.5 & 12.4 & 9.3 & 6.2 & 4.6 & 3.1 \\
\hline Net pension wealth & 14.4 & 9.6 & 7.2 & 4.8 & 3.6 & 2.4 \\
\hline (multiple of individual gross earnings) & 16.1 & 10.8 & 8.1 & 5.4 & 4.0 & 2.7 \\
\hline
\end{tabular}

Assumptions: Real rate of return $3 \%$, real earnings growth $1.25 \%$, inflation $2 \%$, and real discount rate $2 \%$. All systems are modelled and indexed according to what is legislated except for the safety-nets which follow real-wages. Transitional rules apply where relevant. DC conversion rate equal 85\%. Labour market entry occurs at age 20 in 2014. Tax system latest available: 2013.

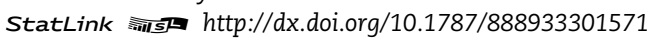




\section{Norway}

\section{Norway: Pension system in 2014}

The new public pension system, beginning in 2011, consists of an income pension, and a guarantee pension for people with no or only a small income pension. The guarantee pension is income-tested against the income pension. In 2006, a mandatory occupational pension was introduced in the private sector as a supplement to the public pension.
Key indicators: Norway

\begin{tabular}{llrr}
\hline & & Norway & OECD \\
\hline Average worker earnings (AW) & NOK & 542386 & 298884 \\
& USD & 72602 & 40007 \\
Public pension spending & \% of GDP & 5.4 & 7.9 \\
Life expectancy & At birth & 81.7 & 80.0 \\
\multirow{2}{*}{ Population over age 65 } & At age 65 & 19.8 & 19.3 \\
& \% of population & 16.4 & 16.2 \\
\hline
\end{tabular}

StatLink Aillsta $h$ ttp://dx.doi.org/10.1787/888933302008

\section{Qualifying conditions}

Persons with a residence period in Norway of at least three years between the ages of 16 and 66 (inclusive) are entitled to the guarantee pension in the new system. A full guarantee pension is granted after a forty year long residence period, and it is reduced proportionally for shorter residence periods.

\section{Benefit calculation}

\section{Income pension}

In the new system pension entitlements are accumulated through income from work or through other types of pension earning, between the age of 13 and 75 years. The individual will each year increase their pension entitlements corresponding to $18.1 \%$ of their pensionable income, up to a ceiling. The pension entitlements are each year increased in line with wage growth.

Many benefits under the National Insurance Scheme are determined in relation to the basic amount (G) that was NOK 85245 as an average for 2014. The ceiling in the new income pension is 7.1 basic amounts. The average wage for a full-time employee in Norway in 2014, based on OECD estimates, was about NOK 542 386. The ceiling on pension earnings is thus about $112 \%$ of the average wage.

From 2011 flexible retirement for the age group 62-75 years based on actuarial neutrality was introduced in the public pension scheme. It is possible to combine work and pension fully or partly from the age of 62 without an earnings test. From 2011 a life expectancy adjustment of the pension for new old-age pensioners was also introduced. The life expectancy divisors are determined for each cohort, based mainly on remaining life expectancy. They are determined when the cohorts are 61 years, and will not be adjusted later. Each cohort will receive a set of separate life expectancy divisors from the age of 62 until the age of 75 . At the time of retirement the annual pension is calculated by dividing the accumulated pension entitlements by the life expectancy divisor.

The income pension will after retirement be indexed to wages, and then subtracted a fixed factor of $0.75 \%$ a year.

\section{Basic (guarantee pension)}

A basic guarantee pension will replace the minimum pension in the current pension system and will be at the same level. The guarantee pension is income tested by $80 \%$ against the income pension.

The minimum pension for a single pensioner was NOK 167963 as an average for 2014 equivalent to about $31 \%$ of average earnings. 
The guarantee pension will be indexed in line with wages, but adjusted for the effect of the life expectancy factor at 67 years. In the long term projections of Statistics Norway life expectancy at 67 is assumed to increase by about $0.5 \%$ a year. According to the projections the guarantee pension will be adjusted to wages, and then subtracted a factor of about $0.5 \%$ a year due to the life expectancy adjustment.

\section{Defined contribution scheme}

From 2006, employers must make a minimum contribution of $2 \%$ of the earnings of their employees to a defined contribution pension plan. If employers offer a defined benefit scheme instead, then the benefits must be at least the same level as the expected benefits under the mandatory $2 \%$ contribution. Contributions are only required on earnings between the basic amount and 12 times the basic amount.

As part of the pension reform flexible retirement from the age of 62 was introduced also in the defined contribution scheme from 2011. The benefits must be withdrawn as a lifetime annuity or at least until the age of 77 . For comparison with the results for other countries, it is assumed that the benefit is taken as a price-indexed annuity calculated using unisex mortality tables.

\section{Voluntary private pension}

People may save for a voluntary pension to top up the public pension and the work-related pension schemes.

\section{Variant careers (public scheme)}

\section{Early retirement}

About two-thirds of all employees have an employer participating in Contractual Early Retirement Schemes (AFP). These schemes, which were introduced in 1989, allow retirement from age 62 .

In the public sector the AFP scheme for the age group 62-66 years has been prolonged also after introducing flexible retirement from 62 years in the public old-age pension scheme from 2011. It is not possible to combine work and pension without an earnings test. There are some qualifying conditions. The annual earnings must be at least one basic amount $(G)$ at the time of retirement. The annual wage must also exceed one basic amount $(G)$ during at least ten years after age 50. Earnings in the ten best years in the period from 1967 until the year prior to retirement must exceed at least twice the basic amount. The AFP pension is calculated in the same manner as the permanent disability pension (granting pension points for the remaining years until 67). In addition AFP pensioners receive a so-called AFP supplement.

From 2011 the AFP scheme in the private sector amounts to a lifetime supplement to the public old-age pension scheme. In the private sector it is possible to combine the public old-age pension, the AFP supplement and work without an earnings test. The supplement is equivalent to pension entitlements of about $4.2 \%$ of pensionable income, and can be accumulated up to the age of 62 . The supplement is based on actuarial neutrality and life expectancy adjustment and can be withdrawn between the age of 62 and 70 .

There are some qualifying conditions for the private sector AFP pension. First, the employee must at the age of 62 be covered by a private AFP scheme for three of the last five years. Second, by the age of withdrawal be employed by participating employer for the last three years. Third, the annual earnings must be at least 1 basic amount $(G)$ at the time of retirement. 


\section{Late retirement}

People can defer their pension after age 67 and continue to work and people can combine working with receiving a pension.

\section{Childcare}

Caregivers are credited with pension earning equivalent to 4.5 basic amounts a year or about NOK 383603 in the income pension. This corresponds to about $71 \%$ of an average full-time wage. Caregivers comprise parents caring for children below 6 years of age and individuals taking unpaid care of disabled, sick or elderly persons in the home.

Parents with lower annual earnings than 4.5 basic amounts have these earnings topped up. Parents with annual earnings exceeding 4.5 basic amounts do not get any top up. The family may apply for having the pension earnings granted to the father instead of the mother, but only one of the parents may receive this kind of pension earnings in any given year. For the other group, pension earnings are granted on the basis of individual applications.

\section{Unemployment}

The unemployed will be credited pension earnings based on the income they had before becoming unemployed up to a ceiling of 7.1 basic amounts. 


\section{Pension modelling results: Norway in 2061, retirement at age 67}

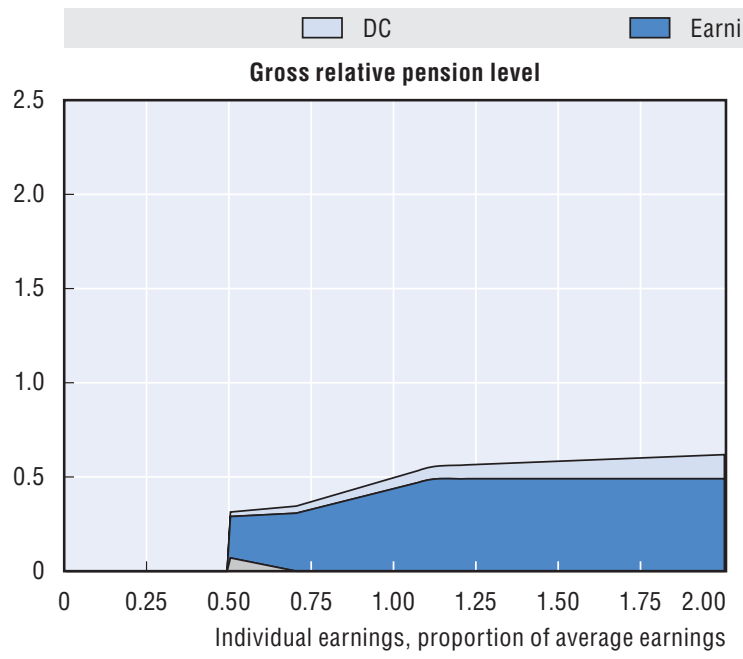

Earnings-related

Basic

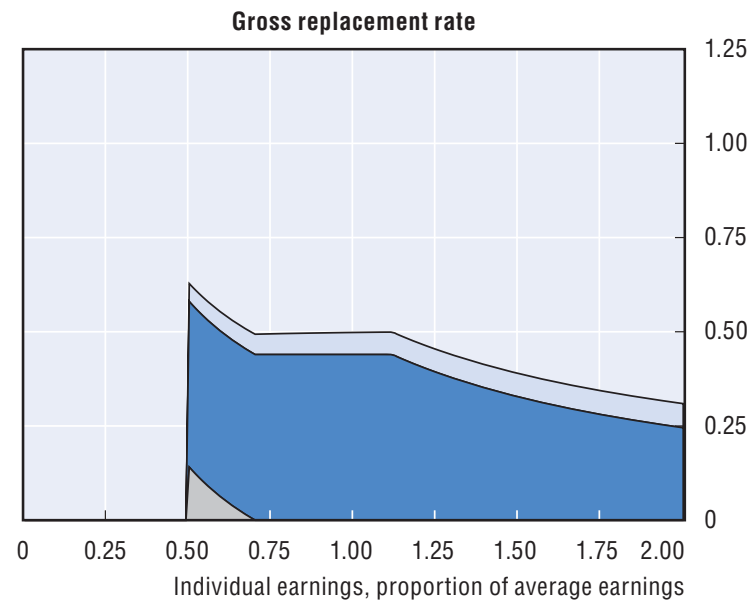

Net

--n-n. Gross

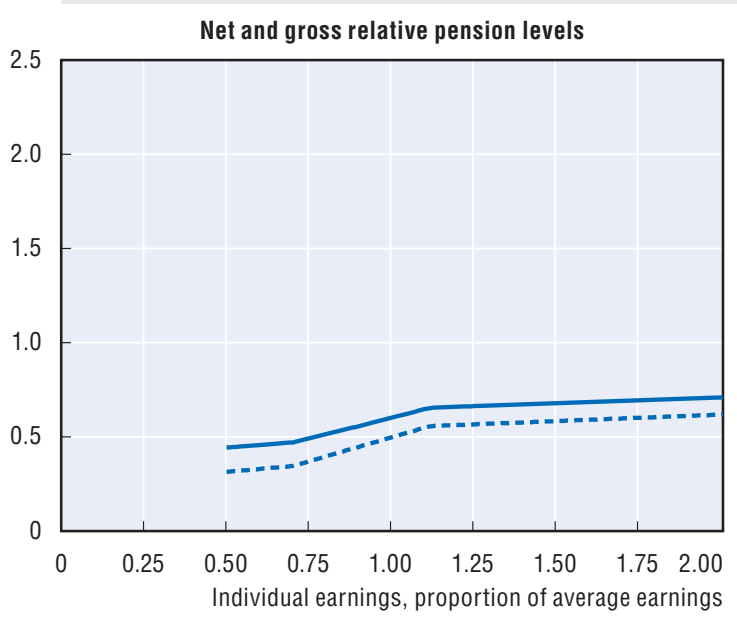

Net and gross replacement rates

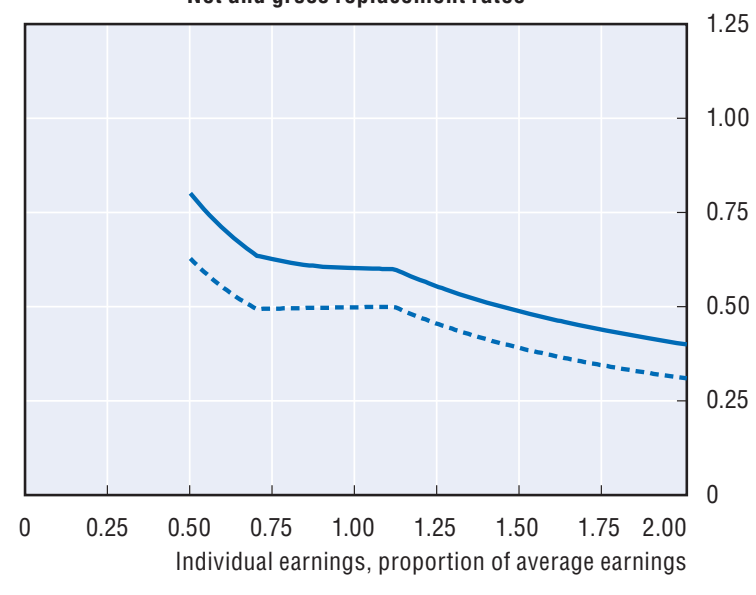

Baseline scenario: Legislation scenario (wage indexation of minimum pension)

\begin{tabular}{|c|c|c|c|c|c|c|}
\hline \multirow{2}{*}{$\begin{array}{l}\text { Men } \\
\text { Women (where different) }\end{array}$} & \multicolumn{6}{|c|}{ Individual earnings, multiple of average } \\
\hline & 0.5 & 0.75 & 1 & 1.5 & 2 & 3 \\
\hline Gross relative pension level & 31.4 & 37.1 & 49.8 & 58.4 & 61.9 & 62.2 \\
\hline \multicolumn{7}{|l|}{ (\% average gross earnings) } \\
\hline Net relative pension level & 44.3 & 49.2 & 60.2 & 67.9 & 71.0 & 71.3 \\
\hline \multicolumn{7}{|l|}{ (\% net average earnings) } \\
\hline Gross replacement rate & 62.8 & 49.5 & 49.8 & 38.9 & 30.9 & 20.7 \\
\hline \multicolumn{7}{|l|}{ (\% individual gross earnings) } \\
\hline Net replacement rate & 80.1 & 62.6 & 60.2 & 48.6 & 40.0 & 28.1 \\
\hline \multicolumn{7}{|l|}{ (\% individual net earnings) } \\
\hline Gross pension wealth & 11.9 & 9.4 & 9.4 & 7.3 & 5.8 & 3.9 \\
\hline (multiple of individual gross earnings) & 13.8 & 10.8 & 10.8 & 8.4 & 6.7 & 4.5 \\
\hline Net pension wealth & 11.6 & 8.5 & 7.8 & 5.8 & 4.6 & 3.0 \\
\hline (multiple of individual gross earnings) & 13.3 & 9.8 & 9.0 & 6.7 & 5.2 & 3.5 \\
\hline
\end{tabular}

Assumptions: Real rate of return 3\%, real earnings growth $1.25 \%$, inflation $2 \%$, and real discount rate $2 \%$. All systems are modelled and indexed according to what is legislated. Transitional rules apply where relevant. DC conversion rate equal 85\%. Labour market entry occurs at age 20 in 2014. Tax system latest available: 2013. 


\section{Poland}

\section{Poland: Pension system in 2014}

The system is based on two notional accounts schemes. Since 2014 participation in the funded scheme is voluntary, as workers can opt in to allocate their contributions to the NDC sub-account to the private DC scheme.
Key indicators: Poland

\begin{tabular}{|c|c|c|c|}
\hline & & Poland & OECD \\
\hline \multirow[t]{2}{*}{ Average worker earnings (AW) } & PLN & 42360 & 141489 \\
\hline & USD & 11978 & 40007 \\
\hline Public pension spending & $\%$ of GDP & 10.8 & 7.9 \\
\hline \multirow[t]{2}{*}{ Life expectancy } & At birth & 76.3 & 80.0 \\
\hline & At age 65 & 17.4 & 19.3 \\
\hline Population over age 65 & $\%$ of population & 15.3 & 16.2 \\
\hline
\end{tabular}

\section{Qualifying conditions}

The pension age is 65 years and three months for men and 60 years and three months for women in 2014. The pension age is gradually increasing from 1 January 2013 by a month in January, May and September until it reaches 67 years for both sexes, for women this will be in 2040 and for men 2020 . The minimum pension requires 21 years' of contributions. This age is increasing to 25 years for men by 2020 and women by 2022 .

\section{Benefit calculation}

\section{Earnings-related}

There are two notional account schemes. A contribution of $16.6 \%$ is credited to the main individuals' notional accounts. The notional interest rate is the growth rate of the covered wage bill but no less than price inflation. This notional interest rate is applied retrospectively to accounts from the year 2000.

A contribution of $2.92 \%$ of earnings is credited to the additional sub-accounts in the Social Security Fund (ZUS). The indexation of contributions to sub-accounts is different from contributions to already existing accounts in the Social Security Fund (ZUS). Moreover they are subject to inheritance. The notional interest rate is the annual growth rate of nominal GDP over the last five years.

Workers can opt-in to allocate $2.92 \%$ of their gross wages to the privately managed DC scheme (OFE).

On February 2014, 51.5\% of the net assets of privately managed pension funds were transferred to the Social Insurance Institution (ZUS). Moreover, the assets of those who chose to stay in privately managed funds will be gradually transferred to the public system ten years prior to the retirement age. Alongside with the changes in functioning of privately managed pension fund a payout mechanism for assets accumulated in those funds has been set up. DC pensions are calculated and paid out by Social Insurance Institution as a combined benefit with the NDC part.

At retirement, accumulated notional capital is divided by the " $g$-value" to arrive at the pension benefit. The g-value is average life expectancy at retirement age: this process is equivalent to the process of annuitisation in funded pension systems. The g-value is calculated using life tables published by the Central Statistical Office.

The ceiling to contributions and pensionable earnings is set at 2.5 times the average base amount in the previous calendar year. In 2014 the ceiling was PLN 112380.

Pension benefits are subject to periodic indexation to account for inflation. As from 1 March 2010, amounts of minimum pensions (including the social pension) have also been increased as a result of indexation. The indexation covers pension benefits awarded before the day fixed as the 
indexation date, that is, before 1 March. Indexation is carried out ex officio and covers all payable benefits. In 2012 there was an exception made to the indexation of pension benefits and on 1 March 2012 all the pensions were increased by PLN 71 instead. In 2013, the indexation rate for pensions was equal to 104\% (from 1 March 2013), and in 2014 the indexation rate was set at 101.6\%.

\section{Minimum pension}

There is a minimum pension under the pay-as-you-go scheme. The guaranteed minimum old-age pension was PLN 844.45 from 1 March 2014.

Indexation is the same as with pensions from the pay-as-you-go system. Additional lump-sum payments for those receiving low pensions were paid in those years where there was no regular indexation of benefits (2005 and 2007).

In the new pension scheme, the minimum retirement guarantee shall be financed by state budget and paid when total mandatory old-age pension is lower than the minimum.

\section{Variant careers}

\section{Early retirement}

There are no provisions for early retirement in the general pension system.

The old pension system (applicable to persons born before 1949) allowed various forms of early retirement for specific groups, such as miners, railway workers, teachers, people working in special conditions and women. From 2005 the miners had their early retirement pension system reinstated according to the pre-1999 rules.

The bridging pensions system that came into force from 2009 covers people working in special conditions, based on the new list (medically verified) - c.a. 270000 . Workers will receive a bridging pension for up to five years (ten years for some occupations such as: pilot, steel workers, etc.) before retirement age. This benefit is financed from state budget (since 2010 also from contributions paid by employers). Bridging pension is, as with the pension formula in the earnings-related system, based on unisex life expectancy for age 60 .

Moreover under the new law, workers who are not entitled to receive the bridging pension and have reached 15 years in special conditions or with special characteristics before 1 January 2009 are entitled to compensation. This compensation will be calculated at the moment of retirement (women: at least 60 years, men: at least 65 years) and added to the initial capital.

From July 2009 compensation benefits are also possible for teachers, from the age of 55 for women and 55 increasing to 57 by 2018 for men if the covered work period is longer than 30 years (can include 20 years of part-time work) and they terminate their employment.

\section{Late retirement}

It is possible to defer both the notional and the funded, defined contribution pension component without any age limits. People who defer claiming pension after normal pension age contribute and earn extra pension.

It is possible to combine work and pension receipt. However, an employment contract has to be ended before the withdrawal of a full pension is possible. The pensioner can thereafter continue to work on a basis of a new contract and receive the full pension. There are some restrictions that apply to the combination of earned income and pension income if a person is working and receiving a pension before reaching the statutory retirement age, or if a person is also a recipient of a disability pensions and has been recognised as partly incapable of work. Income (including pension benefits) is subject to taxation. 


\section{Childcare}

During periods of maternity leave, contributions to the pension system are paid from the state budget based on the maternity benefit, which is the average wage over the past 12 months, net of social security contributions. From 2009, the period of payment depends on the number of children and is 20 weeks for one child, 31 weeks for two children, 33 weeks for three children, 35 weeks for four children and 37 weeks for five or more children.

From 1 January 2010 the father or mother may take an additional parental leave period equal to a maximum of four weeks for one child (from 1 January 2012 to 31 December 2013) increasing to six weeks from 1 January 2014. In case of multiple births the parental leave is increased. Parents on additional maternity leave may work part time (but max. 50\%). In this case the maternity leave is reduced proportionally to the work time. Since the retirement age equalisation process is in place the seniority condition for women will be raised to the level of 25 years in 2022. In 2014 the seniority condition for the minimum pension for women was set at the level of 21 years.

From 1 January 2010 father has the right to parental benefits for two weeks. Parental leave is possible for a period up to 36 months per child. During this time, pension contributions are paid for the schemes in which a person is a member and the amount of social welfare benefit was used as a base (PLN 420) for the pension, disability and health contributions. For 2009-11 the base for contribution payment is minimum wage (c.a. $40 \%$ of average wage) and from $201260 \%$ of average wage (however the base cannot be higher than the average wage over the past 12 months). In both cases, the government pays the contributions on behalf of the parent on leave.

All periods for which contributions are paid qualify for the minimum pension guarantee.

\section{Unemployment}

There is a scheme of pre-retirement allowances, available to unemployed people who were laid off (for example, due to liquidation, bankruptcy or restructuring). Pre-retirement allowances are paid from the state budget to women from 55 and men from 60 until reaching pension age. These rules are in force from May 2004. Earlier pre-retirement benefits were granted to women from age 50 and men from age 55. Pre-retirement benefits are not subject to contributions to the pension scheme.

During periods of unemployment benefit receipt, the government pays the contributions to the pension system based on the size of the unemployment benefit. All the periods for which contributions are paid qualify for the minimum pension guarantee. 


\section{Pension modelling results: Poland in 2061, retirement at age 67}
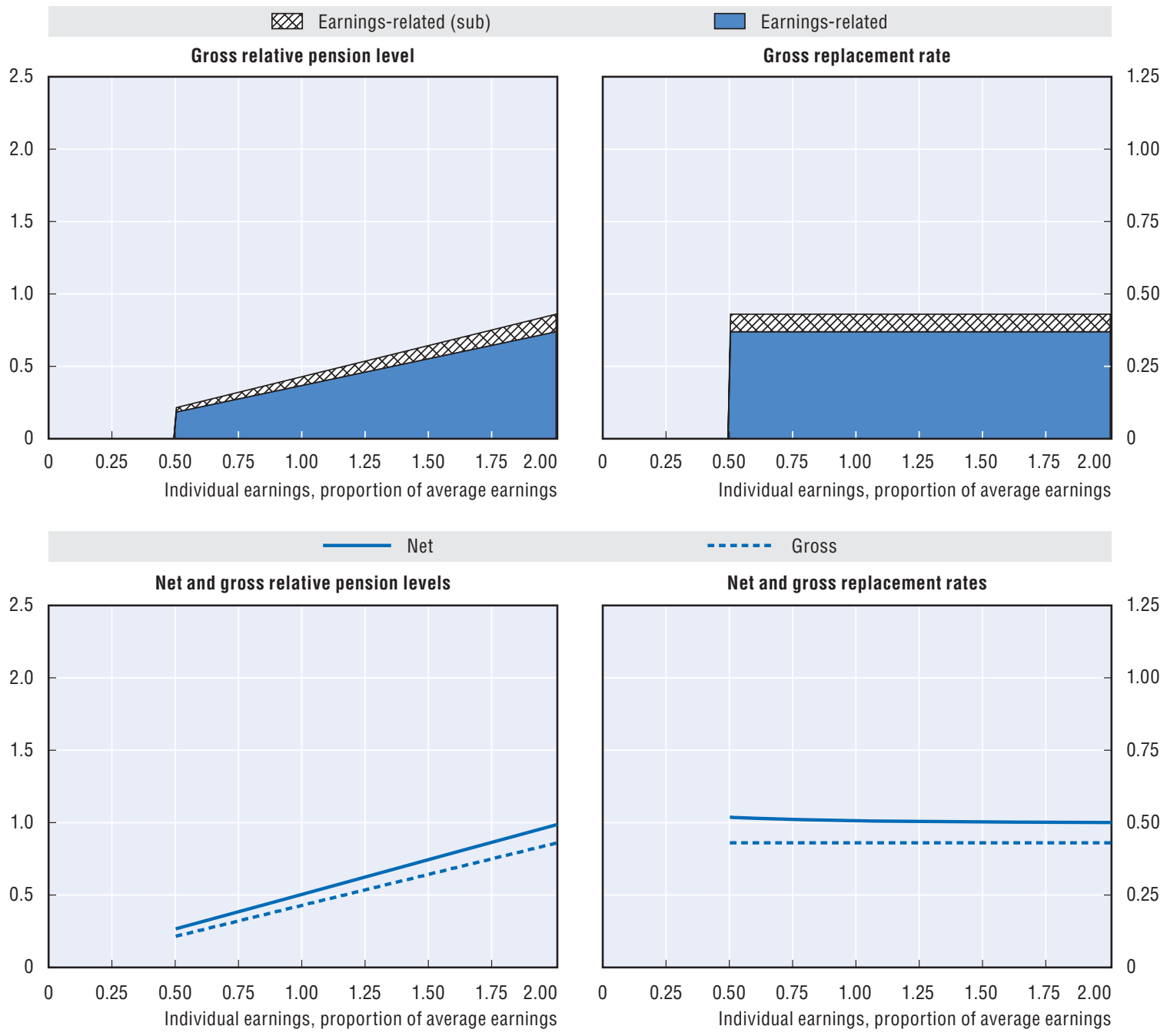

\begin{tabular}{|c|c|c|c|c|c|c|}
\hline \multicolumn{7}{|c|}{ Baseline scenario: Legislation scenario (price indexation of safety-nets schemes) } \\
\hline \multirow{2}{*}{$\begin{array}{l}\text { Men } \\
\text { Women (where different) }\end{array}$} & \multicolumn{6}{|c|}{ Individual earnings, multiple of average } \\
\hline & 0.5 & 0.75 & 1 & 1.5 & 2 & 3 \\
\hline Gross relative pension level & 21.5 & 32.3 & 43.0 & 64.5 & 86.1 & 114.2 \\
\hline \multicolumn{7}{|l|}{ (\% average gross earnings) } \\
\hline Net relative pension level & 26.6 & 38.6 & 50.7 & 74.7 & 98.8 & 130.2 \\
\hline \multicolumn{7}{|l|}{ (\% net average earnings) } \\
\hline Gross replacement rate & 43.0 & 43.0 & 43.0 & 43.0 & 43.0 & 38.1 \\
\hline \multicolumn{7}{|l|}{ (\% individual gross earnings) } \\
\hline Net replacement rate & 51.9 & 51.1 & 50.7 & 50.2 & 50.0 & 45.6 \\
\hline \multicolumn{7}{|l|}{ (\% individual net earnings) } \\
\hline Gross pension wealth & 6.5 & 6.5 & 6.5 & 6.5 & 6.5 & 5.7 \\
\hline (multiple of individual gross earnings) & 7.7 & 7.7 & 7.7 & 7.7 & 7.7 & 6.8 \\
\hline Net pension wealth & 6.0 & 5.8 & 5.7 & 5.6 & 5.6 & 4.9 \\
\hline (multiple of individual gross earnings) & 7.1 & 6.9 & 6.8 & 6.7 & 6.6 & 5.8 \\
\hline
\end{tabular}

Assumptions: Real rate of return $3 \%$, real earnings growth $1.25 \%$, inflation $2 \%$, and real discount rate $2 \%$. All systems are modelled and indexed according to what is legislated. Transitional rules apply where relevant. DC conversion rate equal $85 \%$. Labour market entry occurs at age 20 in 2014. Tax system latest available: 2013. 
Pension modelling results: Poland in 2061, retirement at age 67 (cont.)

\begin{tabular}{|c|c|c|c|c|c|c|}
\hline \multicolumn{7}{|c|}{ Alternative scenario: Wage indexation of safety-nets schemes } \\
\hline \multirow{2}{*}{$\begin{array}{l}\text { Men } \\
\text { Women (where different) }\end{array}$} & \multicolumn{6}{|c|}{ Individual earnings, multiple of average } \\
\hline & 0.5 & 0.75 & 1 & 1.5 & 2 & 3 \\
\hline Gross relative pension level & 23.9 & 32.3 & 43.0 & 64.5 & 86.1 & 114.2 \\
\hline \multicolumn{7}{|l|}{ (\% average gross earnings) } \\
\hline Net relative pension level & 29.3 & 38.6 & 50.7 & 74.7 & 98.8 & 130.2 \\
\hline \multicolumn{7}{|l|}{ (\% net average earnings) } \\
\hline Gross replacement rate & 47.8 & 43.0 & 43.0 & 43.0 & 43.0 & 38.1 \\
\hline \multicolumn{7}{|l|}{ (\% individual gross earnings) } \\
\hline Net replacement rate & 57.1 & 51.1 & 50.7 & 50.2 & 50.0 & 45.6 \\
\hline \multicolumn{7}{|l|}{ (\% individual net earnings) } \\
\hline Gross pension wealth & 7.2 & 6.5 & 6.5 & 6.5 & 6.5 & 5.7 \\
\hline (multiple of individual gross earnings) & 8.6 & 7.7 & 7.7 & 7.7 & 7.7 & 6.8 \\
\hline Net pension wealth & 6.6 & 5.8 & 5.7 & 5.6 & 5.6 & 4.9 \\
\hline (multiple of individual gross earnings) & 7.8 & 6.9 & 6.8 & 6.7 & 6.6 & 5.8 \\
\hline
\end{tabular}

Assumptions: Real rate of return 3\%, real earnings growth $1.25 \%$, inflation $2 \%$, and real discount rate $2 \%$. All systems are modelled and indexed according to what is legislated. Transitional rules apply where relevant. DC conversion rate equal $85 \%$. Labour market entry occurs at age 20 in 2014. Tax system latest available: 2013. 


\section{Portugal}

\section{Portugal: Pension system in 2014}

Portugal has an earnings-related public pension scheme with a means-tested safety net.

\section{Qualifying conditions}

Key indicators: Portugal

\begin{tabular}{|c|c|c|c|}
\hline & & Portugal & OECD \\
\hline \multirow[t]{2}{*}{ Average worker earnings (AW) } & EUR & 17436 & 33036 \\
\hline & USD & 21115 & 40007 \\
\hline Public pension spending & $\%$ of GDP & 13.0 & 7.9 \\
\hline \multirow[t]{2}{*}{ Life expectancy } & At birth & 79.8 & 80.0 \\
\hline & At age 65 & 19.0 & 19.3 \\
\hline Population over age 65 & $\%$ of population & 19.4 & 16.2 \\
\hline
\end{tabular}

The normal retirement age was 66 years in 2014. It will increase to 66 years and two months in 2015. This development follows the automatic process of adjusting the normal age of retirement by two-thirds of gains in life expectancy from age 65 measured as the average of the previous two years. The normal age of retirement can be reduced by four months for each year of contributions exceeding 40 years when the beneficiary turns 65 years of old.

The social pension is available from the age 66 in 2014. Pensioners also receive an additional amount equal to their monthly pension every year in July and December. In 2014 the December additional amount was divided into 12 monthly payments and paid every month instead. A progressive Extraordinary Solidarity Contribution (CES) was implemented for pension incomes over EUR 1000 per month.

\section{Benefit calculation}

\section{Earnings-related}

The pension amounts are calculated according to the following formula:

Pension amount $=$ Reference Earnings $\times$ Accrual Rate $\times$ Sustainability Factor

The annual earnings registered in the social security and taken into account for the Reference Earnings calculation (RE) are adjusted according to the consumer price index (CPI) without considering the housing prices.

For the purpose of calculating the pension over the entire career, the earnings registered between 1 January 2002 and 31 December 2011 are adjusted by applying an index resulting from the weighting of $75 \%$ of the CPI, and $25 \%$ of the average evolution of the earnings which underlie the contributions stated to the social security, whenever this evolution is higher than the CPI. The annual adjustment index cannot be higher than the CPI, plus $0.5 \%$.

The adjustment is made by applying the coefficient, corresponding to each one of the years considered, to the annual earnings taken into account for the reference earnings calculation. The indexes for the calculation basis adjustment are due to be reassessed.

For the reference earnings calculation purpose, whenever the number of calendar years with earnings registration is higher than 40 , it will take into account the best 40 annual earnings, after they have been adjusted. 
The pension accrues at $2 \%$ of the earnings base for each year of contributions for 20 or fewer years' contributions, with a lower limit of $30 \%$. For beneficiaries with 21 or more years of contributions, the accrual rate ranges between $2 \%$ and $2.3 \%$ depending on earnings. The schedule for the accrual rate depends on individual earnings relative to the value of the IAS (Indexante dos Apoios Sociais - Social Support Index; EUR 419.22 in 2014). Each tier of earnings accrues pension at a different rate. Pension accrues for a maximum of 40 years.

\begin{tabular}{lccccc}
\hline Reference earnings/IAS & $\leq 1.1$ & $>1.1-2.0$ & $>2.0-4.0$ & $>4.0-8.0$ & $>8.0$ \\
Accrual rate (\%) & 2.3 & 2.25 & 2.2 & 2.1 & 2 \\
\hline
\end{tabular}

The pensionable earnings measure was the best 10 of the final 15 years. This measure is being extended and will be lifetime average earnings from 2017. Those already paying contributions by 31 December 2001 and who met the eligibility conditions for old-age pension at that date will have their pension calculated on the basis of the most favourable of three possible formulas: 1) applying the previous rules ( $2 \%$ accrual for each year of contributions and earnings being those of the best ten years of the final 15 years); 2) applying the new rules described above to the entire contributory career; and 3) or pro rata application of both rules according to the contributory career. Those already paying contributions by 31 December 2001, but who have not met the eligibility conditions for old-age pension at that date, will have their pension calculated from the most favourable of the three formulas, if they retire between 2002 and 2016; or by the most favourable of formulas No. 2 and 3, if they retire after 31 December 2016. People who joined the system after 2002 will be fully covered by the new rules. For people with more than 40 years' contributions, only the best 40 count in the benefit formula.

The sustainability factor is an adjustment feature of the pensions system to longevity changes; this factor results from the relation between the average life expectancy at age 65 in 2000 (previously 2006) and the one recorded in the year before the pension claim.

The normal age of retirement is now linked to longevity increases. At the beginning of each year an adjustment is made that incorporates the ratio between the average life expectancy at age 65 in the first two of the previous three years and the base year of 2000.

The sustainability factor is now taken into account only for retirement below the normal age or at the date of the invalidity pension conversion into an old-age pension (it is applied when the pensioner completes 65 years of age). This sustainability factor does not apply to the old-age pensions resulting from the conversion of invalidity pensions beginning up to 31 December 2007 or total invalidity pensions, if the insured person:

- At the date when he/she completes 65 years of age, had received this pension for more than 20 years.

- Was registered in the social security on 1 June 2007 and had received this pension for a longer period than half of the time that elapsed between that date and the one on which he/she completes 65 years of age.

The sustainability factor for 2014 was $11.73 \%$ for old-age retirement below the normal age of retirement and 5.43\% for the conversion from invalidity to old-age pension at age 65 .

Although there is a general mechanism for accrual of pensions already in payment that is indexed to prices, with larger increases on smaller pensions, this mechanism was suspended for 2013.

In case of combination of earnings with an old-age pension the annual amount of pension is increased by $2 \%$ of the total earnings registered; this increase is effective from 1 January of each year and it refers to the earnings registered in the previous year. 
An extraordinary solidarity contribution has been levied on all sorts of pension income, independently of its origin (public or private pensions, private pre-funded bank products, etc.). The CES amount is calculated before taxes. The table below shows the extraordinary contributory rate schedule for these contributions on pension income for 2014.

\begin{tabular}{lcc}
\hline Pension income tiers & Pension income tiers (in EUR) & Solidarity Extraordinary Contribution (CES) 2014 \\
\hline 1 & $\leq 1000$ & $0.0 \%$ \\
2 & $>1000$ and $\leq 1800$ & $3.5 \% \times$ PA \\
3 & $>1800$ and $\leq 3750$ & $3.5 \% \times[1.800]+16 \% \times[\mathrm{PA}-1800]$ \\
4 & $>3750$ and $\leq 4611$ & $10 \% \times$ PA \\
5 & $>4611$ and $\leq 7126$ & $10 \% \times[4611]+25 \% \times[\mathrm{PA}-4611]$ \\
6 & $>7126$ & $10 \% \times[4611]+25 \% \times[2515]+55 \times[\mathrm{PA}-7126]$ \\
\hline
\end{tabular}

For 2015, pension amounts below 11 times the IAS (EUR 4 611) will be disregarded and the contributory rate schedule will be as shown in the table below.

\begin{tabular}{lcc}
\hline Pension income tiers & Pension income tiers (in EUR) & Solidarity Extraordinary Contribution (CES) 2015 \\
\hline 1 & $>4611$ and $\leq 7126$ & $15 \% \times[P A-4611]$ \\
2 & $>7126$ & $15 \% \times[2515]+40 \% \times[P A-7126]$ \\
\hline
\end{tabular}

\section{Minimum}

For people aged 66 or more who do not qualify for the earnings-related scheme, the monthly social pension was EUR 199.53 in 2014.

This is only paid if total income for a single person does not exceed $40 \%$ of the IAS or $60 \%$ of the IAS in case of couples. Again, there are 14 monthly payments, but to help cope with the crisis the 14th month payment has been distributed over the 12 calendar months.

Pensioners of the social pension are entitled to receive the Solidarity Extra Supplement on top of their pension. The monthly amount of this benefit is EUR 17.54 for those under 70 years old and EUR 35.06 for those with at least 70 years of age.

\section{Targeted}

The Solidarity Supplement for the Elderly (SSE), the main targeted benefit aimed at fighting poverty among the elderly, came into full effect in 2008 by extending eligibility to people aged 65 or older. Additional eligibility conditions for this benefit are: receiving old-age or survivors' pension (national citizens not entitled to the social pension because they do not fulfil its means test may also be eligible); and fulfilling the SSE very comprehensive means test.

The SSE resembles the Social Insertion Income as it is a supplement equal to the difference between the beneficiary's income and a given threshold, which is at the same time the means test condition. The SSE is therefore equal to the difference between the beneficiary's income and the following Reference Amounts (RA):

- EUR 4909.00 per year for singles.

- EUR 8590.75 per year for couples.

The beneficiary's income is composed of: his/her own income; the spouse's income; part of the income of their sons' households, denominated "family solidarity". The "family solidarity" component is added to the beneficiary's income to determine entitlement and the amount of the SSE. 
To calculate the "family solidarity", for each son/daughter the total yearly income of his/her household is taken and divided by the number of adult equivalents in that household (scale of equivalence: 1 to the first adult; 0.7 for each subsequent adult and 0.5 for each minor) and then, according to the table below, the family solidarity is determined as a percentage of the equivalent income of the household. Those whose sons or daughters households' equivalent income is placed in the fourth tier are not eligible for the SSE.

\begin{tabular}{lcc}
\hline Tier & Equivalent income of the household & Family solidarity (\% of the equivalent income) \\
\hline 1st & $2.5 \times \mathrm{RA}$ & 0 \\
2nd & $>2.5 \times \mathrm{RA}$ and $\leq 3.5 \times \mathrm{RA}$ & 5 \\
3rd & $>3.5 \times \mathrm{RA}$ and $\leq 5 \times \mathrm{RA}$ & 10 \\
4th & $>5 \times \mathrm{RA}$ & Exclusion from SSE \\
\hline
\end{tabular}

\section{Variant careers}

\section{Early retirement}

Early retirement due to long contributory careers has been temporarily suspended since 2012 . Early retirement was previously possible if the insured person was at least 55 and 30 calendar years with earnings registration at age 55 . Workers in very specific set of harduous jobs are entitled to retire earlier (rules not specified here; see unemployment section below for early retirement due to longterm unemployment).

In 2015, a restructured temporary early retirement scheme for long contributory careers was introduced for individuals aged 60 or older and having at least 40 years of contributory career. The penalty for early retirement remained the same: a reduction rate of $0.5 \%$ for each month of anticipation until the normal age of retirement. Each contributory year above the 40 year of contributory career reduces the penalty by four months. After 2016, the rules prior to the 2012 suspension of early retirement will be reintroduced (see paragraphs below).

The (suspended) early retirement due to long contributory careers allowed the social security beneficiaries to claim the pension before normal age of retirement. The pension amount has a reduction rate of $0.5 \%$ for each month of anticipation. Nevertheless, the number of anticipation months will be reduced by 12 months for each period of three years that exceeds those 30 calendar years.

The number of anticipation months is determined between the date of anticipated pension claim and the date when the insured person completes 66 years of age. The insured persons that receive a reduced anticipated pension and have ceased their activity may continue to pay contributions voluntarily in order to increase the pension amount.

If the insured person meets the conditions required to claim anticipated old-age pension without any reduction factor being applied and if he/she does not claim it, the pension will be increased by applying a rate of $0.65 \%$ to the number of months completed between the month when those requirements were met and the date when he/she reaches 65 years of age, or the date of pension beginning if this occurs before that age. 


\section{Late retirement}

If the insured person claims the old-age pension when he/she is older than the normal age of retirement and is entitled to standard retirement at that age then the pension amount will be increased by applying the respective monthly rate multiplied by the number of months completed between the month of pension beginning and the month when he/she has reached the normal age of retirement, until the upper limit of age 70 .

The monthly increase rate varies according to the number of calendar years with earnings registration completed by the insured person until the date of pension beginning, as follows:

\begin{tabular}{lcc}
\hline Age & Contributory career (years) & Monthly increase rates \\
\hline More than 65 years old & 15 to 24 & 0.33 \\
& 25 to 34 & 0.50 \\
& 35 to 39 & 0.65 \\
& More than 40 & 1.00 \\
\hline
\end{tabular}

When calculating the global increase rate, the months with earnings registration due to effective work are taken into account. The increased pension amount cannot be higher than $92 \%$ of the best reference earnings out of the reference earnings on which the statutory pension calculation was based. If the beneficiary dies before requiring the postponed old age pension, the bonus for postponing the retirement will be relevant for computing the survivor's pension, if applicable.

\section{Childcare}

Maternity periods (both full leave and part-time work) count in calculating the pension entitlement. These are credited towards the qualifying conditions. Pensionable earnings for these periods are based on pay in the six months before the second month of the start of the leave. From 2002, periods of up to three years caring for children under 12 working part time can be treated as full-time work.

\section{Unemployment}

Periods on unemployment benefits count in calculating pension benefits. Pensionable earnings for these periods are based on pay in the six months before the second month of the start of the unemployment period. This applies both to unemployment and to social unemployment benefits.

There are special rules applying to people in long-term unemployment. People aged 57 or over who are long-term unemployed can retire at age 62 with full pension without penalties. It is required that the minimum contribution conditions are met and unemployment-benefit entitlement is exhausted.

Early retirement is also possible from age 57 with 22 years' contributions for individuals who become unemployed at age 52 or more. In these cases, the pension is reduced by $0.5 \%$ monthly, with a maximum of five years' reduction applied. The table below presents these rules according to the date people become unemployed. 


\begin{tabular}{|c|c|c|c|}
\hline \multirow{2}{*}{$\begin{array}{l}\text { Unemployment benefit } \\
\text { requirement }\end{array}$} & \multicolumn{2}{|r|}{ Conditions } & \multirow{2}{*}{$\begin{array}{l}\text { Penalty/reduction on pension } \\
\text { amount }\end{array}$} \\
\hline & $\begin{array}{l}\text { At the date of becoming } \\
\text { unemployment. }\end{array}$ & At the date of receiving the pension & \\
\hline \multirow[t]{2}{*}{ Prior to 31 December of 2006} & $\begin{array}{l}50 \text { years or older At least } 20 \text { years } \\
\text { of registered earnings (at age } 50 \text { ). }\end{array}$ & $\begin{array}{l}55 \text { years or older. } \\
\text { Unemployment/unemployment assistance benefits } \\
\text { have been exhausted and still in involuntary } \\
\text { unemployment. }\end{array}$ & $\begin{array}{l}0.5 \% \text { for each month of } \\
\text { anticipation up to the age of } 60 .\end{array}$ \\
\hline & 55 years or older. & $\begin{array}{l}60 \text { years or older. } \\
\text { Entitlement for old-age pension (15 years } \\
\text { of registered earnings). } \\
\text { Unemployment/unemployment assistance benefits } \\
\text { have been exhausted and still in involuntary } \\
\text { unemployment. }\end{array}$ & No reduction. \\
\hline \multirow[t]{2}{*}{ From 1 January of 2007 onwards } & $\begin{array}{l}52 \text { years or older At least } 22 \text { years } \\
\text { of registered earnings (at age } 50 \text { ). }\end{array}$ & $\begin{array}{l}57 \text { years or older. } \\
\text { Unemployment/unemployment assistance benefits } \\
\text { have been exhausted and still in involuntary } \\
\text { unemployment. }\end{array}$ & $\begin{array}{l}0.5 \% \text { for each month } \\
\text { of anticipation up to the age of } 62 \text {. }\end{array}$ \\
\hline & 57 years or older. & $\begin{array}{l}62 \text { years or older. } \\
\text { Entitlement for old-age pension ( } 15 \text { years } \\
\text { of registered earnings). } \\
\text { Unemployment/unemployment assistance benefits } \\
\text { have been exhausted and still in involuntary } \\
\text { unemployment. }\end{array}$ & No reduction. \\
\hline
\end{tabular}

Whenever unemployment is due to an agreed work contract cessation, the pension amount will be subject to an additional reduction rate, which will last until the pensioner reaches the normal age of retirement. Means-tested unemployment assistance subsidy is provided if registered contribution is more than 180 days in the 12 months prior to unemployment and monthly earnings before unemployment is less than $80 \%$ of the minimum wage. This allowance can be extended until beneficiaries meet the conditions for early retirement provided that they are 50 years of age when they became unemployed. 
Pension modelling results: Portugal in 2060, retirement at age 66

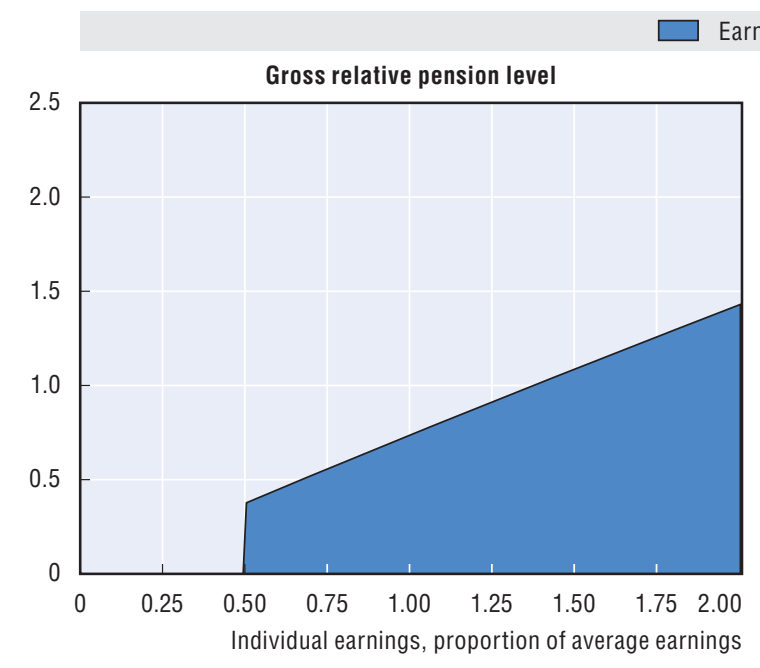

Earnings-related
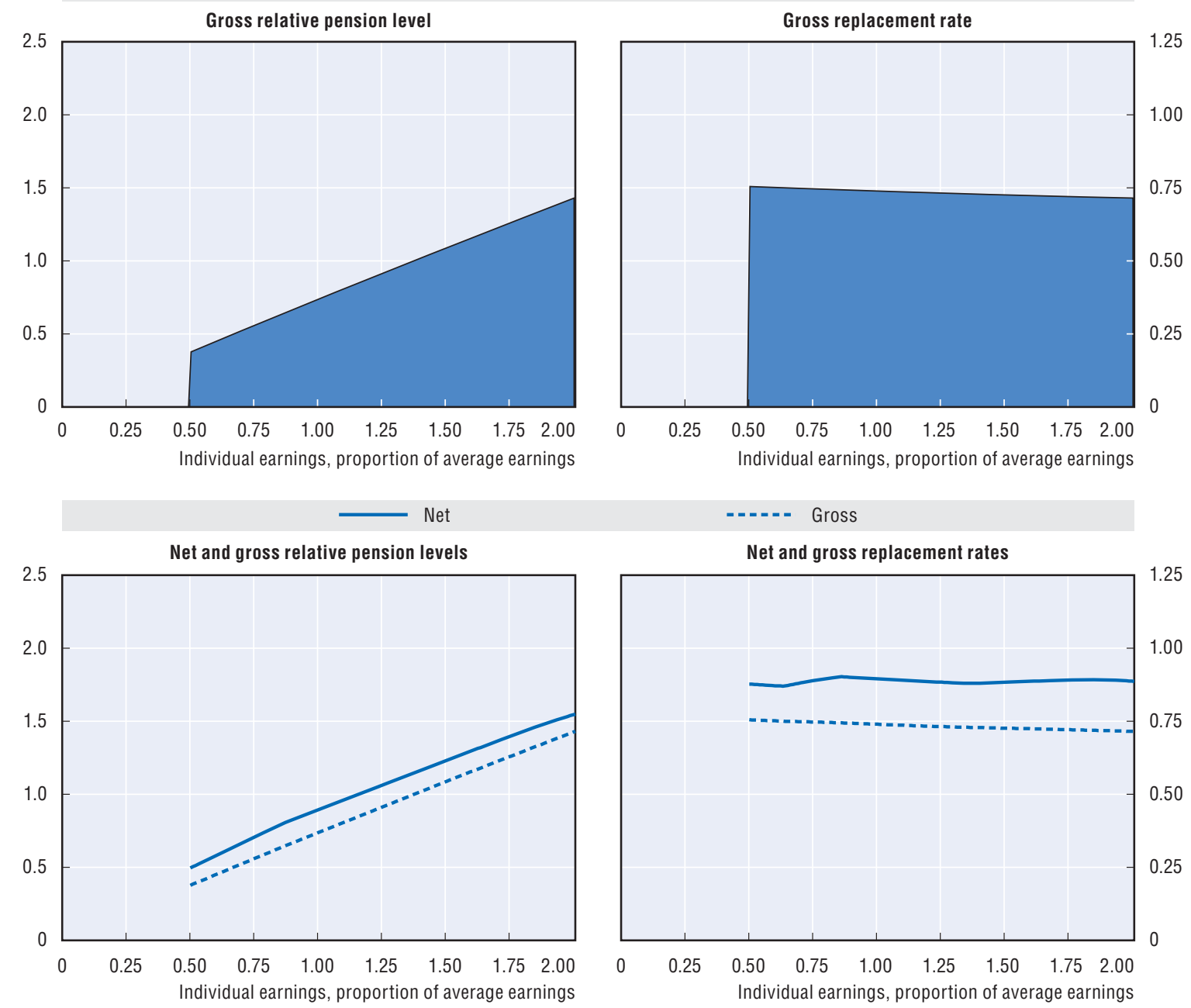

\begin{tabular}{|c|c|c|c|c|c|c|}
\hline \multicolumn{7}{|c|}{ Baseline scenario: Legislation scenario (price indexation of safety nets) } \\
\hline \multirow{2}{*}{$\begin{array}{l}\text { Men } \\
\text { Women (where different) }\end{array}$} & \multicolumn{6}{|c|}{ Individual earnings, multiple of average } \\
\hline & 0.5 & 0.75 & 1 & 1.5 & 2 & 3 \\
\hline Gross relative pension level & 37.5 & 55.9 & 73.8 & 108.7 & 142.9 & 209.5 \\
\hline \multicolumn{7}{|l|}{ (\% average gross earnings) } \\
\hline Net relative pension level & 49.6 & 70.8 & 89.5 & 123.3 & 154.8 & 207.1 \\
\hline \multicolumn{7}{|l|}{ (\% net average earnings) } \\
\hline Gross replacement rate & 75.1 & 74.5 & 73.8 & 72.5 & 71.4 & 69.8 \\
\hline \multicolumn{7}{|l|}{ (\% individual gross earnings) } \\
\hline Net replacement rate & 87.7 & 88.9 & 89.5 & 88.4 & 88.7 & 84.4 \\
\hline \multicolumn{7}{|l|}{ (\% individual net earnings) } \\
\hline Gross pension wealth & 12.7 & 11.9 & 11.8 & 11.6 & 11.4 & 11.2 \\
\hline (multiple of individual gross earnings) & 14.8 & 13.6 & 13.4 & 13.2 & 12.9 & 14.8 \\
\hline Net pension wealth & 12.4 & 11.2 & 10.6 & 9.7 & 9.2 & 8.2 \\
\hline (multiple of individual gross earnings) & 14.5 & 12.3 & 11.2 & 10.6 & 9.4 & 14.5 \\
\hline
\end{tabular}

Assumptions: Real rate of return $3 \%$, real earnings growth $1.25 \%$, inflation $2 \%$, and real discount rate $2 \%$. All systems are modelled and indexed according to what is legislated. Transitional rules apply where relevant. DC conversion rate equal $85 \%$. Labour market entry occurs at age 20 in 2014. Tax system latest available: 2013. 


\section{Russian Federation}

\section{Russian Federation: Pension system in 2014}

The mandatory old-age pension consists of a notional accounts system including a basic flat-rate benefit and a funded defined contribution scheme. There are also statutory social pensions and voluntary private pensions managed by non-state (private) pension funds.
Key indicators: Russian Federation

\begin{tabular}{|c|c|c|c|}
\hline & & Russian Federation & OECD \\
\hline \multirow[t]{2}{*}{ Average worker earnings (AW) } & RUB & 391920 & 2343357 \\
\hline & USD & 6691 & 40007 \\
\hline Public pension spending & $\%$ of GDP & 8.5 & 7.9 \\
\hline \multirow[t]{2}{*}{ Life expectancy } & At birth & 67.9 & 80.0 \\
\hline & At age 65 & 14.4 & 19.3 \\
\hline Population over age 65 & $\%$ of population & 13.2 & 16.2 \\
\hline
\end{tabular}

\section{Qualifying conditions}

The normal pensionable age for the old-age labour pension is 60 years for men and 55 years for women with at least five years of insurance coverage in 2014. In addition to work insurance qualifying period includes military service other type of state service, periods of receipt of public social insurance, care periods, periods of unemployment benefit receipt, periods of participation in paid public works or travel if assigned by the state employment service, periods of wrongful imprisonment, periods of being wrongfully repressed, wrongfully rehabilitated or wrongfully exiled. Accompanying persons where the breadwinner is serving in the military or civil service can also receive insurance periods, but not more than five years in total.

Old-age pension benefits are also paid to individuals suffering from diseases caused by radiation or other man-made accidents and who are above the age of 50 for men or 45 for women with if they have had at least five years of service. The state social pension is paid to disabled persons or individuals not meeting the age requirements from age 65 for men and age 60 for women. The state social pension is not payable abroad. Retirement is not necessary. There is no income test for a working pensioner.

\section{Benefit calculation}

Pension benefits are financed out of the contributions made to the mandatory pension insurance scheme (notional defined contribution). In 2014, the contribution rate paid by the employers is 22\% for salaries up to RUB 624000 and 10\% of salaries exceeding RUB 624000.

\section{Old-age labour pension}

The old-age labour pension is calculated as the sum of two components:

- The notional defined contribution component (including basic part) - a benefit based on the notional account.

- The funded defined contribution component - a benefit based on the value of the individual account with a contribution rate equal to 6\% plus interest from 2016.

The basic flat-rate component was equal to RUB 4687 per month in 2014. Pensioners aged 80 or above are entitled to double the amount of the basic flat-rate "benefit". 
The contribution rate to the merged basic and NDC is $16 \%$ below RUB 624000 and $10 \%$ above. The notional account component (without basic flat-rate "benefit") is calculated on the accumulated notional capital adjusted annually according to the national legislation. The annual coefficient for the pension capital indexation was equal to 1.083 on 1 January 2014.

The monthly pension benefit is calculated as quotient of the amount of pension capital divided by the expected period of pension payment in months. In 2014 it is 228 months (19 years). The assigned NDC component is also adjusted according to the national legislation. The amount of the funded component may be paid as a lump sum in some defined cases.

The old-age labour pension is payable to persons suffered from radiation and man-caused accidents. The amount is $250 \%$ of social pension.

There is no officially stated minimum or maximum monthly pension.

\section{State Social Pension}

The pension is a percentage of the basic flat-rate portion of the labour pension. Benefits are adjusted according to changes in the inflation rate and the average wage.

\section{Safety-net benefits}

There are a range of social assistance benefits available to all categories of pensioners, but their type and amount depend on a region of the Russian Federation (for example, transport expenses, medicine, etc.). Pensioners can choose these benefits in-kind or in cash.

All social assistance benefits paid to the non-working pensioners are based on the minimum subsistence level of a pensioner in the Russian Federation which falls into the national (federal) and regional levels. In 2014 the federal subsistence level of a pensioner is RUB 6617.00 per month. It may differ on regional level.

There are several options for social assistance benefits paid to the non-working pensioners with the total income lower than the subsistence level of a pensioner:

1. Federal supplementary social assistance for individuals with income lower than the federal subsistence level of a pensioner (up to this level); paid by the Pension Fund of the Russian Federation.

2. Regional supplementary social assistance for individuals with income lower than the regional subsistence level of a pensioner (up to this level), but higher than the federal one; paid by the local social security authorities.

Total income of a non-working pensioner includes: pension (or its part), supplementary cash benefit, monthly cash benefit (including an amount of social services); other social assistance benefits in cash under the regional regulations (excluding social assistance paid as a lump sum) as well as the cash equivalent of the social assistance benefits for telephone, housing and utilities and public transport expenses.

\section{Variant careers}

\section{Early retirement}

It is not possible to claim the pension before the normal eligibility age. However, early retirement is possible for special groups of insured persons working in unhealthy work environments. The required number of years of work in an unhealthy environment may vary according to conditions and profession. These early retirement benefits are paid for by the state on a pay-as-you-go basis. As of 1 January 2013, employers who have jobs with special conditions and employees eligible for the early pension provision, are obliged to pay extra insurance contributions to the system of mandatory pension insurance: $2014-4 \%$ and $6 \% ; 2015-6 \%$ and $9 \%$. 


\section{Late retirement}

The old-age labour pension benefits can be deferred. Every additional year of deferral decreases the expected period of pension payment by one year and consequently increase the pension benefit. The minimum expected period of pension payment is 14 years.

\section{Childcare}

Periods of childcare up to 18 months per child with a maximum of three years in total are included in the insurance coverage.

Child allowances: Paid to families with income below the locally determined minimum subsistence level. The child must reside in the household. The allowance varies according to geographic region and is paid for each child from age 18 months to age 18 (age 23 if a full-time student). Supplements are paid if a parent fails to pay alimony. Single parents receive twice the child allowance.

Family (maternity capital) grant: Paid to women after the birth or adoption of the second, third or subsequent child after 1 January 2007. In special cases men are entitled to the grant after the adoption of two children. In 2014 it was RUB 429 408. One of the three options for the capital investment determined by the legislation is financing of the statutory funded pension of a mother or father.

\section{Unemployment}

At the suggestion of the Employment Service and in the lack employment conditions pensions are payable to unemployed persons aged up to 60 years (men) and 55 years (women), but not earlier than two years before eligible age, with insurance period more than 25 and 20 years respectively and required length of service for early retirement in case of company or owner bankruptcy, reduction of the staff. The amount of a pension is determined by the Law on Labour Pensions in the Russian Federation as for insurance part of labour old-age pension. 
Pension modelling results: Russian Federation in 2054 (2049), retirement at age 60 (55)

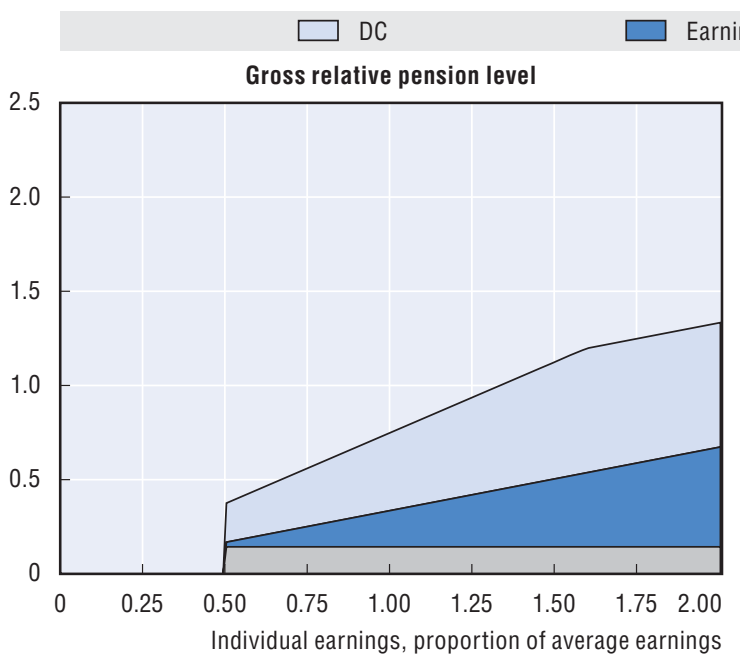

Earnings-related

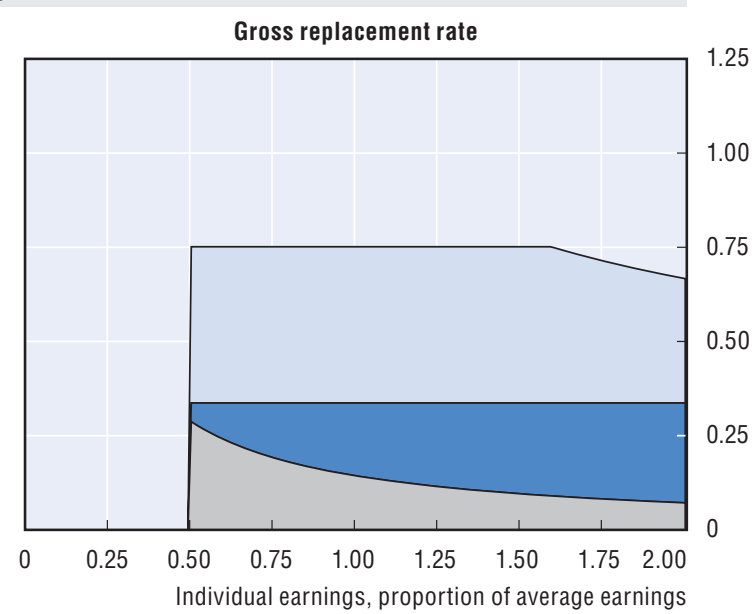

Net

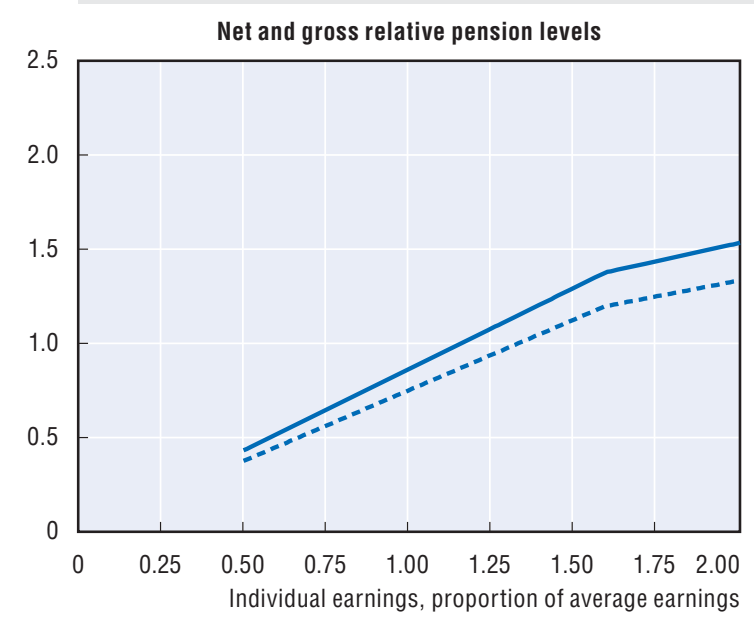

--n--.. Gross

Net and gross replacement rates

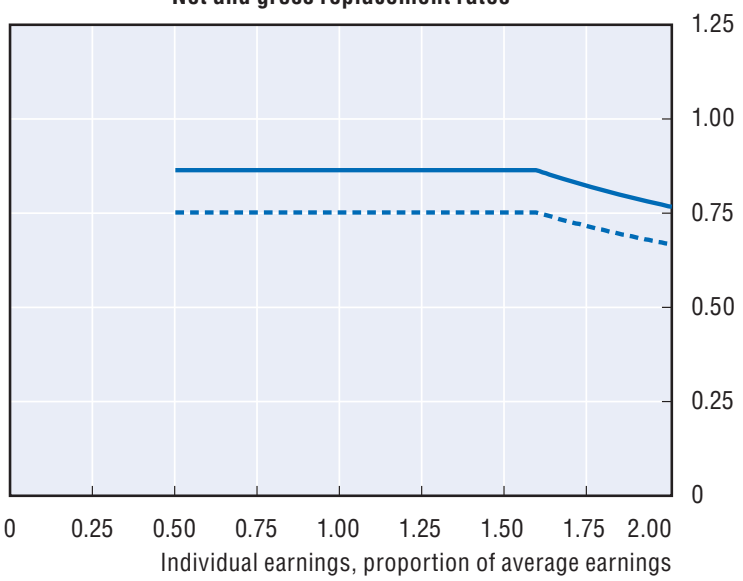

\begin{tabular}{|c|c|c|c|c|c|c|}
\hline \multicolumn{7}{|c|}{ Baseline scenario: Legislation scenario (wage indexation of basic scheme) } \\
\hline \multirow{2}{*}{$\begin{array}{l}\text { Men } \\
\text { Women (where different) }\end{array}$} & \multicolumn{6}{|c|}{ Individual earnings, multiple of average } \\
\hline & 0.5 & 0.75 & 1 & 1.5 & 2 & 3 \\
\hline Gross relative pension level & 37.6 & 56.4 & 75.2 & 112.8 & 133.4 & 167.1 \\
\hline (\% average gross earnings) & 32.0 & 48.1 & 64.1 & 96.1 & 114.1 & 143.5 \\
\hline Net relative pension level & 43.2 & 64.8 & 86.4 & 129.6 & 153.4 & 192.1 \\
\hline (\% net average earnings) & 36.8 & 55.3 & 73.7 & 110.5 & 131.1 & 165.0 \\
\hline Gross replacement rate & 75.2 & 75.2 & 75.2 & 75.2 & 66.7 & 55.7 \\
\hline (\% individual gross earnings) & 64.1 & 64.1 & 64.1 & 64.1 & 57.0 & 47.8 \\
\hline Net replacement rate & 86.4 & 86.4 & 86.4 & 86.4 & 76.7 & 64.0 \\
\hline (\% individual net earnings) & 73.7 & 73.7 & 73.7 & 73.7 & 65.6 & 55.0 \\
\hline Gross pension wealth & 9.6 & 9.6 & 9.6 & 9.6 & 8.6 & 7.1 \\
\hline (multiple of individual gross earnings) & 12.8 & 12.8 & 12.8 & 12.8 & 11.4 & 9.6 \\
\hline Net pension wealth & 9.6 & 9.6 & 9.6 & 9.6 & 8.6 & 7.1 \\
\hline (multiple of individual gross earnings) & 12.8 & 12.8 & 12.8 & 12.8 & 11.4 & 9.6 \\
\hline
\end{tabular}

Assumptions: Real rate of return $3 \%$, real earnings growth $1.25 \%$, inflation $2 \%$, and real discount rate $2 \%$. All systems are modelled and indexed according to what is legislated. Transitional rules apply where relevant. DC conversion rate equal $85 \%$. Labour market entry occurs at age 20 in 2014. Tax system latest available: 2014. 


\section{Saudi Arabia}

\section{Saudi Arabia: Pension system in 2014}

The mandatory public pension consists of an earnings-related old-age pension and an old-age settlement.
Key indicators: Saudi Arabia

\begin{tabular}{|c|c|c|c|}
\hline & & Saudi Arabia & OECD \\
\hline \multirow[t]{2}{*}{ Average worker earnings (AW) } & SAR & 183989 & 150161 \\
\hline & USD & 49020 & 40007 \\
\hline Public pension spending & $\%$ of GDP & & 7.9 \\
\hline \multirow[t]{2}{*}{ Life expectancy } & At birth & 75.4 & 80.0 \\
\hline & At age 65 & 15.5 & 19.3 \\
\hline Population over age 65 & $\%$ of population & 3.0 & 16.2 \\
\hline
\end{tabular}

\section{Qualifying conditions}

The old-age pension age is 60 years for men and 55 years for women with at least 120 months of paid or credited contributions credited contributions. Retirement at any age is possible with 300 months (25 years) of contributions.

\section{Benefit calculation}

\section{Old-age pension}

The pension is based on $2.5 \%$ of the insured's average monthly earnings during the last two years for each year of contributions, up to $100 \%$.

The minimum monthly earnings for benefit calculation purposes are SAR 1500 . The maximum monthly earnings for benefit calculation purposes are SAR 45000.

The average monthly earnings for benefit calculation purposes must not exceed $150 \%$ of the insured's monthly earnings at the beginning of the last five-year contribution period.

If the insured's monthly earnings decrease during the last two years before retirement, special provisions apply to adjust the average monthly earnings used for benefit calculation purposes.

The minimum pension is SAR 1984 per month.

\section{Old-age settlement}

A lump sum is paid equal to $10 \%$ of the insured's average monthly earnings during the last two years before retirement for each month of the first five years of contributions plus $12 \%$ for each additional month.

\section{Variant careers}

\section{Early retirement}

At any age with at least 300 months of contributions and if no longer covered by the programme.

\section{Late retirement}

It is not possible to defer the pension. 


\section{Pension modelling results: Saudi Arabia in 2039, retirement at age 45}

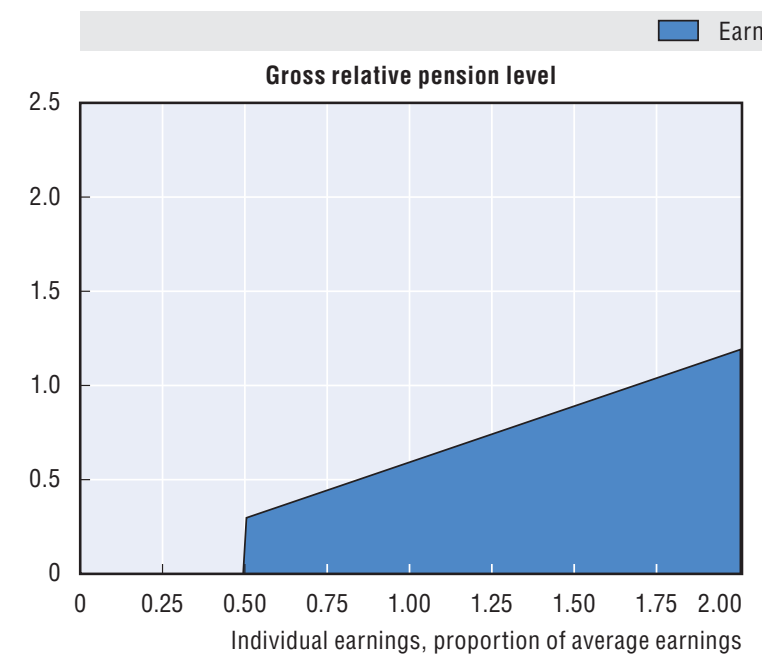

Earnings-related
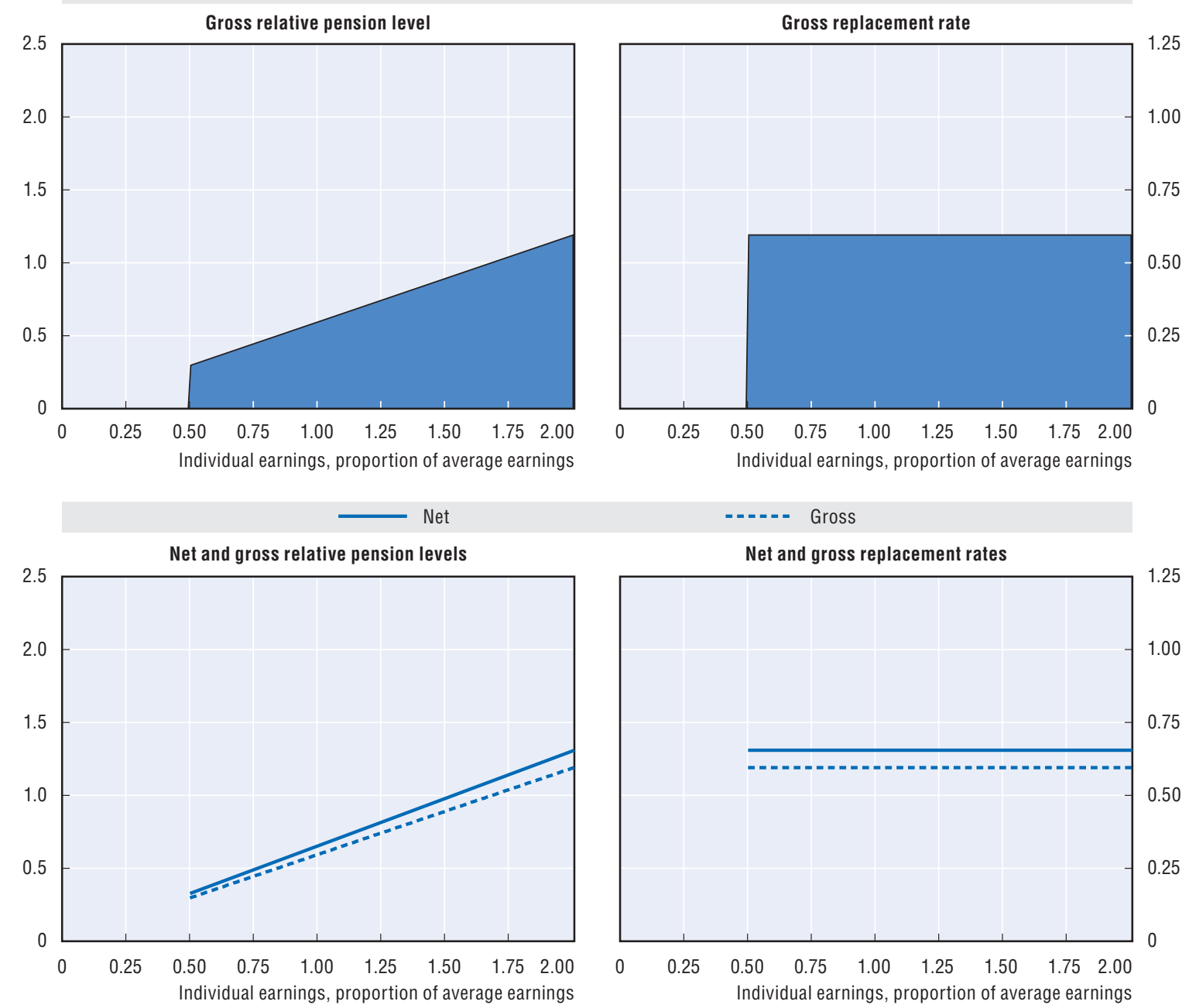

\begin{tabular}{|c|c|c|c|c|c|c|}
\hline \multicolumn{7}{|c|}{ Baseline scenario: Wages indexation of basic pension benefits } \\
\hline \multirow{2}{*}{$\begin{array}{l}\text { Men } \\
\text { Women (where different) }\end{array}$} & \multicolumn{6}{|c|}{ Individual earnings, multiple of average } \\
\hline & 0.5 & 0.75 & 1 & 1.5 & 2 & 3 \\
\hline Gross relative pension level & 29.8 & 44.7 & 59.6 & 89.3 & 119.1 & 174.8 \\
\hline \multicolumn{7}{|l|}{ (\% average gross earnings) } \\
\hline Net relative pension level & 32.7 & 49.1 & 65.4 & 98.2 & 130.9 & 192.1 \\
\hline \multicolumn{7}{|l|}{ (\% net average earnings) } \\
\hline Gross replacement rate & 59.6 & 59.6 & 59.6 & 59.6 & 59.6 & 58.3 \\
\hline \multicolumn{7}{|l|}{ (\% individual gross earnings) } \\
\hline Net replacement rate & 65.4 & 65.4 & 65.4 & 65.4 & 65.4 & 63.9 \\
\hline \multicolumn{7}{|l|}{ (\% individual net earnings) } \\
\hline Gross pension wealth & 14.8 & 14.8 & 14.8 & 14.8 & 14.8 & 14.5 \\
\hline (multiple of individual gross earnings) & 15.6 & 15.6 & 15.6 & 15.6 & 15.6 & 15.2 \\
\hline Net pension wealth & 14.8 & 14.8 & 14.8 & 14.8 & 14.8 & 14.5 \\
\hline (multiple of individual gross earnings) & 15.6 & 15.6 & 15.6 & 15.6 & 15.6 & 15.2 \\
\hline
\end{tabular}

Assumptions: Real rate of return $3 \%$, real earnings growth $1.25 \%$, inflation $2 \%$, and real discount rate $2 \%$. All systems are modelled and indexed according to what is legislated. Transitional rules apply where relevant. DC conversion rate equal $85 \%$. Labour market entry occurs at age 20 in 2014. Tax system latest available: 2014. 


\section{Slovak Republic}

\section{Slovak Republic: Pension system} in 2014

The earnings-related, public scheme is similar to a points system, with benefits that depend on individual earnings relative to the average. Low-income workers are protected by a minimum amount of earnings on which the pension benefit is calculated. All pensioners are eligible for social assistance benefits. Voluntary defined contribution plans were introduced in 2005.
Key indicators: Slovak Republic

\begin{tabular}{llcr}
\hline & & Slovak Republic & OECD \\
\hline \multirow{2}{*}{ Average worker earnings (AW) } & EUR & 10342 & 33036 \\
& USD & 12525 & 40007 \\
Public pension spending & \% of GDP & 7.0 & 7.9 \\
Life expectancy & At birth & 75.3 & 80.0 \\
\multirow{2}{*}{ Population over age 65 } & At age 65 & 16.2 & 19.3 \\
& \% of population & 13.6 & 16.2 \\
\hline
\end{tabular}

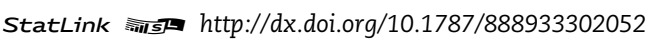

\section{Qualifying conditions}

The pension age is currently 62 years with at least 15 years of contributions. For women with children the pension age is reduced. For instance a woman with five or more children can retire at the age of 57.5 in 2014. The pension ages for women are gradually increasing and all women will have a retirement age of 62 years or higher in 2024. From 2017 and onwards the statutory pensionable age will be indexed with increases in life expectancy at retirement age. The actual increase will be calculated as the change in average life expectancy compared with the reference period and the result will be presented in days. To be eligible for a pension benefit in DC plans at least ten years of contributions are need. This rule was cancelled from 1 January 2015.

\section{Benefit calculations}

\section{Earnings-related}

The pension points are calculated as the ratio of individual earnings to economy-wide average earnings. In addition there is the "solidarity element" which reduce pensions point higher than 1.25. This coefficient will be gradually decreasing from $84 \%$ to $60 \%$ from $2013-18$. Points values lower than one are increased in a similar way and the coefficient for this increase will be gradually rise from $16 \%$ to $22 \%$ in the same time.

The pension benefits at retirement equal the average of all pension points in the reference period (generally years since 1984) multiplied by the total period of pension insurance and the pension-point value at the point of retirement. In 2014 the pension point equalled EUR 10.2524. The pension-point value is indexed to growth of average earnings (the third quarter each calendar year). National average earnings in 2014 were EUR 858.00 per month. Dividing the point value by the earnings figure gives the equivalent to the accrual rate in a defined-benefit scheme, which is just $1.25 \%$.

There is a ceiling to earnings for contributions, which is set at five times average earnings. The earnings data are lagged. The lagging means that the ceiling is slightly less than five time average earnings. 
Pensions in payment are indexed to a mix of growth of average earnings growth and price inflation. From 2013 to 2017 the pension benefits will be increased by fixed amounts. The share of earnings growth and inflation in the indexation will change from 40:60 in 2014; 30:70 in 2015; 20:80 in 2016 and 10:90 in 2017. From 2018 indexation will follow the development of consumer prices for pensioner's households.

Workers joining the defined-contribution plans have their benefits from the public earningsrelated scheme adjusted proportionally.

\section{Minimum}

There is no minimum pension benefit. However, there is a minimum assessment base for pension purposes that is equal to the minimum wage. From 1 January 2013 the minimum assessment base for self-employed persons is $50 \%$ of the average wage two years before. The minimum wage was EUR 352.00 and minimum assessment base for self-employed persons was EUR 402.50 from the beginning of January 2014.

\section{Social assistance}

The Assistance in Material Need target those unable to maintain their living conditions due to bad social situation of low income or no income individuals and households. The benefit is universal, non-contributory and financed thourgh general taxation. The aim of the benefit is to ensure basic living conditions and help citizens with their active participation to overcome unfavorable financial situation.

On 1 January 2014 the minimum income guarantee for pensioner in old-age from the Assistance in Material Need consisted of:

1. A monthly benefit equal to EUR 61.60 (single-pensioner) and EUR 107.10 (couple-pensioners without children).

2. A monthly Housing Allowance equal to EUR 55.80 (single-pensioner) and EUR 89.20 (couple-pensioners without children).

3. A monthly Protection Allowance equal to EUR 63.07 (single-pensioner) and EUR 126.14 (couplepensioners without children).

4. The total monthly amount: EUR 180.47 (single-pensioner) and EUR 322.44 (couple-pensioners without children). These amounts respond to total sum of income in case of person/s reaching retirement age without claim on pension/s and without any personal income.

Individuals with low pension benefits receive the Assistance in Material Need but $25 \%$ of the pension amount is disregard for eligibility of the Assistance. For every insurance year above 25 years an additional one percentage point is disregarded (for example with 40 years of pension contributions $40 \%$ of pension income is disregarded). This means that above mentioned benefit amounts are not maximum amounts for pensioners and that they vary according pension insurance period.

\section{Voluntary defined contribution}

The contribution rate for the voluntary defined-contribution scheme is $4 \%$ of earnings. On 1 September 2012 the contribution rate was lowered to 4\%. However, from 1 January 2017 the contribution rate will gradually increase by 0.25 percentage points each year and reach the target level at $6 \%$ in 2024. Participation in the defined contribution system was mandatory for workers entering the labour market for the first time from 1 January 2005. Other workers had the possibility to choose to join the mixed system or to by 1 June 2006 remain in the public scheme. From 1 January 2008 to 31 March 2012 participation in the mixed system was made voluntary for new entrants. The previous changes have changed the system into a default auto enrolment entrance 
with possibility to opt out with a two years horizon. The auto enrolment rules come into on 1 April 2012. From 1 January 2013 voluntary participation is possible for new entrants and voluntary entrance is possible before the age of 35 years. The defined-contribution pension can be taken as life annuity, fixed-term annuity or as programmed withdrawals. For calculation of the life annuity life insurance companies using cash flow models with unisex intergenerational mortality tables and take into account cost ratio of the system.

\section{Variant careers}

\section{Early retirement}

Early retirement is possible and pension benefits are reduced by $0.5 \%$ for each 30 days of early benefit withdrawal equivalent to $6.5 \%$ per year. An early retirement also requires a pension benefit higher than EUR 237.71 which equals 1.2 times the adult subsistence income level. The subsistence income level is equal to EUR 198.09 and has been so since 1 July 2013. From 1 January 2011 it is not possible to receive an early old-age pension benefit and also have mandatory pension insurance.

\section{Late retirement}

Late retirement is possible and the pension benefit increases by $0.5 \%$ for each 30 days of deferral equal to $6 \%$ per year. For individuals that combine pension benefit withdrawal with work the pension benefit is recalculated automatically every year from 1 January 2015 or upon request when the individual eventually retires adding one half of the points earned during that period.

\section{Childcare}

Individuals caring for children up to the age of six are credited with pension credits paid by the state. The assessment base for the pension contributions is $60 \%$ of average earnings prior to the caring period. Since 1 January 2011 the assessment base has been adjusted to the general ceiling rules and annual average wage two years before the absence year. Provisions for careers with disabled children are more generous until the children reach 18 . The carer and the child have to have permanents and the carer has to be registered.The same rules apply for the defined-contribution scheme (old-age pension saving scheme).

\section{Unemployment}

Unemployment spells are not credited in the pension system. However, the unemployed can use provisions of voluntary pension insurance. Also it is possible to pay contributions for this period retrospectively. 


\section{Pension modelling results: The Slovak Republic in 2061, retirement at age 67}
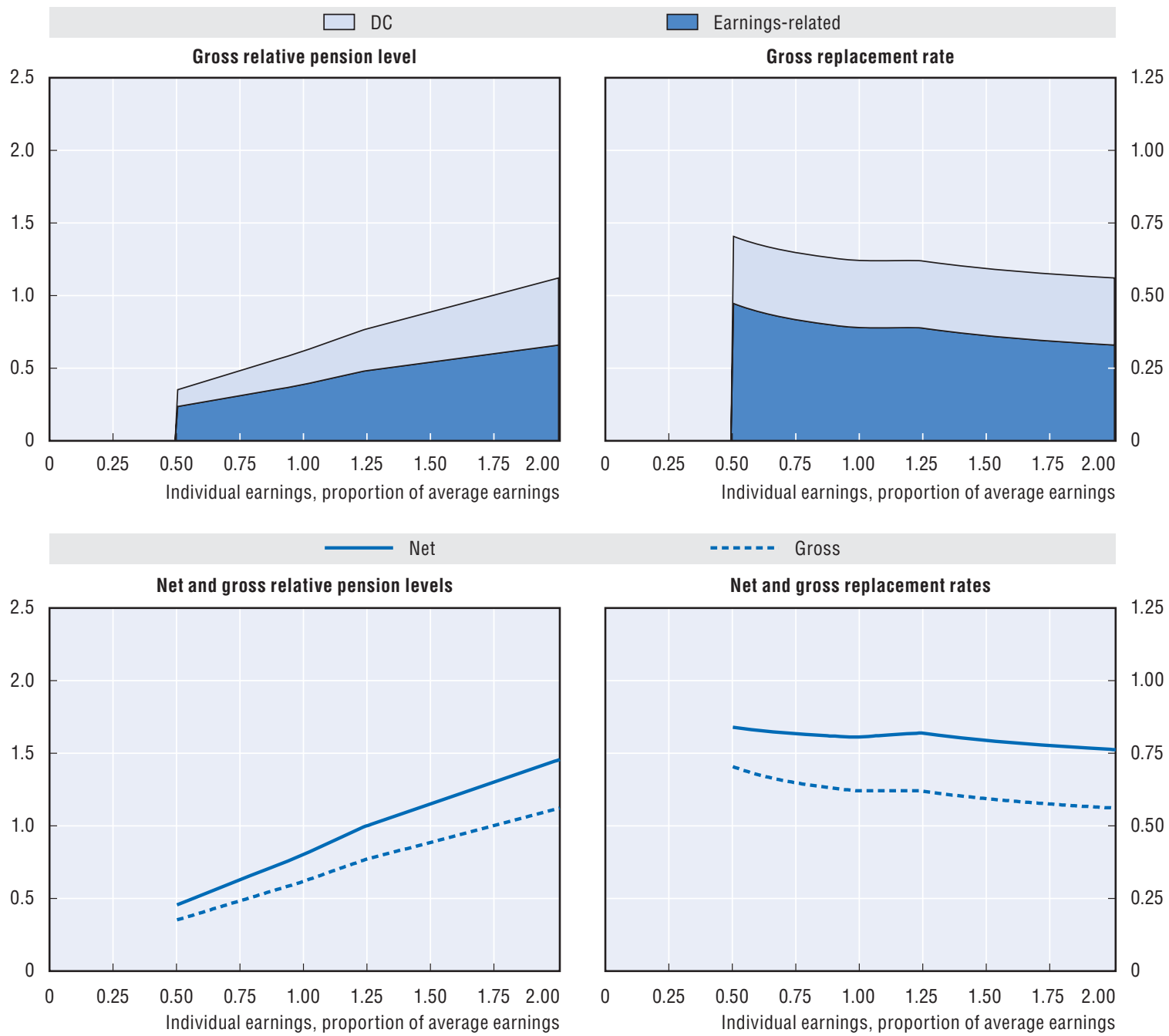

\begin{tabular}{|c|c|c|c|c|c|c|}
\hline \multicolumn{7}{|c|}{ Baseline scenario: Wage indexation of key parameters } \\
\hline \multirow{2}{*}{$\begin{array}{l}\text { Men } \\
\text { Women (where different) }\end{array}$} & \multicolumn{6}{|c|}{ Individual earnings, multiple of average } \\
\hline & 0.5 & 0.75 & 1 & 1.5 & 2 & 3 \\
\hline Gross relative pension level & 35.2 & 48.6 & 62.1 & 88.9 & 112.2 & 158.7 \\
\hline \multicolumn{7}{|l|}{ (\% average gross earnings) } \\
\hline Net relative pension level & 45.7 & 63.1 & 80.6 & 115.5 & 145.7 & 206.0 \\
\hline \multicolumn{7}{|l|}{ (\% net average earnings) } \\
\hline Gross replacement rate & 70.4 & 64.8 & 62.1 & 59.3 & 56.1 & 52.9 \\
\hline \multicolumn{7}{|l|}{ (\% individual gross earnings) } \\
\hline Net replacement rate & 84.0 & 81.7 & 80.6 & 79.4 & 76.2 & 74.2 \\
\hline \multicolumn{7}{|l|}{ (\% individual net earnings) } \\
\hline Gross pension wealth & 9.8 & 9.0 & 8.6 & 8.2 & 7.8 & 7.3 \\
\hline (multiple of individual gross earnings) & 11.6 & 10.7 & 10.2 & 9.8 & 9.2 & 8.7 \\
\hline Net pension wealth & 9.8 & 9.0 & 8.6 & 8.2 & 7.8 & 7.3 \\
\hline (multiple of individual gross earnings) & 11.6 & 10.7 & 10.2 & 9.8 & 9.2 & 8.7 \\
\hline
\end{tabular}

Assumptions: Real rate of return $3 \%$, real earnings growth $1.25 \%$, inflation $2 \%$, and real discount rate $2 \%$. All systems are modelled and indexed according to what is legislated. Transitional rules apply where relevant. DC conversion rate equal $85 \%$. Labour market entry occurs at age 20 in 2014. Tax system latest available: 2013. 


\section{Slovenia}

\section{Slovenia: Pension system in 2014}

The system combines an earnings-related public pension with minimum and targeted schemes.

\section{Qualifying conditions}

Key indicators: Slovenia

\begin{tabular}{llcc}
\hline & & Slovenia & OECD \\
\hline \multirow{2}{*}{ Average worker earnings (AW) } & EUR & 17851 & 33036 \\
& USD & 21618 & 40007 \\
Public pension spending & \% of GDP & 11.4 & 7.9 \\
Life expectancy & At birth & 79.5 & 80.0 \\
\multirow{2}{*}{ Population over age 65 } & At age 65 & 18.9 & 19.3 \\
& \% of population & 17.9 & 16.2 \\
\hline & StatLink -inlst & http://dx.doi.org/10.1787/888933302061
\end{tabular}

The pension age was 58 years and eight months with 40 contribution years for men and 58 years and four months with 38 years and eight months of contributions for women in 2014. The pension ages and years of necessary contributions are gradually increasing and will reach 60 in 2018 for men and 60 in 2020 for women and require 40 years of contributions. With less than 40 years the pension age will be 65 for both men and women from 2020.

\begin{tabular}{|c|c|c|c|c|}
\hline \multirow[t]{2}{*}{ Men (2014) } & Contribution years & 15 & 20 & 40 \\
\hline & Pension age & 65 years & 64 years & 58 years 8 months \\
\hline \multirow[t]{2}{*}{ Men (2018) } & Contribution years & 15 & 20 & 40 \\
\hline & Pension age & 65 years & 65 years & 60 years \\
\hline \multirow[t]{2}{*}{ Women (2014) } & Contribution years & 15 & 20 & 38 years 8 months \\
\hline & Pension age & 64 years & 62 years & 58 years 4 months \\
\hline \multirow[t]{2}{*}{ Women (2020) } & Contribution years & 15 & 20 & 40 \\
\hline & Pension age & 65 years & 65 years & 60 years \\
\hline
\end{tabular}

Until 2019 individuals need 20 years of contributions for pension benefit receipt. Thereafter 15 years of insurance will be sufficient.

\section{Benefit calculation}

\section{Earnings-related}

The old-age pension benefits are calculated net of taxes. The earnings-related scheme gives $26 \%$ of the pension rating base for men and $29 \%$ for women once the minimum qualifying condition (15 years' contributions) has been met. Thereafter, the accrual rate is $1.25 \%$ per year form men. For women the accrual rate was $1.41 \%$ per year in 2014 . The accrual rate for women is gradually changing until it reaches the target rate of $1.25 \%$ in 2023 . The total accrual after 40 years of contributions equal $57.25 \%$ for men and $64.25 \%$ for women in 2014. Subsequently the total accrual rate for each additional year for women the accrual rate will amount to $1.25 \%$ and the accrual rate for 40 years of contributions will amount to $60.25 \%$. The pension rating base is calculated using the best 24 year average of net wages. Past net earnings are uprated with growth of nominal net wages. In 2014 the best consecutive 20 years is used to calculate the pension rating base. The earnings measure is based on a period of best consecutive years since 1970. The period of assessment has been extended since 2013 and will reach 24 years in 2018. 
There is a minimum pension rating base that applies to all pensionable earnings. The Minimum Pension Rating Base is established 1 January each year and is equal to $76.5 \%$ of the average monthly salary. In November 2014 this salary equalled EUR 762.76 after the deductions for taxes and contributions. There is also a ceiling for pensionable earnings set at four times the minimum pension rating base equal to EUR 3051.04 per month in November 2014. Pension benefits in payment are indexed with $60 \%$ of gross average wage growth and $40 \%$ of consumer prices however in 2014 pension benefits where not uprated.

\section{Minimum}

The minimum pension is defined as $26 \%$ of the minimum pension rating base for men and $29 \%$ of the minimum pension rating base for women.

\section{Targeted}

There was (until 31 December 2011) a means-tested social-security allowance for low-income pensioners. From 1 January 2012 allowance was transferred into social protection legislation.

\section{Variant careers}

\section{Early retirement}

For early retirement the pension benefit is reduced as follows:

\begin{tabular}{|c|c|c|c|c|c|c|}
\hline Age (lower limit) & 58 years & 59 years & 60 years & 61 years & 62 years & \\
\hline Women 2014 & 4 months & & & & & \\
\hline Reduction (monthly, \%) & 0.3 & 0.3 & 0.3 & 0.3 & 0 & \\
\hline Reduction (annual, \%) & 2.4 & 3.6 & 3.6 & 3.6 & 0 & \\
\hline Total (\%) & 13.2 & 10.8 & 7.2 & 3.6 & 0 & \\
\hline Age (lower limit) & 58 years & 59 years & 60 years & 61 years & 62 years & 64 years \\
\hline Men 2014 & 8 months & 6 months & 6 months & 6 months & 6 months & \\
\hline Reduction (monthly, \%) & 0.3 & 0.3 & 0.3 & 0.3 & 0.3 & 0 \\
\hline Reduction (annual, \%) & 1.2 & 1.8 & 1.8 & 1.8 & 1.8 & 0 \\
\hline Total (\%) & 18 (max.) & 16.2 & 12.6 & 9.0 & 5.4 & 0 \\
\hline
\end{tabular}

The upper limit for calculating the reduction of the pension benefit is set to 65 years. However due to transitional period the upper limit in 2014 for women is set to 62 years and for men 64 years. This limit is gradually being increased by six months per year to 65 for both women and men. The maximum possible reduction of old age pension for men and women amounts to $18.0 \%$.

\section{Late retirement}

Late retirement is possible and pension benefits are adjusted for pension deferral:

- A new pension benefit bonus has been introduced for each three months of work after an individual met the age conditions for pension benefit withdrawal. Currently 60 years of age and with 40 years of pension qualifying period (without any purchased periods). The maximum bonus for pension benefit deferral is $12 \%$ (three years).

If a person postpones claiming old-age pension at the minimum pension age currently - in 2014 58 year and eight months of age with 40 years of pension qualifying period (without purchased periods) for men and 58 years and four months of age with 38 years and eight months of pension qualifying period (without purchased periods) for women, equalised to 60 from 2019, additional years of insurance up until full pension age attract a higher accrual rate. 


\begin{tabular}{lccc}
\hline & \multicolumn{3}{c}{ Contribution years without purchased period (lower limit) 2014} \\
\hline Men & 41 & 42 & 43 \\
Women & 39 years 8 months & 40 years 8 months & 41 years 8 months \\
Accrual rate (\%) & 4 & 8 & 12 \\
\hline
\end{tabular}

\section{Childcare}

Maternity periods of up to a year are covered by the pension system. The benefits for this period are calculated on the basis of earnings when the mother was working.

In addition, one of the parents who switch to part-time work when the child is three or under is treated as if he or she worked full time. The base for the payment of the contributions is the amount of the compensation or benefit to which they are entitled pursuant to. There is also the possibility of paying voluntary contributions for periods out of the labour market (also for periods of caring for children).

\section{Unemployment}

Recipients of unemployment insurance benefits are covered by the pension system, with the Employment Agency paying the contributions. Persons over age 50 with 25 years' of insurance can receive unemployment benefits for 19 months, workers over age 55 with 25 years' insurance can receive unemployment benefits for 25 months.

For persons with longer periods of unemployment who have exhausted their entitlement to unemployment insurance, the state pays the contribution (Unemployment Extension Contribution) and credits up to one year required until the fulfilment of the conditions for retirement. For unemployed persons aged at least 57 or who completed at least 35 years of insurance period, the Unemployment Extension Contribution is extended for up to two years before the fulfilment of conditions for retirement. The value of unemployment benefits (both insurance and assistance payments) is taken into account when calculating pension benefits. 
Pension modelling results: Slovenia in 2054, retirement at age 60

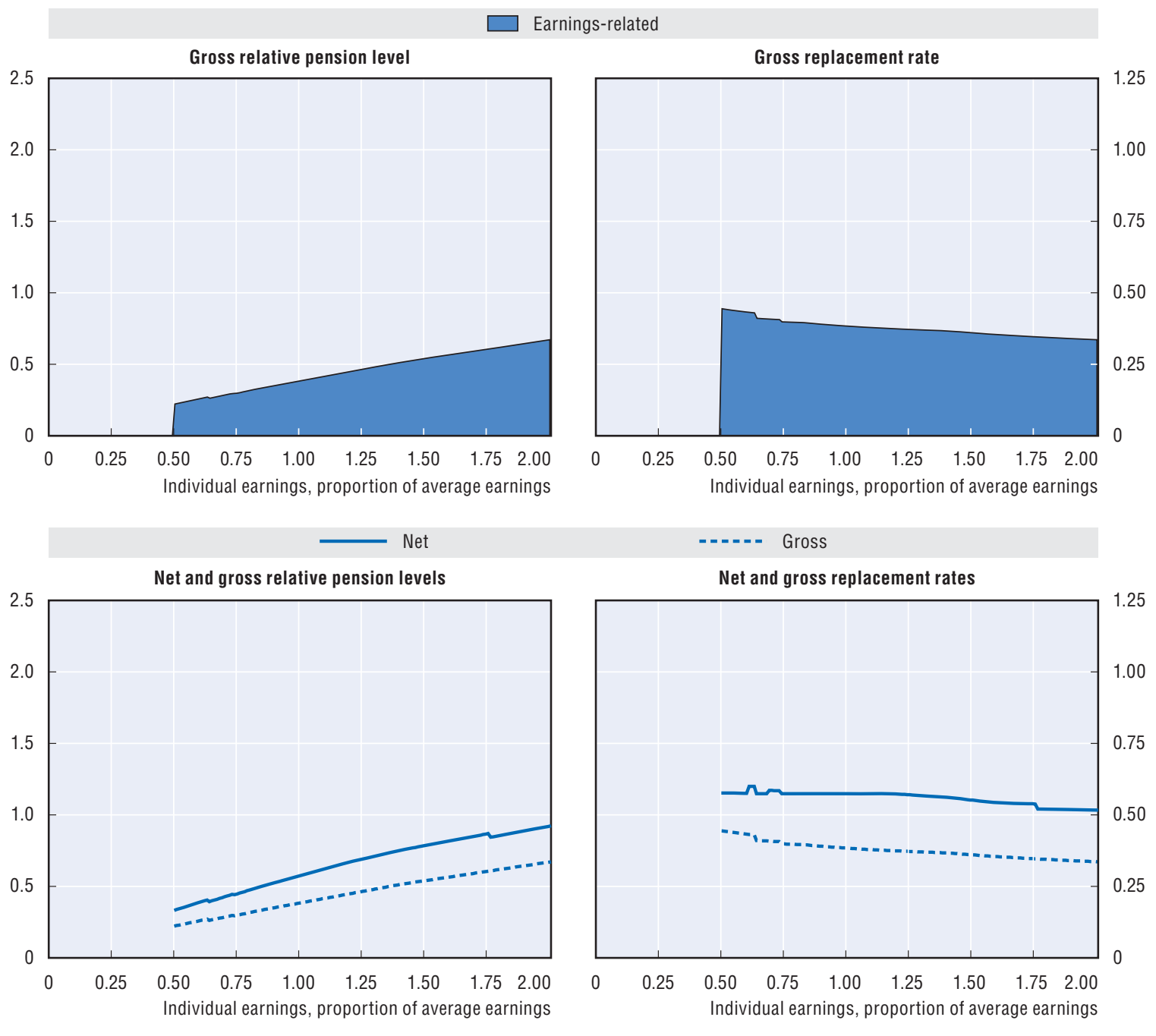

\begin{tabular}{|c|c|c|c|c|c|c|}
\hline \multicolumn{7}{|c|}{ Baseline scenario: Legislation scenario (wage indexation) } \\
\hline \multirow{2}{*}{$\begin{array}{l}\text { Men } \\
\text { Women (where different) }\end{array}$} & \multicolumn{6}{|c|}{ Individual earnings, multiple of average } \\
\hline & 0.5 & 0.75 & 1 & 1.5 & 2 & 3 \\
\hline Gross relative pension level & 22.2 & 29.9 & 38.4 & 54.0 & 67.2 & 72.6 \\
\hline (\% average gross earnings) & 23.4 & 31.4 & 40.4 & 56.9 & 70.7 & 76.4 \\
\hline Net relative pension level & 33.3 & 44.7 & 57.4 & 78.6 & 92.3 & 97.4 \\
\hline (\% net average earnings) & 35.0 & 47.0 & 60.4 & 82.2 & 95.3 & 101.6 \\
\hline Gross replacement rate & 44.4 & 39.8 & 38.4 & 36.0 & 33.6 & 24.2 \\
\hline (\% individual gross earnings) & 46.8 & 41.9 & 40.4 & 37.9 & 35.4 & 25.5 \\
\hline Net replacement rate & 57.6 & 57.4 & 57.4 & 55.1 & 51.7 & 39.4 \\
\hline (\% individual net earnings) & 60.6 & 60.4 & 60.4 & 57.6 & 53.3 & 41.1 \\
\hline Gross pension wealth & 9.8 & 8.8 & 8.5 & 7.9 & 7.4 & 5.3 \\
\hline (multiple of individual gross earnings) & 12.2 & 11.0 & 10.6 & 9.9 & 9.2 & 6.7 \\
\hline Net pension wealth & 9.8 & 8.8 & 8.5 & 7.7 & 6.8 & 4.8 \\
\hline (multiple of individual gross earnings) & 12.2 & 11.0 & 10.6 & 9.6 & 8.3 & 5.9 \\
\hline
\end{tabular}

Assumptions: Real rate of return $3 \%$, real earnings growth $1.25 \%$, inflation $2 \%$, and real discount rate $2 \%$. All systems are modelled and indexed according to what is legislated. Transitional rules apply where relevant. DC conversion rate equal $85 \%$. Labour market entry occurs at age 20 in 2014. Tax system latest available: 2013. 


\section{South Africa}

\section{South Africa: Pension system in 2014}

The public pension is flat rate based on a residency test. There is also a large number of occupational schemes, though coverage is not high at lower-income levels.
Key indicators: South Africa

\begin{tabular}{|c|c|c|c|}
\hline & & South Africa & OECD \\
\hline \multirow[t]{2}{*}{ Average worker earnings (AW) } & ZAR & 144627 & 461978 \\
\hline & USD & 12525 & 40007 \\
\hline Public pension spending & $\%$ of GDP & & 7.9 \\
\hline \multirow[t]{2}{*}{ Life expectancy } & At birth & 57.1 & 80.0 \\
\hline & At age 65 & 13.2 & 19.3 \\
\hline Population over age 65 & $\%$ of population & 5.7 & 16.2 \\
\hline
\end{tabular}

\section{Qualifying conditions}

The pension age was equalised at age 60 for men and women in 2010.

\section{Benefit calculation}

\section{Old-age pension}

The pension is means-tested with individuals having an income of under ZAR 64680 for singles and ZAR 129360 for couples and no more than ZAR 930600 in assets for a single person and ZAR 1861200 for a couple. The benefit amount is up to ZAR 1410 per month for singles and ZAR 2820 for couples. The benefit is increased to ZAR 1430 for those aged over 75 .

\section{Voluntary private pension}

The average contribution rate for occupational schemes is around $15 \%$ of earnings, divided between employers and employees.

\section{Variant careers}

\section{Early retirement}

It is not possible to claim the public pension before the normal eligibility age of 60 .

\section{Late retirement}

Receipt of the old-age pension is not dependent on retirement. It is therefore possible to combine pension and employment as long as the recipient's income does not exceed the means test threshold.

While people are not obliged to claim the public pension on reaching the qualifying age, there is no advantage in deferring a claim.

\section{Childcare}

Eventual public pension entitlement is not affected by periods out of paid work for caring purposes.

\section{Unemployment}

Eventual public pension entitlement is not affected by periods of unemployment. 
Pension modelling results: South Africa in 2054, retirement at age 60

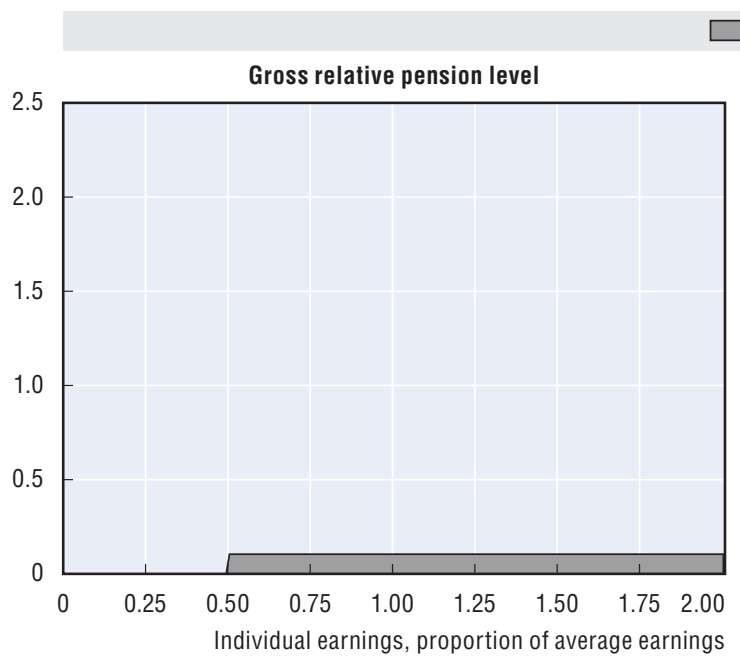

$\mathrm{SA}$

Gross replacement rate

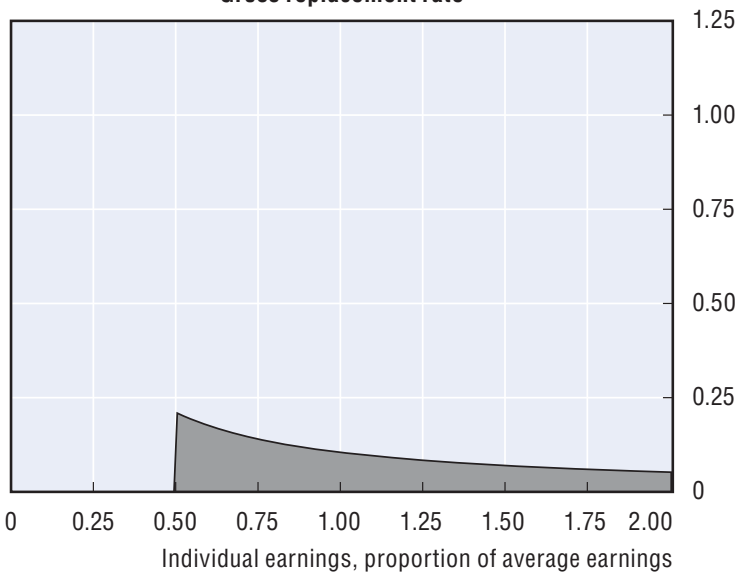

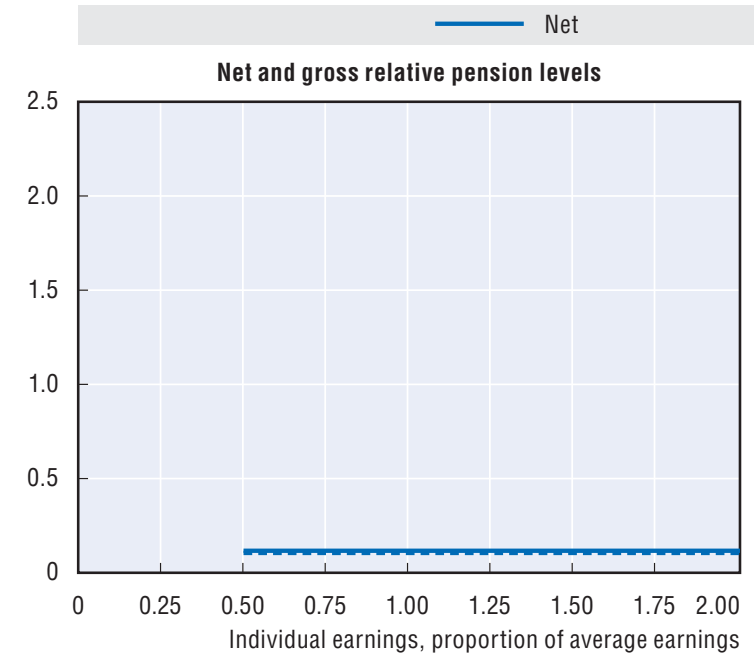

--n-n) Gross

Net and gross replacement rates

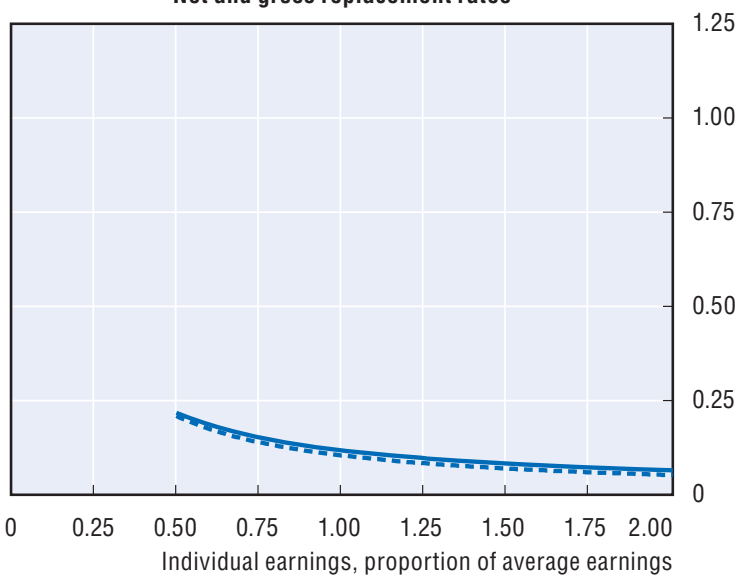

Baseline scenario: Legislation scenario (wage indexation of safety-nets schemes)

\begin{tabular}{|c|c|c|c|c|c|c|}
\hline \multirow{2}{*}{$\begin{array}{l}\text { Men } \\
\text { Women (where different) }\end{array}$} & \multicolumn{6}{|c|}{ Individual earnings, multiple of average } \\
\hline & 0.5 & 0.75 & 1 & 1.5 & 2 & 3 \\
\hline Gross relative pension level & 10.5 & 10.5 & 10.5 & 10.5 & 10.5 & 10.5 \\
\hline \multicolumn{7}{|l|}{ (\% average gross earnings) } \\
\hline Net relative pension level & 11.8 & 11.8 & 11.8 & 11.8 & 11.8 & 11.8 \\
\hline \multicolumn{7}{|l|}{ (\% net average earnings) } \\
\hline Gross replacement rate & 20.9 & 13.9 & 10.5 & 7.0 & 5.2 & 3.5 \\
\hline \multicolumn{7}{|l|}{ (\% individual gross earnings) } \\
\hline Net replacement rate & 21.7 & 15.2 & 11.8 & 8.3 & 6.5 & 4.6 \\
\hline \multicolumn{7}{|l|}{ (\% individual net earnings) } \\
\hline Gross pension wealth & 2.9 & 1.9 & 1.4 & 1.0 & 0.7 & 0.5 \\
\hline (multiple of individual gross earnings) & 3.6 & 2.4 & 1.8 & 1.2 & 0.9 & 0.6 \\
\hline Net pension wealth & 2.9 & 1.9 & 1.4 & 1.0 & 0.7 & 0.5 \\
\hline (multiple of individual gross earnings) & 3.6 & 2.4 & 1.8 & 1.2 & 0.9 & 0.6 \\
\hline
\end{tabular}

Assumptions: Real rate of return 3\%, real earnings growth $1.25 \%$, inflation $2 \%$, and real discount rate $2 \%$. All systems are modelled and indexed according to what is legislated. Transitional rules apply where relevant. DC conversion rate equal 85\%. Labour market entry occurs at age 20 in 2014. Tax system latest available: 2013. 


\section{Spain}

\section{Spain: Pension system in 2014}

The Spanish public pension system consists of a single, earnings-related benefit in the contribution level, with a meanstested minimum pension. There is also a non-contribution means-tested level, which replaces the previous special social assistance scheme.
Key indicators: Spain

\begin{tabular}{|c|c|c|c|}
\hline & & Spain & OECD \\
\hline \multirow[t]{2}{*}{ Average worker earnings (AW) } & EUR & 26162 & 33036 \\
\hline & USD & 31683 & 40007 \\
\hline Public pension spending & $\%$ of GDP & 10.5 & 7.9 \\
\hline \multirow[t]{2}{*}{ Life expectancy } & At birth & 82.0 & 80.0 \\
\hline & At age 65 & 20.5 & 19.3 \\
\hline Population over age 65 & $\%$ of population & 18.3 & 16.2 \\
\hline
\end{tabular}

\section{Qualifying conditions}

Following the pension reform of 2011, the retirement age for a full pension benefit has been increased from 65 years to 65 years and two months in 2014 if an individual has less than 35 years and six months of contributions. The legal retirement age will be 67 years for both men and women in 2027. However if an individual has 38.5 years of contributions retirement with full-pension benefits is possible from age 65 . It is necessary to have 15 years of contributions to qualify for a pension benefit.

\section{Benefit calculation}

\section{Earnings-related}

Previously, the benefit accrued according to the following schedule. The first 15 years' of contributions delivered $50 \%$ of the earnings base. The next ten years provided an extra $3 \%$ per year, $2 \%$ per year thereafter. The maximum accrual was $100 \%$ of the earnings base, reached after 35 years of pension contributions. Following the reform the accrual is still 50\% after 15 years reaching $100 \%$ after 37 years (from year 15 every additional month of contributions will increase the accrual by $0.19 \%$ per month from months 1 to 248 , and $0.18 \%$ per month thereafter). The maximum accrual will still be $100 \%$ of the earnings base.

A new Adjustment Pensions Index (IRP) is applied from 2014 and a Sustainability Factor (FS) will be introduced in 2019 and will be applicable to new pension benefits. This factor takes into account the growth of the life expectancy of the new pensioners.

The earnings base is equal to the past earnings over the last 17 years compared to 15 years previously. From 2022 and onwards the earning base will be calculated with the past 25 annual earnings, up-rated in line with prices, apart from the last two years. This means that the maximum replacement rate relative to final salary is less than $100 \%$.

There is a ceiling to earnings for contributions and benefit purposes of EUR 43164 in 2014.

Since 2014 pension benefits are indexed to a new Adjustment Index calculated according to a number of different factors: number of contributory pensions, the variation of the average pension amount and the balance between revenues and expenses of the Social Security system. The index will produce a range of possible values between a minimum of $0.25 \%$ and a maximum equal to consumer price index and an additional $0.50 \%$. 


\section{Minimum and maximum}

There is a minimum pension benefit payable from age 65 equal to EUR 632.9 per month for single pensioners and EUR 780.9 per month for pensioners with a dependent spouse. There are 14 payments per year. There is also a minimum pension benefit equal to EUR 731.9 per month for widows with children and a minimum pension benefit for orphans.

The maximum pension is EUR 2554.49 per month in 2014 with 14 payments per year.

\section{Non-contributory pension}

The non-contributory pension is granted to people aged over 65 years with less than EUR 5136.6 per year in 2015 and who are not entitled to a contributory pension. The pension amount depends on the family composition and on the household's income.

\section{Variant careers}

\section{Early retirement}

Early retirement is possible four years before the retirement age in the case of involuntary unemployment and 33 years of contributions, and two years before the legal retirement age in the case of voluntary unemployment and 35 years of contributions. Until previously the minimum age was 61 years for involuntary unemployment and with 33 years of contributions. The actuarial reduction on pension benefits for early retirement varies from $2 \%$ to $1.5 \%$ per quarter depending on the length of contributions.

The minimum pension for early retirees is EUR 592.0 per month for pensioners without a dependent spouse, and EUR 731.9 per month for pensioners with a dependent spouse. The minimum benefit increases after age 65 .

Partial retirement is possible from age of 61 years and two months in 2014, with a new employee. In 2027, once the reform is completed, partial retirement will be possible at 63 with 36 years and six months contributed, or 65 years with more than 33 contributed years and less than 36 years and six months) or from 65 years and two months in 2014 (without substitution). Both the new and the partially retired employee will contribute fully to the pension system. Prior to the reform, partially retired only contributed proportionally of the working day effectively worked.

\section{Late retirement}

It is possible to defer the pension benefits withdrawal after normal retirement age. For workers who have contributed between 15 and 25 years and continue working after the age of 67, the pension benefit will increase by $2 \%$ of the base of calculation per additional year. The increase is $2.75 \%$ with 25 to 37 years of contributions and $4 \%$ with 37 years of contributions.

From 67 there is also the possibility of combining partial pension and part-time job. In this case, there is no obligation to replace the remaining working hours.

Since March 2013, it is possible for individuals above the normal retirement age to combine retirement benefit receipt and work. However in these cases the amount of the pension benefit is reduced by the $50 \%$.

\section{Childcare}

Maternity and paternity period are covered. Three years are contributed for benefits like: retirement pension, permanent incapacity pension, widows and orphanage pensions, maternity and paternity leaves. 


\section{Unemployment}

During periods of unemployment-benefit receipt the government pays the employers' contribution and the worker pays the employee's contribution. The base salary for contributions is the average salary in the six months prior to the unemployment period. The duration of the unemployment benefits depend on the number of contributed days during the past six years, varying between four months and two years. The unemployment assistance which is paid thereafter does not create any pension credits except for individuals aged 55 years or more whose contributions are paid by the government until they reach the retirement age. These contributions are levied on the $100 \%$ of the minimum base equal to EUR 753 per month in 2014. 
Pension modelling results: Spain in 2059, retirement at age 65

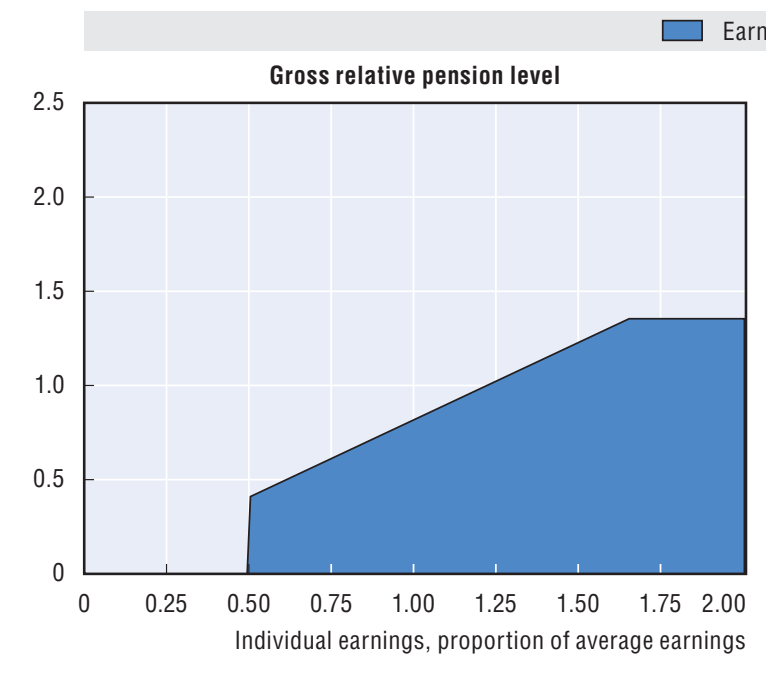

Earnings-related
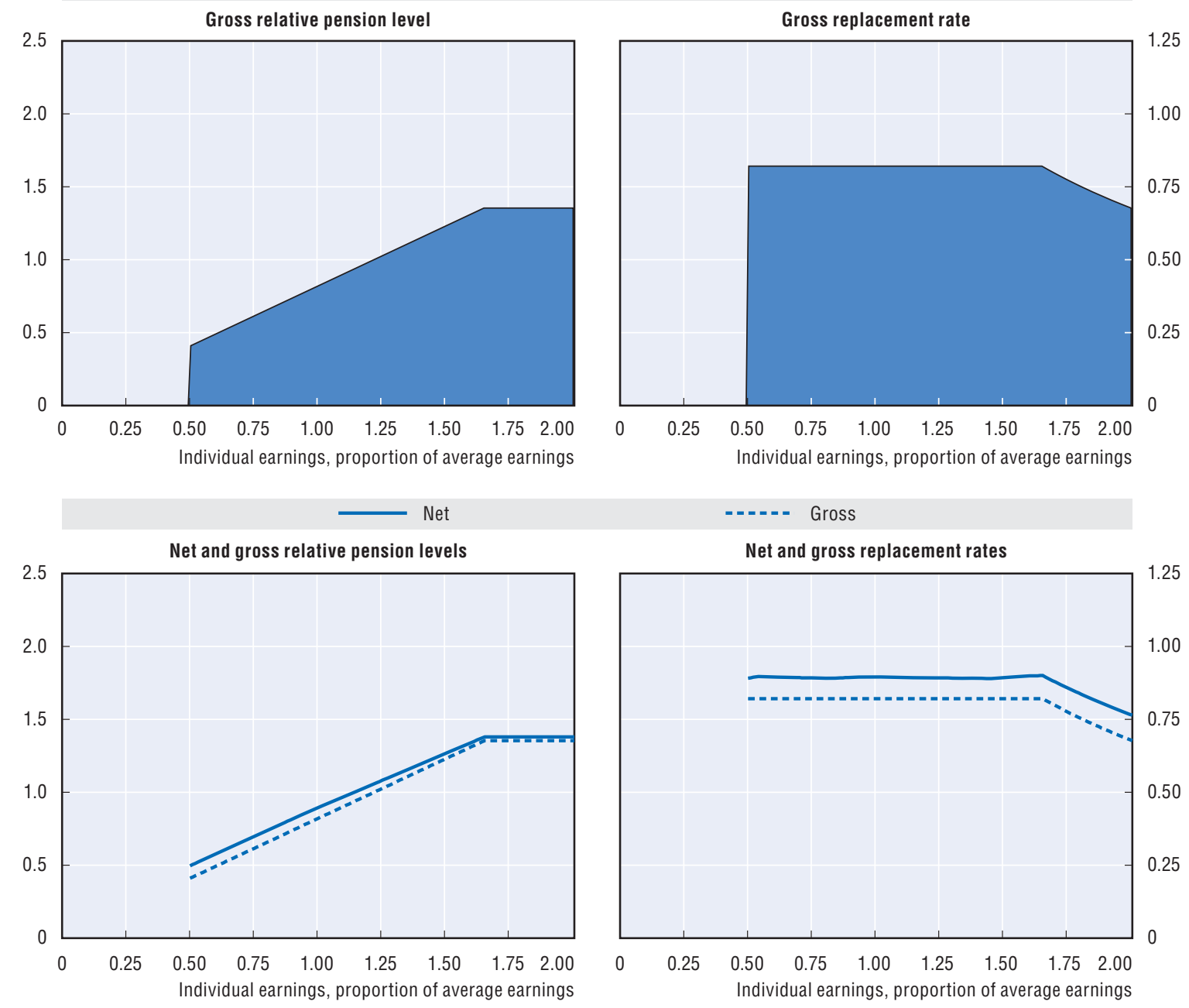

\begin{tabular}{|c|c|c|c|c|c|c|}
\hline \multicolumn{7}{|c|}{ Baseline scenario: Legislation scenario (price indexation of basic scheme) } \\
\hline \multirow{2}{*}{$\begin{array}{l}\text { Men } \\
\text { Women (where different) }\end{array}$} & \multicolumn{6}{|c|}{ Individual earnings, multiple of average } \\
\hline & 0.5 & 0.75 & 1 & 1.5 & 2 & 3 \\
\hline Gross relative pension level & 41.1 & 61.6 & 82.1 & 123.2 & 135.5 & 135.5 \\
\hline \multicolumn{7}{|l|}{ (\% average gross earnings) } \\
\hline Net relative pension level & 49.7 & 69.8 & 89.5 & 126.8 & 138.0 & 138.0 \\
\hline \multicolumn{7}{|l|}{ (\% net average earnings) } \\
\hline Gross replacement rate & 82.1 & 82.1 & 82.1 & 82.1 & 67.7 & 45.2 \\
\hline \multicolumn{7}{|l|}{ (\% individual gross earnings) } \\
\hline Net replacement rate & 89.1 & 89.2 & 89.5 & 89.3 & 76.4 & 54.8 \\
\hline \multicolumn{7}{|l|}{ (\% individual net earnings) } \\
\hline Gross pension wealth & 14.6 & 14.6 & 14.6 & 14.6 & 12.0 & 8.0 \\
\hline (multiple of individual gross earnings) & 17.2 & 17.2 & 17.2 & 17.2 & 14.2 & 9.5 \\
\hline Net pension wealth & 13.6 & 12.7 & 12.2 & 11.5 & 9.4 & 6.3 \\
\hline (multiple of individual gross earnings) & 16.1 & 15.0 & 14.5 & 13.7 & 11.1 & 7.4 \\
\hline
\end{tabular}

Assumptions: Real rate of return $3 \%$, real earnings growth $1.25 \%$, inflation $2 \%$, and real discount rate $2 \%$. All systems are modelled and indexed according to what is legislated. Transitional rules apply where relevant. DC conversion rate equal $85 \%$. Labour market entry occurs at age 20 in 2014. Tax system latest available: 2013. 


\section{Sweden}

\section{Sweden: Pension system in 2014}

The national retirement pension consists of a pay-as-you-go notional accounts system and a mandatory funded defined contribution pension and a defined benefit pensionincome-tested top-up. Occupational pension plans with defined benefit and defined contribution elements have broad coverage.
Key indicators: Sweden

\begin{tabular}{|c|c|c|c|}
\hline & & Sweden & OECD \\
\hline \multirow[t]{2}{*}{ Average worker earnings (AW) } & SEK & 407974 & 312251 \\
\hline & USD & 52272 & 40007 \\
\hline Public pension spending & $\%$ of GDP & 7.4 & 7.9 \\
\hline \multirow[t]{2}{*}{ Life expectancy } & At birth & 81.7 & 80.0 \\
\hline & At age 65 & 19.9 & 19.3 \\
\hline Population over age 65 & $\%$ of population & 20.0 & 16.2 \\
\hline
\end{tabular}

\section{Qualifying conditions}

The earnings-related national pensions can be withdrawn from the age of 61 . Eligibility for the guarantee pension requires three years' residency and the guarantee pension benefit is available from the age of 65 . A maximum guarantee pension benefit requires 40 years' of residency and shorter periods are reduced proportionally.

\section{Benefit calculation}

Contributions of $18.5 \%$ of pensionable pay are credited and then uprated in line with a three-year moving average of economy-wide average earnings. Pensionable pay is defined as earnings less the employee contribution to the pension system (i.e. to both the notional accounts system and the defined contribution system) of $7 \%$ of gross earnings, giving an effective contribution rate on gross earnings of $17.21 \%, 14.88 \%$ to the notional-accounts system and $2.33 \%$ to the defined contribution funded pensions. Contributions are only levied when annual earnings exceed a small floor of SEK 18824 in 2015, just under 5\% of average earnings, although they are due on the whole of earnings for all people earning above the floor. There is a ceiling to benefits calculated in terms of pensionable earnings of SEK 435750 in 2015, giving an effective ceiling relative to gross earnings of SEK 468867 in 2015 (just under 115\% of average worker earnings). Employer contributions are also paid only up to the ceiling. There is an additional tax on earnings above the ceiling for persons up to the age of 65 this tax has the same percentage as the pension contribution.

\section{Earnings-related}

The earnings-related scheme uses notional accounts. The notional accounts are increased every year by the distribution of the pension balances of deceased individual of the same age as the survivors (inheritance gains). The inheritance gains from people who die before the earliest possible retirement age (61 years) are relevant. After this age the inheritance gains factor is estimated on the basis of the mortality observed for an earlier period (computed from five year unisex mortality tables).

At retirement, the accumulated notional capital will be converted into an annuity. This calculation will use a coefficient depending on individual retirement age and contemporaneous life expectancy (based on the previous five year unisex mortality tables). A real discount rate of $1.6 \%$ a year is also included in the calculation of the annuity.

After retirement, pension benefits are uprated with the increase in nominal average earnings less the imputed interest rate in the annuity divisor of $1.6 \%$. There is also a "balance mechanism": if assets (the buffer fund plus the estimated value of assets in the form of contribution revenues) fall 
below liabilities (accrued notional pension capital and capital value of outgoing pensions), then indexation of pensions in payment and returns credited to notional accounts are reduced by the ratio of assets to liabilities. The balance ratio for year $t$ is used to calculate the balance number or the need for activating the balancing mechanism in year $t+2$. An activated balancing mechanism would mean lower replacement rates from the national system but will produce higher results when the pension system recovers and the balance figure increases (the balance index can exceed the income index during the recovery period). The balancing ratio for 2012 and the balance number for 2014 is 0.9837 .

\begin{tabular}{lcccccc}
\hline & 2012 & 2011 & 2010 & 2009 & 2008 & 2007 \\
\hline Balancing ratio & 0.9837 & 1.0198 & 1.0024 & 0.9549 & 0.9826 & 1.0026 \\
\hline
\end{tabular}

For modelling purposes, the annuity coefficients are calculated using the above rules and the relevant mortality data from the UN population database. It is assumed that the balance mechanism does not affect the uprating of benefits.

\section{Basic (guarantee pension)}

The basic "guarantee pension" is an income-tested top-up pension benefit for individuals with low levels of benefit from notional accounts. For a single person, the full guaranteed benefit in 2014 was SEK 94572 for a single pensioner born after 1938 or 24\% of gross average earnings.

The guarantee pension is withdrawn at 100\% against the first SEK 55944 in 2014 of income, for a single person, from the earnings-related pension, thereafter at $48 \%$. This threshold is equivalent to $14 \%$ of average earnings. Only when earnings-related pension exceeds SEK 136420 - nearly $35 \%$ of average earnings - is entitlement to the guarantee exhausted. The guarantee level is price indexed.

There is also a housing benefit that covers $93 \%$ of housing costs up to a maximum of SEK 5000 per month for a single pensioner. From 1 January 2012 an amount of SEK 170 per person was added to the housing allowance. From January 1, 2013 an amount of SEK 340 per household is added. The benefit is an important part of the minimum living standard for Swedish pensioners. This means-tested benefit is not included in the modelled calculations.

\section{Defined contribution}

A further $2.5 \%$ of pensionable income (giving an effective contribution rate against gross earnings of $2.33 \%$ ) is paid into personal pension accounts in the mandatory funded defined contribution system where individuals have a broad choice of where these funds are invested.

At retirement, individual have a choice over the way benefits are withdrawn. The accumulated pension account can convert into an annuity to avoid investment risk. Alternatively, it is possible to choose a variable annuity, where funds continue to be invested by the chosen fund manager. These annuities do not have a guaranteed value. The principle of the pension benefit calculation in this case is that the value of the account is divided by an annuity divisor (based on estimated average life expectancy) and the pension benefit is credited with an estimated future interest rate of $3 \%$ minus administrative costs. If returns exceed $3 \%$, then either an additional payment is made or the balance of the account is higher and so, therefore, is the base for calculating the annual pension.

\section{Quasi-mandatory occupational}

Occupational pension benefit schemes are estimated to cover almost $90 \%$ of employees. There are only four major occupational schemes. The modelling has used the ITP scheme for white-collar workers, which is a funded defined contribution scheme for those born 1979 or later. 


\section{ITP1}

From 1 January 2007, salaried employees born in or after 1979 began to accrue a retirement pension under the new ITP1 plan from the age of 25. It is a complete defined contribution plan. The contribution is $4.5 \%$ of salary portions up to 7.5 income base amounts (SEK 426750 for 2014). For salary portions in excess of 7.5 income-base amounts (divided by 12 for one month) the contribution is $30 \%$. The pensionable salary becomes the gross salary paid out in cash, excluding reimbursement of expenses. Premiums are paid from the first Swedish krona of salary.

The employee can choose the form of the savings and the fund manager. However, at least half the contribution is invested in traditional pension insurance. The employee can also choose repayment cover and family cover of 1, 2, 3 or 4 price base amounts per year over 5, 10, 15 or 20 years. The contributions of those who do not specify a choice are invested in traditional pension insurance with no repayment cover or family cover. This default choice is the one that is modelled.

Employees whose yearly salary exceeds ten income base amounts (SEK 549000 in 2014) may choose to be covered under the new plan upon agreement with their employer. This applies regardless of whether the employee has a traditional ITP2 plan or has taken out an alternative ITP.

\section{Variant careers}

\section{Early retirement}

Earnings-related pension benefit withdrawal is possible from age 61 in the national pension scheme. There is no fixed retirement age. The notional-accounts and annuity calculations provide an automatic actuarial reduction depending on the age of retirement.

The income-tested guarantee pension benefit cannot be claimed before 65 . If the notionalaccounts pension is withdrawn before or after age 65 , the guarantee pension is still calculated as if the pension had been withdrawn at age 65 .

In the new ITP1 plan, pension benefits are normally paid from the age of 65, but may be taken out from the age of 55. Pensions are lifelong but can be paid in full or in part for a limited period of at least five years. The annuity is modelled as one that gives lifelong payments. The size of the pension is determined by the amount of premiums paid, the return, fees and taxes, and for how long the pension is to be disbursed.

\section{Late retirement}

It is possible to defer the notional accounts and premium pension with no upper age limit, again with automatic actuarial adjustments. It is also possible to combine work and pension receipt. Finally, pensions can be withdrawn partially (at 25,50 or $75 \%$ of the full pension). The guarantee pension is adjusted against other pensions from the Swedish old-age pension system and from comparable foreign national pensions, but is not reduced by wage income, capital income, occupational pension or private pension insurance. Thus, it is also possible to combine work with receipt of the guarantee pension.

It is possible to defer the ITP1 occupational pension after age 65. No additional pension rights can be accrued after age 65 , unless you have reached a special agreement with your employer.

\section{Childcare}

Years are credited under the public pension scheme for any period when you have and live with children aged four or below. In a household with two parents the credits go to the parent with the lowest income if an active choice is not made. Individuals receive the best of three different ways of calculating the credit. First, if income is zero or lower than previous earnings, then the credits are based on the earnings the year before the child was born. Secondly, for low-income workers or people 
who were not working before childcare responsibilities started, the credits are based on $75 \%$ of economy-wide average earnings. Thirdly, if income actually rises or does not decrease to a great extent as childcare responsibilities begin, then the credit is set at one income base amount. In all three cases, the government makes the total contributions to the earnings-related national pension system (covering both notional accounts and funded defined contribution scheme).

Furthermore, parental benefits paid are also considered as pensionable income. The beneficiary pays the employee pension contribution of $7 \%$ on benefit income. The government makes all the "employer contributions" of $10.21 \%$ for incomes from social security including parental benefits.

The parental benefit is payable for 480 days as follows:

- 390 days at $80 \%$ of the parent's annual income up to a ceiling of 10 price base amounts (equivalent to an annual salary of SEK 444000 in 2014).

- 90 days at a universally applicable flat rate of SEK 180 per day.

The parental benefit is computed daily. Parents on low income or no income at all receive a minimum guaranteed benefit of SEK 180/day. The 480 cash benefit days are divided equally between the parents (i.e. 240 days to each parent). A parent may also transfer up to 180 of her or his days to the other parent.

Under the ITP occupational plan, there is a recommendation that the employer contributes, through insurance, to an employee's pension during periods of up to 13 months for parental leave (and most do so).

\section{Unemployment}

Unemployment benefits and training allowances paid to the unemployed taking up labourmarket programmes counts as pensionable income, with the government paying the "employer" contribution. Income-related unemployment benefits equal $80 \%$ of previous earnings for the first two hundred days. From day 201 up to day 300 the benefit is $70 \%$ of previous earnings. Thereafter the benefit period is ended unless the benefit recipient is a parent of a child below the age of 18 if so the unemployment benefit remains at $70 \%$ of previous earnings for an extended period of 150 days. The unemployment benefits are disbursed up to a ceiling of SEK 680 per day and subject to a minimum payment of SEK 320 per day (applies only if the unemployed person has worked full time during 12 months preceding unemployment).

After the receipt of days in unemployment the beneficiary is entitled to be enrolled within the job and development guarantee programme. A participant in the job and development guarantee programme is entitled to activity support or development benefits. If the jobseeker has had an unemployment benefit before enrolment in the jobs and development guarantee then this benefit will equal $65 \%$ of earnings from the time before unemployment (max. SEK 680 per day). If the jobseeker has not previously been entitled to unemployment benefits he or she will receive the daily benefit of SEK 223 per day. 
Pension modelling results: Sweden in 2059, retirement at age 65
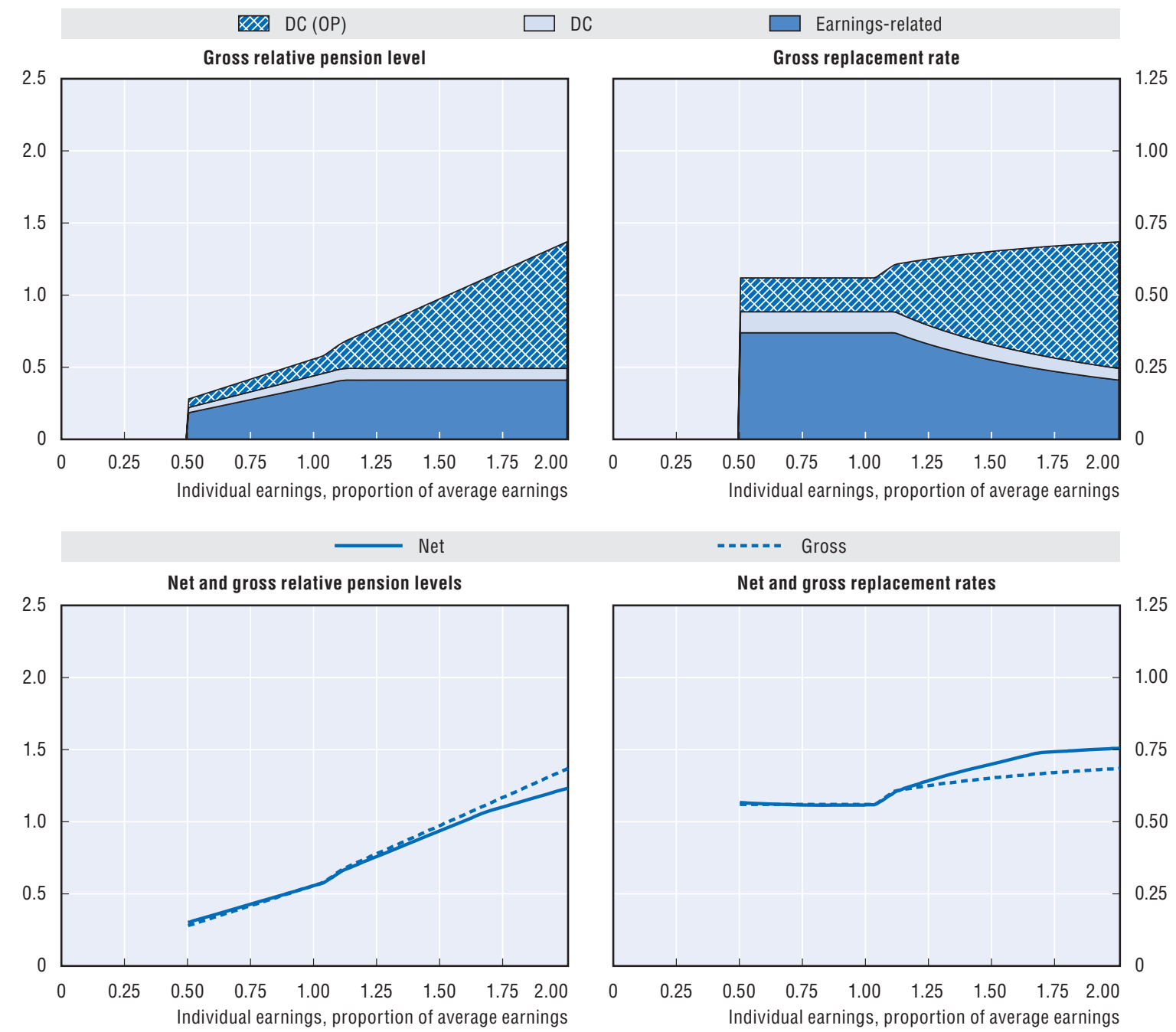

\begin{tabular}{|c|c|c|c|c|c|c|}
\hline \multicolumn{7}{|c|}{ Baseline scenario: Legislation scenario (price indexation of guarantee pension) } \\
\hline \multirow{2}{*}{$\begin{array}{l}\text { Men } \\
\text { Women (where different) }\end{array}$} & \multicolumn{6}{|c|}{ Individual earnings, multiple of average } \\
\hline & 0.5 & 0.75 & 1 & 1.5 & 2 & 3 \\
\hline Gross relative pension level & 28.0 & 42.0 & 56.0 & 97.8 & 137.0 & 215.3 \\
\hline \multicolumn{7}{|l|}{ (\% average gross earnings) } \\
\hline Net relative pension level & 30.2 & 43.0 & 55.8 & 94.2 & 123.3 & 170.0 \\
\hline \multicolumn{7}{|l|}{ (\% net average earnings) } \\
\hline Gross replacement rate & 56.0 & 56.0 & 56.0 & 65.2 & 68.5 & 71.8 \\
\hline \multicolumn{7}{|l|}{ (\% individual gross earnings) } \\
\hline Net replacement rate & 56.7 & 55.8 & 55.8 & 70.1 & 75.5 & 76.9 \\
\hline \multicolumn{7}{|l|}{ (\% individual net earnings) } \\
\hline Gross pension wealth & 9.7 & 9.7 & 9.7 & 11.4 & 12.1 & 12.7 \\
\hline (multiple of individual gross earnings) & 10.9 & 10.9 & 10.9 & 12.9 & 13.6 & 14.3 \\
\hline Net pension wealth & 7.8 & 7.4 & 7.2 & 8.2 & 8.1 & 7.5 \\
\hline (multiple of individual gross earnings) & 8.8 & 8.4 & 8.1 & 9.2 & 9.1 & 8.4 \\
\hline
\end{tabular}

Assumptions: Real rate of return $3 \%$, real earnings growth $1.25 \%$, inflation $2 \%$, and real discount rate $2 \%$. All systems are modelled and indexed according to what is legislated. Transitional rules apply where relevant. DC conversion rate equal $85 \%$. Labour market entry occurs at age 20 in 2014. Tax system latest available: 2013. 
Pension modelling results: Sweden in 2059, retirement at age 65 (cont.)

\begin{tabular}{|c|c|c|c|c|c|c|}
\hline \multicolumn{7}{|c|}{ Alternative scenario: Wage indexation of guarantee pension } \\
\hline \multirow{2}{*}{$\begin{array}{l}\text { Men } \\
\text { Women (where different) }\end{array}$} & \multicolumn{6}{|c|}{ Individual earnings, multiple of average } \\
\hline & 0.5 & 0.75 & 1 & 1.5 & 2 & 3 \\
\hline Gross relative pension level & 33.5 & 42.4 & 56.0 & 97.8 & 137.0 & 215.3 \\
\hline \multicolumn{7}{|l|}{ (\% average gross earnings) } \\
\hline Net relative pension level & 35.2 & 43.4 & 55.8 & 94.2 & 123.3 & 170.0 \\
\hline \multicolumn{7}{|l|}{ (\% net average earnings) } \\
\hline Gross replacement rate & 66.9 & 56.5 & 56.0 & 65.2 & 68.5 & 71.8 \\
\hline \multicolumn{7}{|l|}{ (\% individual gross earnings) } \\
\hline Net replacement rate & 66.1 & 56.3 & 55.8 & 70.1 & 75.5 & 76.9 \\
\hline \multicolumn{7}{|l|}{ (\% individual net earnings) } \\
\hline Gross pension wealth & 11.7 & 9.8 & 9.7 & 11.4 & 12.1 & 12.7 \\
\hline (multiple of individual gross earnings) & 13.1 & 11.0 & 10.9 & 12.9 & 13.6 & 14.3 \\
\hline Net pension wealth & 9.2 & 7.5 & 7.2 & 8.2 & 8.1 & 7.5 \\
\hline (multiple of individual gross earnings) & 10.3 & 8.4 & 8.1 & 9.2 & 9.1 & 8.4 \\
\hline
\end{tabular}

Assumptions: Real rate of return 3\%, real earnings growth $1.25 \%$, inflation $2 \%$, and real discount rate $2 \%$. All systems are modelled and indexed according to what is legislated. Transitional rules apply where relevant. DC conversion rate equal $85 \%$. Labour market entry occurs at age 20 in 2014. Tax system latest available: 2013. 


\section{Switzerland}

\section{Switzerland: Pension system in 2014}

The Swiss retirement pension system has three parts. The public scheme is earningsrelated and has a progressive formula in addition there is an income-tested supplementary benefit. A mandatory occupational person regime was introduced in 1985. The occupational pension can be supplemented on a voluntary basis.
Key indicators: Switzerland

\begin{tabular}{llcc}
\hline & & Switzerland & OECD \\
\hline Average worker earnings (AW) & CHF & 90522 & 39719 \\
& USD & 91179 & 40007 \\
Public pension spending & \% of GDP & 6.6 & 7.9 \\
Life expectancy & At birth & 82.5 & 80.0 \\
\multirow{2}{*}{ Population aged over 65 } & At age 65 & 20.8 & 19.3 \\
& \% of population & 18.2 & 16.2 \\
\hline
\end{tabular}

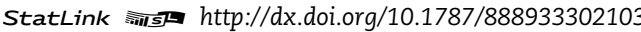

\section{Qualifying conditions}

The pensionable age in the public scheme and mandatory occupational pensions is currently 65 for men and 64 for women. A full pension requires contributions during 44 years for men and 43 years for women.

\section{Benefit calculation}

\section{Earnings-related}

The public earnings-related pension benefit is based on average lifetime earnings. Average lifetime earnings depend on the number of years during which contributions have been made and the person's average income from age 20 until reaching the retirement age. Pension benefits are subject to both upper and lower limits. Between these two thresholds, the "two-branch" benefit calculation formula favours average incomes. The benefit calculation tends to redistribute from high towards low incomes. With full contributions, pension benefits will be between CHF 14040 and CHF 28080 . These are equivalent $16 \%$ and $31 \%$ of average worker earnings. The maximum benefit is reached when average lifetime earnings are CHF 84240 equivalent to 93\% of economy-wide average earnings. The maximum pension benefit paid to couples may not exceed $150 \%$ of the maximum benefit for single persons.

Pension benefits in payment are adjusted every two years with $50 \%$ to prices and $50 \%$ to nominal earnings.

\section{Mandatory occupational}

A mandatory occupational pension insurance system was introduced in 1985. It is built around "defined credits" to an individual's pension account and applies to people earning an annual income of at least CHF 21060 per annum. The credits vary by age:

\begin{tabular}{lcccc}
\hline Age & $25-34$ & $35-44$ & $45-54$ & $55-64 / 65$ \\
Old-age credits (as \% of co-ordinated salary) & 7 & 10 & 15 & 18 \\
\hline
\end{tabular}

The value of accumulated credits at retirement depends on the required interest applied to earlier years' contributions. The interest rate is currently $1.75 \%$. The old-age credits are calculated each year as a percentage of the co-ordinated salary. This is equal to the gross annual income minus 
the co-ordination deduction (CHF 24 570) but at most CHF 59 670. If the interest rate is broadly equivalent to the growth rate of co-ordinated salary, then a full career in the system will give a man at age 65 accumulated credits of $500 \%$ of co-ordinated salary. However, higher (or lower) outcomes are possible if the interest rate exceeds (is less than) growth in co-ordinated salary. The modelling assumes that the interest rate applied to the credits will be equivalent to the growth rate of coordinated salary over the long term.

The employer must pay at least half of these old-age credits, the employee the remainder.

The individual pension account is converted into an annual retirement benefit upon retirement, using a conversion factor rate of $6.80 \%$. In addition, the retiree is entitled to receive at least a quarter of his/her retirement assets as a lump sum.

The mandatory system corresponds to a statutory minimum guaranteed by law. Registered provident institutions (pension funds) are free to provide benefits exceeding the law. Such pension benefits are referred to as "over-obligatory" benefits. Most retired employees enjoy "over-obligatory" benefits of this kind.

\section{Targeted}

Means-tested supplementary benefits are paid when earnings-related benefits and other sources of income are insufficient to cover basic living costs. The amount of annual benefit paid corresponds to the difference between recognised expenditure and calculated income (benefits, earned income, return on assets, etc.). Recognised expenses for single people include:

\begin{tabular}{lc}
\hline Factors in calculating supplementary benefits (PC) & Annual amount (single person living at home) \\
\hline Coverage of essential needs & CHF 19210 \\
Maximum gross rent & CHF 13200 \\
Maximum amount for reimbursement of sickness and invalidity costs & CHF 25000 \\
\hline
\end{tabular}

The supplementary benefit is indexed in the same way as the public old-age pensions. There are also discretionary cantonal additions for low-income pensioners; these are disregarded in the model.

\section{Social assistance}

The right to obtain social assistance in situations of distress is guaranteed by the Federal Constitution. The implementation and financing is done by the cantons.

\section{Voluntary}

Voluntary pensions saving are encouraged through tax exemptions of contributions. Contributions can be saved in a bank account or paid into a dedicated insurance policy, from which no withdrawals are permitted. In 2014 the maximum that could be invested amounted to CHF 6739 for employees and CHF 33696 for the self-employed. A maximum of five years of extra contributions can be made after the ordinary retirement age. Voluntary private pension cannot be withdrawn until at most five years before the pensionable age. The benefits are subject to income tax.

\section{Variant careers}

\section{Early retirement}

Early retirement in the public pension's scheme is possible from age 63 for men and age 62 for women. In cases of early pension benefit withdrawal the full pension benefit value is reduced by $6.8 \%$ for each year of early claiming. 
Early retirement is possible in the occupational schemes and can be claim from age 58 . It is the pension funds that define the terms of early retirement. As a general rule, the conversion rate applied to the employee's pension assets to obtain the annual pension benefit is reduced by between 0.15 and 0.2 percentage points for each year of early retirement. The 0.2 point reduction is equivalent to an actuarial adjustment, as conventionally measured, of $2.95 \%$ per year of early retirement (increasing with the extent of early retirement). Including also the loss of contributions and credits as a result of early retirement, the theoretical benefit is $7.1 \%$ (one year) $-6.35 \%$ (five years) lower per year of early retirement. Pension benefits withdrawal and gainful employment is possible to some extent.

\section{Late retirement}

Both public and occupational pensions can be deferred after normal pension age. The public pension can be deferred for up to five years. The public pension is increased according to the following schedule:

\begin{tabular}{lcccc}
\hline Deferral & 1 year & 2 years & 3 years & 4 years \\
Adjustment $(\%)$ & 5.2 & 10.8 & 17.1 & 24.0 \\
\hline
\end{tabular}

Contributions are not levied after age 65 for men and age 64 for women if earnings are below CHF 16800 per year. For earnings above this level contributions are levied but no additional pension entitlement can be earned. Occupational pension benefit can be deferred until age 70. The pension funds themselves define the terms. As a general rule, the conversion rate is increased by 0.2 percentage points for each year of deferral according to a recommendation of the Federal Social Insurance Office. In principle, it is possible to combine pension receipt and work. People do not continue to contribute after 65 under the public pension scheme.

\section{Childcare}

Childcare years for children under age 16 are credited in the public scheme as if earnings had amounted to three times the minimum pension in the year when the caring parent retires. For 2014, this was equal to CHF 42 120. If the caring parent is married during the caring period, the credits are split equally between the spouses or registered partnership. Credits for childcare are not granted in occupational schemes.

\section{Caring for close relatives}

Caring periods for close relatives are credited as a bonus for care-taking. This credit is not possible to claim in combination with the child care credit. The bonus corresponds to three times the minimum annual old-age pension benefit. Bonuses acquired during the years of a civil marriage (or registered partnership) are shared half and half by the partners. Credits for caring of close relative are not required in occupational pension schemes.

\section{Unemployment}

Unemployment benefits are subject to social security contributions and count as earnings towards the public pension. The unemployment insurance pays $80 \%$ of previous earnings. Individuals with no dependent children and who receive an allowance of more than CHF 140 per day or who are not disabled receive $70 \%$ of the insured salary. The duration of unemployment insurance varies between 90 and 640 days. Individuals on social assistance do not pay contributions. If incomes are very low then the municipal authorities often pay the minimum contribution. 
Unemployed persons who receive daily unemployment-insurance benefits remain insured on a mandatory basis against the risks of death and invalidity in occupational schemes. There is no obligation to pay contributions towards old-age pensions. The unemployed may pay their old-age pension contributions (both the employee's and the employer's shares).

Any daily allowances received in the event of sickness/accident are similarly subject to contributions. 
Pension modelling results: Switzerland in 2059 (2058), retirement at age 65 (age 64)
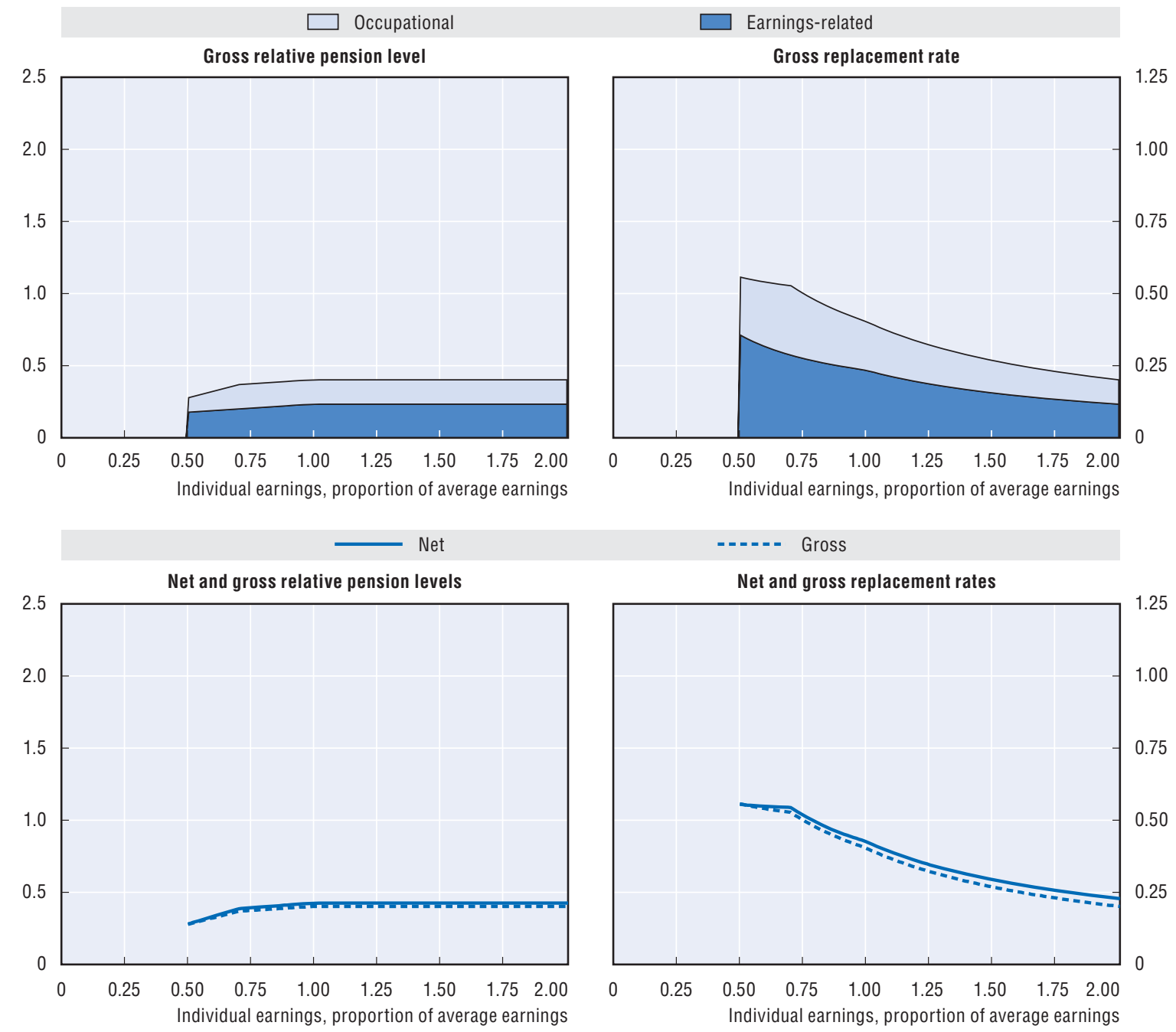

\begin{tabular}{|c|c|c|c|c|c|c|}
\hline \multicolumn{7}{|c|}{ Baseline scenario: Legislation scenario ( $50 \%$ wage and $\mathbf{5 0} \%$ price indexation of targeted pensions) } \\
\hline \multirow{2}{*}{$\begin{array}{l}\text { Men } \\
\text { Women (where different) }\end{array}$} & \multicolumn{6}{|c|}{ Individual earnings, multiple of average } \\
\hline & 0.5 & 0.75 & 1 & 1.5 & 2 & 3 \\
\hline Gross relative pension level & 27.9 & 37.5 & 40.2 & 40.2 & 40.2 & 40.2 \\
\hline (\% average gross earnings) & 27.6 & 37.1 & 39.9 & 39.9 & 39.9 & 39.9 \\
\hline Net relative pension level & 31.7 & 43.5 & 46.9 & 46.9 & 46.9 & 46.9 \\
\hline (\% net average earnings) & 31.3 & 43.1 & 46.5 & 46.5 & 46.5 & 46.5 \\
\hline Gross replacement rate & 55.7 & 50.0 & 40.2 & 26.8 & 20.1 & 13.4 \\
\hline (\% individual gross earnings) & 55.1 & 49.5 & 39.9 & 26.6 & 19.9 & 13.3 \\
\hline Net replacement rate & 61.4 & 57.1 & 46.9 & 31.5 & 24.2 & 16.9 \\
\hline (\% individual net earnings) & 60.7 & 56.5 & 46.5 & 31.2 & 23.9 & 16.7 \\
\hline Gross pension wealth & 10.7 & 9.5 & 7.7 & 5.1 & 3.8 & 2.6 \\
\hline (multiple of individual gross earnings) & 12.5 & 11.1 & 9.0 & 6.0 & 4.5 & 3.0 \\
\hline Net pension wealth & 8.5 & 7.7 & 6.2 & 4.2 & 3.1 & 2.1 \\
\hline (multiple of individual gross earnings) & 9.8 & 9.0 & 7.3 & 4.8 & 3.6 & 2.4 \\
\hline
\end{tabular}

Assumptions: Real rate of return $3 \%$, real earnings growth $1.25 \%$, inflation $2 \%$, and real discount rate $2 \%$. All systems are modelled and indexed according to what is legislated. Transitional rules apply where relevant. DC conversion rate equal $85 \%$. Labour market entry occurs at age 20 in 2014. Tax system latest available: 2013. Pension age 64 for women. 
Pension modelling results: Switzerland in 2059 (2058), retirement at age 65 (age 64) (cont.)

\begin{tabular}{|c|c|c|c|c|c|c|}
\hline \multicolumn{7}{|c|}{ Alternative scenario: Full-wage indexation of minimum pensions } \\
\hline \multirow{2}{*}{$\begin{array}{l}\text { Men } \\
\text { Women (where different) }\end{array}$} & \multicolumn{6}{|c|}{ Individual earnings, multiple of average } \\
\hline & 0.5 & 0.75 & 1 & 1.5 & 2 & 3 \\
\hline Gross relative pension level & 28.4 & 40.9 & 49.9 & 53.4 & 53.4 & 53.4 \\
\hline (\% average gross earnings) & 28.2 & 40.4 & 49.1 & 52.6 & 52.6 & 52.6 \\
\hline Net relative pension level & 32.4 & 47.7 & 57.8 & 62.0 & 62.0 & 62.0 \\
\hline (\% net average earnings) & 32.2 & 47.1 & 56.9 & 61.0 & 61.0 & 61.0 \\
\hline Gross replacement rate & 56.9 & 54.5 & 49.9 & 35.6 & 26.7 & 17.8 \\
\hline (\% individual gross earnings) & 56.5 & 53.8 & 49.1 & 35.1 & 26.3 & 17.5 \\
\hline Net replacement rate & 62.8 & 62.6 & 57.8 & 41.7 & 32.0 & 22.3 \\
\hline (\% individual net earnings) & 62.3 & 61.7 & 56.9 & 41.0 & 31.5 & 22.0 \\
\hline Gross pension wealth & 13.7 & 14.2 & 13.4 & 9.4 & 7.1 & 4.7 \\
\hline (multiple of individual gross earnings) & 15.4 & 15.7 & 14.8 & 10.4 & 7.8 & 5.2 \\
\hline Net pension wealth & 10.9 & 11.5 & 10.8 & 7.6 & 5.7 & 3.8 \\
\hline (multiple of individual gross earnings) & 12.2 & 12.8 & 11.9 & 8.4 & 6.3 & 4.2 \\
\hline
\end{tabular}

Assumptions: Real rate of return $3 \%$, real earnings growth $1.25 \%$, inflation $2 \%$, and real discount rate $2 \%$. All systems are modelled and indexed according to what is legislated. Transitional rules apply where relevant. DC conversion rate equal $85 \%$. Labour market entry occurs at age 20 in 2014. Tax system latest available: 2013. Pension age 64 for women.

StatLink त्ञाI $h$ ttp://dx.doi.org/10.1787/888933301681 


\section{Turkey}

\section{Turkey: Pension system in 2014}

An earnings-related public scheme with an income-tested safety net and a flat-rate supplementary pension.

\section{Qualifying conditions}

The current pension age is 60 years for men and 58 years for women with at least 7200 days of contributions. The pension age is gradually rising to 65 for men from 2036 to 2044 and to 65 for women from 2036 to 2048. New entrants to the pension system between September 1999 and October 2008 can retire at the age of 60 for men and 58 for women with a minimum of 7000 days of contributions. An alternative condition is 25 years of coverage with 4500 days of contributions. After October 2008 an alternative eligibility condition is 65 years of age with a minimum of 5400 days of contributions. The means-tested pension benefit is payable only to those with no other social security rights, the disabled or those aged 65 years or over.

\section{Benefit calculation}

\section{Earnings-related}

\section{Between September 1999 and October 2008}

The pension under the scheme is based on average lifetime earnings revalued in line with real GDP growth and the change of CPI [ $1+$ GDP $) \times(1+\mathrm{CPI})]$. The pension has a non-linear formula with years of coverage. The first ten years earn a pension of $35 \%$ of pay, with $2 \%$ per year extra for the next 15 years and $1.5 \%$ per year thereafter.

\section{After October 2008}

The pension under the new scheme is based on average lifetime earnings revalued in line with real GDP growth and the change of CPI [ $1+$ CPI $+30 \%$ GDP $)]$. The accrual rate is $2 \%$ for one year of coverage and it cannot exceed $90 \%$ of pension.

There is a floor above which contributions are required. This was TRY 1071.0 for the first half of 2014 and TRY 1134.0 for the second half of 2014.

There is a ceiling to pensionable earnings; its value was TRY 6961.5 for the first half of 2014 and TRY 7371.1 for the second half of 2014.

According to the law acted in 1999 pensions are indexed monthly and follow the consumer price index. But since 2003 indexation of pensions in payment is determined once or twice a year, either by Budget Laws/Other Laws or by Board of Cabinet. With the reform the pensions are indexed with CPI of the preceding six months and twice a year, in January and July. For the first half of 2014, pensions were increased by $3.27 \%$ and for the second half of 2014 , pensions were increased $5.70 \%$ (this rule is 
not implemented for civil servants because of collective agreements directed to financial and social rights for public officials in general, and service branch). For 2014, pensions are increased by TRY 175 for civil servants.

\section{Minimum}

The minimum pension level for workers was TRY 952.7 for first half of 2014 and TRY 1007.0 for the second half of 2014, for self-employed was TRY 671.5 for first half of 2014 and TRY 709.85 for second half of 2014 and for civil servants was TRY 1261.1 for 2014. These figures as stated are minimum level of pensions.

As a general rule the amount of pensions shall not be less than $35 \%$ or $40 \%$ if the insurer has dependant spouses or children, of the average monthly earning determined in January of the year of request, considering lower limits of earnings subject to premium determined for each year in service terms. Thus, the minimum pension varies among the insurers. Except for this rule there is no specified minimum pension.

\section{Targeted}

The means-tested pension is paid quarterly. For 2014 the pension was TRY 141.56 per month.

\section{Variant careers}

\section{Early retirement}

Workers in specific industries (e.g. mining) and people with disabilities can retire early but other workers cannot claim pensions before the eligibility ages.

\section{Late retirement}

It is possible to defer the pension beyond the normal pension age. For civil servants the statutory retirement age is 65 with some exceptions for specific groups.

\section{Childcare}

Childcare periods up to two years per child and for a maximum of three children are taken into account provided that the insured pays the contributions.

\section{Unemployment}

There are no credits for periods of unemployment. 


\section{Pension modelling results: Turkey in 2059, retirement at age 65}

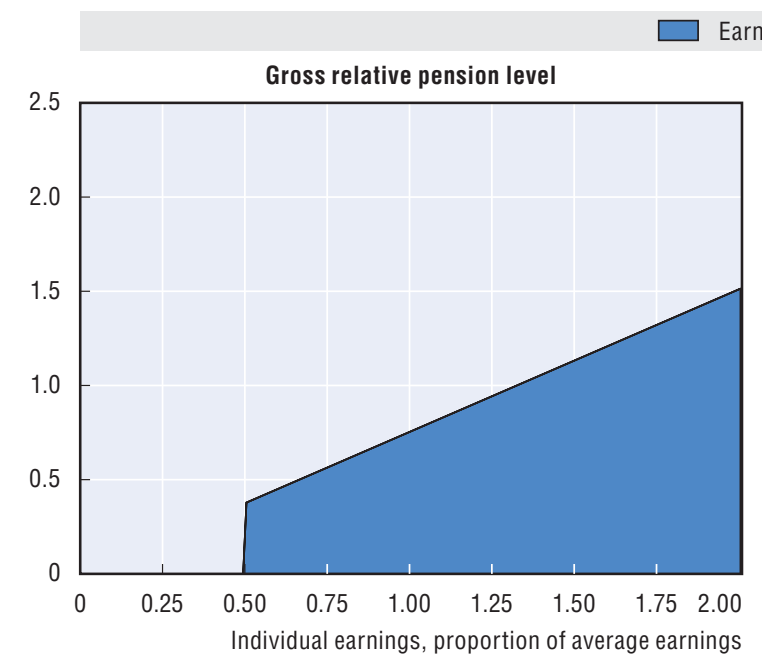

Earnings-related
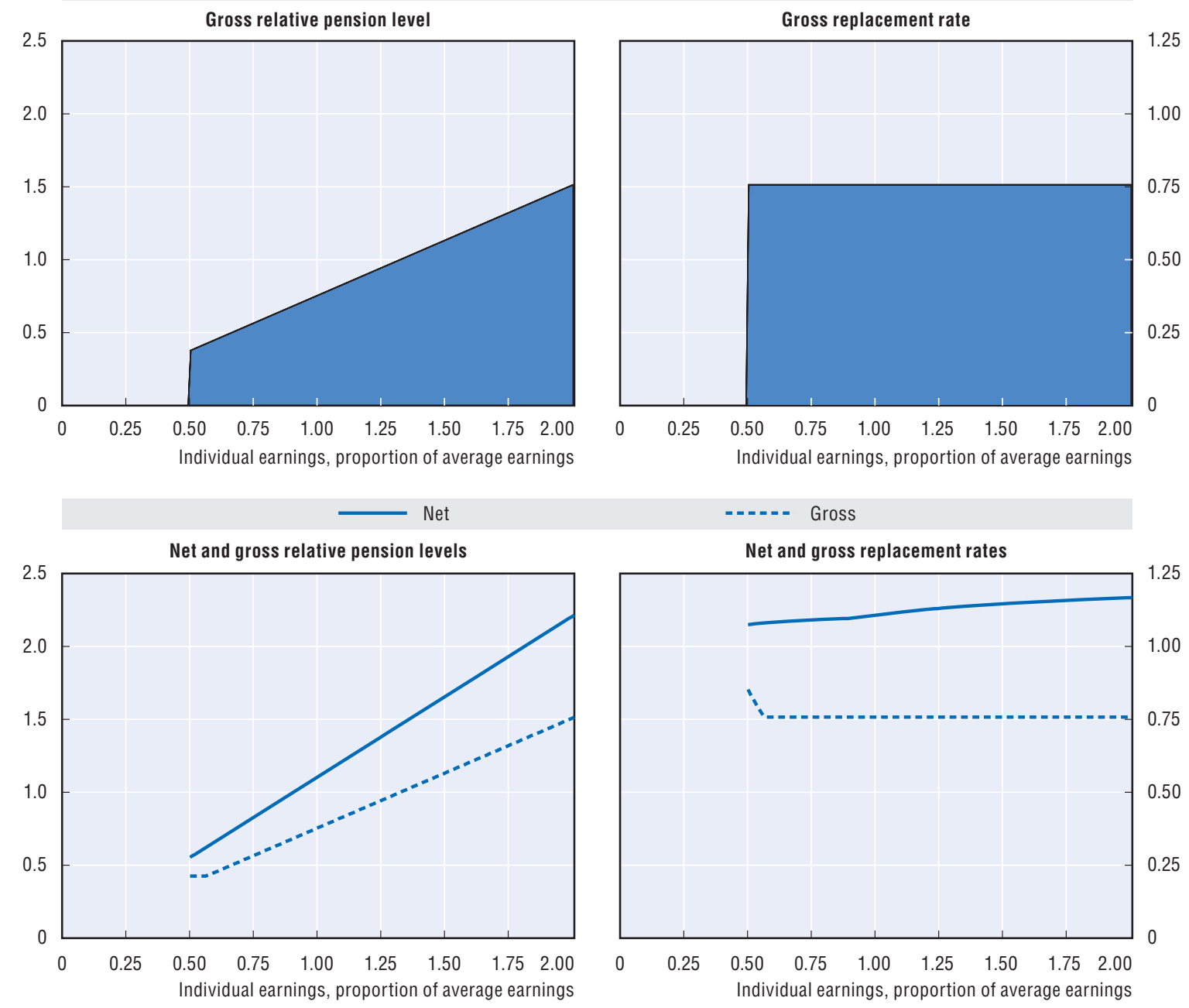

\begin{tabular}{|c|c|c|c|c|c|c|}
\hline \multicolumn{7}{|c|}{ Baseline scenario: Legislation scenario (price indexation of minimum pension benefits) } \\
\hline \multirow{2}{*}{$\begin{array}{l}\text { Men } \\
\text { Women (where different) }\end{array}$} & \multicolumn{6}{|c|}{ Individual earnings, multiple of average } \\
\hline & 0.5 & 0.75 & 1 & 1.5 & 2 & 3 \\
\hline Gross relative pension level & 37.9 & 56.8 & 75.7 & 113.6 & 151.4 & 227.1 \\
\hline \multicolumn{7}{|l|}{ (\% average gross earnings) } \\
\hline Net relative pension level & 52.4 & 78.6 & 104.8 & 157.2 & 209.6 & 314.5 \\
\hline \multicolumn{7}{|l|}{ (\% net average earnings) } \\
\hline Gross replacement rate & 75.7 & 75.7 & 75.7 & 75.7 & 75.7 & 75.7 \\
\hline \multicolumn{7}{|l|}{ (\% individual gross earnings) } \\
\hline Net replacement rate & 98.0 & 102.5 & 104.8 & 109.9 & 113.0 & 115.1 \\
\hline \multicolumn{7}{|l|}{ (\% individual net earnings) } \\
\hline Gross pension wealth & 12.3 & 12.3 & 12.3 & 12.3 & 12.3 & 12.3 \\
\hline (multiple of individual gross earnings) & 14.3 & 14.3 & 14.3 & 14.3 & 14.3 & 14.3 \\
\hline Net pension wealth & 12.3 & 12.3 & 12.3 & 12.3 & 12.3 & 12.3 \\
\hline (multiple of individual gross earnings) & 14.3 & 14.3 & 14.3 & 14.3 & 14.3 & 14.3 \\
\hline
\end{tabular}

Assumptions: Real rate of return $3 \%$, real earnings growth $1.25 \%$, inflation $2 \%$, and real discount rate $2 \%$. All systems are modelled and indexed according to what is legislated. Transitional rules apply where relevant. DC conversion rate equal $85 \%$. Labour market entry occurs at age 20 in 2014. Tax system latest available: 2013. 
Pension modelling results: Turkey in 2059, retirement at age 65 (cont.)

\begin{tabular}{|c|c|c|c|c|c|c|}
\hline \multicolumn{7}{|c|}{ Alternative scenario: Wage indexation of minimum pension benefits } \\
\hline \multirow{2}{*}{$\begin{array}{l}\text { Men } \\
\text { Women (where different) }\end{array}$} & \multicolumn{6}{|c|}{ Individual earnings, multiple of average } \\
\hline & 0.5 & 0.75 & 1 & 1.5 & 2 & 3 \\
\hline Gross relative pension level & 42.6 & 56.8 & 75.7 & 113.6 & 151.4 & 227.1 \\
\hline \multicolumn{7}{|l|}{ (\% average gross earnings) } \\
\hline Net relative pension level & 59.0 & 78.6 & 104.8 & 157.2 & 209.6 & 314.5 \\
\hline \multicolumn{7}{|l|}{ (\% net average earnings) } \\
\hline Gross replacement rate & 85.2 & 75.7 & 75.7 & 75.7 & 75.7 & 75.7 \\
\hline \multicolumn{7}{|l|}{ (\% individual gross earnings) } \\
\hline Net replacement rate & 110.3 & 102.5 & 104.8 & 109.9 & 113.0 & 115.1 \\
\hline \multicolumn{7}{|l|}{ (\% individual net earnings) } \\
\hline Gross pension wealth & 13.9 & 12.3 & 12.3 & 12.3 & 12.3 & 12.3 \\
\hline (multiple of individual gross earnings) & 16.1 & 14.3 & 14.3 & 14.3 & 14.3 & 14.3 \\
\hline Net pension wealth & 13.9 & 12.3 & 12.3 & 12.3 & 12.3 & 12.3 \\
\hline (multiple of individual gross earnings) & 16.1 & 14.3 & 14.3 & 14.3 & 14.3 & 14.3 \\
\hline
\end{tabular}

Assumptions: Real rate of return 3\%, real earnings growth $1.25 \%$, inflation $2 \%$, and real discount rate $2 \%$. All systems are modelled and indexed according to what is legislated. Transitional rules apply where relevant. DC conversion rate equal $85 \%$. Labour market entry occurs at age 20 in 2014. Tax system latest available: 2013. 


\section{United Kingdom}

\section{United Kingdom: Pension system in 2014}

The public scheme has two tiers, (a flatrate basic pension and an earnings-related additional pension), which are complemented by a large voluntary private pension sector. The public scheme is currently being reformed into a flat-rate basic pension. An income-related non-taxable benefit (pension credit) targets extra spending on the poorest pensioners.

\section{Qualifying conditions}

State Pension age is currently 65 years for men and 62.5 years for women. The pension age for women is gradually rising to 65 years by November 2018. Increases of the State Pension age to 66 years by October 2020 and to 67 years between 2026 and 2028 have been legislated. The Government has also proposed that subsequent State Pension age changes are to be based on changes in life expectancy. Under the old system, an individual reaching state pension age qualifies for a full basic State Pension by: i) paying; or ii) having been treated as having paid; or iii) being credited with, National Insurance contributions, for 30 qualifying years in their potential working lives. A proportionally reduced basic state pension is paid to people with fewer than 30 qualifying years, to a minimum of one qualifying year of contribution or credits. People reaching State Pension age from 6 April 2016 will require 35 years of contributions to receive a full new State Pension amount, and the minimum qualifying period will be 10 years.

\section{Benefit calculation}

\section{Basic}

The full basic State Pension for a single person is GBP 113.10 per week in 2014/15. The announced policy intention is that the full new State Pension will be set at a level above that of the current level of Pension Credit.

\section{Earnings-related}

In addition to the basic State Pension, in the current system people can get additional earningsrelated State Pension, which can range from less than GBP 1 to close to GBP 200 a week, depending on work history. The earnings-related scheme will not be part of the new State Pension, and will not be available for people reaching state pension age from April 2016.

\section{Contracting out}

Occupational and personal pension arrangements have been able to choose to "contract-out" of the additional pension element of the State Pension. The adoption of the new State Pension will lead to the abolition of the option of contracting out. 


\section{Workplace Private Pension Provision}

In October 2012, the government began rolling out automatic enrolment into workplace pension schemes. Once complete in February 2018, all employers will have a legal duty to enrol all qualifying workers aged between 22 and State Pension age who earn over GBP 10000 in 2014/15 into a qualifying workplace scheme. Minimum contributions will build to $8 \%$ of a statutory earnings band between GBP 5772 to GBP 41865 in 2014/15 by October 2018.

To support automatic enrolment, the government established the National Employment Savings Trust (NEST), a trust-based occupational defined contribution scheme. NEST has a public service obligation to admit any workers automatically enrolled by their employer, and is designed to provide low-cost, quality pension provision for low to moderate earners, transient workers and smaller employers that the market finds difficult to serve.

\section{Targeted}

Pension Credit, is a tax free weekly benefit for people who are living on low incomes and guarantees all pensioners an income above a certain level. Pension Credit is an income related benefit and is not based on National Insurance contributions. There are two elements to the Pension Credit, the Guarantee Credit and the Savings Credit. The Guarantee Credit ensures a minimum level of income by providing financial help for people who have reached the qualifying age (see below) and whose income is below the standard minimum guarantee amount. In 2014/15 this was GBP 148.35 for individuals and GBP 226.50 for couples (these amounts may be higher for people with severe disabilities, caring responsibilities or certain housing costs).

The savings credit is an extra amount for people aged 65 or over who have made modest provision for their retirement. It is designed to reduce the effective withdrawal rate of benefits from $100 \%$ under its predecessors to $40 \%$. People, whose income (excluding any guarantee credit) is below their guarantee credit minimum guarantee and above the savings credit threshold, GBP 120.35 for individuals and GBP 192.00 for couples respectively in 2014/15, receive $60 \%$ of the difference between their income and the threshold up to a maximum of GBP 16.80 for individuals and GBP 20.70 for couples, respectively. For people with incomes above their guarantee credit minimum guarantee (that is they are not entitled to the guarantee credit), the maximum savings credit is reduced by $40 \%$ of their income over their guarantee level.

The qualifying age for Pension Credit is gradually increasing to 65 alongside the increase in women's State Pension age and will increase further as State Pension age raises beyond 65 for both men and women. The savings credit element of the scheme will not be available to those who reach state pension age on or after 6 April 2016 (i.e. the same cohort which qualify for the new State Pension).

\section{Variant careers}

\section{Early retirement}

It is not possible to claim a State Pension age early. Voluntary pension benefits can be claimed from the age allowed by the scheme.

\section{Late retirement}

Deferral of the state pension has always been possible in order to earn extra State Pension increments. This extra State Pension is paid on top of the normal State Pension when a person eventually claims for the first time or claims again. 
Until 6 April 2005, deferral of the State Pension earned approximately $7.5 \%$ for each year (equivalent to $1 \%$ for every seven weeks). From 6 April 2005, the increment increased to about $10.4 \%$ for each year (or $1 \%$ for every five weeks).

The amount of extra money a person gets depends on how long they put off claiming their State Pension. They may choose one of the following options:

- A higher weekly state pension for life (if the State Pension is deferred for at least five weeks).

- A one-off taxable lump-sum payment (if the State Pension is continuously deferred for at least one year). The lump-sum is made up of the State Pension foregone during the deferral period plus interest which is guaranteed to be at least two percentage points above the (Bank of England) base rate. The choice has to be made when the State Pension is eventually claimed.

- For those who reach State Pension age from April 2016, it will not be possible to take a lump-sum payment. To receive a higher weekly State Pension for life, the State Pension will need to be deferred for at least nine weeks. The extra State Pension received for deferring will be awarded at a lower rate than for those who reached State Pension age prior to April 2016.

\section{Childcare}

Both tiers of the public pension scheme (basic State Pension and State Second Pension) provide protection for periods of child care. This covers both people not in paid work and those working but earning below the lower earnings limit (LEL) who therefore do not contribute to the system. Prior to 6 April 2010, for the basic State Pension, protection was provided by Home Responsibilities Protection (HRP), and covered years where Child Benefit was awarded for at least one child under 16. HRP reduced the number of years required for a full basic State Pension so that, with sufficient HRP, only 20 years' work (including periods when National Insurance contributions may have been credited) was required. For the State Second Pension, years where Child Benefit was awarded for a child under age six were credited; caring parents were deemed to have earnings at the low earnings threshold.

HRP has been replaced by a system of weekly National Insurance credits for parents and carers. People attaining State Pension age after 2010 may be awarded credits if they have Child Benefit for a child under age 12. These credits may count towards their basic State Pension and State Second Pension entitlement. Any years of HRP acquired before 2010 have been converted to qualifying years of National Insurance credits.

\section{Unemployment}

Periods of unemployment on insurance or assistance benefits are credited to a person's National Insurance contributions record for the basic State Pension. There are no National Insurance credits for periods on these benefits for the State Second Pension. 
Pension modelling results: United Kingdom in 2062, retirement at age 68
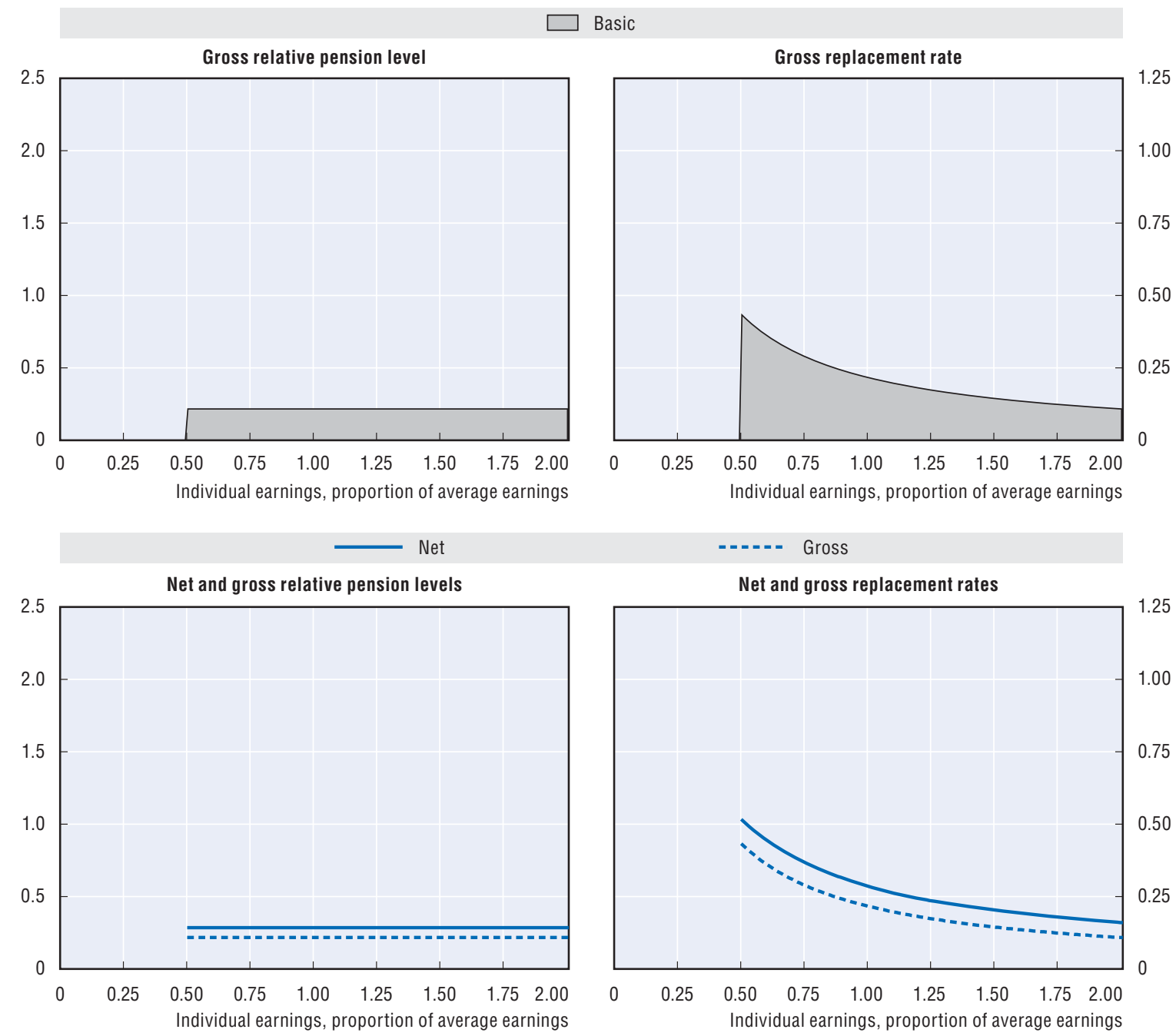

\begin{tabular}{|c|c|c|c|c|c|c|}
\hline \multicolumn{7}{|c|}{ Baseline scenario: Legislation scenario (wage indexation of basic pension benefits) } \\
\hline \multirow{2}{*}{$\begin{array}{l}\text { Men } \\
\text { Women (where different) }\end{array}$} & \multicolumn{6}{|c|}{ Individual earnings, multiple of average } \\
\hline & 0.5 & 0.75 & 1 & 1.5 & 2 & 3 \\
\hline Gross relative pension level & 21.6 & 21.6 & 21.6 & 21.6 & 21.6 & 21.6 \\
\hline \multicolumn{7}{|l|}{ (\% average gross earnings) } \\
\hline Net relative pension level & 28.5 & 28.5 & 28.5 & 28.5 & 28.5 & 28.5 \\
\hline \multicolumn{7}{|l|}{ (\% net average earnings) } \\
\hline Gross replacement rate & 43.3 & 28.9 & 21.6 & 14.4 & 10.8 & 7.2 \\
\hline \multicolumn{7}{|l|}{ (\% individual gross earnings) } \\
\hline Net replacement rate & 51.7 & 36.7 & 28.5 & 20.3 & 16.0 & 11.4 \\
\hline \multicolumn{7}{|l|}{ (\% individual net earnings) } \\
\hline Gross pension wealth & 7.1 & 4.7 & 3.6 & 2.4 & 1.8 & 1.2 \\
\hline (multiple of individual gross earnings) & 7.8 & 5.2 & 3.9 & 2.6 & 1.9 & 1.3 \\
\hline Net pension wealth & 7.1 & 4.7 & 3.6 & 2.4 & 1.8 & 1.2 \\
\hline (multiple of individual gross earnings) & 7.8 & 5.2 & 3.9 & 2.6 & 1.9 & 1.3 \\
\hline
\end{tabular}

Assumptions: Real rate of return $3 \%$, real earnings growth $1.25 \%$, inflation $2 \%$, and real discount rate $2 \%$. All systems are modelled and indexed according to what is legislated. Transitional rules apply where relevant. DC conversion rate equal $85 \%$. Labour market entry occurs at age 20 in 2014. Tax system latest available: 2013. 


\section{United States}

\section{United States: Pension system} in 2014

The publicly provided pension benefit, known as social security, has a progressive benefit formula. There is also a meanstested top-up payment available for lowincome pensioners.
Key indicators: United States

\begin{tabular}{llcc}
\hline & & United States & OECD \\
\hline \multirow{2}{*}{ Average worker earnings (AW) } & USD & 50075 & 40007 \\
& USD & 50075 & 40007 \\
Public pension spending & \% of GDP & 6.7 & 7.9 \\
Life expectancy & At birth & 78.9 & 80.0 \\
\multirow{2}{*}{ Population over age 65} & At age 65 & 19.3 & 19.3 \\
& \% of population & 14.7 & 16.2 \\
\hline
\end{tabular}

\section{Qualifying conditions}

The pension age (called normal retirement age - NRA) is 66 years in 2014, and will increase to 67 years by 2022. Eligibility for retirement benefits depends on the number of years in which contributions are made with a minimum requirement of ten years' contributions.

\section{Benefit calculation}

\section{Earnings-related}

The earnings-related pension benefit formula is progressive. The first USD 816 a month of relevant earnings attracts a 90\% replacement rate. The band of earnings between USD 816 and USD 4917 a month is replaced at $32 \%$. These thresholds are $22 \%$ and $133 \%$ of the national average wage index for 2012, respectively. A replacement rate of 15\% applies between the latter threshold and the earnings ceiling. A 50\% dependants' addition is available to married couples where secondary earners have built up a smaller entitlement and for a qualifying dependent child.

Earlier years' earnings are revalued up to the year in which the recipient reaches age 60 in line with growth in economy-wide average earnings. There is no adjustment of earnings for years after age 60 years. The basic benefit is computed for payment at age 62 years. Thereafter, the basic benefit is adjusted in line with price increases. The benefit is based on the career average earnings for the 35 highest years of earnings, after revaluing, including years with zero earnings if needed to total 35 years.

The earnings ceiling for both contributions and benefits is USD 117000 a year, corresponding to $264 \%$ of the national average wage index in 2012. This index follows the growth in economy-wide wages.

Pensions in payment are adjusted in line with price increases.

\section{Targeted}

There is a means-tested benefit for the elderly, known as Supplemental Security Income. Individuals aged 65years or older without an eligible spouse can be eligible for up to USD 8652 a year depending on assets and other income. The maximum benefit rate for cases where both members of a couple are eligible is USD 12984 (50\% higher than the rate for singles). These benefit rates are equivalent to around $19 \%$ and $29 \%$ of average earnings in 2014 , respectively. The maximum benefit is indexed to price increases. 
The asset tests are strict: individuals without an eligible spouse are limited to USD 2000 worth of assets and eligible couples to USD 3000 , excluding personal belongings, a home, a car, funeral insurance and life insurance (the last two up to USD 1500 in value). There is a small (USD 20 per month) "disregard" applied against most types of income in calculating the benefit. Another disregard is provided for earnings in the amount of USD 65 a month and one-half of the remaining earnings. After all appropriate disregards have been applied the benefit is then withdrawn at a $100 \%$ rate against total countable income above this level.

The analysis is complicated by the fact that states and the District of Columbia can supplement the federally determined minimum. While 6 states pay only the federal minimum, 32 administer their own system, six offer supplements that are operated solely by the federal Social Security Administration (SSA), and seven offer supplements administered by both the state and SSA. The average supplemental payment administered by SSA in these 13 states is $18 \%$ of the maximum federal benefit for pensioners without an eligible spouse and $30 \%$ for couples where both members are eligible. Note that the modelling does not include these additional payments.

\section{Voluntary private pension}

There is an additional voluntary pension which is assumed to be defined contribution. The contribution rate is assumed to be $9 \%$.

\section{Variant careers}

\section{Early retirement}

Early retirement is possible from 62 , subject to an actuarial reduction. For each year of retirement before the normal age, the benefit is reduced by $6.67 \%$. However, after three years, the reduction falls to $5 \%$. This applies to retirees with a NRA of over 65 .

\section{Late retirement}

Initial receipt of the pension may be deferred until after NRA, and credit is given for deferment up to age 70. The actuarial increment for those attaining age 62 in 2012 and later is $8 \%$ for each year deferred.

It is also possible to combine work and pension receipt subject to an earnings test. For beneficiaries who are receiving benefits in a year before the year they reach their NRA, the pension is reduced by $50 \%$ of earnings in excess of USD 15 480. For workers who have reached their NRA, there is no benefit reduction based on earnings.

\section{Childcare}

There are no provisions for credits during periods of childcare (except for workers who become disabled at younger ages, who may drop years of child care from their benefit computation).

\section{Unemployment}

There are no provisions for credits during periods of unemployment. However periods of unemployment may be omitted from the calculation of earnings for benefit purposes in many cases as only the highest 35 years of earnings are considered. Periods of disability are omitted from the 35 years of earnings considered. 
Pension modelling results: United States in 2061, retirement at age 67

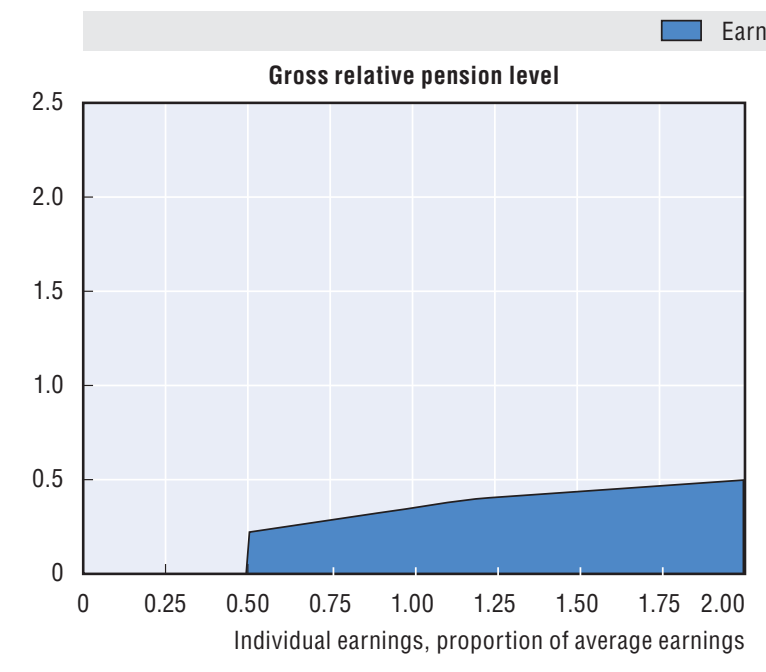

Earnings-related
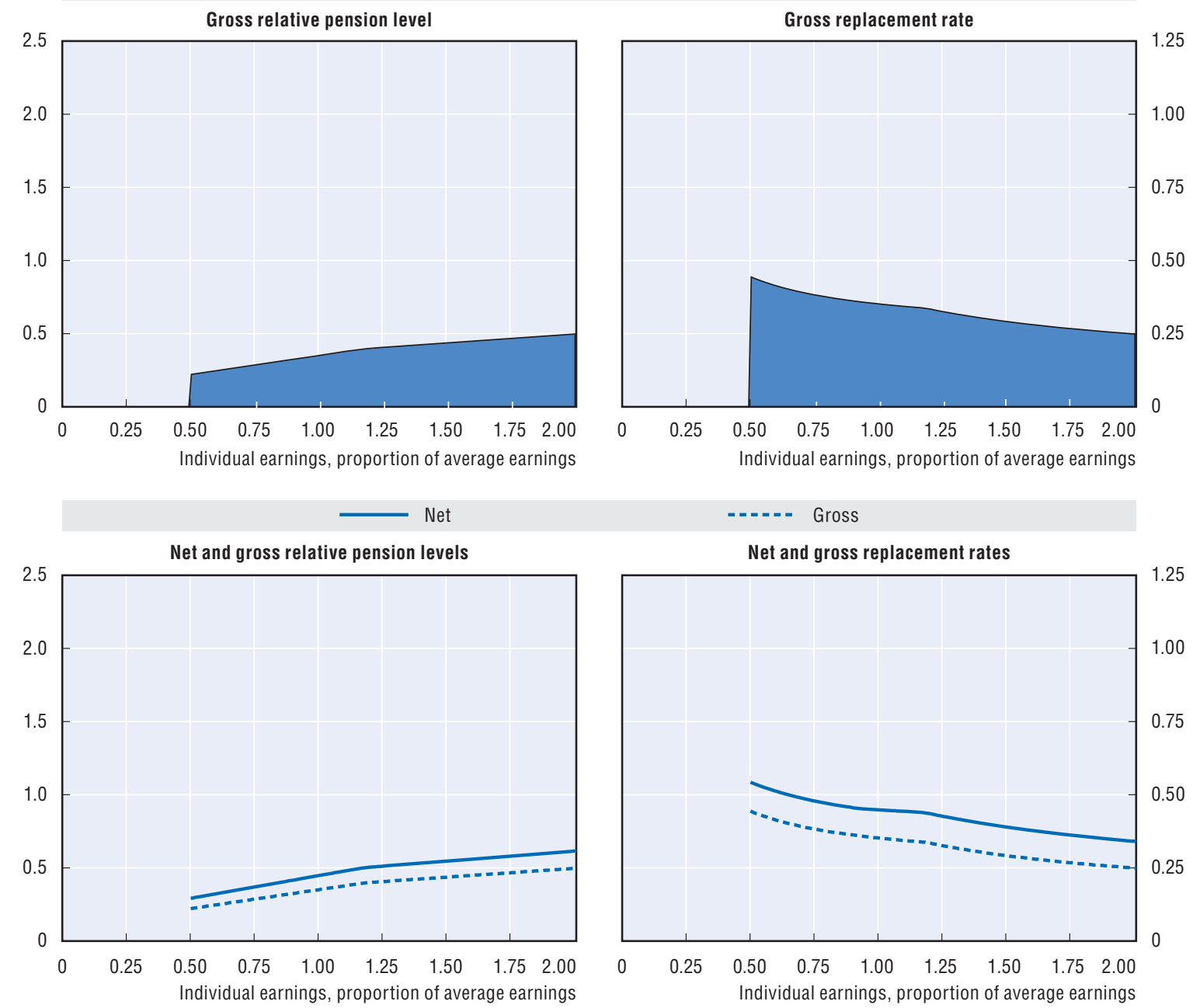

\begin{tabular}{|c|c|c|c|c|c|c|}
\hline \multicolumn{7}{|c|}{ Baseline scenario: Legislation scenario (price indexation of targeted pension benefits) } \\
\hline \multirow{2}{*}{$\begin{array}{l}\text { Men } \\
\text { Women (where different) }\end{array}$} & \multicolumn{6}{|c|}{ Individual earnings, multiple of average } \\
\hline & 0.5 & 0.75 & 1 & 1.5 & 2 & 3 \\
\hline Gross relative pension level & 22.2 & 28.7 & 35.2 & 43.7 & 49.8 & 53.9 \\
\hline \multicolumn{7}{|l|}{ (\% average gross earnings) } \\
\hline Net relative pension level & 29.3 & 37.0 & 44.8 & 54.7 & 61.6 & 66.2 \\
\hline \multicolumn{7}{|l|}{ (\% net average earnings) } \\
\hline Gross replacement rate & 44.4 & 38.2 & 35.2 & 29.1 & 24.9 & 18.0 \\
\hline \multicolumn{7}{|l|}{ (\% individual gross earnings) } \\
\hline Net replacement rate & 54.3 & 47.8 & 44.8 & 38.9 & 34.0 & 25.1 \\
\hline \multicolumn{7}{|l|}{ (\% individual net earnings) } \\
\hline Gross pension wealth & 7.2 & 6.2 & 5.7 & 4.7 & 4.0 & 2.9 \\
\hline (multiple of individual gross earnings) & 8.0 & 6.9 & 6.4 & 5.3 & 4.5 & 3.3 \\
\hline Net pension wealth & 7.1 & 6.0 & 5.5 & 4.4 & 3.7 & 2.7 \\
\hline (multiple of individual gross earnings) & 7.9 & 6.7 & 6.1 & 5.0 & 4.2 & 3.0 \\
\hline
\end{tabular}

Assumptions: Real rate of return $3 \%$, real earnings growth $1.25 \%$, inflation $2 \%$, and real discount rate $2 \%$. All systems are modelled and indexed according to what is legislated. Transitional rules apply where relevant. DC conversion rate equal $85 \%$. Labour market entry occurs at age 20 in 2014. Tax system latest available: 2013. 


\section{ORGANISATION FOR ECONOMIC CO-OPERATION AND DEVELOPMENT}

The OECD is a unique forum where governments work together to address the economic, social and environmental challenges of globalisation. The OECD is also at the forefront of efforts to understand and to help governments respond to new developments and concerns, such as corporate governance, the information economy and the challenges of an ageing population. The Organisation provides a setting where governments can compare policy experiences, seek answers to common problems, identify good practice and work to co-ordinate domestic and international policies.

The OECD member countries are: Australia, Austria, Belgium, Canada, Chile, the Czech Republic, Denmark, Estonia, Finland, France, Germany, Greece, Hungary, Iceland, Ireland, Israel, Italy, Japan, Korea, Luxembourg, Mexico, the Netherlands, New Zealand, Norway, Poland, Portugal, the Slovak Republic, Slovenia, Spain, Sweden, Switzerland, Turkey, the United Kingdom and the United States. The European Union takes part in the work of the OECD.

OECD Publishing disseminates widely the results of the Organisation's statistics gathering and research on economic, social and environmental issues, as well as the conventions, guidelines and standards agreed by its members. 


\section{Pensions at a Glance 2015 OECD AND G20 INDICATORS}

\section{Contents}

Chapter 1. Recent pension reforms

Chapter 2. The role of first-tier pensions

Chapter 3. How incomplete careers affect pension entitlements

Chapter 4. Sensitivity of replacement rates to the model parameters

Chapter 5. Design of pension systems

Chapter 6. Pension entitlements

Chapter 7. Demographic and economic context

Chapter 8. Incomes and poverty of older people

Chapter 9. Finances of retirement-income systems

Chapter 10. Private pensions and public pension reserve funds

Chapter 11. Pensions at a Glance 2015: Country profiles

Consult this publication on line at $\boldsymbol{h t t p : / / d x . d o i . o r g / 1 0 . 1 7 8 7 / p e n s i o n \_ g l a n c e - 2 0 1 5 - e n . ~}$

This work is published on the OECD iLibrary, which gathers all OECD books, periodicals and statistical databases. Visit www.oecd-ilibrary.org for more information.

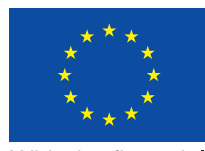

ISBN 978-92-64-24063-6 $812015201 \mathrm{P}$

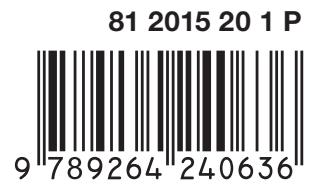

